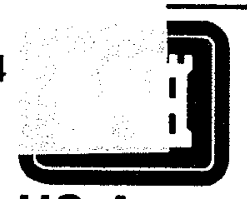

US Army Corps of Engineers

Waterways Experiment

\title{
Nonlinear, Incremental Structural Analysis of McAlpine Lock Replacement for Chamber, Miter Gate, and Culvert Valve Monoliths
}

by Barry D. Fehl, Guillermo A. Riveros, Sharon Garner

Technical Report ITL-97-4

May 1997
US-CE-C Properiy of hise

United States Government 
The contents of this report are not to be used for advertising, publication, or promotional purposes. Citation of trade names does not constitute an official endorsement or approval of the use of such commercial products.

The findings of this report are not to be construed as an official Department of the Army position, unless so designated by other authorized documents. 


\section{Nonlinear, Incremental Structural Analysis of McAlpine Lock Replacement for Chamber, Miter Gate, and Culvert Valve Monoliths}

by Barry D. Fehl, Guillermo A. Riveros, Sharon Garner

U.S. Army Corps of Engineers

Waterways Experiment Station

3909 Halls Ferry Road

Vicksburg, MS 39180-6199

Final report

Approved for public release; distribution is unlimited 


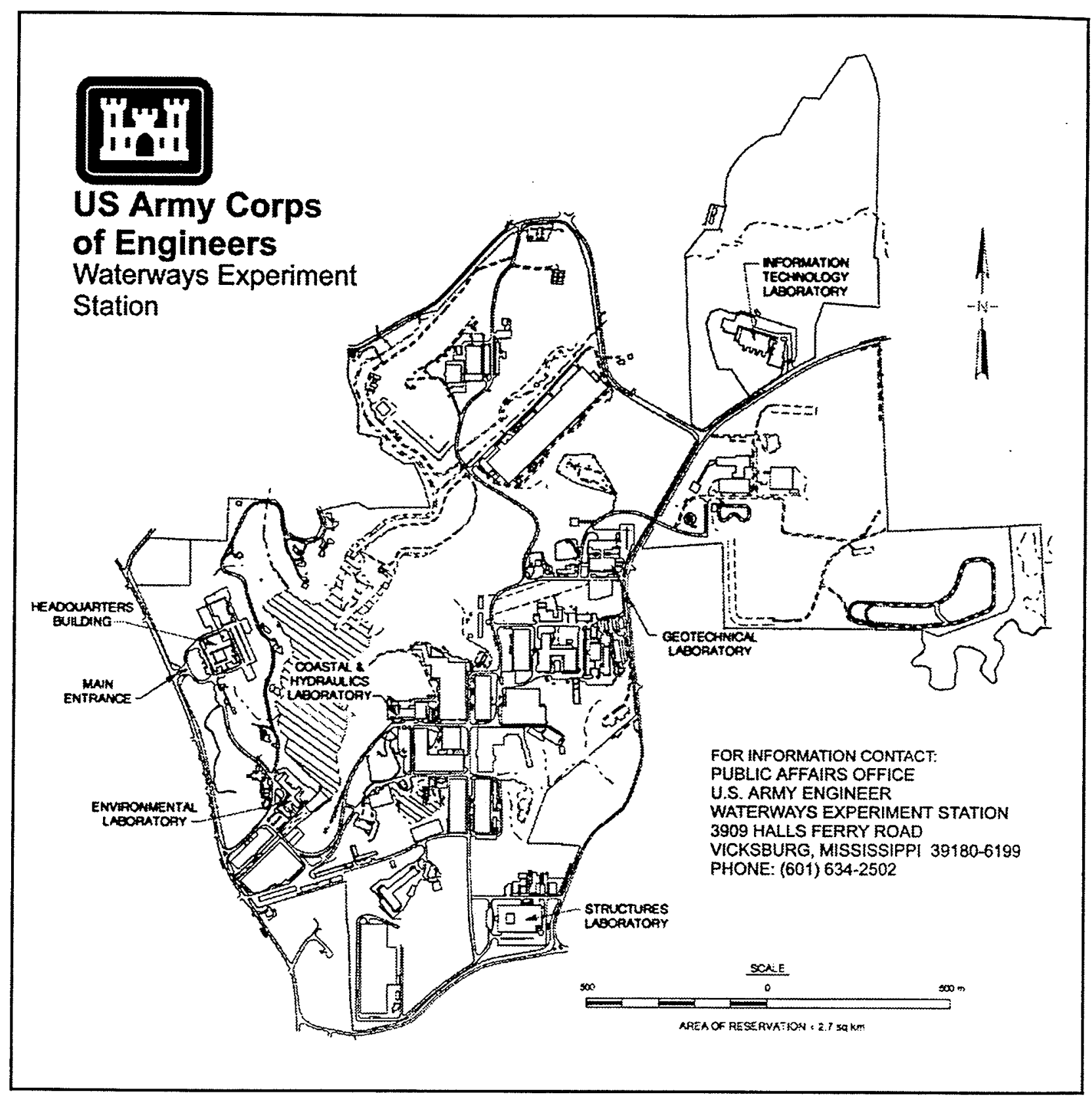

Waterways Experiment Station Cataloging-in-Publication Data

Fehl, Barry D., 1957-

Nonlinear, incremental structural analysis of McAlpine Lock Replacement for chamber, miter gate, and culvert valve monoliths / by Barry D. Fehl, Guillermo A. Riveros, Sharon Garner ; prepared for U.S. Army Corps of Engineers.

207 p. : ill. ; $28 \mathrm{~cm}$. -- (Technical report; ITL-97-4)

Includes bibliographic references.

1. McAlpine Locks and Dam (Ky.) -- Evaluation. 2. Locks (Hydraulic engineering) -Kentucky. 3. Dams -- Kentucky. 3. Structural analysis (Engineering) -- Kentucky -- Testing. I. Riveros, Guillermo A. II. Garner, Sharon B. III. United States. Army. Corps of Engineers. IV. U.S. Army Engineer Waterways Experiment Station. V. Information Technology Laboratory (U.S. Army Engineer Waterways Experiment Station) VI. Title. VII. Series: Technical report (U.S. Army Engineer Waterways Experiment Station) ; ITL-97-4.

TA7 W34 no.ITL-97-4 


\section{Contents}

Preface $\ldots \ldots \ldots \ldots \ldots \ldots \ldots \ldots \ldots \ldots \ldots$

1 -Introduction $\ldots \ldots \ldots \ldots \ldots \ldots \ldots \ldots \ldots \ldots \ldots \ldots \ldots \ldots$

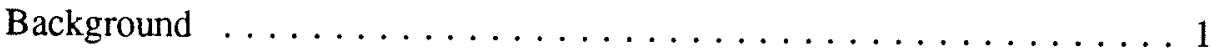

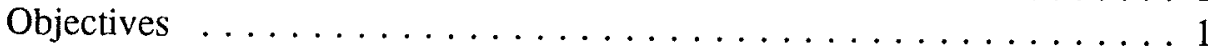

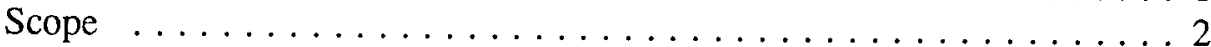

2-Material Parameters $\ldots \ldots \ldots \ldots \ldots \ldots \ldots \ldots \ldots \ldots \ldots \ldots$

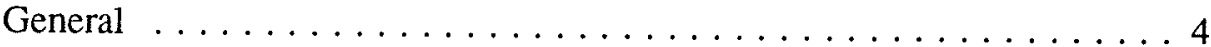

Thermal Properties . . . . . . . . . . . . . . . . . 5

Mechanical Properties $\ldots \ldots \ldots \ldots \ldots \ldots \ldots$

3-Modeling Parameters $\ldots \ldots \ldots \ldots \ldots \ldots \ldots$

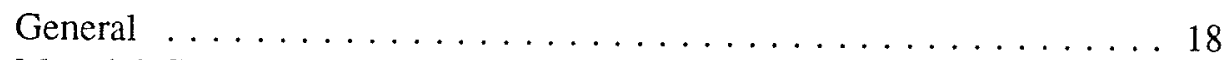

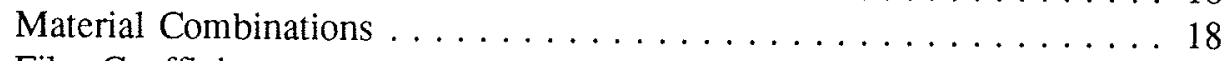

Film Coefficients . . . . . . . . . . . . . . . . . 19

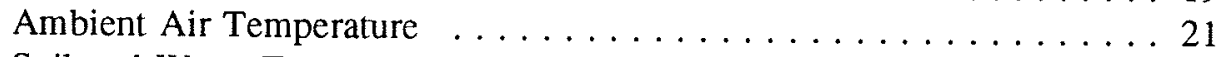

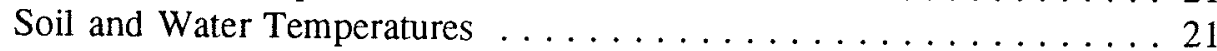

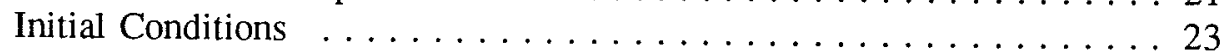

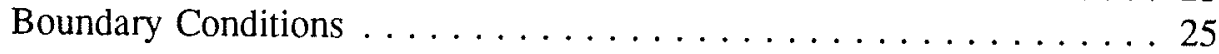

4 -Parametric Analyses-Chamber Monolith . . . . . . . . . . 26

General .......................... 26

Material Combinations ................... 30

Lift Heights . ..................... 42

5-Additional Analyses-Chamber Monolith . . . . . . . . . . . 64

General . . . . . . . . . . . . . . . . . . . . . . 64

Extended Analysis . . . . . . . . . . . . . . . . 65

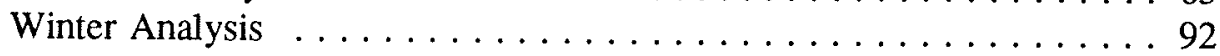

Final Analysis . . . . . . . . . . . . . . . 116

6 -Miter Gate Monolith Analyses . . . . . . . . . . . . . . 132

Heat Transfer Analysis . . . . . . . . . . . . . . . . . 132

Results . . . . . . . . . . . . . . . . . . . . . . . . . . 134

Stress Analyses . . . . . . . . . . . . . . . . . . . . 134

Results . . . . . . . . . . . . . . . . . . . . . 138

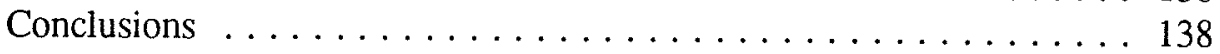


7-Culvert Valve Monolith Analyses . . . . . . . . . . . . . . . . 159

Background . . . . . . . . . . . . . . . . . . 159

Model Description . . . . . . . . . . . . . . . . . . . 160

Heat Transfer Analysis Results . . . . . . . . . . . . . . . . 161

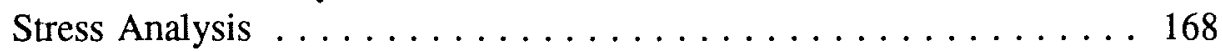

Summary . . . . . . . . . . . . . . . . 196

8-Conclusions and Recommendations . . . . . . . . . . . 197

Conclusions . . . . . . . . . . . . . . . . . . . 197

Recommendations . . . . . . . . . . . . . . . . 198

References . . . . . . . . . . . . . . . . . . . . . 199

SF 298 


\section{Preface}

The work described in this report was conducted for the U.S. Army Engineer District, Louisville, by the Computer-Aided Engineering Division (CAED), Information Technology Laboratory (ITL), and the Structural Mechanics Division (SMD), Structures Laboratory (SL), U.S. Army Engineer Waterways Experiment Station (WES). The investigation was authorized by DD form 448, MIPR No. RMB 93-515, dated 12 April 1993.

The investigation was accomplished under the general supervision of Dr. N. Radhakrishnan, Director, ITL; Mr. Bryant Mather, Director, SL, and under the direct supervision of Mr. H. Wayne Jones, CAED, and Drs. Reed Mosher and Robert Hall of SMD. This report was prepared by Messrs. Barry D. Fehl and Guillermo Riveros, CAED, and Ms. Sharon Garner, SMD. The authors would like to acknowledge Mr. Byron McClellan, Mr. Larry Dalton, and Mr. Steve Farkus, CEORL-ED-DS, for their support and encouragement during the performance of the work described herein.

At the time of publication of this report, Director of WES was Dr. Robert W. Whalin. Commander was COL Bruce K. Howard, EN.

The contents of this report are not to be used for advertising, publication, or promotional purposes. Citation of trade names does not constitute an official endorsement or approval of the use of such commercial products. 


\section{Conversion Factors, Non-SI to SI Units of Measurement}

Non-SI units of measurement used in this report can be converted to SI units as follows:

\begin{tabular}{|l|c|l||}
\hline Multiply & By & To Obtain \\
\hline \hline Btu's (International Table) & 1055.56 & joules \\
\hline degrees (angle) & 0.01745329 & radians \\
\hline Fahrenheit degrees & $5 / 9$ & Celsius degrees or Kelvins' \\
\hline feet & 0.3048 & meters \\
\hline inches & 2.54 & centimeters \\
\hline kips (force) per square inch & 6.894757 & megapascals \\
\hline miles (U.S. nautical) & 1.852 & kilometers \\
\hline miles per hour (U.S. statute) & 1.609344 & kilometers per hour \\
\hline pounds (mass) per cubic foot & 16.01846 & kilograms per cubic meter \\
\hline pounds (mass) per cubic inch & $27,679.9$ & kilograms per cubic meter \\
\hline pounds (force) per square inch & 6894.757 & pascals \\
\hline square inches & 6.4516 & square centimeters \\
\hline tons (2,000 pounds, mass) & 907.1847 & kilograms \\
\hline $\begin{array}{l}\text { To obtain Celsius (C) temperature readings from Fahrenheit (F) readings, use the following } \\
\text { formula: C }=(5 / 9) \text { (F - 32). To obtain Kelvin (K) readings, use: }\end{array}$ & (K) = (5/9) (F - 32) + 273.15. \\
\hline
\end{tabular}




\section{Introduction}

\section{Background}

In January 1993, the U.S. Army Engineer Waterways Experiment Station was requested to perform a nonlinear, incremental structural analysis (NISA) of the McAlpine Lock Replacement Project for the Louisville District. The McAlpine project will be constructed at the existing McAlpine locks, which are located in the shipping canal of the Ohio River at mile $607 .^{1}$ This location is also near downtown Louisville, Kentucky. The new 1,200-ft-long lock will replace the existing $600-\mathrm{ft}$ chamber currently used as the auxiliary lock chamber. The lock will be constructed as gravity wall monoliths founded on a rock foundation. The geometry of the monoliths is typical of geometry of other gravity type lock walls.

The NISA process has been used for approximately the last 10 years to evaluate massive concrete structures for their constructability and to provide a means for consideration of the effects of various changes to construction procedures. Guidance for the performance of a NISA was available at the time this study began through Engineer Technical Letter (ETL) 1110-2-324, "Special Design Provisions for Massive Concrete Structures." Also, at the time the study began, a new ETL, "Nonlinear, Incremental Structural Analysis of Massive Concrete Structures" was in final draft form and a decision was made, in consultation with Headquarters, U.S. Army Corps of Engineers, to use the new ETL as the guide in performing the NISA of McAlpine locks.

\section{Objectives}

The objectives of this study were to accomplish the following:

a. Evaluate a typical chamber monolith to determine the maximum lift heights possible and the maximum concrete placing temperature.

\footnotetext{
1 A table of factors for converting non-SI units of measurement to SI (metric) units is provided on page vi.
} 
$b$. Using the results from the chamber monolith analyses, determine whether or not the miter gate monolith is constructable using the same construction parameters.

c. Again, using the results from the chamber monolith analyses, determine whether or not the culvert valve monolith is constructable using the same construction parameters.

$d$. Determine if additional reinforcement beyond the basic design reinforcement is required to control cracking due to thermal loads in the culvert valve monolith.

\section{Scope}

In order to meet the objectives outlined above, a plan of action was developed to provide a systematic approach to achieving these desired objectives. The basis for this plan of action was the new ETL discussed above. Using the geometry of a typical chamber monolith and information from the new ETL, the first three analyses to be performed were analyses which evaluated three different combinations of material properties as shown in Table 1, where the bandwidths shown are percentages of the actual test data. The analyses of the combinations presented in Table 1 were to be performed using lift heights of $7.5 \mathrm{ft}$, a placing temperature of $70^{\circ} \mathrm{F}$, and a start of construction around 1 June to produce maximum temperatures within the monolith. In addition, it was agreed that reinforcing would be included in the analyses, that the foundation would be modeled with continuum elements, and 5-day placing intervals would be assumed.

\begin{tabular}{|l|l|l|l|}
\hline \hline $\begin{array}{l}\text { Table 1 } \\
\text { Material Property Combinations }\end{array}$ \\
\hline \hline Combination & Creep, percent & Shrinkage, percent & Adiabatic Temp. Rise, percent \\
\hline \hline 1 & 0 & 0 & 110 \\
\hline 2 & 85 & 85 & 110 \\
\hline 3 & 85 & 115 & 110 \\
\hline
\end{tabular}

Once the analyses were completed using the combinations outlined in Table 1, the worst of combinations 2 and 3 was to be used to evaluate the chamber monolith with lift heights of $10 \mathrm{ft}$. Provided the $10-\mathrm{ft}$ lifts did not indicate excessive cracking for the chamber monolith, a two-dimensional (2-D) analysis of a typical miter gate monolith was to be performed as a confirmatory analysis. The results from the 2-D analysis of the chamber monolith were also to be implemented on the three-dimensional (3-D) analysis of the culvert valve monolith to confirm its constructability. 
In addition to the above analyses, the ETL requires an analysis at a second start date and the inclusion of service loads. These items were to be included in analyses subsequent to the material combination study and the lift height study.

Chapter 2 of this report will present the material properties used in the analysis and further discussion on the modeling parameters is contained in Chapter 3. Chapter 4 will present the results of parametric studies on materials and lift heights for the typical chamber monolith while Chapter 5 will present analyses of the chamber monolith with service loads included and a winter start analysis. Chapter 6 presents the results of the confirmatory analysis of the miter gate monolith and Chapter 7 provides the results for the 3-D analysis of the culvert valve monolith. Chapter 8 consists of conclusions and recommendations resulting from the analyses presented in Chapters 4,5 , and 6. 


\section{Material Parameters}

\section{General}

The material properties of both the concrete and the foundation are an integral part of performing a NISA. Properties are needed for both the heat transfer analyses and the stress analyses. For foundation properties used in the analyses, the properties are assumed constant with respect to time, but for concrete there are properties that are time-dependent as well as properties which are constant with respect to time. It is because of the time-dependent properties in concrete that such an extensive analysis is required on massive concrete structures, such as the lock walls of the McAlpine Lock Replacement Project.

In order to perform the NISA for the McAlpine project, an extensive testing program was undertaken to determine the material properties to be used in the analyses. The testing program included performing tests for all constant and time-dependent properties of the concrete and all of the properties of the rock. Testing of the concrete was performed on concrete mixtures which are based on mixture designs expected to be used in the field during construction. Testing of the rock was performed on rock cores taken by the Louisville District at the project site. The test methods and test results are reported in "Concrete Mixture Selection and Characterization Study McAlpine Locks Replacement, Ohio River" (Bombich, Neeley, and Gamer, in preparation).

Since gravity-type monoliths will be used to form the replacement lock walls at the McAlpine project, two different concrete mixtures will be used. Unlike U-frame type construction where the slab of a monolith creates a structural member between the lock walls, the lock walls of a gravity-type lock act independently of one another and hence must be independently stable. This creates a condition where the size of the monolith is dictated primarily by a design which satisfies the overturning stability of the structure. In order to achieve a more cost-effective design, two different concrete mixtures are often used in construction of gravity type monoliths. For the exterior portions of the monolith such as the face of the chamber wall and other exposed surfaces, a concrete mixture is used which is similar to mixtures used for other mass concrete construction such as U-frame locks. For interior portions of the monolith, a lower strength concrete is used. This arrangement provides the 
necessary weight to satisfy the weight needs for stability requirements and provides durable exterior surfaces, but reduces cost since the lower strength interior mixture will not require as much cement.

The remainder of this chapter will be dedicated to discussing the various properties used in the McAlpine lock replacement NISA.

\section{Thermal Properties}

Thermal properties are the properties needed to perform the heat transfer analysis, which will provide the temperatures needed for input into the stress analysis. Both concrete and rock properties are needed, since the rock is included in the heat transfer analysis.

\section{Rock}

Because the rock does not change with time, all of the properties of the rock are assumed constant with respect to time. The rock properties needed for the heat transfer analysis are density, specific heat, and thermal conductivity. The properties used in the heat transfer analysis were obtained from the characterization study (Bombich, Neeley and Garner, in preparation) and are reported in Table 2.

\begin{tabular}{|c|c|}
\hline $\begin{array}{l}\text { Table } 2 \\
\text { Properties of Rock }\end{array}$ & \\
\hline Property & Input Value \\
\hline Density & $0.0952 \mathrm{lb} / \mathrm{in}^{3}$ \\
\hline Specific heat & $0.21 \mathrm{Btu} / \mathrm{b}-{ }^{\circ} \mathrm{F}$ \\
\hline Thermal conductivity & 2.62 Btu/in. day- ${ }^{\circ} \mathrm{F}$ \\
\hline Coefficient of thermal expansion & $5.20 \times 10^{-6} \mathrm{in} . / \mathrm{in} . /^{\circ} \mathrm{F}$ \\
\hline Elastic modulus & $7.5 \times 10^{6} \mathrm{lb} / \mathrm{in}^{2}$ \\
\hline Poisson's ratio & 0.20 \\
\hline
\end{tabular}

\section{Concrete}

Unlike the rock, the heat transfer analysis uses one property which is timedependent, the adiabatic temperature rise. The adiabatic temperature rise is a measure of the heat of hydration of the cementitious materials in the concrete. The remaining properties used in the heat transfer analysis (density, specific heat and thermal conductivity) are all assumed to be constant, are shown in 

Tabie 3, and were taken from the characterization study (Bombich, Neeley, and Gamer, in preparation).

\section{Table 3 \\ Properties of Concrete}

\begin{tabular}{|c|c|c|}
\hline Paporiv & Input Value Interior Mixture & Input Value Exterior Mixture \\
\hline Densivy & $0.0846{\mathrm{lb} / \mathrm{in} .^{3}}^{3}$ & $0.0846 \mathrm{lb} / \mathrm{in}^{3}$ \\
\hline Spocifio neat & $0.242 \mathrm{Btu} / \mathrm{b}-{ }^{\circ} \mathrm{F}$ & $0.242 \mathrm{Btu} / \mathrm{b}-{ }^{\circ} \mathrm{F}$ \\
\hline Themal conductivity & 2.604 Btu/in.-day. ${ }^{\circ} \mathrm{F}$ & 2.604 Btu/in.-day- ${ }^{\circ} \mathrm{F}$ \\
\hline Coefficient of thermal expansion & $5.20 \times 10^{-6} \mathrm{in} . / \mathrm{in} .{ }^{\circ} \mathrm{F}$ & $5.053 \times 10^{-6} \mathrm{in} . / \mathrm{in} . /^{\circ} \mathrm{F}$ \\
\hline
\end{tabular}

The sest for adiabatic temperature rise is a tesi which measures the magniwide of the temperature rise of the concrete in an adiabatic condition, i.e. completely insulated enviromment. The temperatures obtained from the test are used in the heat transfer analysis to compute heat flux values which model the hear generated by the concrete in the structure. Use of the adiabatic temperawre tise is achieved through the use the subroutine HETVAL (previous NISA aralyses haye wsed the subroutine DFLUX) contained in ABAQUS (Hibbitt, Karlsson, and Sorensen 1989). HETVAL is arranged so that the heat flux in each int is computed according to its age and based on the temperatures btained from the adiabaic temperature rise test.

The resulis of the actual adiabatic temperature rise test can be input into the somotine HETYAL, but to ensure the calculations of the subroutine are being ostomed correcty a test problem on a single element which is totally malated should be performed. Such a test problem was executed for both mintures of the MCAlphie project, with results of the analyses shown along whe the ise resuls in migure 1.

As mod in Charter 1, a decision was made to use the newly developed LIT NISA ts the guidance document for the McAlpine NISA. Because of this decision, an prover bound for the adiabatic temperature rise curve had to be used which incicased the curve based on test data by 10 percent. The results of increasing the adiabatic temperature rise curves by 10 percent are shown in Figure 2 and are compared to the curves developed from the test data.

\section{Mechanical Properties}

Mechanical properties are the properties needed to perform the stress analysis, which will provide the results on which decisions concerning the construction of the various monoliths can be made. Unlike NISA studies performed in the past on Melvin Price locks (Truman, Petruska, and Ferhi 1992) and Olmsted locks (Gamer et al. 1992), which were soil-founded structures and in 



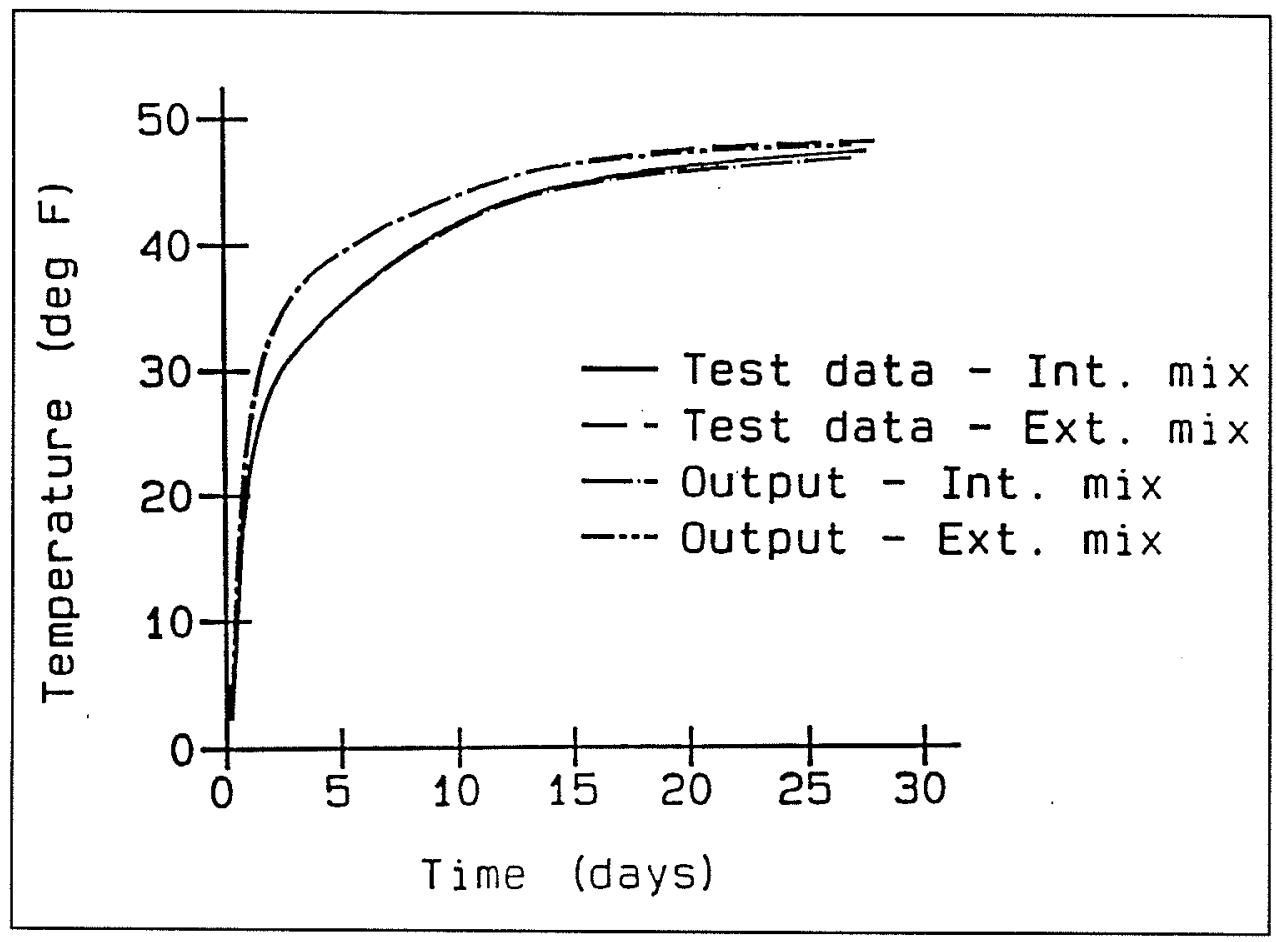

Figure 1. Adiabatic temperature rise test data and curve fits

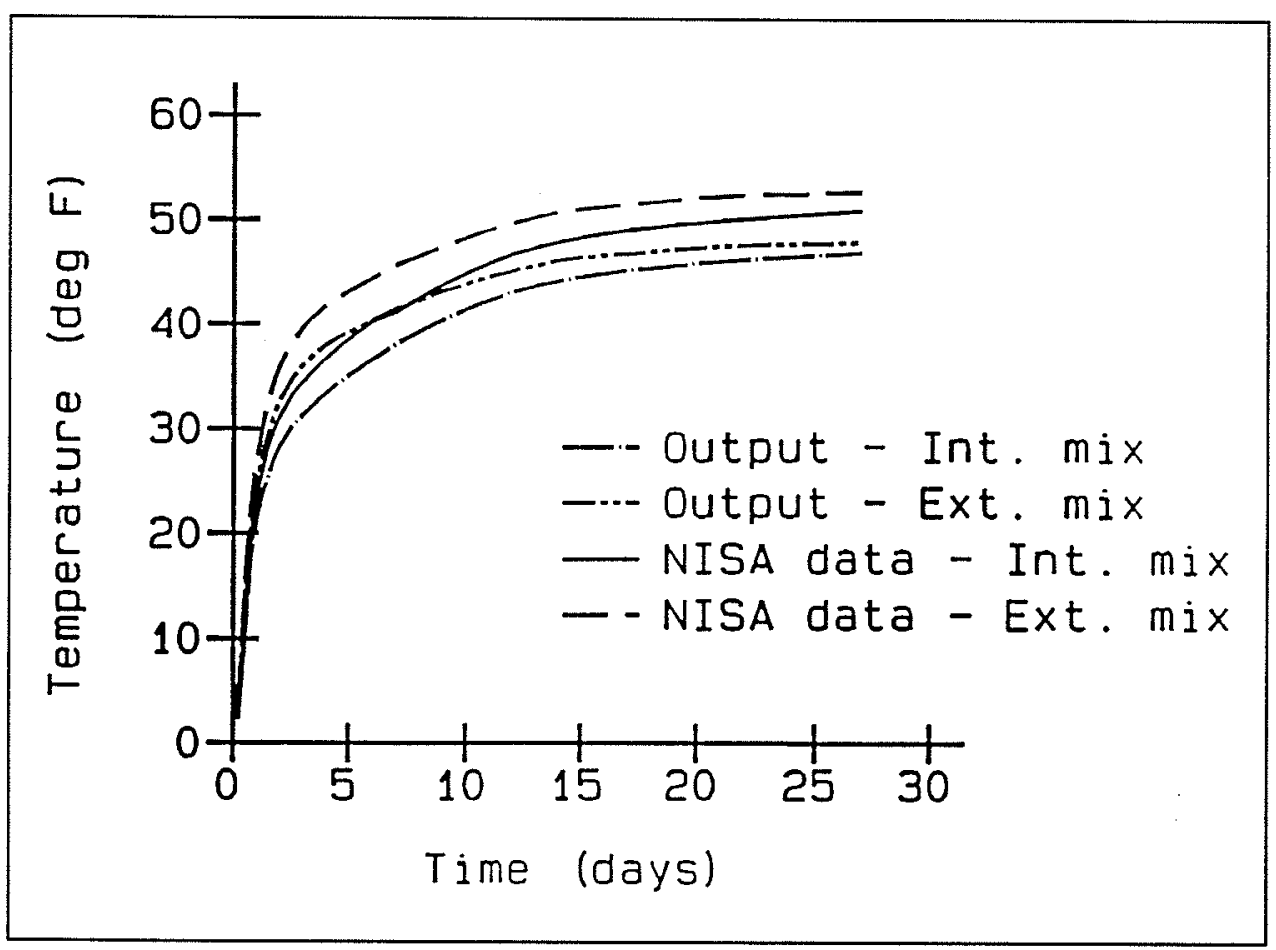

Figure 2. Adiabatic temperature rise curve fits and curves used in NISA 
which the foundations were modeled with springs, the McAlpine project is founded on rock and therefore the foundation was modeled with finite elements. This will require, as for the heat transfer analysis, properties for the rock as well as the concrete.

\section{Rock}

The foundation rock at the McAlpine project can be described as a competent limestone. Not only does it have a high modulus value (see Table 2) but it also contains very little fragmentation. The material properties for the rock are all constant with respect to time and are assumed to be completely linear elastic. The properties needed for the stress analysis are the density, the coefficient of thermal expansion, the elastic modulus, and Poisson's ratio. The properties used in the analyses were obtained from the characterization study (Bombich, Neeley, and Garner, in preparation) and are reported in Table 2.

\section{Concrete}

For the stress analysis, the concrete is treated as a nonlinear material with respect to time. While the calculations within each time increment treat the concrete as an elastic material, the stiffness is reformulated in each time increment based on the existing strain state in the concrete and on the change in the material properties.

Not all of the concrete properties are considered to be time-dependent. Density, Poisson's ratio, and the coefficient of thermal expansion are all assumed to be constant in the stress analysis. These constant properties are given for both the interior and exterior mixtures in Table 3 and were taken from the characterization study (Bombich, Neeley, and Gamer, in preparation). Although Poisson's ratio is known to vary at early times, and it is possible that the coefficient of thermal expansion changes as concrete ages, using a constant value for these two values is assumed to be sufficient.

Time-dependent properties modeled in the stress analysis portion of a NISA are the modulus of elasticity, creep, shrinkage, and the cracking criteria. Each of these properties must be calibrated to a mathematical function which relates the magnitude of the property to the age of the concrete. The calibration is done using another subroutine available in ABAQUS (Hibbitt, Karlsson, and Sorensen 1989) called UMAT. UMAT contains the necessary mathematical functions needed to model the various time-dependent properties. The calibration is performed by adjusting the parameters of these functions so that they approximate the data of the test results. Once the functions are adjusted so that the best possible curve fits are attained, UMAT is ready to be used for performing the stress analysis. Results of the calibrations performed on the exterior and interior mixtures are presented in the following paragraphs. Results of the testing are reported in Bombich, Neeley, and Garner (in 
preparation). In addition, for this NISA study, the UMAT subroutine used was contained in ANACAP-U software (ANATECH Research Corp., 1992).

The first property considered is the modulus of elasticity. The mathematical function used in UMAT to describe the aging modulus of elasticity $E(t)$ is

$$
\begin{aligned}
E(t) & =E_{1}\left[1-e^{x l(t-1)}\right]+E_{2}\left[1-e^{x(t-1)}\right] \\
& +D(t-1)+E(1) \text { for } t \geq t_{o} \text { days }
\end{aligned}
$$

where $E_{1}, E_{2}, D, x_{1}$ and $x_{2}$ are the constants used to calibrate the function to fit the test data, $E(1)$ is the modulus of elasticity in psi at one day, and $t$ is the age of the concrete in days. The constants used to fit the equation to the McAlpine mixtures are given in Table 4. Figures 3 and 4 show how the resulting equation fits the actual test data for the interior and exterior mixtures, respectively. In addition, at the time the material properties were calibrated, data were only available through 90 days. Based on these data, the resulting mathematical curve fit for both mixtures continued to increase without an upper bound. Therefore, maximum values for the modulus had to be included in the UMAT subroutine. The maximum values used were $5.5 \times 10^{6} \mathrm{psi}$ for the interior mixture and $5.0 \times 10^{6}$ psi for the exterior mixture. The maximums were determined based on discussions between material engineers from the Louisville District and the Ohio River Division.

\begin{tabular}{|l|l|l|}
\hline \multicolumn{2}{|l|}{$\begin{array}{l}\text { Table } 4 \\
\text { Constants Used in Modulus of Elasticity }\end{array}$ Function } \\
\hline \hline Constant & Interior Mixture & Exterior Mixture \\
\hline \hline$E_{1}$ & $1.69920 \times 10^{6}$ & $0.99105 \times 10^{6}$ \\
\hline$E_{2}$ & $0.34298 \times 10^{6}$ & $0.68969 \times 10^{6}$ \\
\hline$D$ & $0.11725 \times 10^{5}$ & $0.85266 \times 10^{4}$ \\
\hline$E(1)$ & $1.009 \times 10^{6}$ & $1.456 \times 10^{6}$ \\
\hline$x_{1}$ & -0.135854 & -0.196233 \\
\hline$X_{2}$ & -2.649150 & -2.649150 \\
\hline
\end{tabular}

The next property considered is creep. The mathematical function used in UMAT to describe the time-dependent creep $C(t)$ is

$$
\begin{aligned}
C(t) & =A_{1}\left[1-e^{r(t-t o)}\right]+A_{2}\left[1-e^{r 2(t-t o)}\right] \\
& +A_{3}\left[1-e^{r 3(t-t o)}\right] \text { for } t \geq t_{o} \text { days }
\end{aligned}
$$

where $A_{1}, A_{2}, A_{3}, r_{1}, r_{2}$ and $r_{3}$ are the constants used to calibrate the function to fit the test data, $t$ is the age of the concrete in days, and $t_{o}$ is the age at loading 


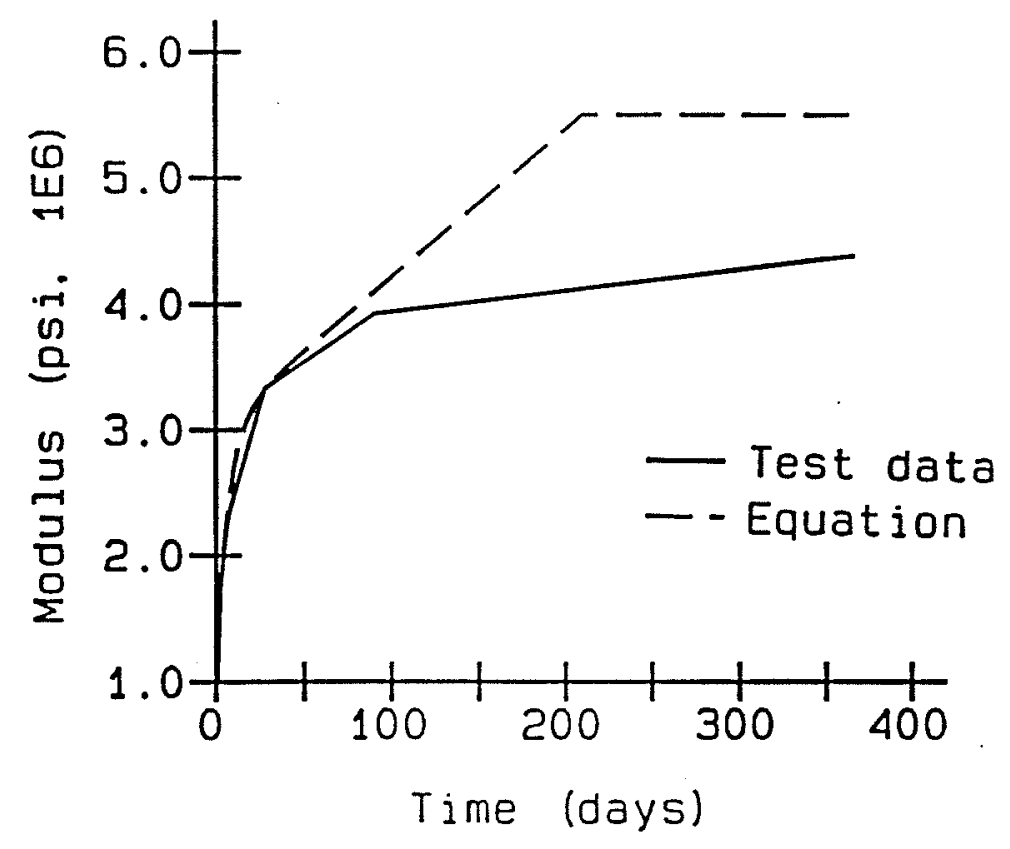

Figure 3. Modulus of elasticity test data and curve fit for interior mixture

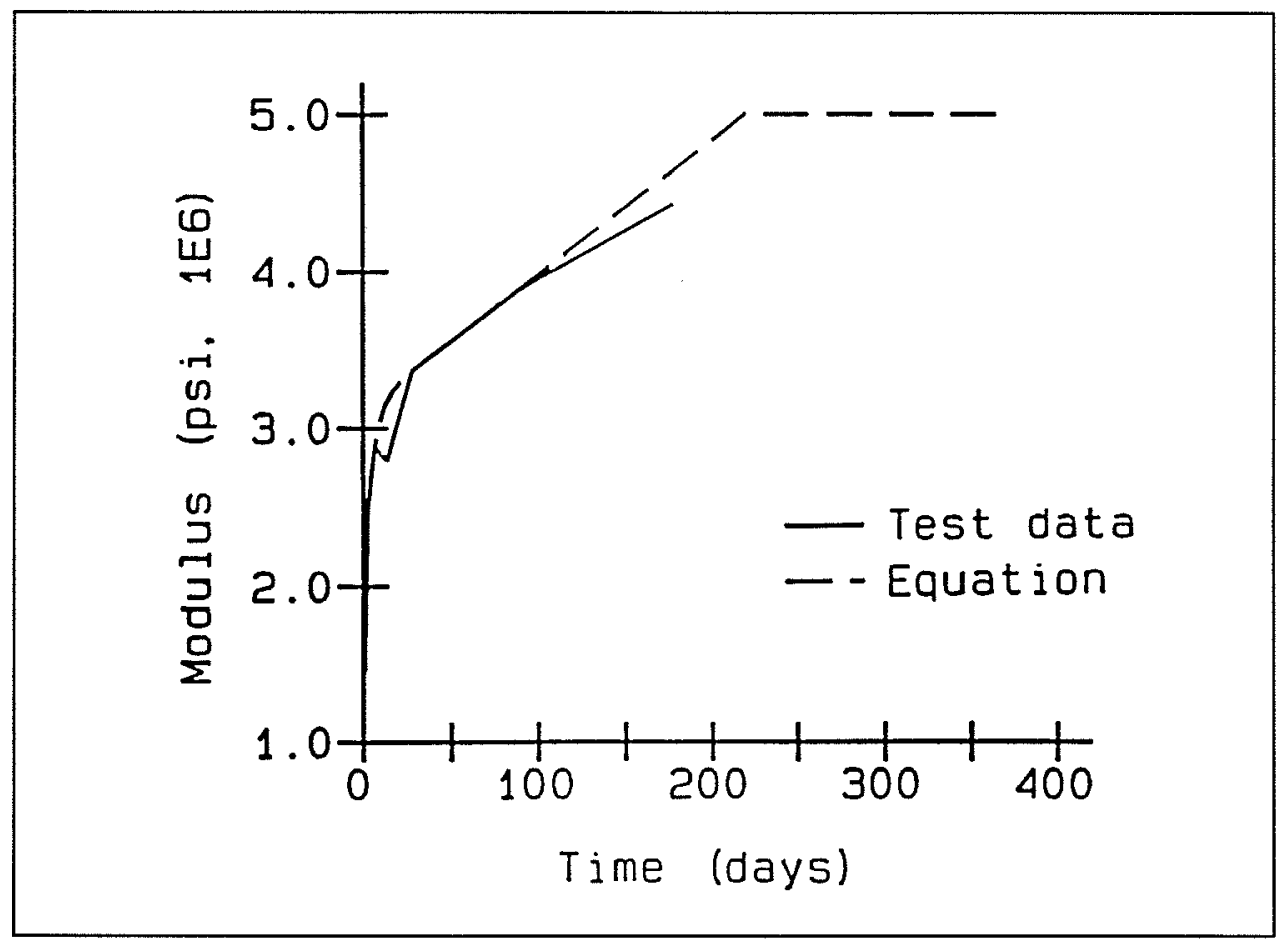

Figure 4. Modulus of elasticity test data and curve fit for exterior mixture 
in days. The constants used fit the equation to the McAlpine mixtures are given in Table 5. Figures 5, 6, and 7 show how the numerical data fit the test data of the interior mixture at 1,3 , and 14 days, respectively. Figures 8,9 , and 10 compare numerical data to test data for the exterior mixture at 1,3 , and 14 days, respectively. As can be seen in the figures, the 3- and 14-day data from the model agree well with the test data, but there is a significant difference at 1 day. The difference seen for the interior mixture at 1 day is attributed to loading problems during the test, while the difference for the exterior mixture is a result of the difficulty in getting one equation to satisfy curves at three different times.

\begin{tabular}{|c|c|c|}
\hline Constant & Interior Mixture & Exterior Mixture \\
\hline$A_{1}$ & $0.3786 \times 10^{-6}$ & $0.35411 \times 10^{-6}$ \\
\hline$A_{2}$ & $0.39886 \times 10^{-6}$ & $0.11525 \times 10^{-6}$ \\
\hline $\mathrm{A}_{3}$ & $0.17433 \times 10^{-6}$ & $0.11741 \times 10^{-6}$ \\
\hline$r_{1}$ & -0.0105966 & -0.0105966 \\
\hline$r_{2}$ & -0.1324575 & -0.1324575 \\
\hline$r_{3}$ & -1.7661 & -1.7661 \\
\hline
\end{tabular}

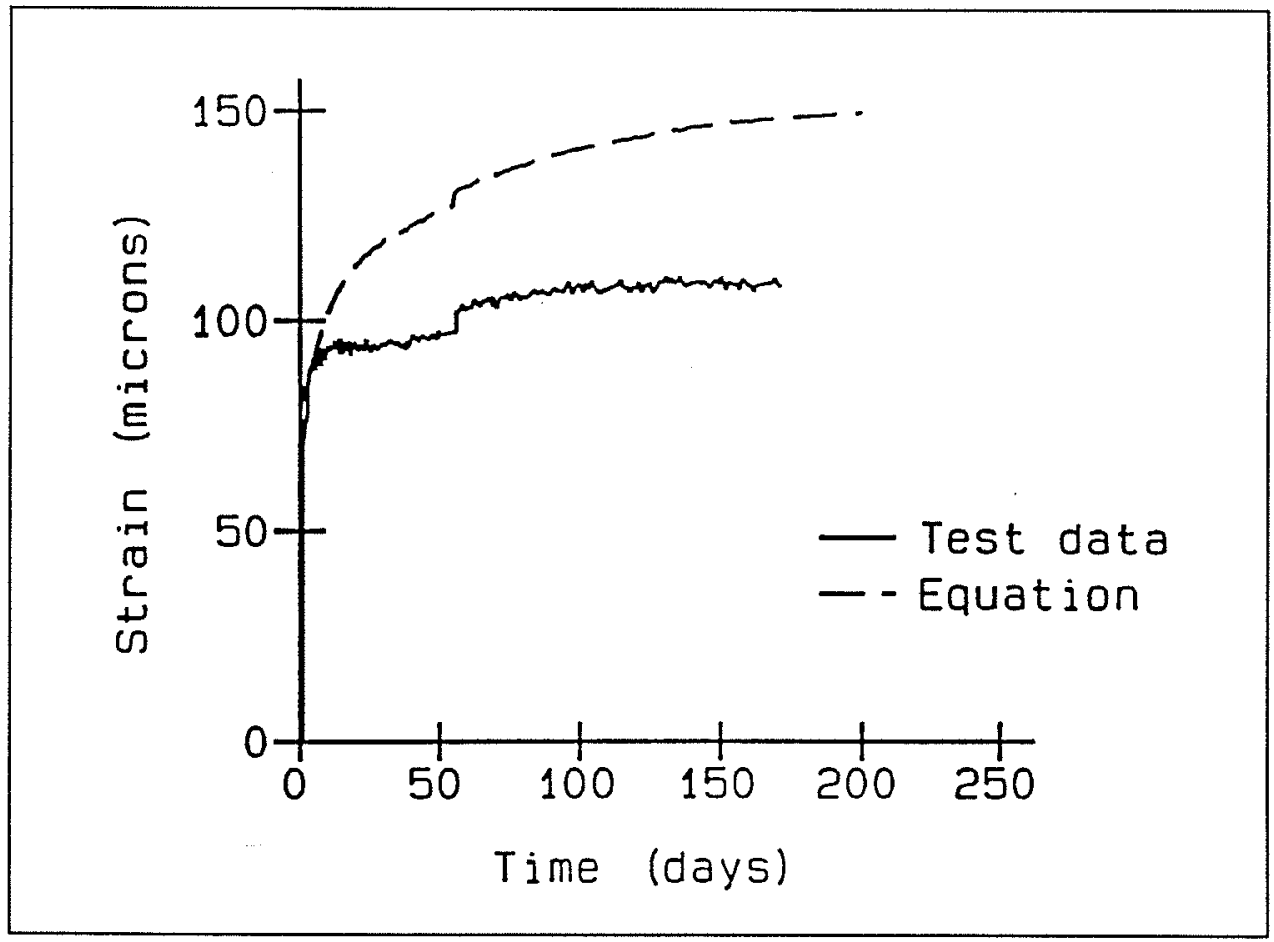

Figure 5. Creep test data at 1 day and calibration curve for interior mixture 


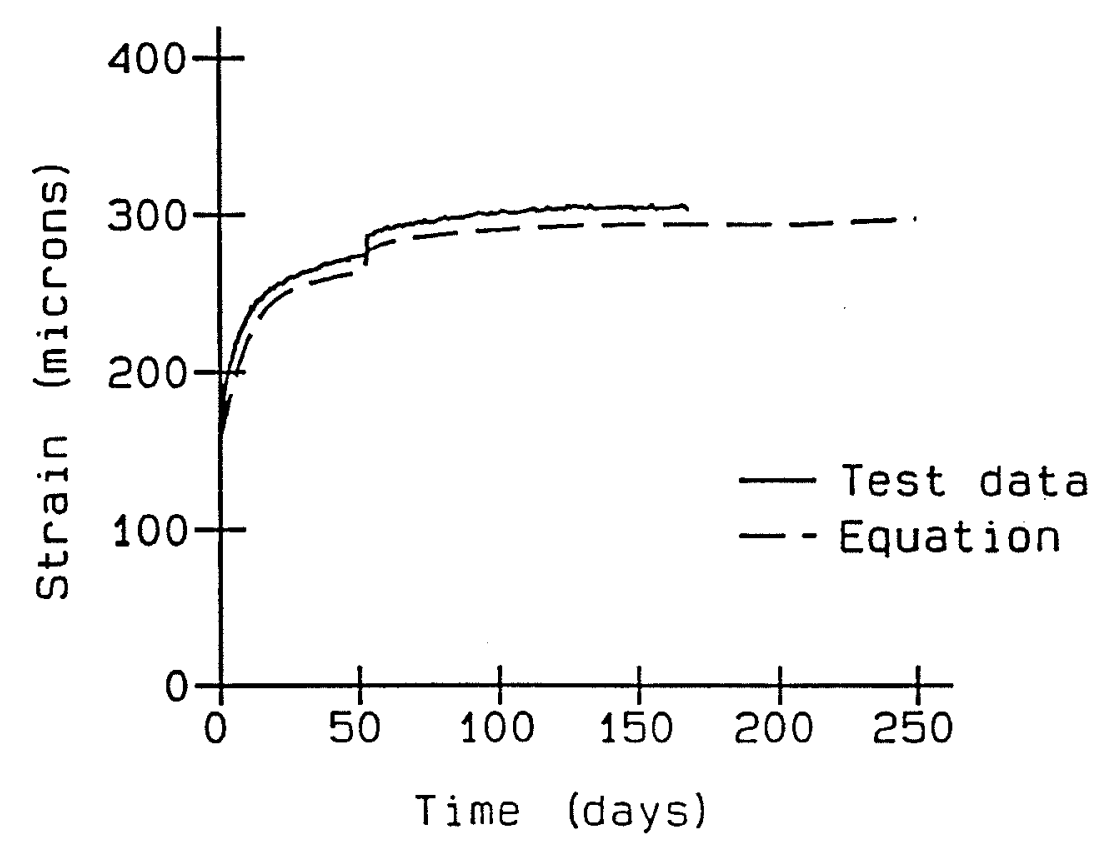

Figure 6. Creep test data at 3 days and calibration curve for interior mixture

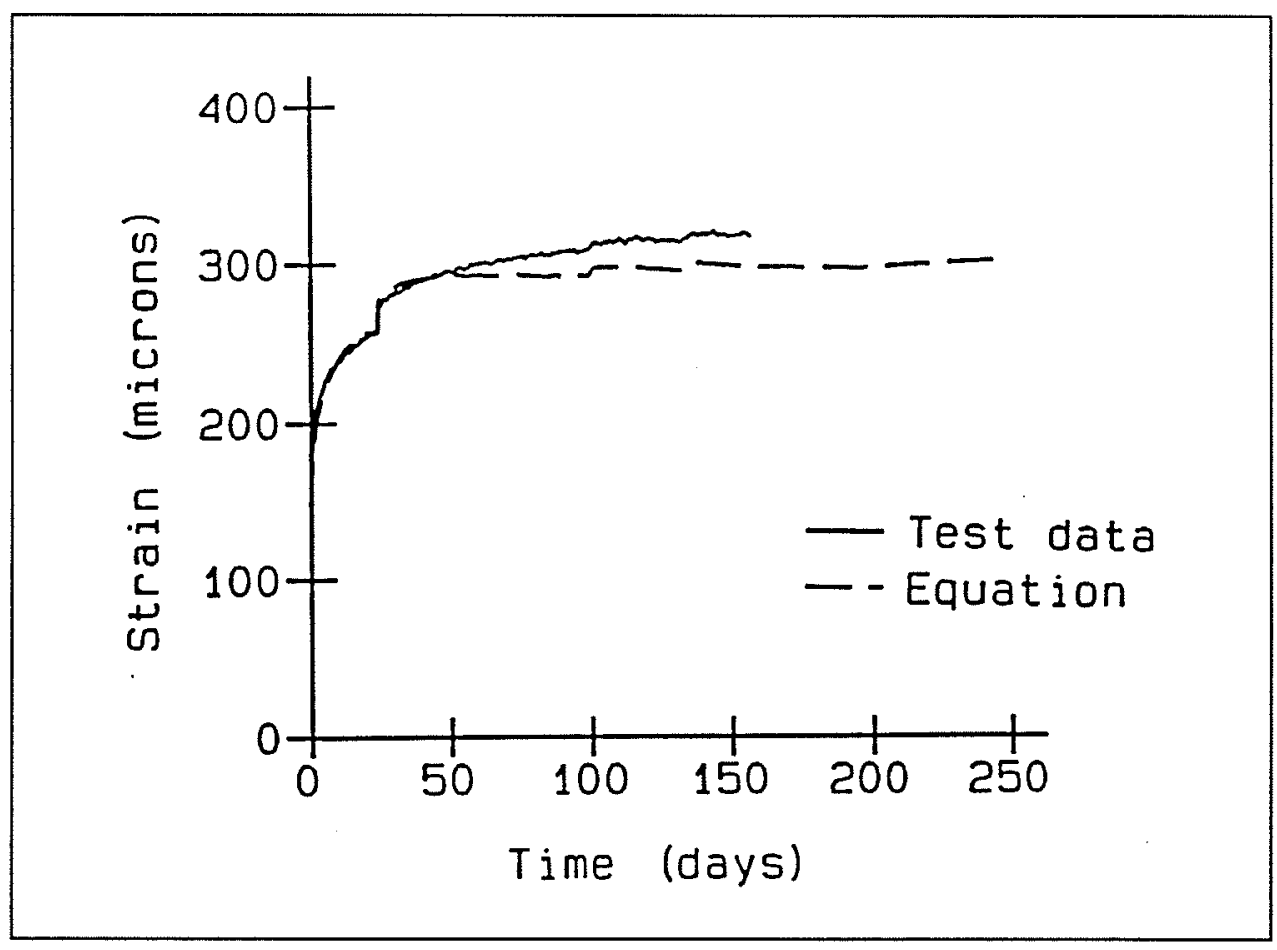

Figure 7. Creep test data at 14 days and calibration curve for interior mixture 


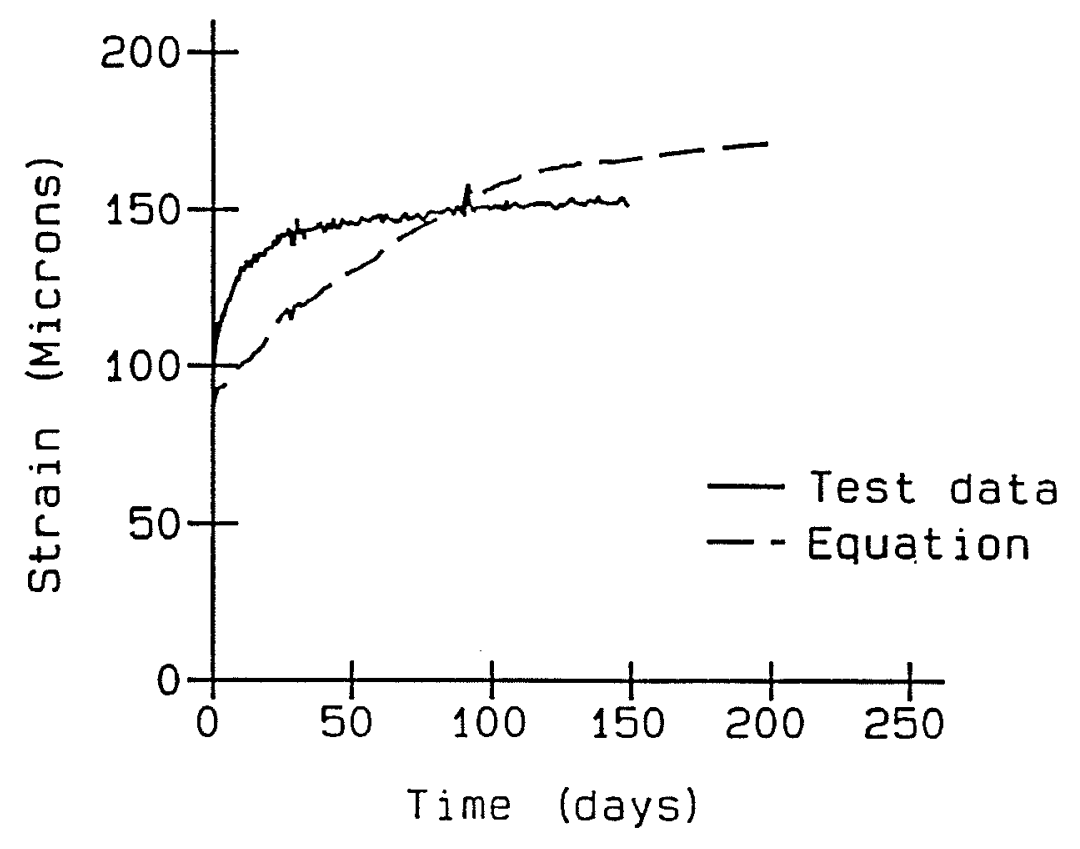

Figure 8. Creep test data at 1 day and calibration curve for exterior mixture

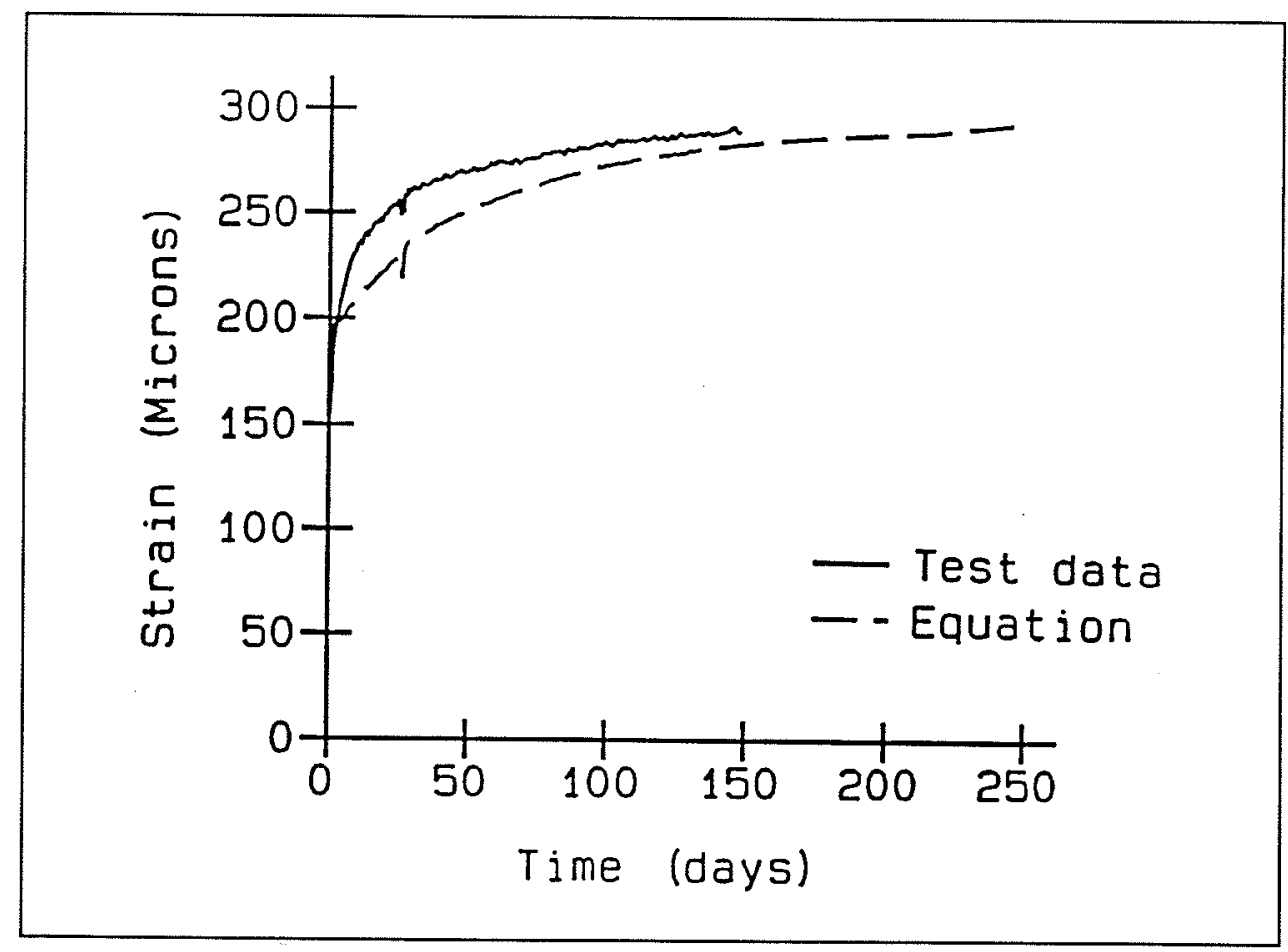

Figure 9. Creep test data at 3 days and calibration curve for exterior mixture 


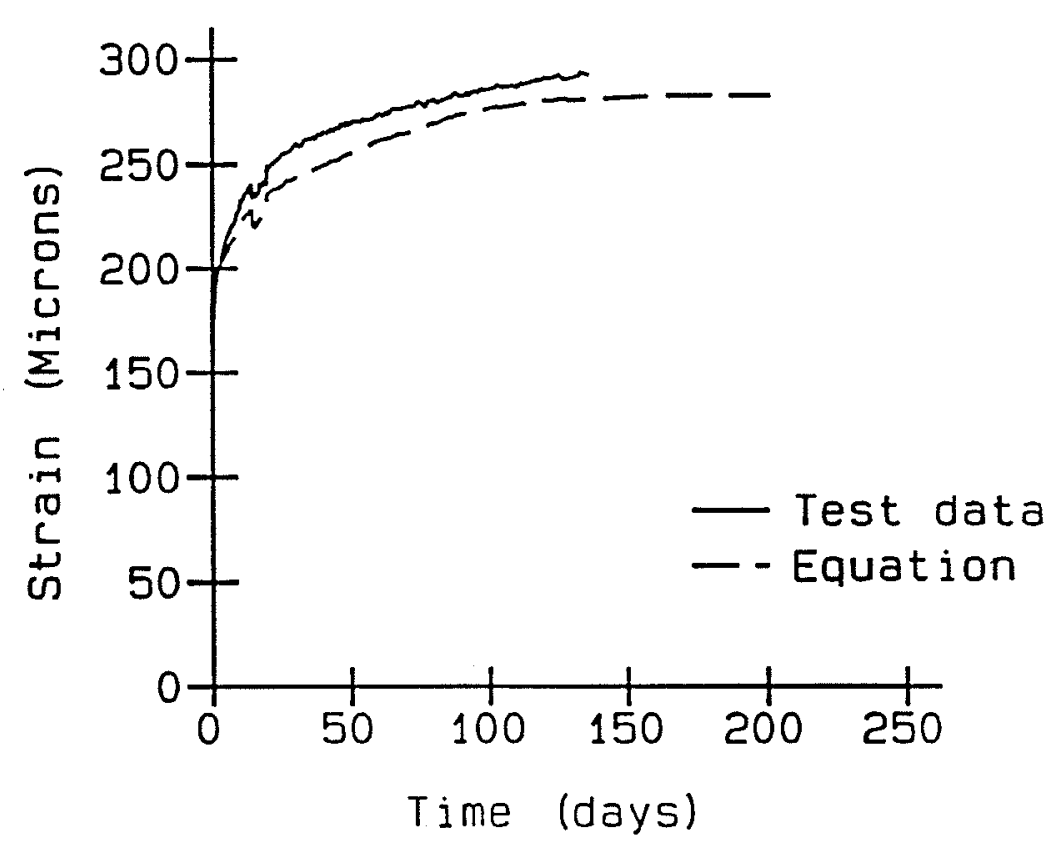

Figure 10. Creep test data at 14 days and calibration curve for exterior mixture

The expression used in UMAT for shrinkage $\varepsilon_{\text {shrinkage }}$ is

$$
\varepsilon_{\text {shrinkage }}=S_{1}\left[1-e^{z t}\right]+S_{2} t
$$

where $S_{1}, S_{2}$, and $z$ are the constants used to fit the curve to the test data and $t$ is the time since the time of placement in days. The constants used in the shrinkage equation to calibrate the equation to the mixtures for the McAlpine project are given in Table 6. Curves from the test results are compared to curves from the equations in Figure 11 for the interior mixture and Figure 12 for the exterior mixture. In addition, it should be noted that while the curve for the interior mixture looks as if it continues to increase indefinitely, a maximum value of 50 millionths in./in. of strain was established within UMAT.

\begin{tabular}{|c|c|c|}
\hline Constant & Interior Mixture & Exterior Mixture \\
\hline$s_{1}$ & $0.12594 \times 10^{-4}$ & $0.26663 \times 10^{-4}$ \\
\hline$S_{2}$ & $0.13579 \times 10^{-6}$ & 0.0 \\
\hline$z$ & -0.096333 & -0.071599 \\
\hline
\end{tabular}




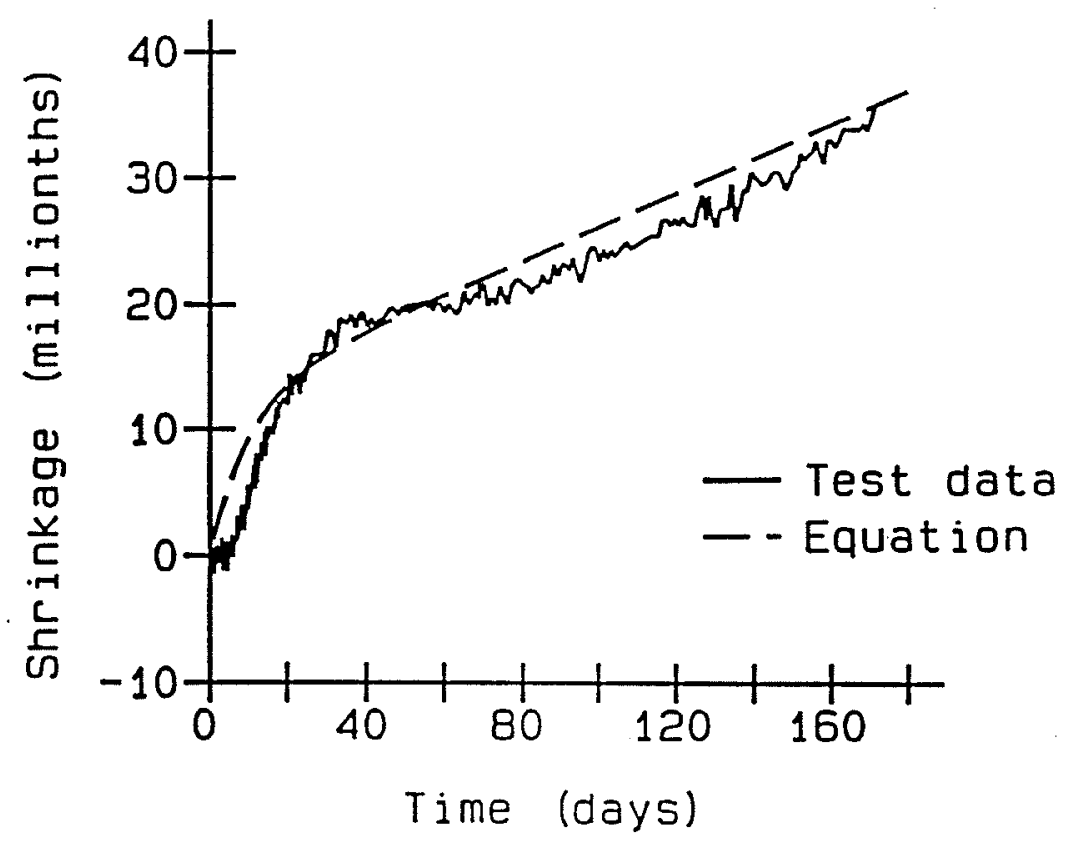

Figure 11. Shrinkage test data and curve fit for interior mixture

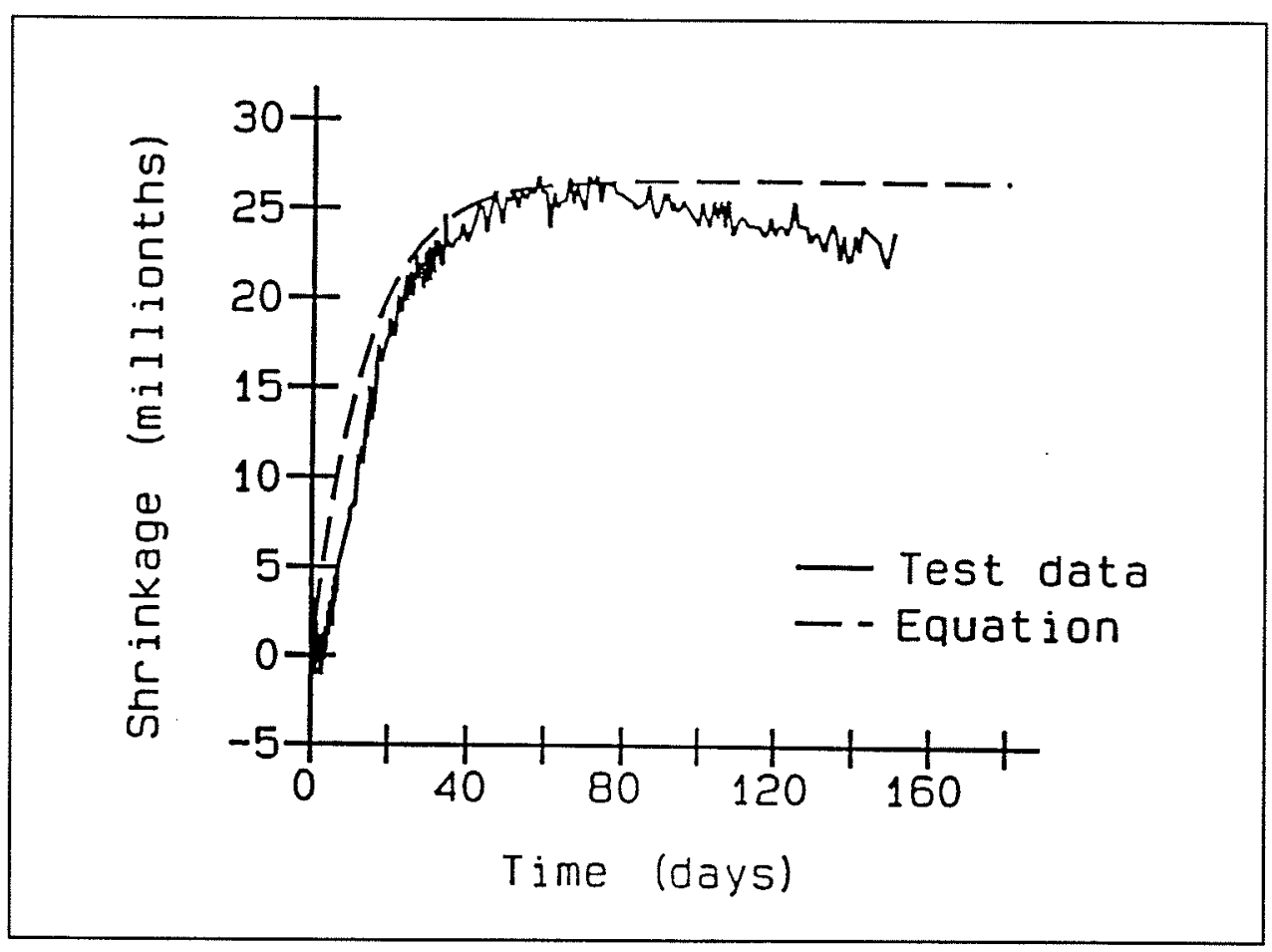

Figure 12. Shrinkage test data and curve fit for exterior mixture 
The final parameter to be presented is the cracking strain capacity, which is used to define the failure surface. The failure surface is then used to determine whether or not a point is cracked. The failure criterion used in a NISA is a stress-strain relationship, where the maximum strain remains at a fixed value but the maximum stress value is continually increasing since it is a function of the modulus of elasticity. The failure surface is then defined by a straight line between the maximum strain value and the maximum stress value at any given time. A detailed discussion of the cracking criterion is included in the ETL.

Since the strain capacity will vary from one mixture to another, a method was developed for computing the maximum strain capacity and this method is presented in the ETL. This value can be determined using the results of the slow load beam test. A slow load beam test was performed for the interior mixture only and the results are reported in Bombich, Neeley, and Gamer (in preparation).

Maximum strain capacity can best be computed by using Figure 13. The slow load beam failed at day 117 of the test at a strain of 159 microns and a stress of 350 psi $\left(\varepsilon_{s}\right.$ and $\sigma_{s}$, respectively, in Figure 13). Knowing that the beam failed at day 117 , the modulus of elasticity $E(t)$ can be computed using the equation above which results in a value of $4.41 \times 10^{6} \mathrm{psi}$. The computed modulus can then be used to determine the slope of the failure surface and its intersection with the strain axis which is $\varepsilon_{\mathrm{f}}$ and is computed as follows:

$$
\varepsilon_{f}=\varepsilon_{s}+\frac{\sigma_{s}}{E_{s}(t)}
$$

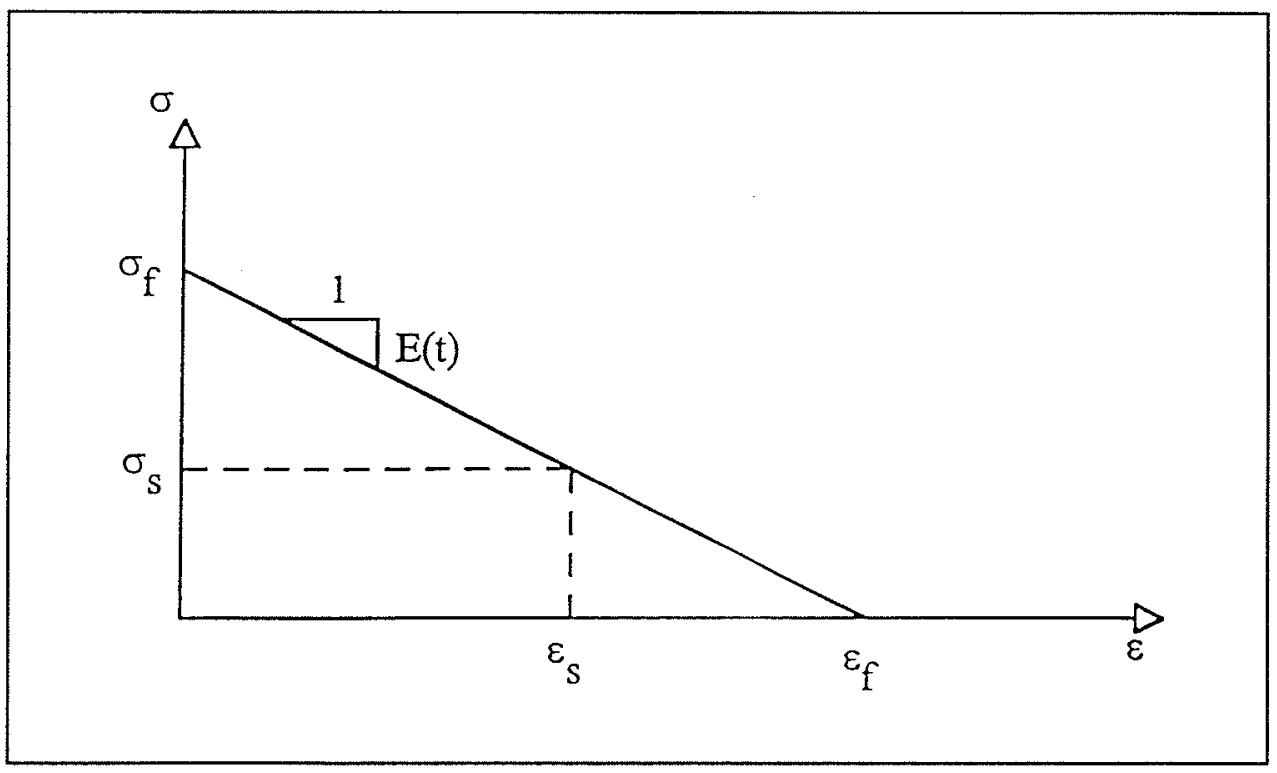

Figure 13. Plot used to compute failure surface 


$$
\varepsilon_{f}=159.0+\frac{350.0}{4.41 \times 10^{6}}=238 \text { microns }
$$

The input used by ABAQUS is the strain capacity for the uniaxial tension case, which is half of this calculated maximum strain value. Hence, the value used in the ABAQUS input was 119 microns. The corresponding value on the vertical axis for stress $\sigma_{f}$ is a function of the modulus of elasticity and is therefore time-dependent and can be computed as follows:

$$
\sigma_{f}(t)=\varepsilon_{f} E(t)
$$

Another item associated with the failure surface is the cracking potential. The cracking potential is calculated at points that have not cracked to provide an indication of how close the stress-strain state is to the failure surface. For the point shown in Figure 14, the cracking potential would be equivalent to the distance $l_{1}$ divided by the distance $l_{1}+l_{2}$ multiplied by 100 to give a percentage. This percentage is calculated at each integration point and can be presented on a contour plot to show areas in which the potential for cracking may be high.

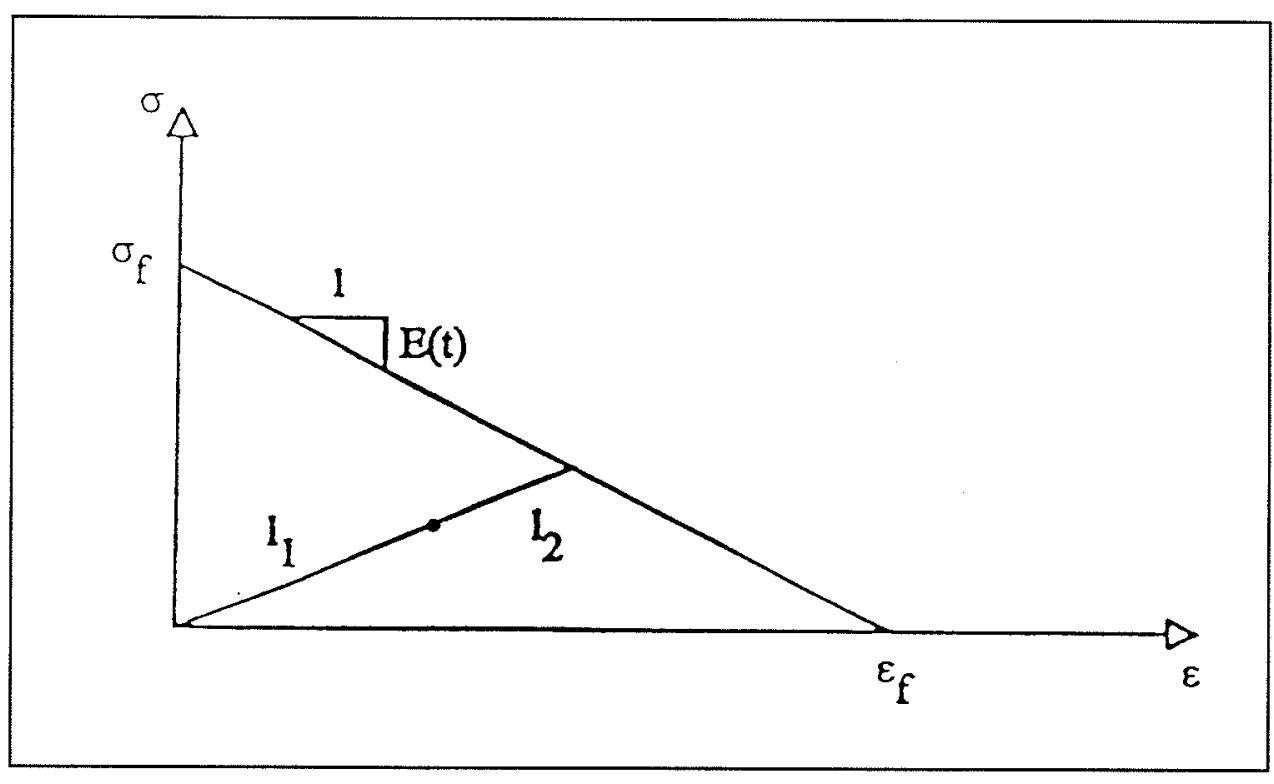

Figure 14. Plot demonstrating cracking potential calculation 


\section{Modeling Parameters}

\section{General}

There are a number of parameters in the finite element model for which assumptions must be made in order to best approximate conditions in the field. The various input parameters needed for the physical aspects of the model include film coefficients, ambient conditions for air, water, and soil, the initial conditions, and the boundary conditions. Various combinations of material properties to be used in the analyses are also required when performing a NISA. Detailed discussions of these items are included in this chapter.

In addition to the items mentioned above the interval of concrete placement must be considered, as well as the starting date for construction. The interval of concrete placements will be 5 days between lifts. Five days is typically the minimum interval allowed in specifications to allow the concrete to gain some strength prior to a new lift of concrete being placed on top of it. Five days is used in the NISA analysis because the shortest interval between placements will likely produce the highest temperature within the concrete. The start date for the initial analyses was also chosen to create the highest possible temperature in the concrete. The start dates selected were June 10 for the chamber monolith and June 21 for the miter gate and culvert valve monoliths. These dates were selected so that lifts in the massive portion of the walls would be in the process of being placed during the hottest temperatures of the summer.

\section{Material Combinations}

As stated in Chapter 1, the new ETL on NISA for massive concrete structures was used as guidance for the performance of the McAlpine NISA and the material combinations from that ETL are shown in Table 1. Since combination 1 is a reference analysis with no creep or shrinkage, only combinations 2 and 3 are considered for use on subsequent analyses. Combination 3 is intuitively the case which should provide the worst conditions and was shown to be the controlling combination in the analysis of the Olmsted locks (Gamer et al. 1992). Combination 2 is also included because it was the controlling condition for the NISA performed on the Melvin Price auxiliary 
lock project (Truman, Petruska, and Ferhi 1992). An initial set of analyses will be performed using these various combinations (reported in Chapter 4) to determine which combination should be used on subsequent analyses.

\section{Film Coefficients}

Film coefficients are used in the heat transfer portion of the analysis to model convection. Convection is the process which controls heat flow between a solid and a fluid. Convection is a function of the rate of fluid flow over the surface of the solid, so for a NISA this would be the wind or water speeds acting on the concrete or rock surfaces.

To determine the film coefficient resulting from air, monthly average wind speeds were obtained from the National Climatic Data Center for Louisville, Kentucky, and are shown in Table 7. Using the data in Table 7, months with similar wind speeds were grouped together to reduce the number of changes of the film coefficients in the analysis file. This resulted in three groups of months (November through April, May and June, and July through October). After grouping the months, an average wind speed was assigned to each group. These wind speeds, which were used in computing the film coefficients to be used in the analyses, are shown in Table 7.

\begin{tabular}{|c|c|c|c|c|}
\hline \multicolumn{5}{|c|}{$\begin{array}{l}\text { Table } 7 \\
\text { Average Monthly Wind Speeds and Associated Film Coefficients } \\
\text { for Louisville, KY }\end{array}$} \\
\hline Month & $\begin{array}{l}\text { Wind Speed } \\
(\mathrm{mph})\end{array}$ & $\begin{array}{l}\text { Wind Speeds for } \\
\text { Analysis (mph) }\end{array}$ & $\begin{array}{l}\text { Film Coefticient } \\
\text { Btu/day-in.'- }{ }^{2} \mathrm{~F}\end{array}$ & $\begin{array}{l}\text { Film Coefficient with } \\
\text { Forms, Btu/day-in. }{ }^{\circ}-{ }^{\circ} \mathrm{F}\end{array}$ \\
\hline Jan & 9.67 & 9.7 & 0.663 & 0.141 \\
\hline Feb & 9.67 & 9.7 & 0.663 & 0.141 \\
\hline Mar & 0.25 & 9.7 & 0.663 & 0.141 \\
\hline Apr & 9.79 & 9.7 & 0.663 & 0.141 \\
\hline May & 8.06 & 7.8 & 0.565 & 0.136 \\
\hline Jun & 7.49 & 7.8 & 0.565 & 0.136 \\
\hline Jul & 6.79 & 6.8 & 0.514 & 0.132 \\
\hline Aug & 6.45 & 6.8 & 0.514 & 0.132 \\
\hline Sep & 6.79 & 6.8 & 0.514 & 0.132 \\
\hline Oct & 7.25 & 6.8 & 0.514 & 0.132 \\
\hline Nov & 8.98 & 9.7 & 0.663 & 0.141 \\
\hline Dec & 9.33 & 9.7 & 0.663 & 0.141 \\
\hline
\end{tabular}


Once the wind speeds to be used in the analysis are determined, the film coefficients associated with those wind speeds can be computed. The film coefficients are computed using the equation from the new NISA ETL:

$$
h=0.165+0.0513(V)
$$

where

$$
\begin{aligned}
& h=\text { film coefficient }\left(\text { Btu/day-in. }{ }^{2}-\mathrm{F}\right) \\
& V=\text { wind speed }(\mathrm{mph})
\end{aligned}
$$

The resulting film coefficients based on the above equation are provided in Table 7. Also shown are the associated film coefficients for the time period when forms are assumed to be in place ( 2 days). The film coefficient for an insulated surface such as concrete with forms in place is:

$$
h^{\prime}=1 /\left[R_{\text {formwork }}+(1 / h)\right]
$$

where

$$
\begin{aligned}
h^{\prime} & =\text { film coefficient with forms }\left(\mathrm{Btu} / \mathrm{day}-\mathrm{in} .{ }^{2}-{ }^{\circ} \mathrm{F}\right) \\
R_{\text {formwork }} & =\mathrm{R} \text { value for formwork }\left(\mathrm{day}-\mathrm{in} .^{2}-{ }^{\circ} \mathrm{F} / \mathrm{Btu}\right) \\
h & =\text { film coefficient for free surface }\left(\mathrm{Btu} / \mathrm{day}-\mathrm{in} .{ }^{2}-{ }^{\circ} \mathrm{F}\right)
\end{aligned}
$$

$R_{\text {formwork }}$ is 5.6 day-in. $.^{2}{ }^{\circ} \mathrm{F} /$ Btu and is based on using a plywood form with a thickness of $0.75 \mathrm{in}$. and having a conductivity of $0.134 \mathrm{Btu} / \mathrm{day}-\mathrm{in} .{ }^{\circ} \mathrm{F}$.

Due to errors in calculating the film coefficients, the actual film coefficients used in the analyses were different from those reported in Table 7. The actual film coefficients used were $0.3956 \mathrm{Btu} / \mathrm{day}-\mathrm{in} .^{2}{ }^{2}{ }^{\circ} \mathrm{F}$ for a wind speed of $9.7 \mathrm{mph}, 0.3504 \mathrm{Btu} / \mathrm{day}-\mathrm{in} .^{2}{ }^{\circ} \mathrm{F}$ for a wind speed of $7.8 \mathrm{mph}$, and $0.3267 \mathrm{Btu} /$ day-in. ${ }^{2}{ }^{\circ} \mathrm{F}$ for a wind speed of $6.8 \mathrm{mph}$. Actual film coefficients used in the analyses for the times when formwork was in place were $0.1229 \mathrm{Btu} / \mathrm{day}-$ in. ${ }^{2}{ }^{\circ} \mathrm{F}$ for a wind speed of $9.7 \mathrm{mph}, 0.1182 \mathrm{Btu} /$ day-in. ${ }^{2}-^{\circ} \mathrm{F}$ for a wind speed of $7.8 \mathrm{mph}$, and $0.1154 \mathrm{Btu} / \mathrm{day}-\mathrm{in}^{2}{ }^{2}{ }^{\circ} \mathrm{F}$ for a wind speed of $6.8 \mathrm{mph}$. The analyses presented in this report were not reanalyzed because the error in the calculation was not found until the writing of this report and performing the analyses again would have resulted in a substantial delay in the submittal of the report. In addition, a separate analysis was performed on material combination 3 for the 7-1/2-ft lift case using the correct film coefficients. Where compared to the analysis with incorrect coefficients, the difference between the two analyses showed that use of the incorrect coefficients was actually slightly conservative. The analysis using the incorrect film coefficients had a total of 66 integration points that cracked, while the analysis using the correct film 
coefficients had a total of 62 cracked integration points. Therefore it can be concluded that use of the incorrect film coefficients will not have a significant effect on the results reported.

\section{Ambient Air Temperature}

For surfaces exposed to the air temperatures, a curve which defines the ambient air temperatures as a function of time must be developed. The curve will then be used in ABAQUS and along with the film coefficients will determine the amount of heat flow in and out of solid materials such as the concrete and the rock.

To account for the case where construction may occur during an extremely hot summer or during an extremely cold winter, the ambient air temperature curve is developed to account for both of these cases. These extreme seasons are determined by evaluating the monthly average temperatures on record, obtained from the National Climatic Data Center, and finding the month which had the highest average temperature and the month which had the lowest average temperature. The monthly average temperature is used so that data for brief hot or cold periods of a few days are not used for development of the ambient curve. Once the hottest and coldest months are selected, a sinusoidal curve which envelopes the months selected is used to approximate the yearly cycle of temperatures.

For the McAlpine project, the coldest January on record had an average monthly temperature of $24.5^{\circ} \mathrm{F}$. Due to the fact that the hottest monthly average temperature for July on record was $88^{\circ} \mathrm{F}$ and the hottest monthly average temperature for August on record was $86.9^{\circ} \mathrm{F}$, two months were used to obtain the upper bound of the ambient temperature curve. The monthly average temperatures used in determining the ambient temperature curve are plotted in Figure 15 along with other monthly average temperatures. Using a sine wave to model the yearly cycle of the ambient temperature, the curve was adjusted so that the minimum and maximum peaks enveloped the hottest and coldest months on record. The resulting curve is also shown in Figure 15. The minimum temperature of the extreme ambient curve shown and used in the analyses was $23{ }^{\circ} \mathrm{F}$ while the maximum was $92^{\circ} \mathrm{F}$.

\section{Soil and Water Temperatures}

The new NISA ETL requires that service loads be applied at the end of the stress analysis, but has no requirements for including the service load conditions in the heat transfer analysis. A decision was made on the McAlpine project to include the service load condition in the heat transfer analysis for the chamber monolith and extend the analysis for an additional year with these conditions imposed. This decision required development of ambient curves for 


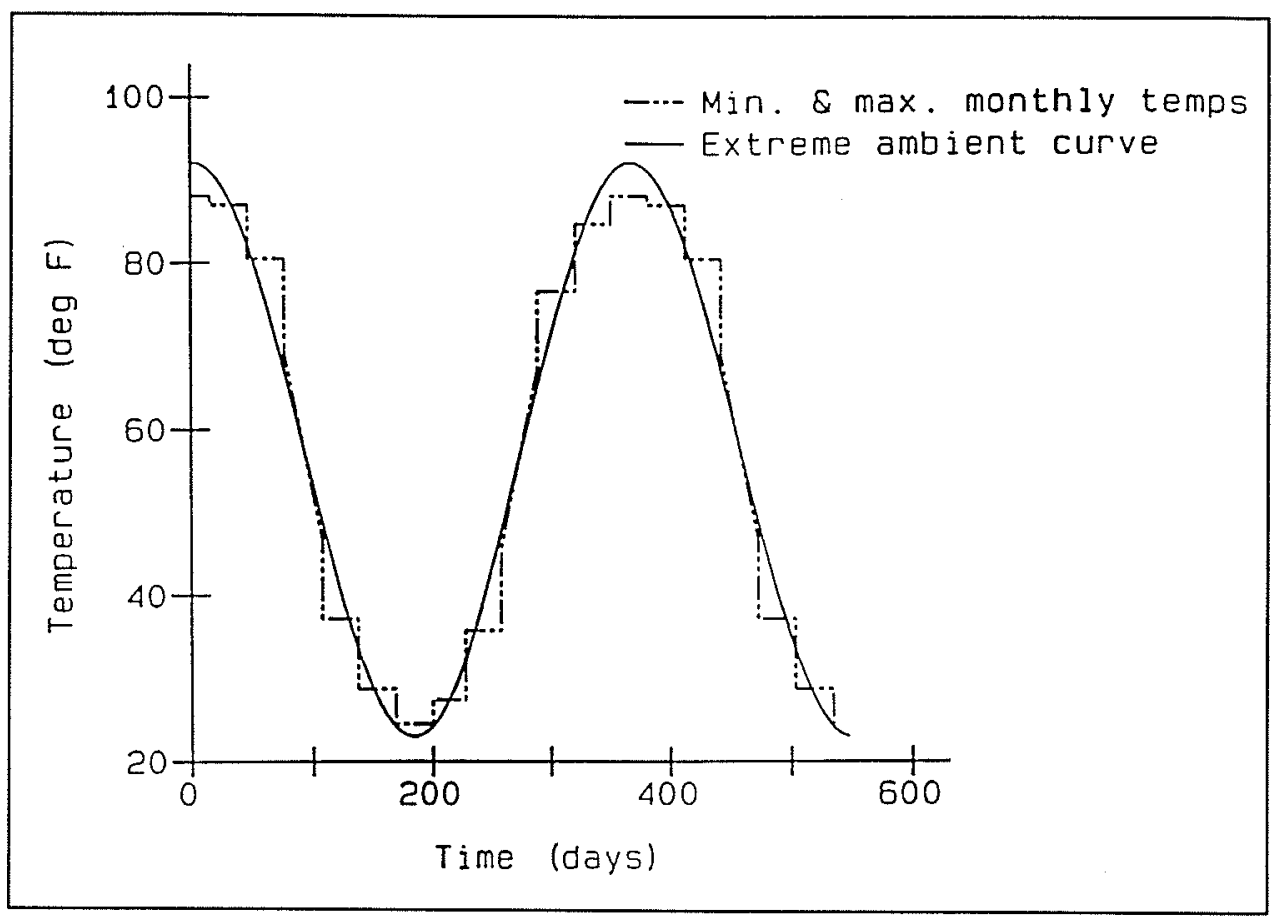

Figure 15. Extreme ambient temperature curve and monthly temperature data used in calculation of the curve (Time $=0$ is July 15)

the soil and the water so that modeling of the soil and water could be done without adding elements to the model.

The most accurate method for modeling the temperatures of the backfill would have been to include additional elements with soil properties in the area where the backfill is to be placed. While including soil elements may have been the most accurate method, it would have been very time-consuming, due to the sloping face of the monolith in the area of backfill. It was felt that modeling the soil using a curve which simulated the changing temperatures in the soil would provide adequate results. Therefore, a cyclic curve had to be developed which would provide the temperatures of the soil at the surfaces where backfill was placed.

To develop the necessary curve, a single column of two-dimensional elements was used. The column contained $15 \mathrm{ft}$ of concrete elements and $15 \mathrm{ft}$ of soil elements, as shown in Figure 16. A heat transfer analysis was then performed for a period of 2 years with film coefficients applied to the surface of the soil as described above along with the ambient air temperature as shown in Figure 15. From this analysis the temperatures in the second year of the analysis which resulted at the surface of the concrete were taken and used to develop the soil temperature curve. The temperatures used to develop the curve were the temperatures which resulted at the soil-concrete interface of the model shown in Figure 16. The resulting curve is shown in Figure 17. 


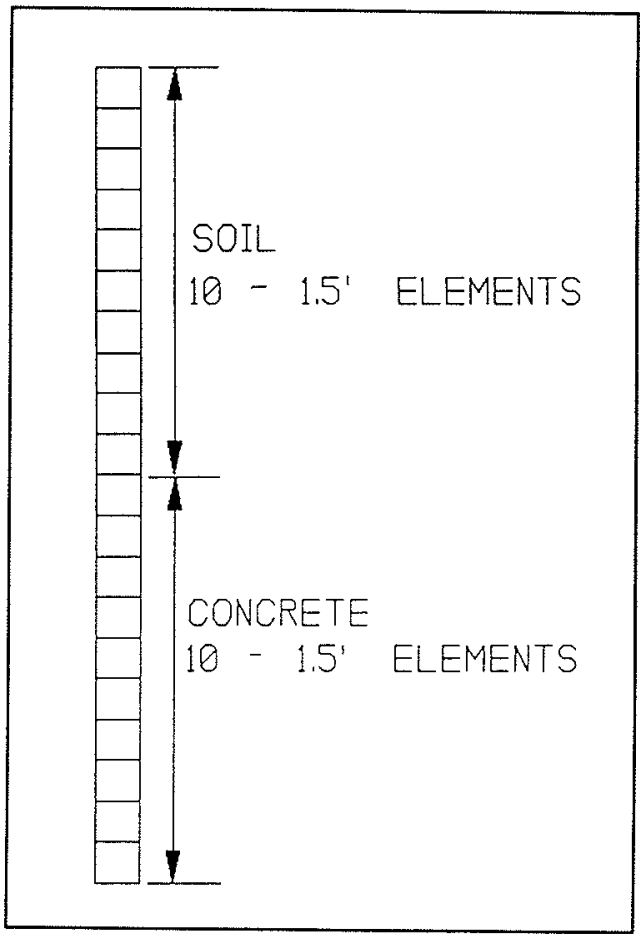

Figure 16. Column of elements used in analysis to develop curve for modeling soil temperatures
A curve was also needed for modeling the water for the service load condition. Use of elements for water is not necessarily the best modeling technique, since during filling and emptying the water is moving. In the Phase II study on the Olmsted project (Garner et al. 1992) it was determined from data that the shape of the average water temperature curve followed the average daily temperature curve very closely, with two exceptions. First, there was approximately a 30-day phase shift of the water temperatures compared to air temperatures; i.e., maximum and minimum temperatures of the water occurred 30 days later than they did for air. Also, the minimum temperature of the water remained at approximately $40^{\circ} \mathrm{F}$. Once a curve is developed, these changes in water temperature can be modeled through the use of a very high film coefficient.

Using the information obtained in the Olmsted NISA, a curve for the water temperature was developed based on the extreme ambient air temperature by simply shifting the curve 30 days and using a minimum temperature of $40^{\circ} \mathrm{F}$. The resulting curve is shown in Figure 17. After reviewing initial results using this curve, it was determined that using the extreme ambient air temperature curve for the water was likely to be too severe. Therefore, it was decided that the analysis should be performed again using the water temperature curve used in the Olmsted NISA. This curve is also shown in Figure 17. It was agreed that the Olmsted water temperature curve should be used because it was more practical even though it too was based on the extreme ambient curve for the Olmsted project, but the maximum temperature of that curve is only $85^{\circ} \mathrm{F}$ as opposed to the maximum of $92^{\circ} \mathrm{F}$ for the McAlpine curve.

\section{Initial Conditions}

\section{Heat transfer analysis}

The initial conditions for the heat transfer analysis are the temperature of the rock at the start of the analysis and the temperature of the concrete at the time it is placed. On other NISA studies, a column of elements using the properties of the foundation was analyzed for a period of 1 year to obtain an initial temperature distribution in the foundation to be used at the beginning of 


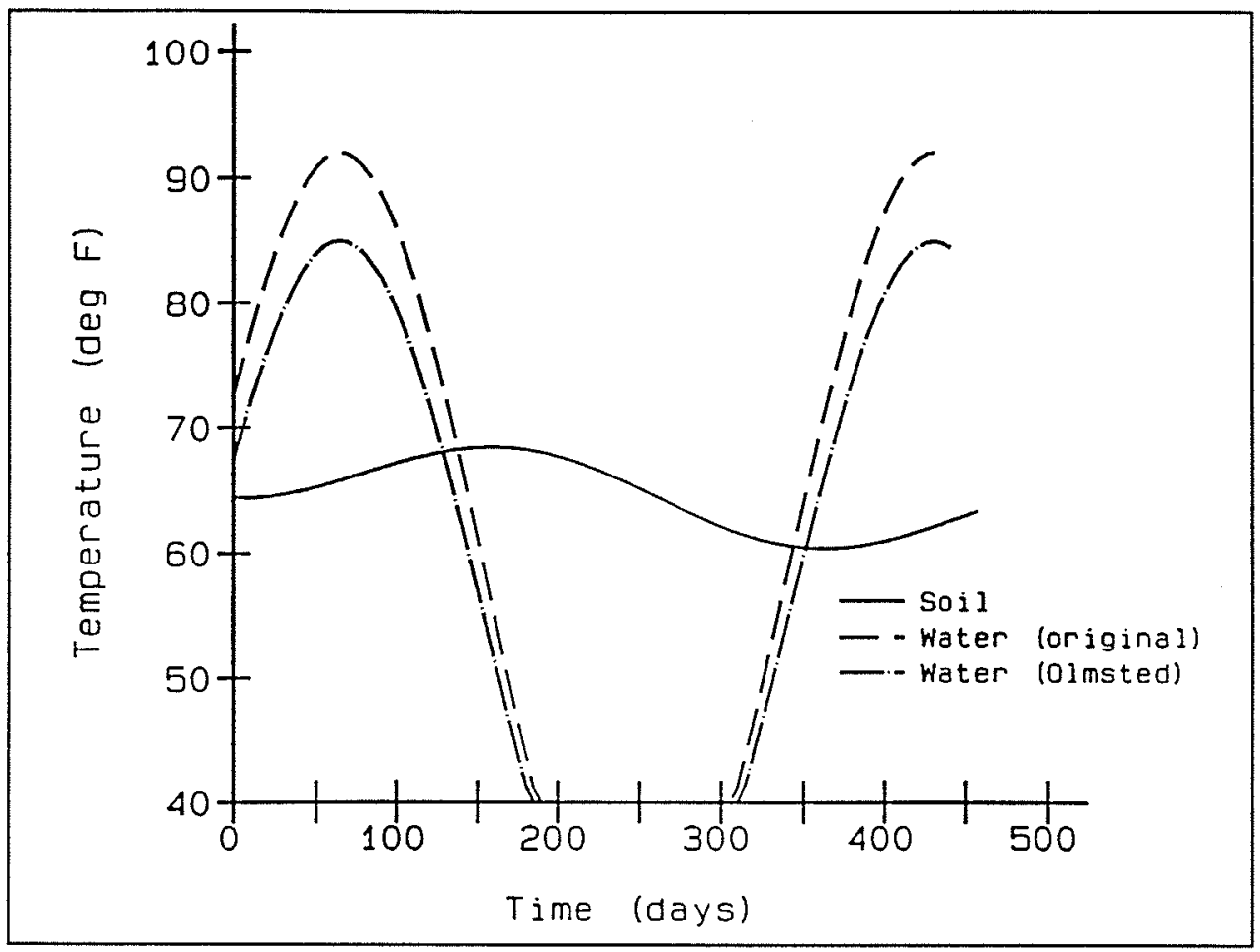

Figure 17. Soil and water temperature curves (Time $=0$ is June 10)

the analysis. This method of determining the initial temperature distribution is very effective when the top of the foundation is all at one elevation, but when the shape of the foundation is irregular like the rock foundation at the McAlpine project, then a single column of elements does not provide sufficient information.

For the NISA study on the McAlpine lock replacement, a temperature analysis of the entire rock foundation was needed to obtain the initial temperature distribution of the foundation. To achieve this initial temperature distribution, the foundation was analyzed for 180 days prior to the placement of the first lift of concrete. So if concrete placement began on June 10, the heat transfer analysis had to begin on December 12 . This 180-day period was used to allow the rock to reach a state of equilibrium with the ambient air.

The initial condition for the concrete as stated previously, is the temperature at which the concrete is placed. For the analyses which used summer starts, a placing temperature of $70^{\circ} \mathrm{F}$ was used. For winter starts, the placing temperature is based on the ambient air temperature for the day the concrete is placed, except the placing temperature is never allowed to go below $40^{\circ} \mathrm{F}$. 


\section{Stress analysis}

Initial conditions for the stress analysis are based on the start of construction and the time of set of the concrete. The stress analysis was started on June 10 , so the temperatures in the foundation of the rock at 180 days of the heat transfer analysis were the initial temperatures used for the rock and were used as the reference temperatures for the stress-free state of the rock. Each lift of concrete is placed in a stress-free state. The time of set used for the concrete was $12 \mathrm{hr}$. The time set is the time in which it is assumed the concrete can begin to carry load. It is at this time of set that the subroutine UMAT will save the temperatures in the new lift as the stress-free reference temperatures.

\section{Boundary Conditions}

\section{Heat transfer analysis}

For the heat transfer analysis, the boundary condition was applied at the base of the rock and a constant temperature of $60^{\circ} \mathrm{F}$ was used. This temperature may be slightly higher than what might be expected at the depth of the foundation used, but due to the large foundation, it is unlikely that this discrepancy had any effect on the results in the monolith. The boundary conditions at the exposed faces of the concrete and the rock are changed as the analysis progresses based on the air, water, and soil amplitude curves and on the film coefficients applied to these faces as described earlier.

\section{Stress analysis}

For the chamber monolith analysis the bottom edge of the foundation was restrained against any vertical movement and the sides of the foundation were restrained against any horizontal movement. The foundation size for the chamber monolith was $174 \mathrm{ft}$ wide by $90 \mathrm{ft}$ deep. This is based on parametric studies from Foster and Jones (1994), which showed that if stresses within a structure were to be unaffected by the foundation support conditions, then the width of the foundation needed to be three times the width of the structure's base and the depth of the foundation needed to be one and one-half times the width of the structure's base. Analysis of the miter gate monolith, which used a much smaller foundation in combination with elastic springs, is described further in Chapter 6. 


\section{Parametric Analyses- Chamber Monolith}

\section{General}

The first analyses performed were a set of parametric studies on a typical chamber monolith. The geometry of the typical chamber monolith used is shown in Figure 18 with concrete placement shown for lifts of $10 \mathrm{ft}$. The portion of the monolith to be constructed with the exterior concrete mixture is indicated by crosshatching and the portion to be constructed using the interior concrete mixture is indicated by the concrete symbols. Reinforcing around the culvert and gallery is also shown in Figure 18. Figure 19 shows all of the reinforcing included in the numerical model. All reinforcing for the analyses discussed in this chapter was assumed to be No. 9 bars spaced at 12 in. Reinforcing is modeled in ABAQUS using an option in the input which allows the size and location of a reinforcing bar to be specified and then, based on these parameters, stiffness of the elements is revised to account for the presence of the reinforcing bar.

The finite element grid for the chamber monolith is shown in Figure 20a. The mesh density was established primarily by considering two items. First, due to the approach used in developing the heat transfer portion of the ABAQUS code, there is a relationship between the length of the minimum time increment used and the size of the element used in the grid. This relationship is described in the new ETL, and based on a minimum time increment of 0.25 day, the maximum distance between nodes which should be used to avoid numerical instability problems is $13.8 \mathrm{in}$. Exceeding the maximum calculated node spacing should be kept to a minimum, particularly if the spacing is in the same direction that heat flow is expected. Secondly, since adjustments to lift heights were anticipated in subsequent analyses, the grid was set up so that the portion of the monolith above the culvert could accommodate 5-ft, 7-1/2-ft, and 10-ft lifts.

Also included in these parametric analyses were gap elements along the landside vertical face of the monolith. Preliminary analyses showed that allowing full contact and bond at this surface was providing a large area of 


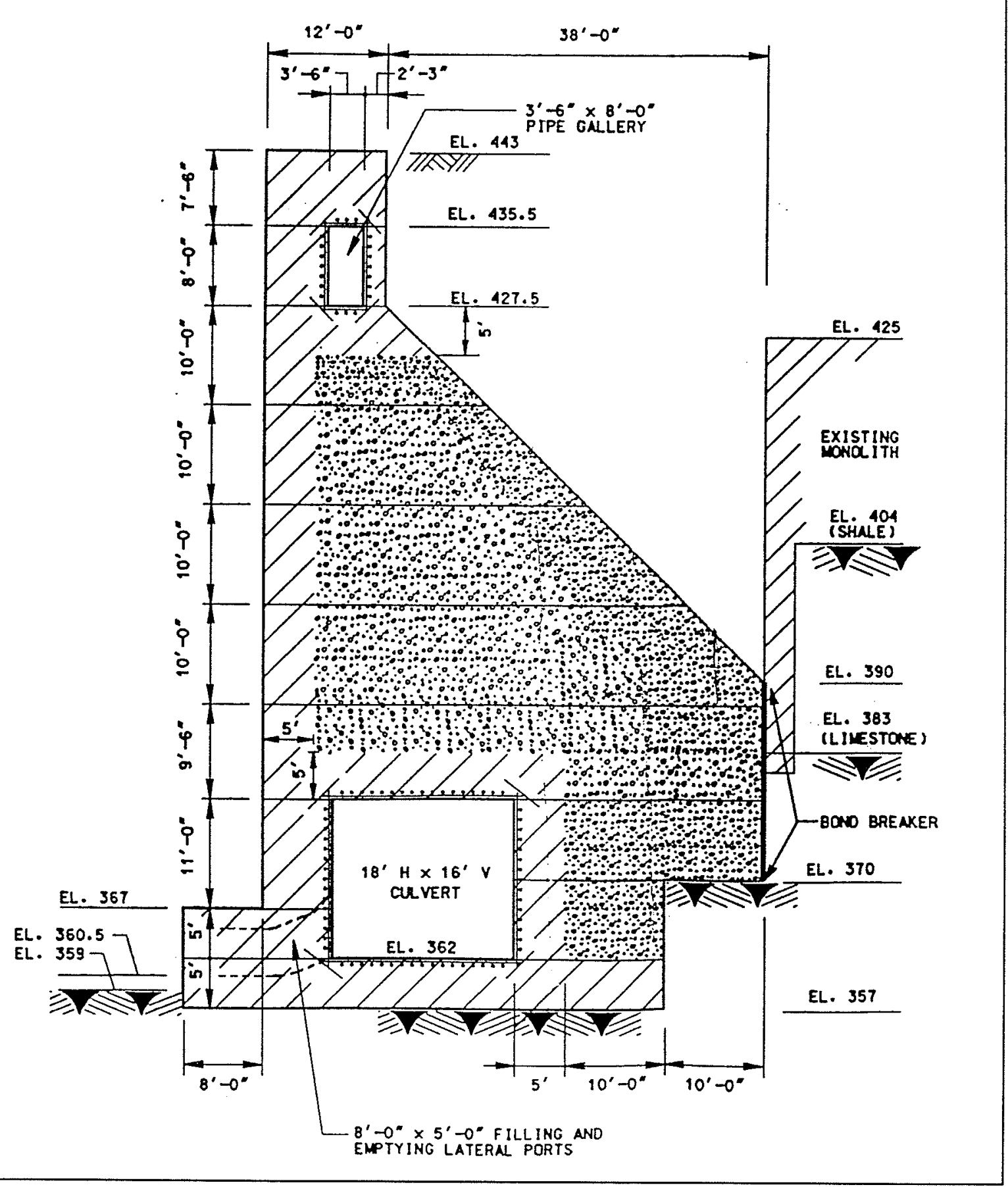

Figure 18. Geometry of a typical chamber monolith

restraint and was a major contributor to the cracking that was being predicted in these analyses. The location of the gap elements is shown in Figure $20 \mathrm{~b}$ as gap 1. Two other locations for including gap elements are also shown in Figure $20 \mathrm{~b}$ and will be discussed in further detail in Chapter 5. The gap 


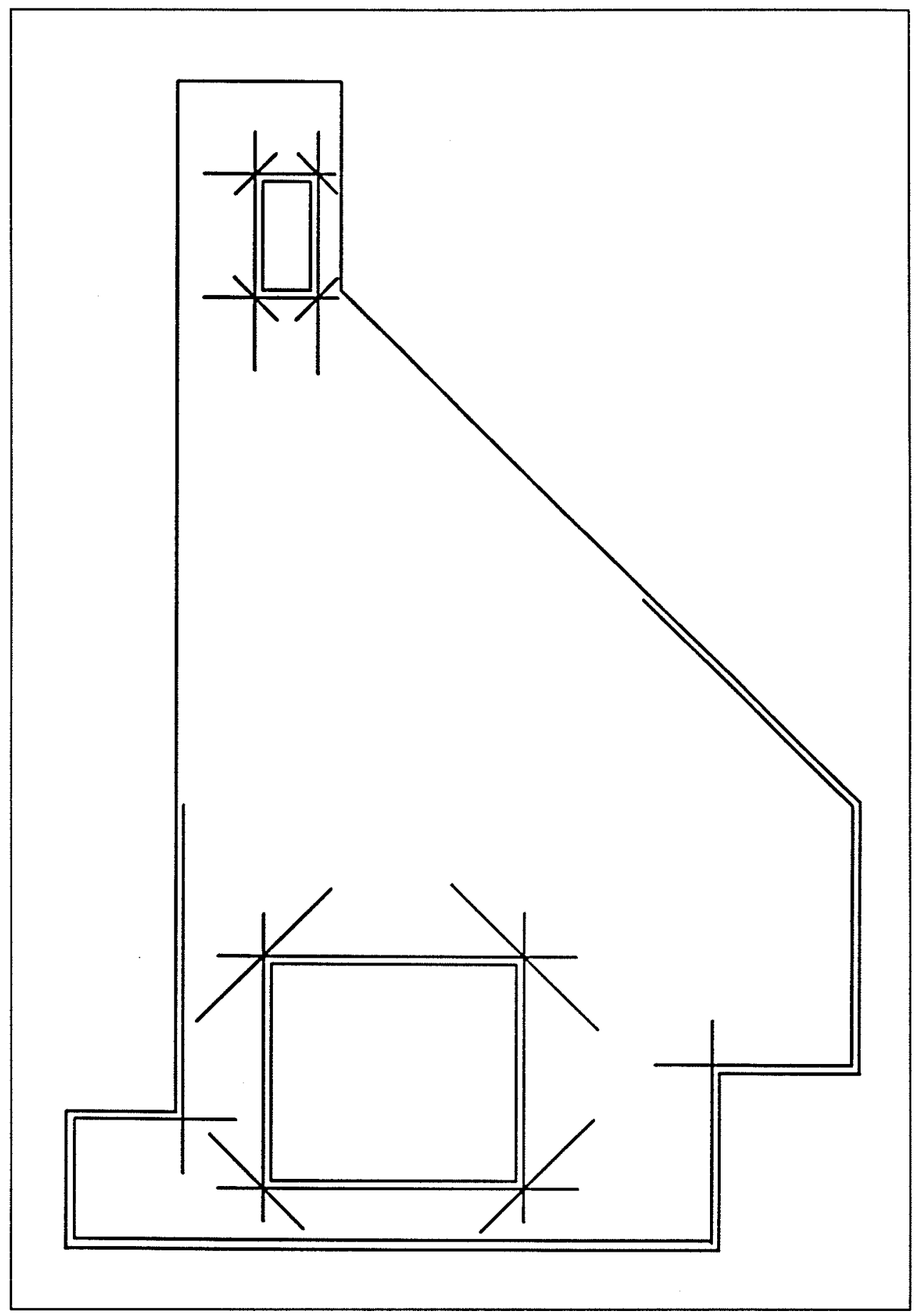

Figure 19. Reinforcement included in finite element model

elements that were included allow compression when the surfaces come into contact but do not allow tension across the interface.

The parametric studies described in this chapter are for the purpose of evaluating the material combinations required by the ETL and as shown in 


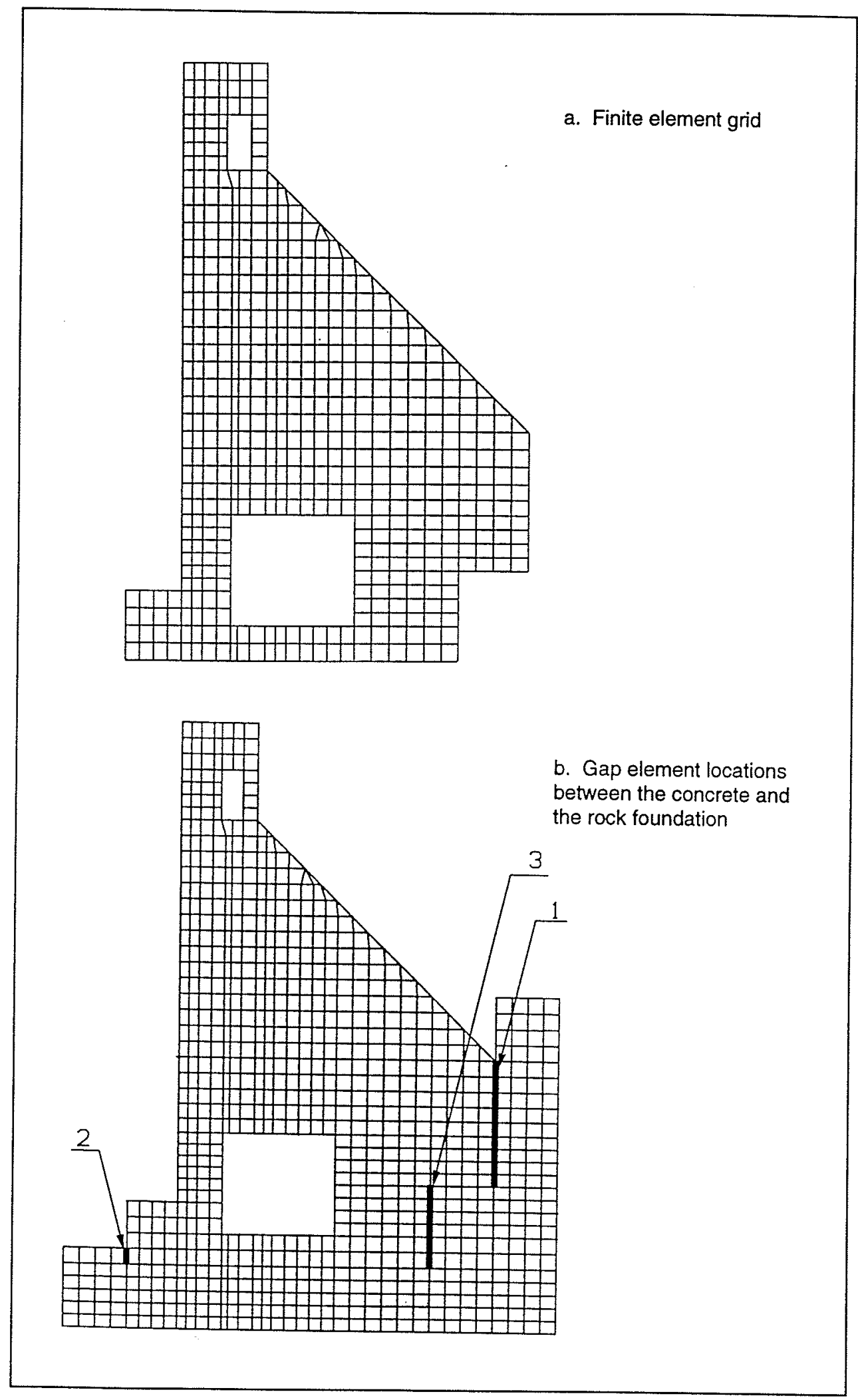

Figure 20. Finite element grid and locations of gap elements for the typical chamber monolith 
Table 1 and to determine the maximum acceptable lift height up to a maximum of $10 \mathrm{ft}$. The material combinations were evaluated first so that the worst material combination could be determined and used on all subsequent analyses. The material combinations were evaluated using 7-1/2-ft lifts. The lift height evaluation was done using the results of the analysis from the material combination parametric study, which provided the worst combination of material properties, and comparing these results to the analysis performed on a model with $10-\mathrm{ft}$ lifts. A determination could then be made as to whether or not 10 -ft lifts were acceptable and based on the decision, the final analyses of the chamber monolith could be performed. Lift arrangements for 7-1/2-ft and 10 -ft lifts are shown in Figure 21.

It should be noted that monolith behavior will not be discussed in detail in this chapter. The primary focus will be on comparing the various analyses to determine which parameters to use in subsequent analyses, i.e. material combination and lift height. A more detailed discussion of monolith behavior is contained in Chapter 5.

\section{Material Combinations}

\section{Heat transfer analysis}

As described in Chapter 3, the heat transfer analysis was started 180 days prior to placement of the concrete to allow the rock to reach an equilibrium with the ambient air prior to the first lift of concrete being placed. The results of the heat transfer analysis presented will be only for the portion of the analysis for the period of time after concrete was placed. The heat transfer analysis presented in this section is the analysis of the 7-1/2-ft lifts (as shown in Figure 21) and the temperature results of this analysis are used for all three of the stress analyses that need to be performed to evaluate the material combinations.

Contour plots of the concrete monolith and a portion of the rock foundation are shown in Figures 22 through 25 at various points in time of the analysis. Figure 22 is taken 62 days after the start of construction and is shown because this is the point in time when the maximum temperature in the concrete has been attained. While the temperature in the center of the monolith is high, the gradients are not extremely high because the air temperature is still very warm. The plot in Figure 23 occurs only 14 days after the plot in Figure 22 and is taken 6 days after the last lift of concrete was placed. Figure 23 is very similar to Figure 22, with only a slightly lower maximum temperature in the center of the monolith and a slightly increased gradient from the center of the monolith to the exposed surfaces.

Figure 24 is taken 210 days after the start of construction, which is on January 6 and is only 5 days prior to the ambient air temperature reaching its minimum value. The temperature in the center of the monolith is still in the 


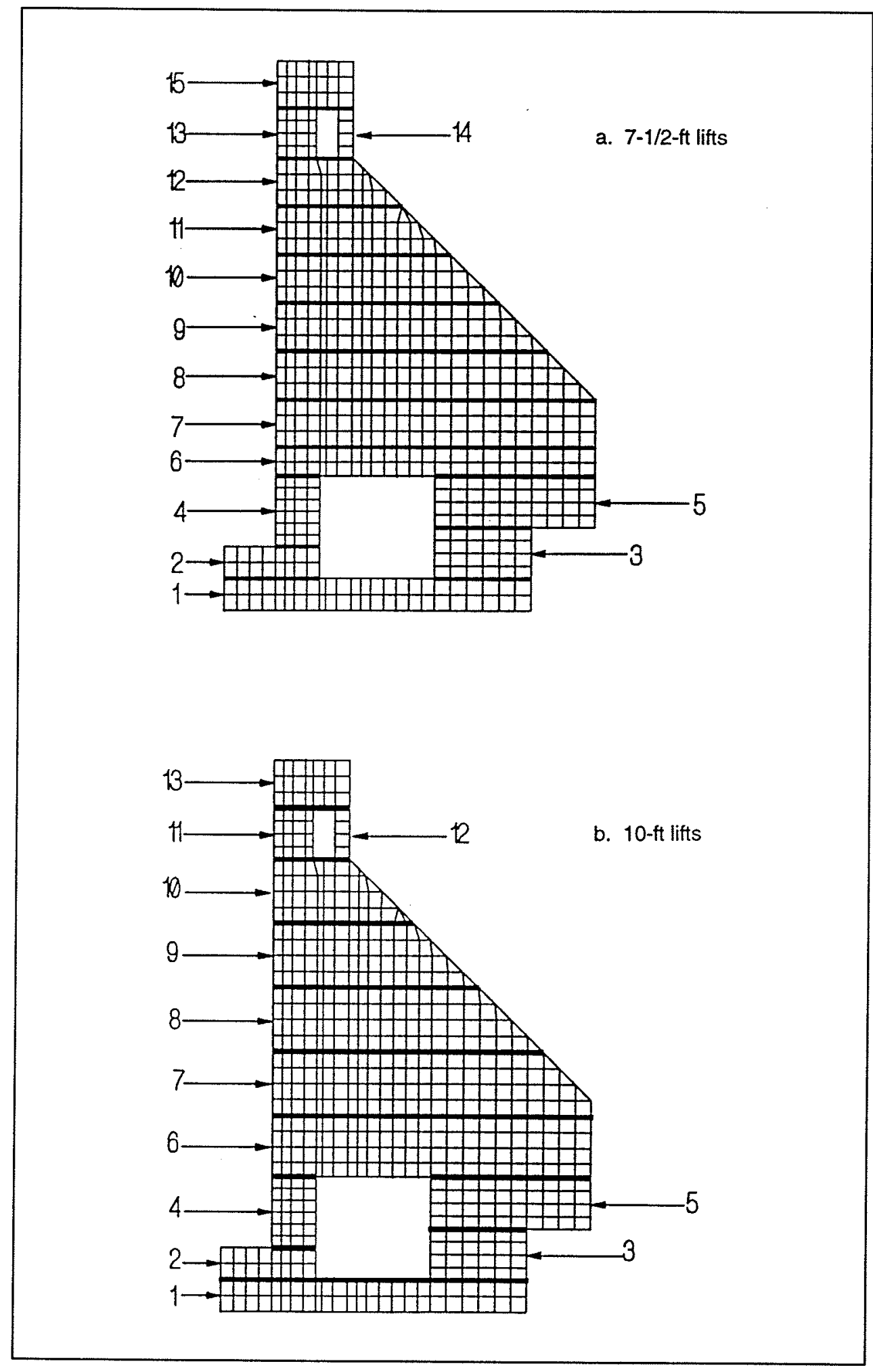

Figure 21. Lift placements for typical chamber monolith 


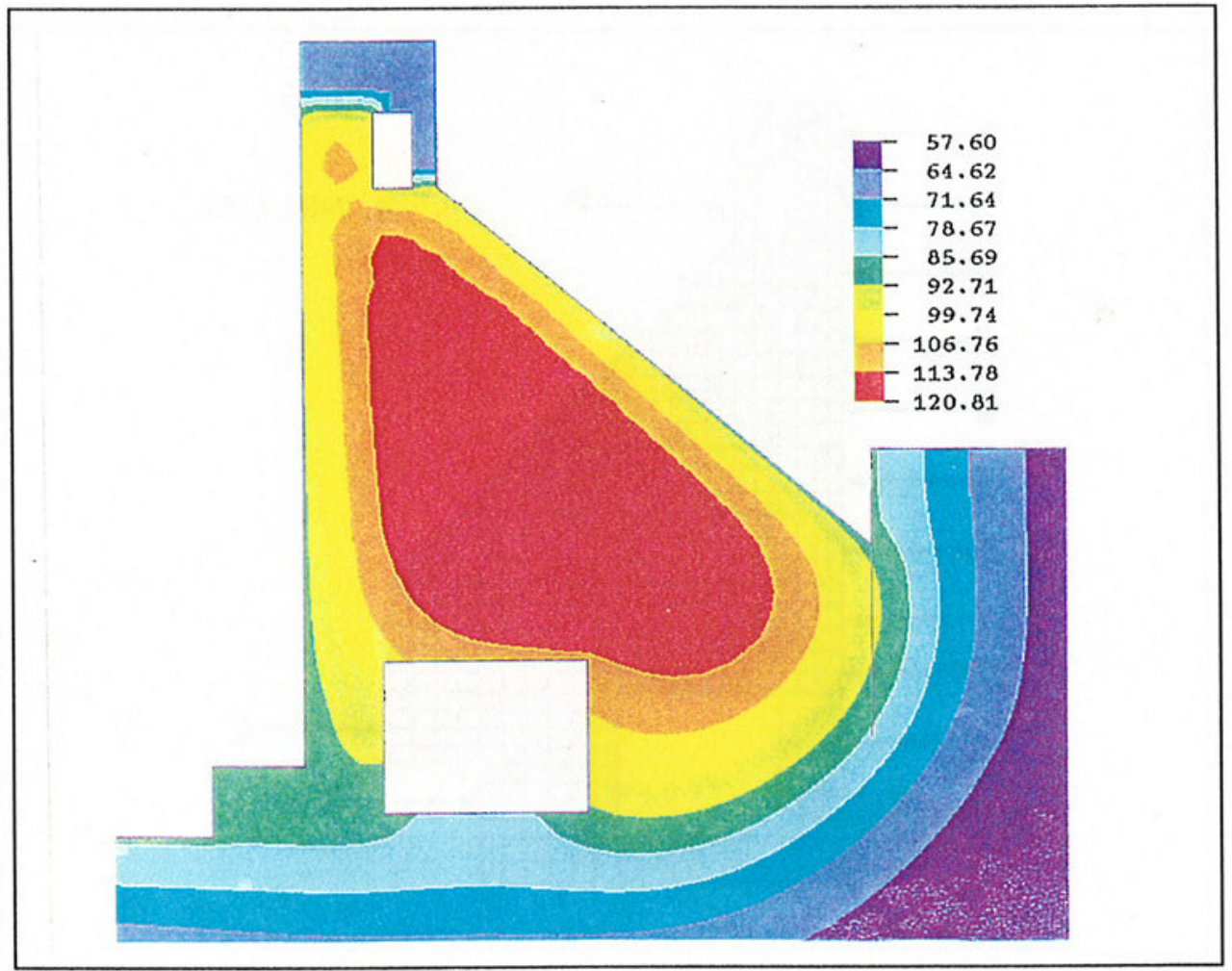

Figure 22. Temperature contour, 62 days after start of construction, 7-1/2-ft lifts

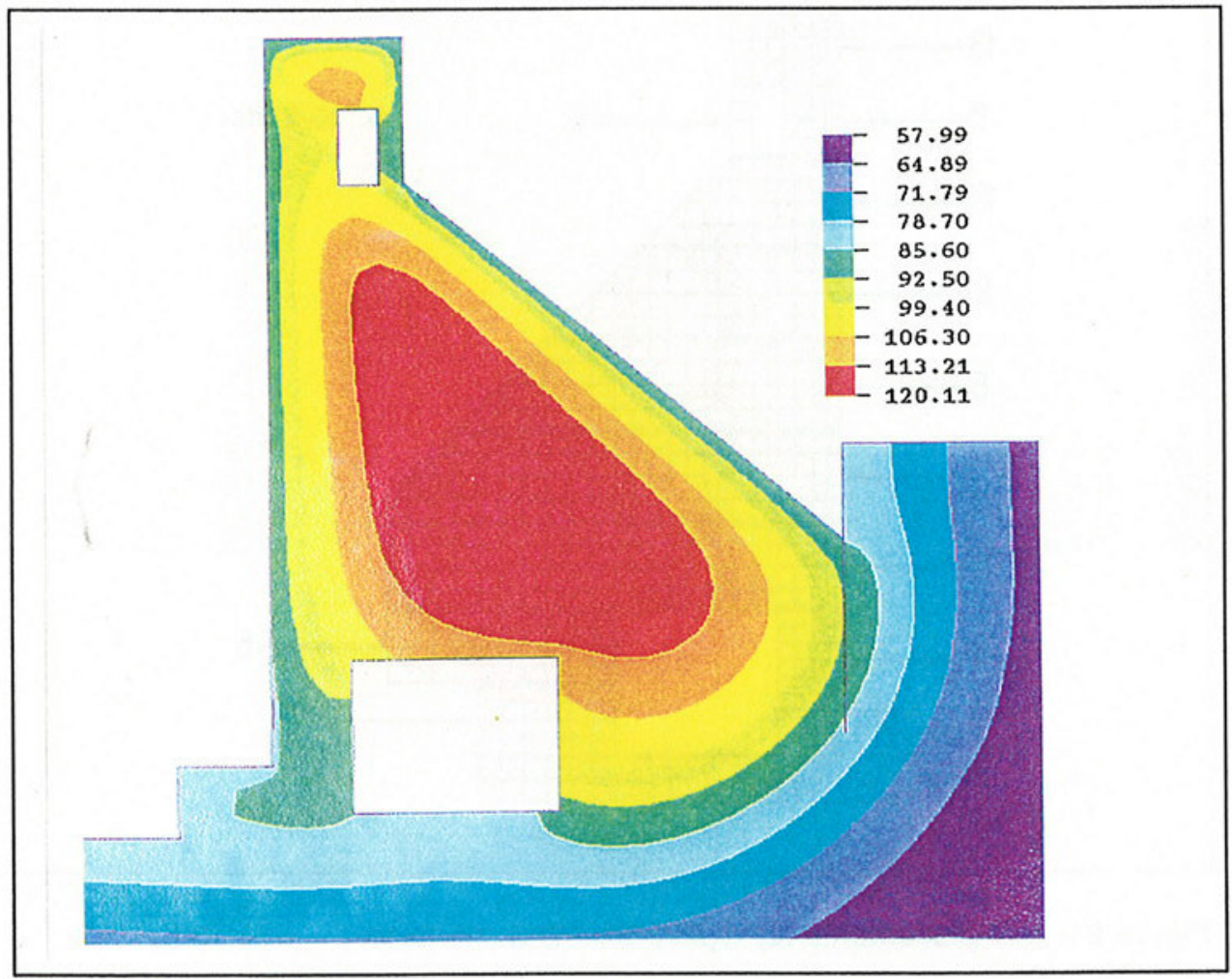

Figure 23. Temperature contour, 76 days after start of construction, 7-1/2-ft lifts 


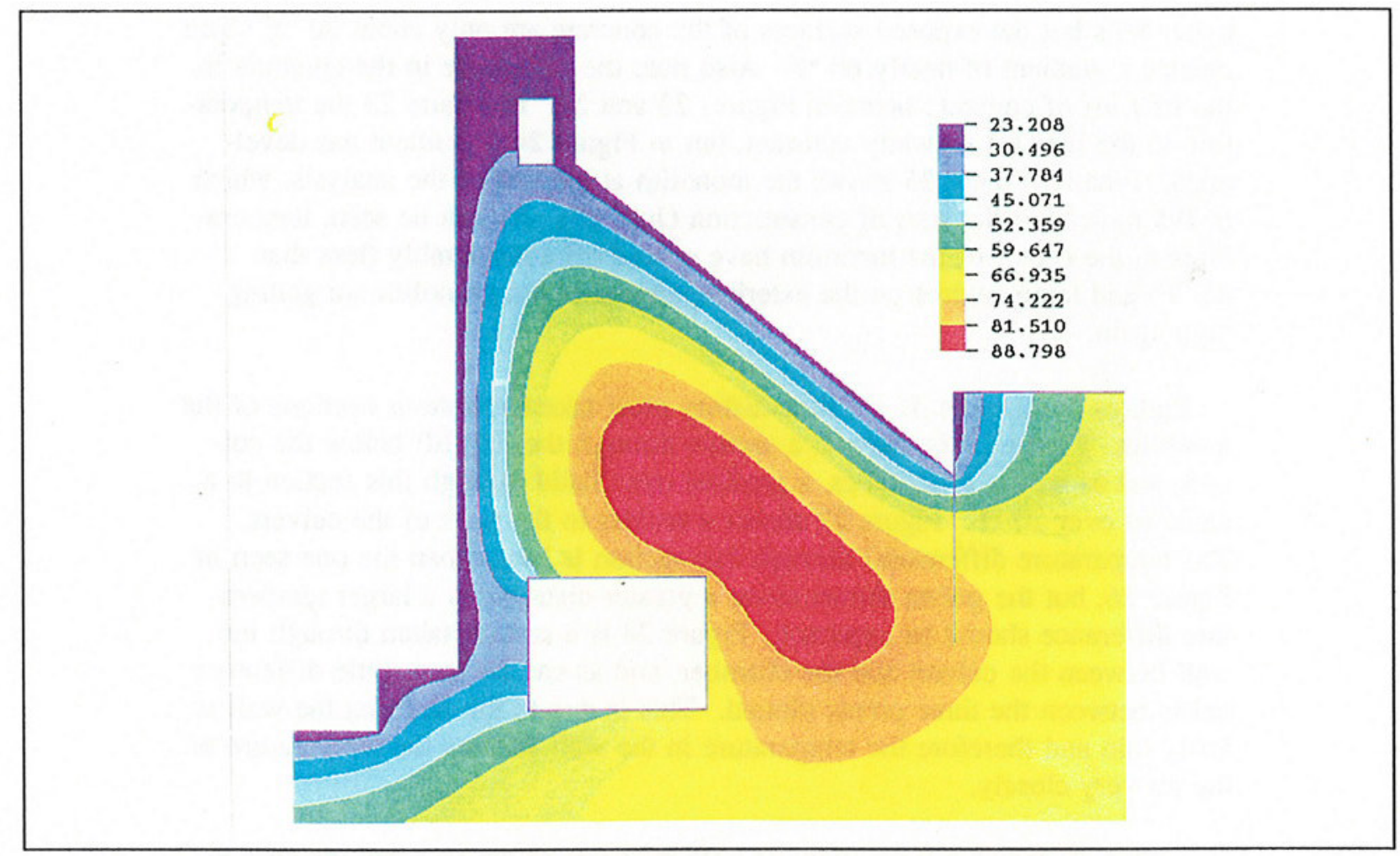

Figure 24. Temperature contour, 210 days after start of construction, 7-1/2-ft lifts

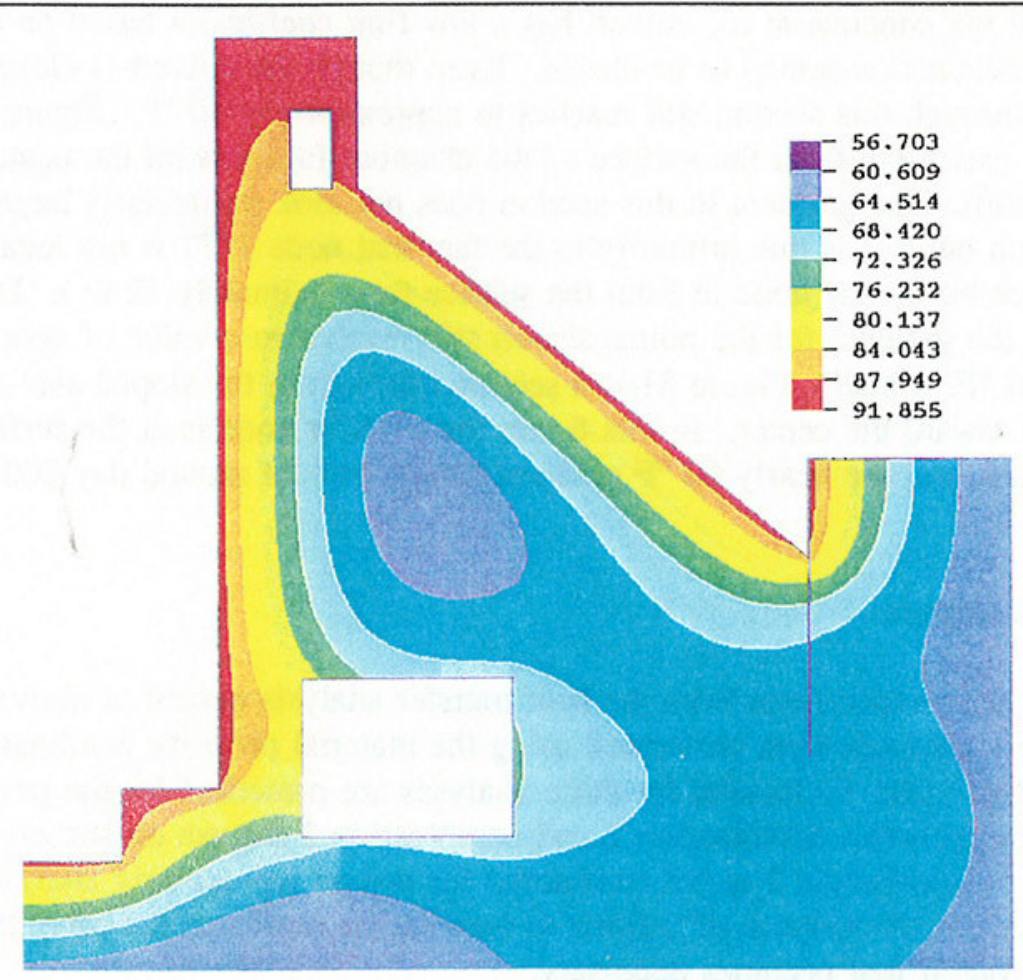

Figure 25. Temperature contour, 395 days after start of construction, 7-1/2-ft lifts 
upper $80^{\prime} \mathrm{s}$ but the exposed surfaces of the concrete are only about $30^{\circ} \mathrm{F}$. This creates a gradient of nearly $60^{\circ} \mathrm{F}$. Also note the difference in the contours in the first lift of concrete between Figures 23 and 24 . In Figure 23 the temperature in the first lift is nearly constant, but in Figure 24 a gradient has developed. Finally, Figure 25 shows the monolith at the end of the analysis, which is 395 days after the start of construction (July 10). As can be seen, temperatures in the center of the monolith have cooled off considerably (less than $65^{\circ} \mathrm{F}$ ) and temperatures on the exterior portions of the monolith are getting high again.

Figures 26 through 31 are time-history plots taken at various sections of the monolith. Figure 26 is taken at a section through the first lift below the culvert, and as winter approaches, a gradient does build through this section to a value of over $20^{\circ} \mathrm{F}$. Figure 27 shows a section to the right of the culvert. The temperature differential through this section is larger than the one seen in Figure 26, but the points shown cover a greater distance so a larger temperature difference should be expected. Figure 28 is a section taken through the wall between the culvert and the chamber, and as can be seen, little difference exists between the three points plotted. This is due to the fact that the wall is fairly thin and therefore the temperature in the wall follows the temperature of the air very closely.

Figure 29 shows a large gradient occurring due to the fact that the section starts at the surface of the concrete and extends toward the center of the monolith. The gradient in this section is moderated somewhat by the fact that the surface of the concrete at the culvert has a low film coefficient based on the fact the culvert is assumed to be closed. Even though the culvert is closed, the gradient through this section still reaches to approximately $40^{\circ} \mathrm{F}$. Figure 30 is a section extending from the surface of the chamber face toward the center of the monolith. The gradient in this section does not look particularly large for its location but this is due primarily to the fact that node 1277 is not located at the surface but is one node in from the surface (approximately 12 in.). Despite this fact, the gradient for the points shown still reaches to a value of approximately $30^{\circ} \mathrm{F}$. Finally, Figure 31 is a section taken from the sloped side of the monolith toward the center. In this figure the exterior node is at the surface of the concrete and the nearly $60^{\circ} \mathrm{F}$ gradient can be seen at around day 200 .

\section{Stress analysis}

Using the temperatures from the heat transfer analysis described above, three stress analyses were performed using the material property combinations described in Table 1. Results for these analyses are presented for the purpose of selecting between combination 2 and combination 3 for use on subsequent

analyses. Combination 1 is not considered for use on any ensuing analyses but is included for the purpose of helping to explain the results of the other two combinations if that becomes necessary. 

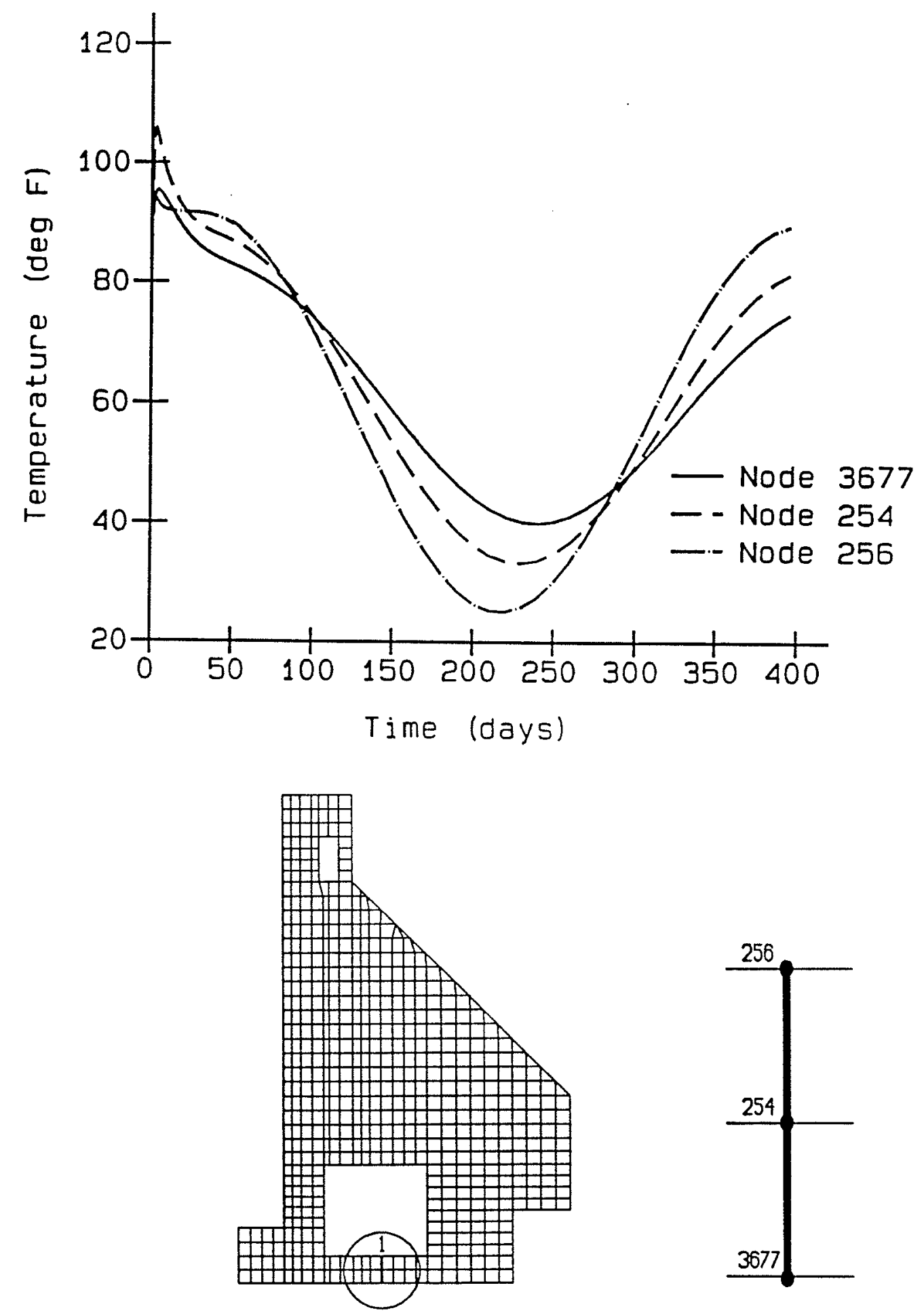

Figure 26. Temperature time-history at section 1 for $7-1 / 2$-ft lift placement 

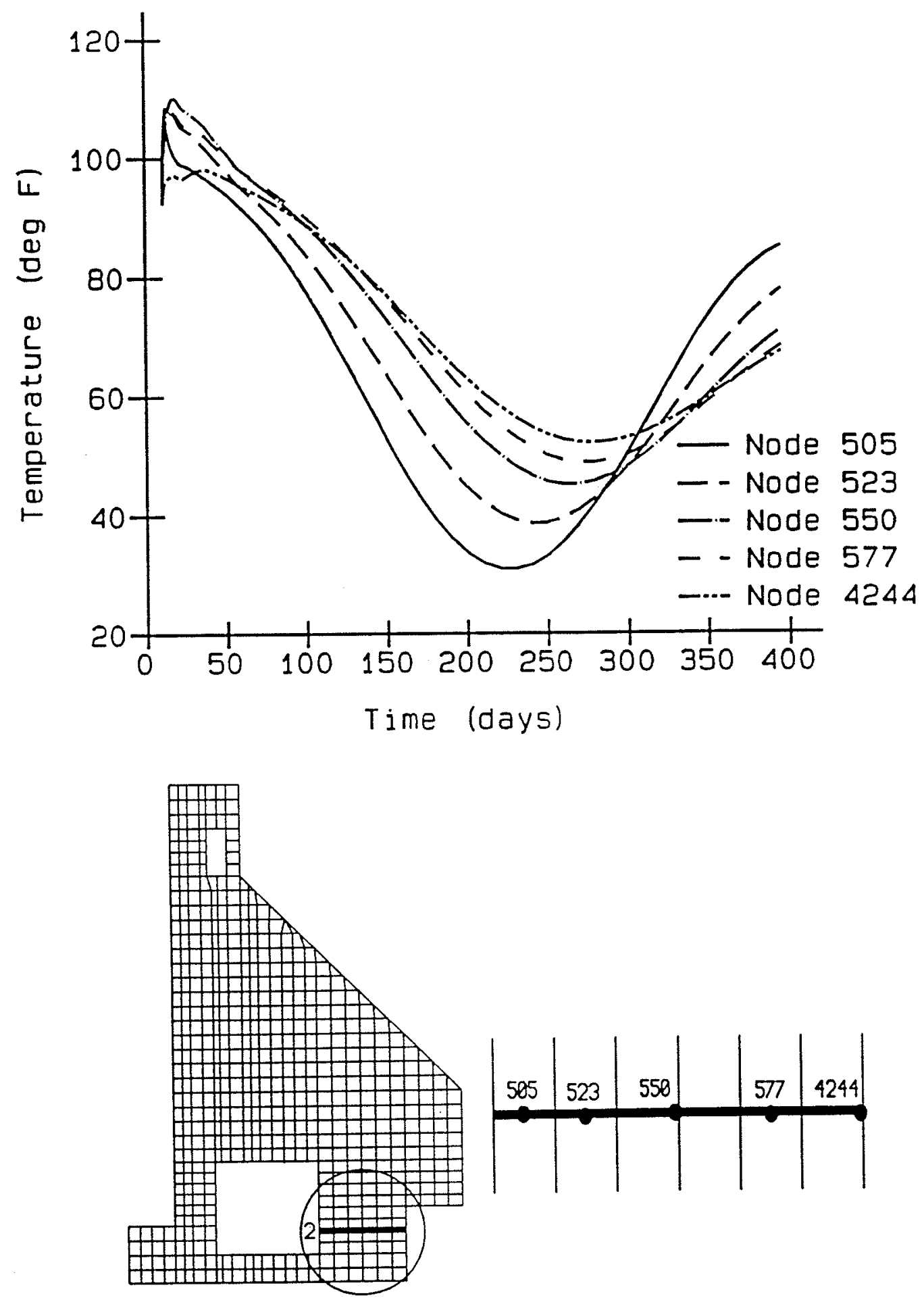

Figure 27. Temperature time-history at section 2 for $7-1 / 2-f t$ lift placement 

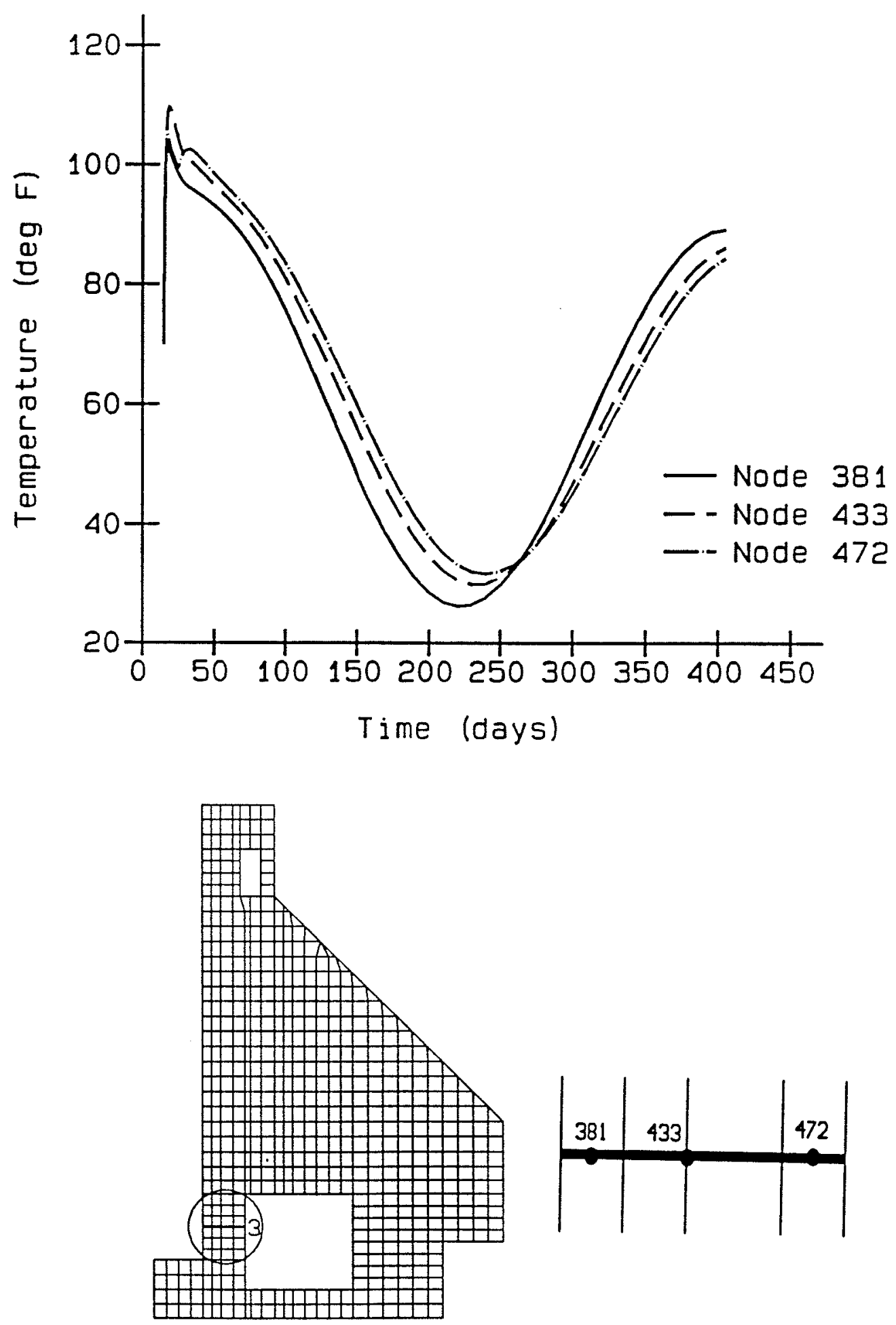

Figure 28. Temperature time-history at section 3 for $7-1 / 2-f t$ lift placement 

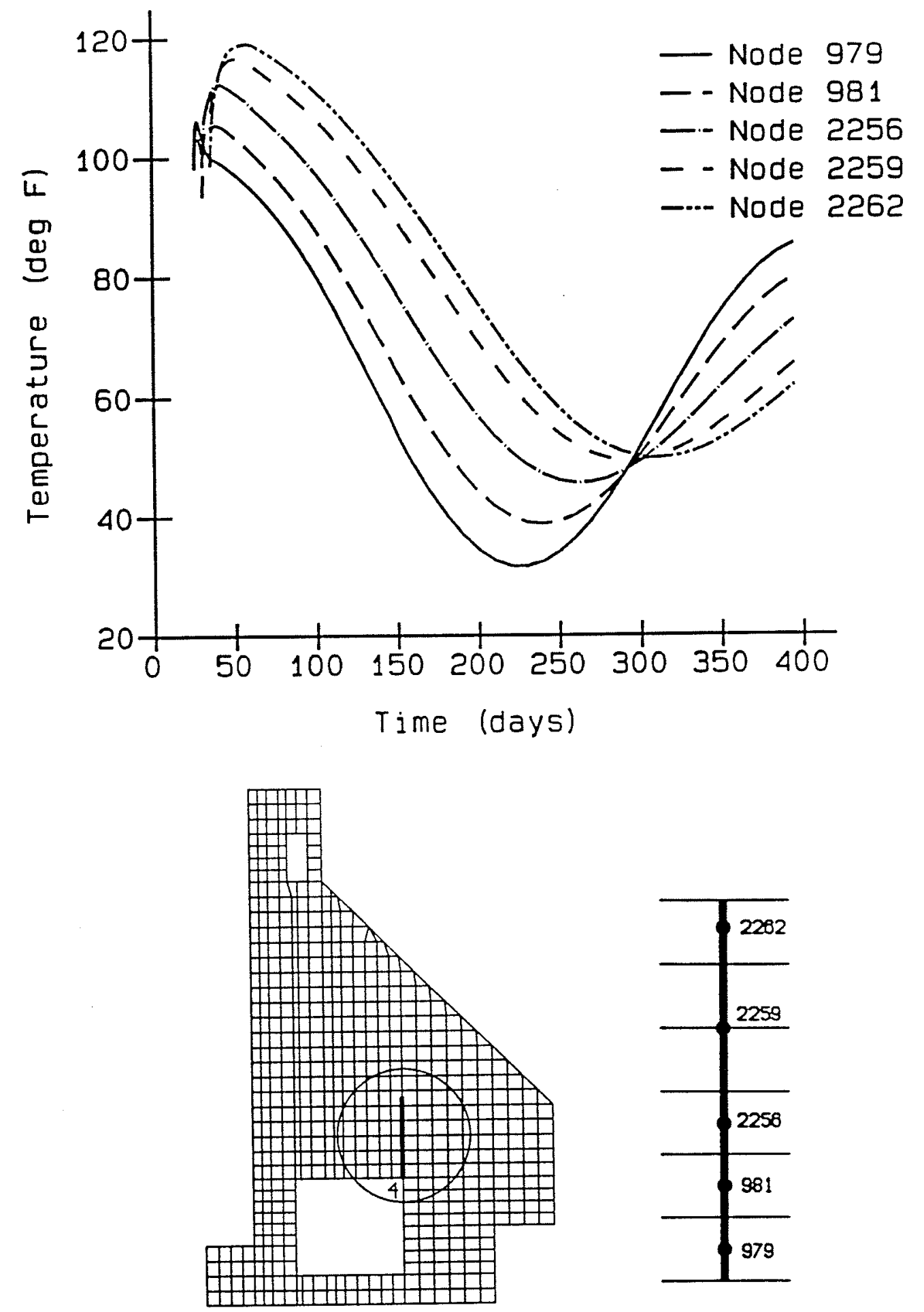

Figure 29. Temperature time-history at section 4 for $7-1 / 2-f t$ lift placement 

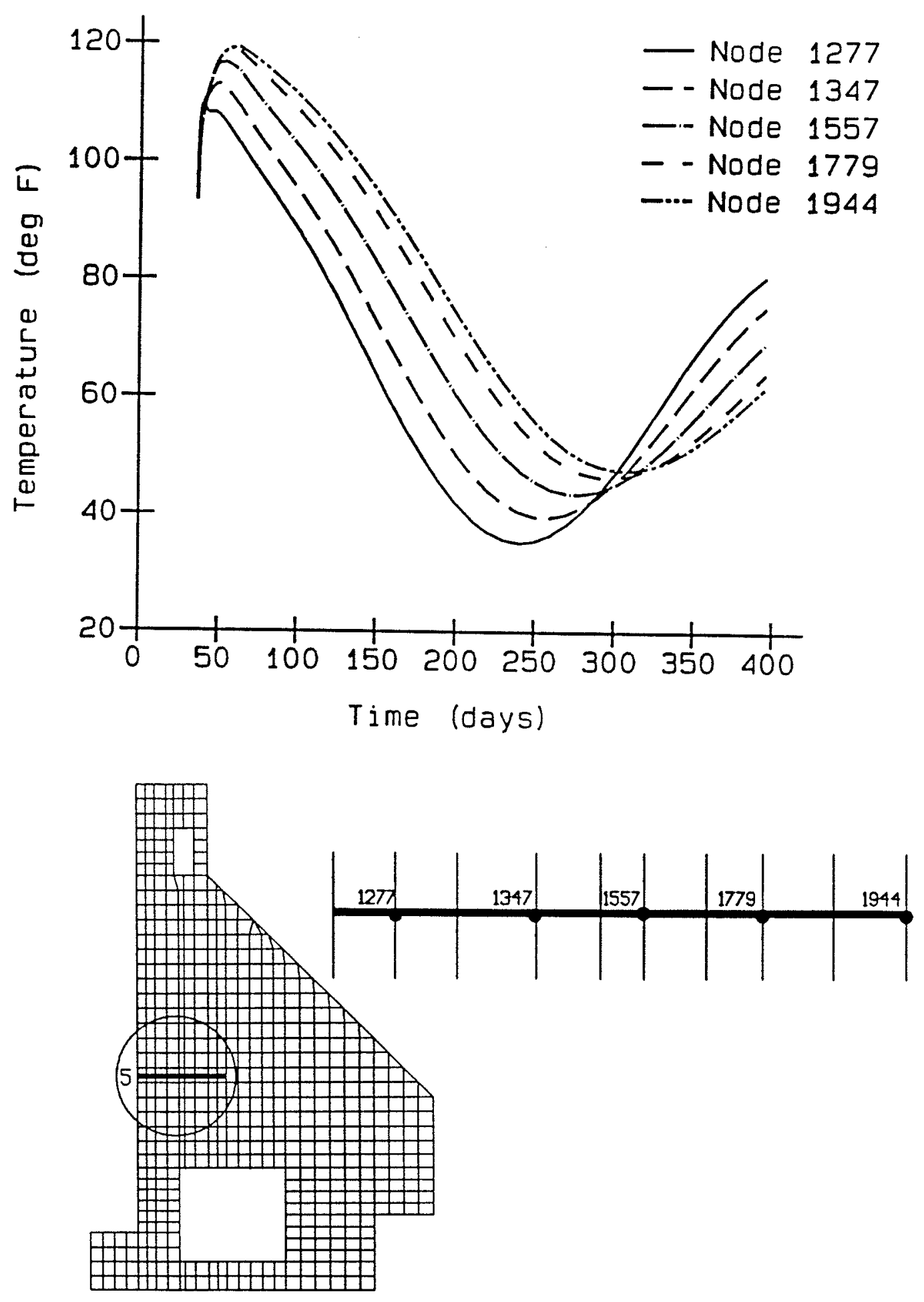

Figure 30. Temperature time-history at section 5 for $7-1 / 2-\mathrm{ft}$ lift placement 

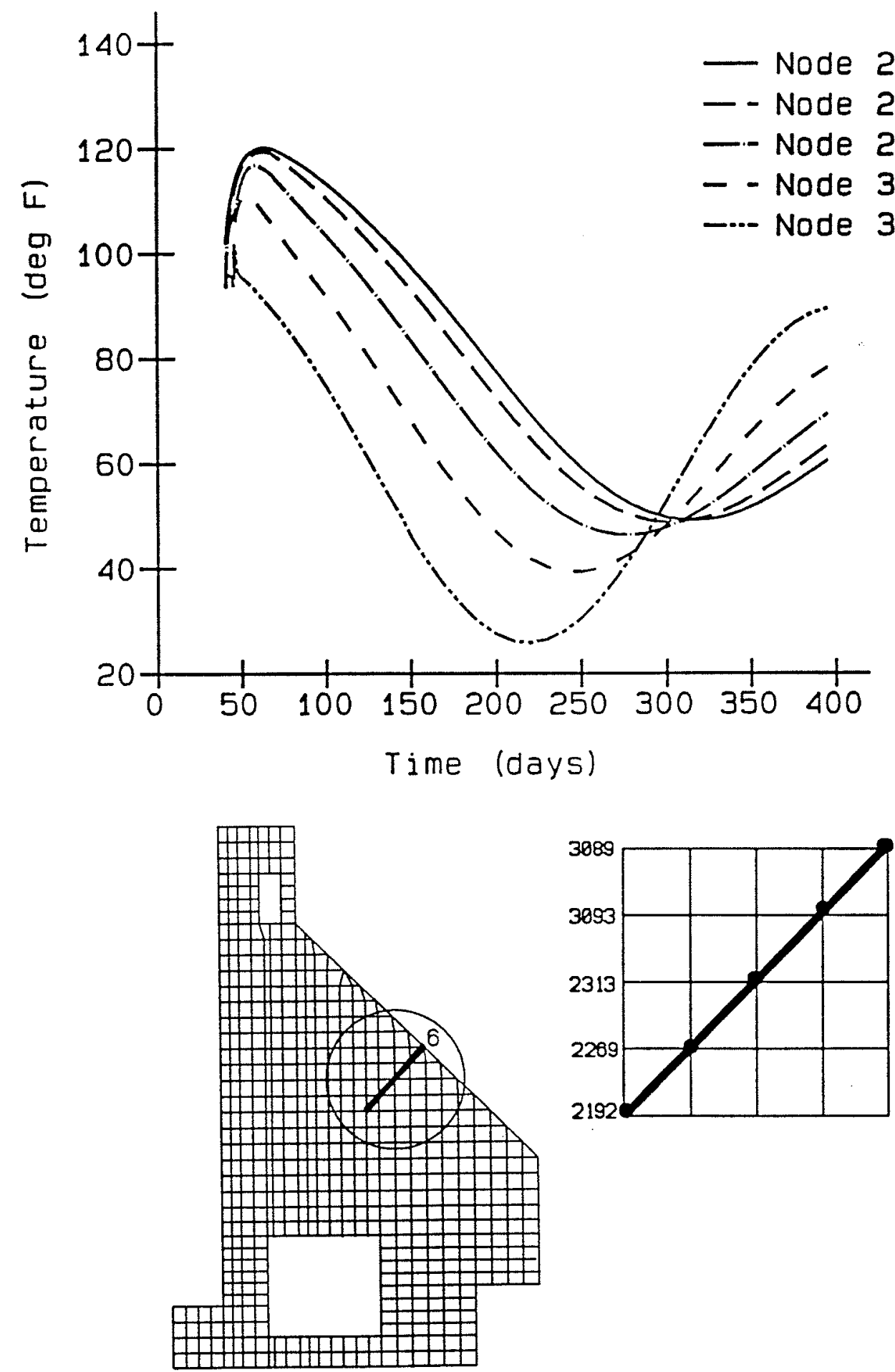

Figure 31. Temperature time-history at section 6 for $7-1 / 2-\mathrm{ft}$ lift placement 
Plots of the cracking patterns for each of the combinations are presented as well as stress time-history plots for determining which combination to use. Figures 32 through 40 are plots of integration points that have cracked. Cracking predicted in the analysis for combination 1 is shown at days 165,250 , and 405 in Figures 32, 35, and 38, while cracking predicted in the analyses for combinations 2 and 3 is shown at days 160, 260, and 405 in Figures 33, 34, $36,37,39$, and 40 . If the different crack plots are compared at a given time, it can be seen that the cracking in the monolith is very similar from one combination to another. While the cracking patterns are not exactly identical, the total number of integration points which have been predicted to crack in each analysis are the same for combinations 2 and 3 (64 points cracked) and combination 1 is very similar (57 points cracked).

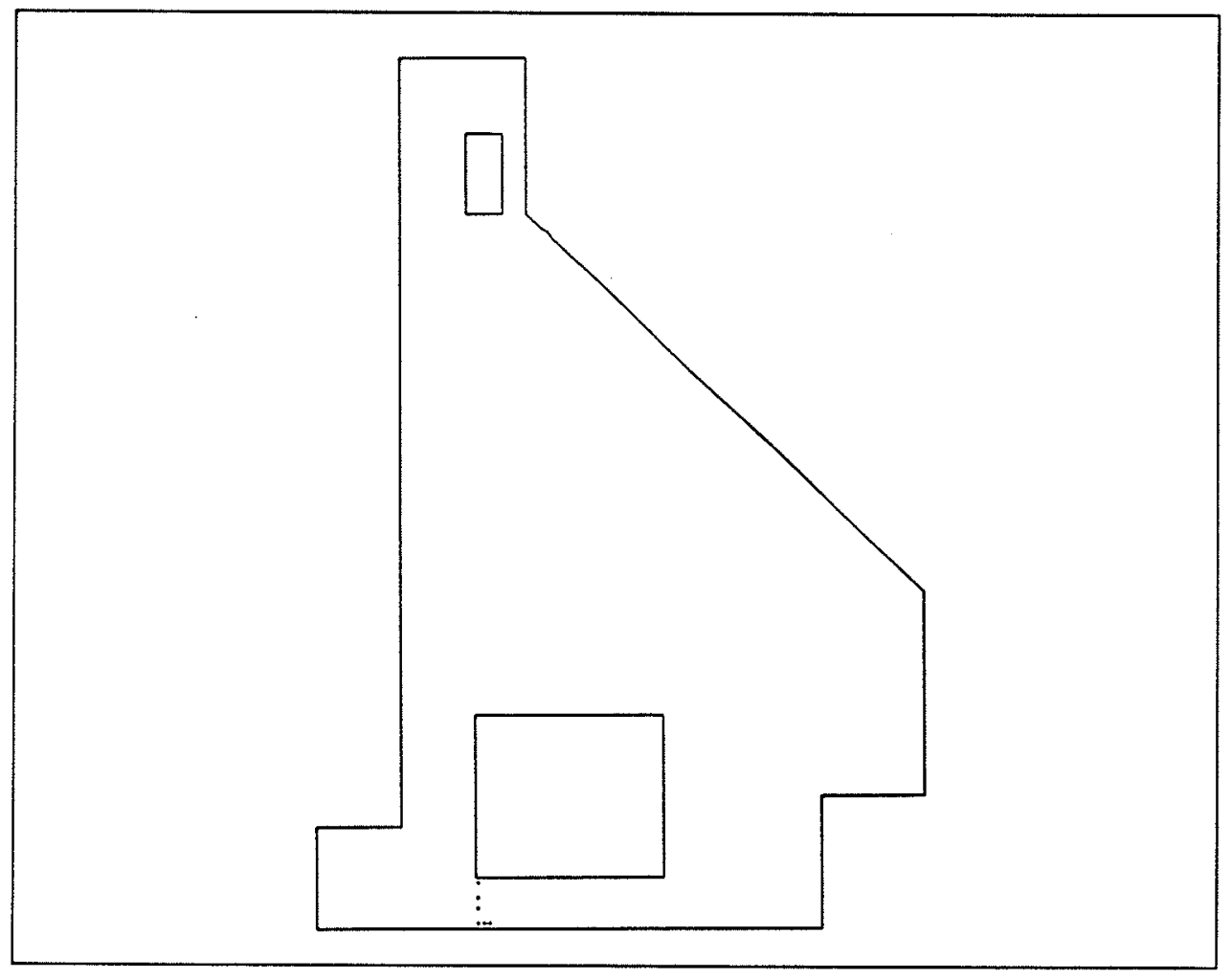

Figure 32. Cracking predicted at day 165 using material combination 1

Figures 41,42 , and 43 are time-history plots of three different locations in the monolith. Figure 41 is for a point located at the lower left-hand corner of the culvert where a crack formed and propagated down to the rock/concrete interface. The resulting horizontal stresses for all three analyses are very close, with combinations 2 and 3 being almost identical. Figure 42 is a point located at the upper left-hand comer of the culvert, one integration point above the crack which occurred at this location. Again the behavior for all three combinations is very similar. Finally, Figure 43 presents stresses at a point at the upper right-hand comer of the culvert. As with the first two figures, little 


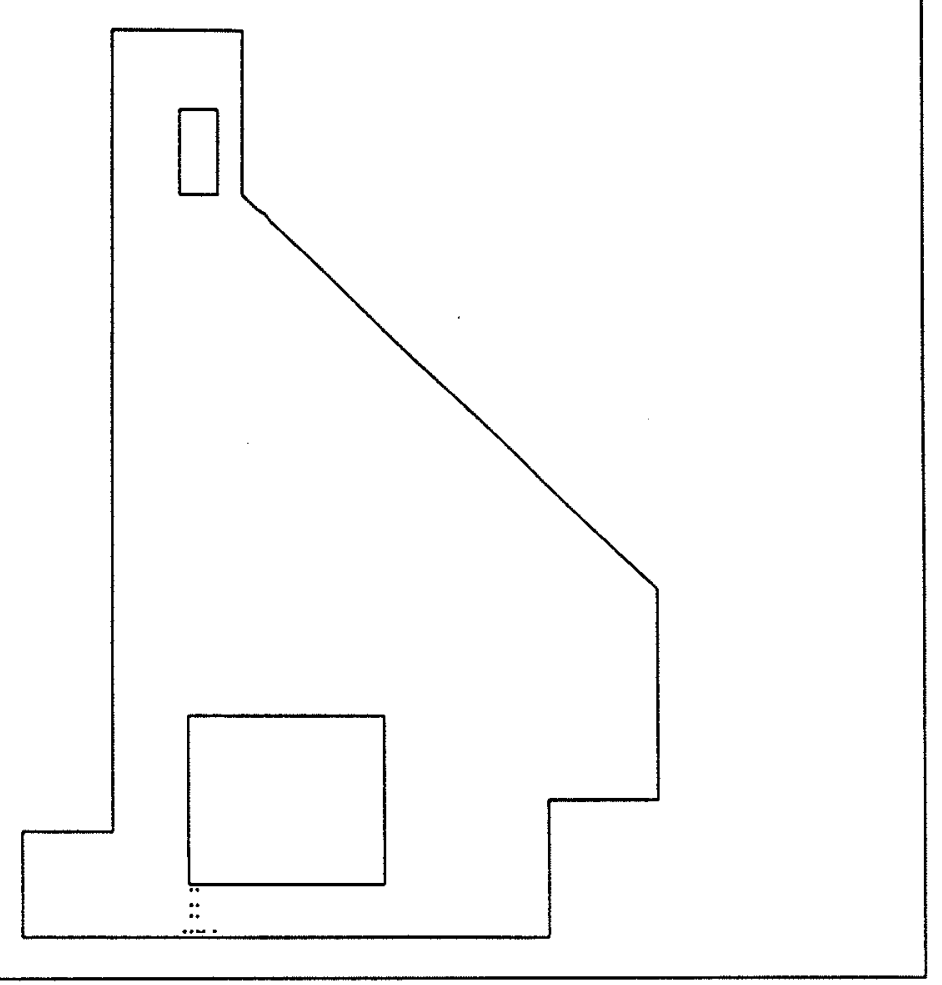

Figure 33. Cracking predicted at day 160 using material combination 2

difference exists between the three analyses and virtually no difference between the results from combinations 2 and 3 can be seen.

It can be seen that for the material properties specified for this project, little difference occurs due to adjusting the amount of creep and shrinkage used in the analysis. Since differences were virtually nonexistent between material combinations 2 and 3, a decision was made to use combination 3 for the remaining analyses of the McAlpine Lock Replacement NISA, since combination 3 is intuitively the worst case.

\section{Lift Heights}

\section{Heat transfer analysis}

After a decision was made concerning the material combination, analyses for evaluating lift heights could be performed. While a number of points cracked in the previous analyses, the cracks were not in critical locations, and it was felt additional measures could be taken to reduce the number of points that cracked. Therefore, an analysis was performed using $10-\mathrm{ft}$ lifts. Heat transfer analysis results for the 10-ft lift arrangement are presented in this 


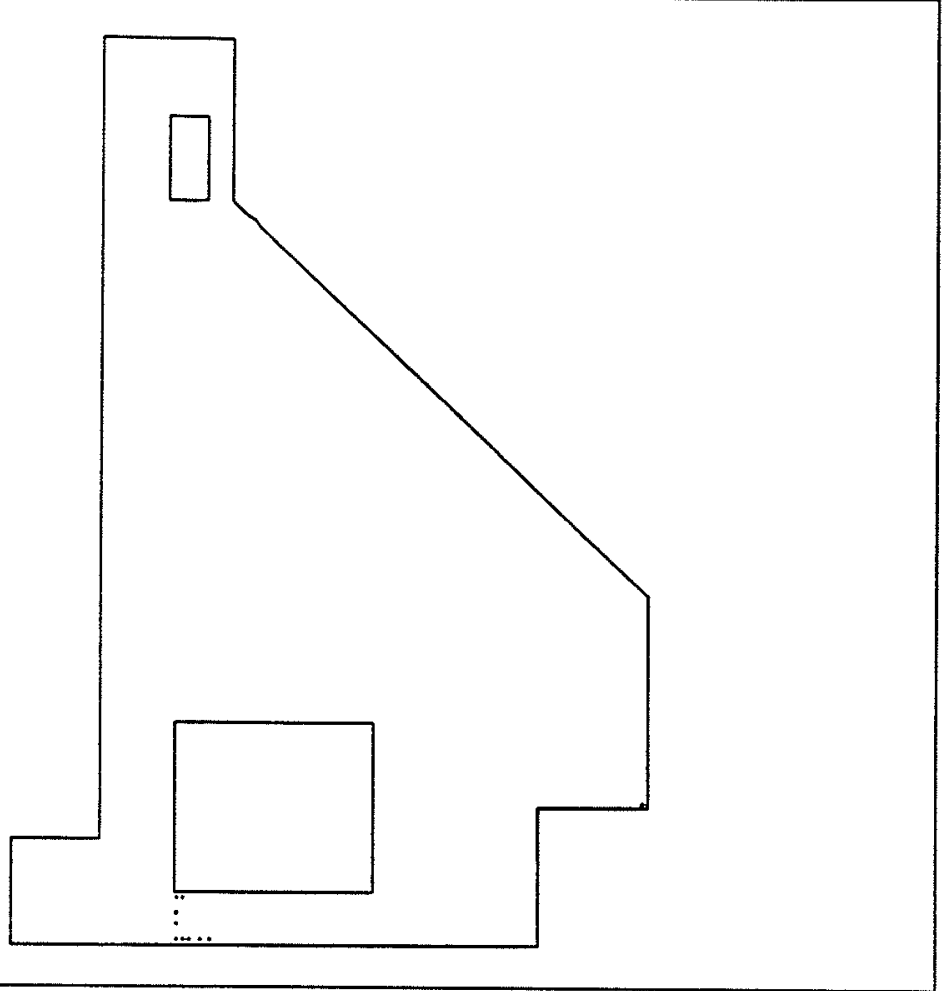

Figure 34 . Cracking predicted at day 160 using material combination 3

chapter with temperature contour plots and with comparisons to the 7-1/2-ft arrangement at several points in the structure.

Figures 44 through 47 are temperature contour plots. Figure 44 shows the temperature contours at day 63 when the maximum temperature of $123.3^{\circ} \mathrm{F}$ is reached. This is $2.5^{\circ} \mathrm{F}$ higher than the maximum reached for the $7-1 / 2-\mathrm{ft}$ lift arrangement, but occurs at approximately the same time. By day 77 the maximum temperature has dropped to $120.0^{\circ} \mathrm{F}$, slightly lower than the $7-1 / 2-\mathrm{ft}$ analysis. The fact that the temperature is lower for the 10 - $\mathrm{ft}$ lift analysis at this time is likely due to the fact that the lifts near the midheight of the monolith in the 7-1/2-ft lift plan were placed at a later date than the same lifts for the $10-\mathrm{ft}$ lift plan and therefore there may still be a small amount of heat generation occurring in the 7-1/2-ft plan. Figure 46 shows temperatures at 220 days after the start of construction and corresponds to the coldest part of the winter. As in the previous analysis, a steep gradient exists from the center of the monolith to the surface. Finally, at the end of the analysis, comparing Figure 47 (day 385) for the 10-ft lift analysis to Figure 25 (day 395) of the $7-1 / 2-\mathrm{ft}$ analysis, it can be seen that they are nearly identical with the difference being attributed primarily to the fact that the results are shown at slightly different times.

In Figures 48 through 53, time-history plots of temperature are shown comparing temperatures from the two heat transfer analyses at various points in the 


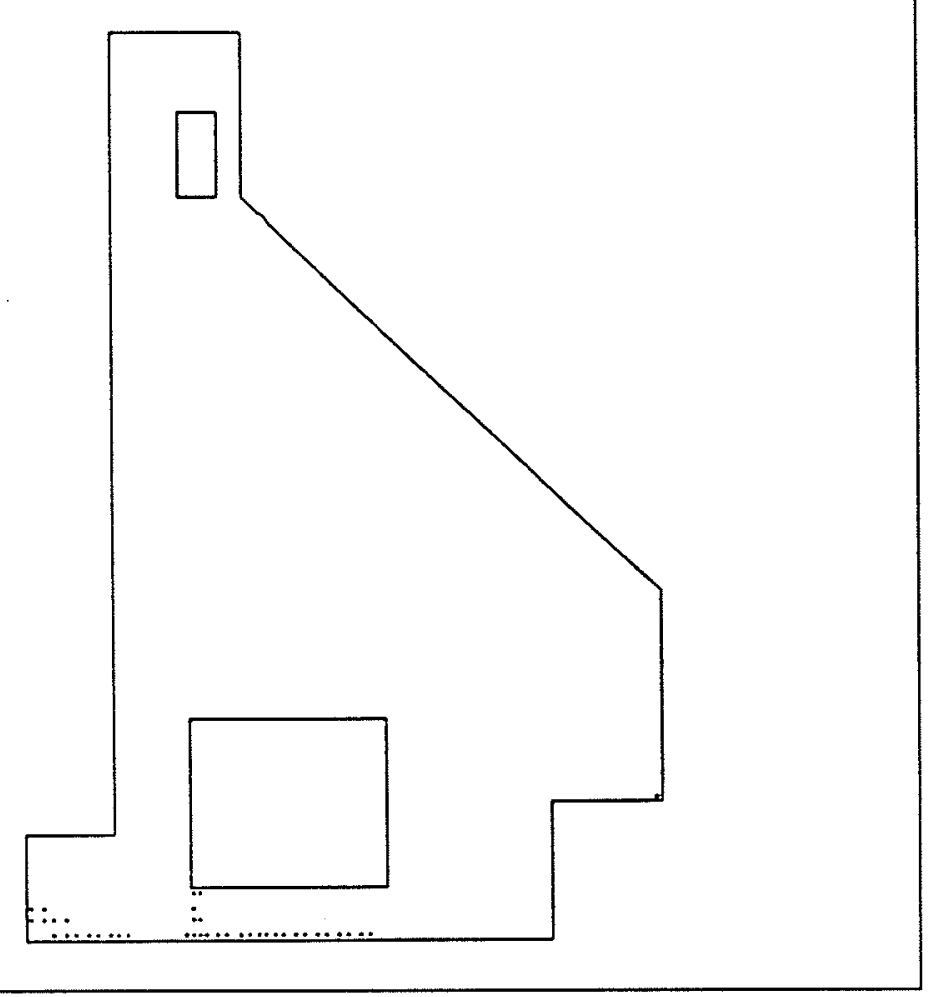

Figure 35. Cracking predicted at day 250 using material combination 1

structure. The tendency of the curves is the same in all six figures, as there is an initial difference between the two analyses but by day 100 the curves are essentially the same. The initial differences would even be less noticeable if the placements were at the same time. Using higher lifts in the second analysis meant that some of the points shown were activated earlier in the analysis. Figures 48 through 53 show that increasing the lift heights has little effect on internal heat generation.

\section{Stress analysis}

Stress analysis was performed using the temperature results from the heat transfer analysis using $10-\mathrm{ft}$ lifts and material combination 3 , as described in Table 1. The determination as to whether to use $7-1 / 2-\mathrm{ft}$ lifts or $10-\mathrm{ft}$ lifts will be done by comparing the cracking which occurred and by comparing stress time-histories at several points, as was done when comparing the various material combinations.

Figures 54, 55, and 56 are plots of the integration points which have cracked at days 160,250 , and 395 after the start of construction, respectively. If Figure 54, taken at day 160, is compared back to Figure 34 for the 7-1/2-ft lift scheme, it can be seen that the $10-\mathrm{ft}$ lift case produces a slightly worse condition at this point in time. Figure 55 shows the cracking at day 250 , 


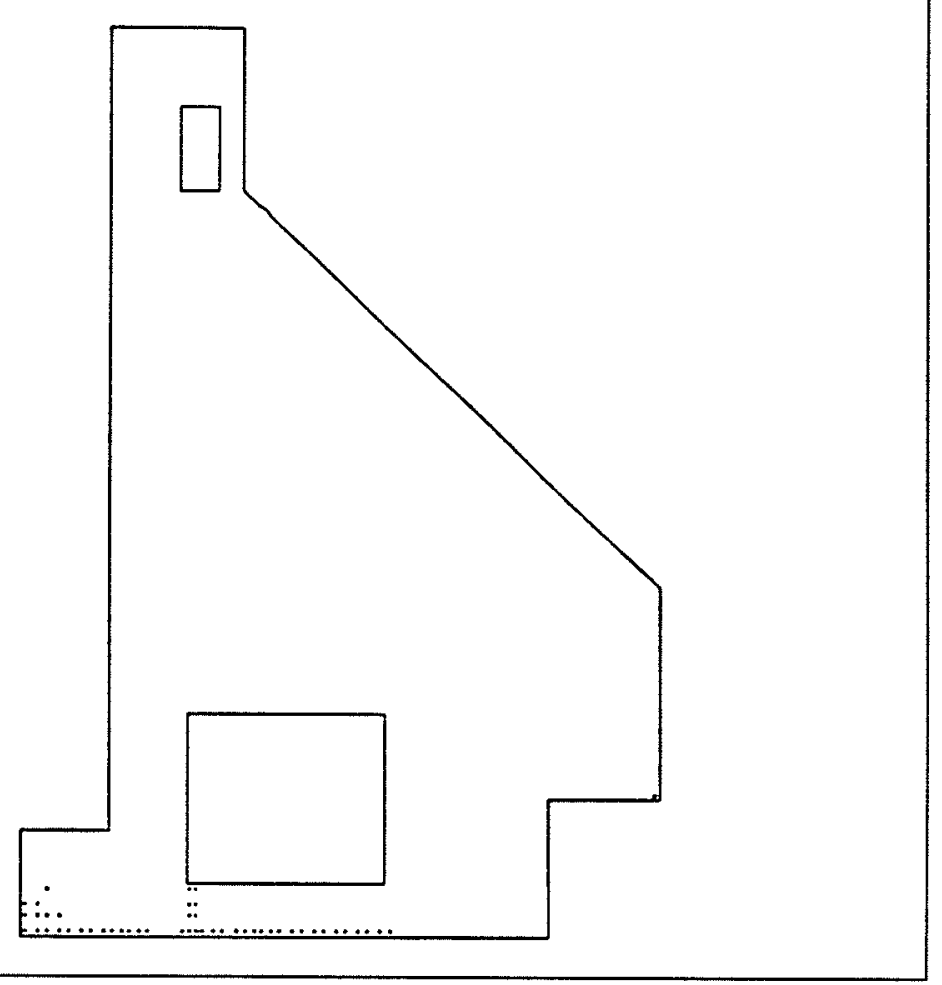

Figure 36. Cracking predicted at day 260 using material combination 2

while Figure 37 shows the cracking at day 260 . While there is a slight time differential, it can be seen in comparing the two figures that the cracking patterns for the two different construction sequences are very similar. Figures 56 and 40 are the final cracking pattems for the two analyses. Again, the two figures are very similar. There are a few more points cracked in the area below the lower left-hand comer of the culvert for the 10-ft lift analysis, but in general the cracking for the two cases is virtually the same. The total number of points cracked for the 7-1/2-ft lift plan was 64 , while the total number of points cracked for the $10-\mathrm{ft}$ lift plan was 68 . The additional cracked points occurred in the area below the lower left-hand comer of the culvert.

Figures 57, 58, and 59 compare the stress time-histories of the two lift plans at the same points in the structure at which the three material combination analyses were compared. While the agreement between the 7-1/2-ft lift plan and the $10-\mathrm{ft}$ lift is not as good as the agreement between material combinations 2 and 3 , there still is reasonably good agreement between the results of the two plans. In addition, from looking at the points presented in Figures 57, 58 , and 59, as well as the crack plots, it is unclear as to which of the two plans provides better results. Because the two plans are so similar in their behavior and since it is expected that a cost savings could be achieved by using 10 -ft lifts instead of 7-1/2-ft lifts, a decision was made to use $10-\mathrm{ft}$ lifts for the remainder of the analyses on the chamber monolith as well as on the miter gate monolith analysis and the culvert valve monolith analysis. 


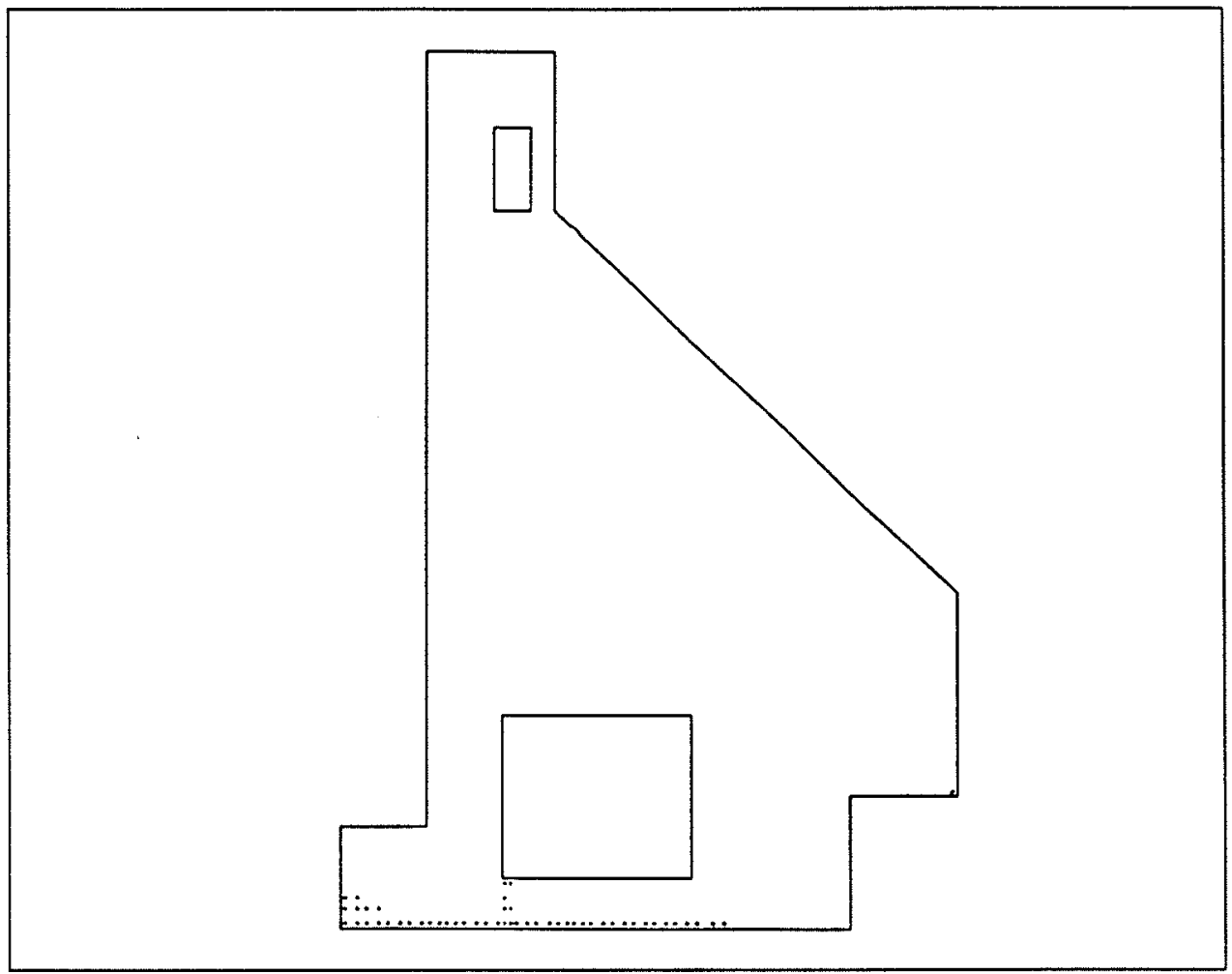

Figure 37. Cracking predicted at day 260 using material combination 3

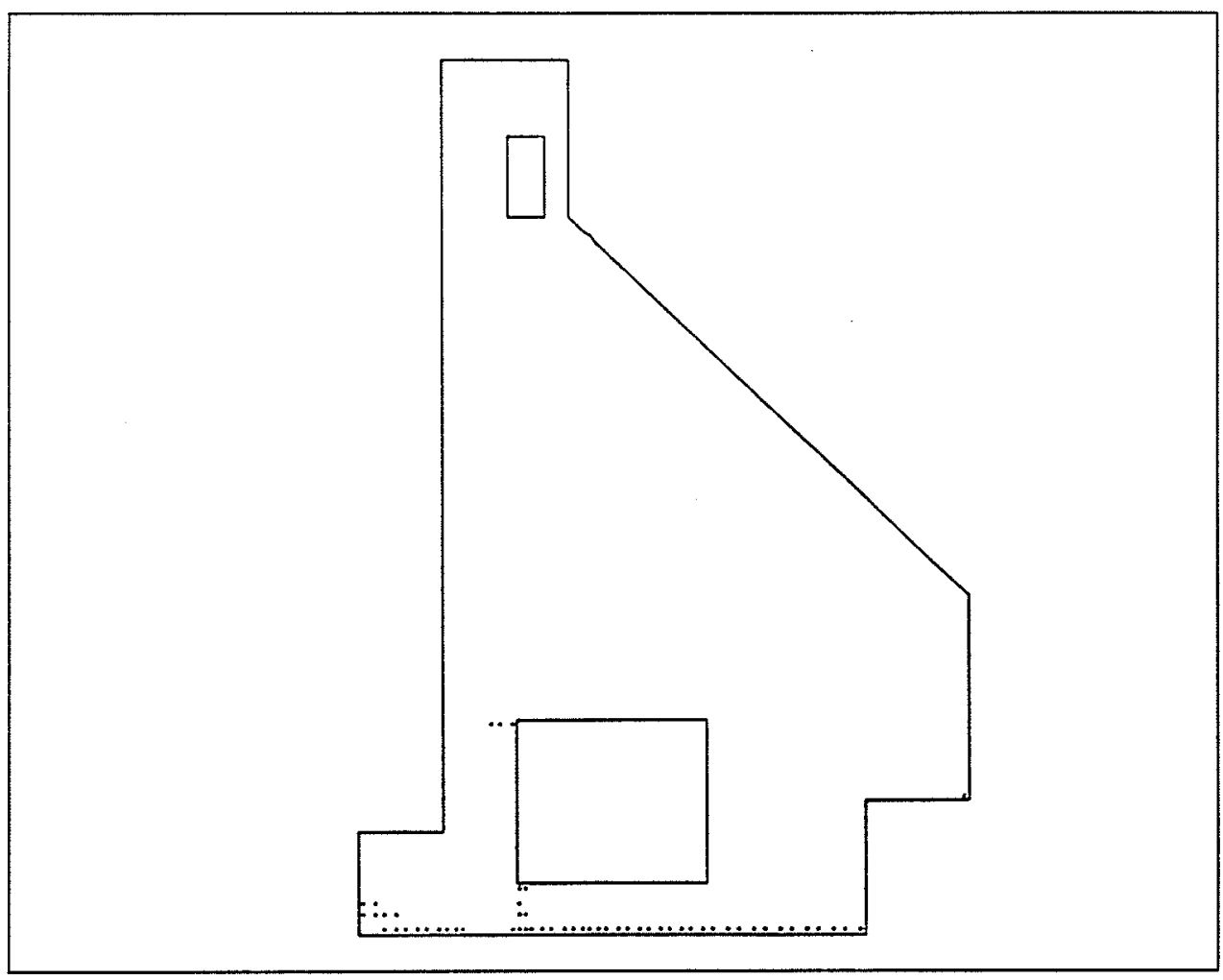

Figure 38. Cracking predicted at day 405 using material combination 1 


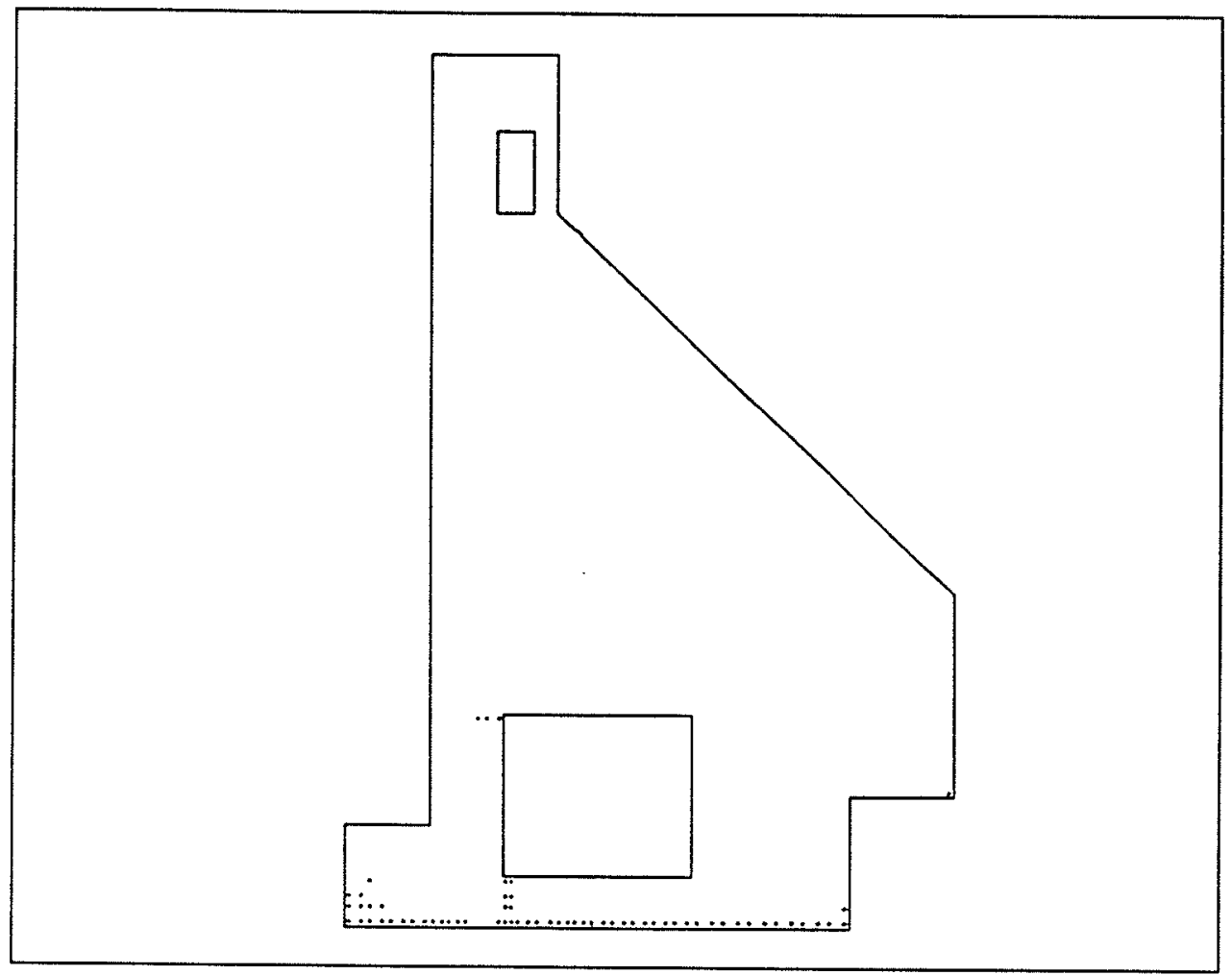

Figure 39. Cracking predicted at day 405 using material combination 2

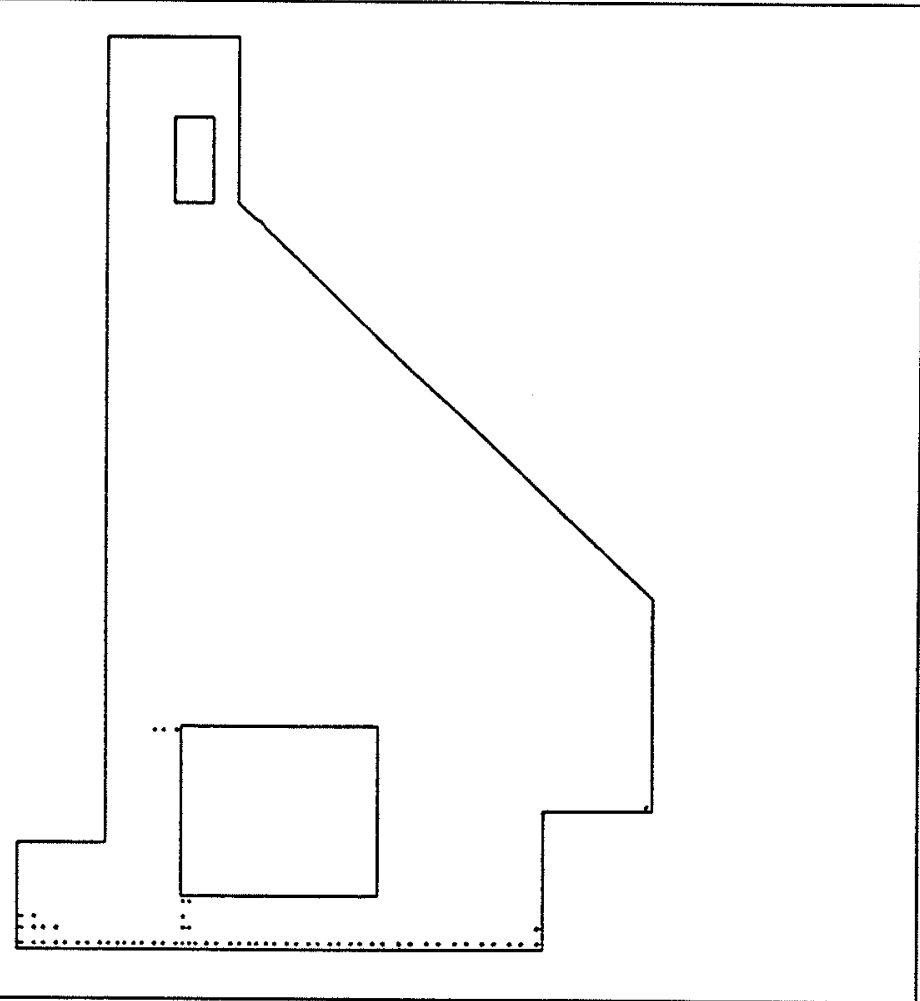

Figure 40 . Cracking predicted at day 405 using material combination 3 


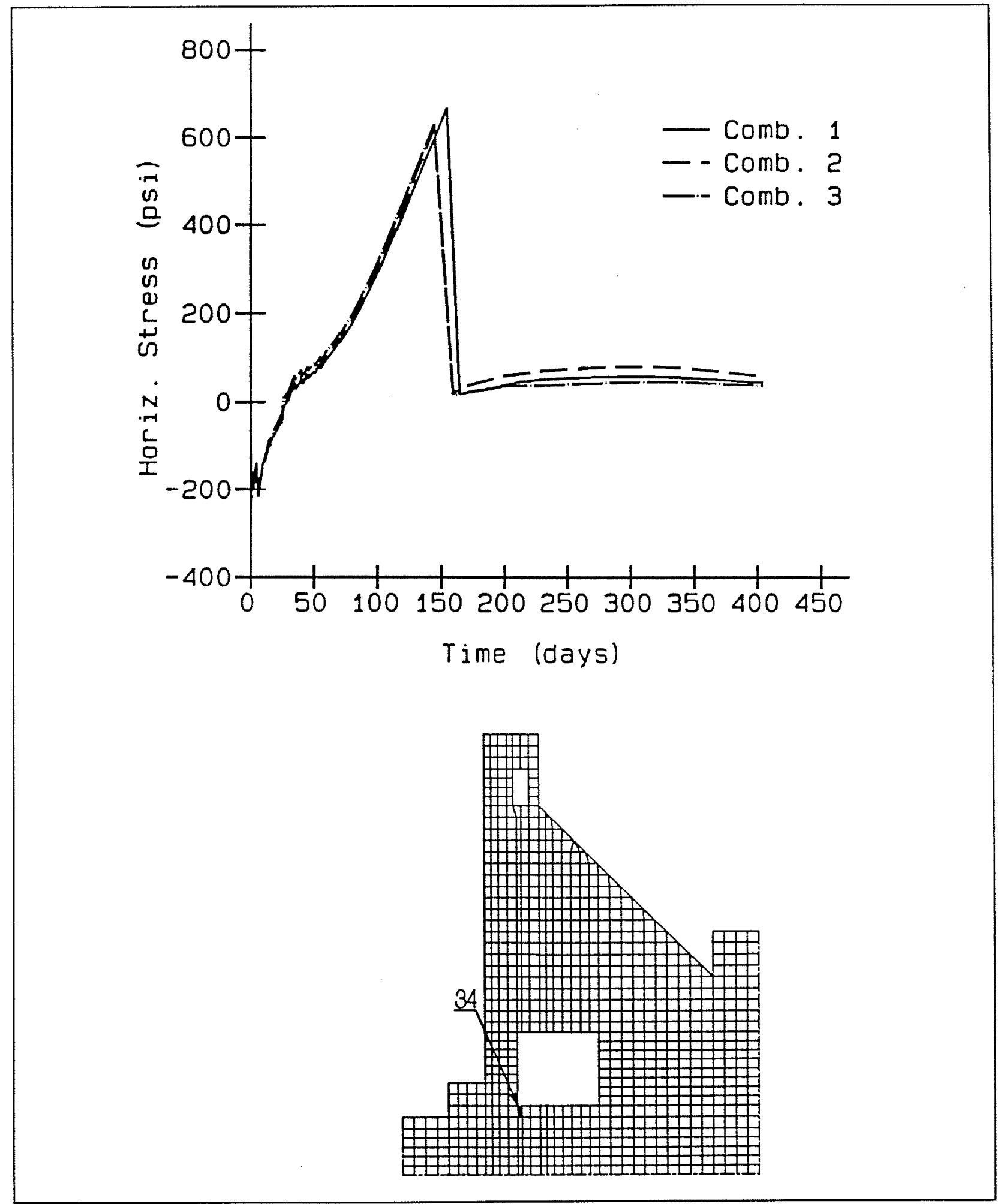

Figure 41 . Time-history of horizontal stress of element 34 , integration point 3 


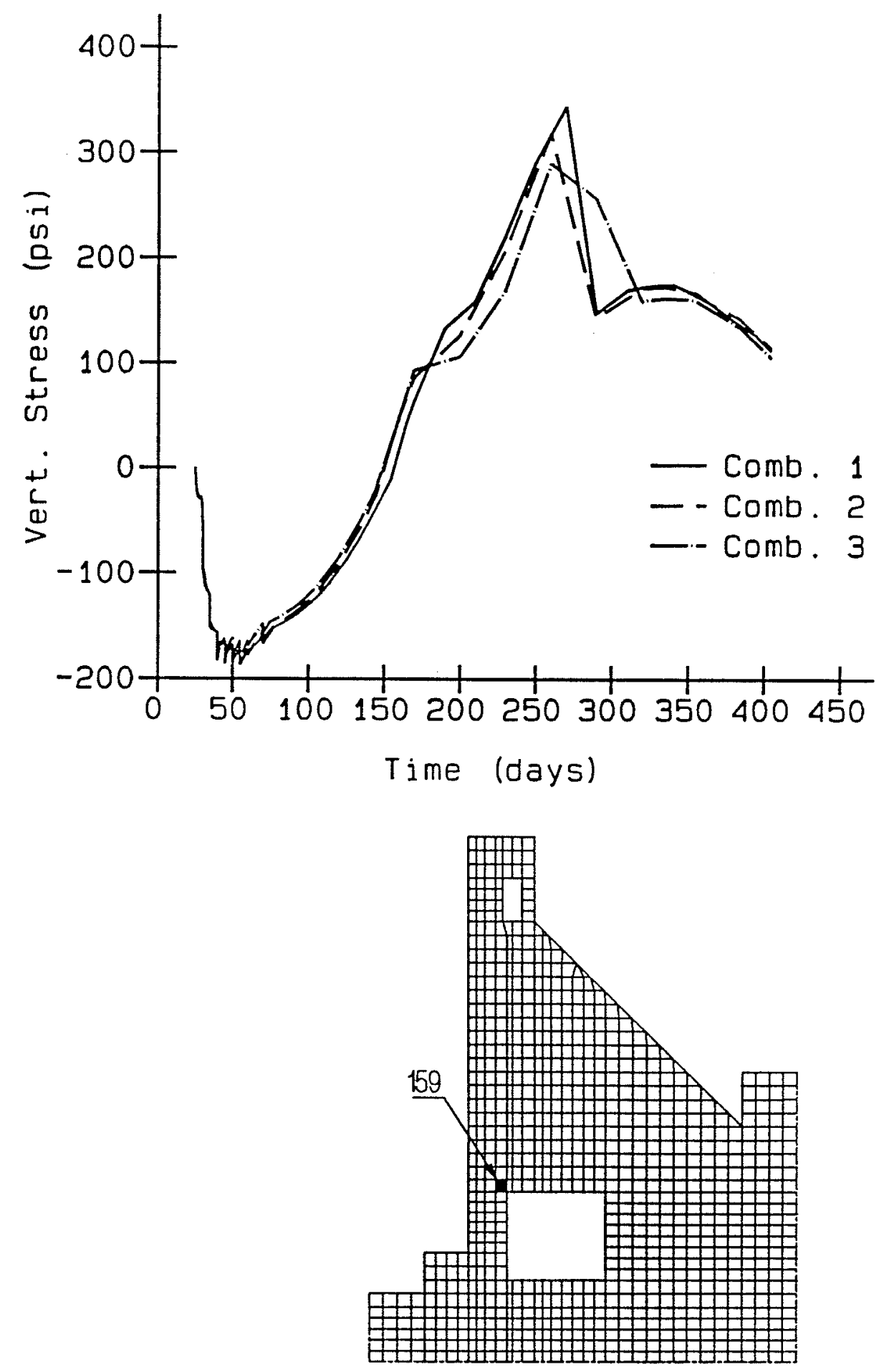

Figure 42. Time-history of vertical stress of element 159, integration point 2 


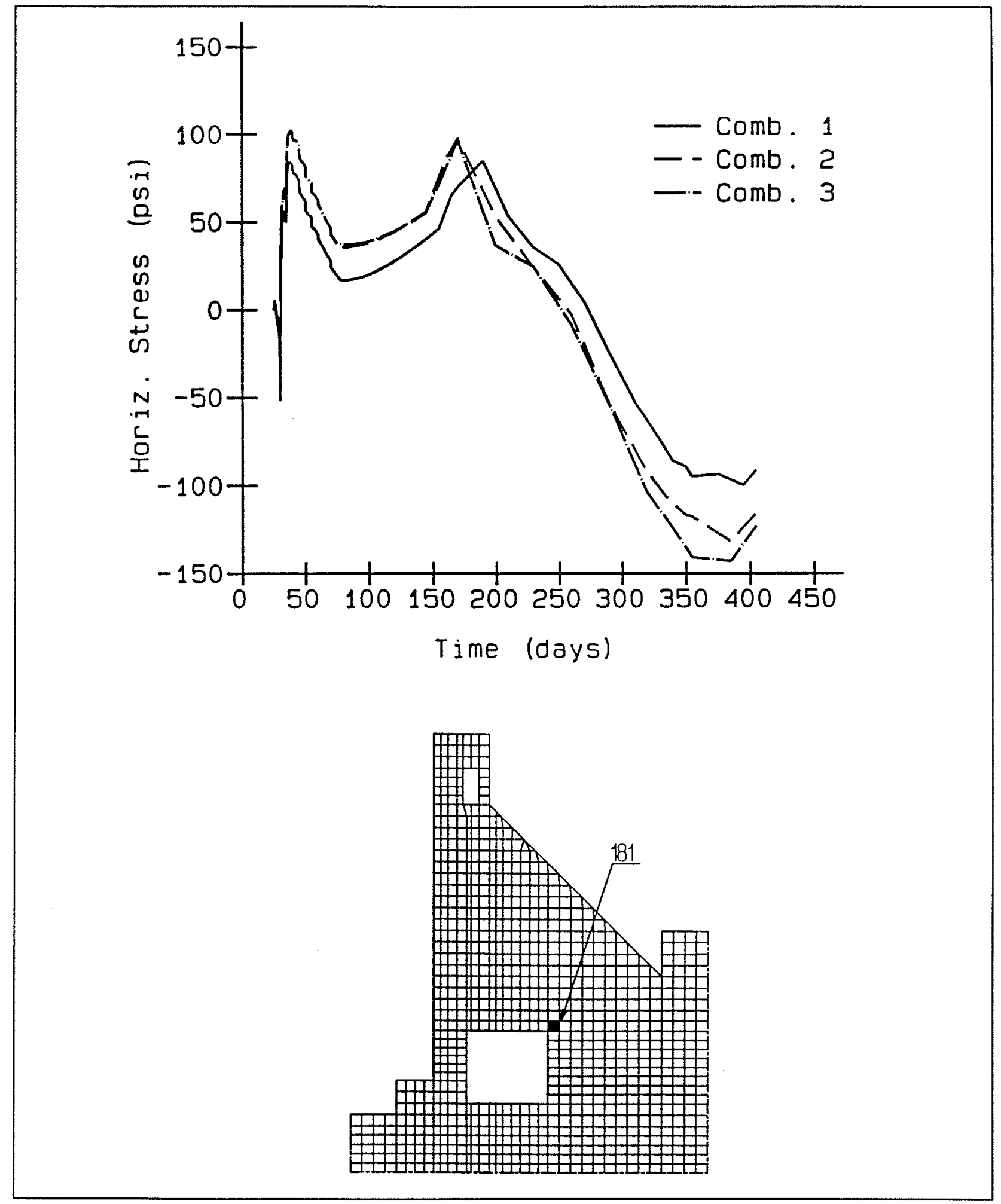

Figure 43. Time-history of horizontal stress of element 181 , integration point 1 


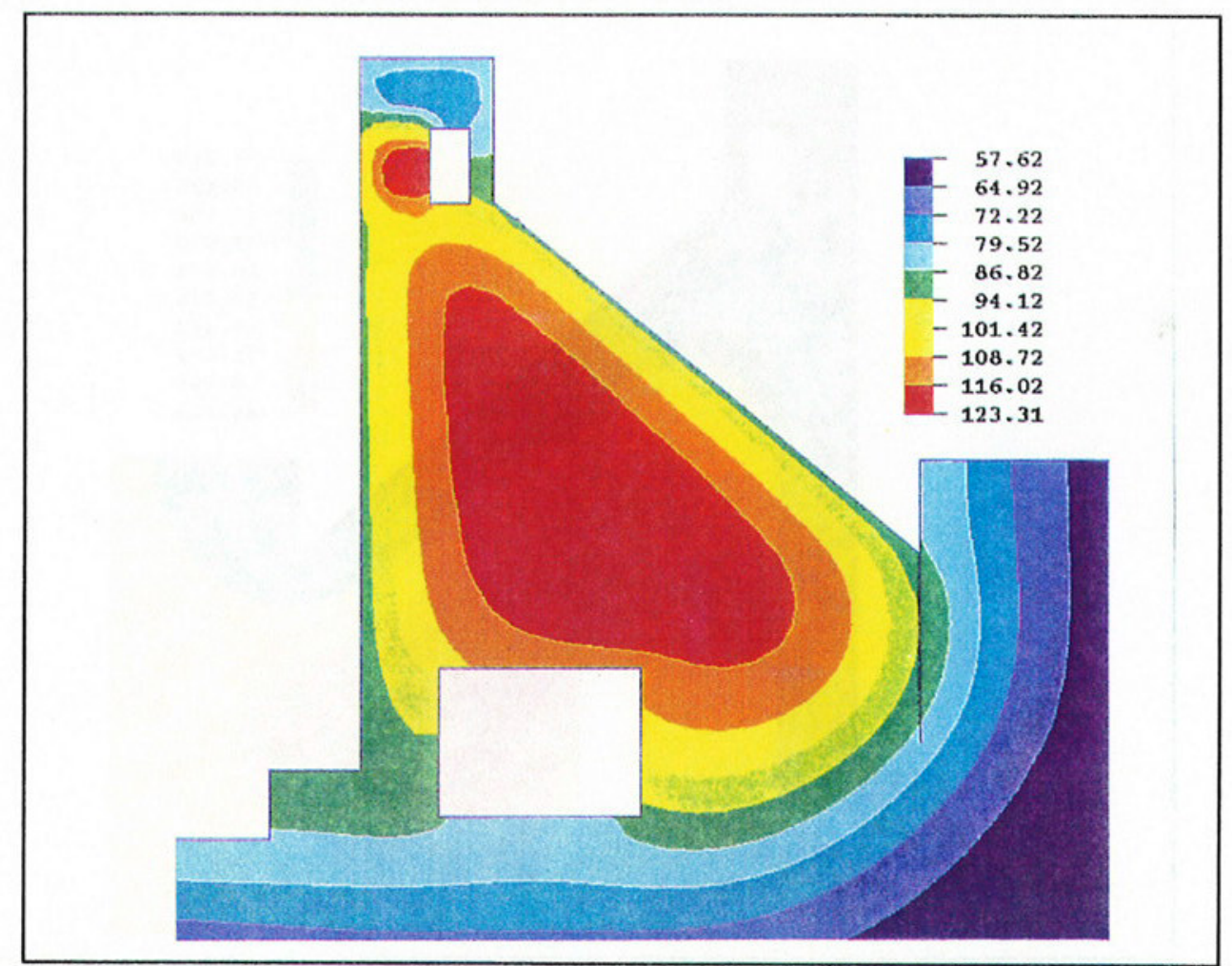

Figure 44. Temperature contour, 63 days after start of construction, 10-ft lifts

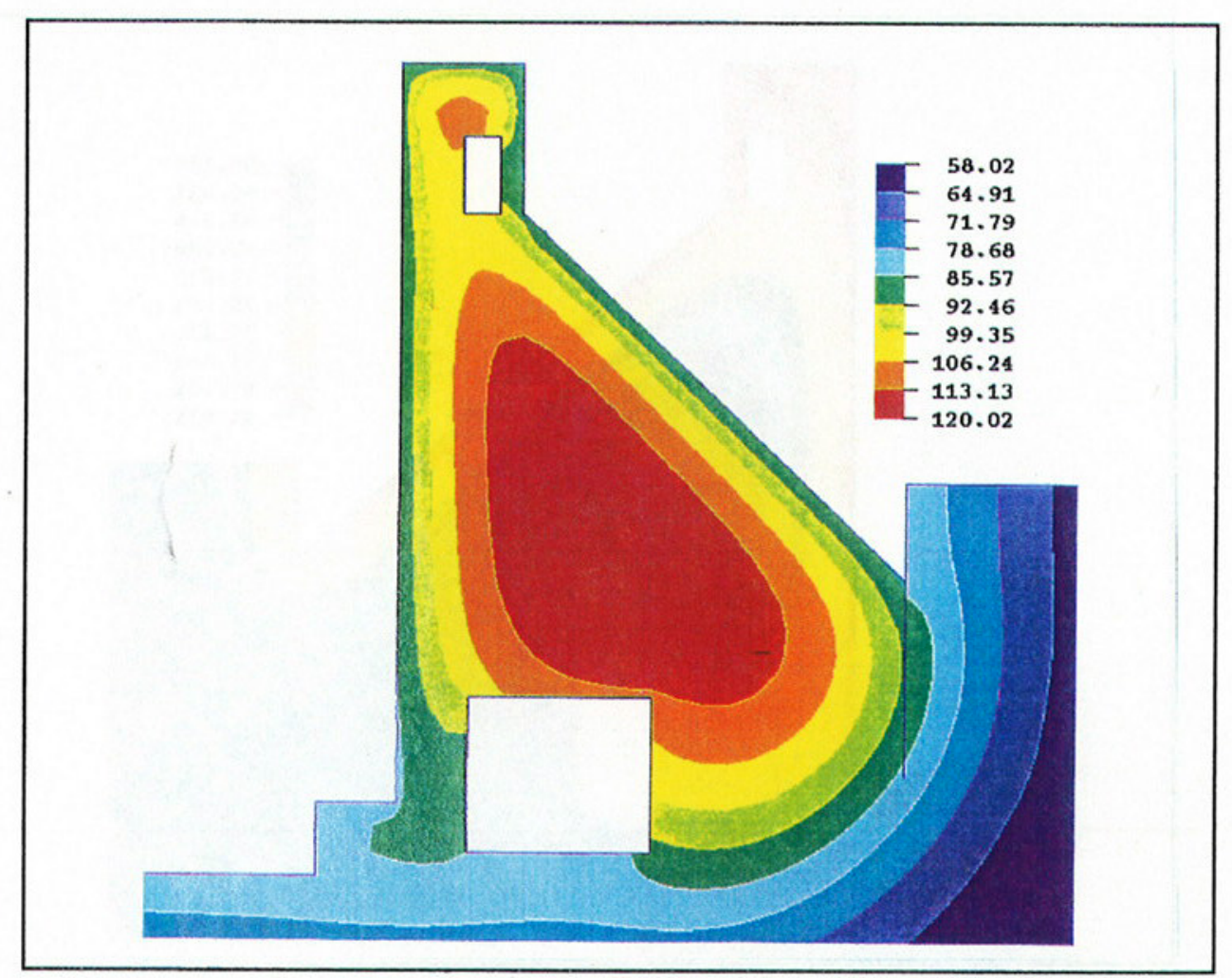

Figure 45. Temperature contour, 77 days after start of construction, 10-ft lifts 


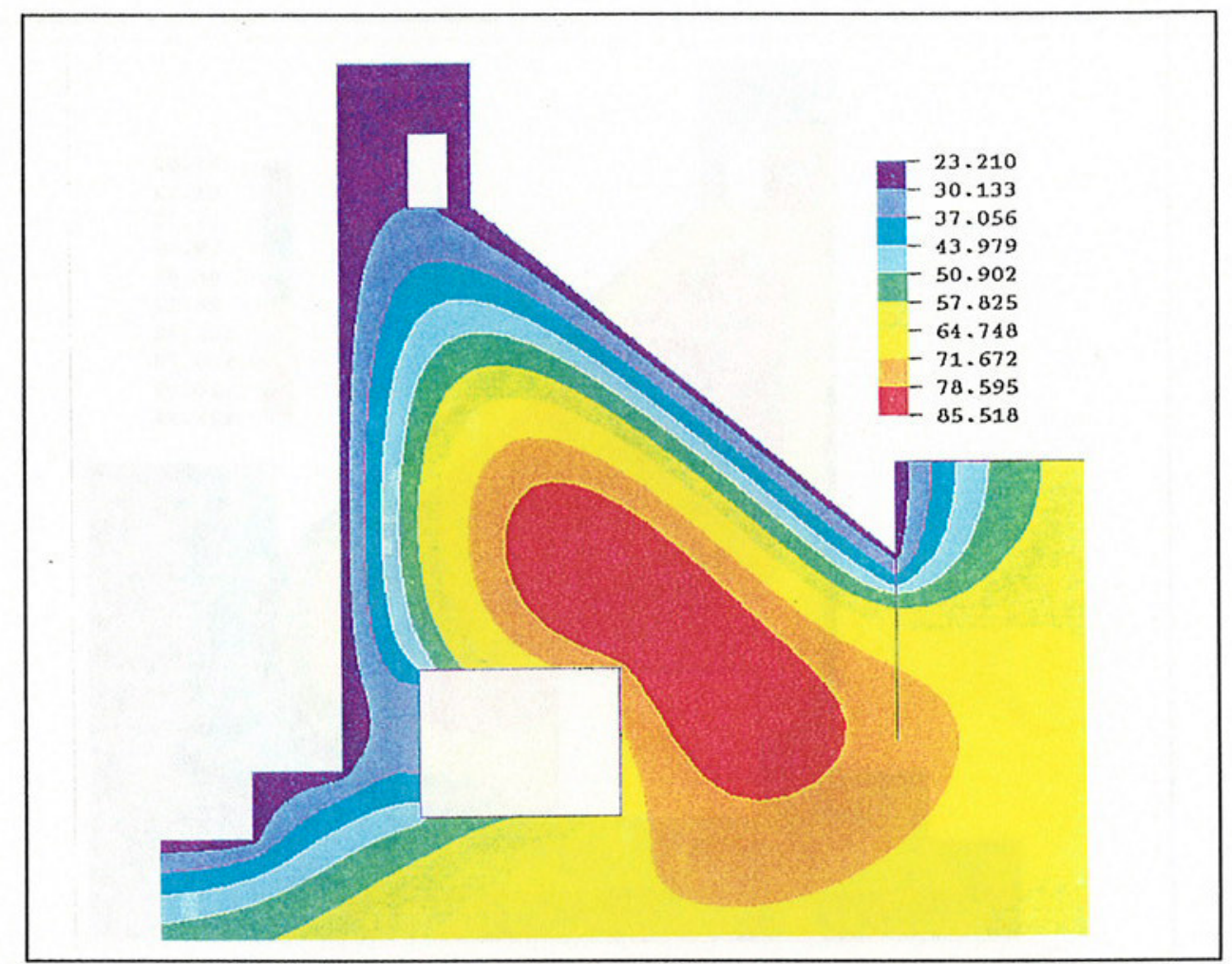

Figure 46. Temperature contour, 220 days after start of construction, 10-ft lifts

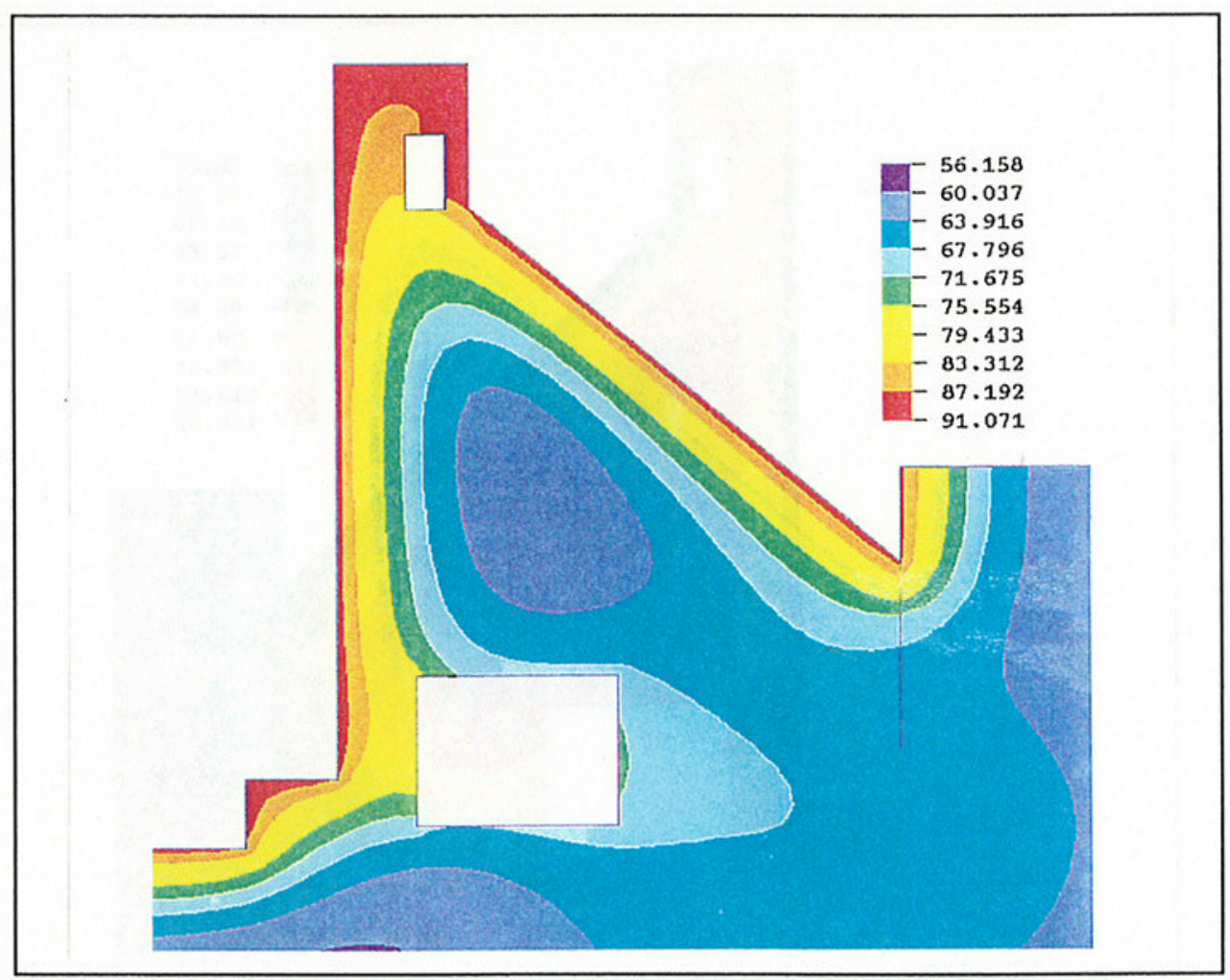

Figure 47. Temperature contour, 385 days after start of construction, 10-ft lifts 

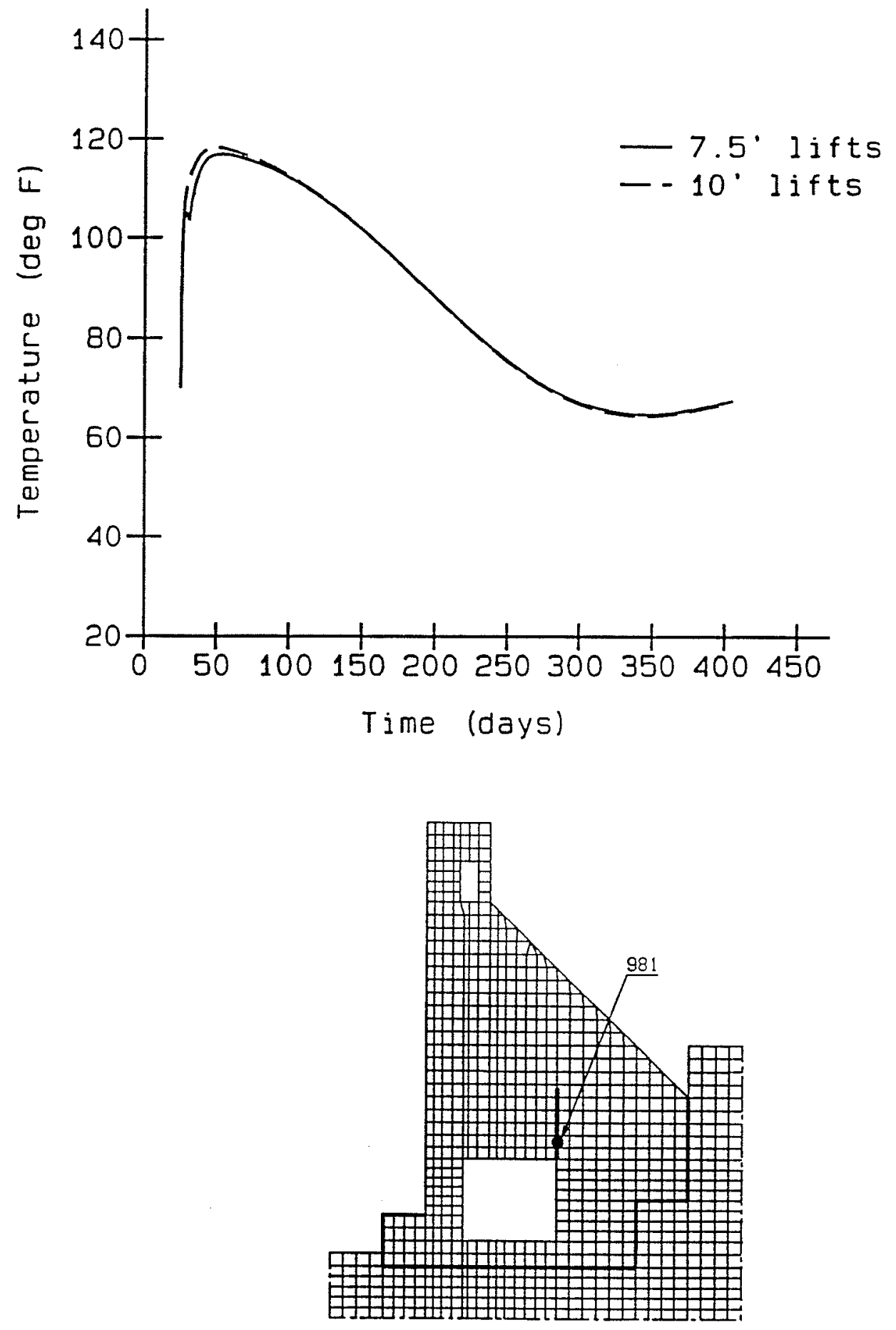

Figure 48. Temperature time-history at node 981 comparing 7-1/2-ft and 10-ft lift placements 

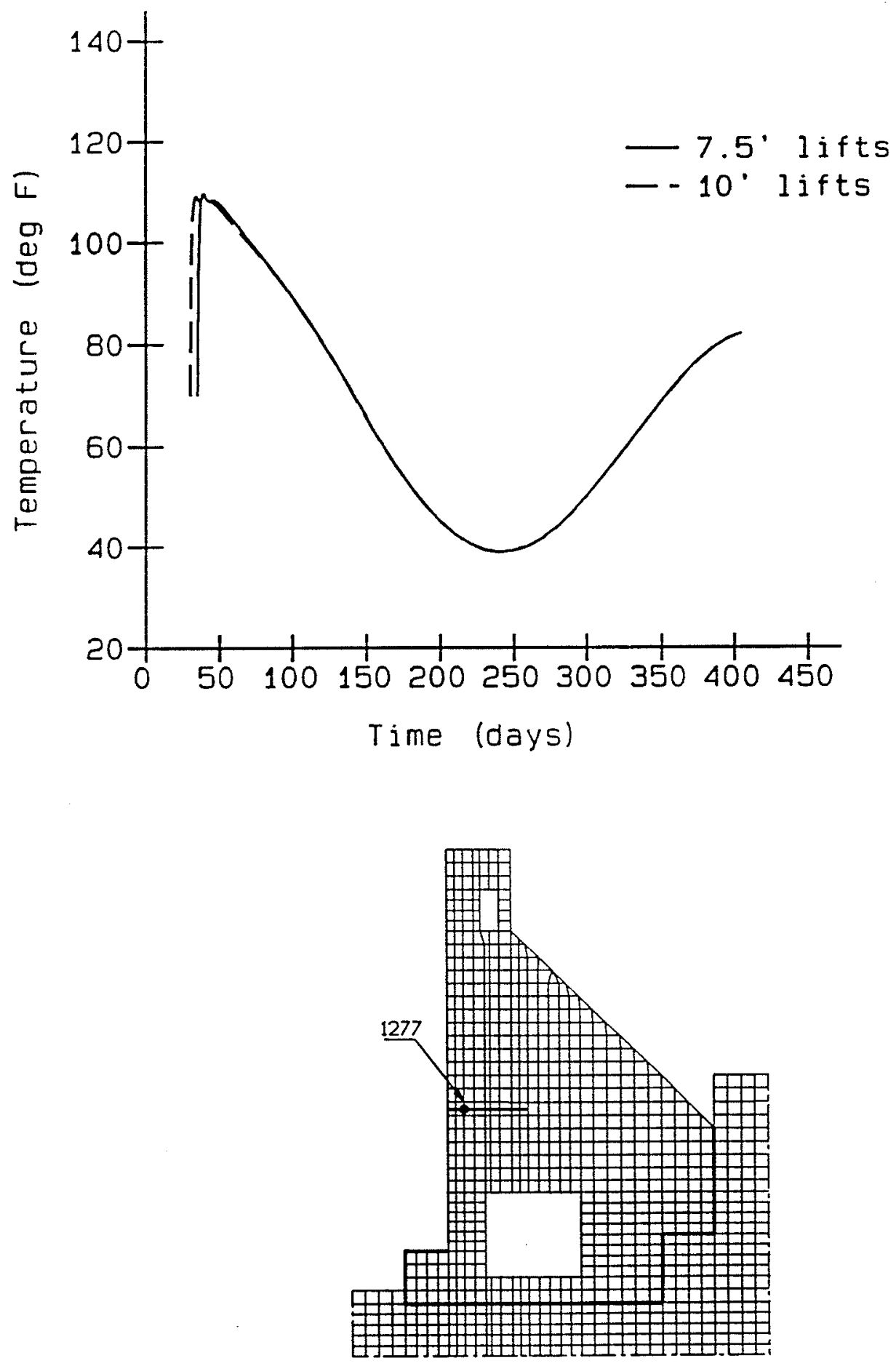

Figure 49. Temperature time-history at node 1277 comparing 7-1/2-ft and 10-ft lift placements 

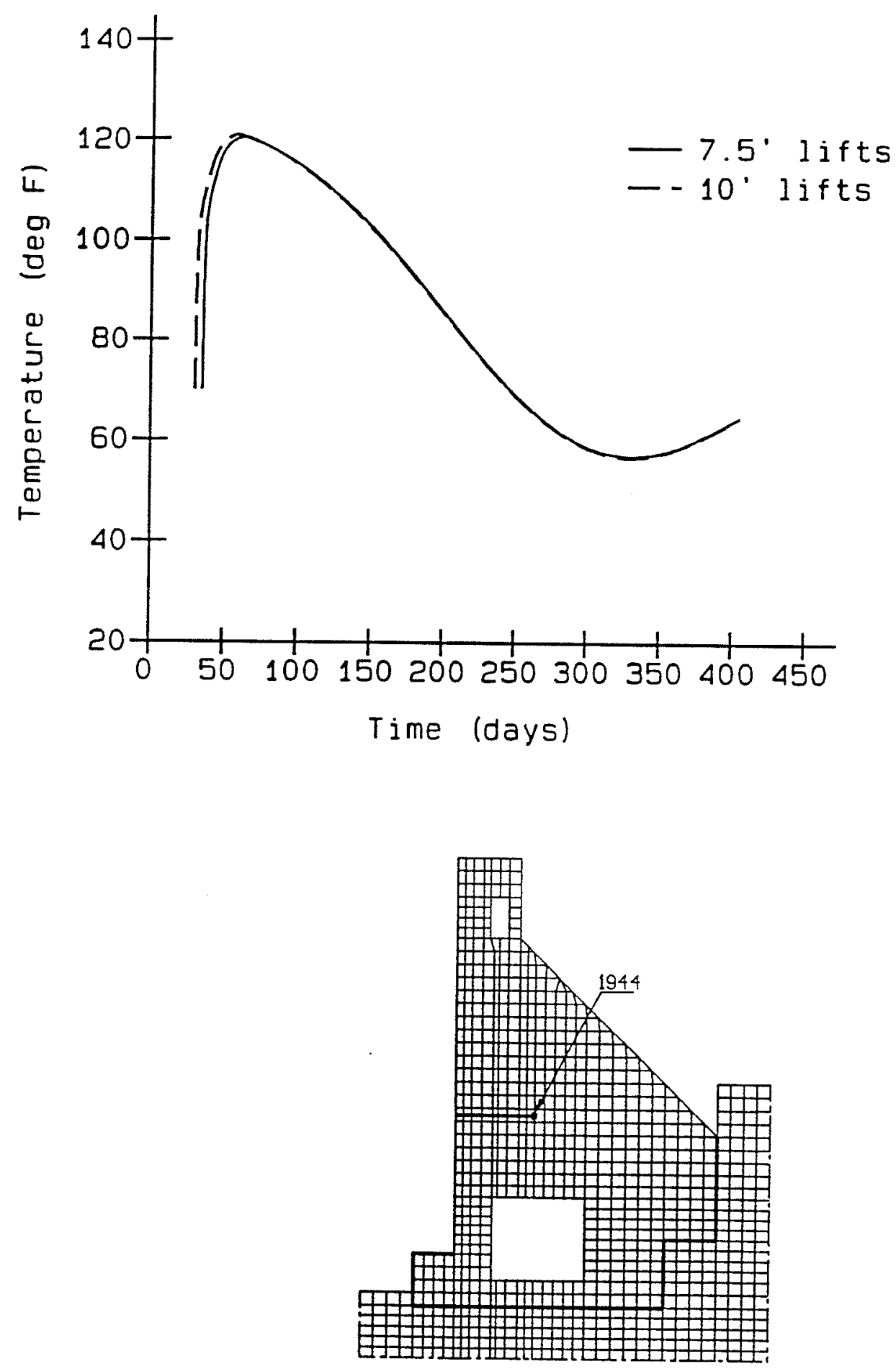

Figure 50. Temperature time-history at node 1944 comparing 7-1/2-ft and 10-ft lift placements 

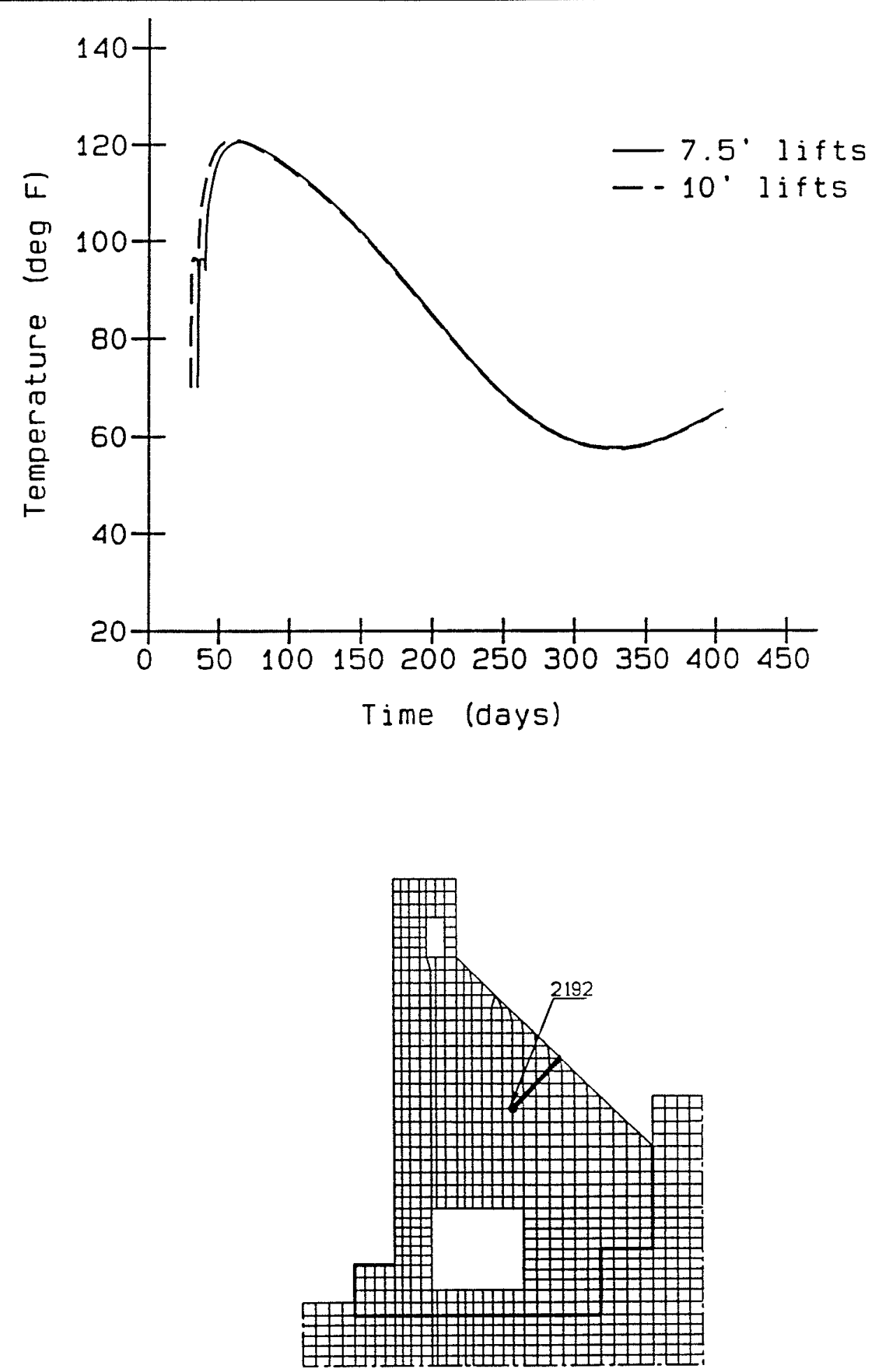

Figure 51. Temperature time-history at node 2192 comparing 7-1/2-ft and 10-ft lift placements 

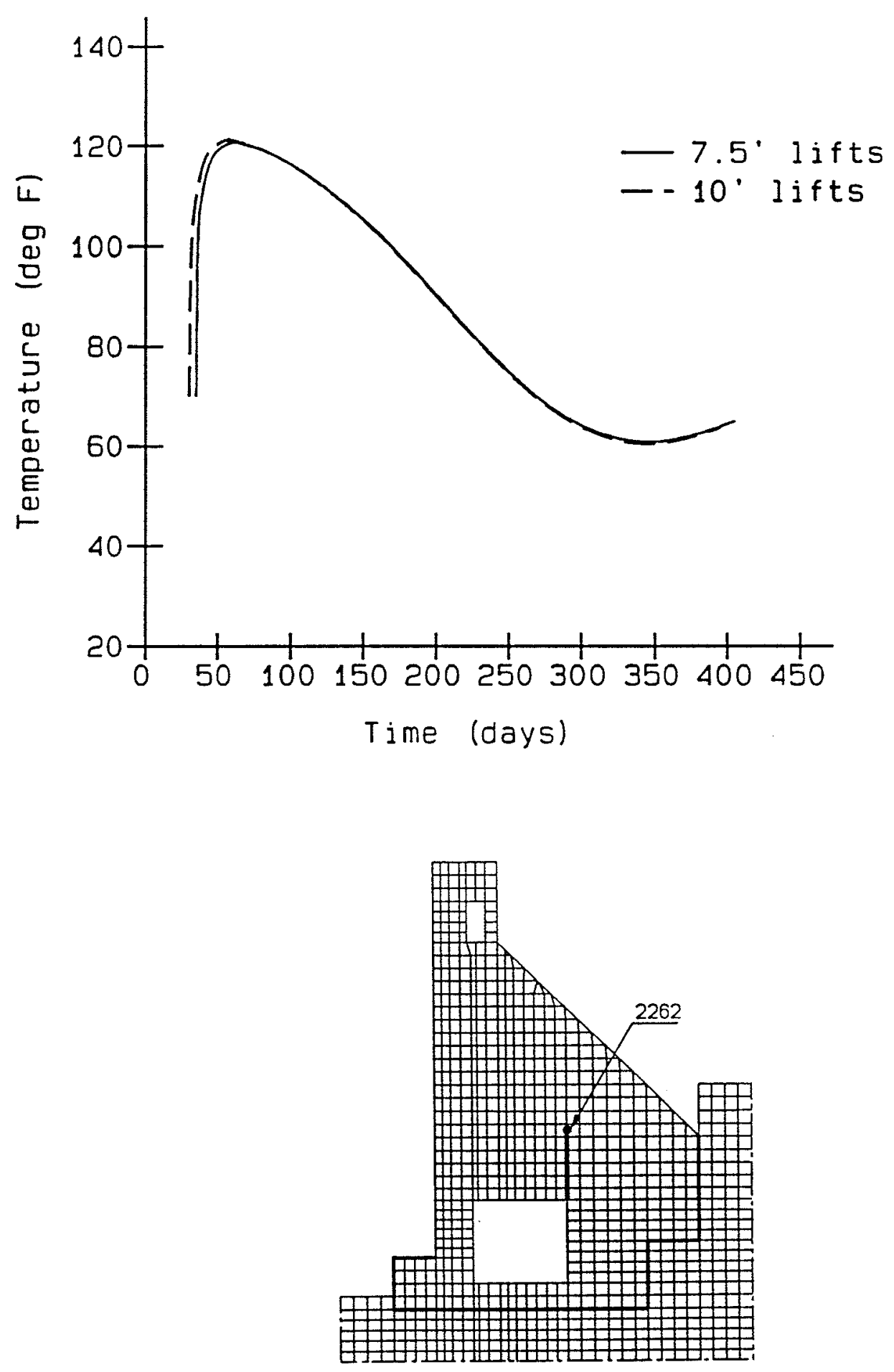

Figure 52. Temperature time-history at node 2262 comparing 7-1/2-ft and 10-ft lift placements 

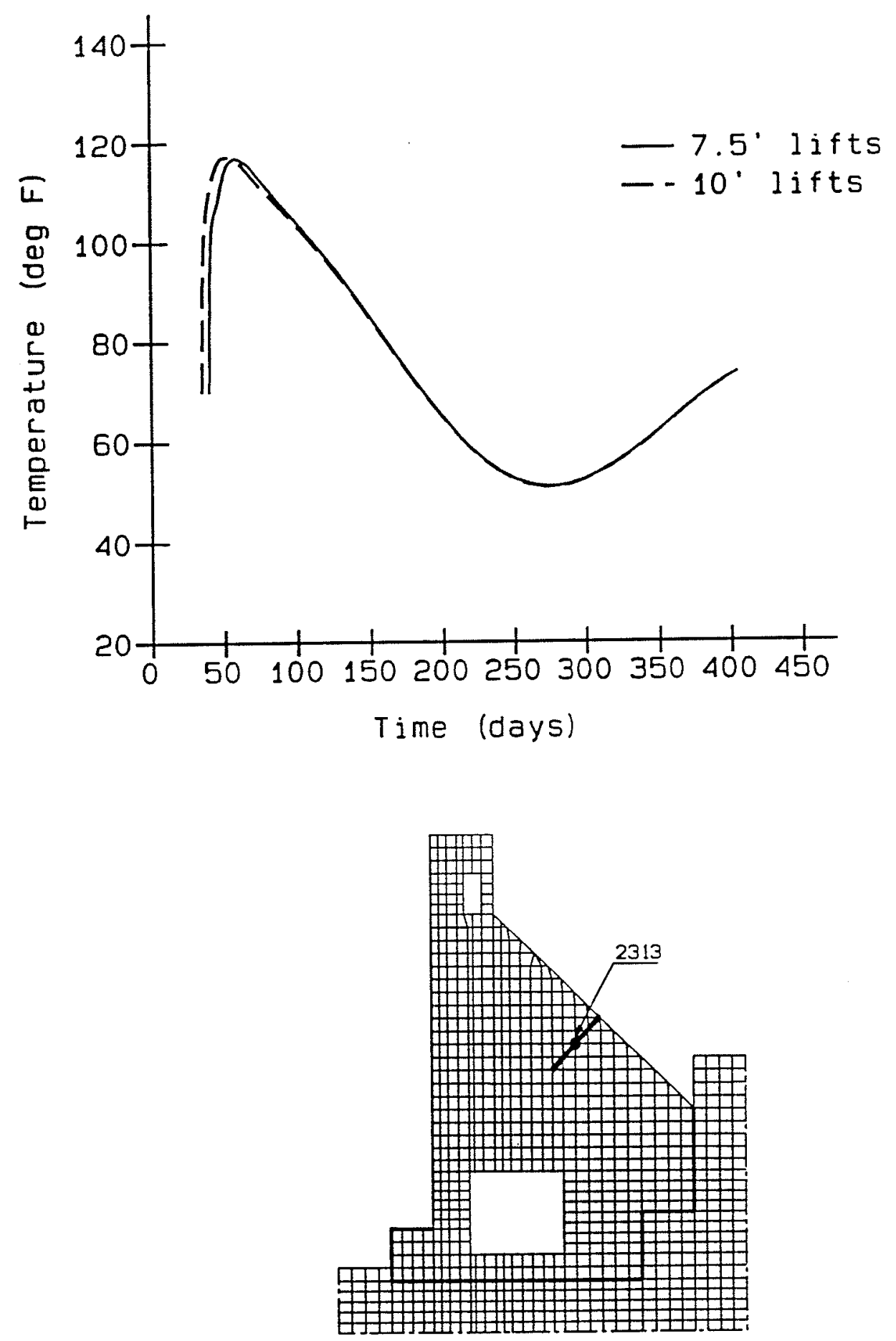

Figure 53. Temperature time-history at node 2313 comparing 7-1/2-ft and 10-ft lift placements 


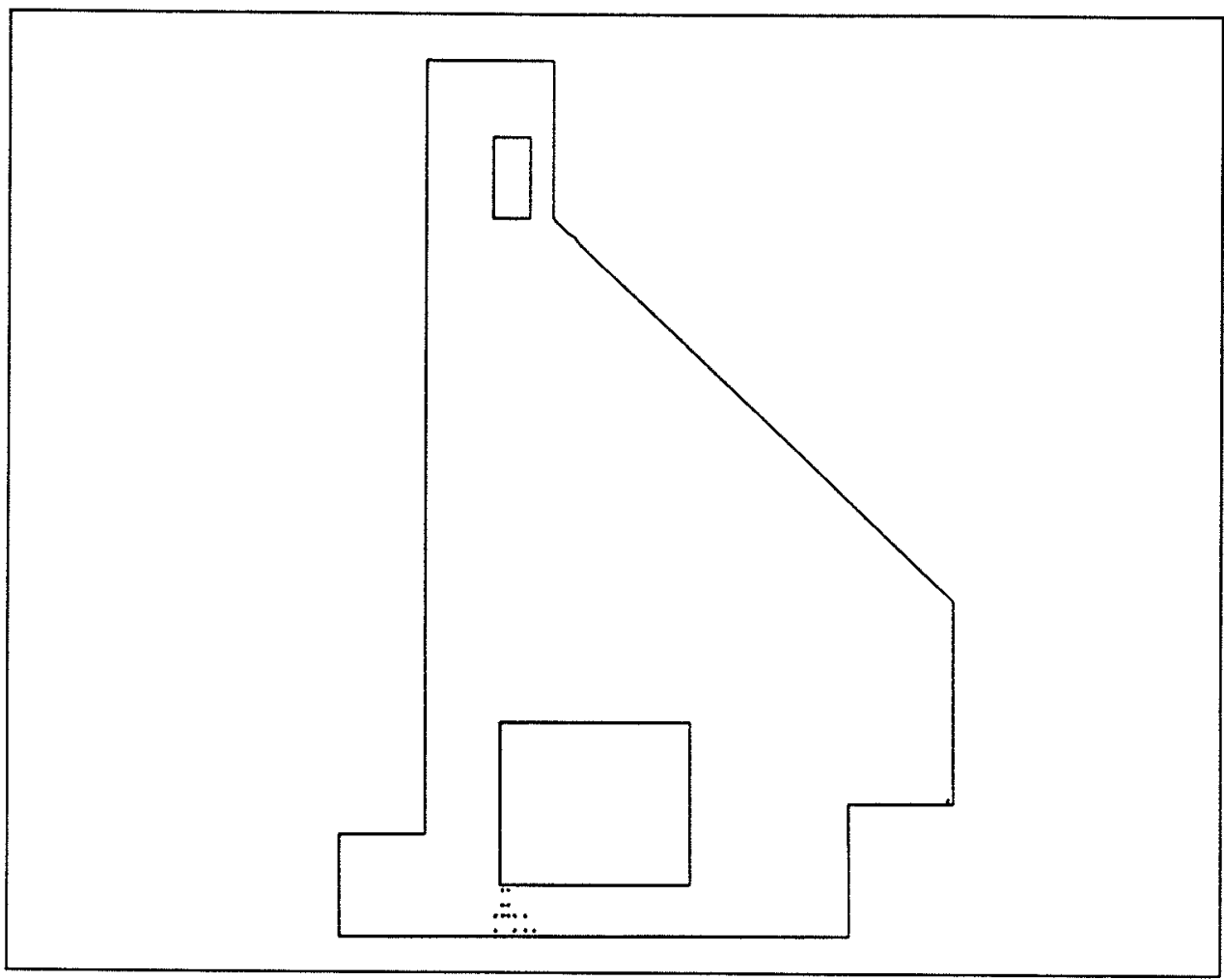

Figure 54. Cracking predicted at day 160 using 10-ft lifts

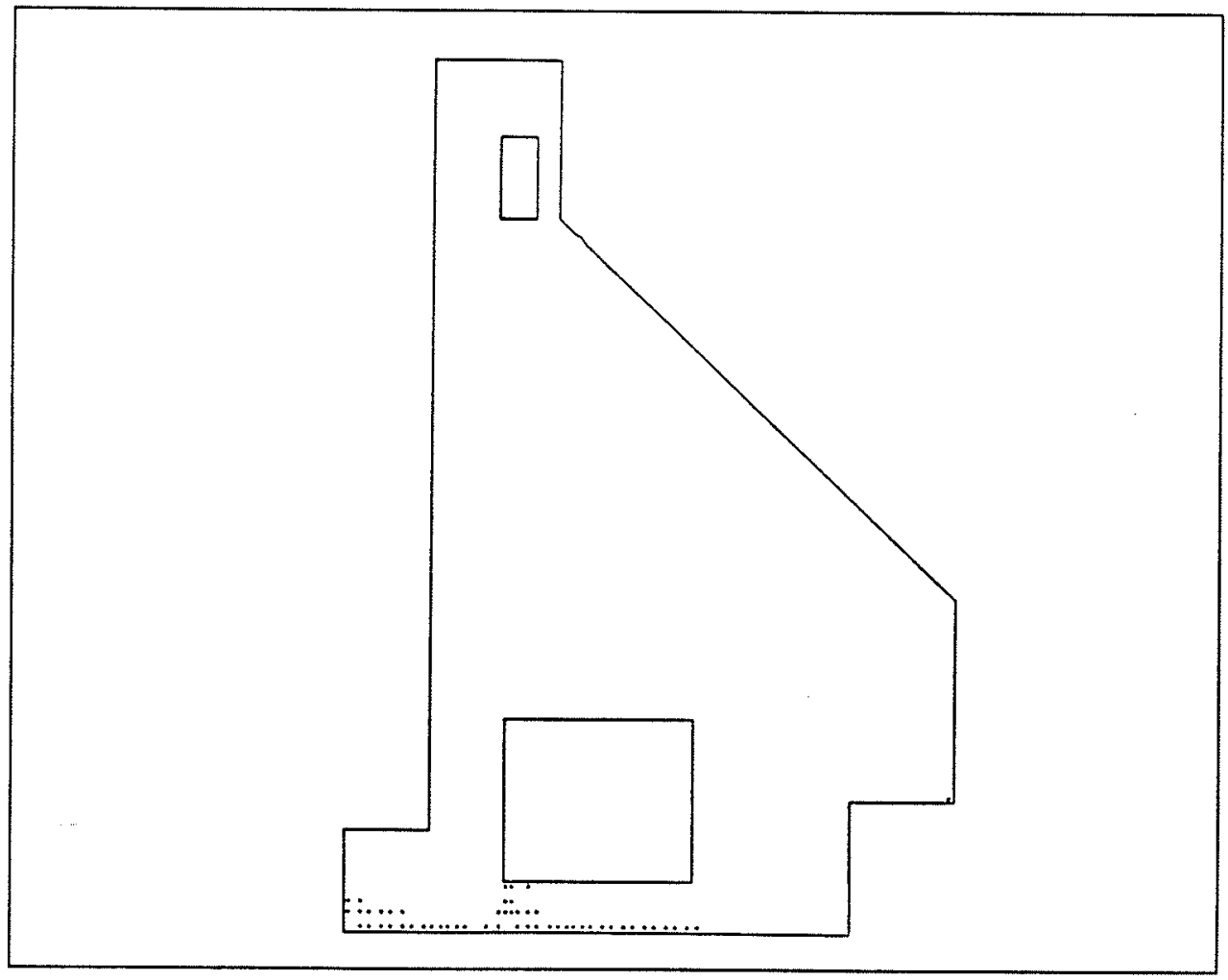

Figure 55. Cracking predicted at day 250 using 10 -ft lifts 


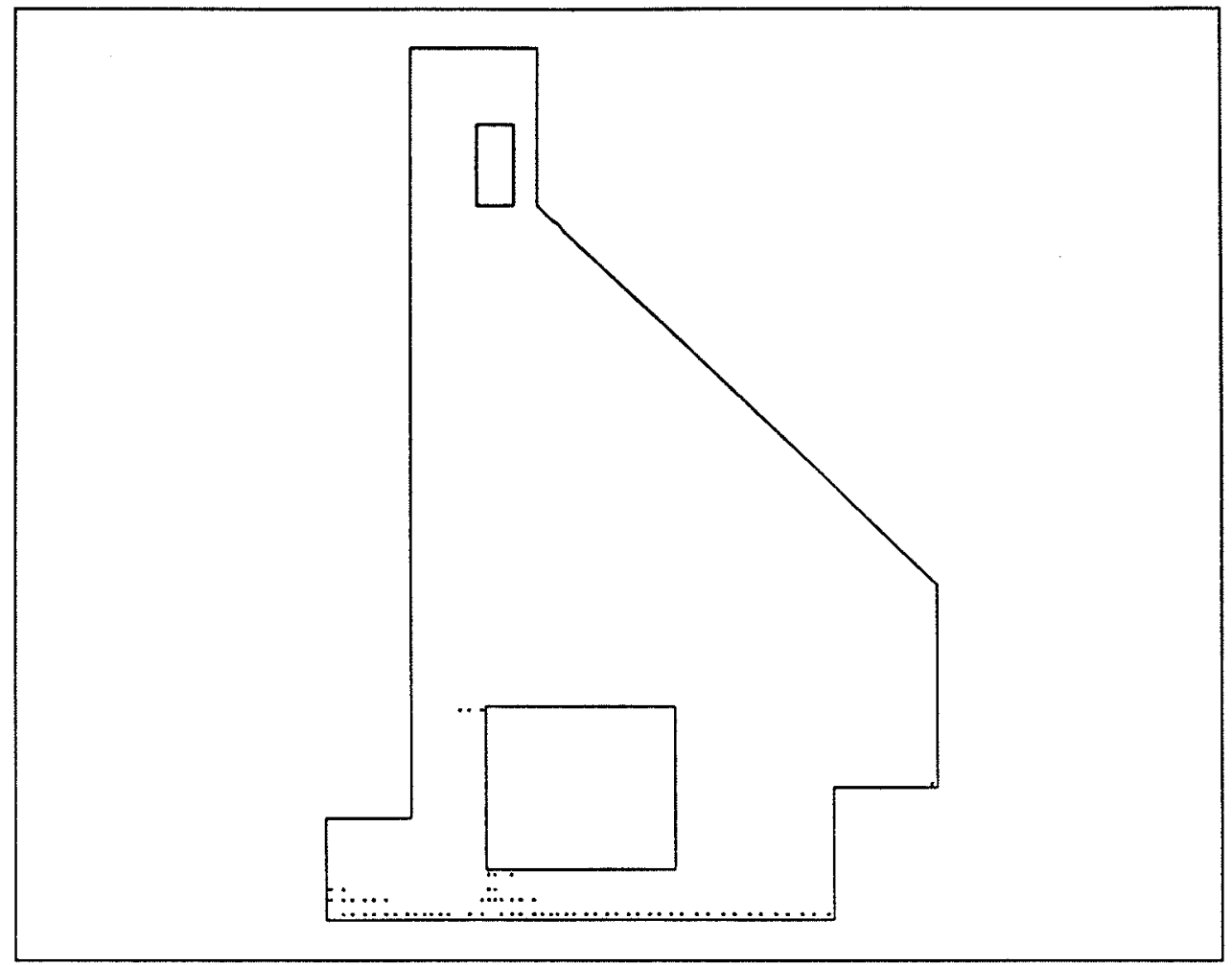

Figure 56. Cracking predicted at day 395 using 10-ft lifts 

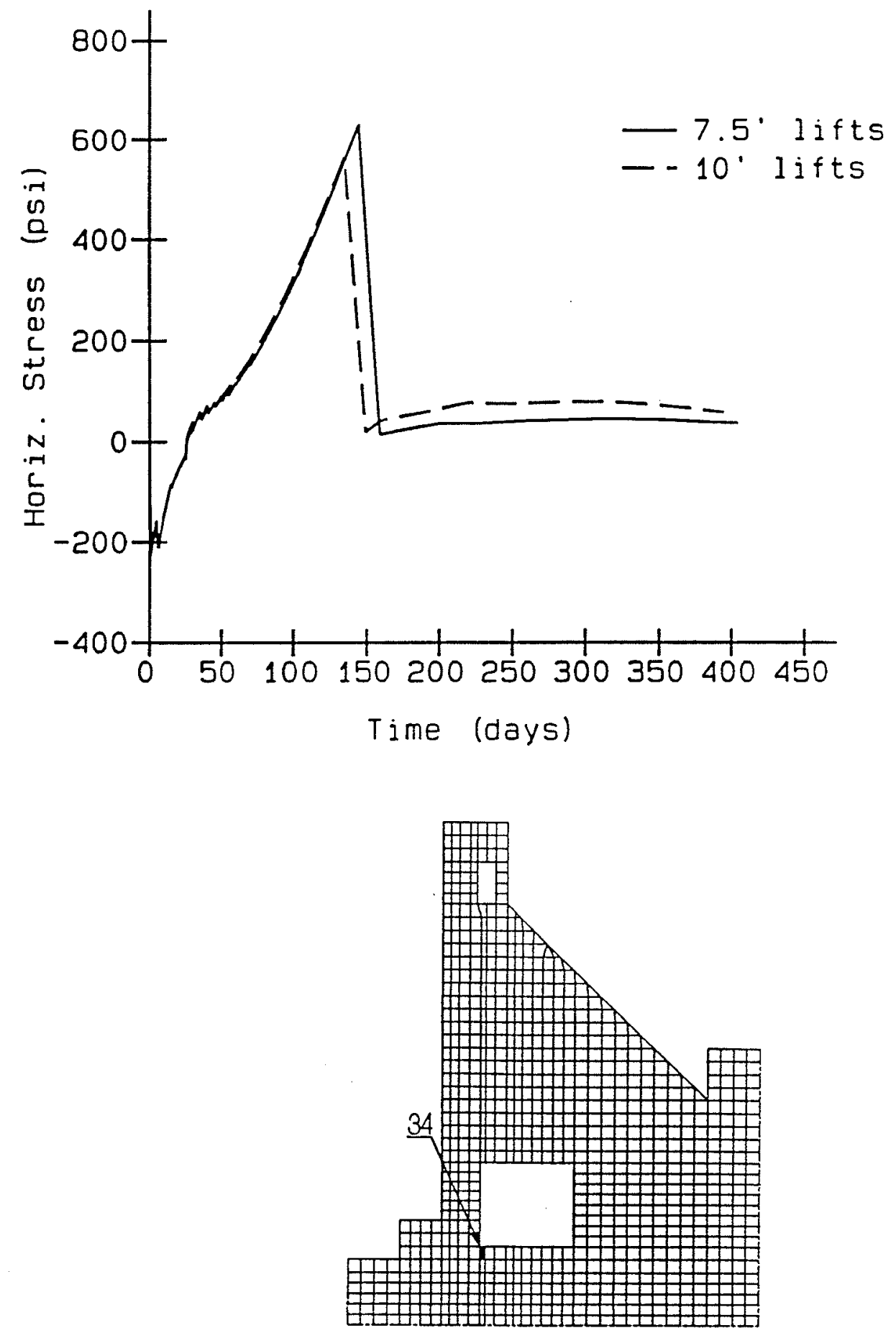

Figure 57. Time-history of horizontal stress at element 34 , integration point 3 , comparing 7-1/2-ft and 10-ft lift analyses 

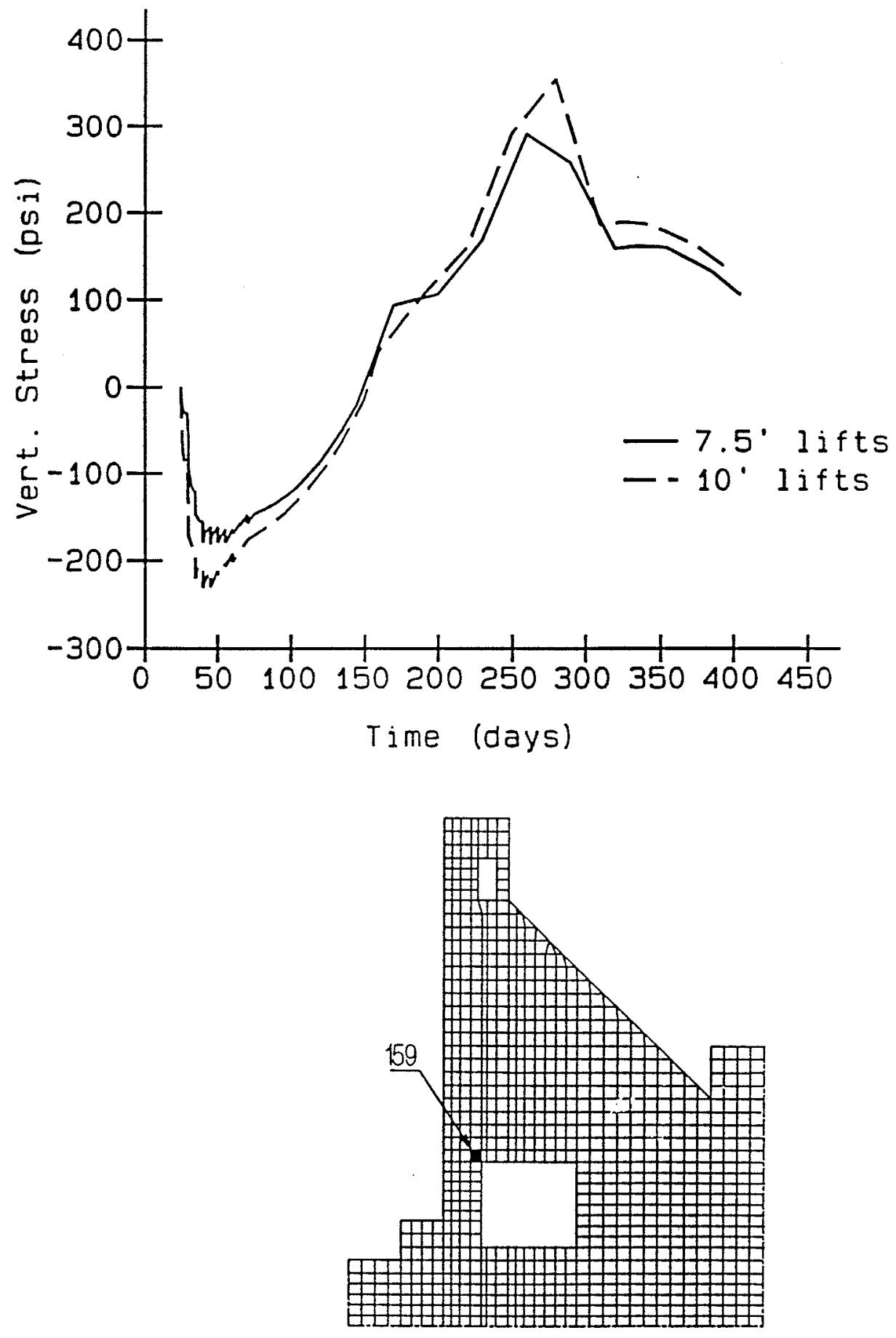

Figure 58. Time-history of vertical stress at element 159 , integration point 2 , comparing $7-1 / 2-\mathrm{ft}$ and 10-ft lift analyses 

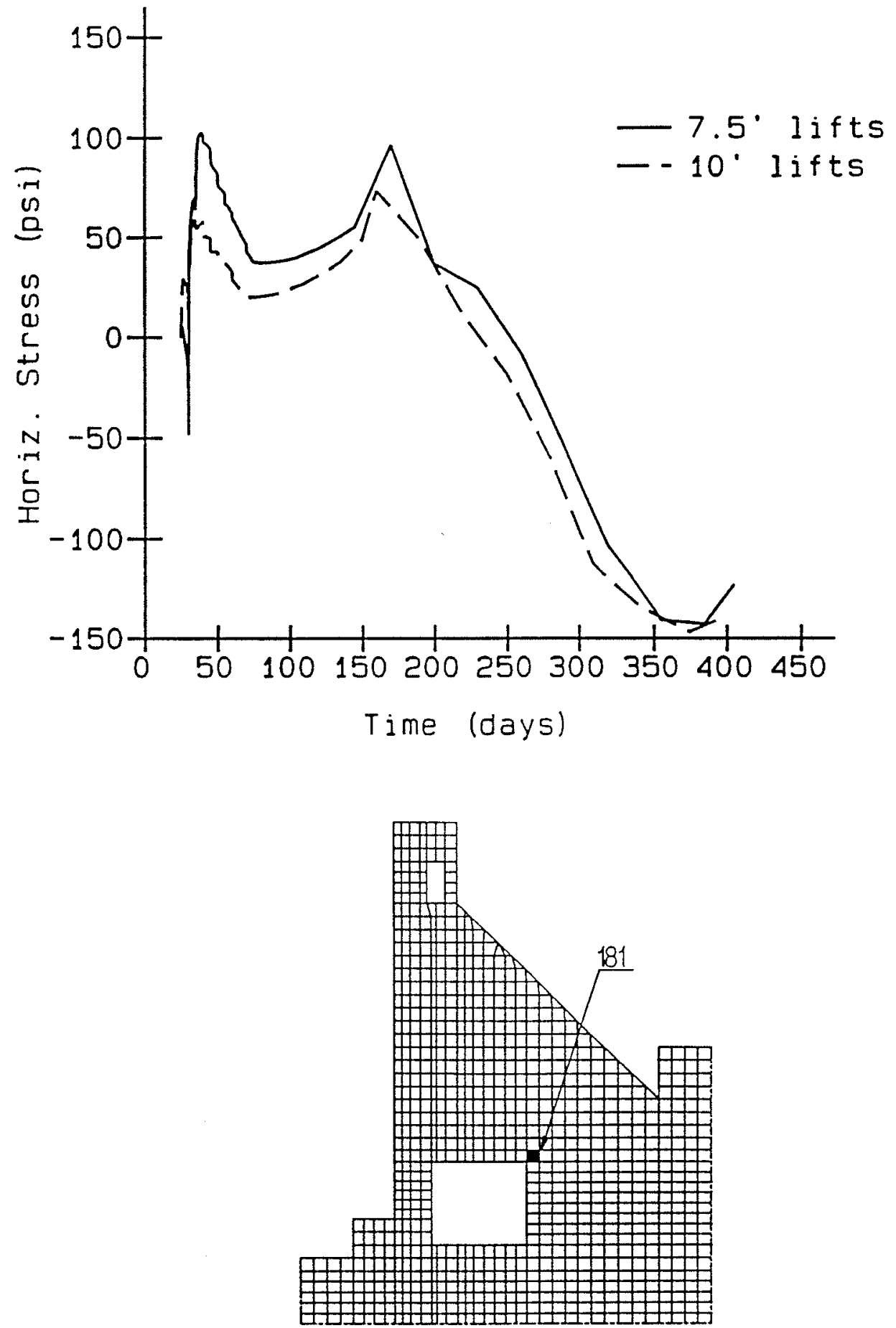

Figure 59. Time-history of horizontal stress at element 181 , integration point 1 , comparing $7-1 / 2-f t$ and 10-ft lift analyses 


\section{Additional Analyses- Chamber Monolith}

\section{General}

Upon completion of the analyses described in Chapter 4 on material combinations and lift heights, additional analyses were performed to further understand the behavior of the monolith and to provide information in the decision-making process.

The first of these analyses was the extended analysis to be performed using the 10-ft lift arrangement described in Chapter 4 . The primary purpose of the extended analysis was to take the existing analysis of the $10-\mathrm{ft}$ lifts and extend the analysis for an additional year with the service loads being in place for the additional time. In addition, a decision was also made to include a gap element on the vertical surface between the concrete and rock in the chamber area as shown in Figure $20 \mathrm{~b}$ by gap No. 2. This gap element was included to eliminate some of the restraint against thermal expansion and contraction.

The second of the analyses was the winter analysis. The same model changes applied to the model for the extended analysis were applied to the model for the winter analysis. The winter analysis was performed using a November 1 construction start date to satisfy the requirement of the new ETL which requires at least two analyses with different start times.

The third analysis was the final analysis. The final analysis was performed to evaluate the effects of some proposed changes from the parameters used in the extended analysis. The differences in final analysis from the extended analysis are that the model included a third gap element, changed the water temperatures applied to the chamber and culvert surfaces, and changed the reinforcing in the area below the culvert. These changes will be discussed in further detail later in the chapter.

The primary emphasis of Chapter 4 was simply to compare the various parametric combinations. Explanation of the behavior was not addressed. This chapter contains detailed discussions of the monolith behavior, particularly for the first analysis described, which is an extended analysis with service 
loads applied and a summer start of construction. In this analysis not only will crack patterns be reviewed but displacements, stress contours, and reinforcing stresses will all be used to help explain the monolith's behavior. Some explanation will be given for the other two analyses, but the discussion will focus on the first analysis. Detailed discussions of all of the analyses performed are not necessary since the general behavior is the same from one analysis to the next.

\section{Extended Analysis}

As described above, the first analysis to be performed was a repeat of the 10-ft lift analysis described in Chapter 4 except that a gap element was placed on the vertical interface between the rock and concrete in the chamber (gap No. 2 shown in Figure 20b) and the analysis was extended for 1 year with the service loads applied at the beginning of the additional year.

\section{Heat transfer analysis}

Since it was desired to include the effects of the service loads in the heat transfer analysis, the water and soil had to be modeled in the heat transfer analysis. Water was modeled in the chamber to an elevation of $420 \mathrm{ft}$ and the soil was modeled to the top of the wall on the landside of the monolith. The method of applying the effects of the water and soil is to define a curve which models the changing temperature within the soil and water and apply that to the surfaces they come in contact with by using film coefficients. Application of the water and soil in the heat transfer analysis is discussed in more detail in Chapter 3.

Since the model was unchanged (except for the addition of the gap element) for the extended analysis, the results prior to application of the service loads will be identical to those presented in Chapter 4 . The inclusion of the gap element should not have an impact on the results during the first part of the analysis since the gap elements used for the heat transfer portion of the analysis use a high conductivity, which provides nearly the same condition as if the rock and concrete were in contact with each other. Since the first part of the analysis is essentially unchanged, temperature contours are presented only for the extended part of the analysis. Figure 60 shows the temperature contours at day 465 , which is 35 days (October 20) after the water and soil were included in the model. The effect of the water can be seen by warm temperatures on the chamber face and around the culvert. The effect of the soil can be seen by the cool temperatures on the landside of the monolith. At this point in time, temperature gradients are not large. Figure 61 shows temperature contours at day 585, which is near the coldest part of the winter. As can be seen in this figure, the portion of the monolith exposed to the ambient air is in the $20^{\circ} \mathrm{F}$ range while the soil and water moderate the temperatures at the other surfaces. This creates a situation where the temperature gradients are much smaller in the second winter than they were in the first for most of the 


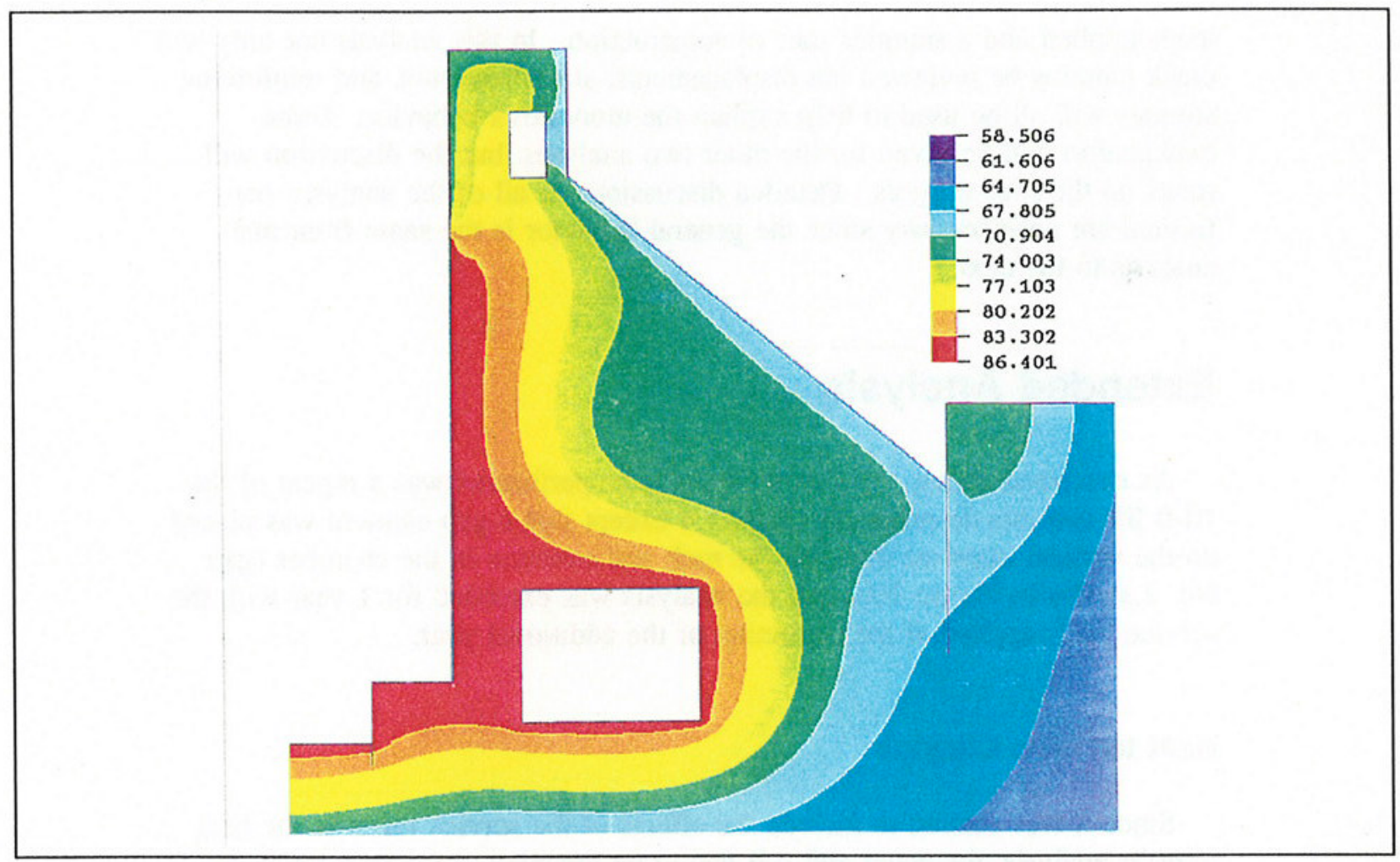

Figure 60. Temperature contour, 465 days after start of construction, extended analysis

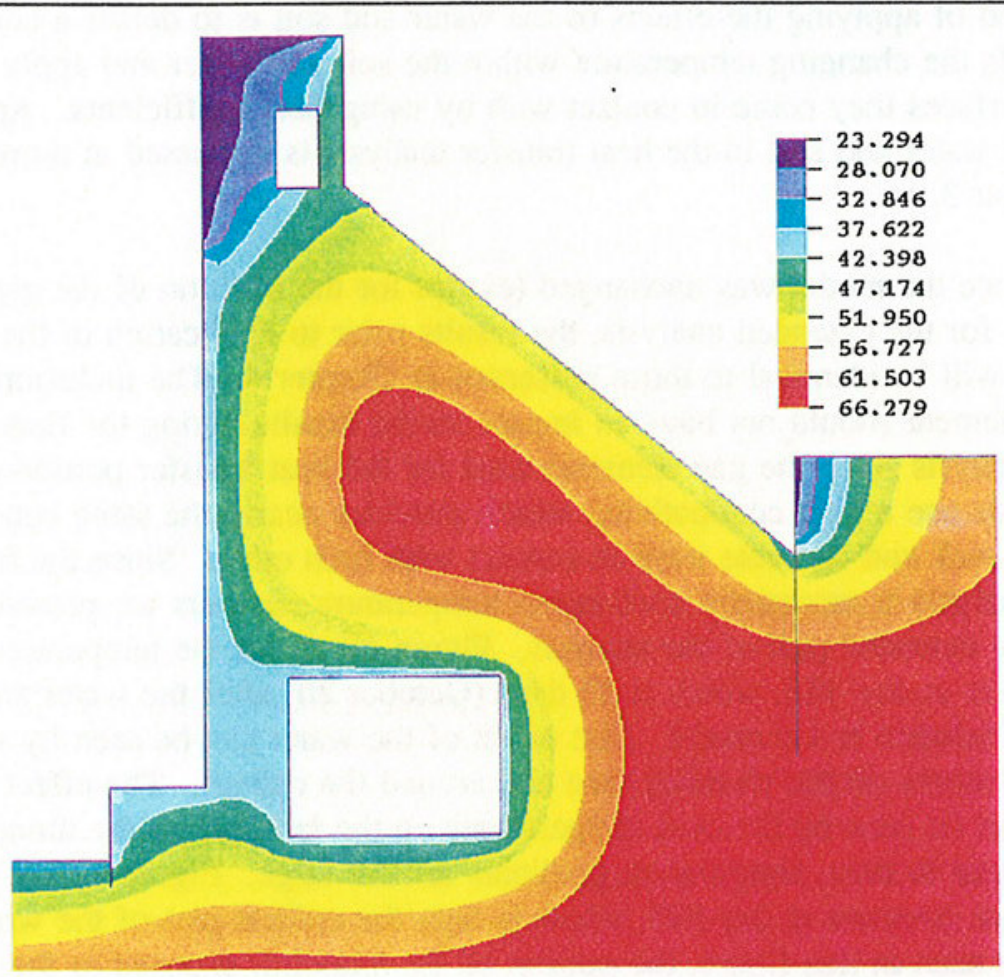

Figure 61. Temperature contour, 585 days after start of construction, extended analysis 
monolith. This can be seen by comparing Figure 61 with Figure 46 . Gradients from the center of the monolith to the exposed surfaces are much larger for the first winter, but it should also be noted that a gradient exists in the extended portion of the analysis from the culvert vertically into the rock foundation.

Figures 62 through 67 are time-history plots of temperatures at various sections of the structure. Figures 62, 63, and 65 are all sections taken at the culvert and in each of these plots the addition of the water creates a larger gradient in the second winter than was seen in the first. This is due to the fact that until the service loads were applied, the culvert was assumed to be covered and therefore was insulated. The addition of the water causes rapid temperature changes at the culvert walls and results in larger gradients. For Figures 64,66 , and 67 , gradients in the second winter after the application of the service loads are smaller since the water and the soil moderate the temperatures at the surface. This moderating effect of the water is due to the fact that the temperature of the water never drops below $40^{\circ} \mathrm{F}$. For the soil it is due to the fact that the soil acts as an insulator. In general, review of the temperature results indicates that addition of the service loads tempers the thermal changes which occur to the monolith and should be beneficial to the monolith's behavior.

\section{Stress analysis}

The only changes to the model for performing the stress analysis were to extend the analysis for a year, add the loads due to the service loads, and include the gap element at the vertical rock/concrete interface in the chamber which will allow compression but no tension. The service loads consist of the water in the chamber up to elevation 420 and water in the culvert with the head calculated based on the chamber water elevation. Soil loading is applied on the landside of the monolith to the top of the monolith. The soil density used was 126 pcf with a lateral earth pressure coefficient of 0.47 .

Figure 68 shows the cracking pattern at day 160 of the analysis. Referring back to Figure 54, it can be seen that adding a gap element at the vertical surface on the left side of the monolith does change the cracking pattern. Cracking at day 160 occurs now entirely at the rock/concrete interface, whereas before the cracking began below the culvert. Figures 69 and 55 are taken at days 260 and 250, respectively, and it can be seen by comparing these two plots that the cracking is very similar between the two cases except that the vertical crack below the culvert has moved to the right side of the culvert and the cracking near the lower left-hand comer of the monolith has been reduced. Both of these changes are of course a direct result of removing the restraint that had been induced by the rock prior to including the gap element. Again, at day 395 (Figures 70 and 56) the cracking patterns are very similar, with a slight improvement being shown by the extended analysis. Figure 70 is the final cracking pattem of the monolith because the extended part of the analysis did not produce any additional cracking. This may have been 

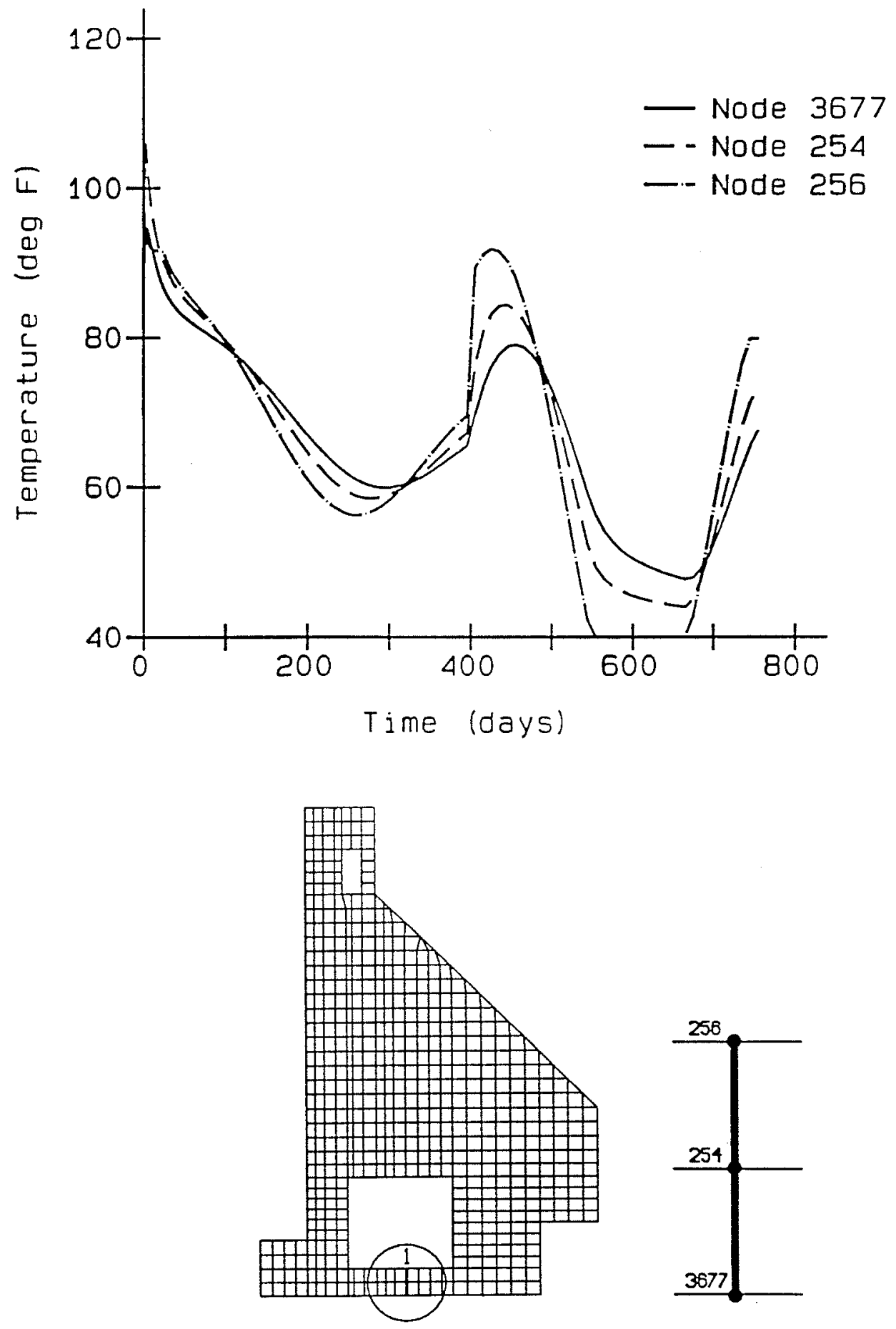

Figure 62. Temperature time-history at section 1 for extended analysis 

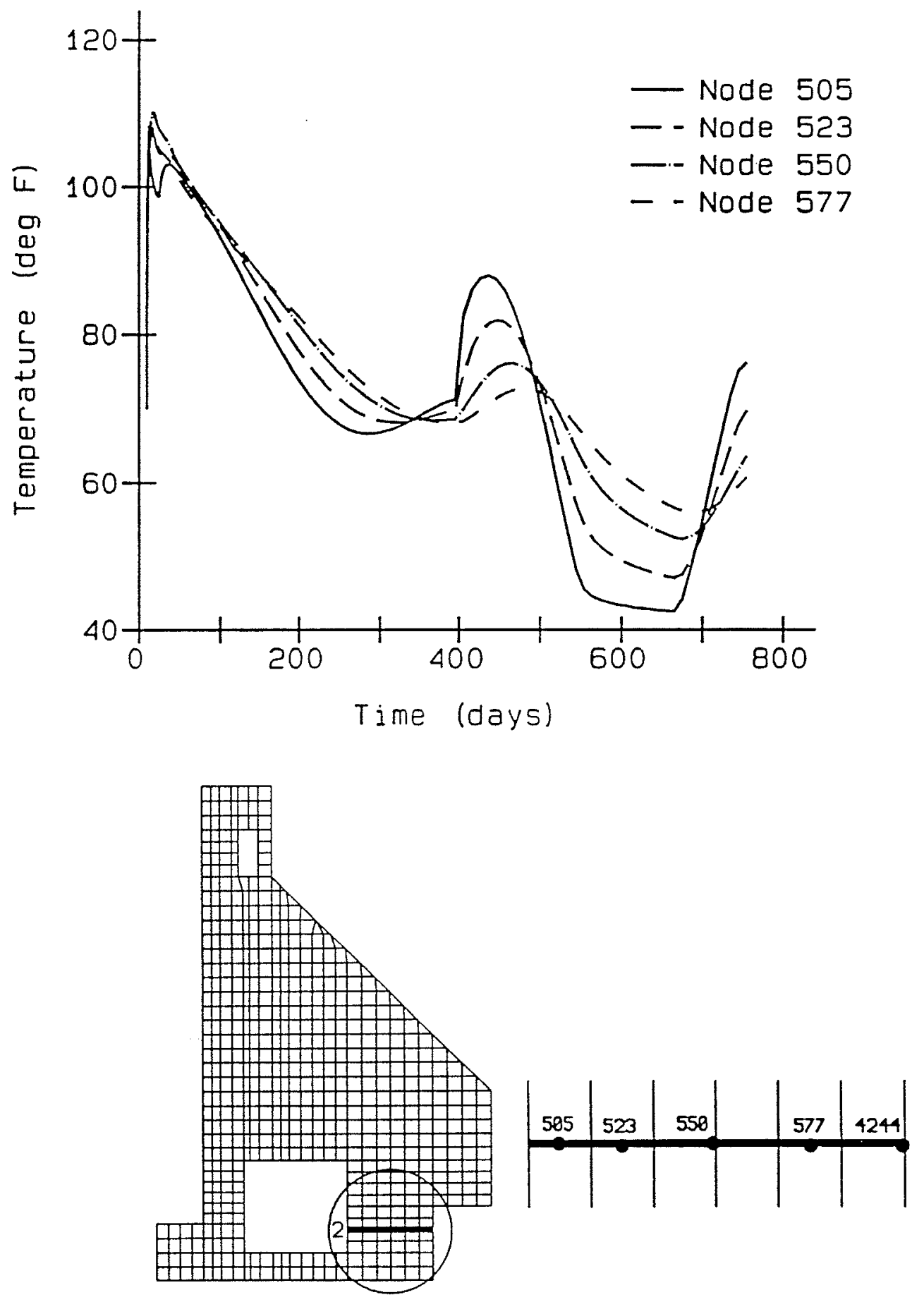

Figure 63. Temperature time-history at section 2 for extended analysis 

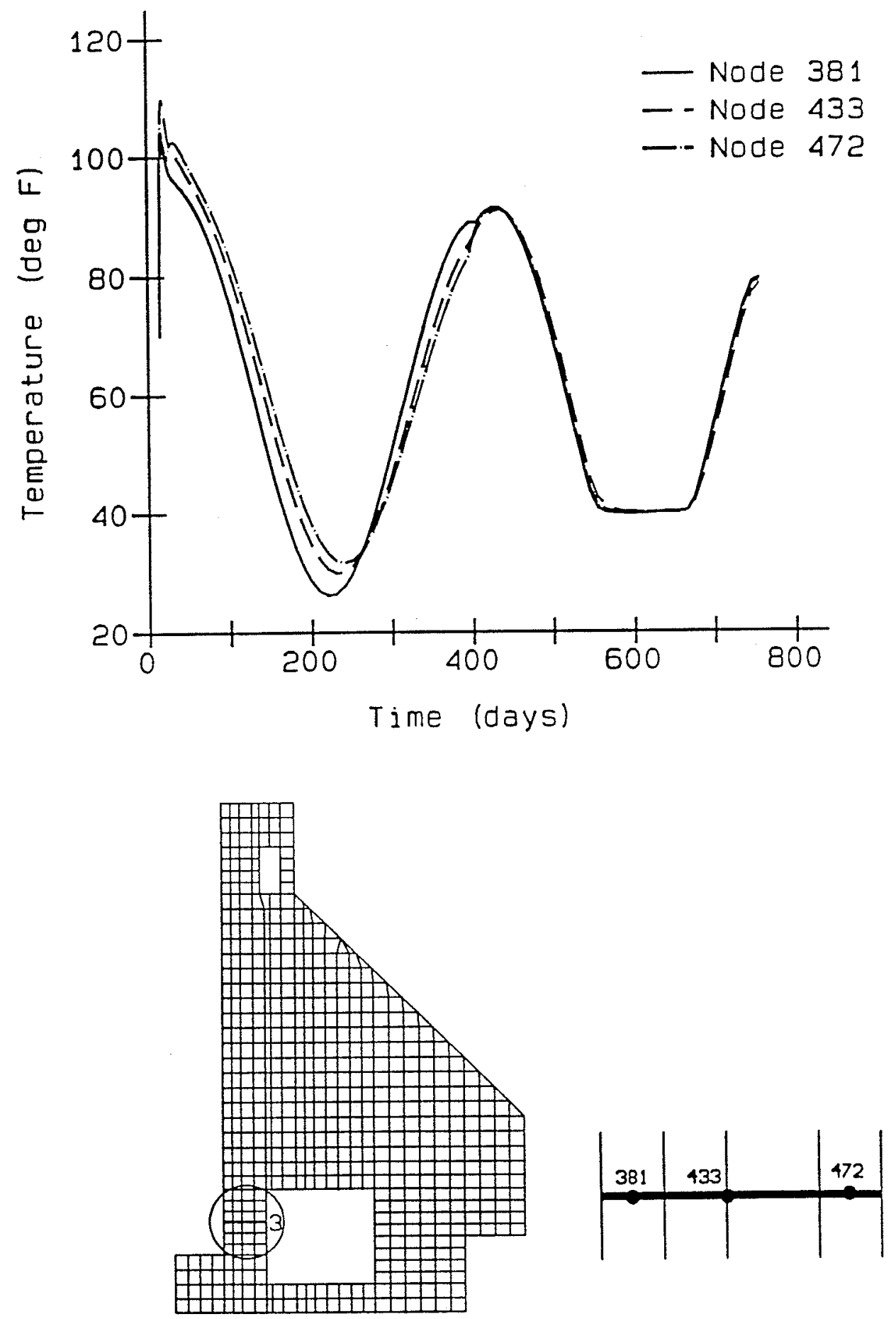

Figure 64. Temperature time-history at section 3 for extended analysis 

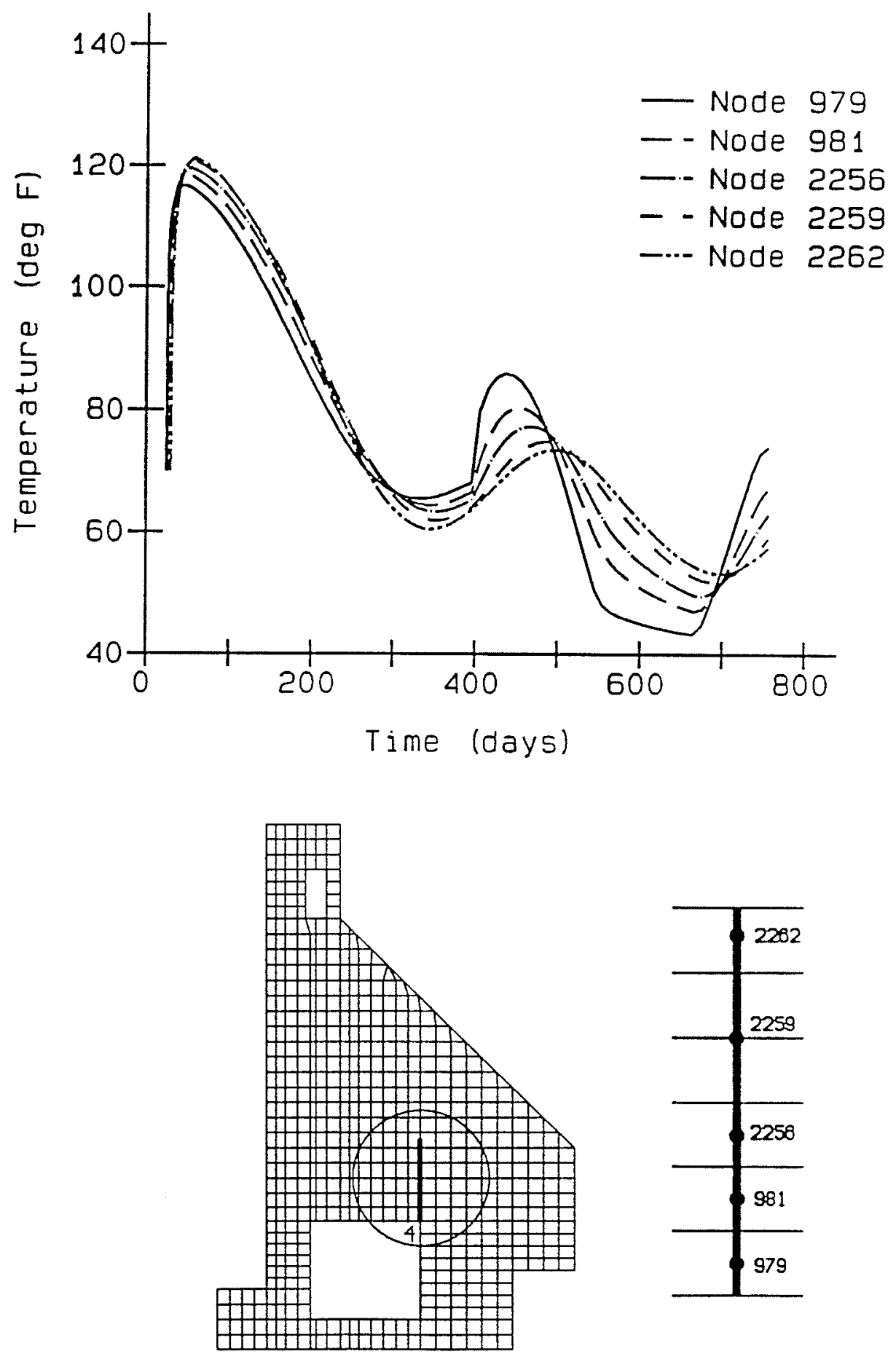

Figure 65. Temperature time-history at section 4 for extended analysis 

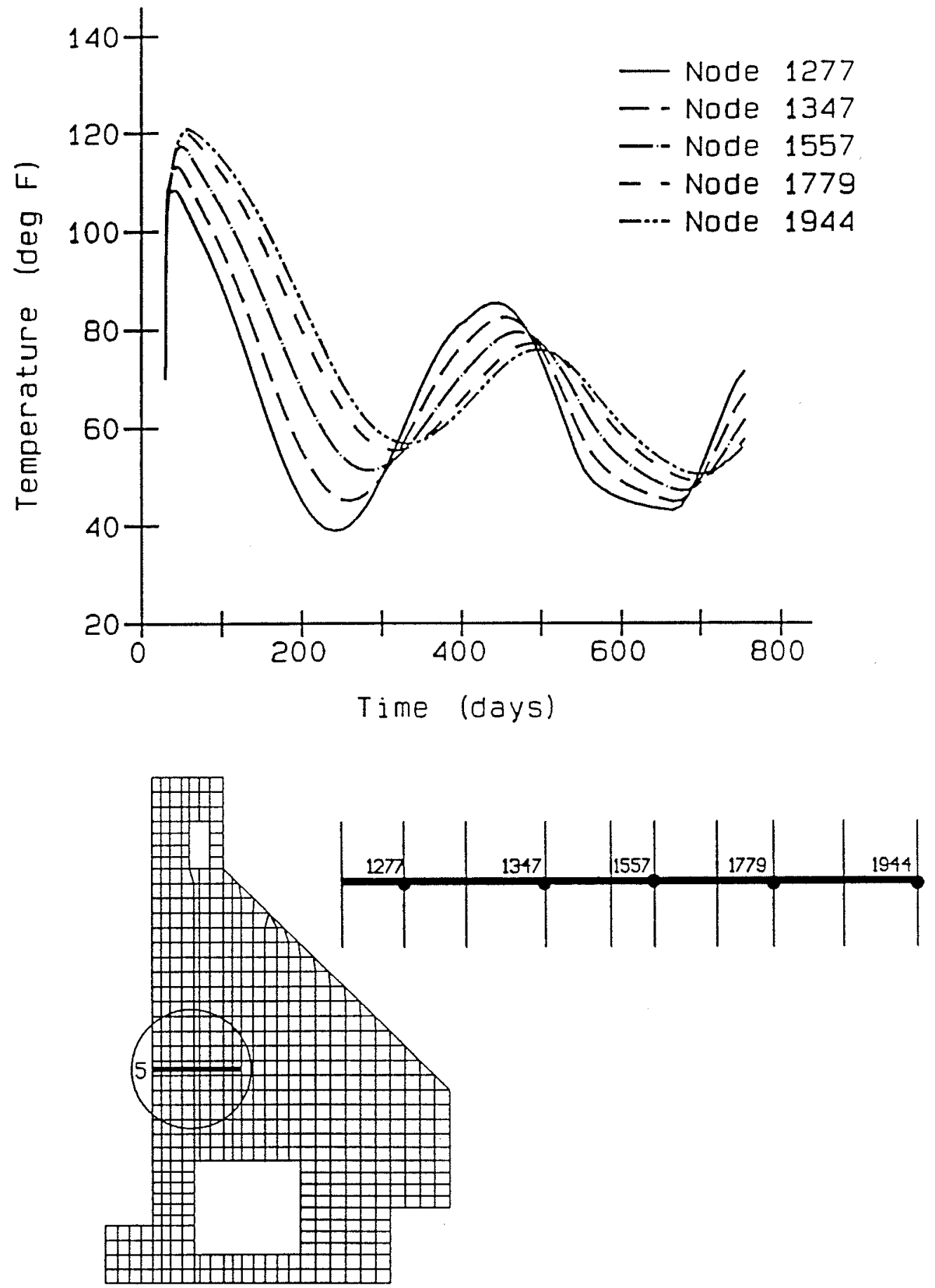

Figure 66. Temperature time-history at section 5 for extended analysis 

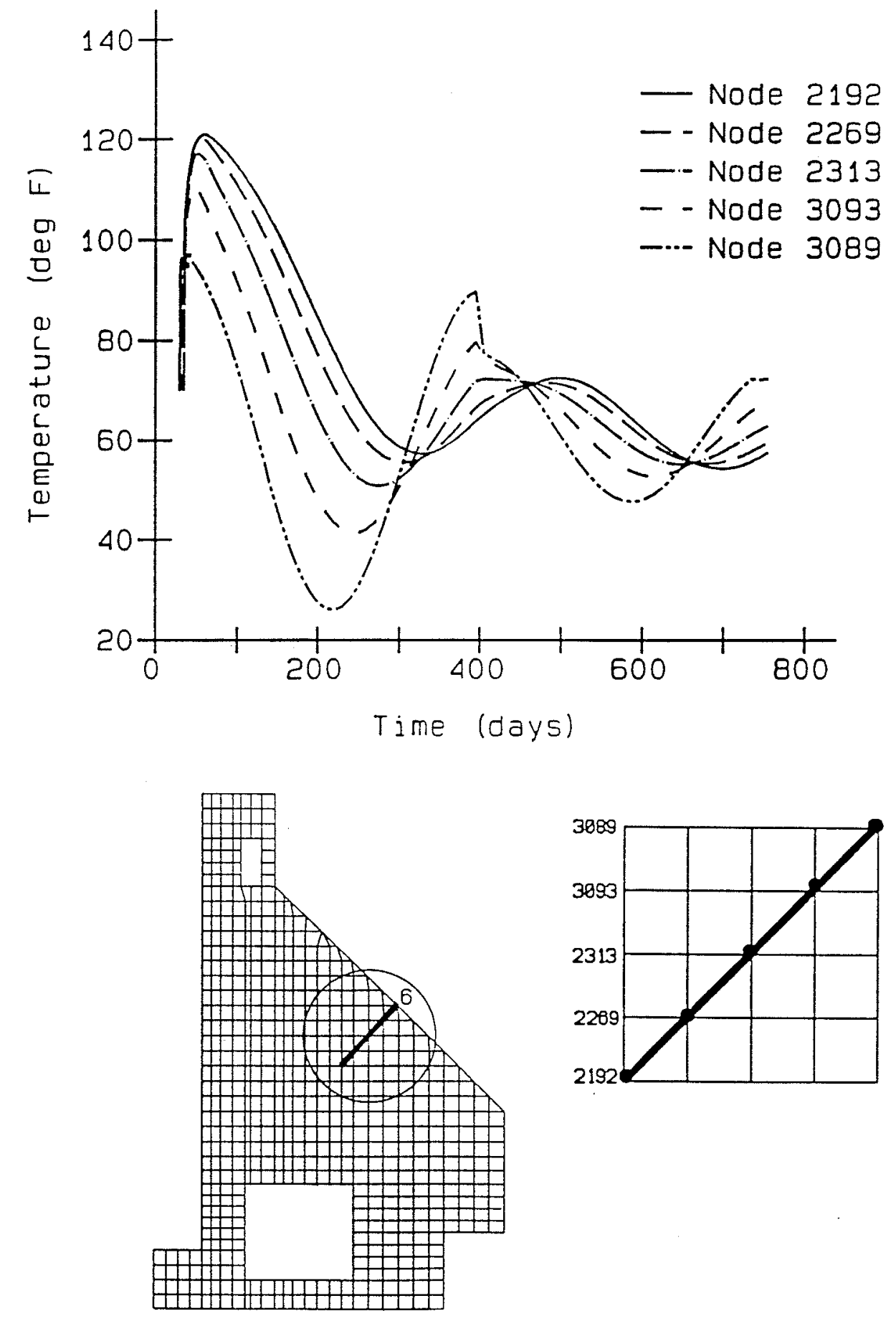

Figure 67. Temperature time-history at section 6 for extended analysis 


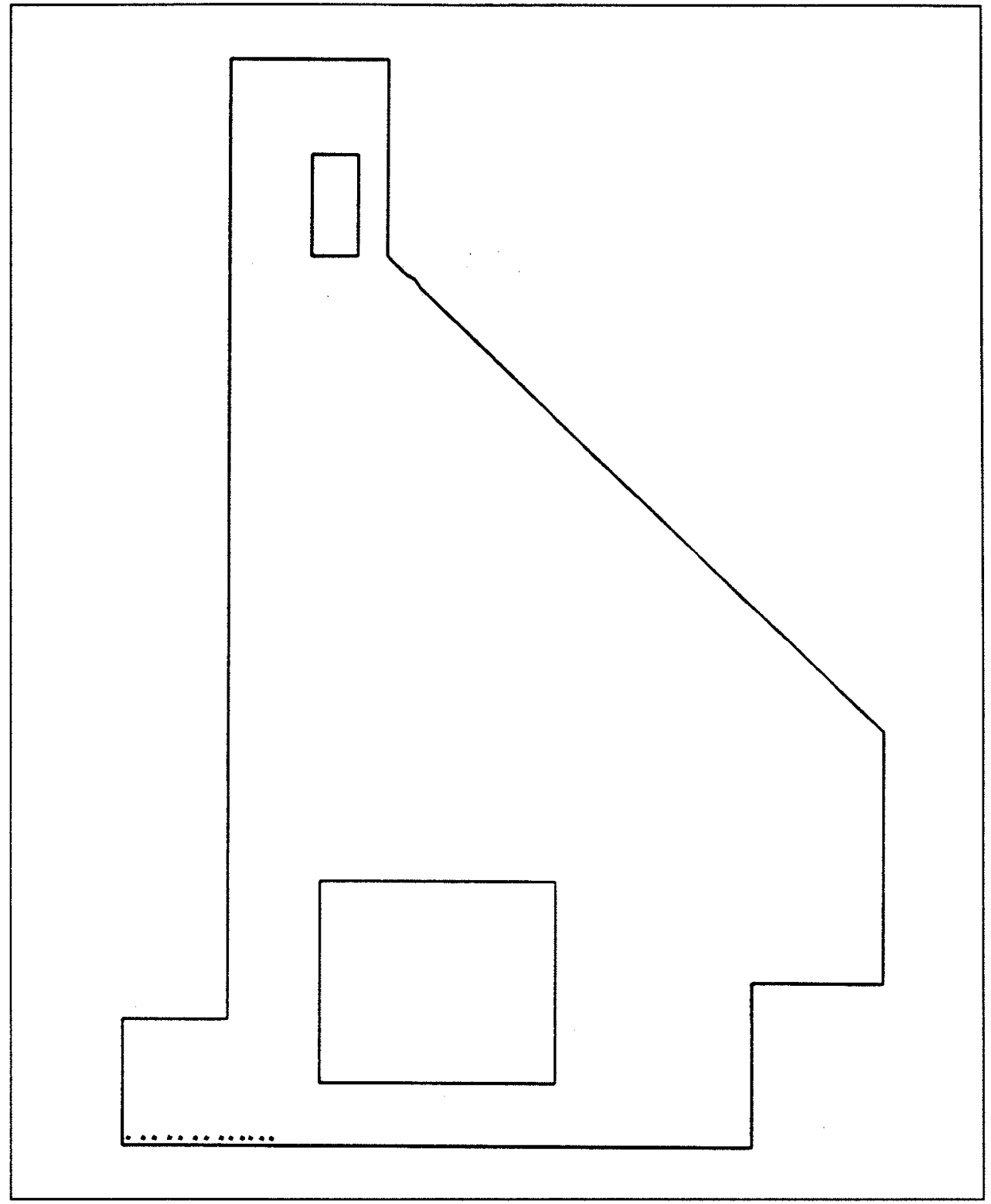

Figure 68 . Cracking predicted at day 160 of the extended analysis

expected by reviewing the contour and time-history plots in Figures 60 through 67 , since the gradients in general were reduced in the extended portion of the analysis.

Figures 71,72 , and 73 are enlarged views of different portions of the structure showing a closer view of the cracked points in order that the direction of the predicted cracks can be seen. As can be seen in Figures 71 and 72, most of the points cracked at the base of the structure are on an inclined plane, indicating that shearing is occurring. This is supported by Figures 75 and 76, which show the shear stresses building up along the base and by the horizontal and vertical stresses seen in Figures 78 and 83, respectively. A Mohr's circle 


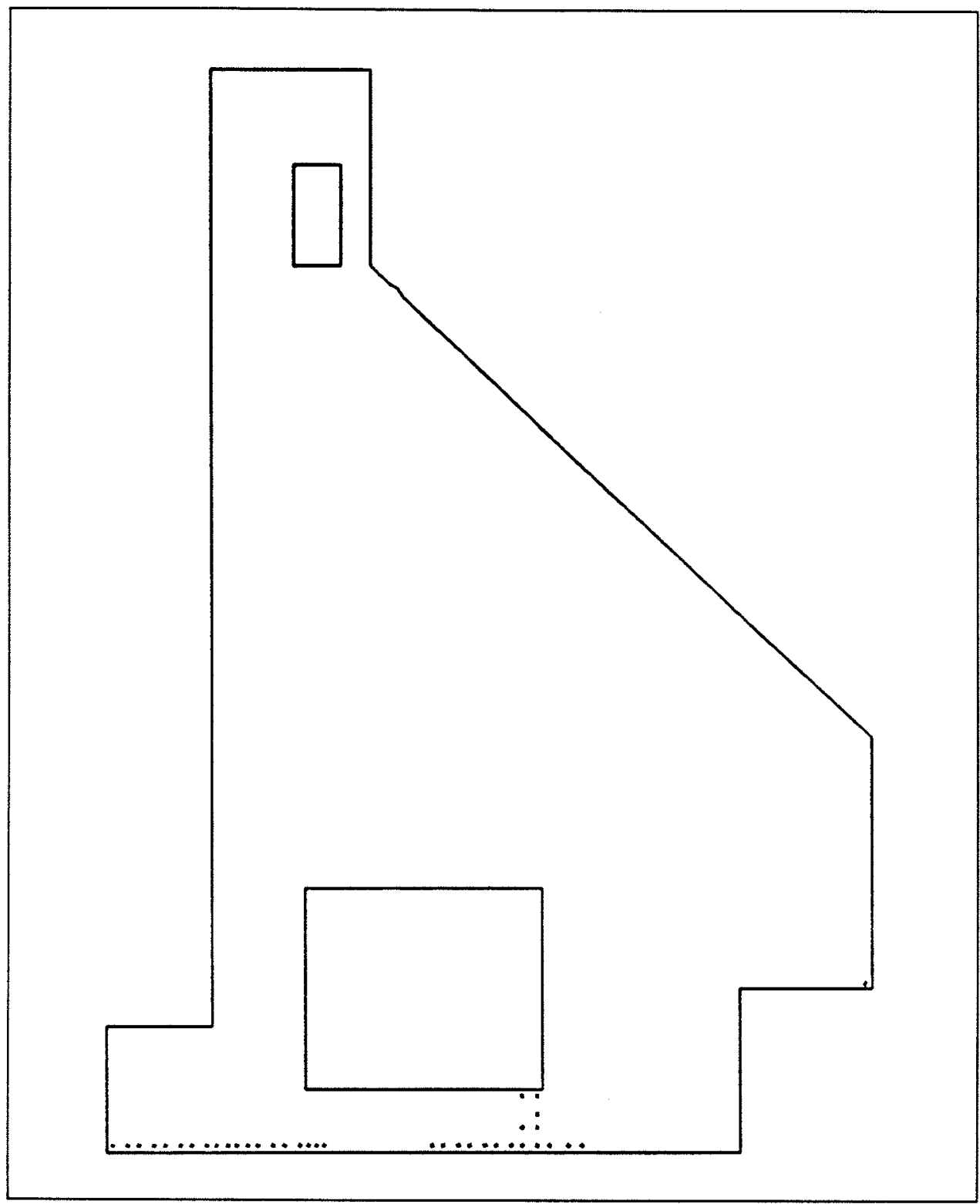

Figure 69. Cracking predicted at day 260 of the extended analysis

calculation was performed just prior to cracking for the point in the lower lefthand comer of Figure 71 in an attempt to predict the direction of the crack through the use of a hand calculation. The Mohr's circle and calculations are shown in Figure 74 and as can be seen, a crack angle (from vertical) of $42 \mathrm{deg}$ is predicted. This does not match well with the crack angle in Figure 72 and upon further investigation it was found that the actual predicted angle was $66 \mathrm{deg}$. This discrepancy can be attributed to the fact that ANACAP-U (ANATECH Research Corp. 1992), which contains the UMAT subroutine used by ABAQUS, bases its prediction of crack direction on principal strain and the Mohr's circle calculation is based on principal stress. Due to creep which occurs, the principal stresses and strains do not necessarily correspond. 


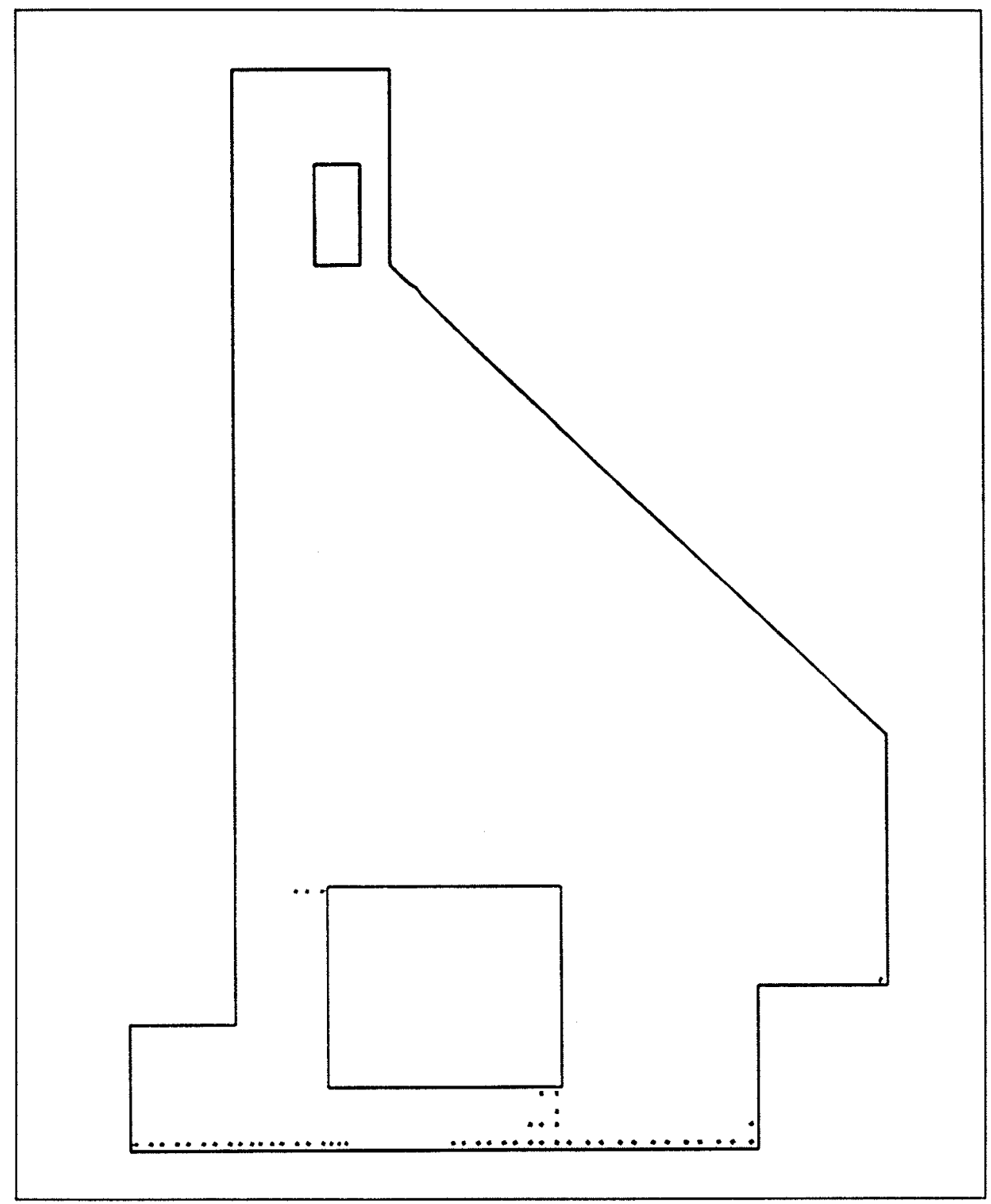

Figure 70 . Cracking predicted at day 395 of the extended analysis

Figure 73 shows the cracking which occurred at the upper left-hand corner of the culvert. As can be seen, the cracks are nearly horizontal, but are inclined slightly due to a small horizontal component. Further explanation of the cracking occurring at this comer of the culvert is given later.

Figures 75 and 76 show the shear stress contours at 75 and 115 days after the start of construction, respectively. As can be seen, shear stresses at these times are very low tension or compressive over a large portion of the structure. It is only near the base of the monolith, in the lower left-hand comer, that the shear stresses begin to get high. Figure 76 is only 5 days prior to the cracking that begins in the lower left-hand comer of the monolith and, as can be seen, 


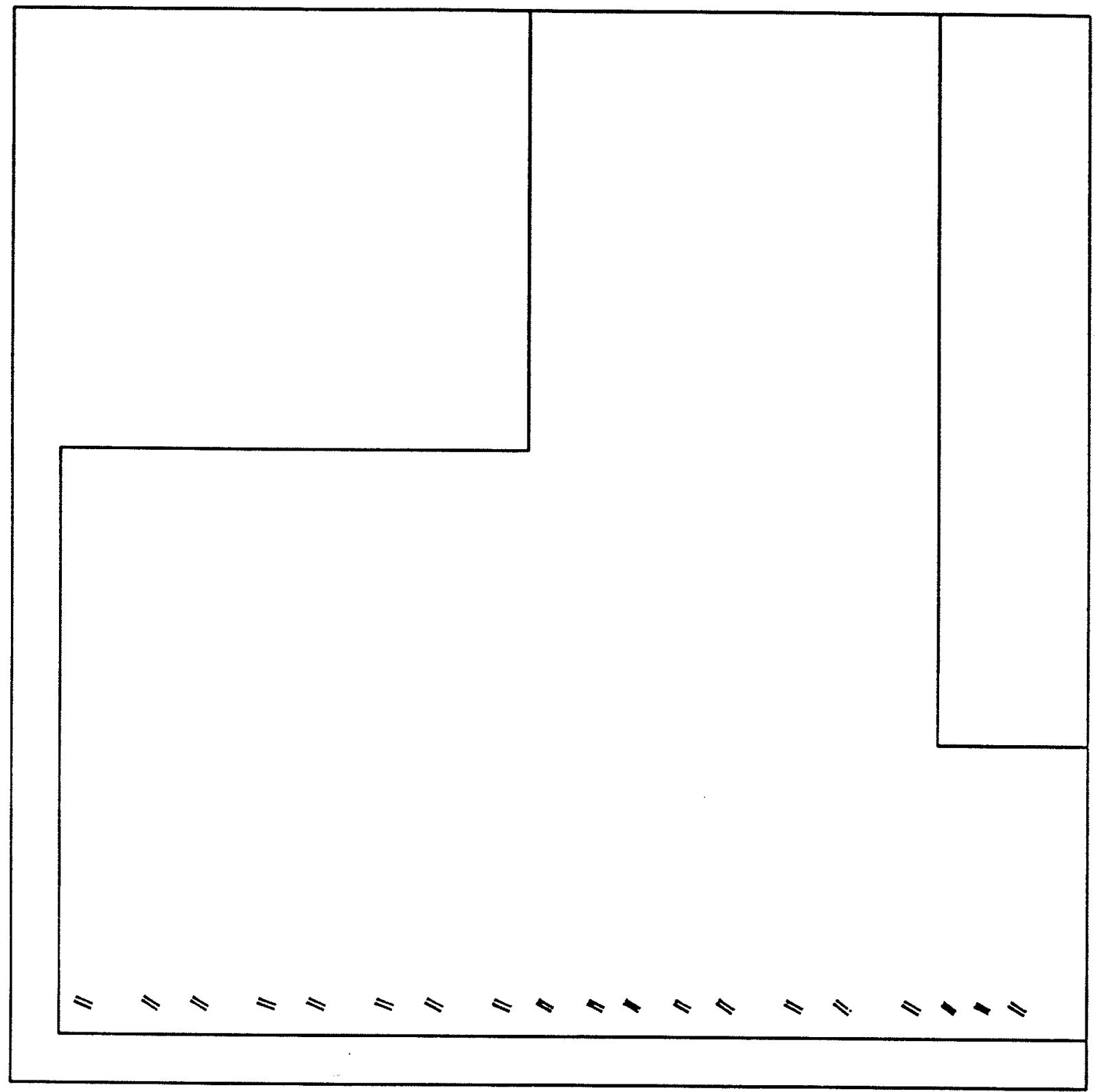

Figure 71. Enlarged view of final cracking pattern in base of monolith on the chamber side of the monolith

the shear stresses have become relatively large, indicating they play an important part in the cracking.

Figure 77 is a horizontal stress contour at day 75 . As can be seen in this plot, tension stresses in the horizontal direction are building up in the area below the culvert. This is a result of the concrete cooling and contracting and being restrained by the rock. This buildup continues as can be seen in Figure 78, where horizontal stresses have built up to tensile values of over $400 \mathrm{psi}$ at day 115 , which is just prior to cracking. Figures 79 and 80 (days 250 and 375 , respectively) show how the horizontal tensile stresses have been reduced 


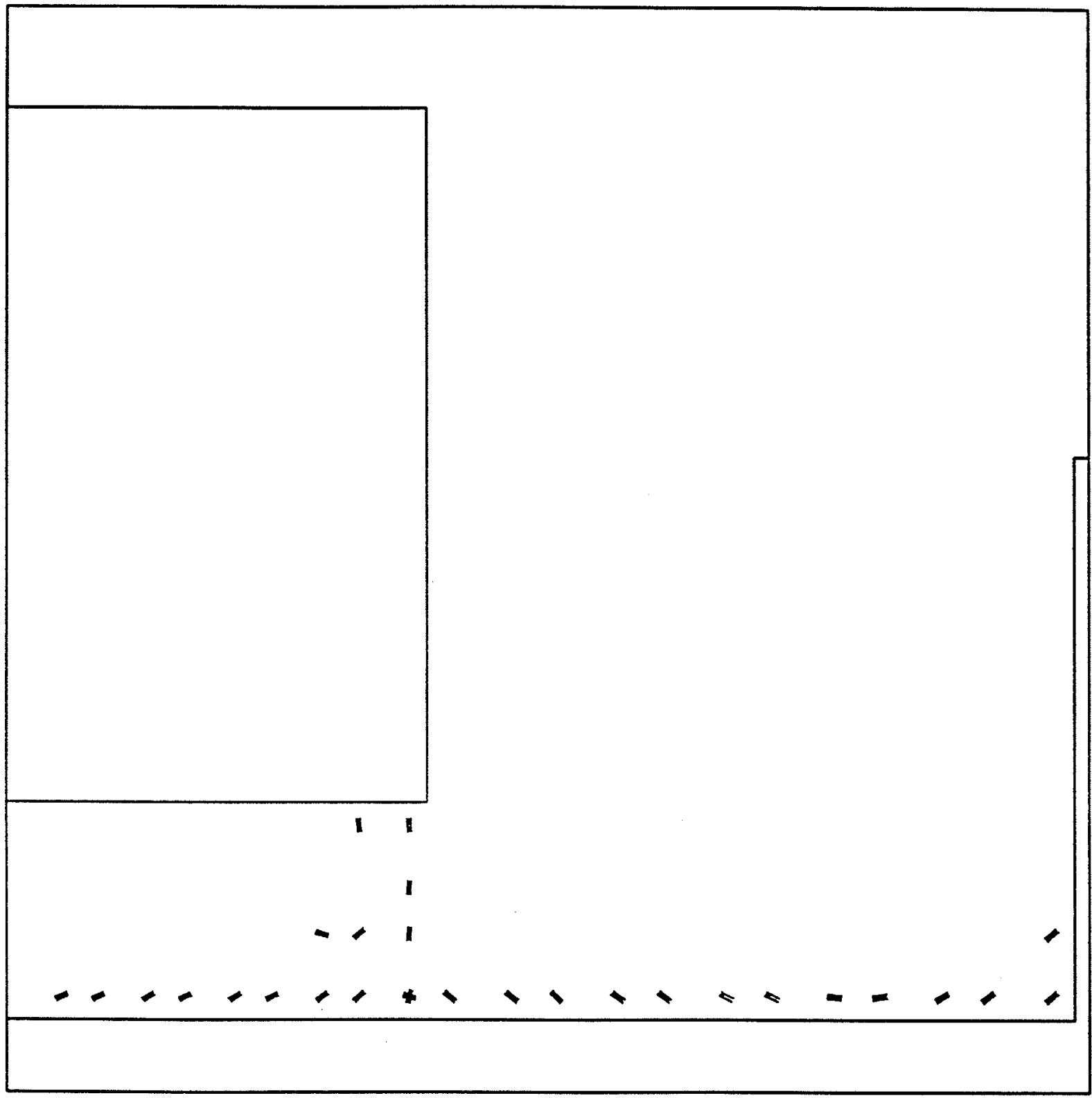

Figure 72. Enlarged view of final cracking pattern in base of monolith on the landside of the monolith

to small values where cracking has occurred, but in the uncracked areas of the base, high tensile stresses remain. Figure 81 shows the horizontal stress contours at day 615,1 year after the plot shown in Figure 79. As can be seen by comparing the two plots, there is little change in the second year of the analysis. The same is true when comparing Figures 82 and 80 , which are also about 1 year apart. The fact that the horizontal stresses are so close from one year to the next would indicate that the volume changes which induced the tension in the base of the monolith are nearly the same for the construction condition with a closed culvert to the condition with water and soil in place. 


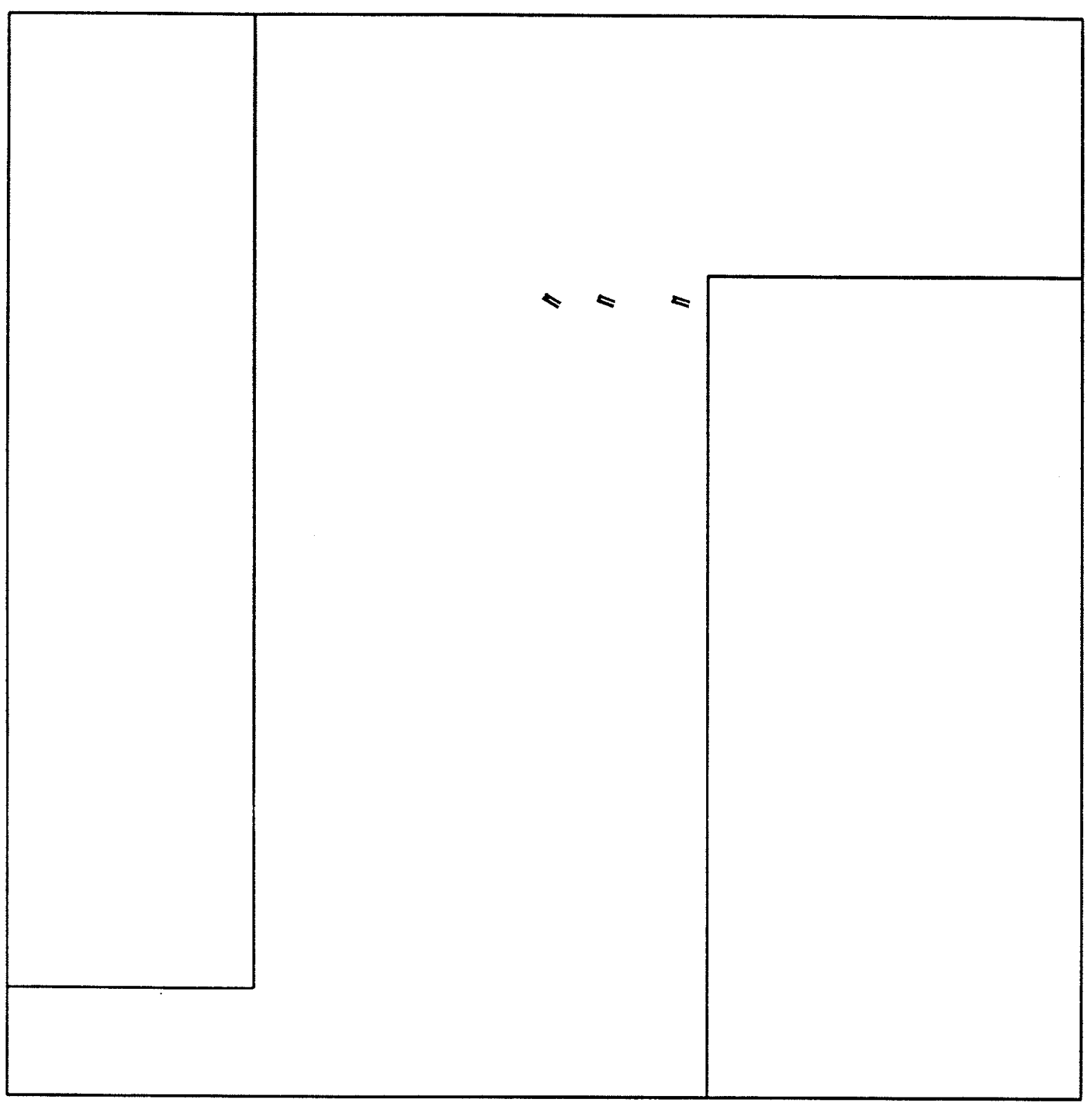

Figure 73. Enlarged view of final cracking pattern near the upper left-hand corner of the culvert

Questions may arise as to how the concrete can still carry a tensile load after it cracks. This phenomenon is seen in Figure 80, where places that have cracked are still indicating tensile stress in excess of $300 \mathrm{psi}$. When an integration point cracks, it is no longer allowed to carry tension in the direction normal to the crack; however the criteria do not prevent tension from occurring in directions that are not normal to the crack. Therefore, since the cracks are at an angle, the concrete can still carry tension in the horizontal direction.

Figures 83 through 87 are contour plots of the vertical stresses. Figure 83 is a plot at day 115 and the vertical component can be seen to be large at this point in time and therefore is obviously an influence on the cracking that 


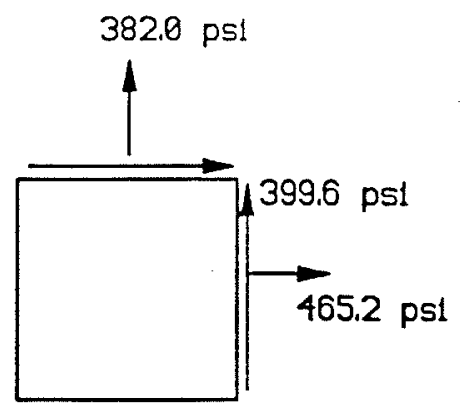

$(0,8)$

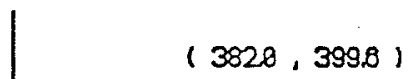

Center of Circle $=\frac{382.0+465.2}{2}=423.6 \mathrm{psi}$

$\theta_{p}=$ direction of max. principal stress

$$
2 \theta_{p}=\tan ^{-1} \frac{\tau_{x y}}{\left(\sigma_{x}-\sigma_{y}\right) / 2}
$$

$$
\theta_{p}=42^{\circ}
$$

Figure 74. Mohr's circle of stress for stresses at the lower left-hand corner of the base at day 110 


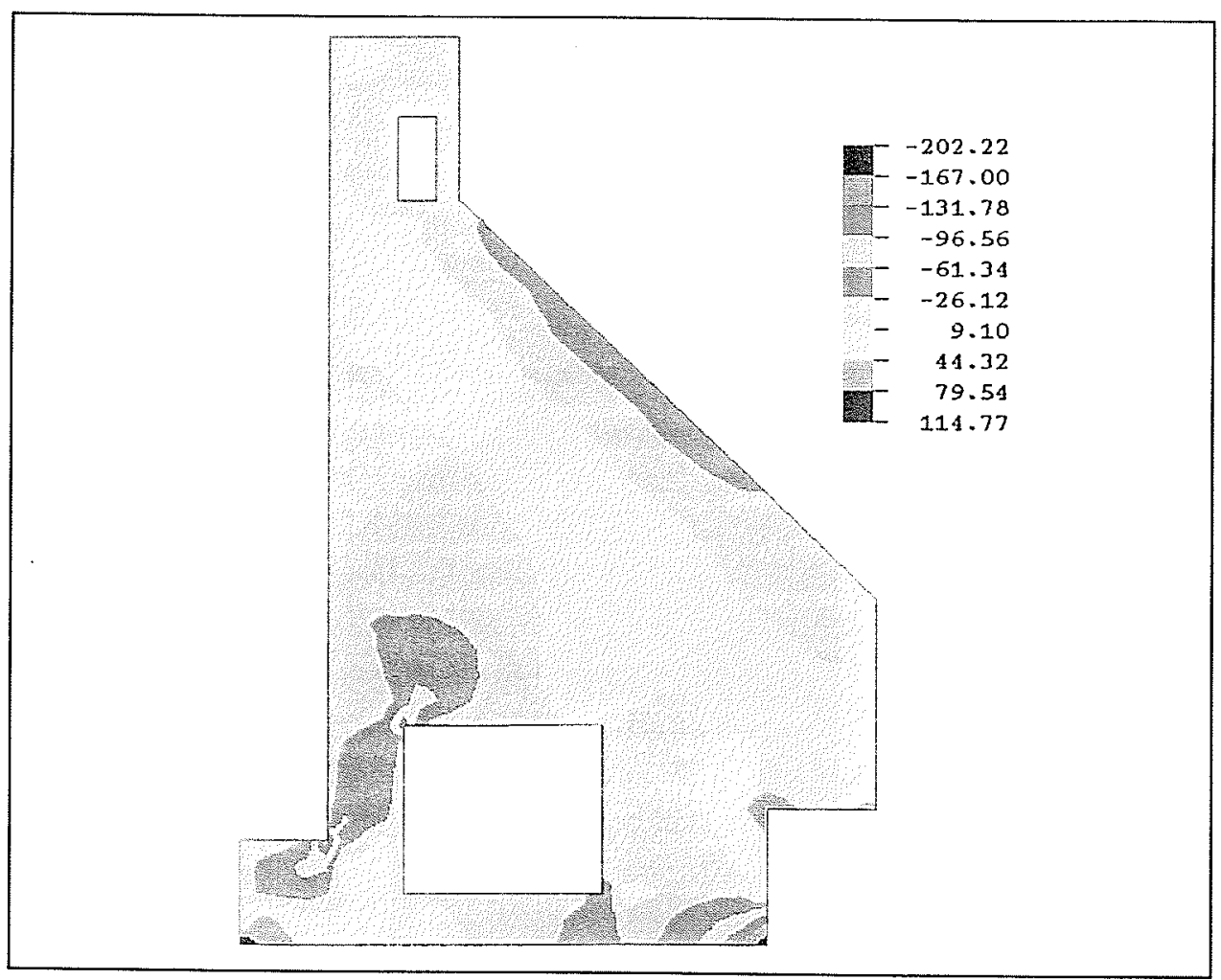

Figure 75 . Shear stress contour at day 75 of the extended analysis

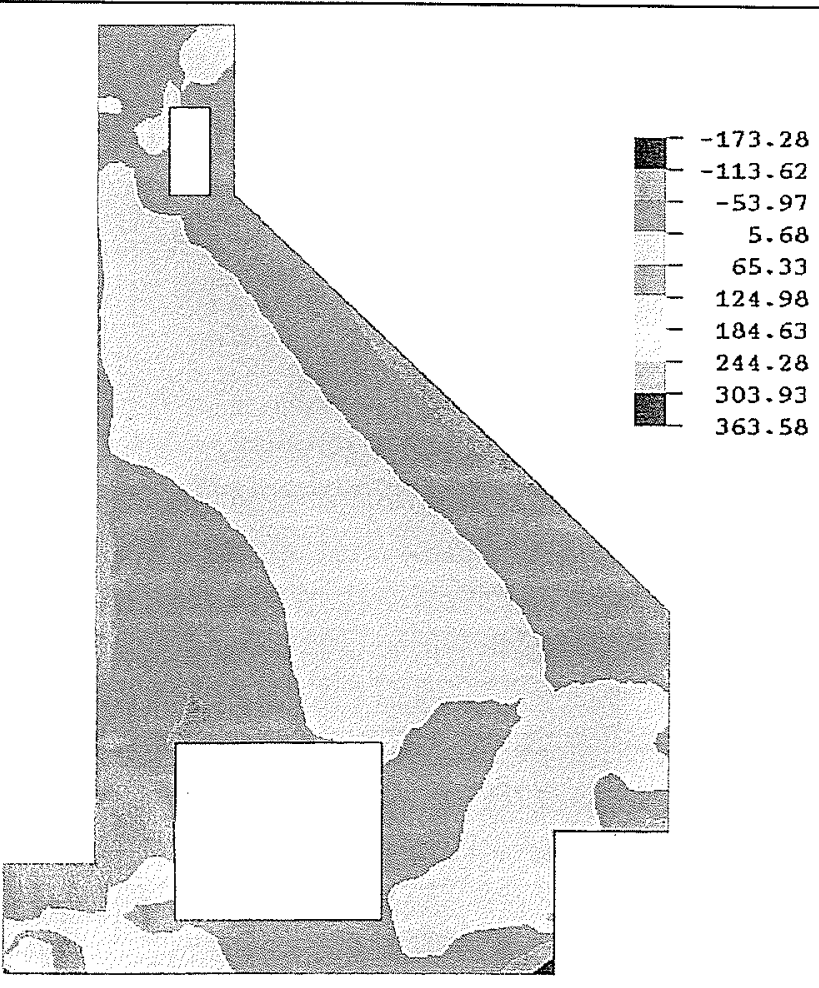

Figure 76. Shear stress contour at day 115 of the extended analysis 


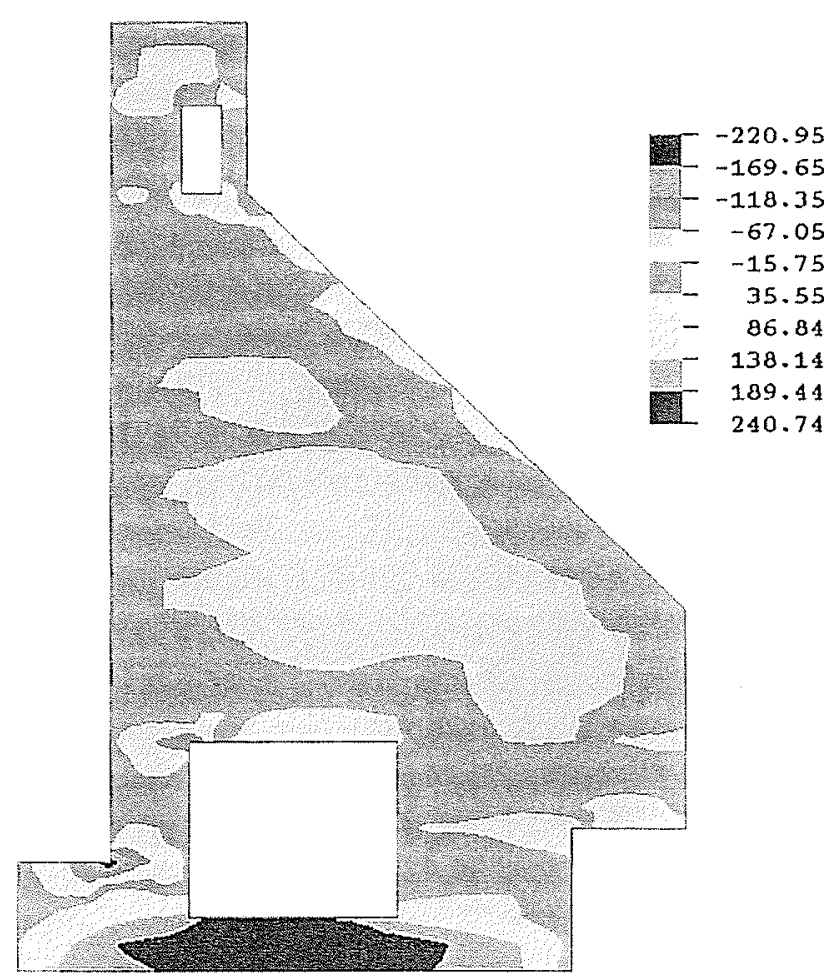

Figure 77 . Horizontal stress contour at day 75 of the extended analysis

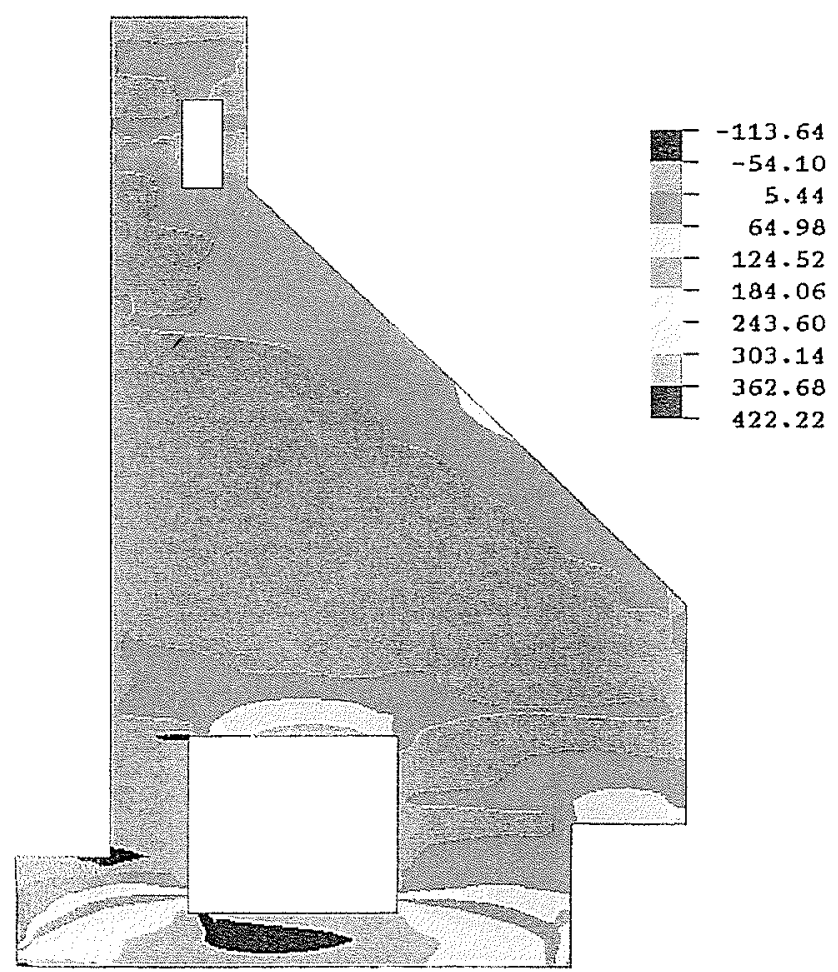

Figure 78. Horizontal stress contour at day 115 of the extended analysis 


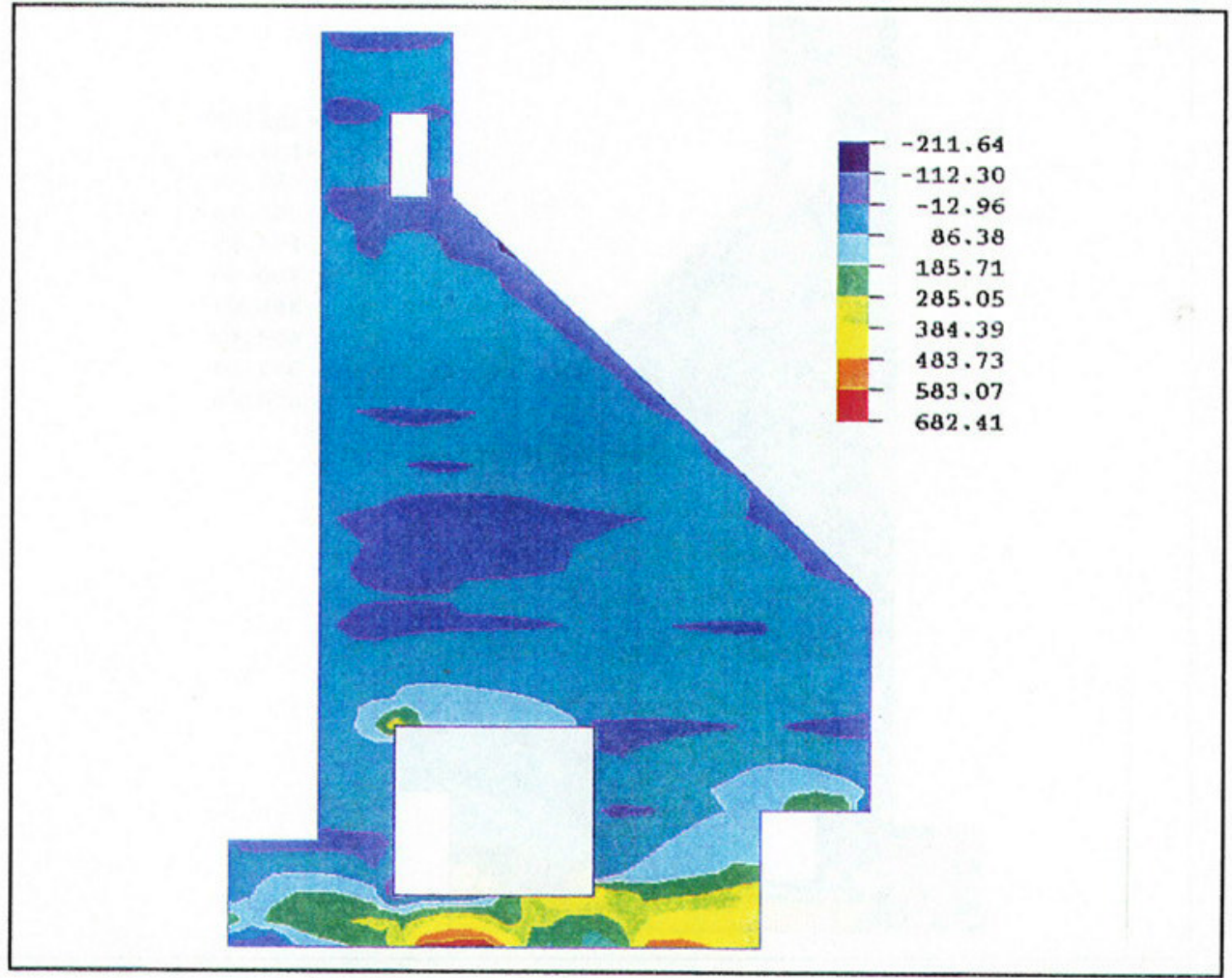

Figure 79. Horizontal stress contour at day 250 of the extended analysis

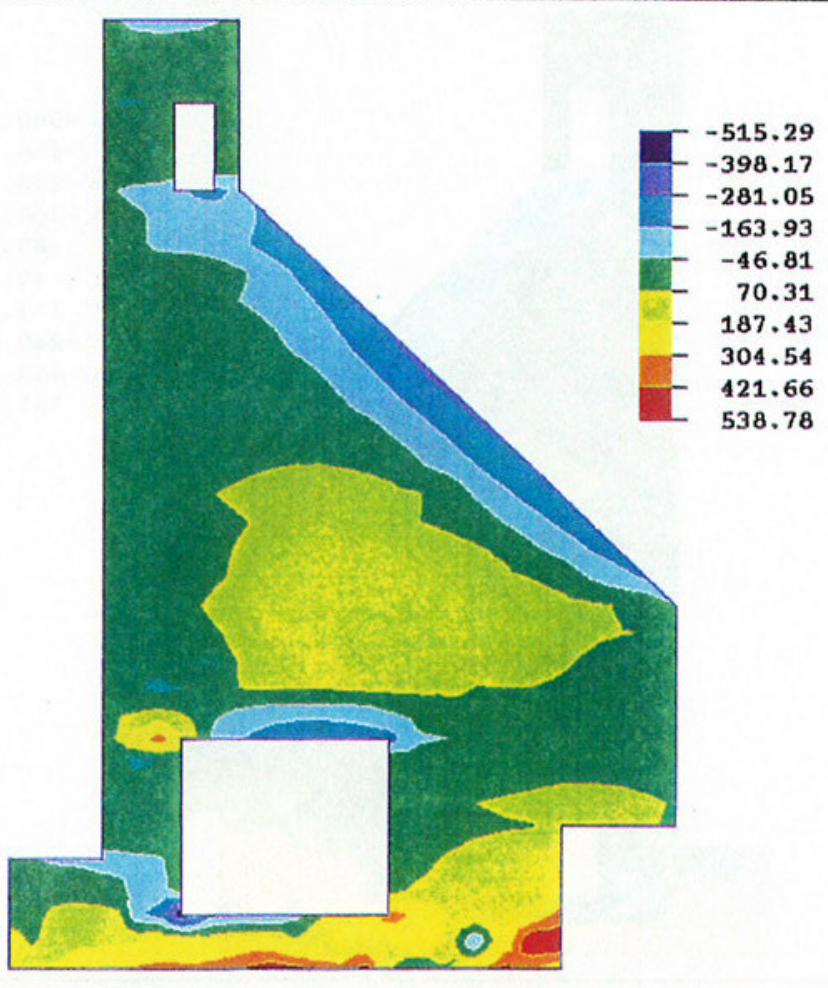

Figure 80 . Horizontal stress contour at day 375 of the extended analysis 


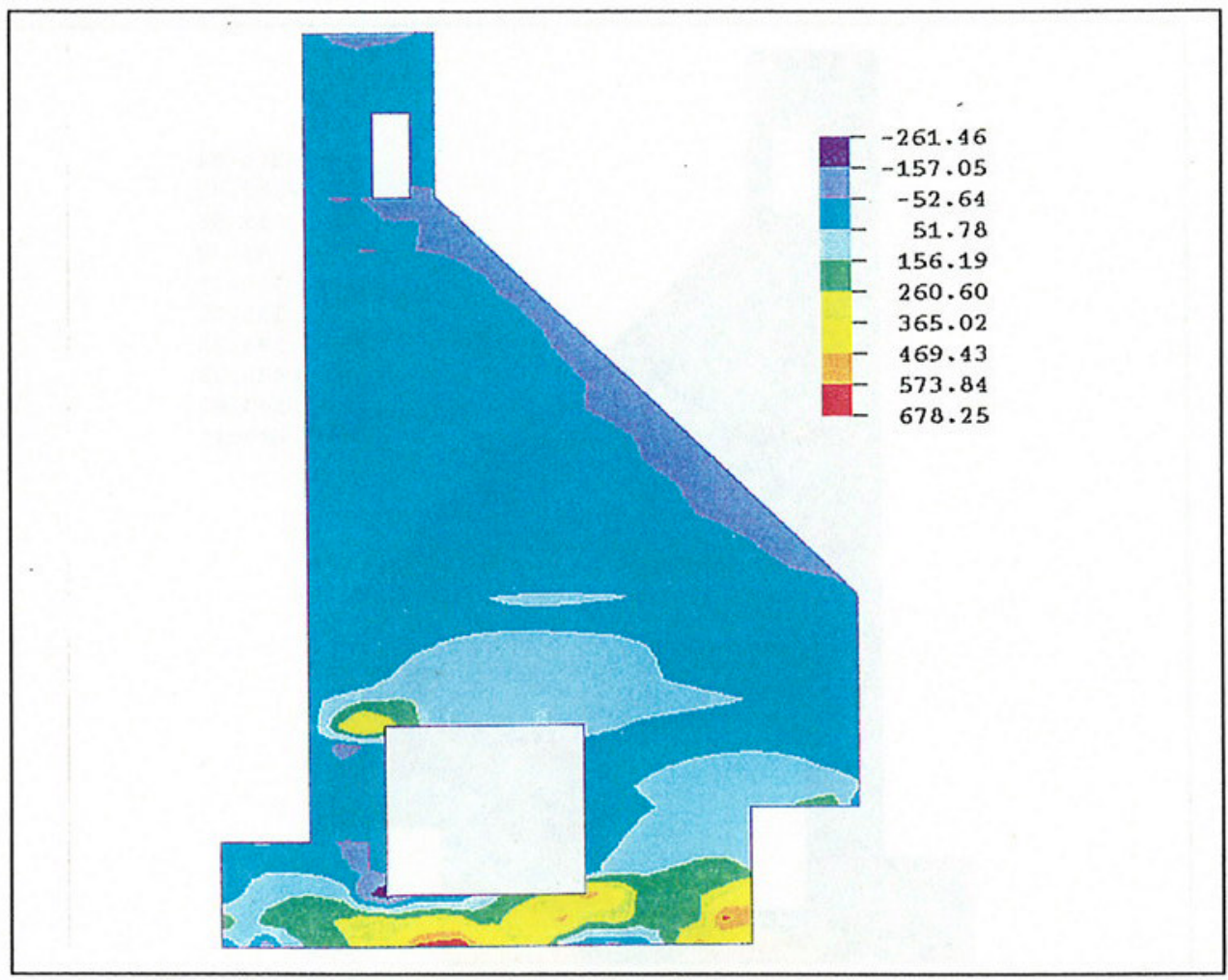

Figure 81. Horizontal stress contour at day 615 of the extended analysis

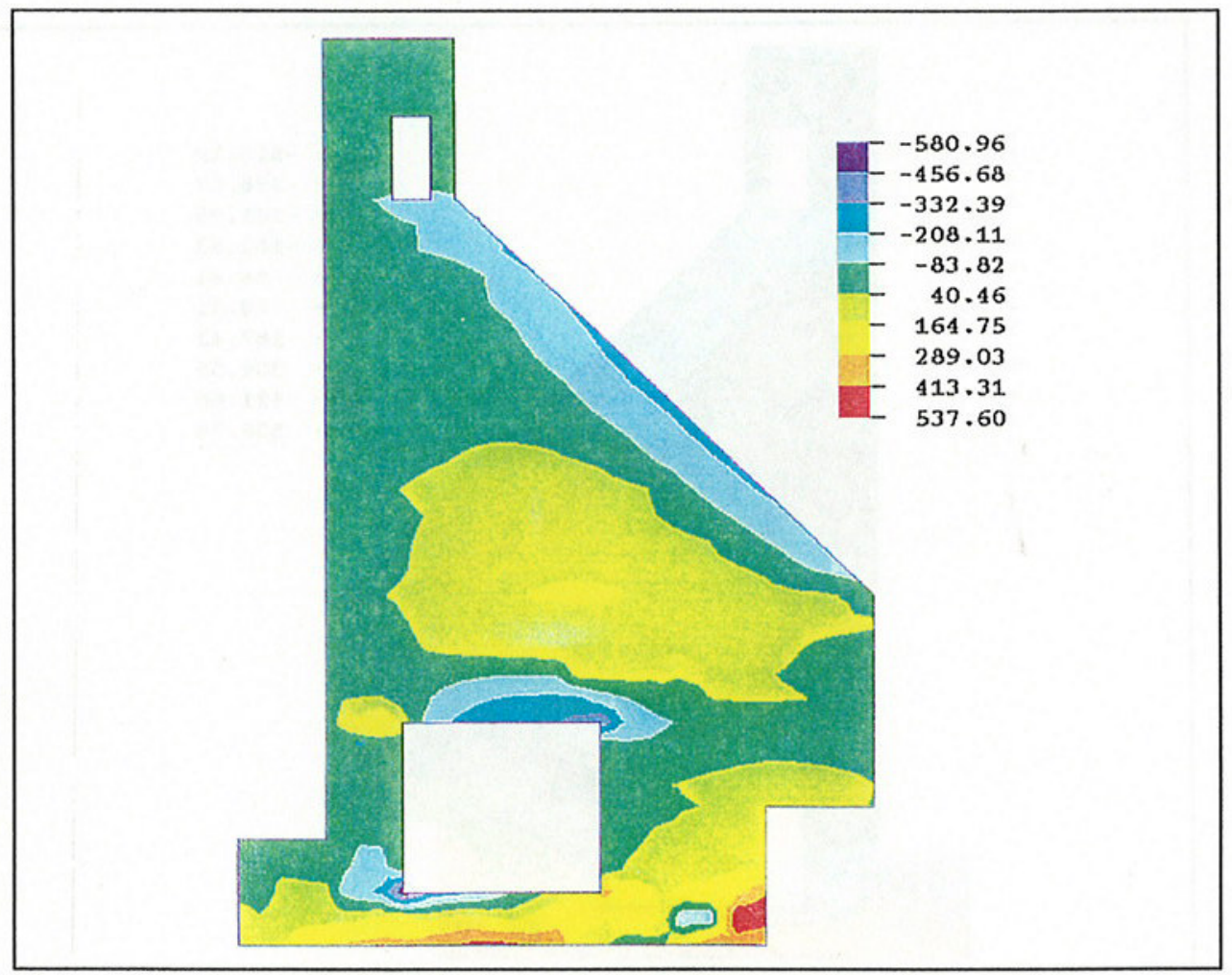

Figure 82. Horizontal stress contour at day 755 of the extended analysis 


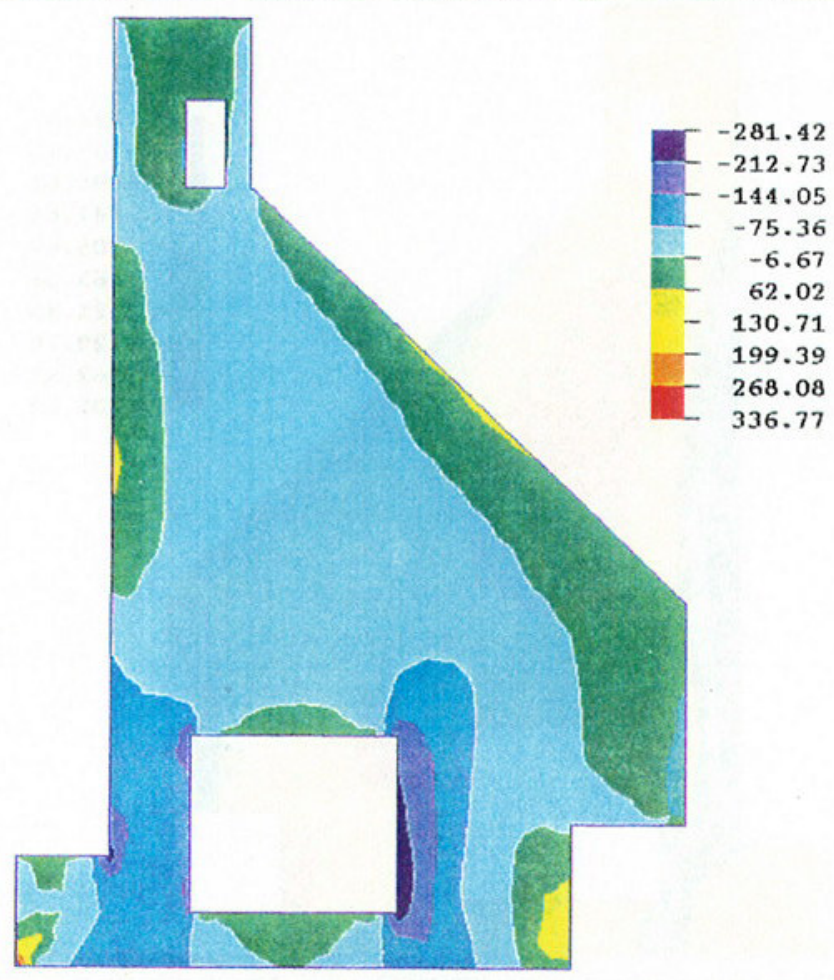

Figure 83. Vertical stress contour at day 115 of the extended analysis

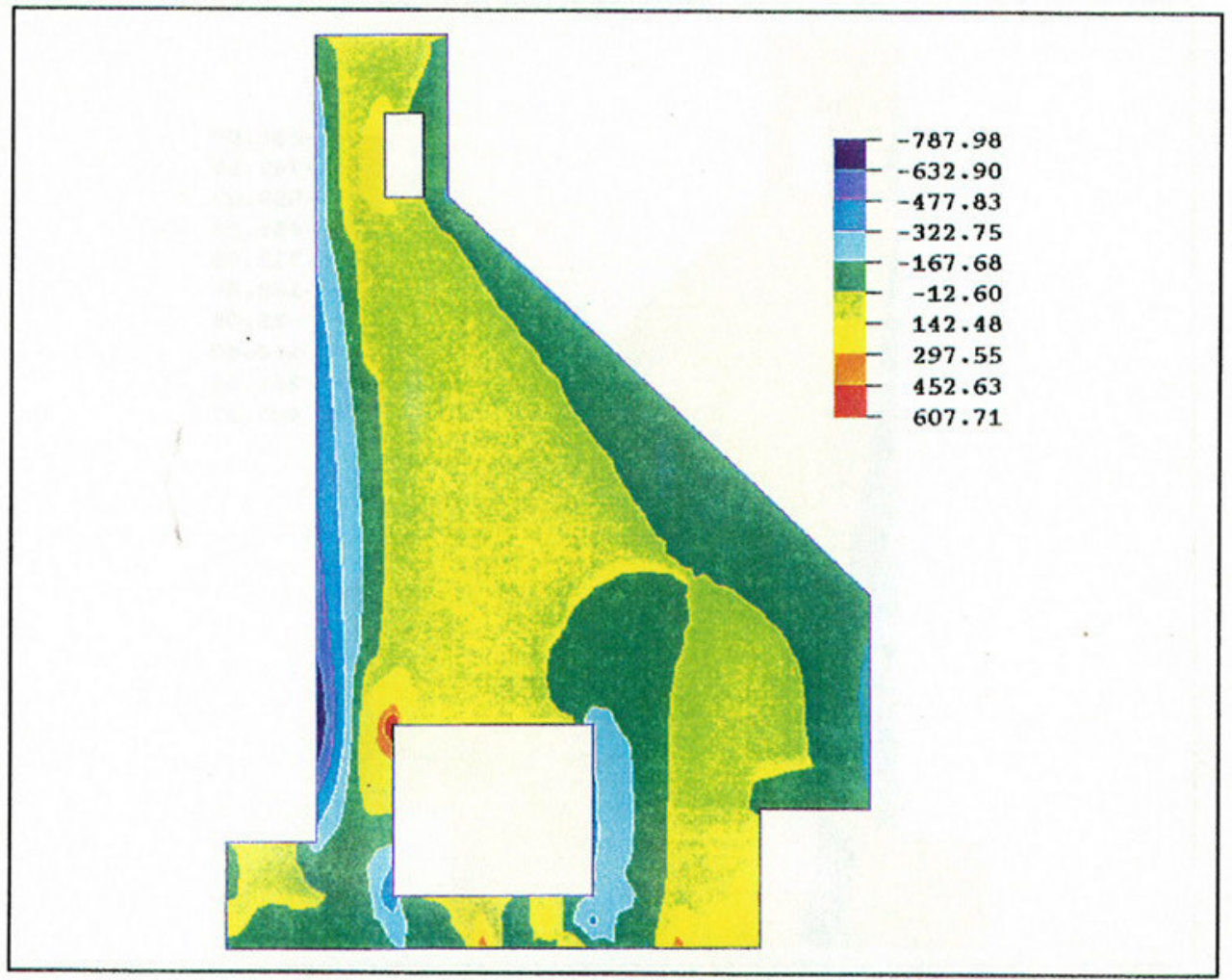

Figure 84. Vertical stress contour at day 290 of the extended analysis 


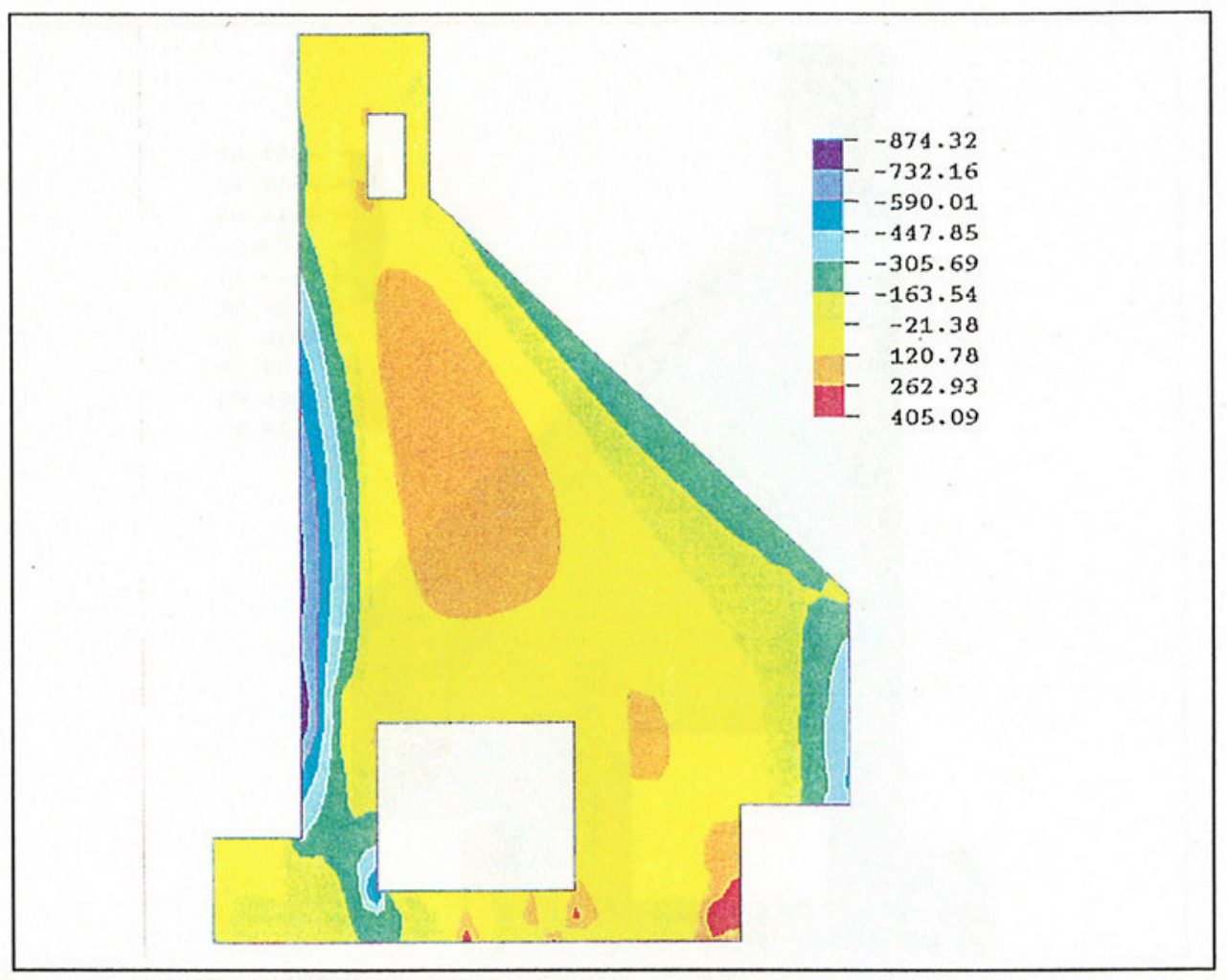

Figure 85 . Vertical stress contour at day 395 of the extended analysis

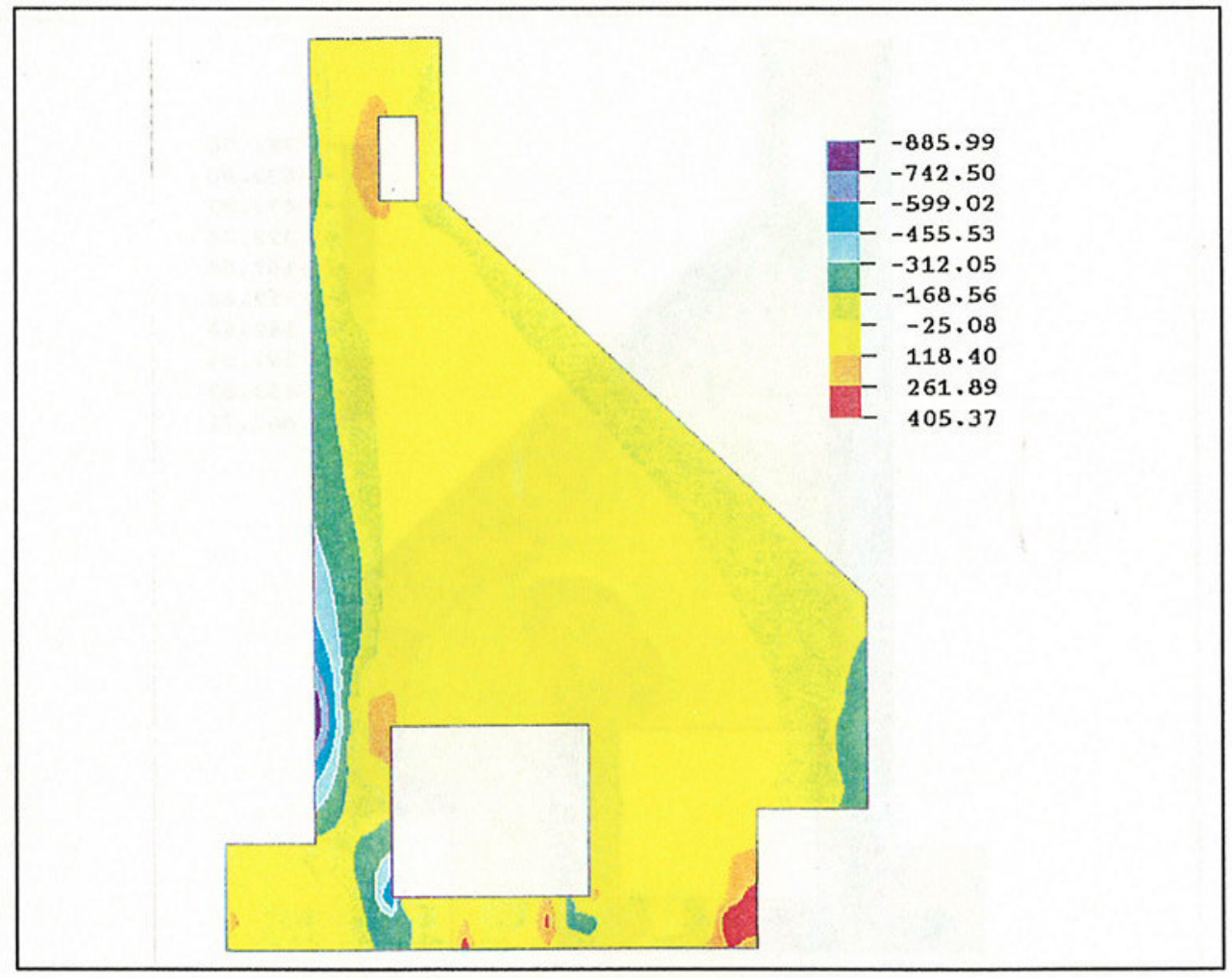

Figure 86. Vertical stress contour at day 615 of the extended analysis 


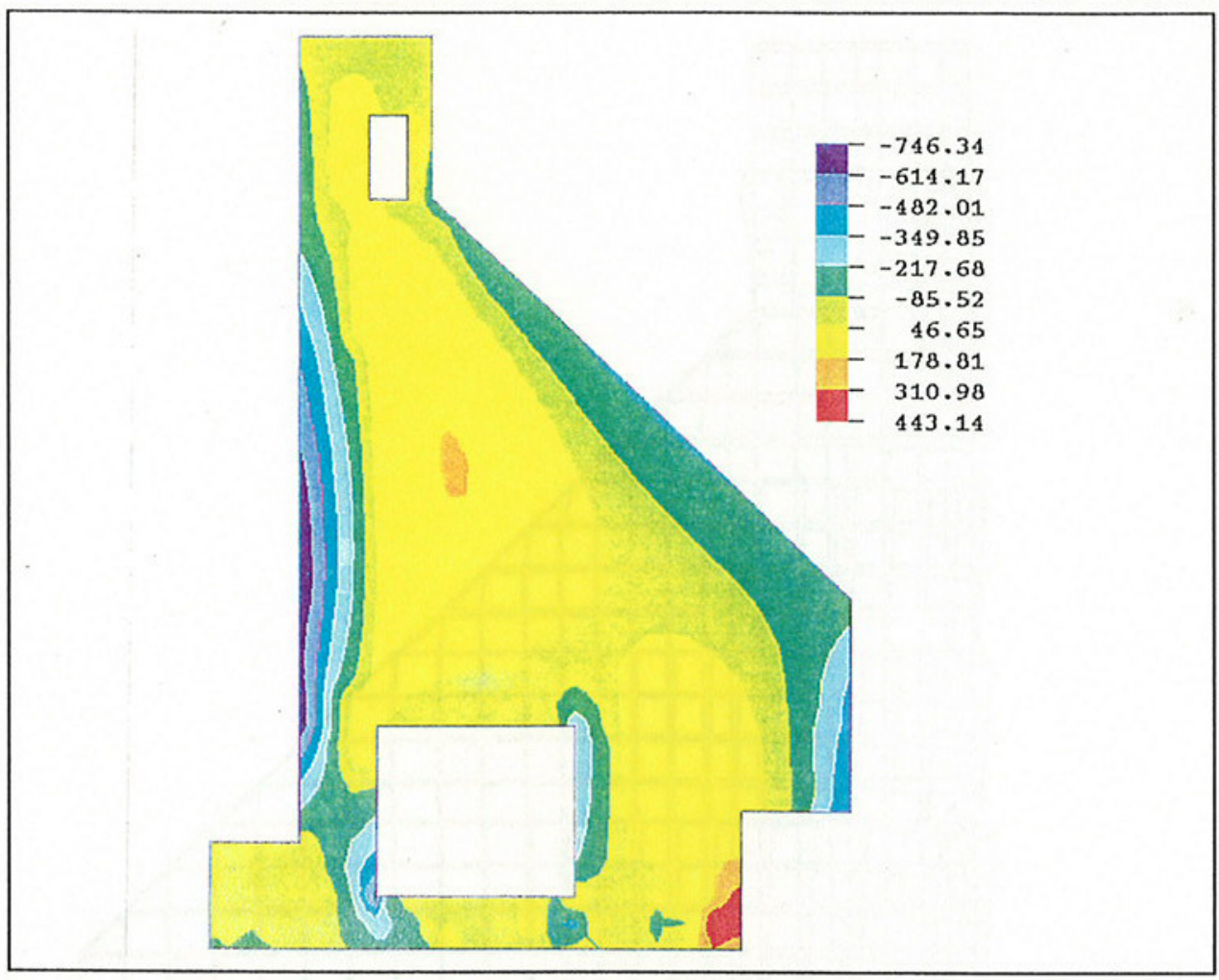

Figure 87 . Vertical stress contour at day 755 of the extended analysis

occurs. Figure 84 is taken at day 290 and while some fairly high tensile stress values exist at the tips of the crack at the base (approximately $300 \mathrm{psi}$ ) the highest values exist at the top of the wall between the culvert and the chamber. The vertical stresses at this location go from a tension stress of $600 \mathrm{psi}$ at the culvert to a compressive stress of $788 \mathrm{psi}$ at the chamber face. This stress distribution represents a bending type behavior and this behavior can be seen in the displaced shape plot of Figure 91, where the wall in question is being rotated, but due to the mass of the monolith above the culvert a restraint against this rotation occurs, creating the stress state seen in Figure 84. Figure 85 is taken at day 395 and remnants of the behavior can still be seen, but the tensile stresses by this time have been greatly reduced because of cracking. By day 395 the buildup of vertical stress is occurring primarily at the rock/concrete interface to the right of the culvert. Figure 86 at day 615 and Figure 87 at day 755 show that the behavior in the second year is very similar to the first, as was the case for the horizontal stresses.

Figures 88 through 92 are deflected shapes of the monolith at various times. Figure 88 shows the monolith at day 75 and already at this time the base can be seen contracting, which results in the tensile values seen in earlier stress plots. The chamber face is deflecting toward the lock center line due to the expansion of the mass of concrete above the culvert. By day 125 (Figure 89) the contraction of the base can be seen in both vertical faces at the ends of the first lift. In addition, the mass above the culvert has begun to cool and the entire mass is contracting. Figure 90 is taken at day 250 and large deflections 


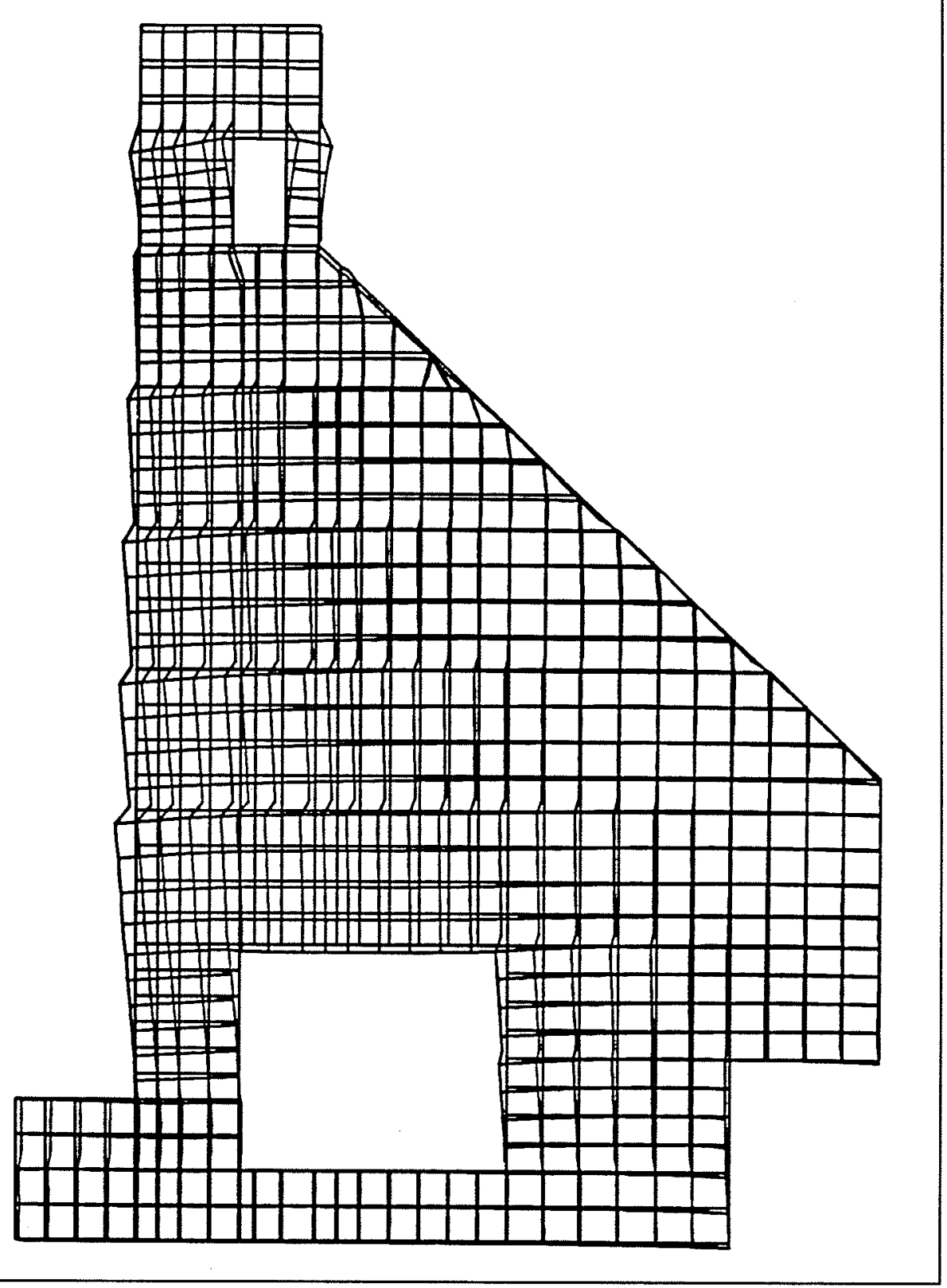

Figure 88. Deflected shape of monolith at day 75 of the extended analysis

are occurring in the base due to cracking at the toe of the monolith and in the area below the lower right-hand corner of the culvert. At day 310 , as seen in Figure 91, the behavior is similar to that seen in Figure 90, but the bending discussed earlier at the top of the wall between the culvert and the chamber can be seen clearly. Finally, Figure 92 shows the displaced shape at the end of the first year (day 375) and it can be seen that the concrete is once again expanding due to the fact that the air temperatures are warmer.

Finally, in Figures 93 and 94, the reinforcing stresses are shown for element 52, which is the element below the lower right-hand comer of the culvert 


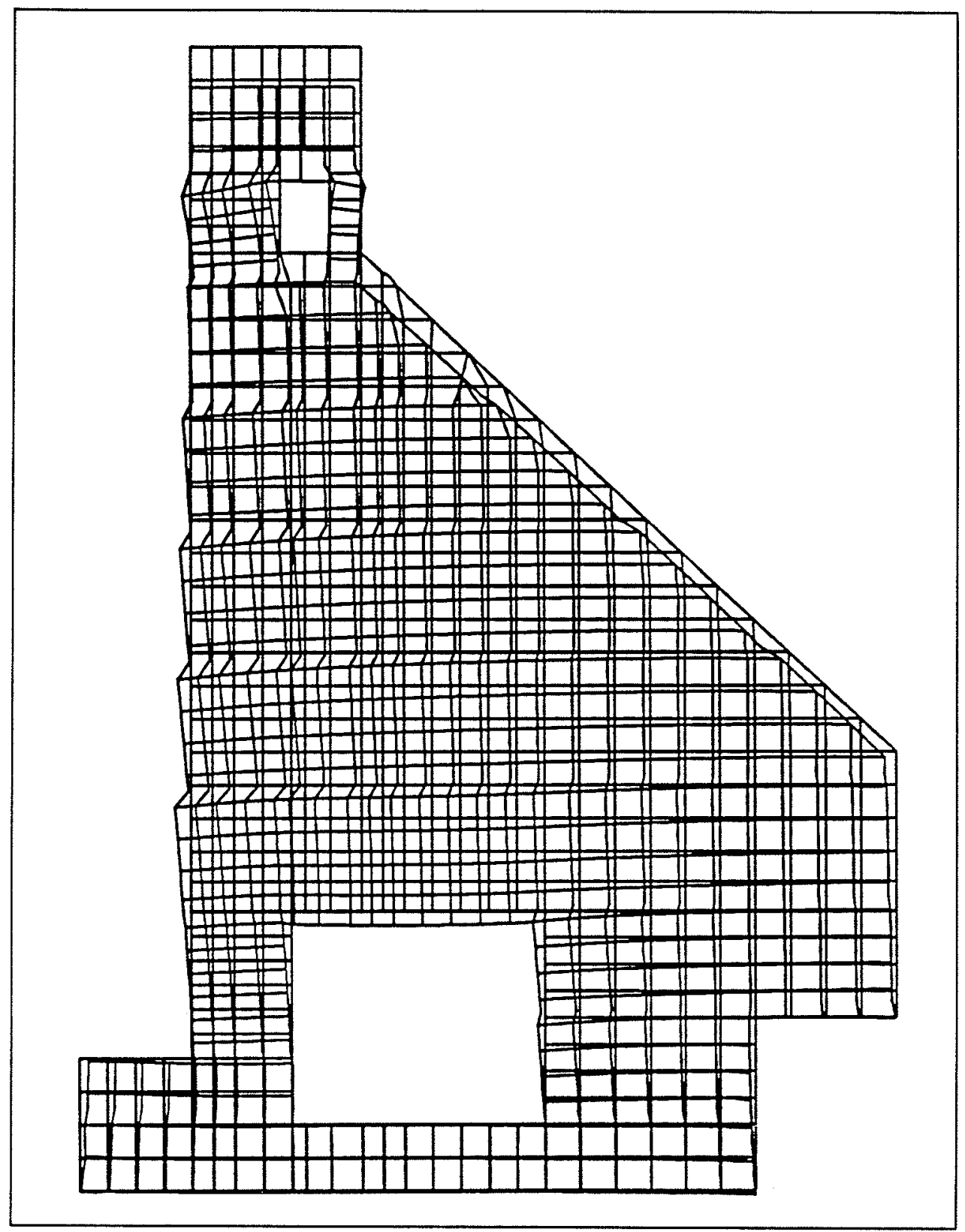

Figure 89. Deflected shape of monolith at day 125 of the extended analysis

where the vertical crack occurred, and element 88 , located at the top left-hand comer of the culvert. Point 1 is the integration point on the left side of the element and integration point 2 is on the right side of the element. As can be seen in Figure 93, the maximum stress occurs at integration point 1 for the horizontal bar and the stress is over $110 \mathrm{ksi}$, which is well above the yield stress of $60 \mathrm{ksi}$. The reinforcing is assumed to be elastic as modeled. Therefore, the stresses shown in Figure 93 are not the stresses which would actually occur, since yielding of the reinforcing would begin to occur at about $60 \mathrm{ksi}$ and instead of increased stresses the crack would begin to open. While the stresses shown in Figure 93 may not be accurate, they are higher than is 


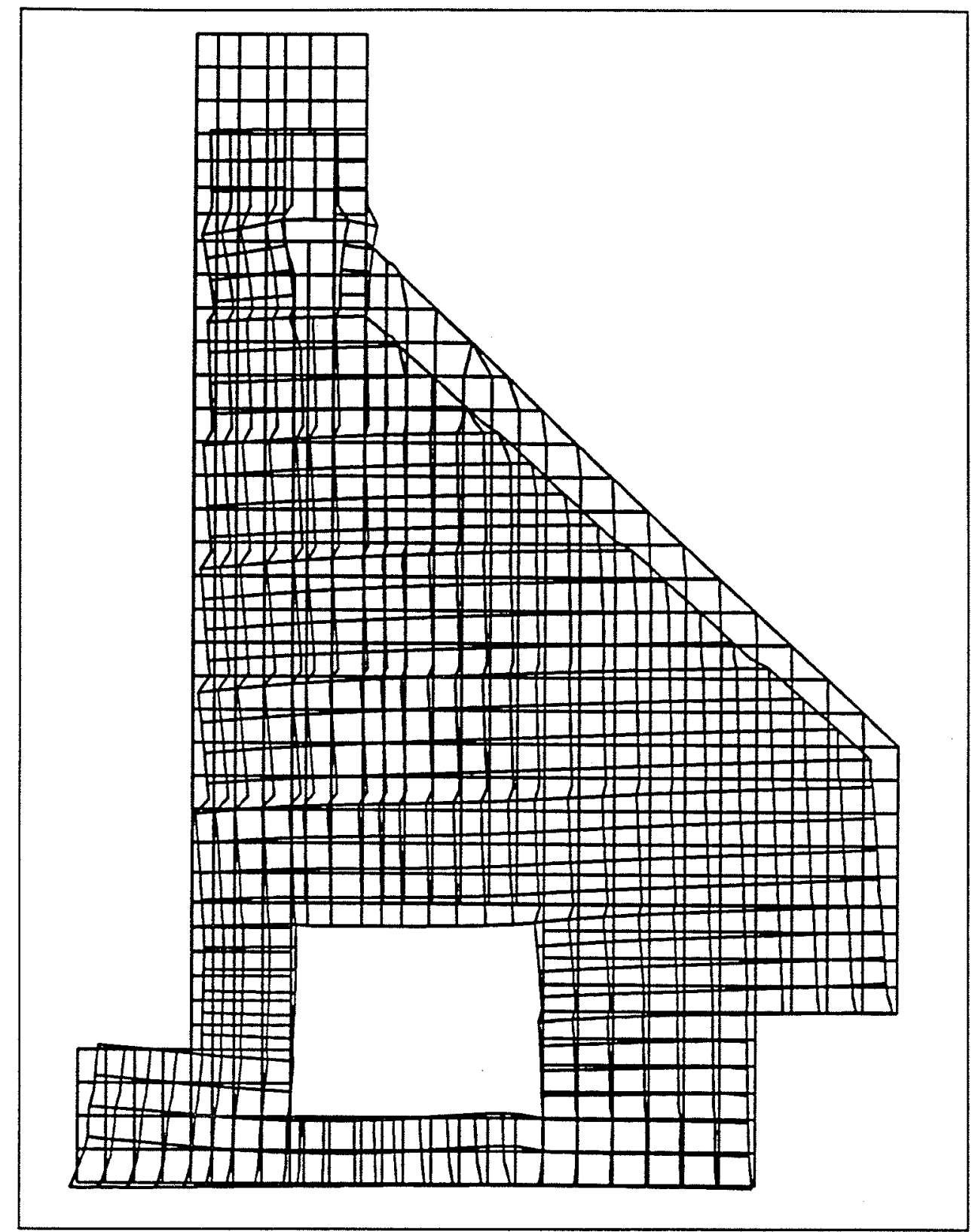

Figure 90 . Deflected shape of monolith at day 250 of the extended analysis

physically possible based on specifications for the material and additional steps should be taken to reduce the stresses in the reinforcing in this area. Figure 94 shows that stresses in the reinforcing do get up to $40 \mathrm{ksi}$, which indicates that the reinforcing that was modeled (No. 9 at 12-in. spacing) should be sufficient to arrest the crack that occurs at that location.

After considering the results presented for the extended analysis described above, a decision was made that if cracking actually occurs in the field it would not adversely affect the performance of the monolith, despite the fact that a number of points at the base of the monolith exceed the cracking 


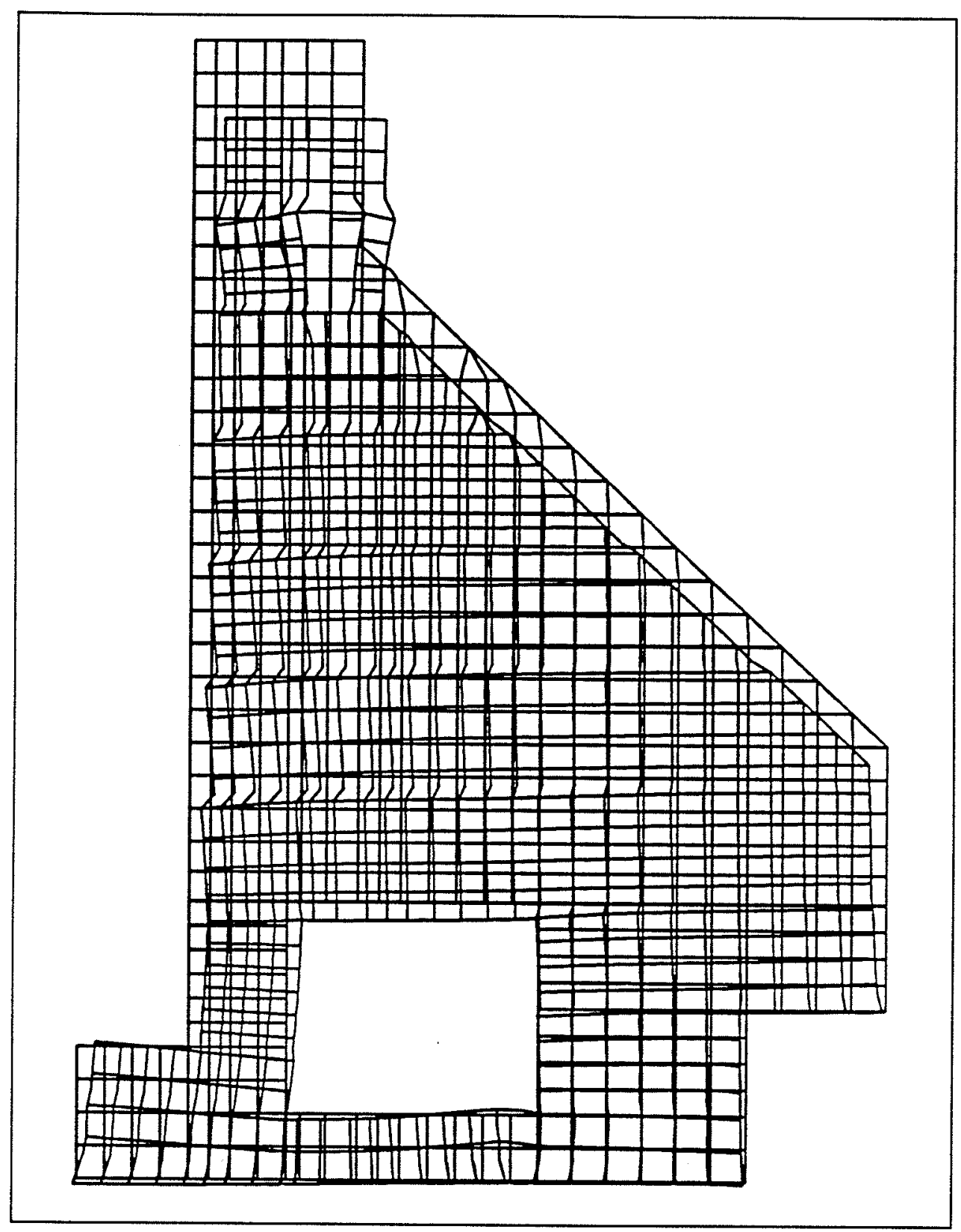

Figure 91 . Deflected shape of monolith at day 310 of the extended analysis

criteria. While it was felt that the analysis showed that the behavior of the monolith was acceptable it was felt that some improvement could be made, particularly with respect to the high stresses which occurred in the reinforcing below the culvert. In addition, an intermediate run was made which included No. 18 reinforcing bars in the area beneath the culvert (results of this analysis are not reported) and this analysis showed a large improvement in the resulting stresses in the reinforcing. This led to the decision to perform a second analysis using a summer start in which another gap element was added and the reinforcing beneath the culvert was increased to No. 11 bars at 12 -in. spacing. Results of the second extended analysis are presented later in this chapter. 


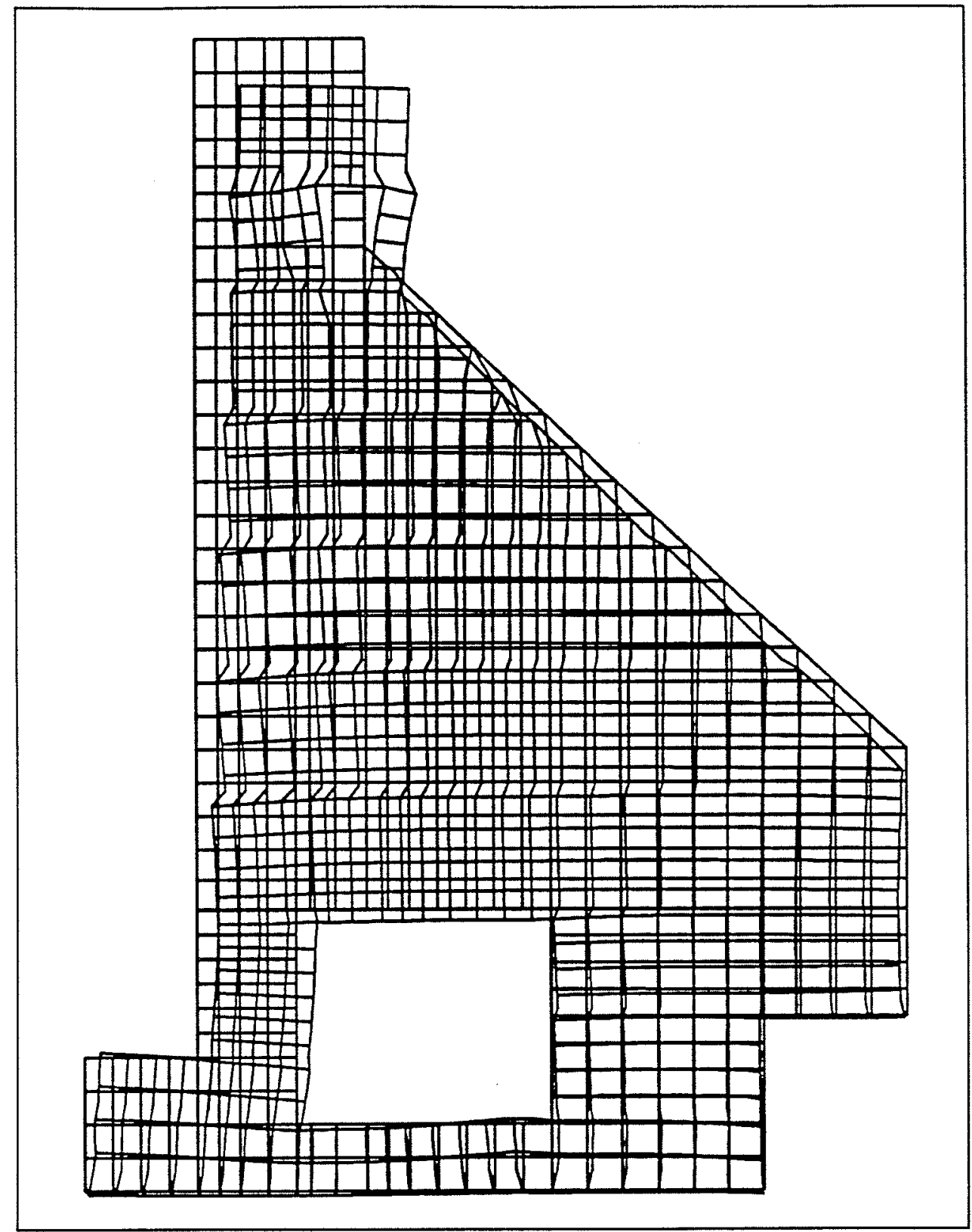

Figure 92 . Deflected shape of monolith at day 375 of the extended analysis

\section{Winter Analysis}

An analysis that simulated construction during the winter months was performed concurrently with the extended analysis described above, and results are described below. The winter analysis parameters are identical to those used for the extended analysis described above except that the start of construction was assumed to be November 1 instead of June 10. The change in the start date requires that insulation be provided for a given period of time. 


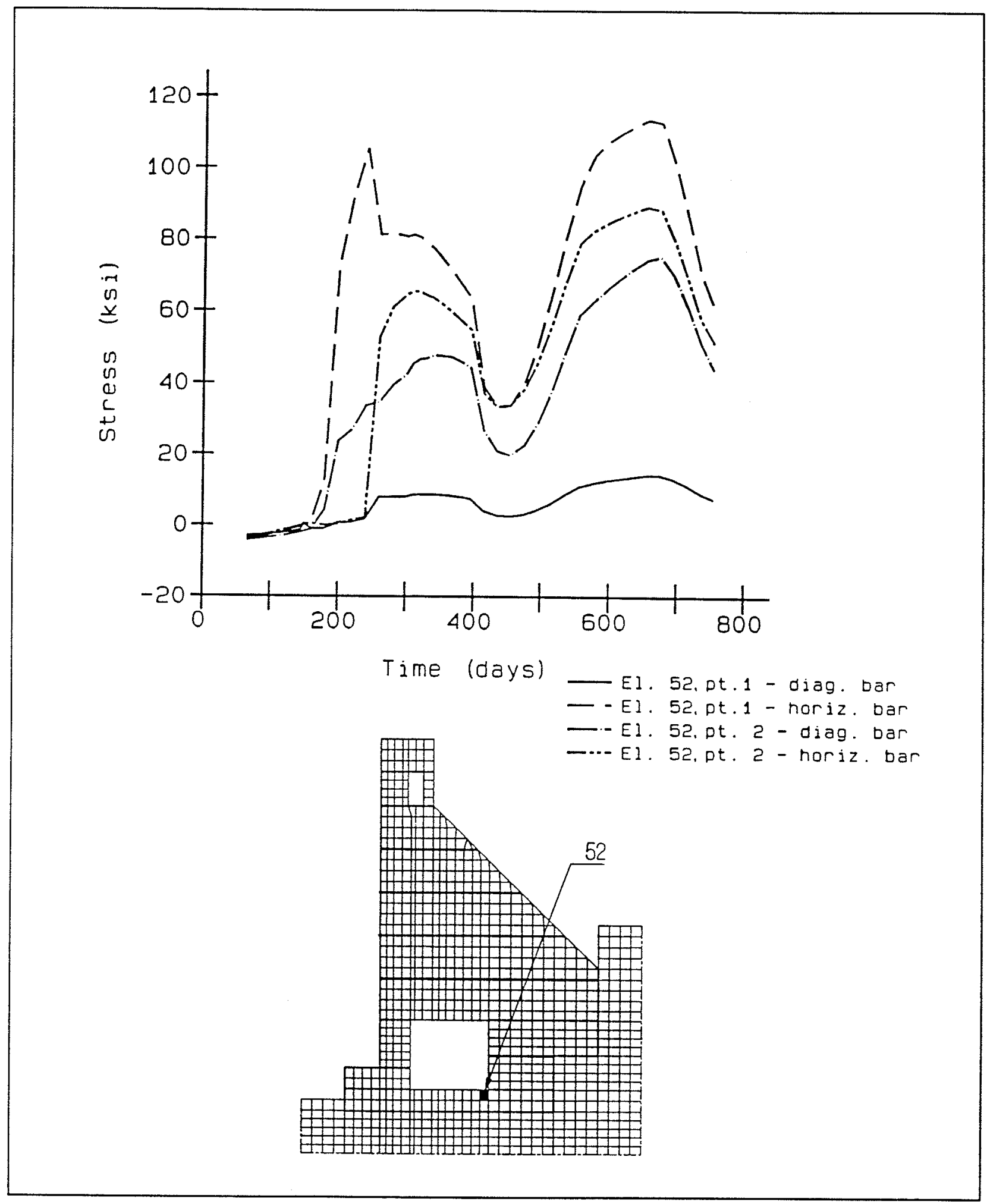

Figure 93 . Reinforcing stresses in element 52 of the extended analysis 


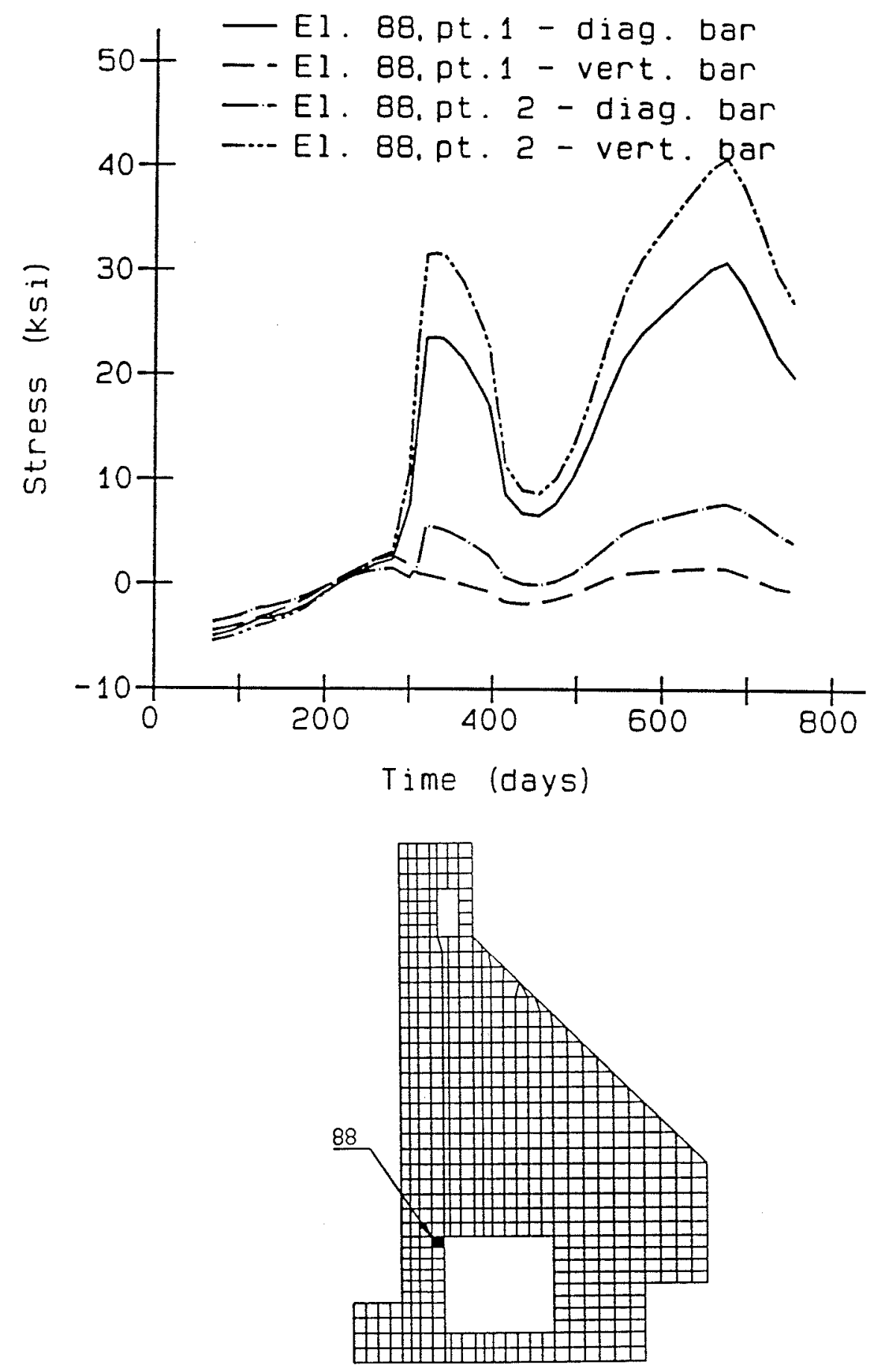

Figure 94. Reinforcing stresses in element 88 of the extended analysis 
Based on results from the NISA of the Olmsted Locks, a decision was made to use insulation with an insulating value of $\mathrm{R}=2 \mathrm{hr}-\mathrm{ft}^{2}-{ }^{\circ} \mathrm{F} / \mathrm{Btu}$ and to keep it in place for 45 days. These insulating values were included in the heat transfer analysis.

\section{Heat transfer analysis}

Starting construction in the winter has a significant effect on the temperatures reported in the heat transfer analysis as might be expected. The maximum temperature after the start of construction can be seen at day 58 in Figure $95\left(89^{\circ} \mathrm{F}\right)$. This is approximately $34^{\circ} \mathrm{F}$ below the maximum temperature seen in the summer start analysis, but most of this difference can be attributed to the placing temperature, which was $70^{\circ} \mathrm{F}$ for the summer start analysis and is $40^{\circ} \mathrm{F}$ for the winter start analysis. The effect of the insulation can also be seen in Figure 95. The insulation is still in place for the surfaces above the toe of the monolith and the insulation keeps the surface temperatures well into the $40^{\circ} \mathrm{F}$ range for the surface of the lock chamber while the toe of the monolith has cooled into the middle 20's. It can be seen by looking at this plot how the insulation reduces the gradient. If the insulation were not in place, a gradient of over $60^{\circ} \mathrm{F}$ would exist but with the insulation included it keeps the gradient to around $40^{\circ} \mathrm{F}$.

Figure 96 is a temperature contour at 73 days after the start of construction, very near the coldest point in the winter. Again, the removal of insulation can be seen to be up to the first lift above the culvert. It would appear that removal of the insulation after 45 days could be critical because as it is removed it increases the gradient by $15^{\circ} \mathrm{F}$ to $20^{\circ} \mathrm{F}$. This increase in gradient will not continue at the same rate, though, since the center of the mass will continue to cool and the ambient temperatures will begin to rise. In addition, thermal gradients of $60^{\circ} \mathrm{F}$ were observed in the extended analysis as well.

Figure 97 is during the summer (day 250) and so the temperatures on the exterior are higher than those at the interior. This plot is taken at approximately the same time as the plot in Figure 47 for the summer start analysis and as can be seen by comparing Figures 97 and 47, the plots are very similar. This would indicate that after 1 year, the effects of the heat of hydration have been dissipated. Figure 98 is taken at day 435 , which is very near the coldest day of the year in the second year of the analysis. Water is in place already for the plot presented in Figure 98 and once again the contours are very similar to those seen in Figure 61, which are the temperature contours for the same point in time for the summer start analysis. Figure 99 is taken at day 635 during the second summer and some steep gradients appear around the culvert, but since the surface is warm and the interior cool, these gradients should not be detrimental. Finally, Figure 100 is a plot taken at the end of the analysis (day 755).

Figures 101 through 106 are temperature time-histories taken at the sections presented in the previous analyses. As described for the extended analysis, for 


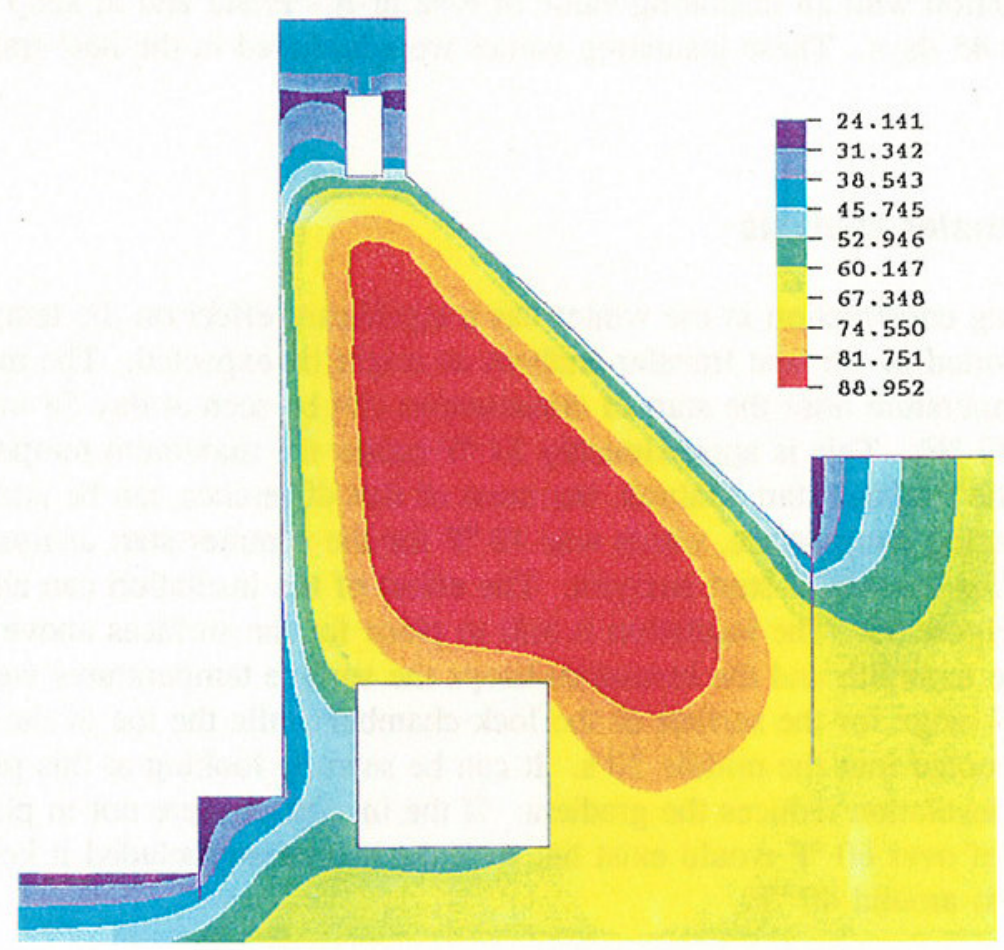

Figure 95. Temperature contour, 58 days after start of construction, winter analysis

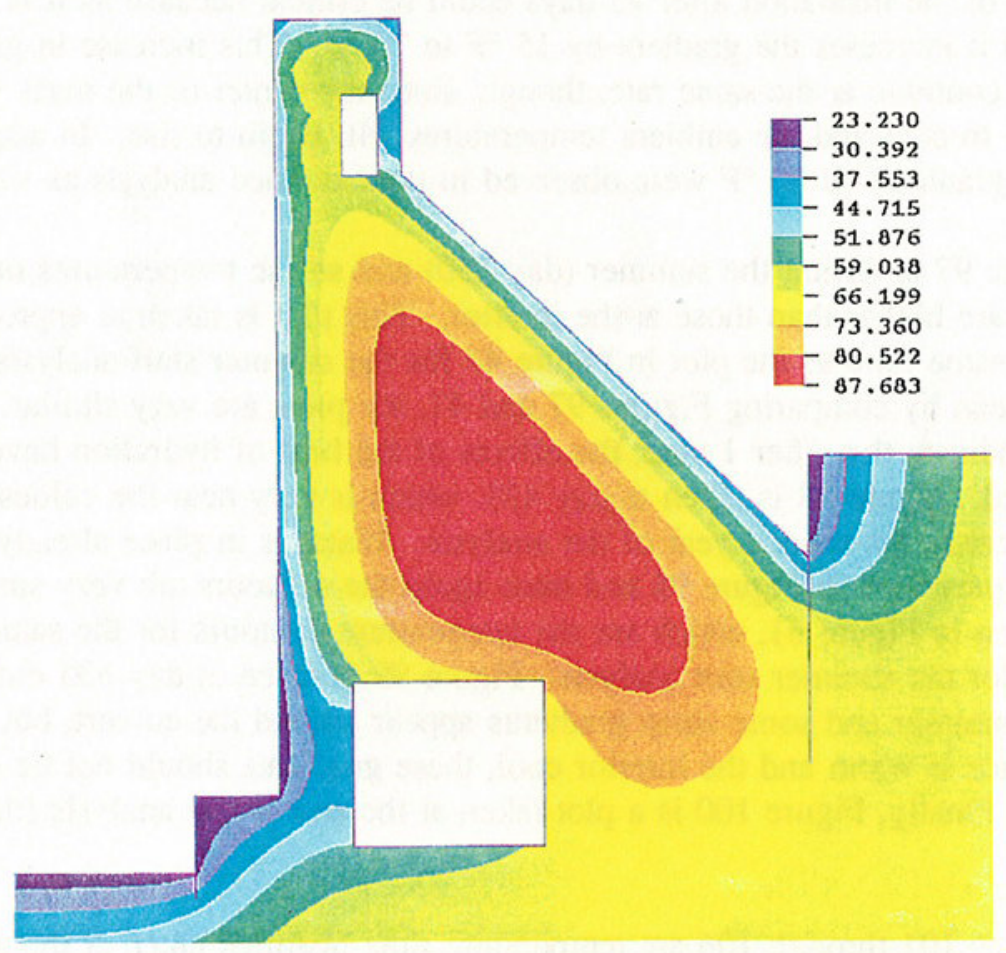

Figure 96. Temperature contour, 73 days after start of construction, winter analysis 


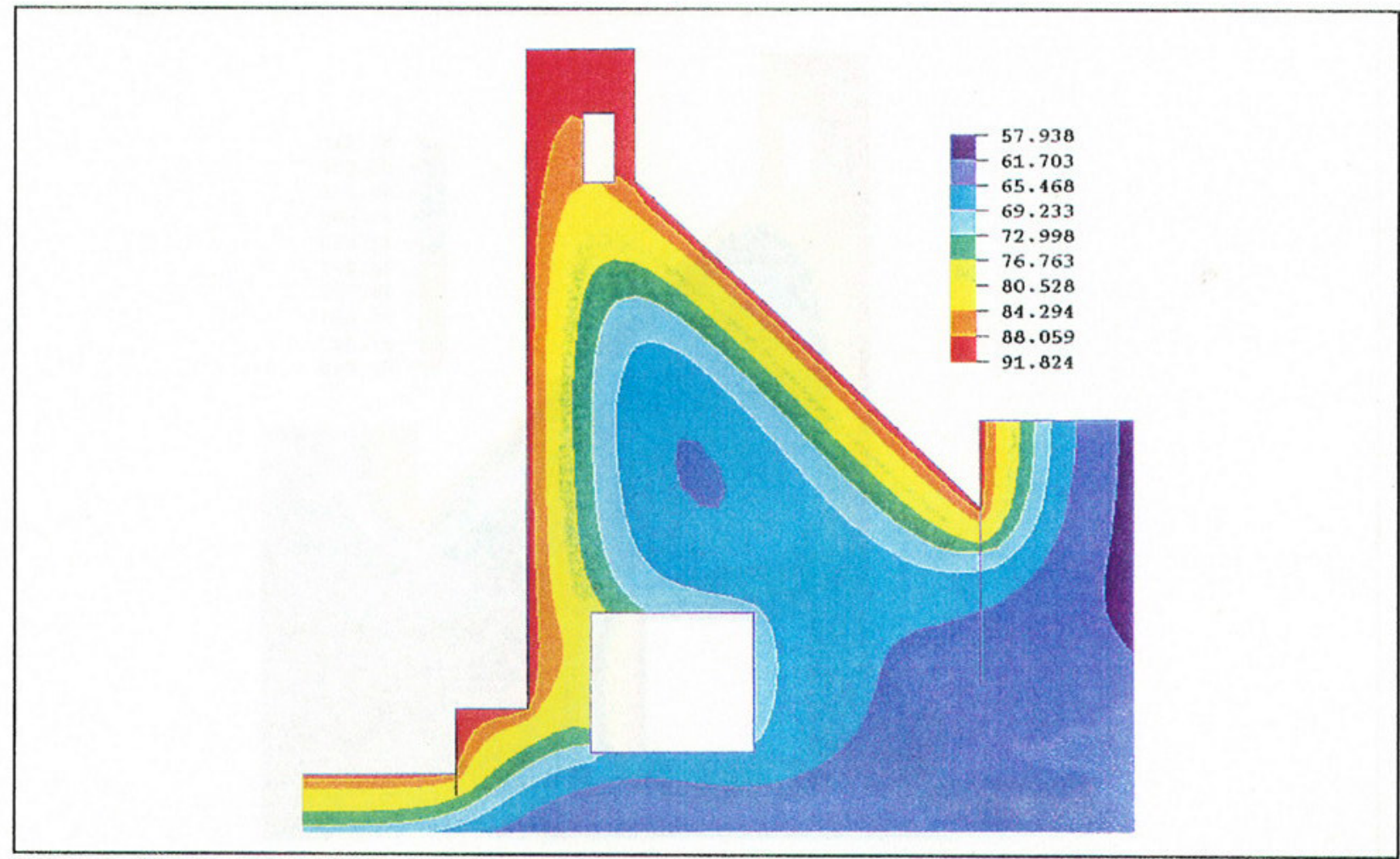

Figure 97. Temperature contour, 250 days after start of construction, winter analysis

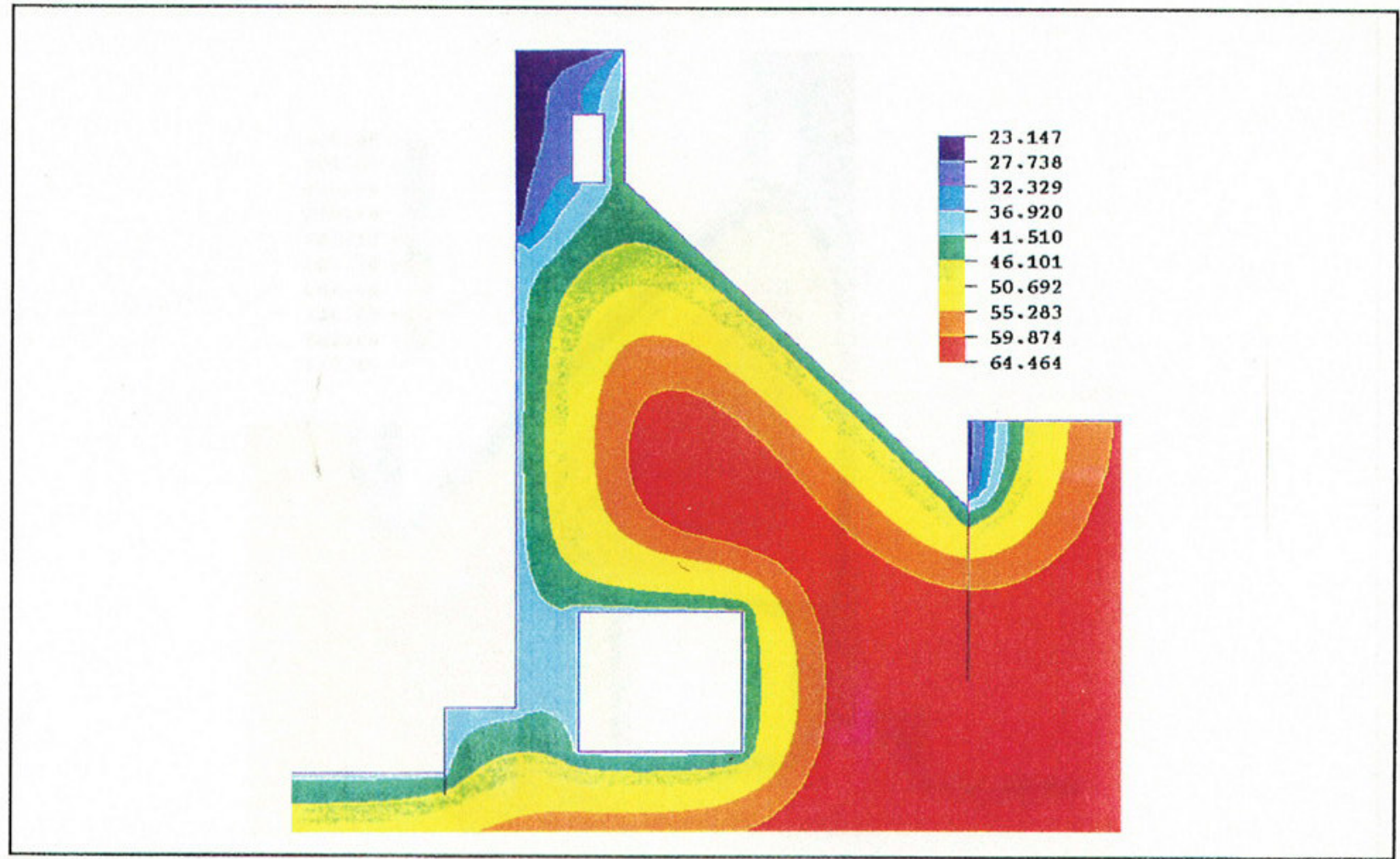

Figure 98. Temperature contour, 435 days after start of construction, winter analysis 


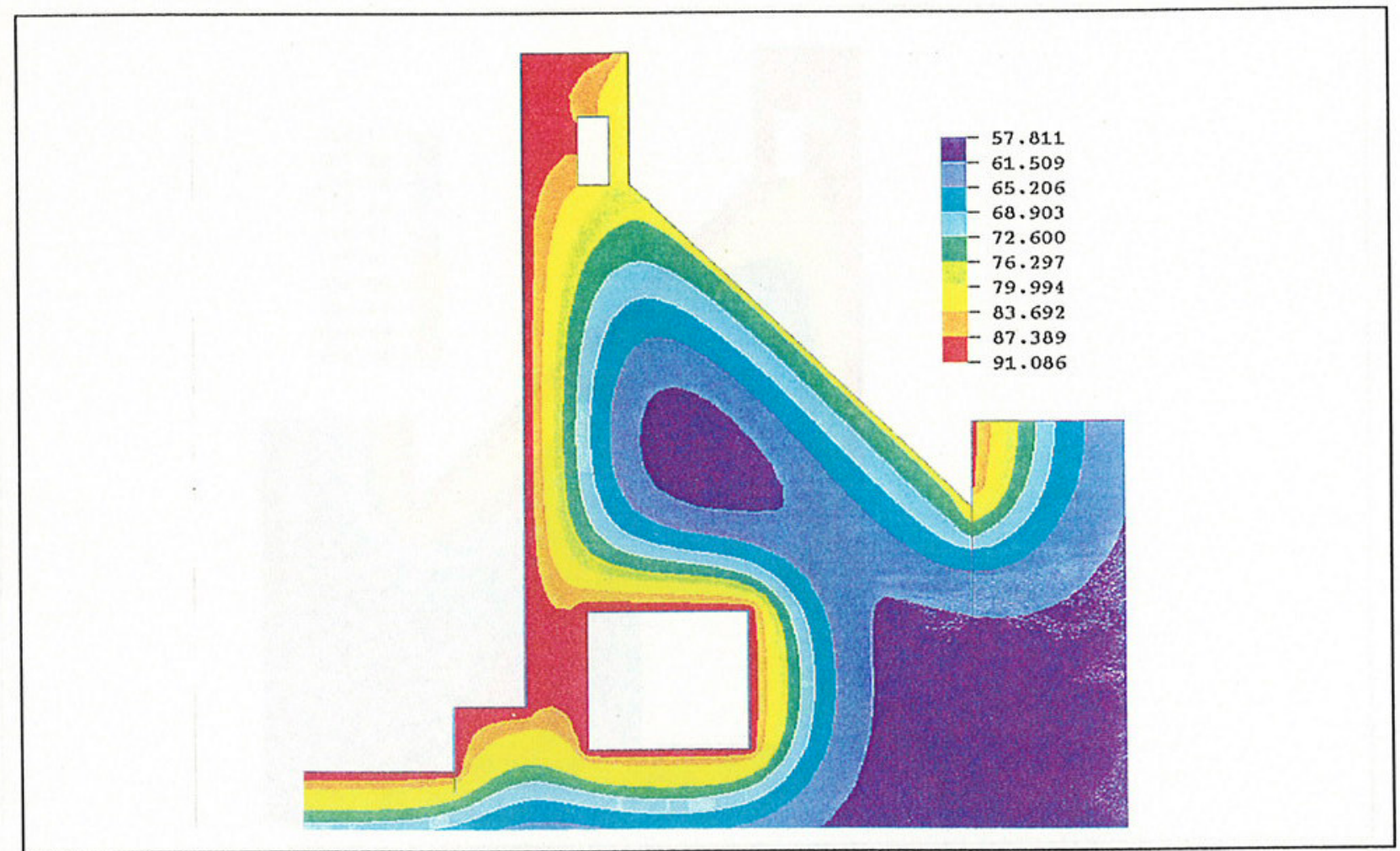

Figure 99. Temperature contour, 635 days after start of construction, winter analysis

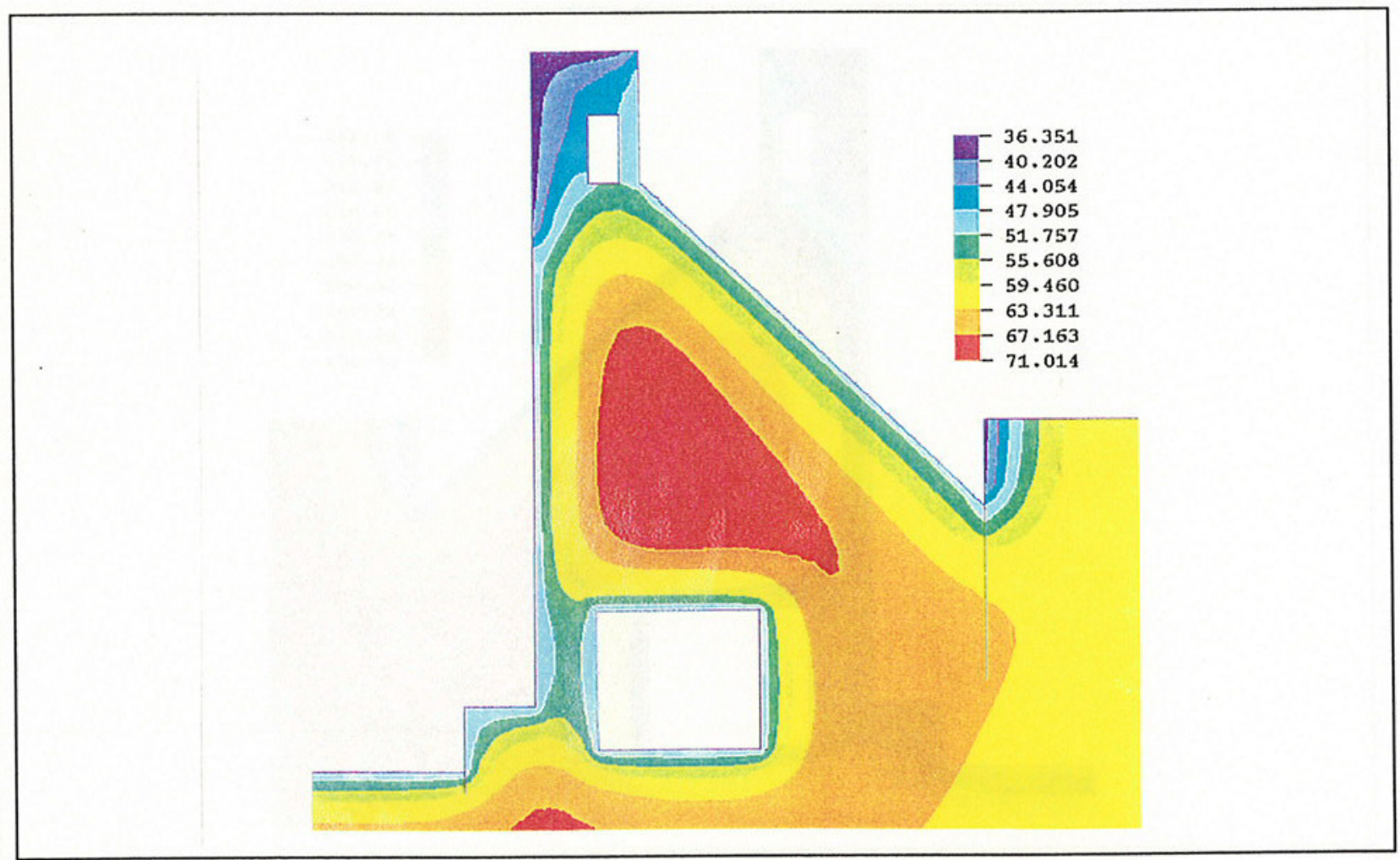

Figure 100. Temperature contour, 755 days after start of construction, winter analysis 

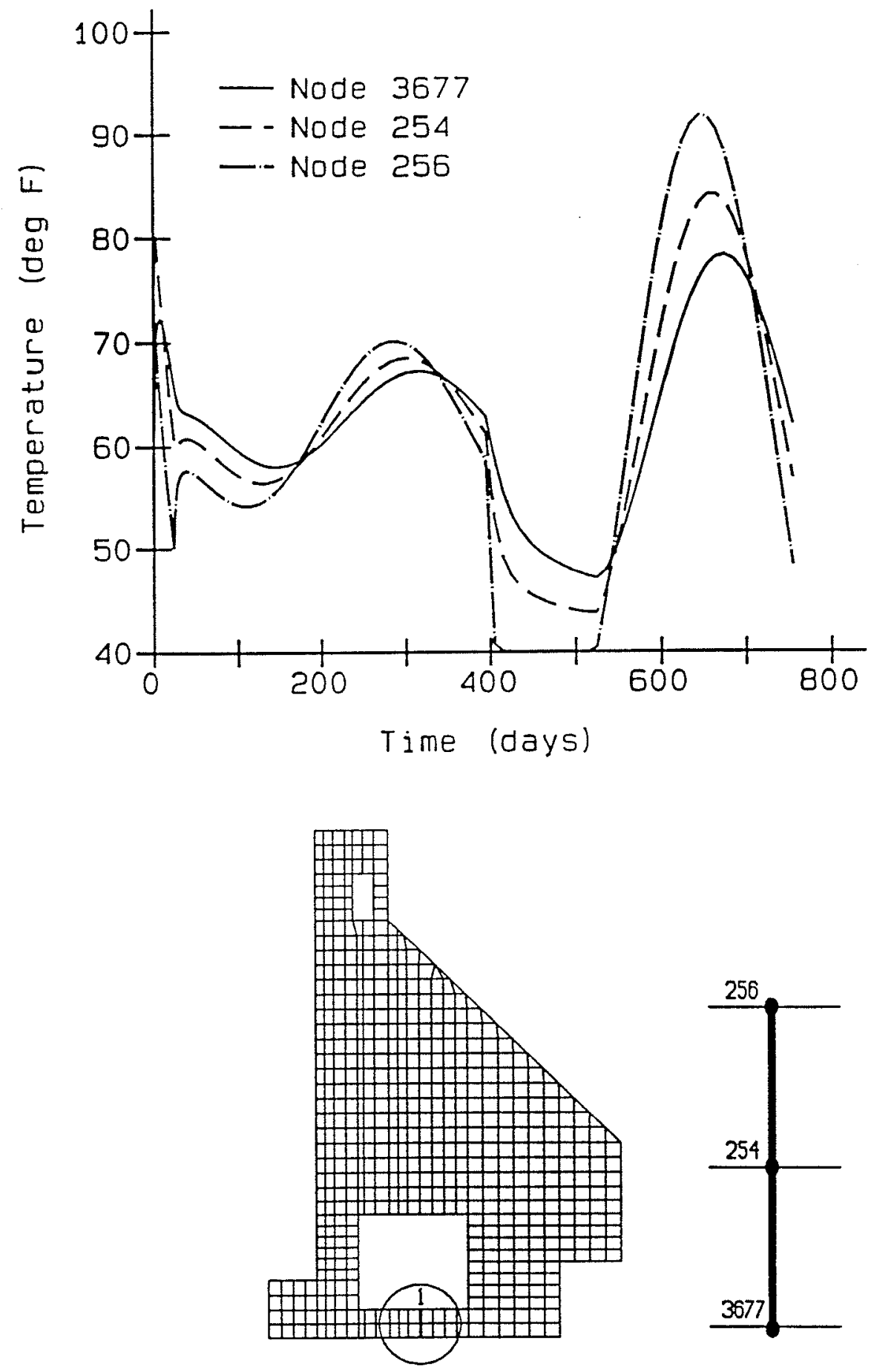

Figure 101. Temperature time-history at section 1 for winter analysis 

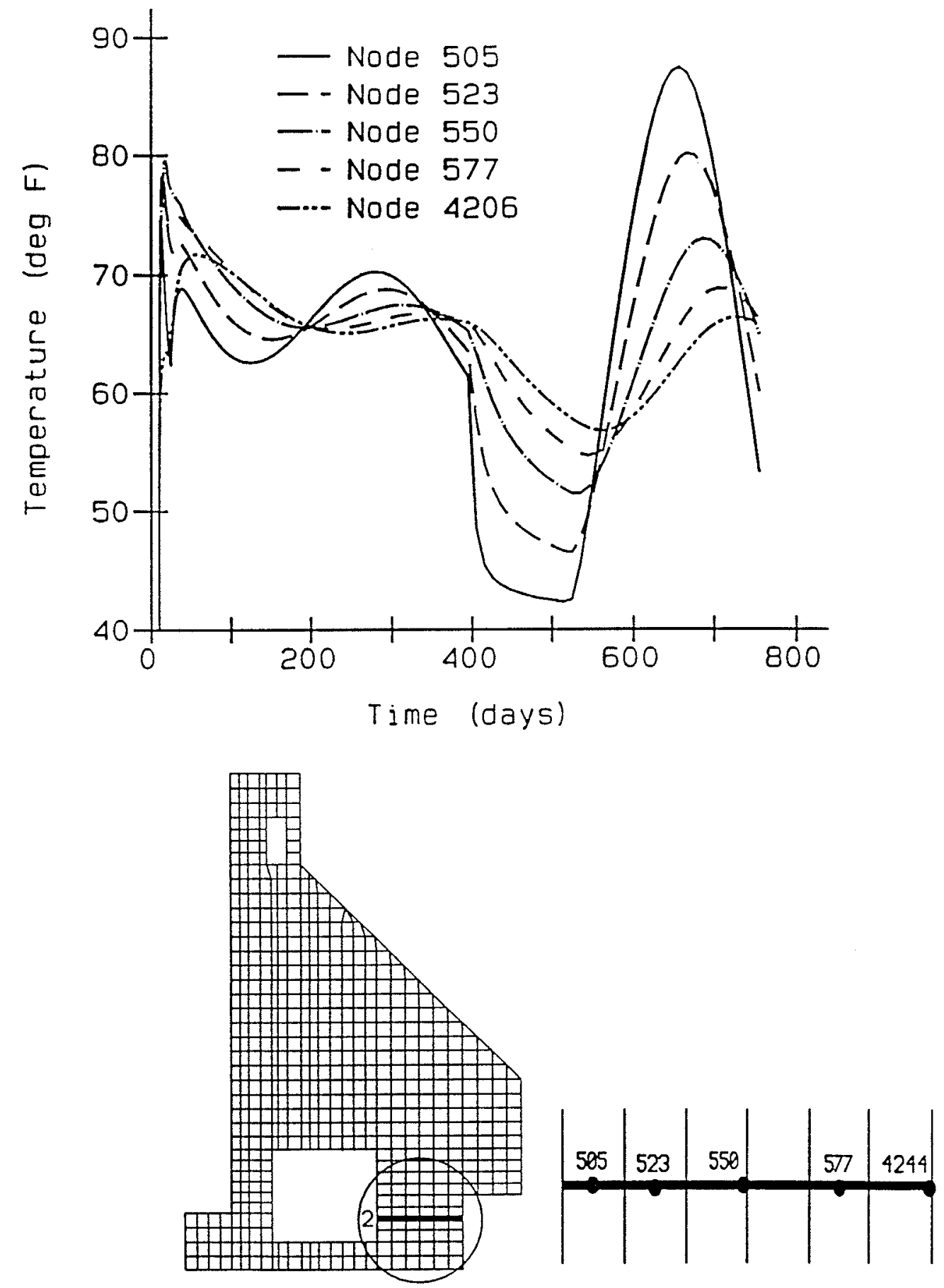

Figure 102. Temperature time-history at section 2 for winter analysis 


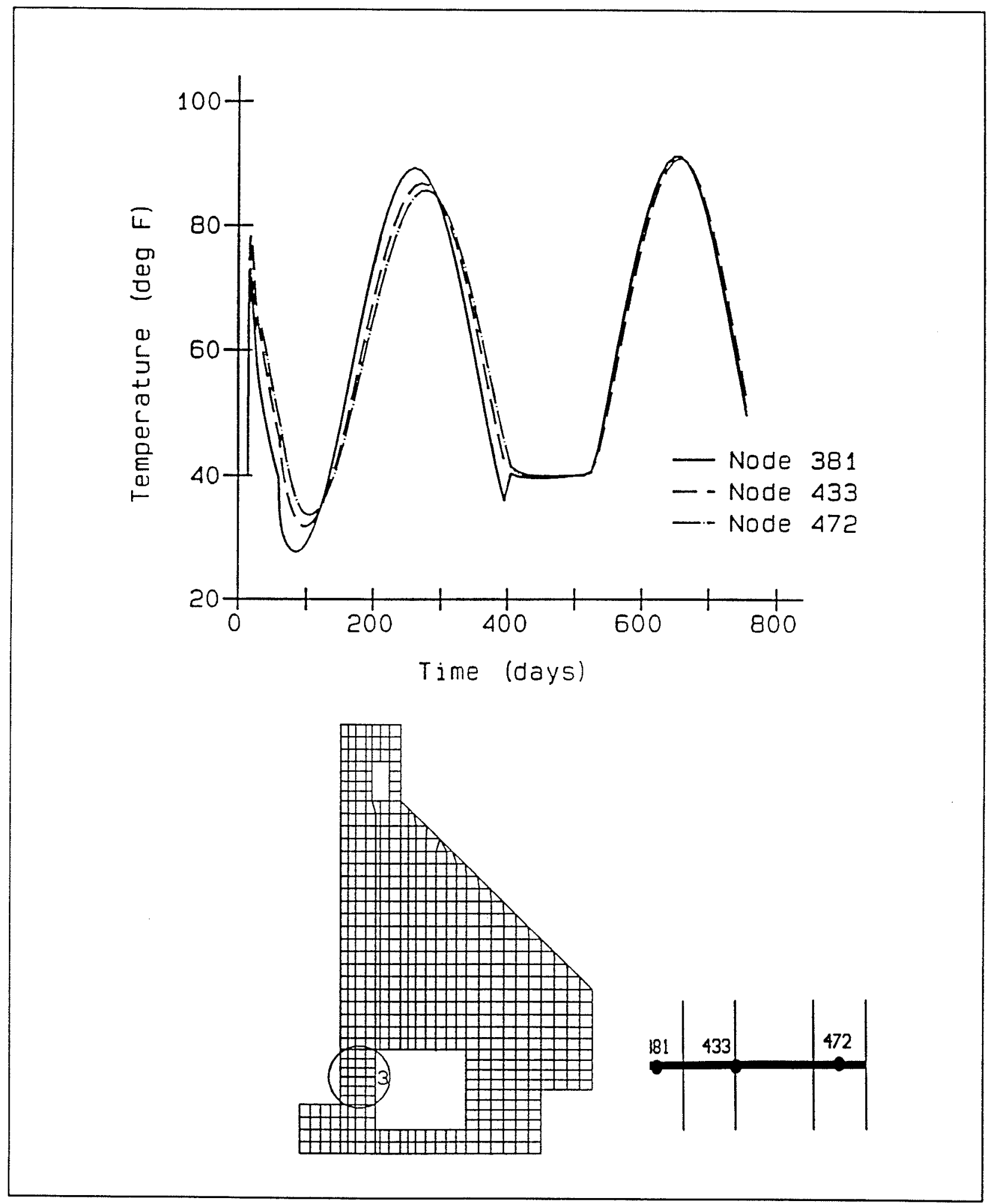

Figure 103. Temperature time-history at section 3 for winter analysis 

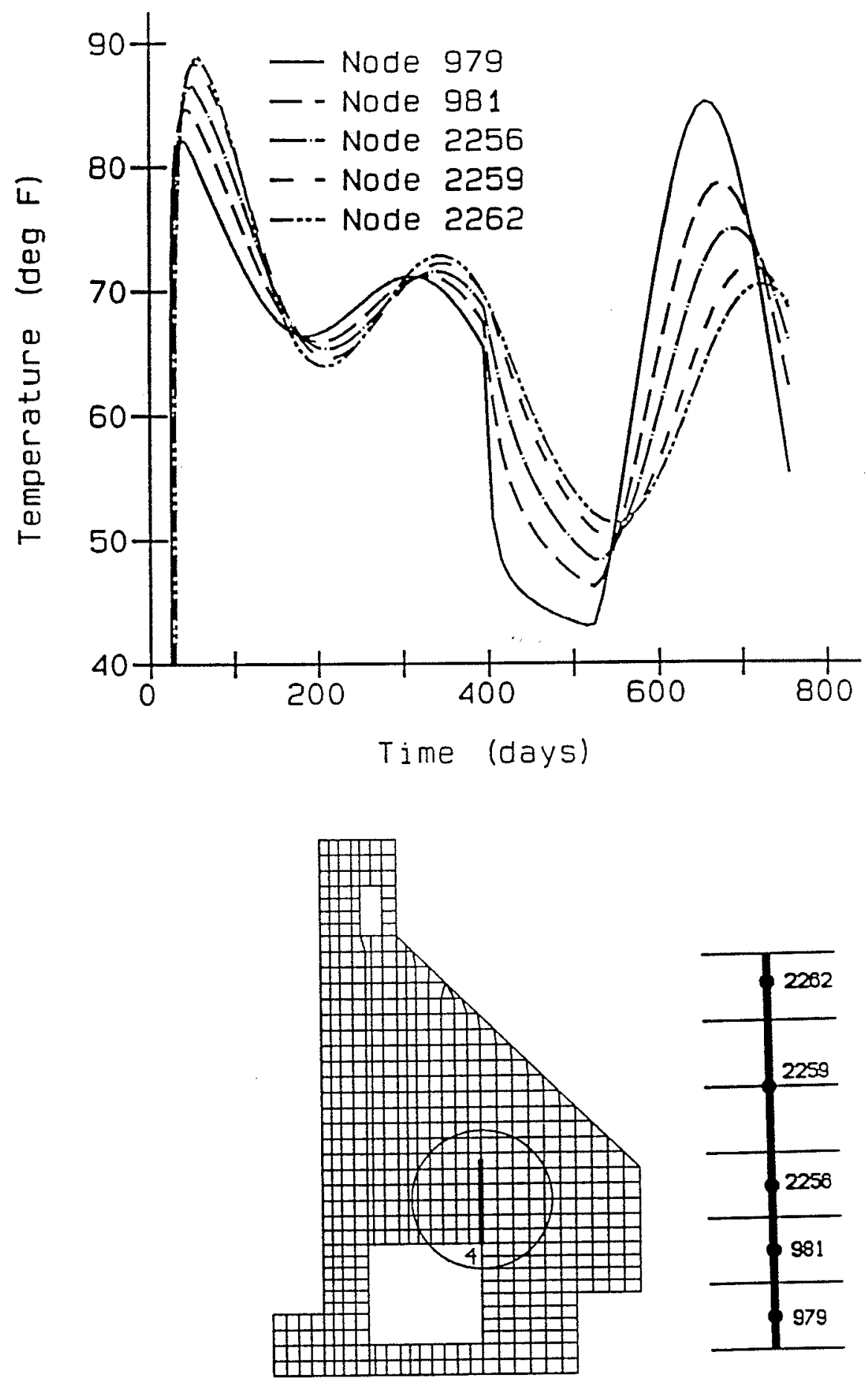

Figure 104. Temperature time-history at section 4 for winter analysis 

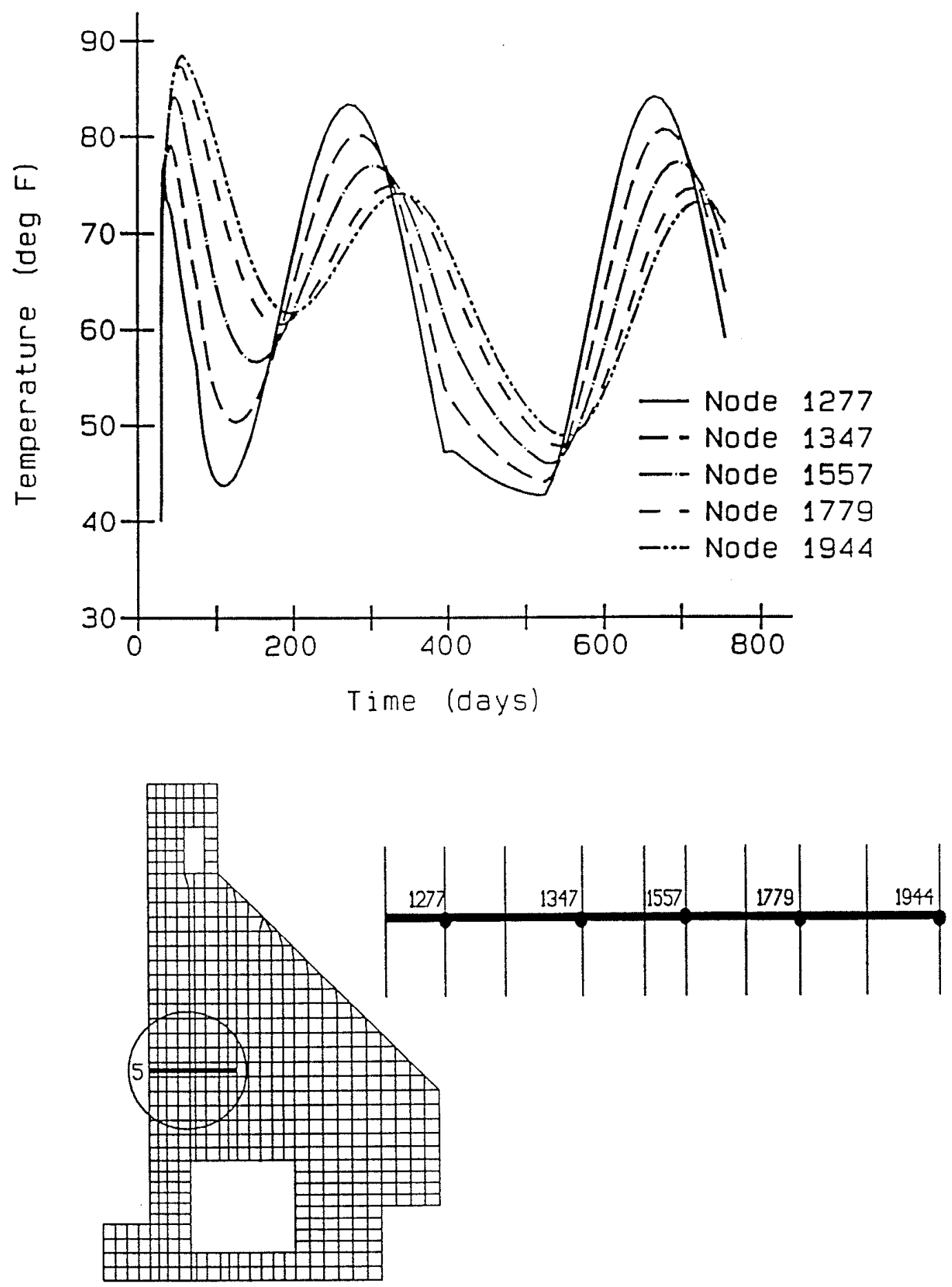

Figure 105. Temperature time-history at section 5 for winter analysis 

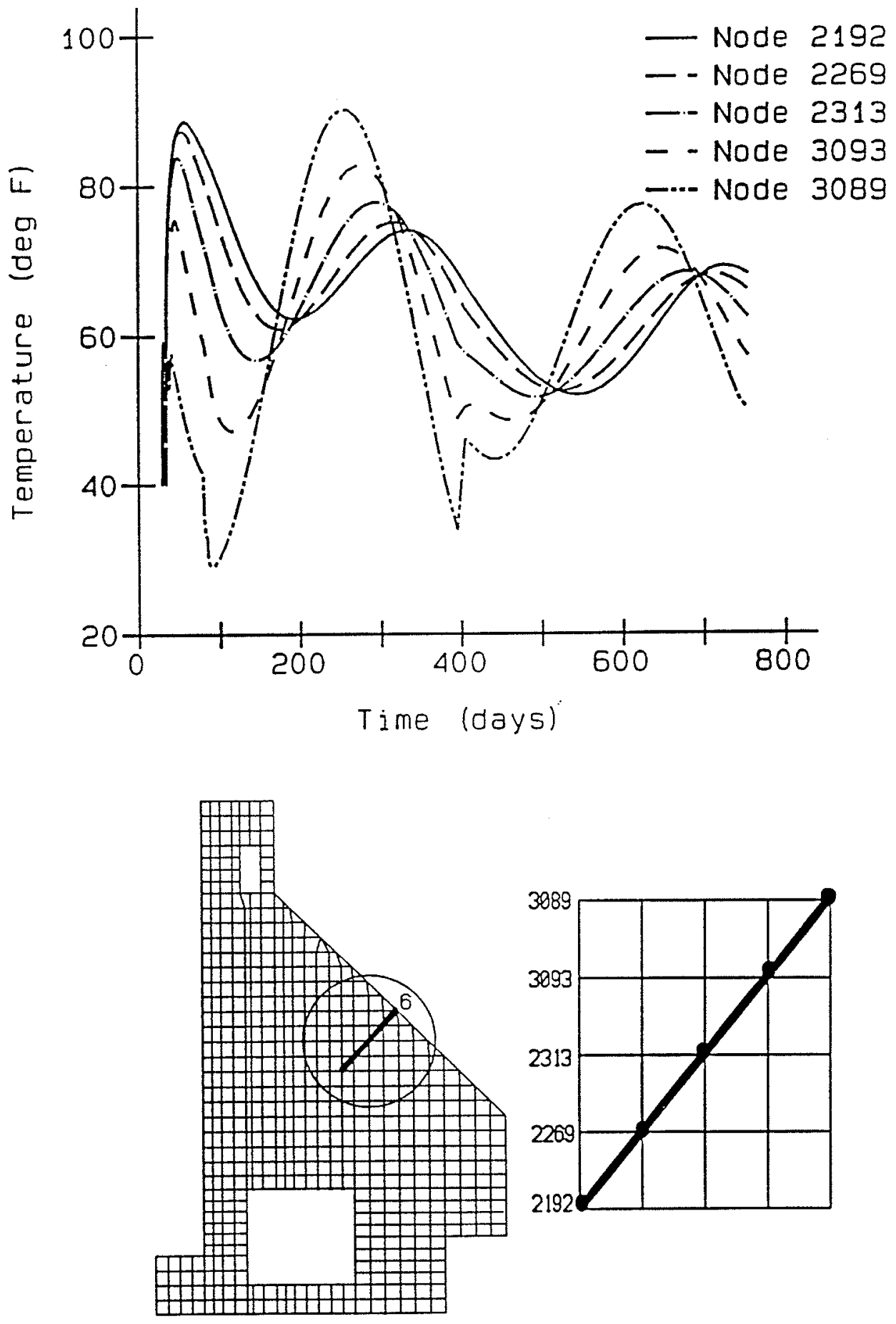

Figure 106. Temperature time-history at section 6 for winter analysis 
the sections that extend from the culvert, the gradients through these sections remained small due to the insulating effect of the closed culvert, but when water was introduced, the gradient was increased significantly for sections 1,2 , and 4 (Figures 101, 102, and 104, respectively). Because the wall that section 3 (Figure 103) was taken through was not extremely thick and was exposed to water on both sides, the gradient in section 3 was reduced with the introduction of water. The gradients seen in sections 5 and 6 (Figures 105 and 106 , respectively) showed a significant decrease in the gradient for the winter, which can be attributed to the fact that the water temperature does not go below $40^{\circ} \mathrm{F}$.

\section{Stress analysis}

Results from the stress analysis using the winter start showed that for the assumed insulation requirements ( $R=2$ and 45 days duration) this protection should be adequate if the monolith is constructed during the winter months. Predicted cracking is shown in Figures 107, 108, and 109. The initial cracking point is in the lower left-hand comer of the monolith and occurs at day 85 , but it never extends any further. Figure 107 is taken at day 460, which is well into the second winter of the analysis. In this plot, cracking occurs at both comers of the culvert. Figure 108, taken at day 520, shows how the crack below the culvert extends through the base of the monolith but the crack above the culvert has not extended any. Figure 109 shows cracking at day 580 and all cracking in the analysis has occurred by this point in time. A total of 10 integration points cracked in the winter analysis, which is a vast improvement over the analyses with summer starts.

In addition to the cracking being much less, the stresses in the reinforcing at the crack locations are much smaller as well and as might be expected. Stresses in the reinforcing at the crack below the culvert are shown in Figure 110 and, as can be seen, the maximum stress doesn't even reach $40 \mathrm{ksi}$, which is well below the yield strength of the reinforcing. Figure 111 shows the reinforcing stresses at the crack above the culvert and, as can be seen, they are very minimal.

Figures 112 through 121 are contour stress plots at various points in time in the analysis and include shear stresses, horizontal stresses, and vertical stresses. In general, the stresses are lower than was seen in the extended analysis except for some isolated cases such as the horizontal stress below the culvert at day 440 (Figure 117), which is just prior to cracking. The stress reaches a maximum value of $740 \mathrm{psi}$, but it should be noted that at the time shown, stresses are low everywhere else in the structure.

An interesting plot is Figure 113, which is the shear stresses at day 245. The shear is building to a fairly high tensile value on the landside face of the monolith which can be attributed to the large mass above the culvert heating up and expanding due to ambient conditions. Also seen in Figure 113 are some high shear stresses at the lower left-hand comer of the culvert. Both of 


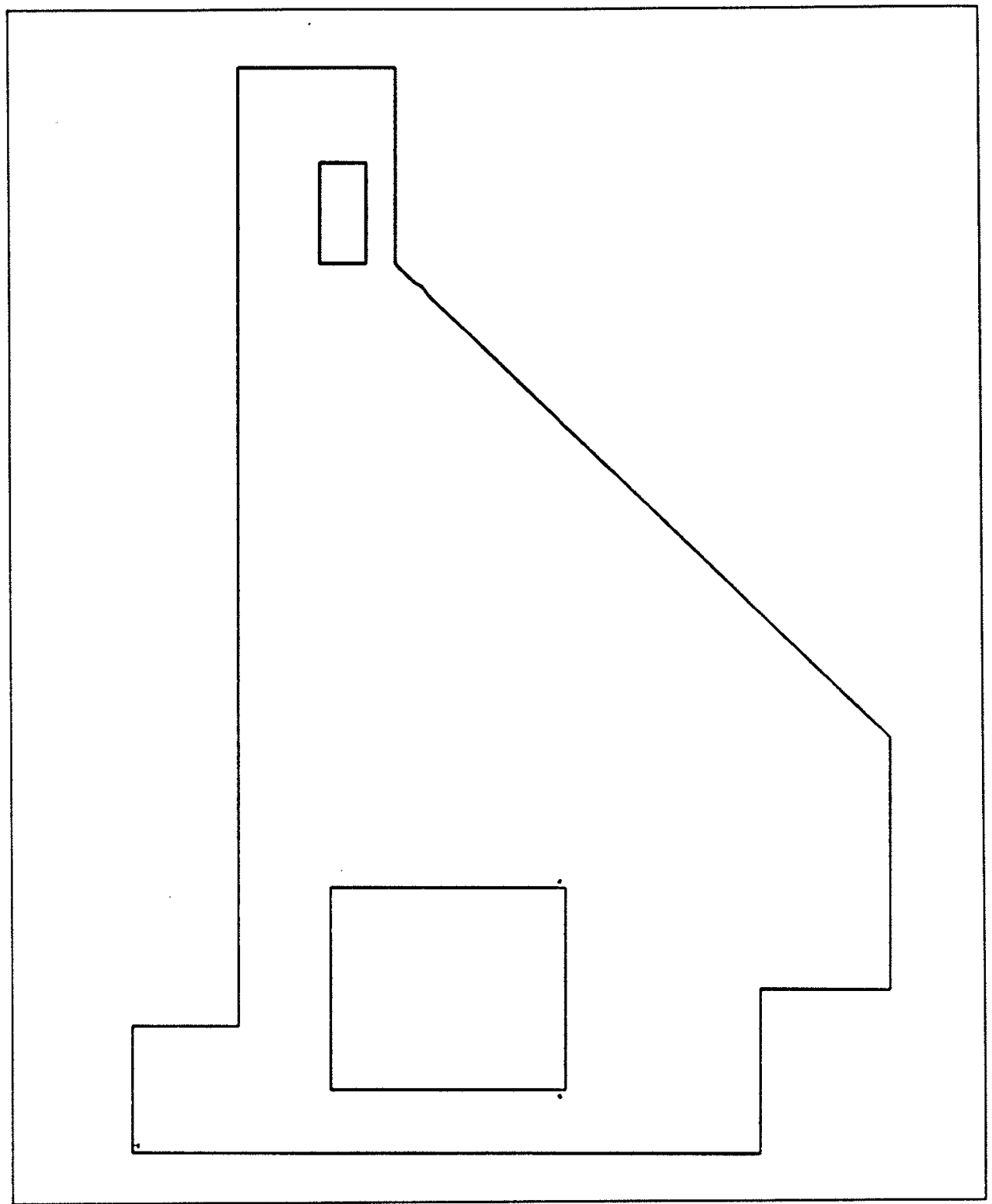

Figure 107. Cracking predicted at day 460 of the winter analysis

these shear stress buildups can be seen occurring in the second year in Figure 115 as well, which is a shear stress plot at day 600 . Figure 120 shows the vertical stresses at day 440 and a small contribution of vertical tensile stress can be seen in the lower right-hand comer of the culvert where the only significant crack in the winter analysis occurs. Also seen in this plot is the bending behavior of the wall between the culvert and the chamber, which was seen so clearly in the extended analysis results. The behavior in Figure 120 is the same, but the magnitude of the stresses is much smaller.

Finally, Figures 122 and 123 are deflected shapes of the monolith at days 380 and 460 , respectively. Comparing the deflections in the base of these two 


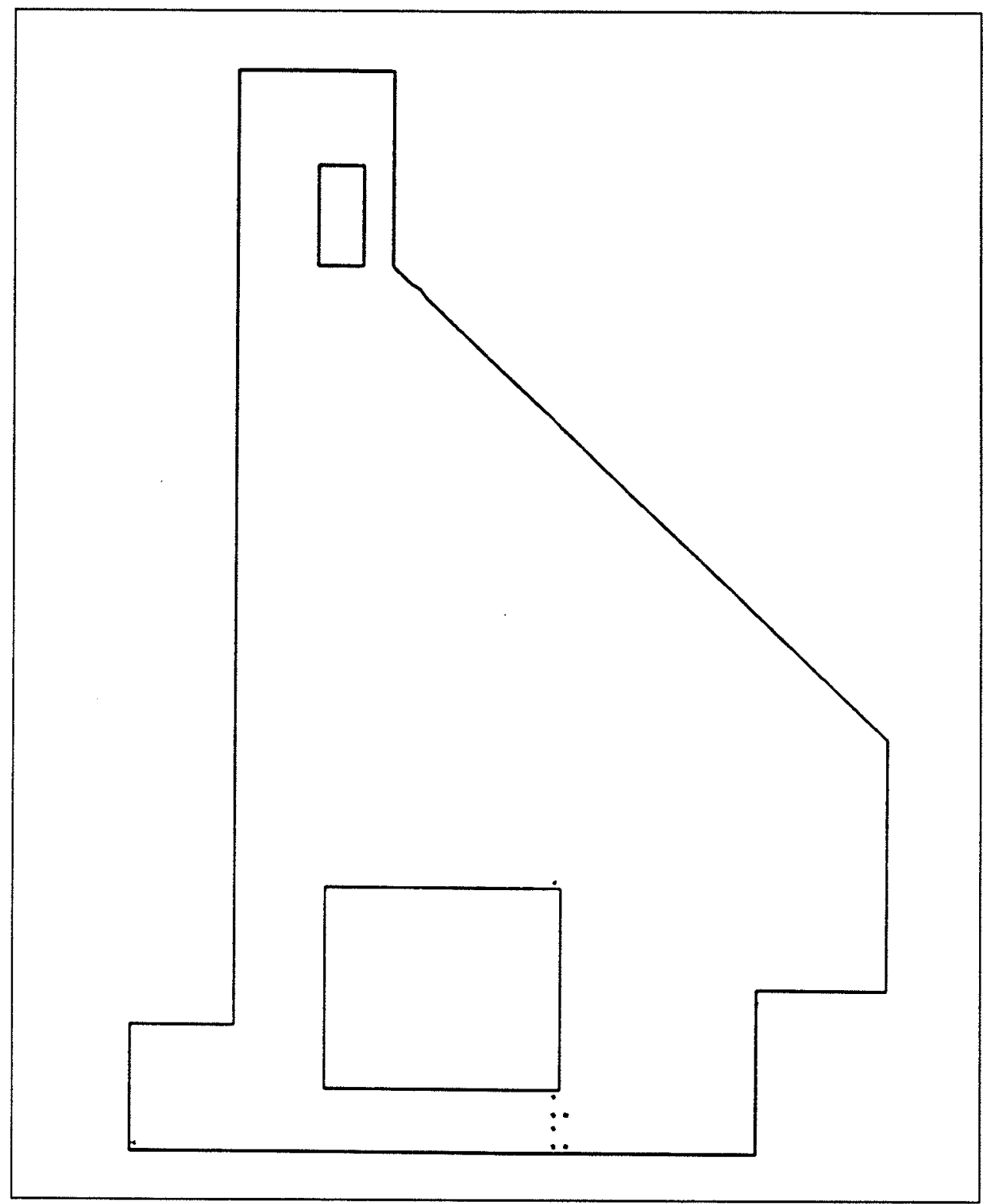

Figure 108. Cracking predicted at day 520 of the winter analysis

plots, it can be seen how the base of the monolith is contracting in the horizontal direction. This contraction is being restrained by the vertical face of the rock to the right of the culvert and by the rock beneath the base of the monolith which leads to the buildup of stresses seen in Figure 117 and eventually the cracking seen in Figures 107, 108, and 109.

\section{Final Analysis}

The final analysis of the chamber monolith was performed to include the addition of gap elements on the vertical rock/concrete interface next to the 


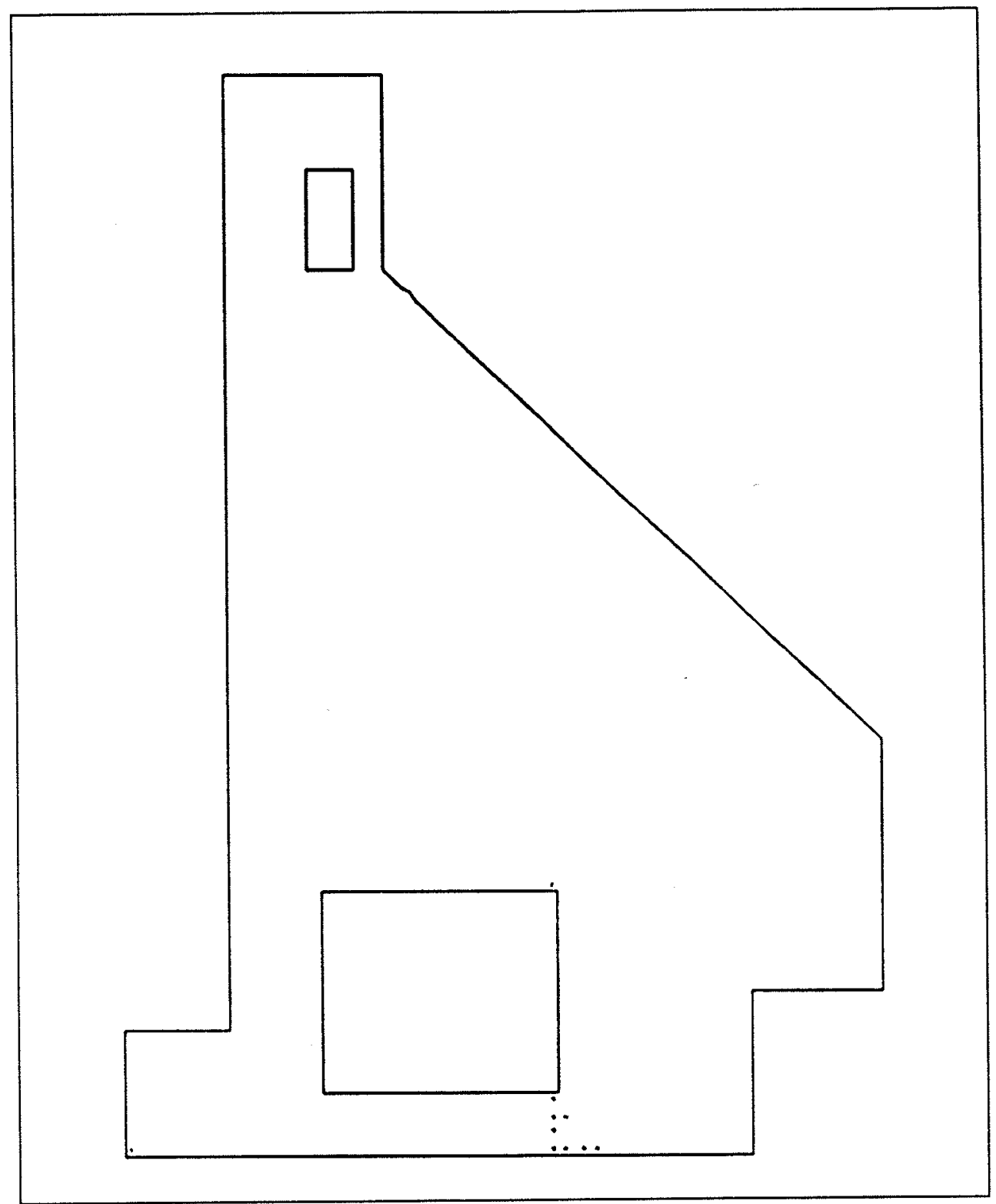

Figure 109. Cracking predicted at day 580 of the winter analysis

landside of the culvert (gap No. 3 in Figure 20b), change the reinforcement in the base of the monolith to No. 11 bars, and revise the water temperature amplitude curve. The gap element was added and the reinforcing was changed in anticipation that this would reduce the stress in the reinforcement where the cracking was occurring at the lower right-hand comer of the culvert. The water temperature was changed because it was felt that the extreme ambient curve computed for the McAlpine NISA was too severe. The final analysis was performed to confirm that the changes would improve the behavior as expected and the results of this analysis are presented below. 

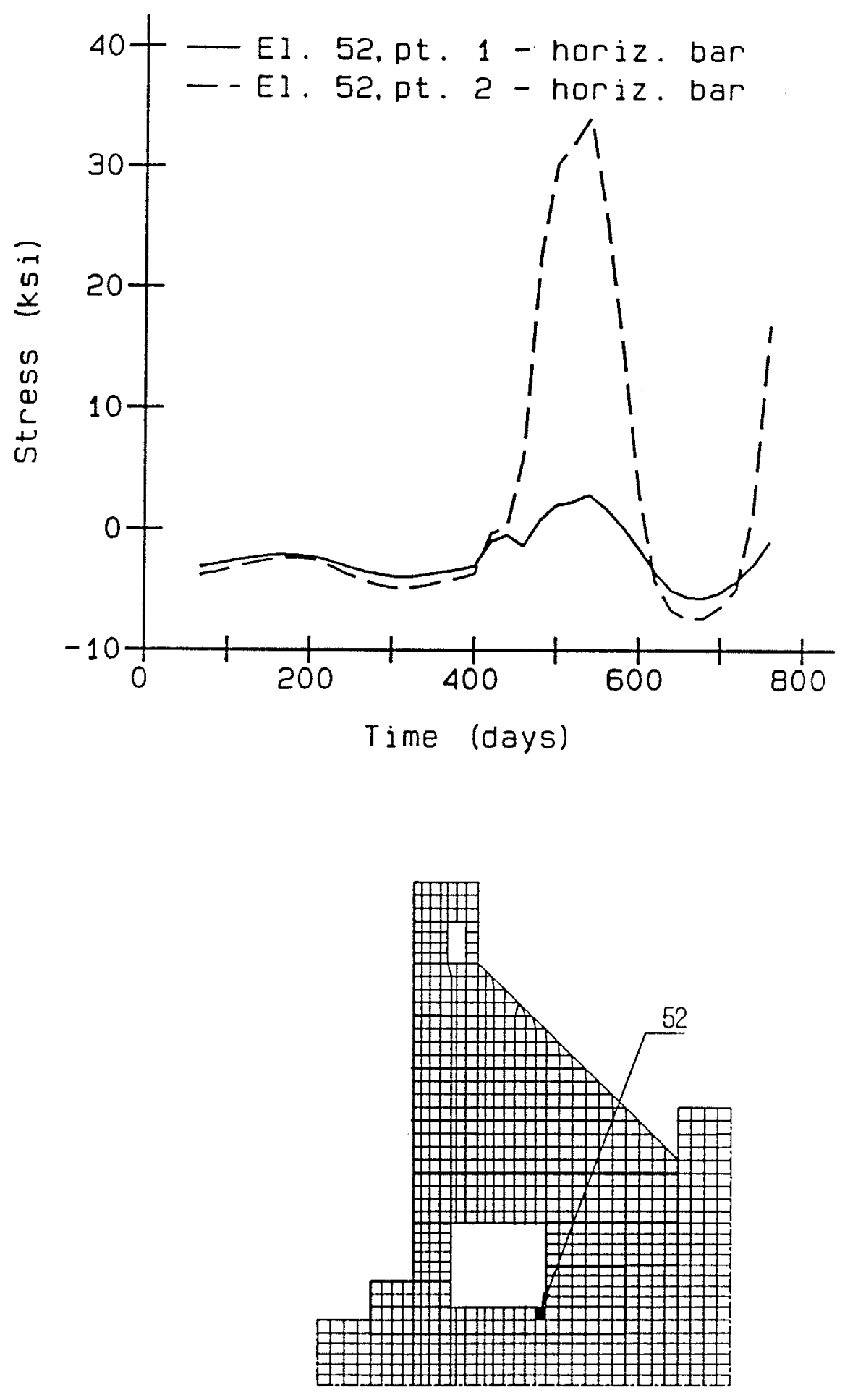

Figure 110. Reinforcing stresses in element 52 of the winter analysis 

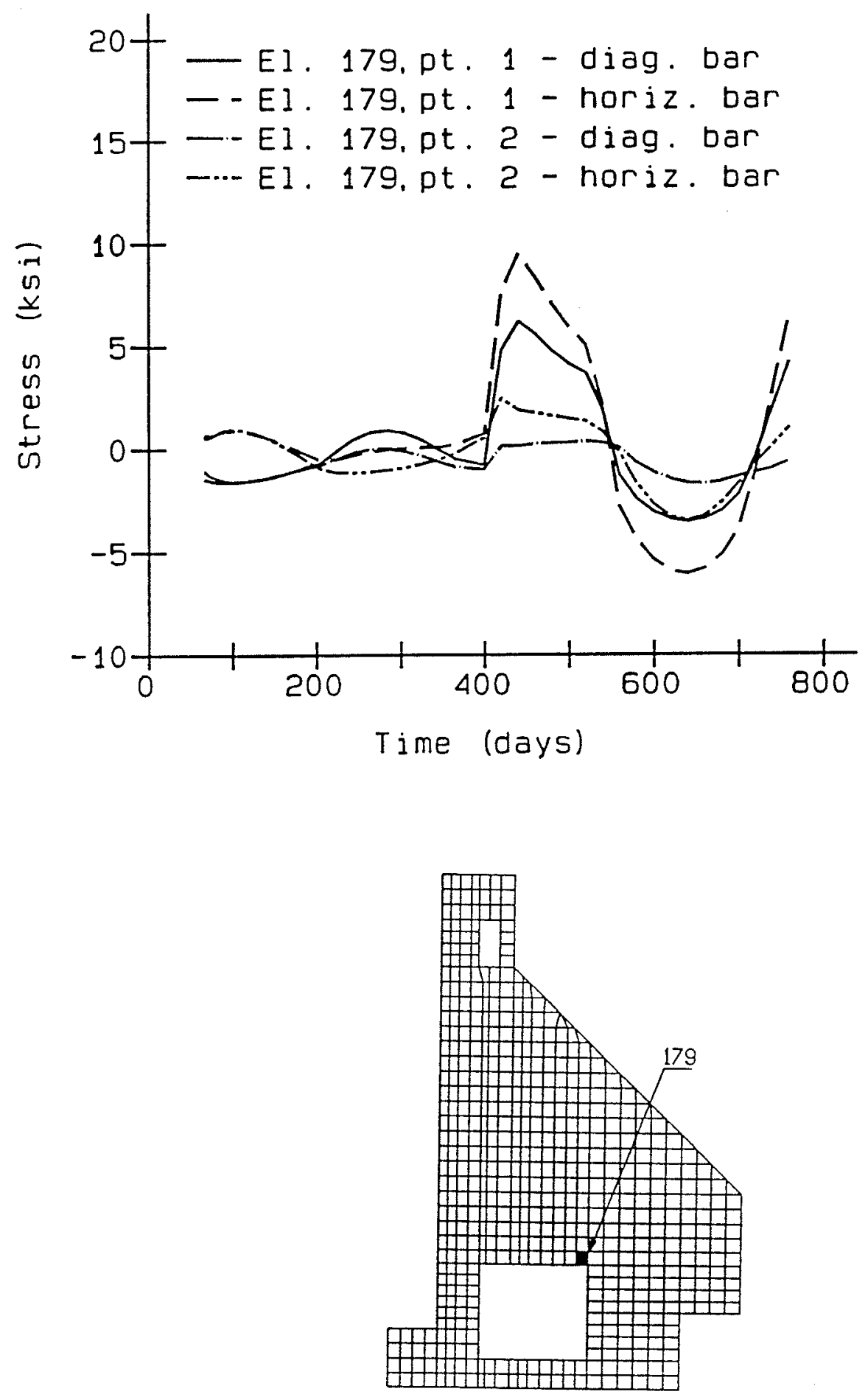

Figure 111. Reinforcing stresses in element 179 of the winter analysis 


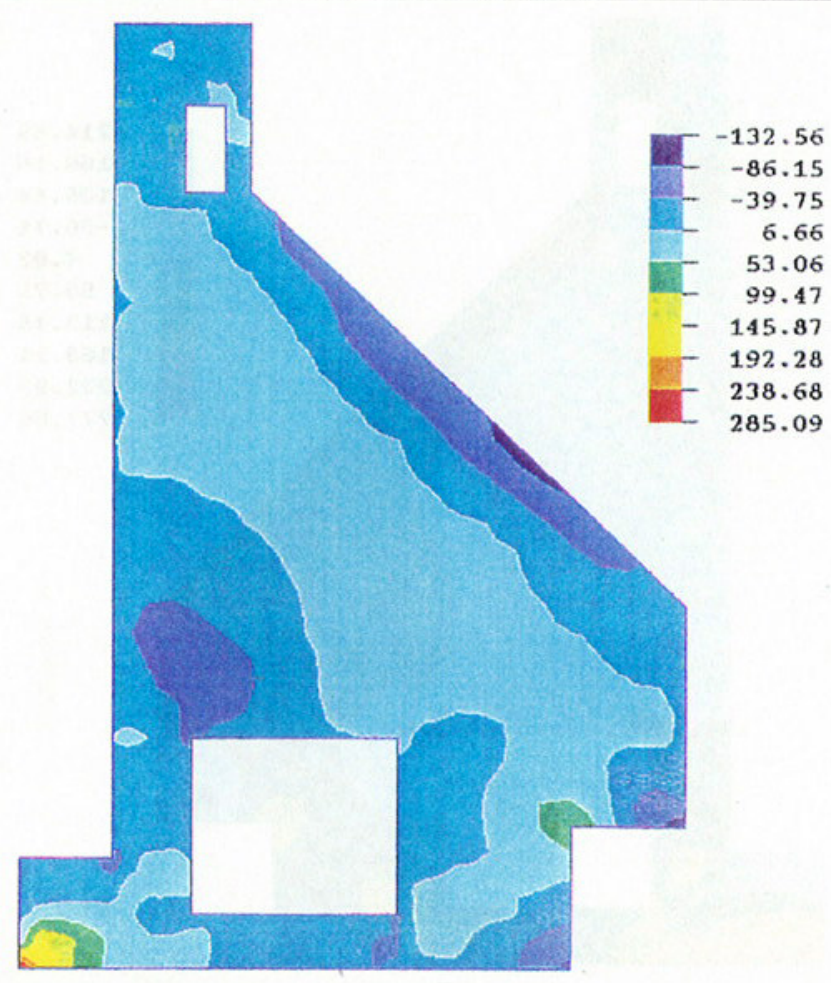

Figure 112. Shear stress contour at day 83 of the winter analysis

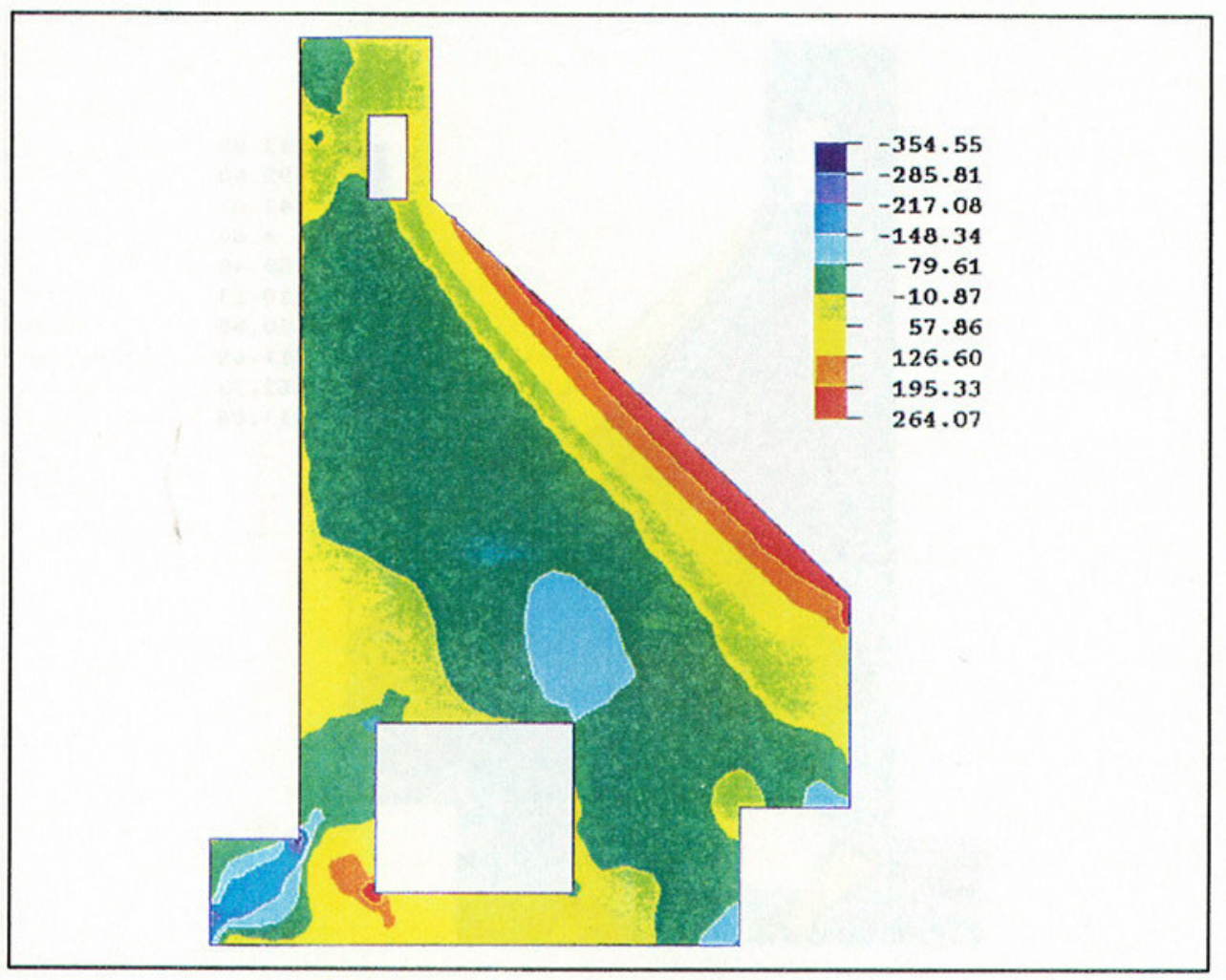

Figure 113. Shear stress contour at day 245 of the winter analysis 


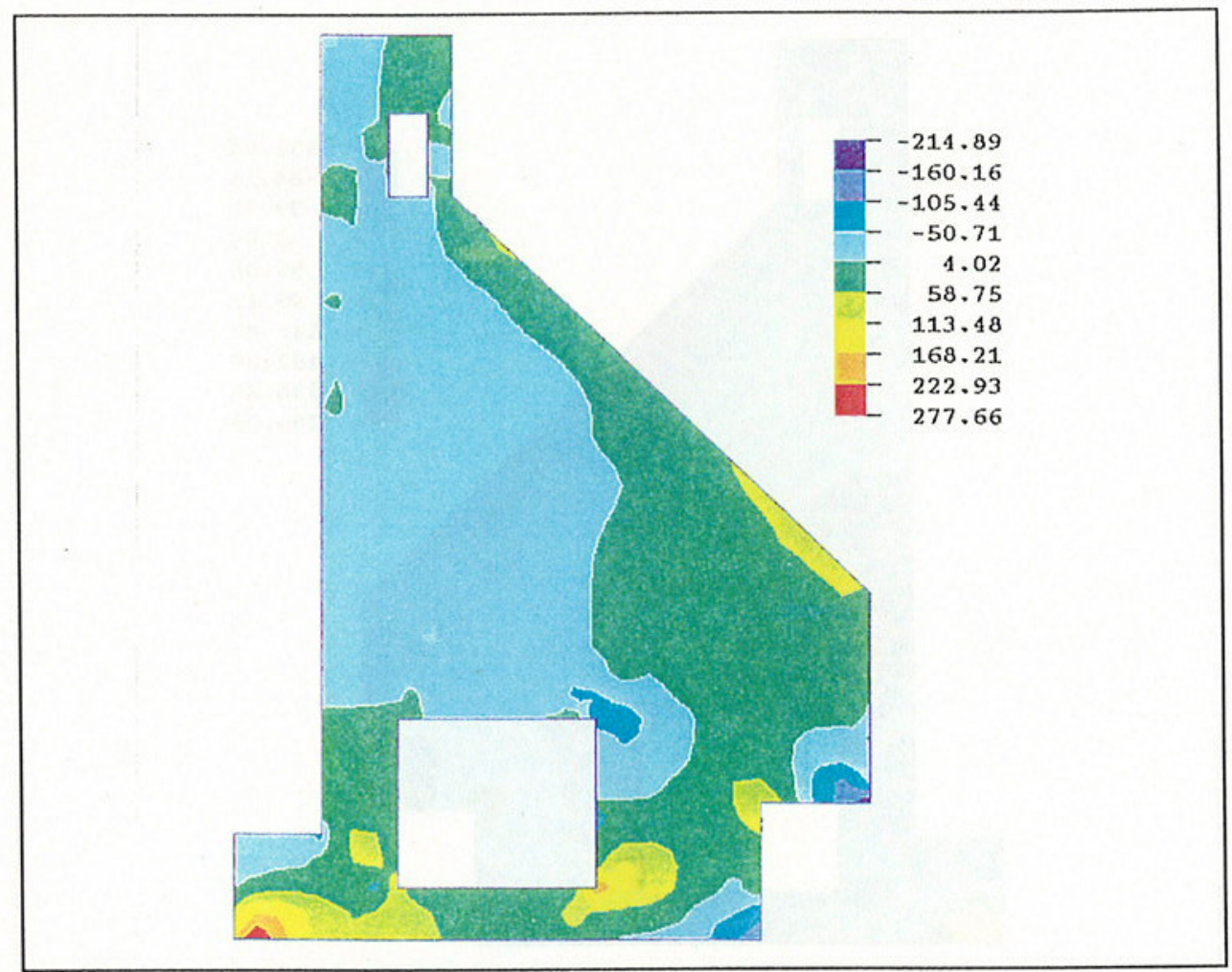

Figure 114. Shear stress contour at day 440 of the winter analysis

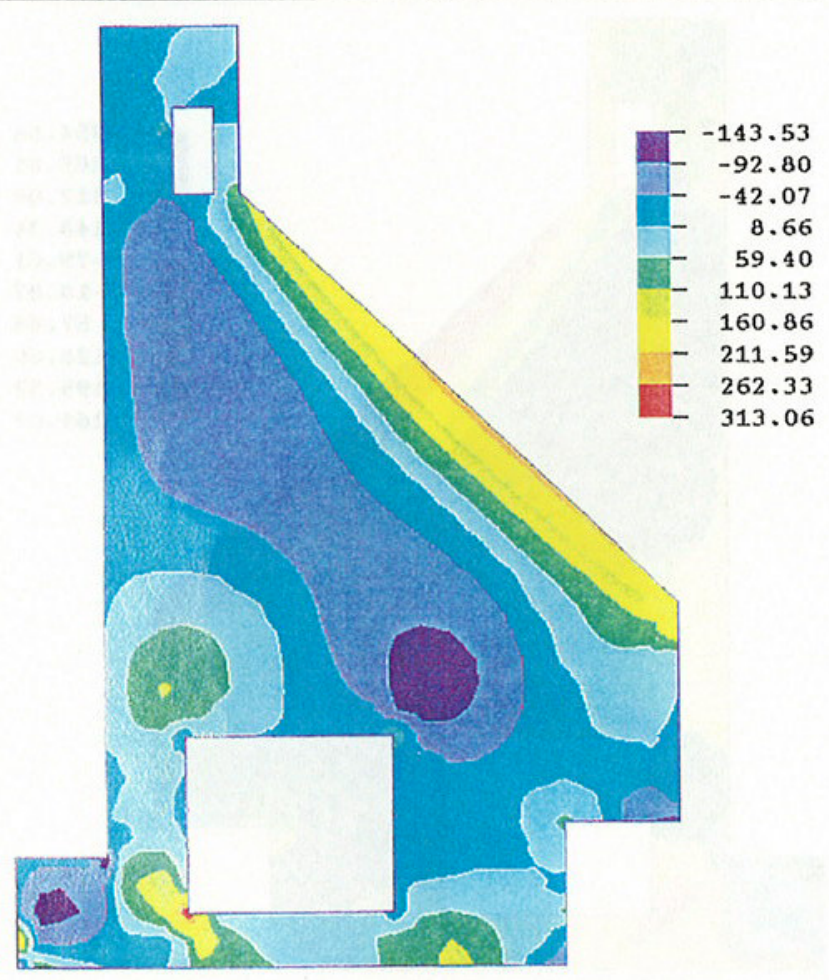

Figure 115. Shear stress contour at day 600 of the winter analysis 


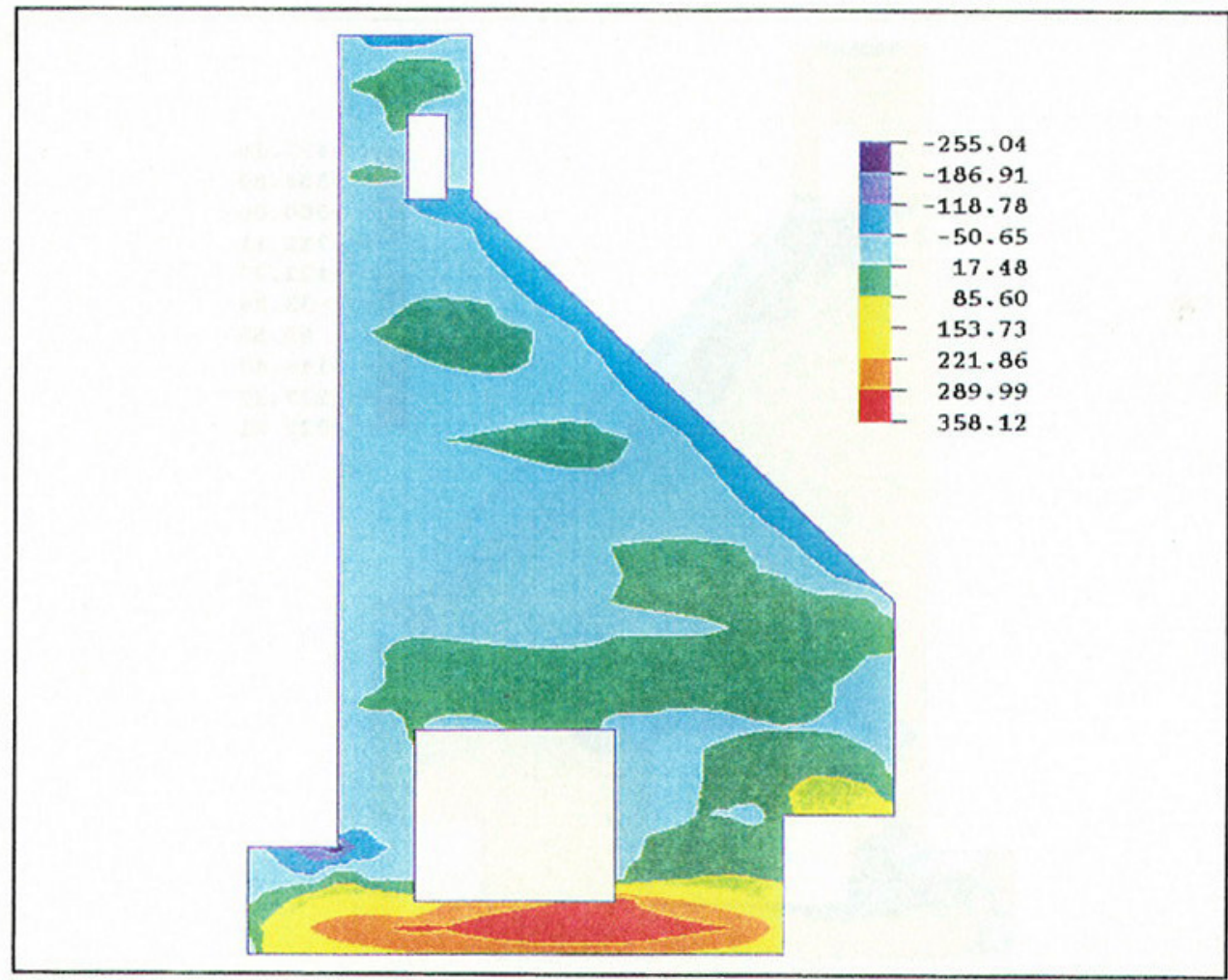

Figure 116. Horizontal stress contour at day 160 of the winter analysis

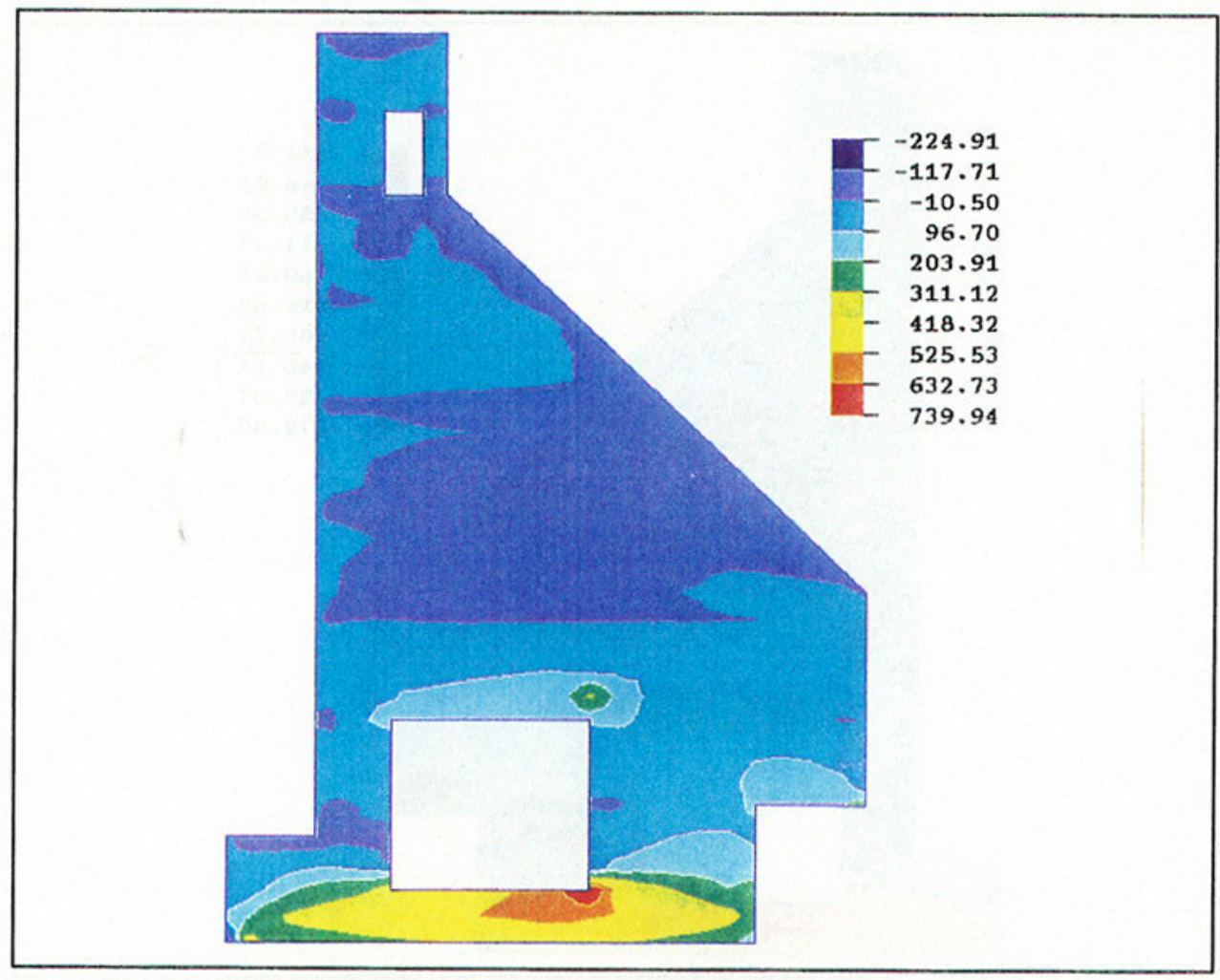

Figure 117. Horizontal stress contour at day 440 of the winter analysis 


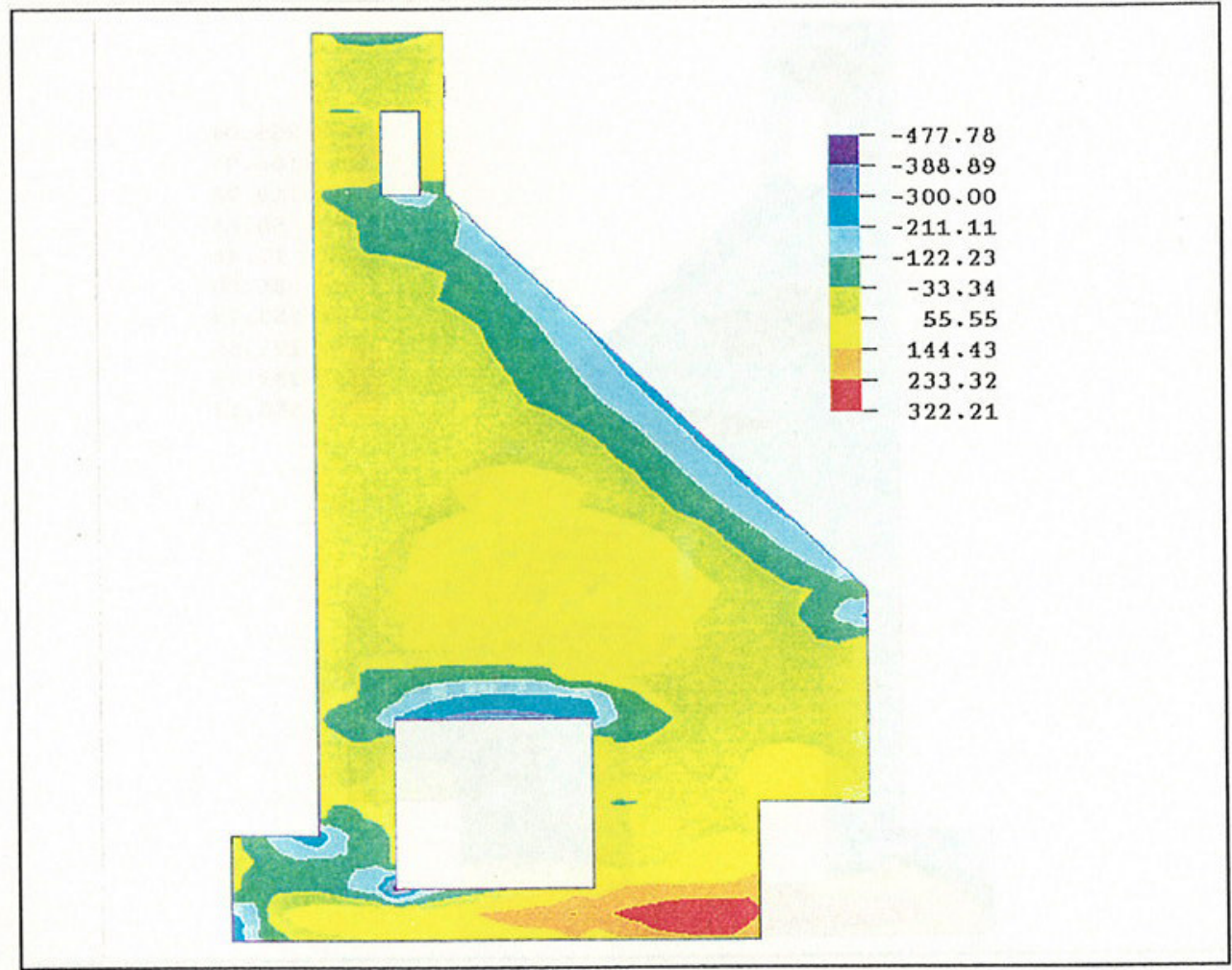

Figure 118. Horizontal stress contour at day 600 of the winter analysis

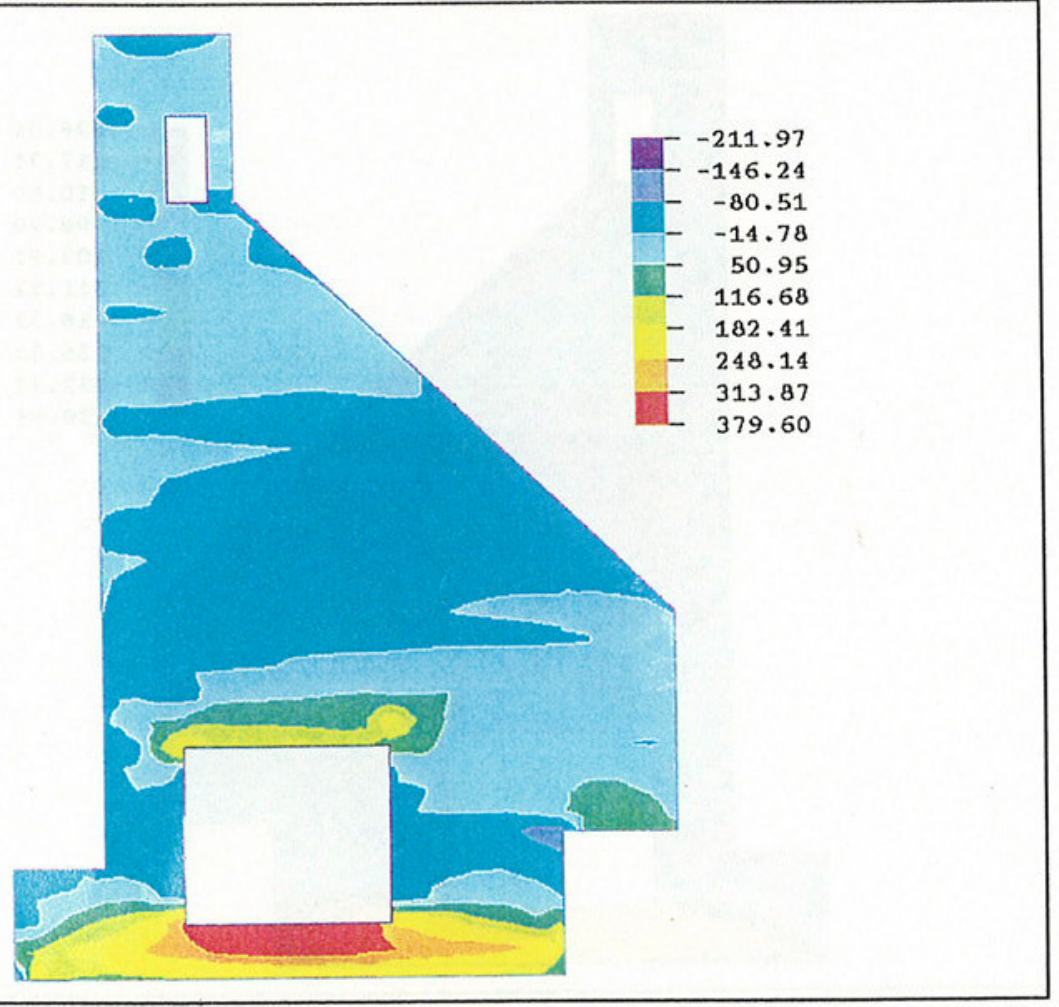

Figure 119. Horizontal stress contour at day 760 of the winter analysis 


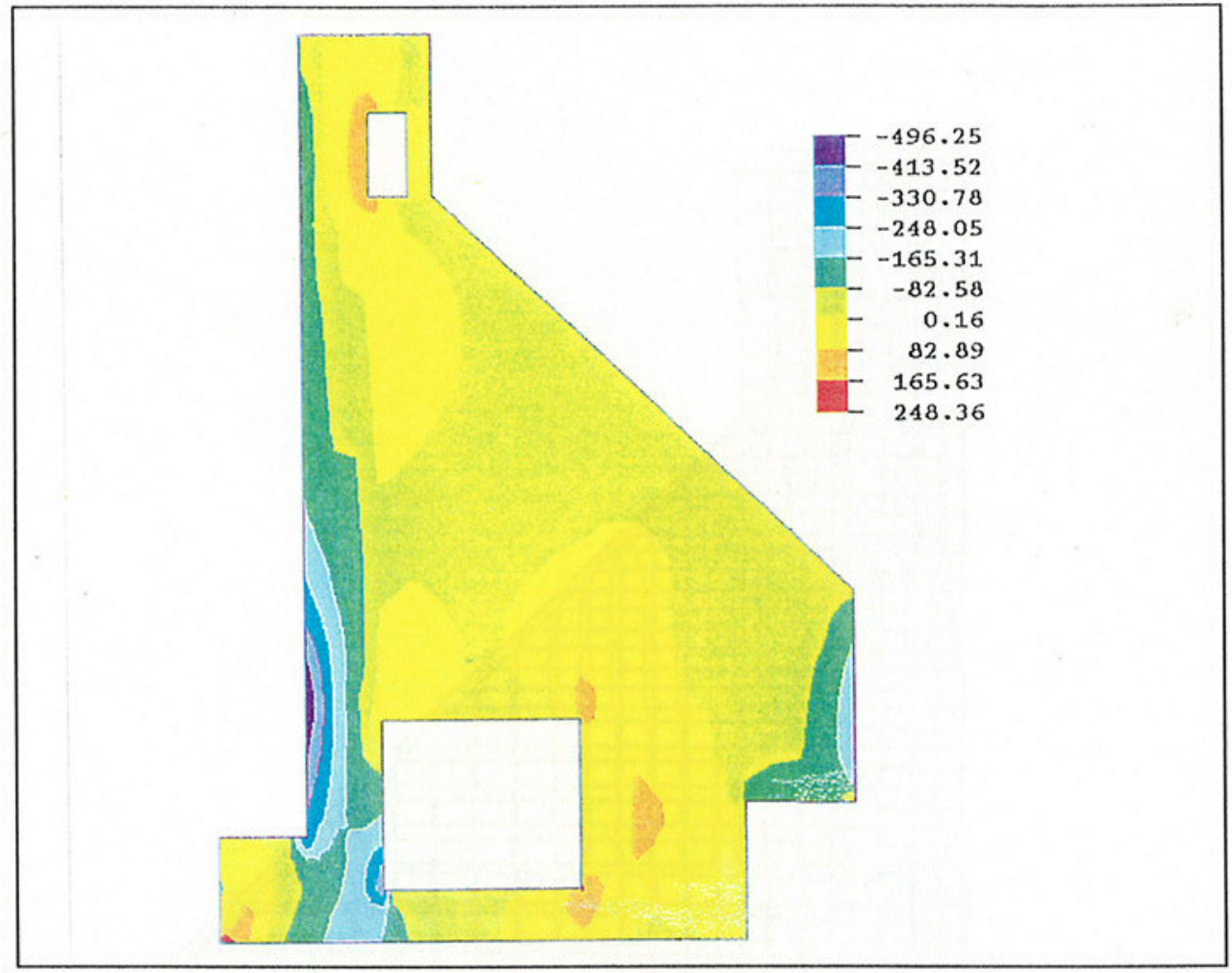

Figure 120. Vertical stress contour at day 440 of the winter analysis

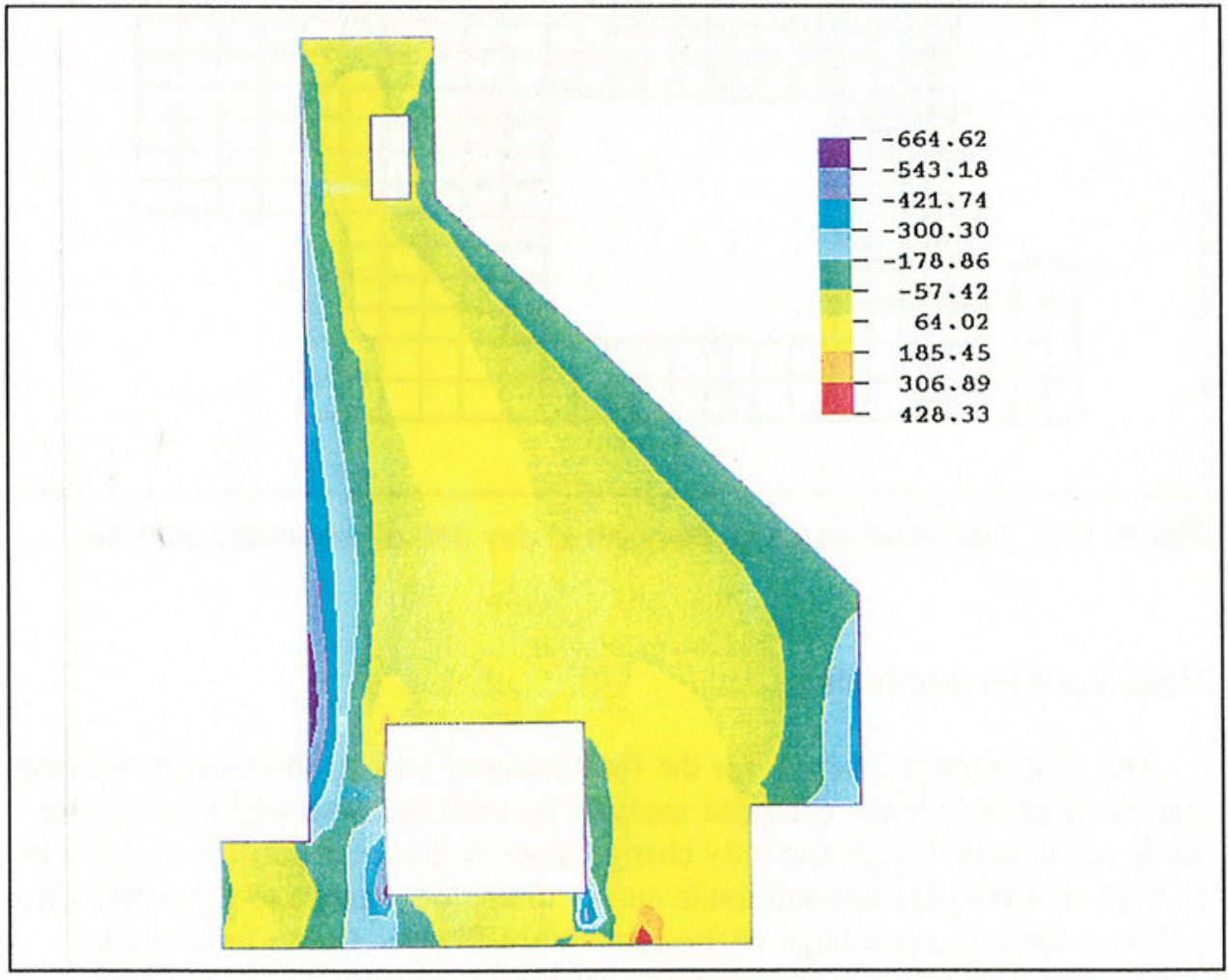

Figure 121. Vertical stress contour at day 540 of the winter analysis 


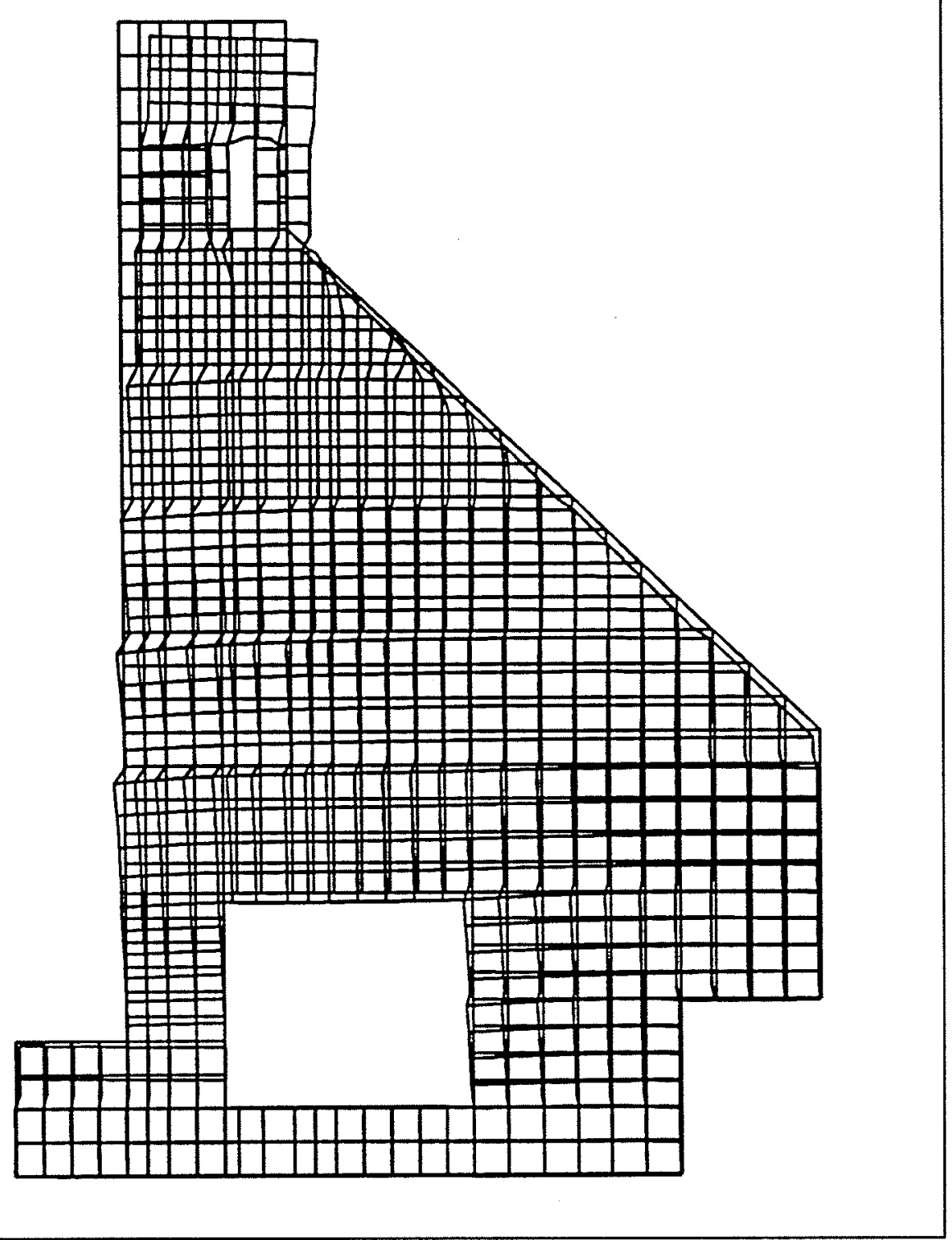

Figure 122. Deflected shape of monolith at day 380 of the winter analysis

\section{Heat transfer analysis}

The heat transfer analysis for the final analysis will be identical to the heat transfer analysis for the extended analysis up until the time when the service loads are included since the only change made in the heat transfer model was to the water temperature amplitude curve. Since the change to the water temperature curve is not a large change (reference Figure 16), no time-history plots of temperature will be presented. It can be seen by comparing Figure 124 (day 475) from the final analysis to Figure 60 (day 465) of the 


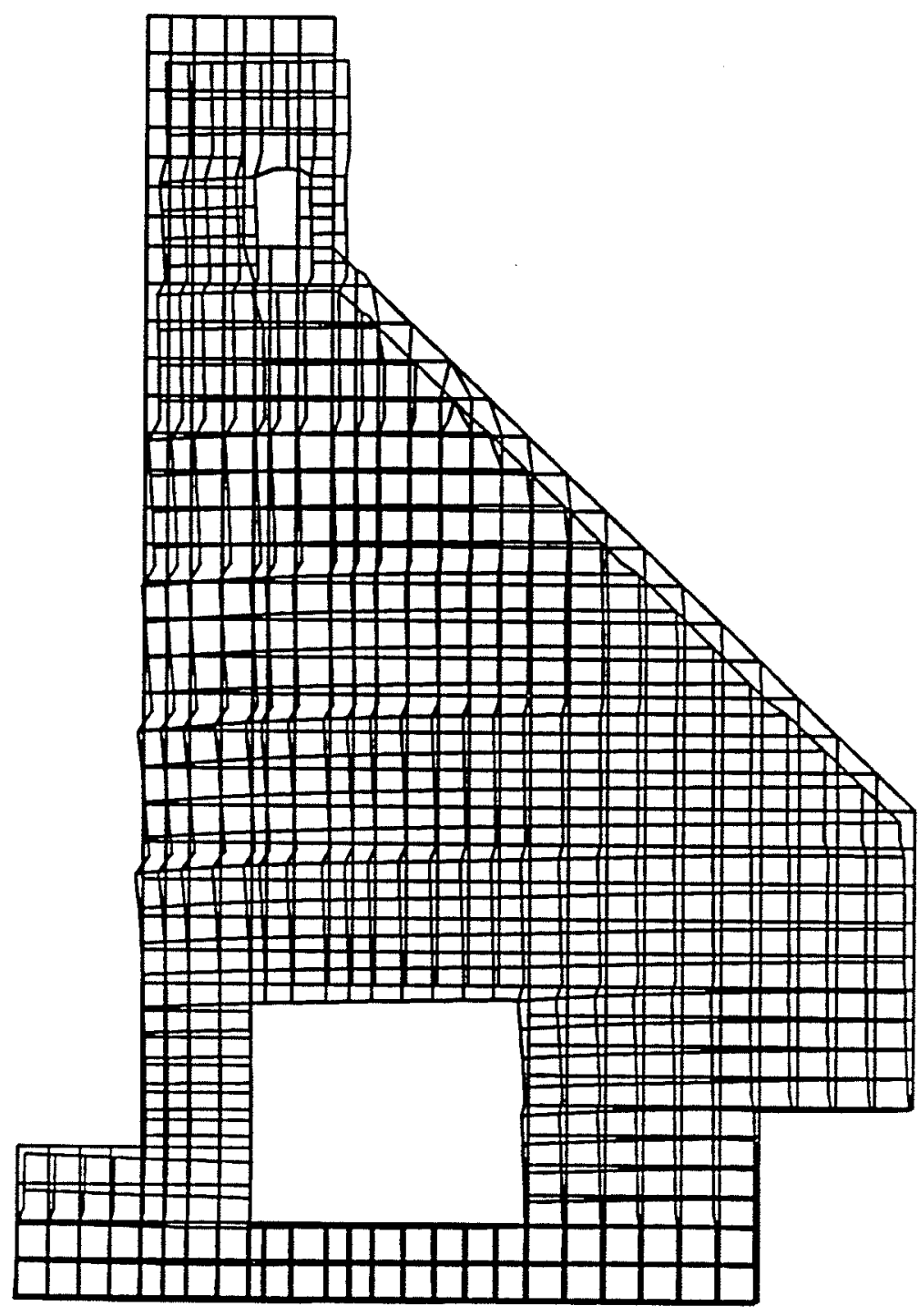

Figure 123. Deflected shape of monolith at day 460 of the winter analysis

extended analysis that in general the contours did not change very much, with the primary change being that the area of the monolith exposed to the water is about $6^{\circ} \mathrm{F}$ cooler in Figure 124. Figure 125 is a contour at day 555 of the final analysis and can be compared to Figure 61 (day 585) of the extended analysis. Figures 125 and 61 are nearly identical, since these plots are taken during the winter and the water temperature in both analyses is the minimum $40^{\circ} \mathrm{F}$. The differences can be attributed primarily to a difference of 30 days in the times in which they are shown. 


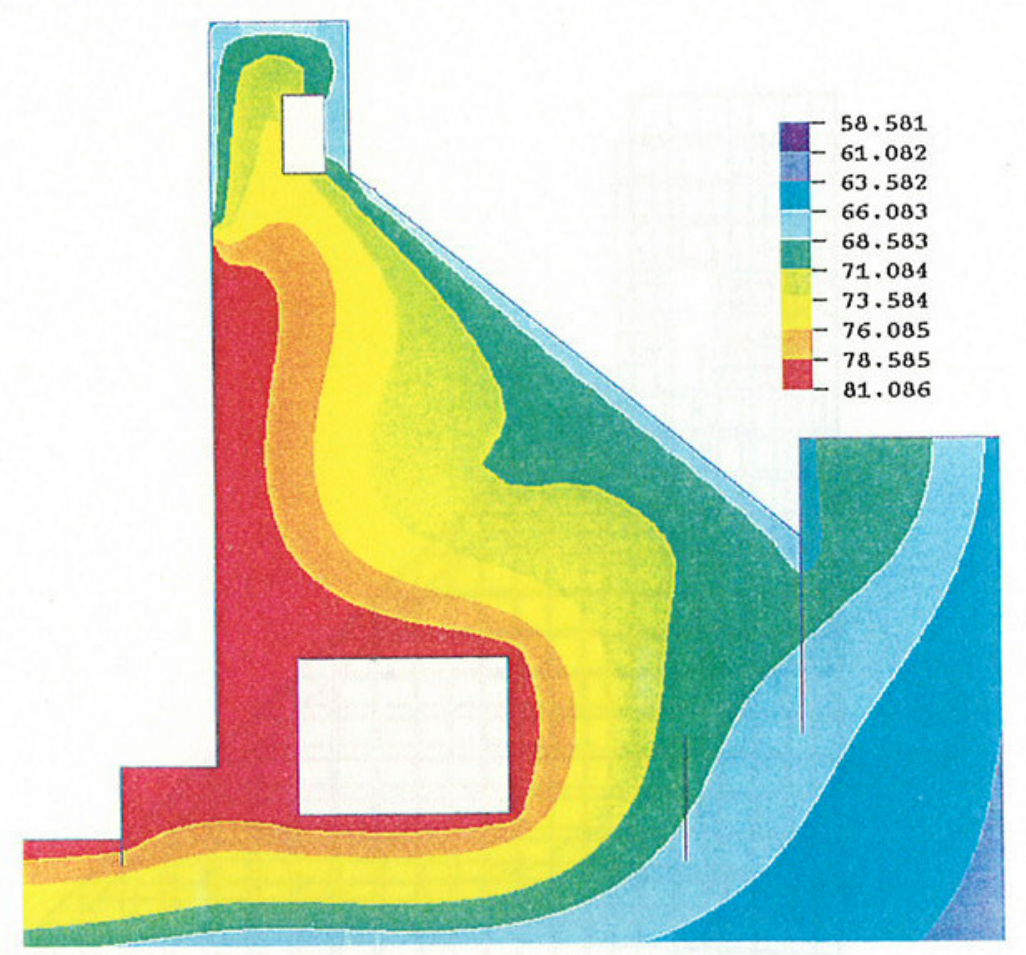

Figure 124. Temperature contour, 475 days after start of construction, final analysis

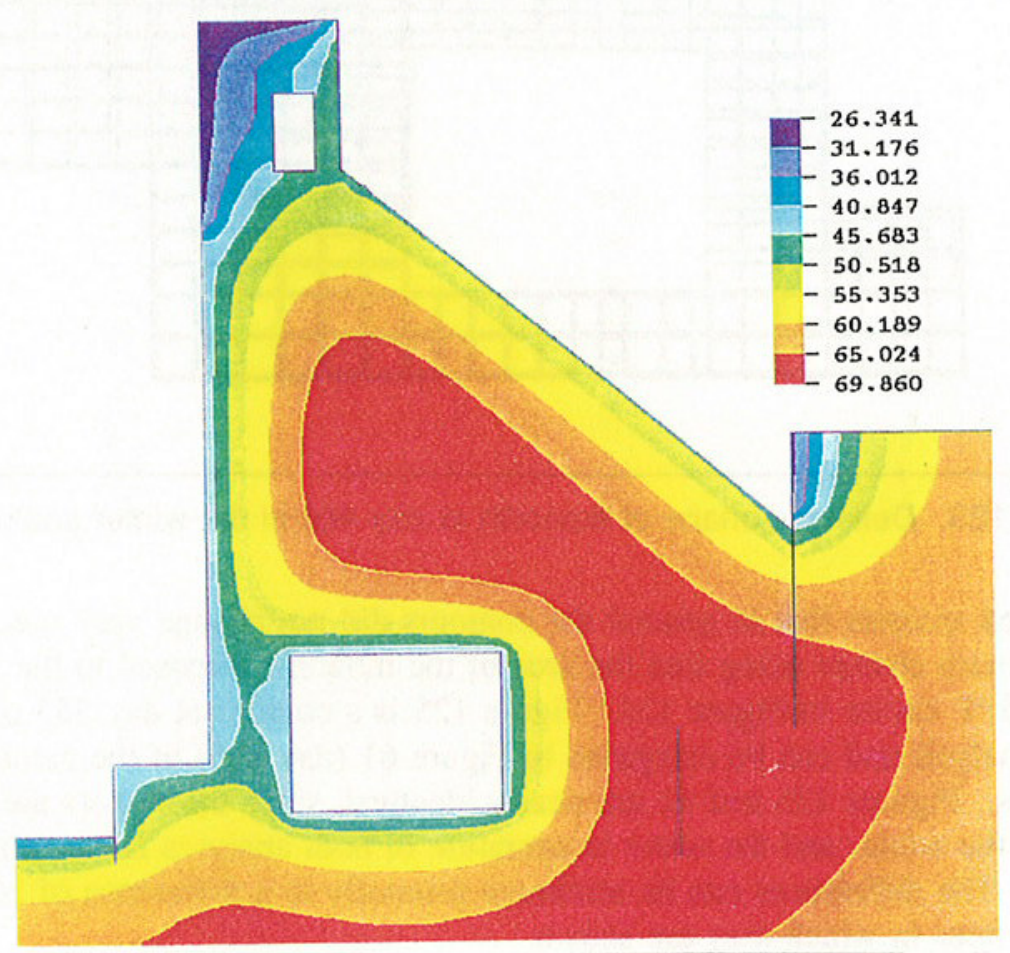

Figure 125. Temperature contour, 555 days after start of construction, final analysis 


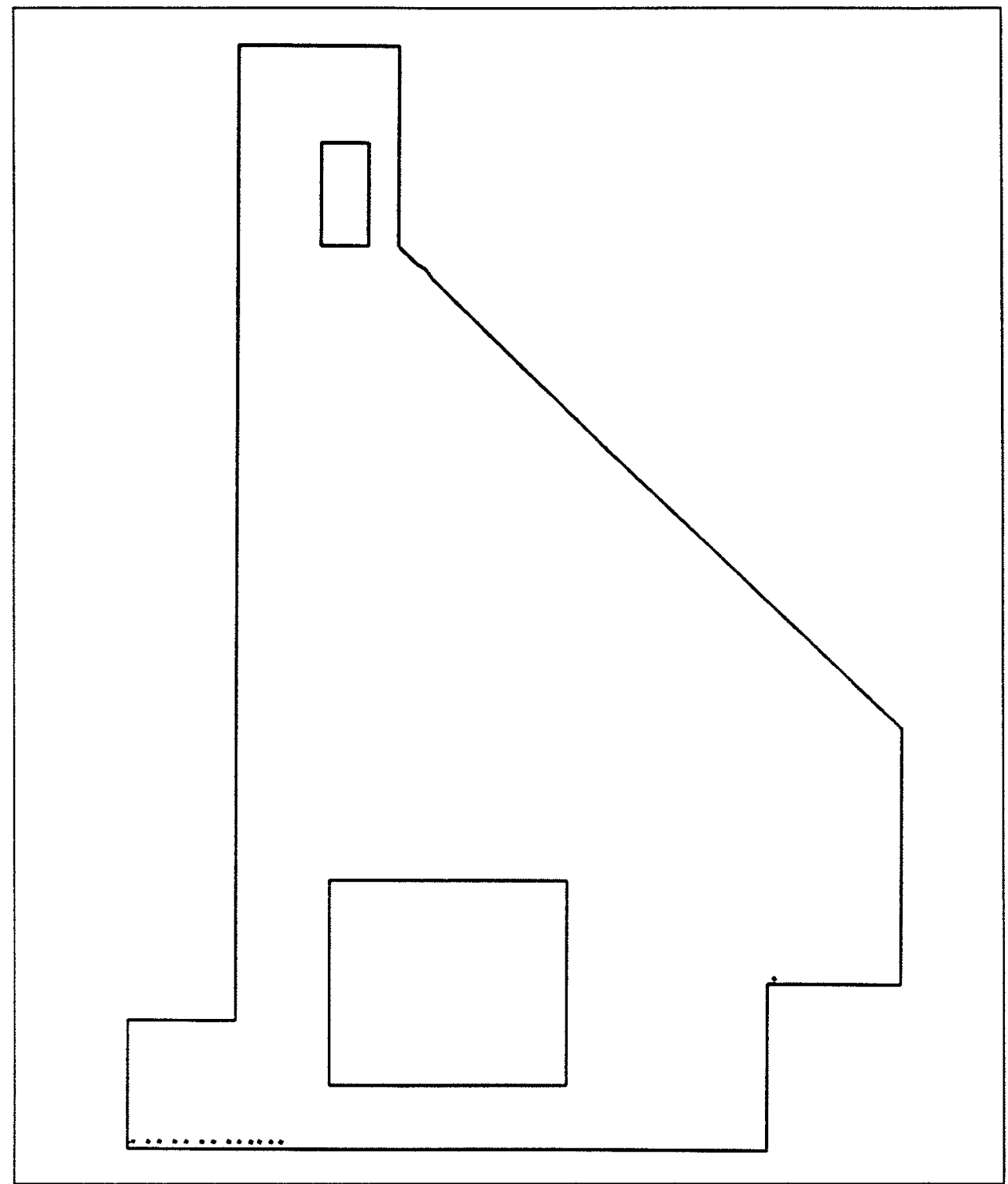

Figure 126. Cracking predicted at day 160 of the final analysis

\section{Stress analysis}

As can be seen by comparing the predicted cracking in the final analysis (Figures 126 through 129) to the cracking predicted in the extended analysis (Figures 68 through 70 ) the changes made for the final analysis only changed the final cracking pattem slightly. Cracking progressed at nearly the same rate in the final analysis as it did in the extended analysis. Cracking was reduced slightly at the end of the first year (Figure 128) of the final analysis compared to the cracking at the end of the first year (Figure 70) of the extended analysis, but by the time the final analysis was completed (Figure 129), the cracking is nearly identical. There is some reduction of cracking along the base and this can be attributed to the gap elements included at the vertical rock/concrete 


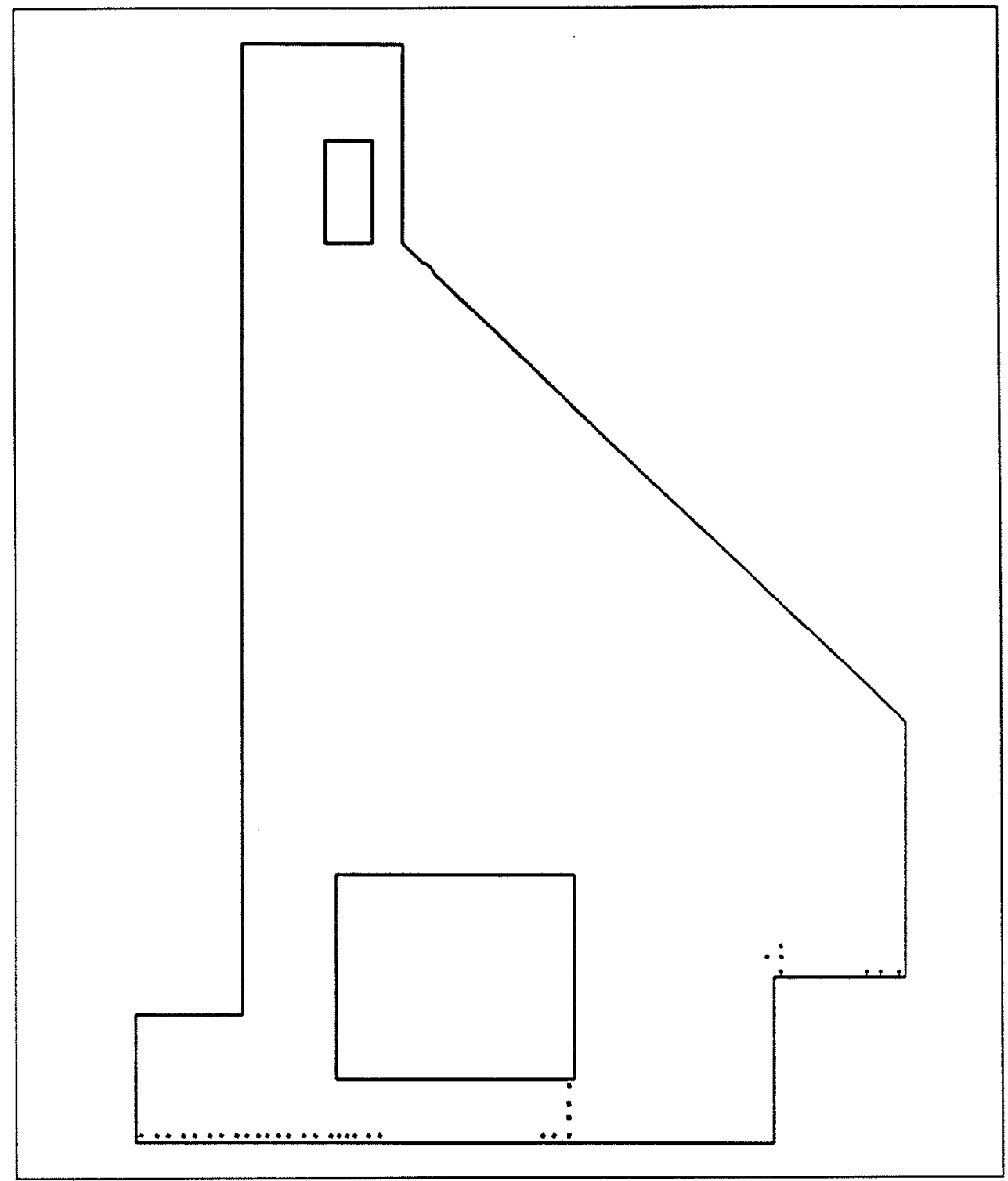

Figure 127. Cracking predicted at day 260 of the final analysis

interface next to the culvert, but this also resulted in some cracking occurring at the top of the interface. Prior to performing the analysis it had been anticipated that cracking at the top of the rock/concrete interface would occur, but cracking at this location is not detrimental to the function of the monolith.

Further evidence that the final analysis model changes improved behavior can be seen in Figures 130 and 131. Figure 130 shows the reinforcing stresses for element 52 and the results can be compared to the reinforcing stresses shown in Figure 93. As can be seen in Figure 130, the reinforcing stresses have been reduced significantly in the final analysis to a maximum value of less than $80 \mathrm{ksi}$. While this is still above the yield point it is not so high that a large amount of yielding should occur. Figure 131 for the final analysis can be compared to Figure 94 of the extended analysis (both are for element 88 ). 


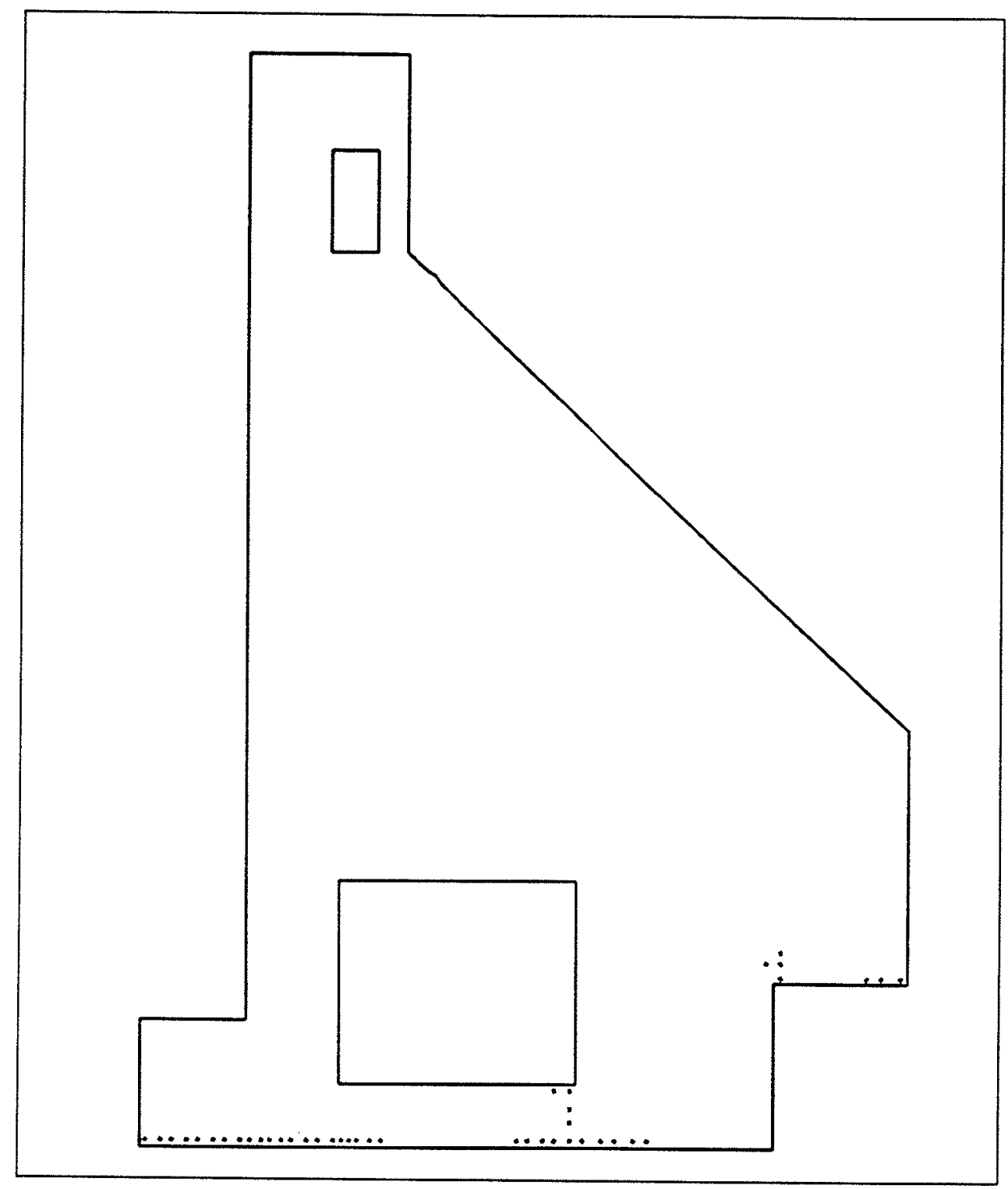

Figure 128. Cracking predicted at day 395 of the final analysis

As can be seen in Figure 131, cracking in the final analysis at this location did not occur until the second year and the reinforcing stresses are approximately $10 \mathrm{ksi}$ less than they were in the extended analysis. This would indicate that the changes made have improved the structural behavior.

Figures 132 through 137 are stress contour plots of the final analysis, which can be compared back to plots from the extended analysis. Table 8 shows which plots are at the same or nearly the same times from the two analyses and what is being presented in the plots to provide easy reference. Comparison of the plots will show that the two analyses are nearly identical with differences in the contours being very localized. Not only are the shapes of the contours very similar but magnitudes of stresses are also very nearly the same. 


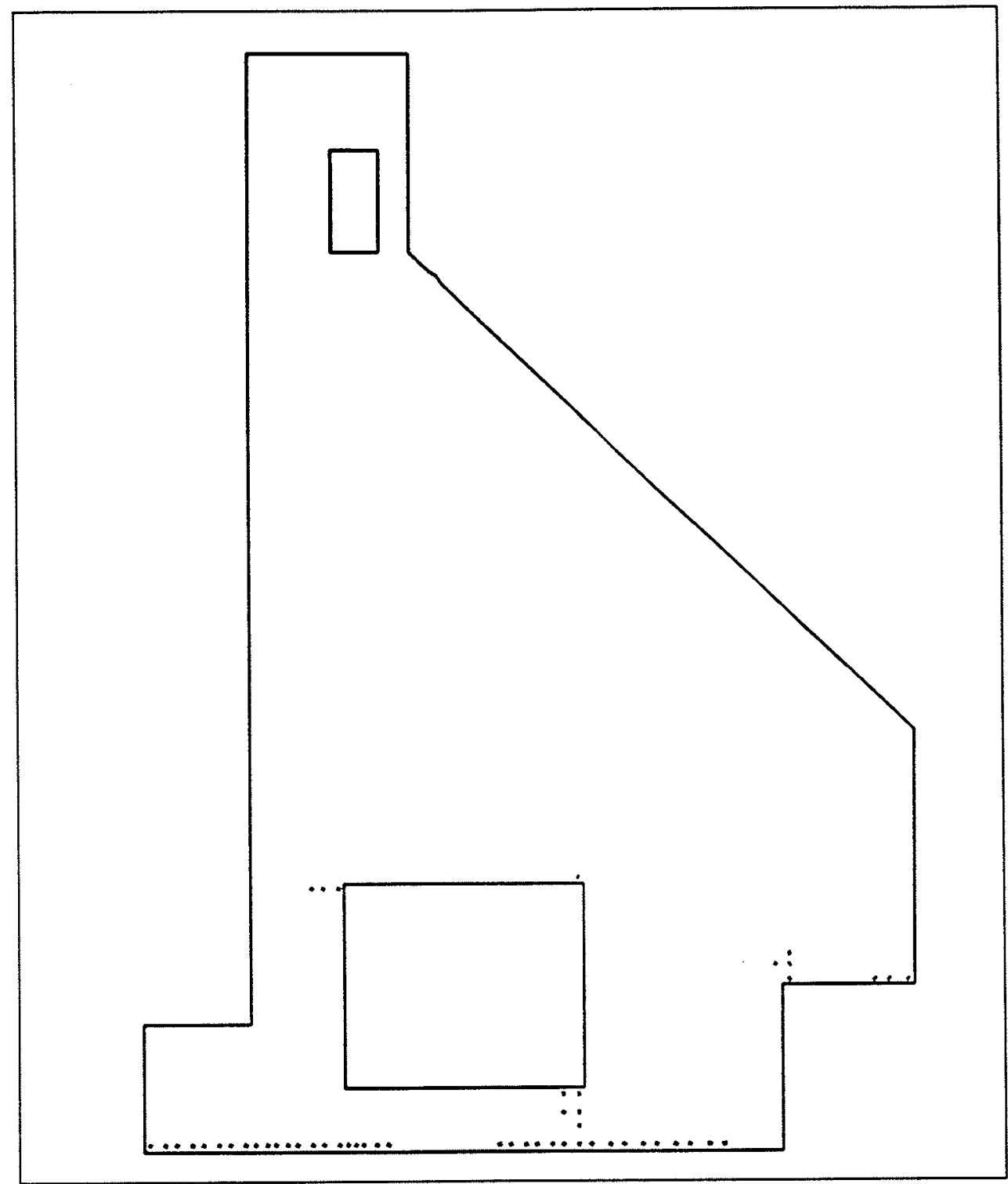

Figure 129. Cracking predicted at day 755 of the final analysis

Finally, Figures 138 through 142 are cracking potential percentage contours taken at various times from the final analysis. The primary purpose of presenting the cracking potential percentage contours is to demonstrate that for portions of the monolith above the culvert, the potential for cracking is low. Only in the area around the gallery do the percentages even reach a cracking potential percentage of 70 percent and for the remainder of the monolith, the cracking potential percentage stays below 60 percent. These plots indicate that the manner in which reinforcing is used in this monolith is very effective. 


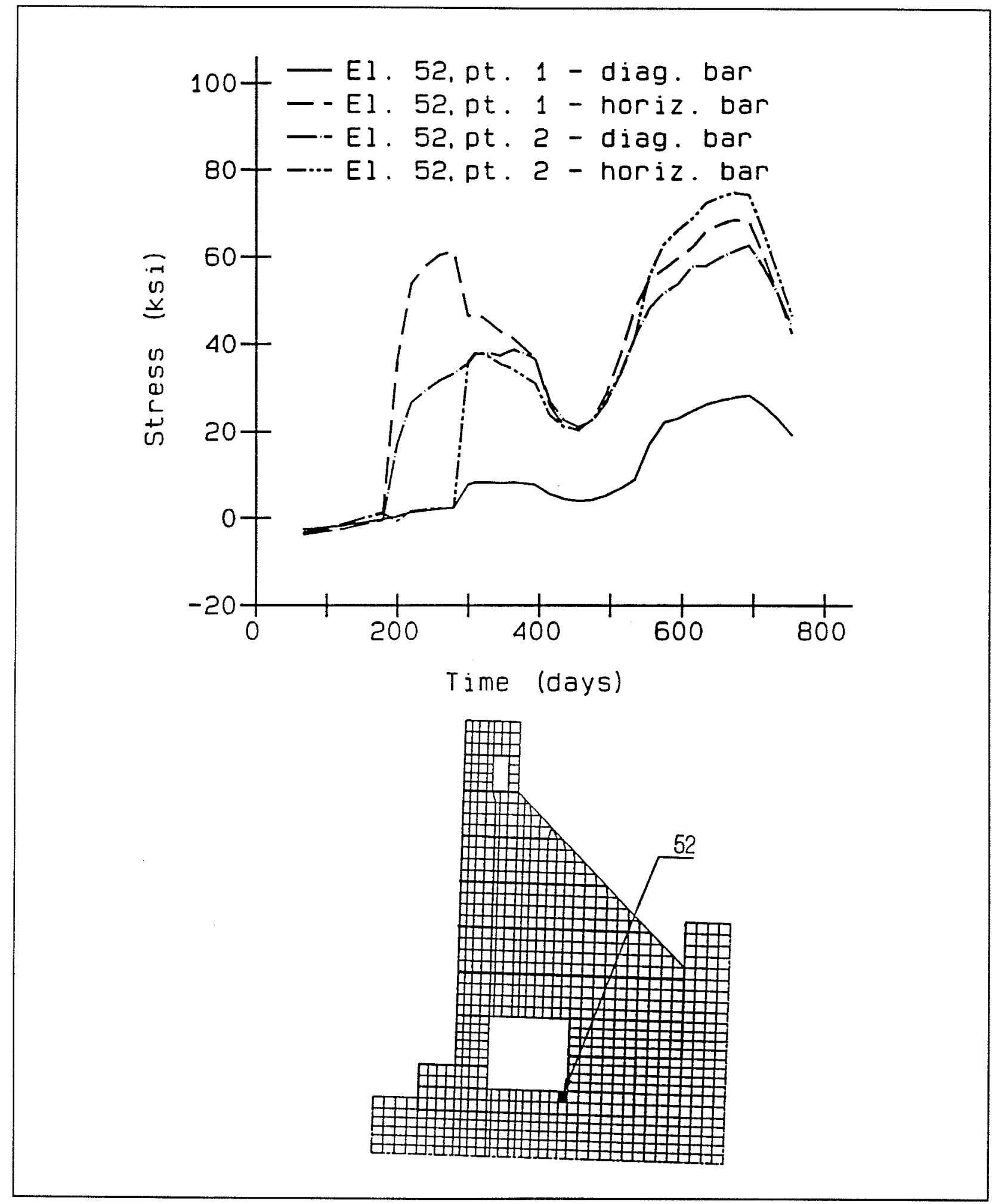

Figure 130. Reinforcing stresses in element 52 of the final analysis 


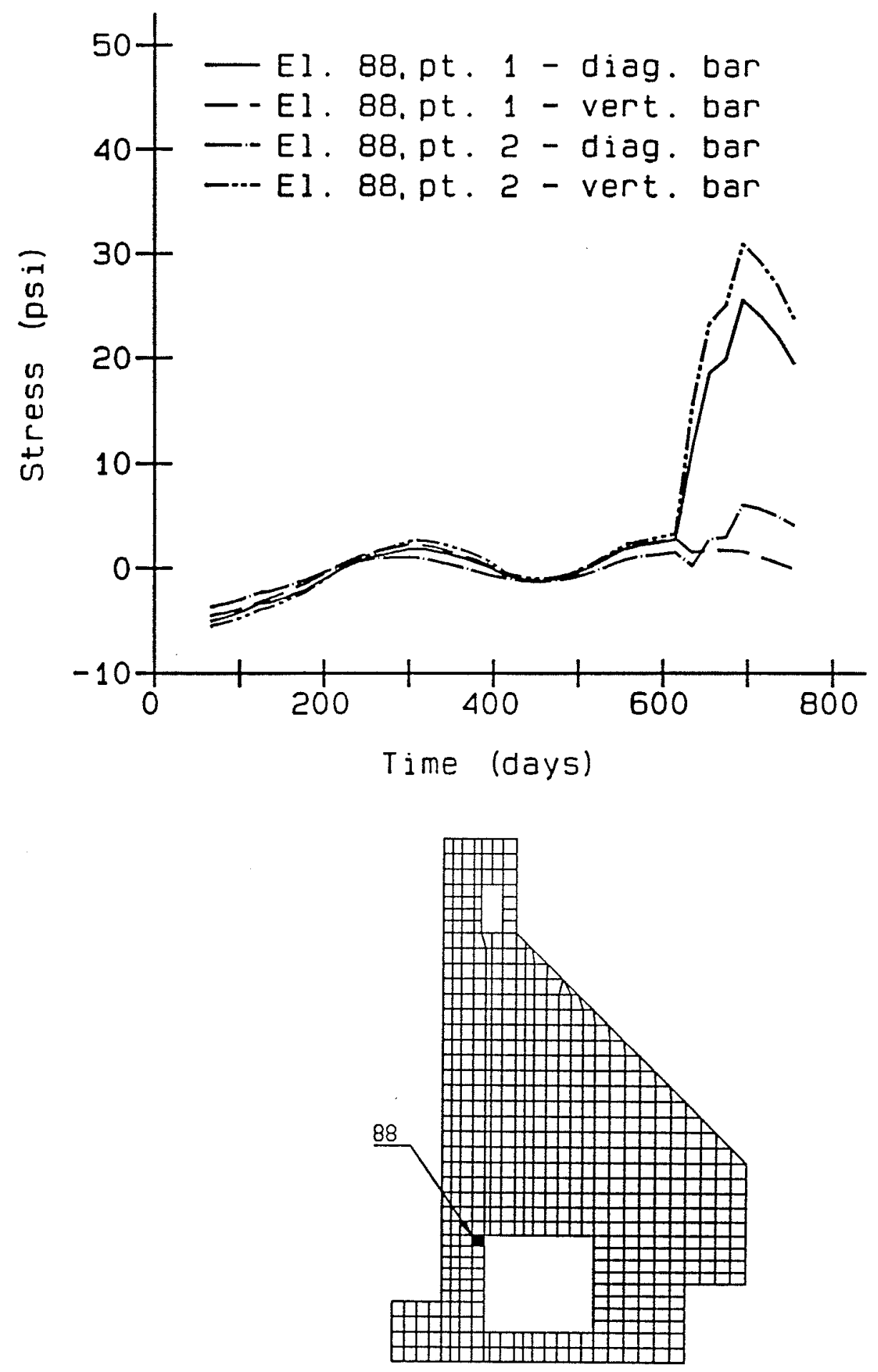

Figure 131. Reinforcing stresses in element 88 of the final analysis 


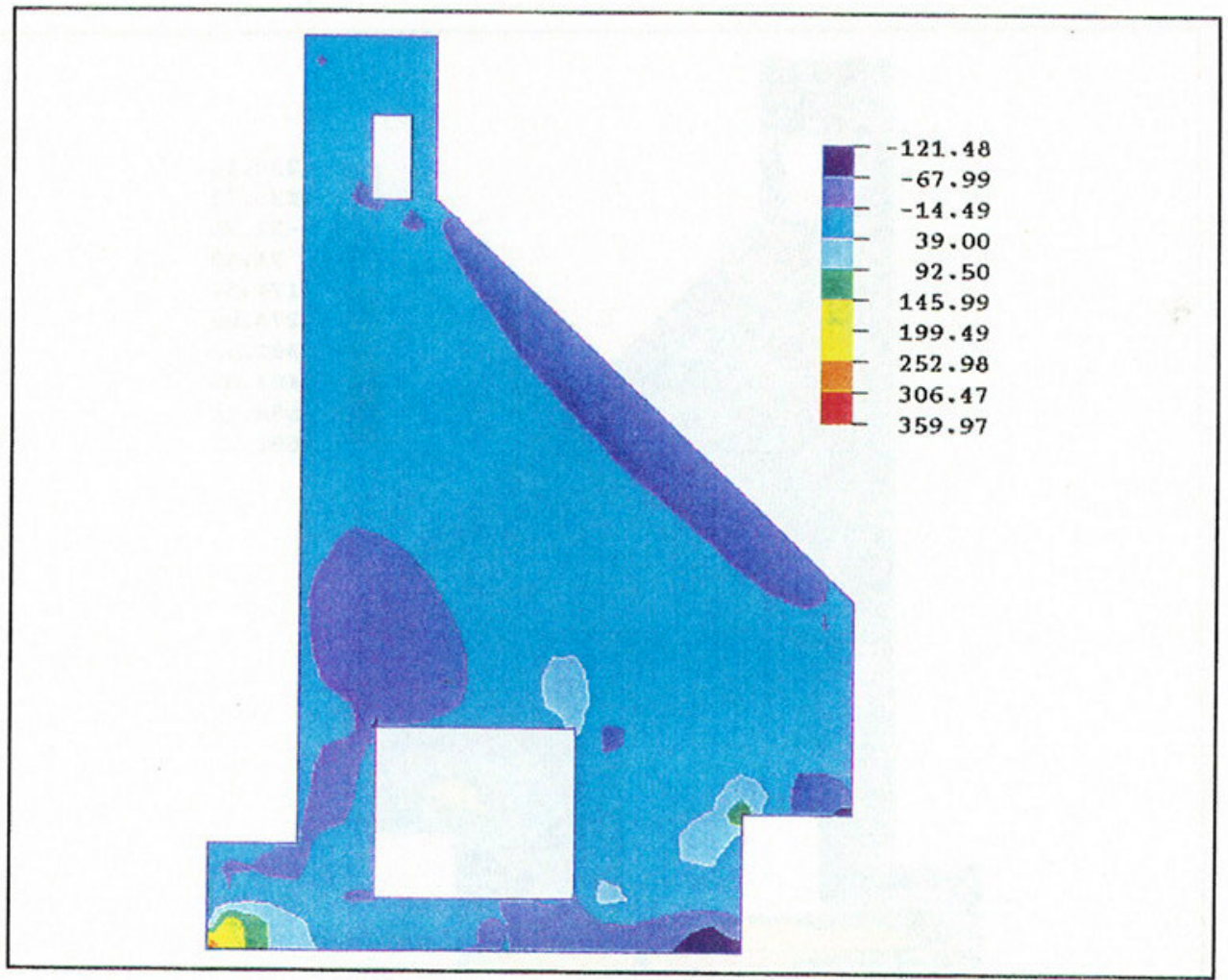

Figure 132. Shear stress contour at day 115 of the final analysis

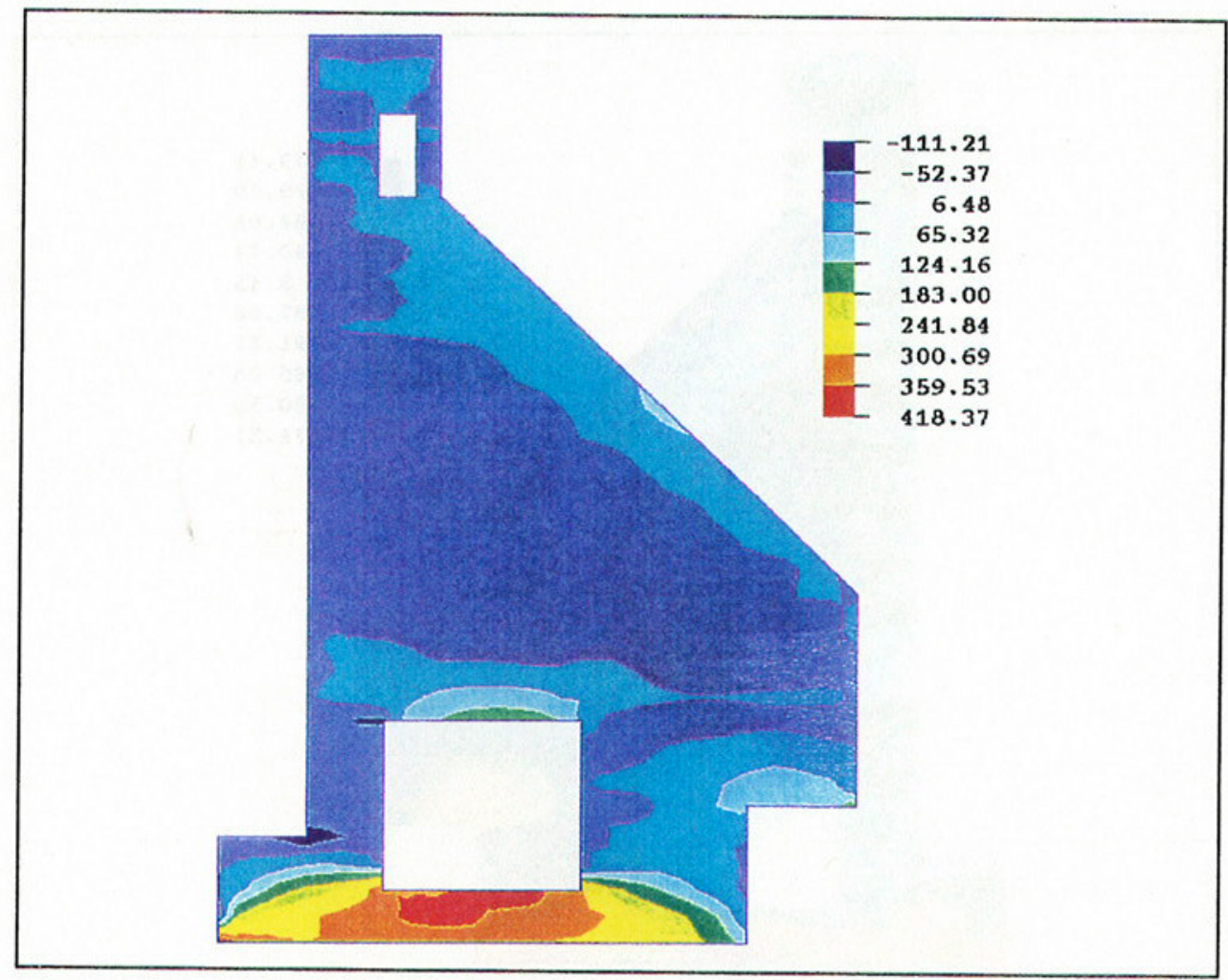

Figure 133. Horizontal stress contour at day 115 of the final analysis 


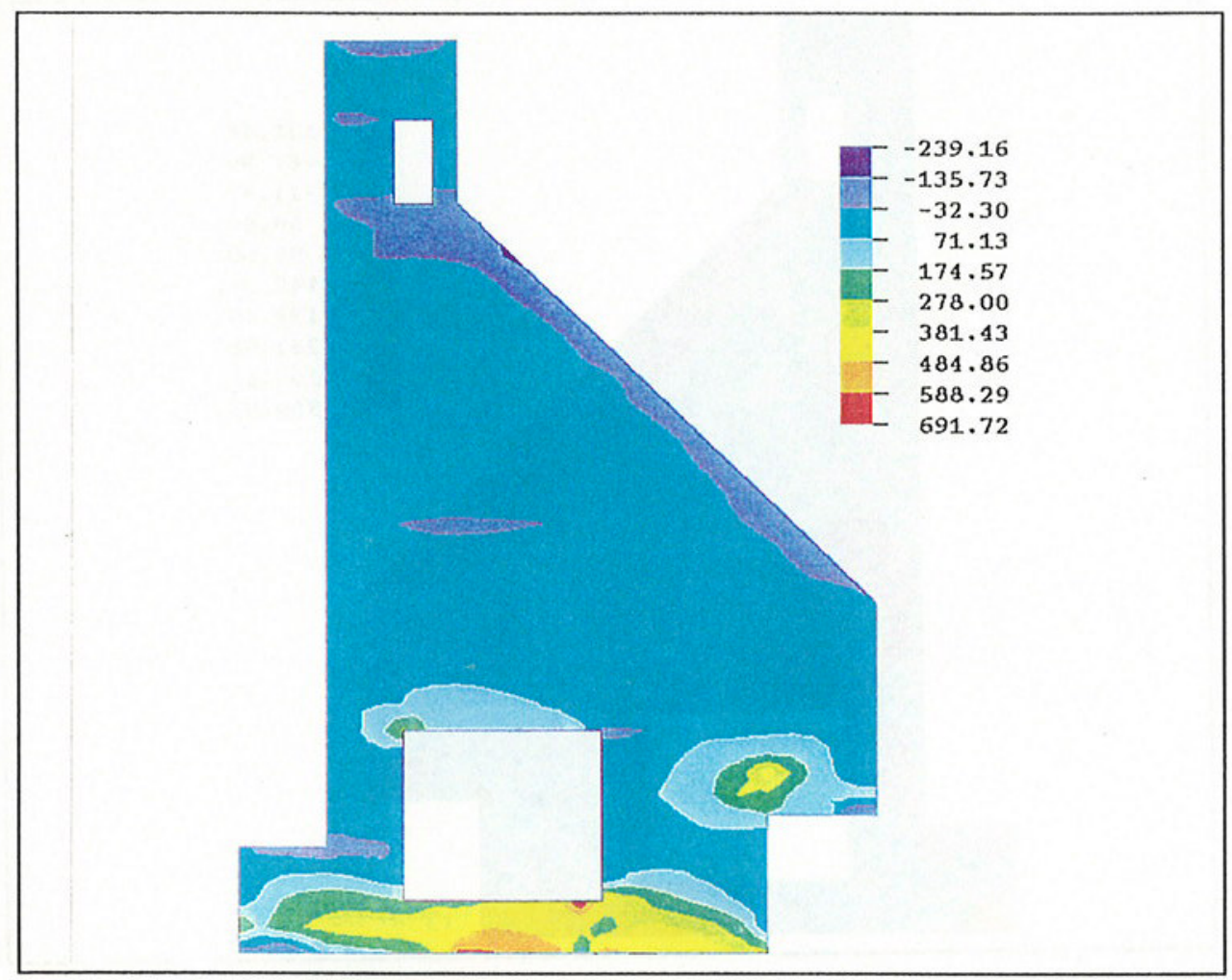

Figure 134. Horizontal stress contour at day 260 of the final analysis

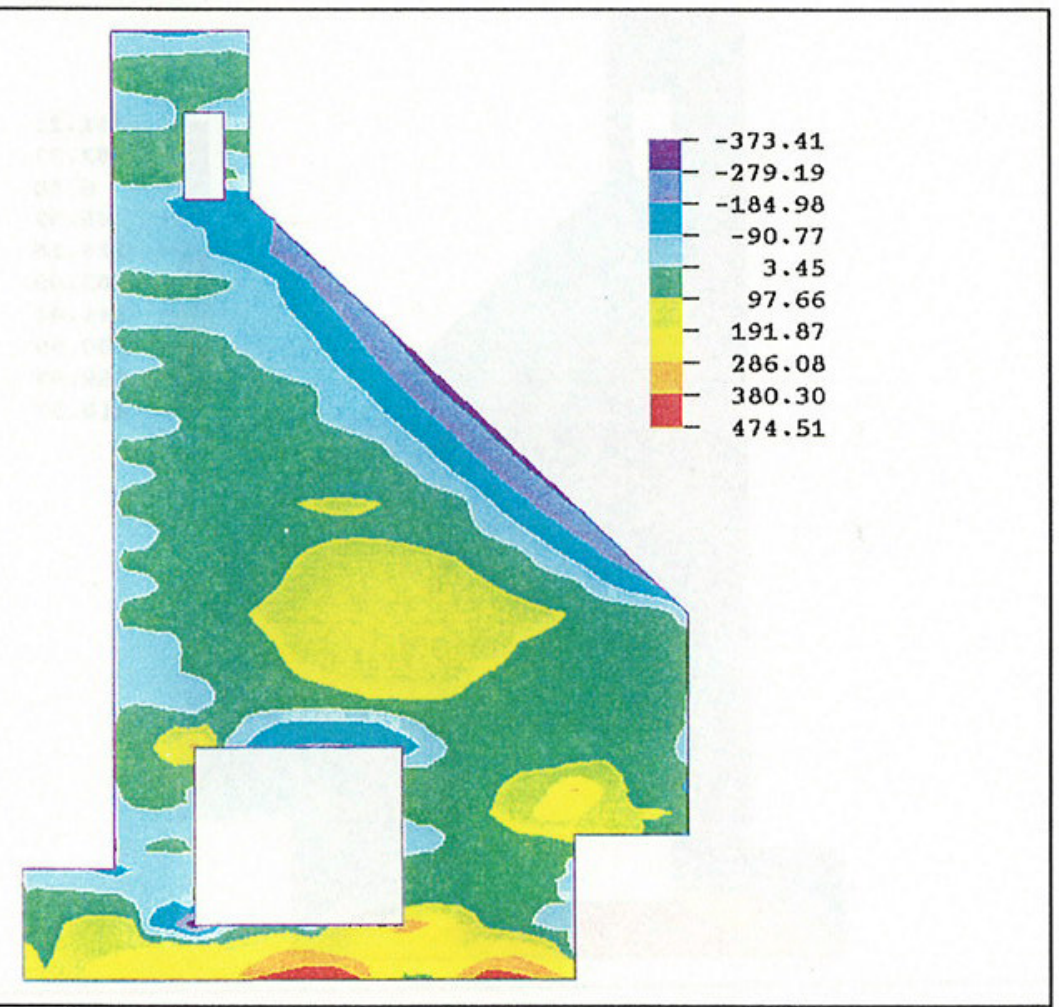

Figure 135. Horizontal stress contour at day 365 of the final analysis 


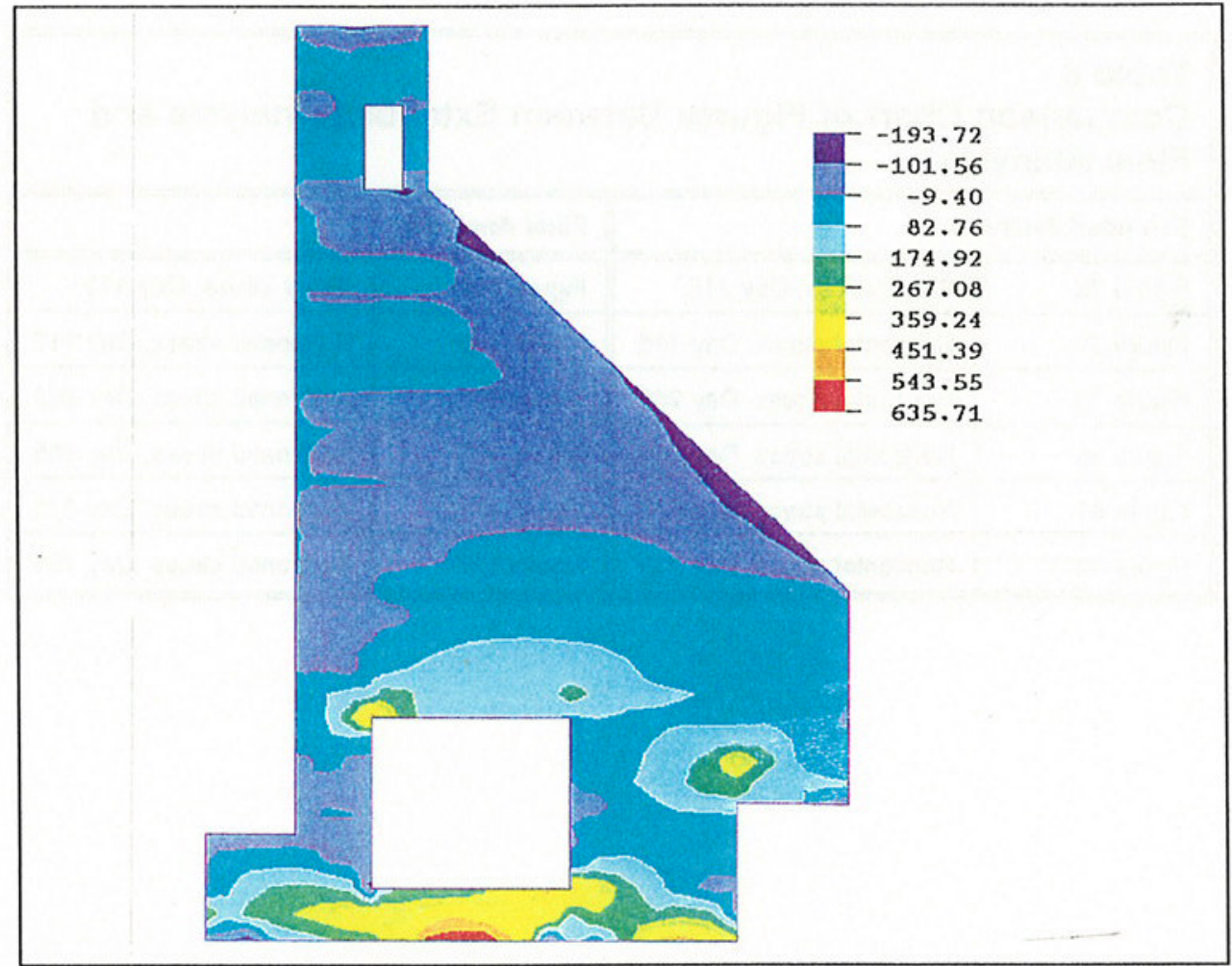

Figure 136. Horizontal stress contour at day 615 of the final analysis

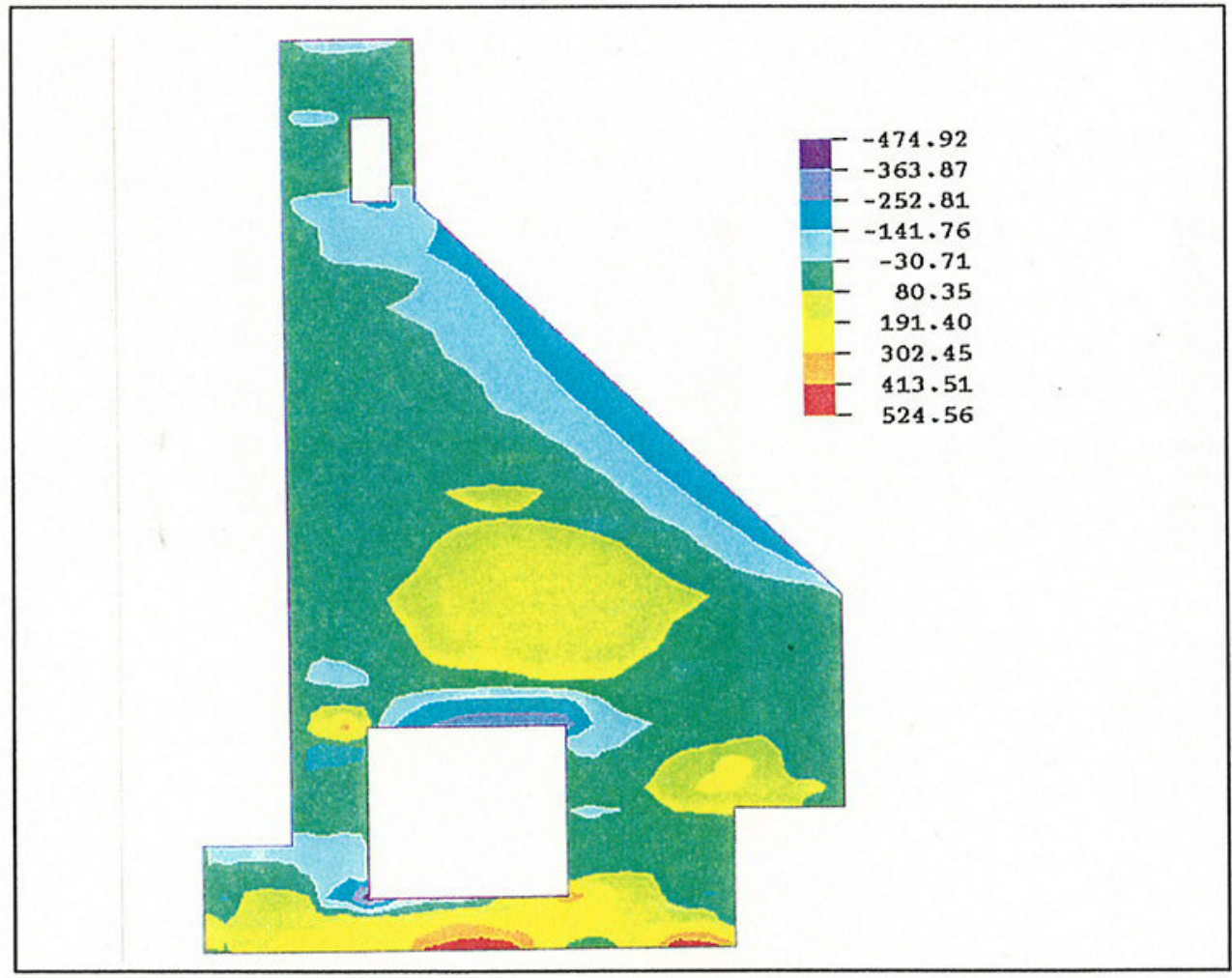

Figure 137. Horizontal stress contour at day 755 of the final analysis 


\begin{tabular}{|c|c|c|c|}
\hline \multicolumn{4}{|c|}{$\begin{array}{l}\text { Table } 8 \\
\text { Comparison Chart of Figures Between Extended Analysis and } \\
\text { Final Analysis }\end{array}$} \\
\hline \multicolumn{2}{|c|}{ Extended Analysis } & \multicolumn{2}{|c|}{ Final Analysis } \\
\hline Figure 76 & Shear stress, Day 115 & Figure 132 & Shear stress, Day 115 \\
\hline Figure 78 & Horizontal stress, Day 115 & Figure 133 & Horizontal stress, Day 115 \\
\hline Figure 79 & Horizontal stress, Day 250 & Figure 134 & Horizontal stress, Day 260 \\
\hline Figure 80 & Horizontal stress, Day 375 & Figure 135 & Horizontal stress, Day 365 \\
\hline Figure 81 & Horizontal stress, Day 615 & Figure 136 & Horizontal stress, Day 615 \\
\hline Figure 82 & Horizontal stress, Day 755 & Figure 137 & Horizontal stress, Day 755 \\
\hline
\end{tabular}




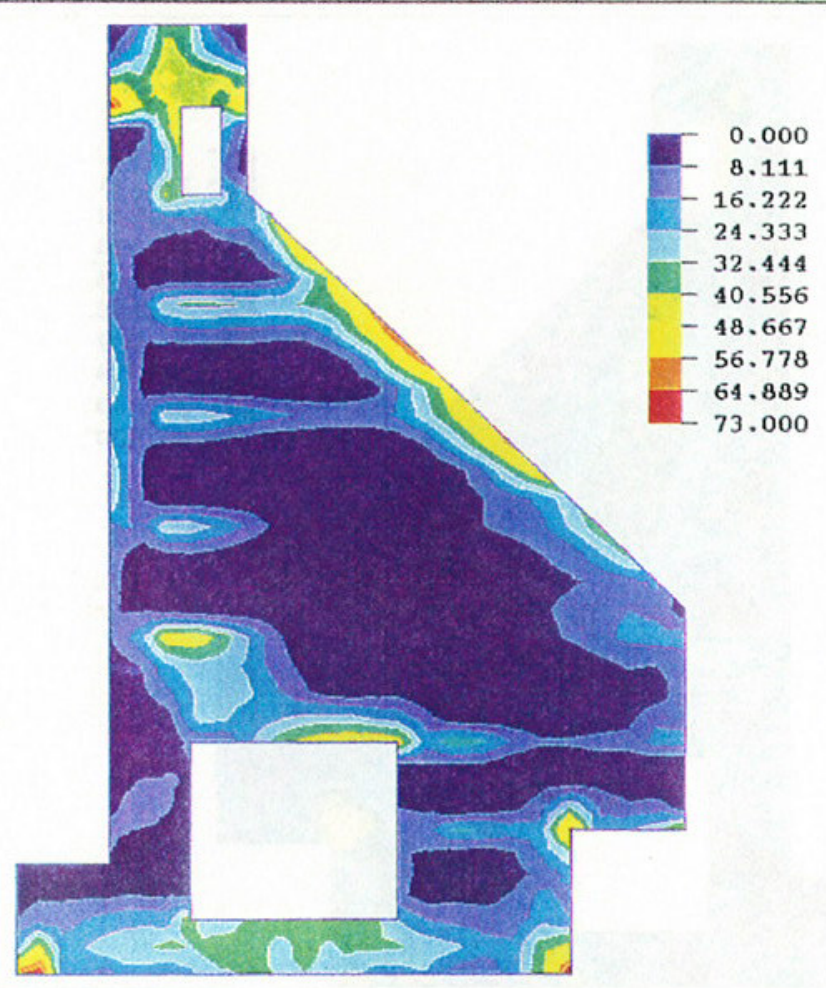

Figure 138. Cracking potential percentage contour at day 115 of the final analysis

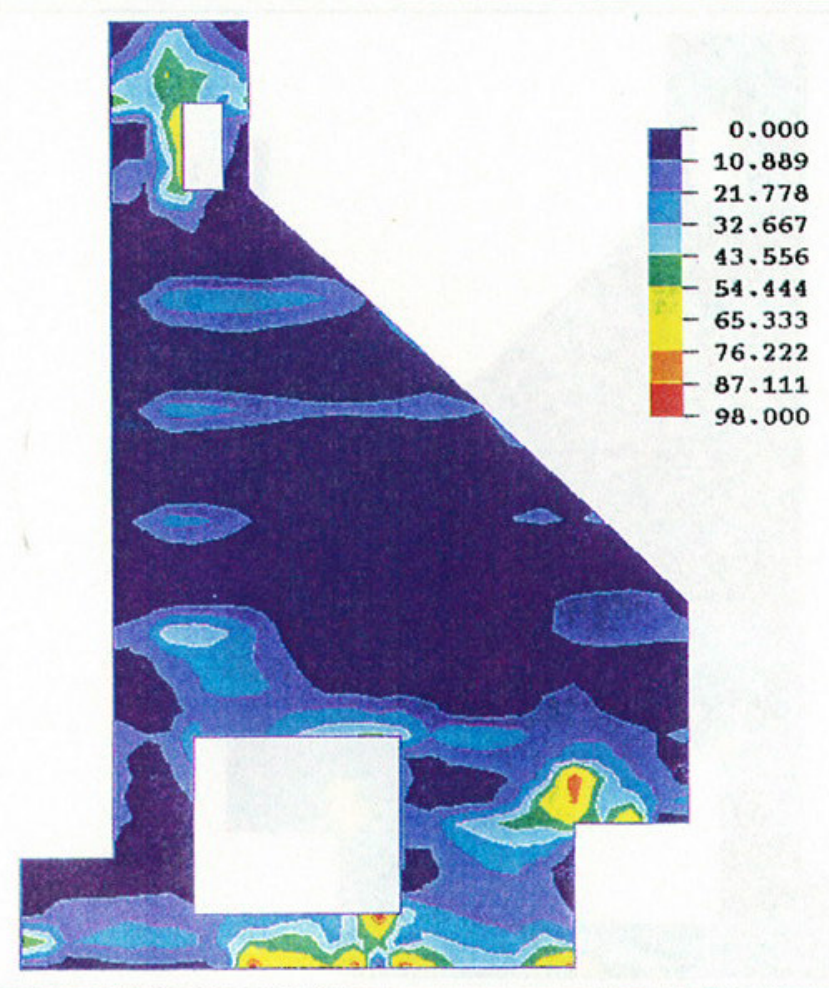

Figure 139. Cracking potential percentage contour at day 260 of the final analysis 


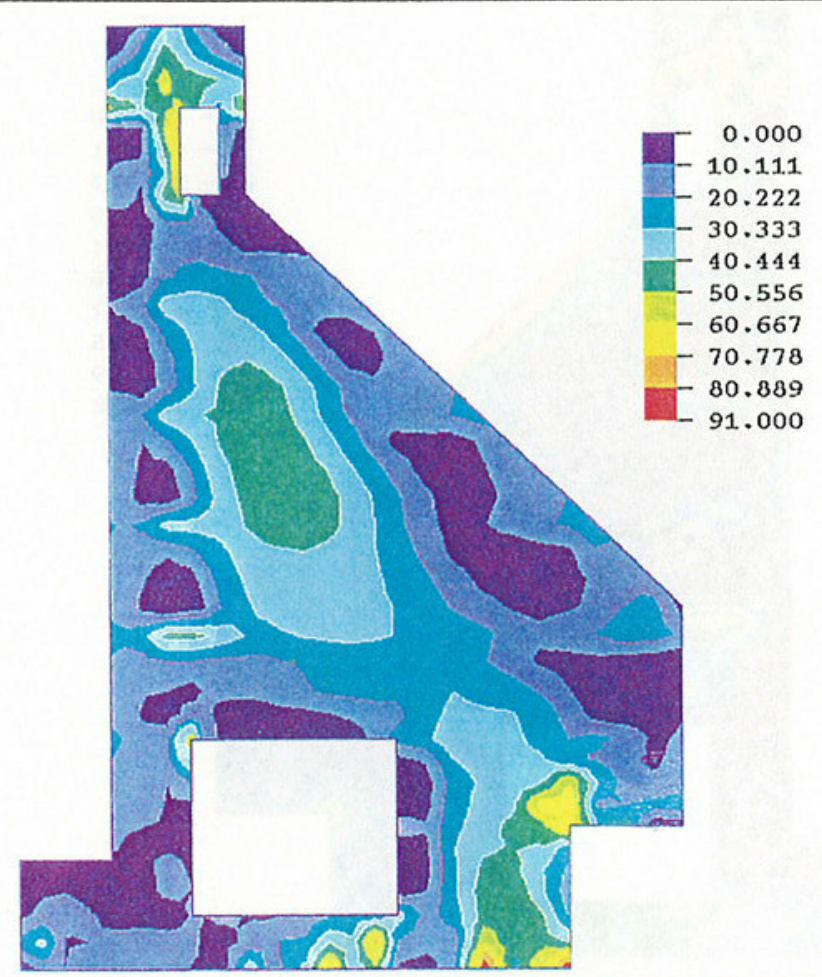

Figure 140. Cracking potential percentage contour at day 395 of the final analysis

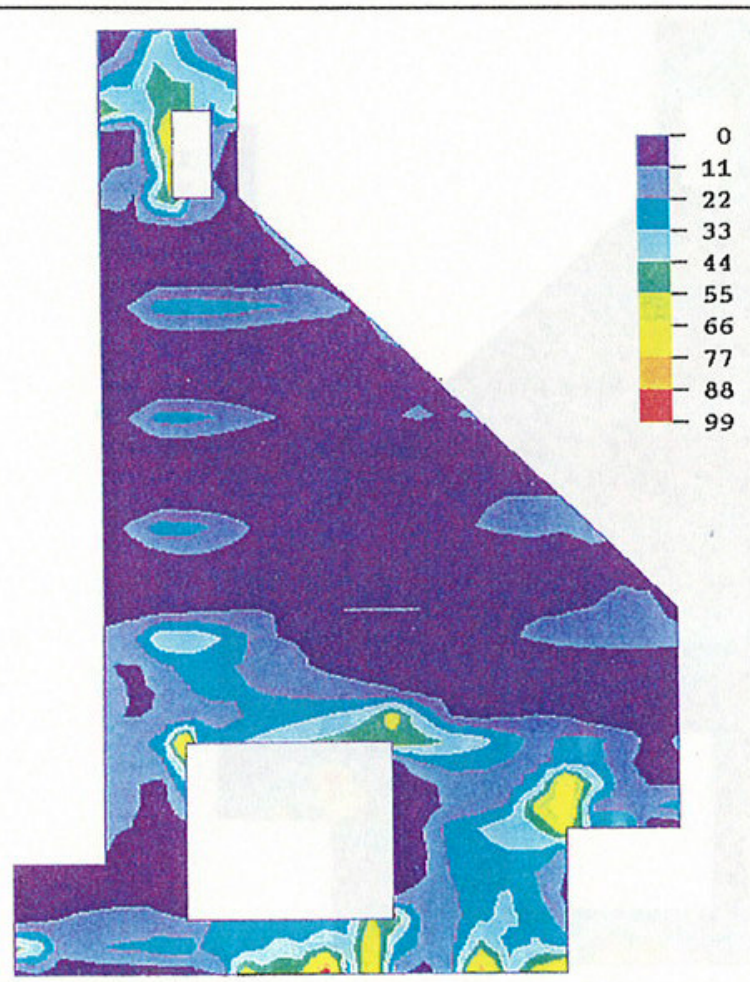

Figure 141. Cracking potential percentage contour at day 575 of the final analysis 


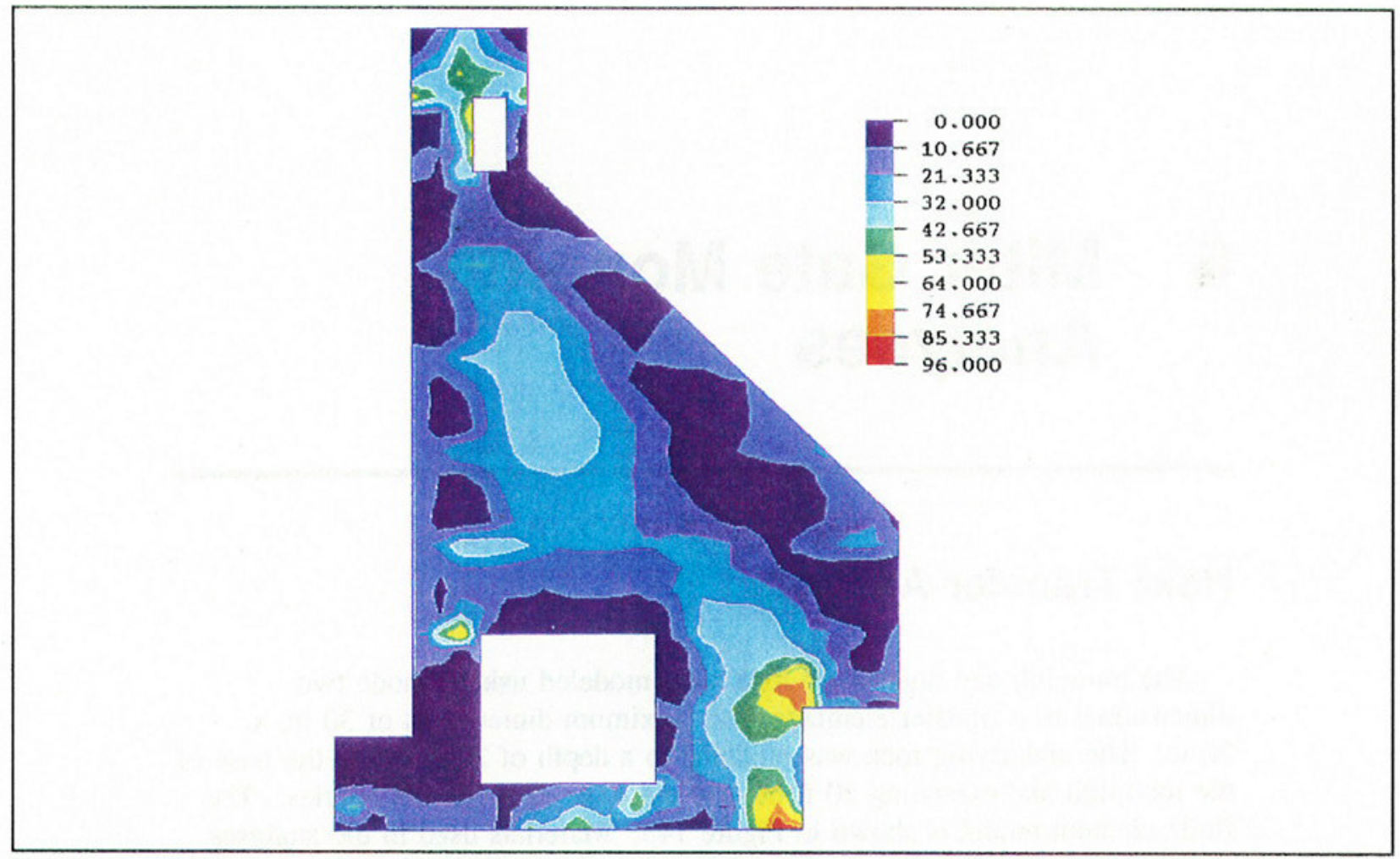

Figure 142. Cracking potential percentage contour at day 755 of the final analysis 


\section{Miter Gate Monolith Anallyses}

\section{Heat Transfer Analysis}

The monolith and underlying rock were modeled using 8-node twodimensional heat transfer elements with maximum dimensions of 30 in. $x$ $30 \mathrm{in}$. The underlying rock was modeled to a depth of $20 \mathrm{ft}$ below the base of the monolith and extending $20 \mathrm{ft}$ beyond the outer concrete boundaries. The finite element model is shown in Figure 143. Materials used in the analyses and lift sequence are also shown in this figure. Material properties used in the heat transfer analysis are given in Tables 2 and 3 (Chapter 2). Adiabatic temperature rise curves for the two concretes used in the analyses are shown in Figure 1.

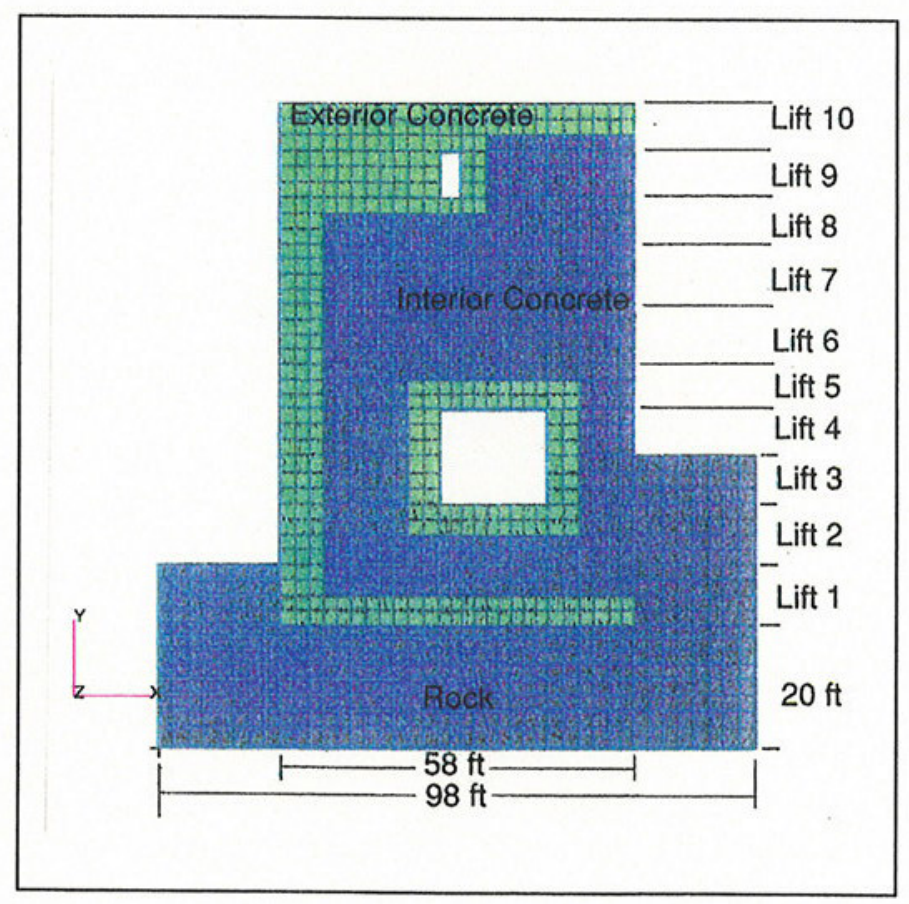

Boundary conditions for the heat transfer analysis are listed below.

a. The temperature at the base of the rock was held constant at $54^{\circ} \mathrm{F}$.

b. No lateral heat loss was allowed at outer rock boundaries.

Figure 143. Grid for gate bay monolith analyses 
c. Film coefficients at exposed rock and concrete faces were as given in Chapter 3. All openings were assumed covered. Covered openings were simulated by using a film coefficient of $0.01 \mathrm{Btu} / \mathrm{day}-\mathrm{in}^{2}-{ }^{\circ} \mathrm{F}$ at inside surfaces. Exposed surfaces were subjected to the ambient temperature curve shown in Figure 144.

d. Initial rock temperatures were determined from an analysis detailed below. Initial concrete temperature was $70^{\circ} \mathrm{F}$ for all lifts.

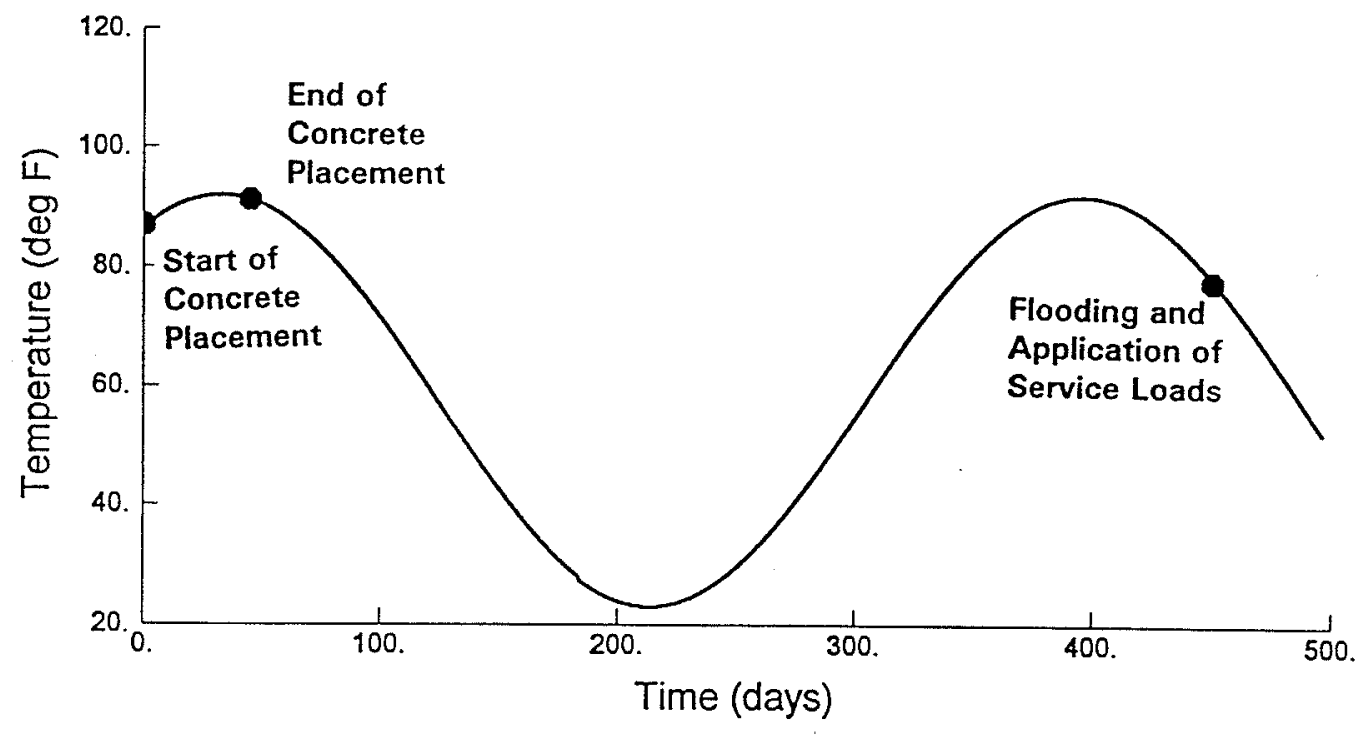

Figure 144. Ambient air temperature and concrete placement milestones

Initial rock temperatures were determined by an analysis of the rock elements only. All elements had a start-of-analysis temperature of $54^{\circ} \mathrm{F}$, and film coefficients were as given in Chapter 3. Rock surfaces were subjected to the ambient temperature curve for an analysis period of 1-1/2 years (544 days). Temperatures at the end of this analysis were used as the starting rock temperatures for the monolith analysis.

In the heat transfer analysis, lift 1 was placed on June 21 and subsequent lifts were placed at 5-day intervals. The final lift, lift 10 , was placed 45 days after the start of concrete placement. On day 450 the monolith was flooded with water at a temperature of $87^{\circ} \mathrm{F}$. Because the ambient temperature curve for water lags the ambient air temperature curve by about 30 days, this was $11^{\circ} \mathrm{F}$ warmer than the air temperature. The analysis was then continued for an additional 5 days. Heat transfer analysis milestones are noted on the ambient temperature curve in Figure 144. 


\section{Results}

Interior temperatures remained as high as $120^{\circ} \mathrm{F}$ for up to 100 days after the final concrete placement, while exterior temperatures dropped to near ambient shortly after placement. During the first $\mathbf{1 5 0}$ days of the analysis, the underlying rock was cooler than the air temperature. This allowed quicker dissipation of internal concrete temperatures at the base and lower right-hand areas of the monolith where the concrete abutted rock. Temperature contours at 60 days, 150 days, 210 days, and 450 days are shown in Figures 145 and 146. By day 450 , when the monolith was flooded, interior temperatures were cooler than exterior temperatures. Temperature histories at quarter points across the center of lift 7 are shown in Figure 147.

\section{Stress Analyses}

The grid shown in Figure 143 was also used in the stress analysis. Elements were 8 node plane stress with reduced integration. Reinforcing is shown in Figure 148.

Foster and Jones (1994) suggest a rock depth of 1-1/2 times the foundation width and a width of 3 times the foundation width for ensuring boundary conditions at the foundation edges will not affect the stresses in the structure. However, since the rock was to be modeled as an elastic material, the rock exterior to the existing grid (as shown in Figure 143) could adequately be modeled using vertical and lateral springs at the outer boundaries. Modeling the foundation using the springs instead of elements greatly reduces the amount of computer resources required to perform the analysis. To calculate the spring coefficients a model of the rock $150 \mathrm{ft}$ in depth was constructed and a uniform load was applied at the top surface of the model. Displacements at a depth of $20 \mathrm{ft}$ were obtained from the analysis. From these displacements a representative displacement was selected and a spring coefficient was calculated from this displacement using the elastic modulus of the rock (7,500,000 psi) and an average tributary length of 15 in., the average length between adjacent nodes. This spring coefficient was then applied uniformly to the boundary of the rock elements.

The bond-breaking material between the sides of the monolith and the adjoining rock was simulated by adding an extra set of nodes at the concrete/rock boundary and joining the nodes with gap elements. Material properties for the rock, the interior concrete, and the exterior concrete are given in Chapter 2.

Loading for the analysis included nodal temperatures from the heat transfer analysis, concrete dead load, which was applied when forms were removed, and service loads, which were applied on day 455 . Vertical and ceiling forms were assumed to be removed 2 and 5 days after concrete placement, respectively. Service loads included exterior soil to the top of concrete on the 


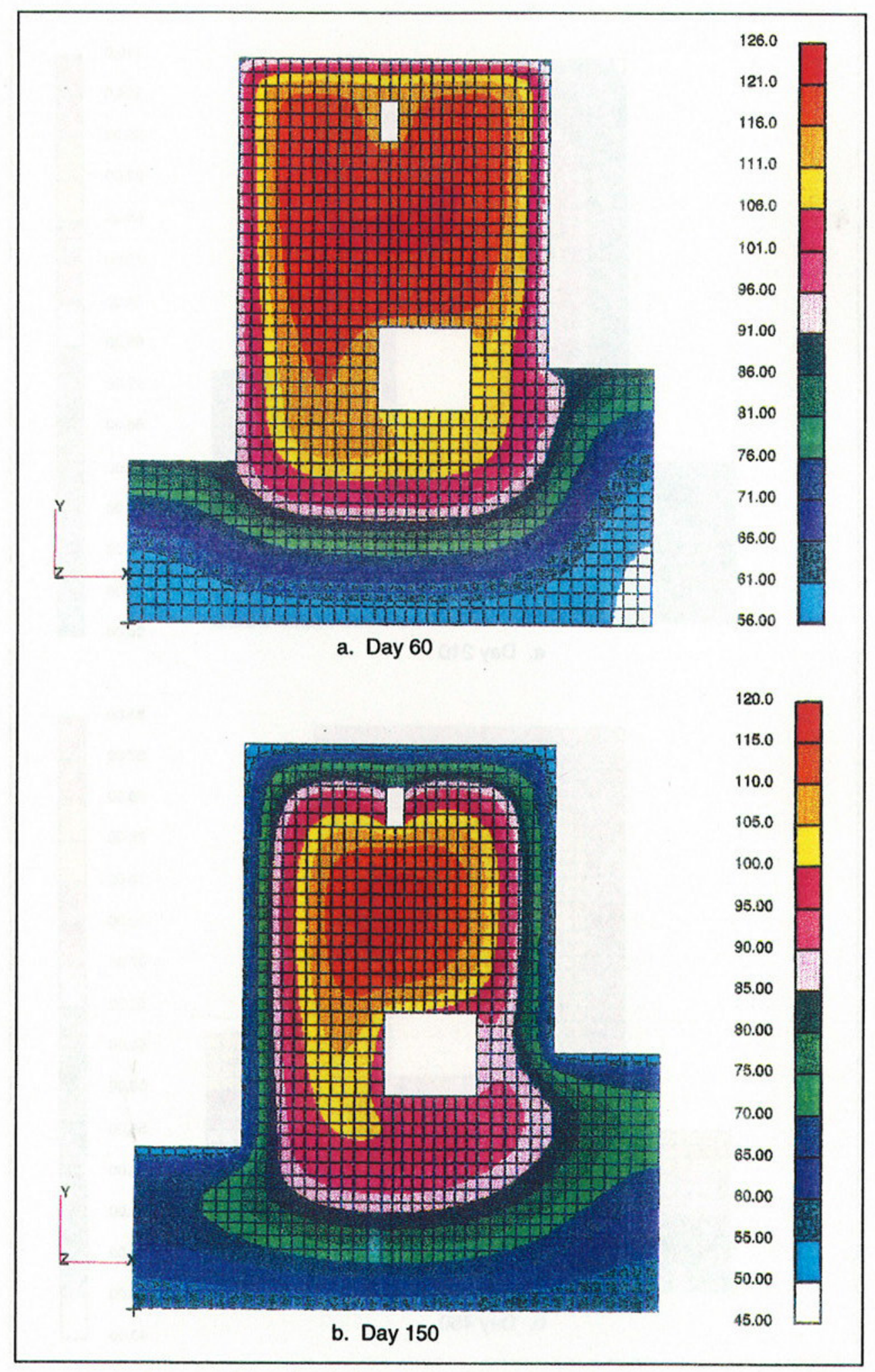

Figure 145. Temperature contours, days 60 and 150 


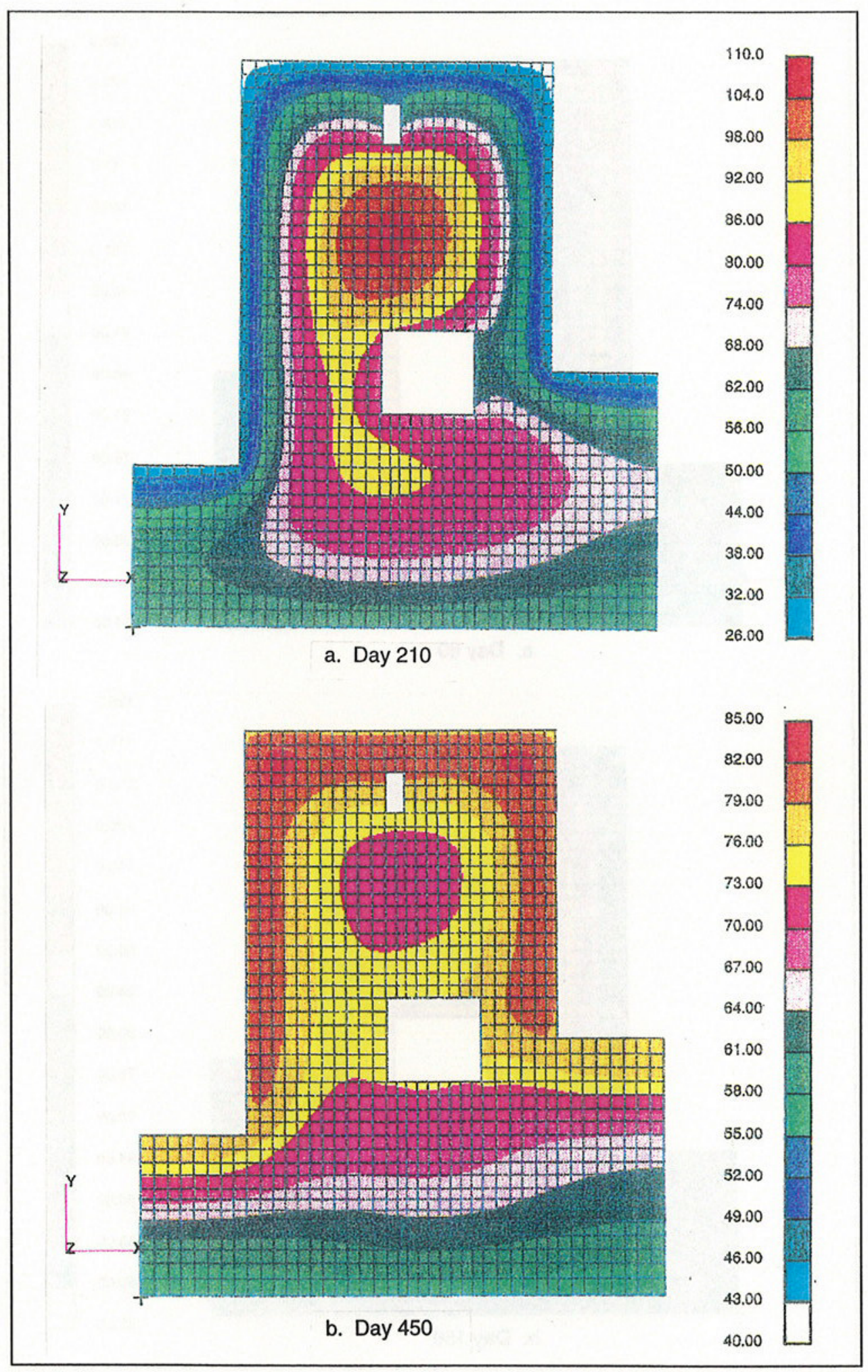

Figure 146. Temperature contours, days 210 and 450 


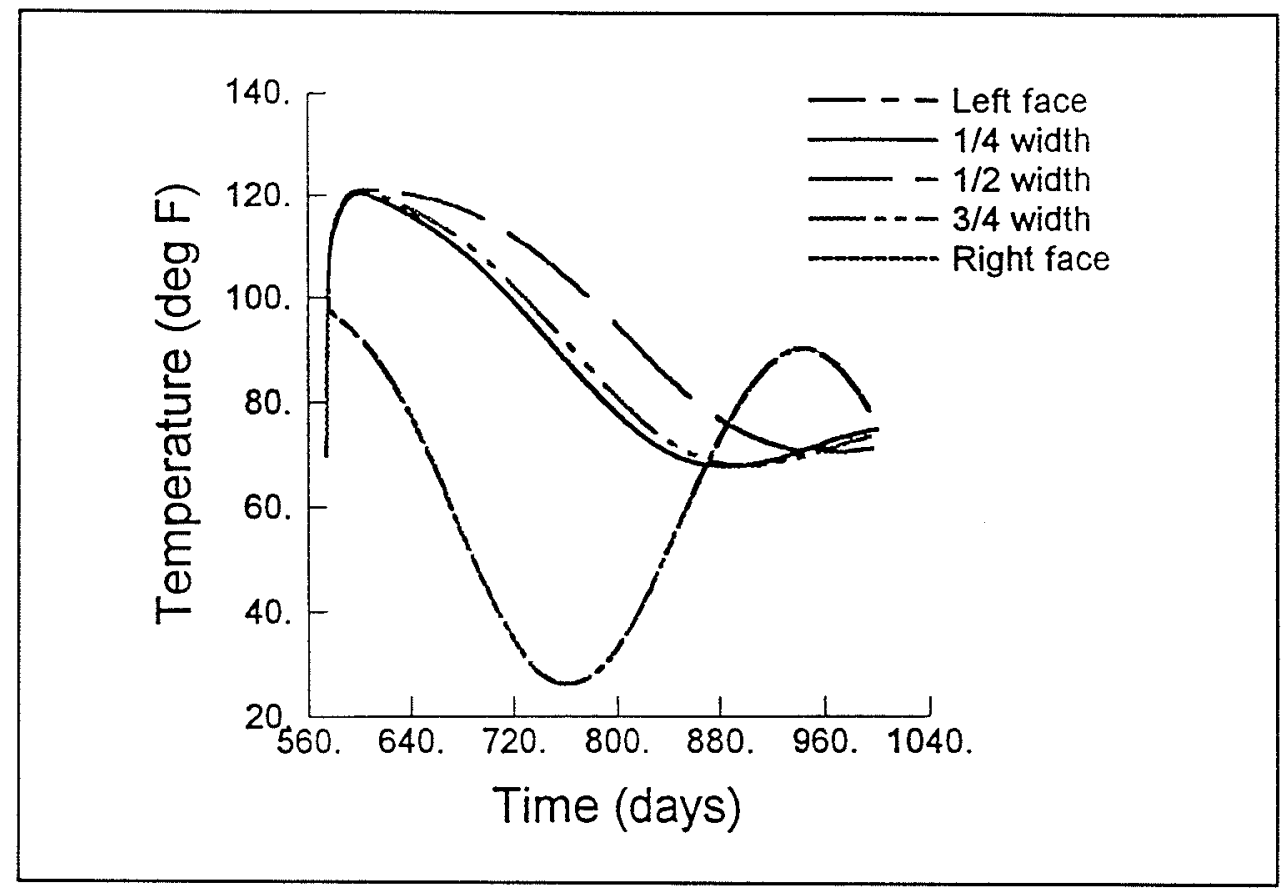

Figure 147. Nodal temperatures, center of lift 7

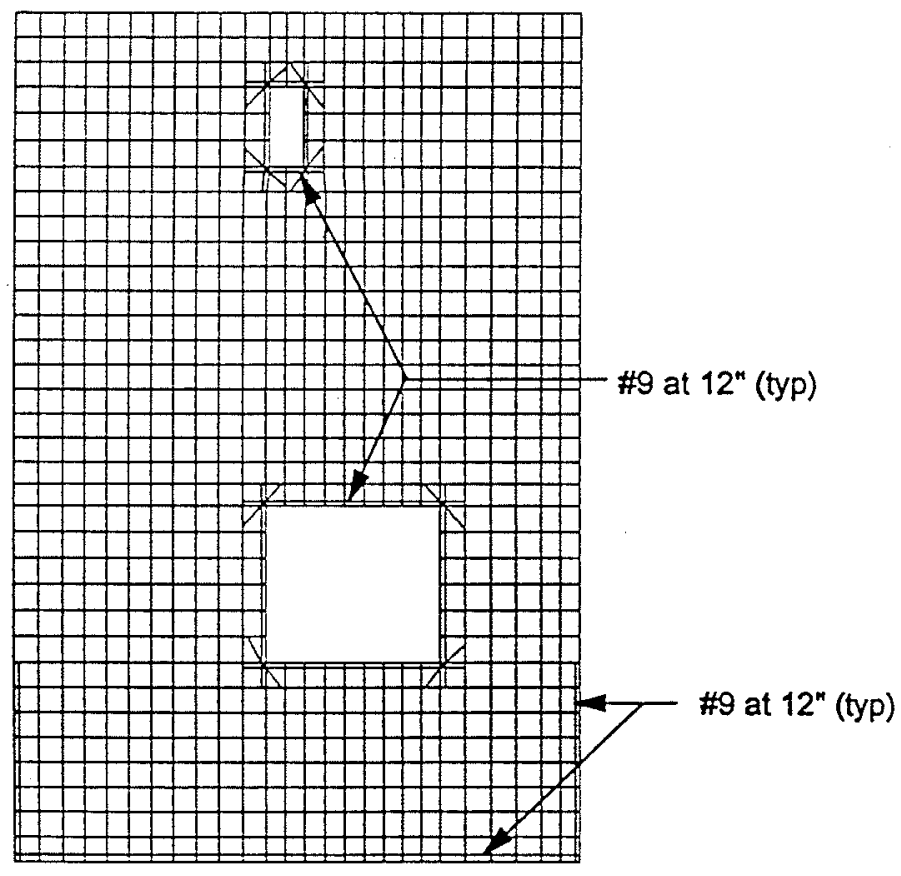

Figure 148. Monolith reinforcing 
landside and water to elevation 383 on the interior lock face. As for the chamber monolith analysis, a soil density of $126 \mathrm{pcf}$ was used with a lateral earth pressure coefficient of 0.47 .

\section{Results}

Crack plots at days 59, 77, 303, and 454 are shown in Figures 149 through 152. Crack potential contours for days 49,283 , and 454 are shown in Figures 153 through 156 . Stresses for days $60,240,450$, and 455 are shown in Figures 157 through 164.

Initial cracking, shown in Figure 149, occurred at the base of the monolith on the landside approximately 60 days after the start of concrete placement. Stresses in horizontal reinforcement in the right-hand base element, shown in Figure 165, were compressive throughout the analysis. By day 60 the area below and to the right of the culvert was several degrees cooler than the concrete on the other side of the culvert due to heat loss through the rock due to the thinner concrete section. However, contraction due to cooling was prevented by the bond between the concrete and the rock. Since the rock was elastic, cracking occurred in the concrete at the integration points nearest the rock/concrete interface. By day 65 this cracking extended up the right-hand face of the two lower right-hand elements in lift 1. By day 77, horizontal cracks, shown in Figure 150, formed near the right-hand side of the interface between lifts 1 and 2 due to high vertical stresses in that area. Stresses in the vertical reinforcement in this face were low throughout the analysis and are shown in Figure 166. Little additional cracking occurred until after the monolith was flooded on day 450 . By day 450 the interior concrete was cooler than the exterior concrete, and vertical stresses around the culvert were on the order of 100 to 300 psi in Figure 160. The additional cooling that occurred when the culvert was flooded increased those stresses and resulted in the cracking shown in Figure 152. However, these cracks did not extend beyond one integration point into the culvert walls except at the lower left-hand comer, where cracking occurred at a second integration point. Reinforcing stresses at this comer, shown in Figure 167, were less than 20,000 psi and decreased between days 454 and 455 . Reinforcing stresses at the lower right-hand comer remained compressive and are shown in Figure 168. Maximum cracking potentials for day 454 are shown in Figure 156. The maximum cracking potential at the culvert corners and base was 82.5 percent. Maximum cracking potential around the gallery was 66 percent. Cracking potentials throughout the rest of the monolith were less than 20 percent.

\section{Conclusions}

Maximum principal stresses were low throughout most of the analysis except in lift 1, at the outer faces of the monolith, and at culvert corners. High tensile stresses in the first lift were a result of restraint to lateral strains 


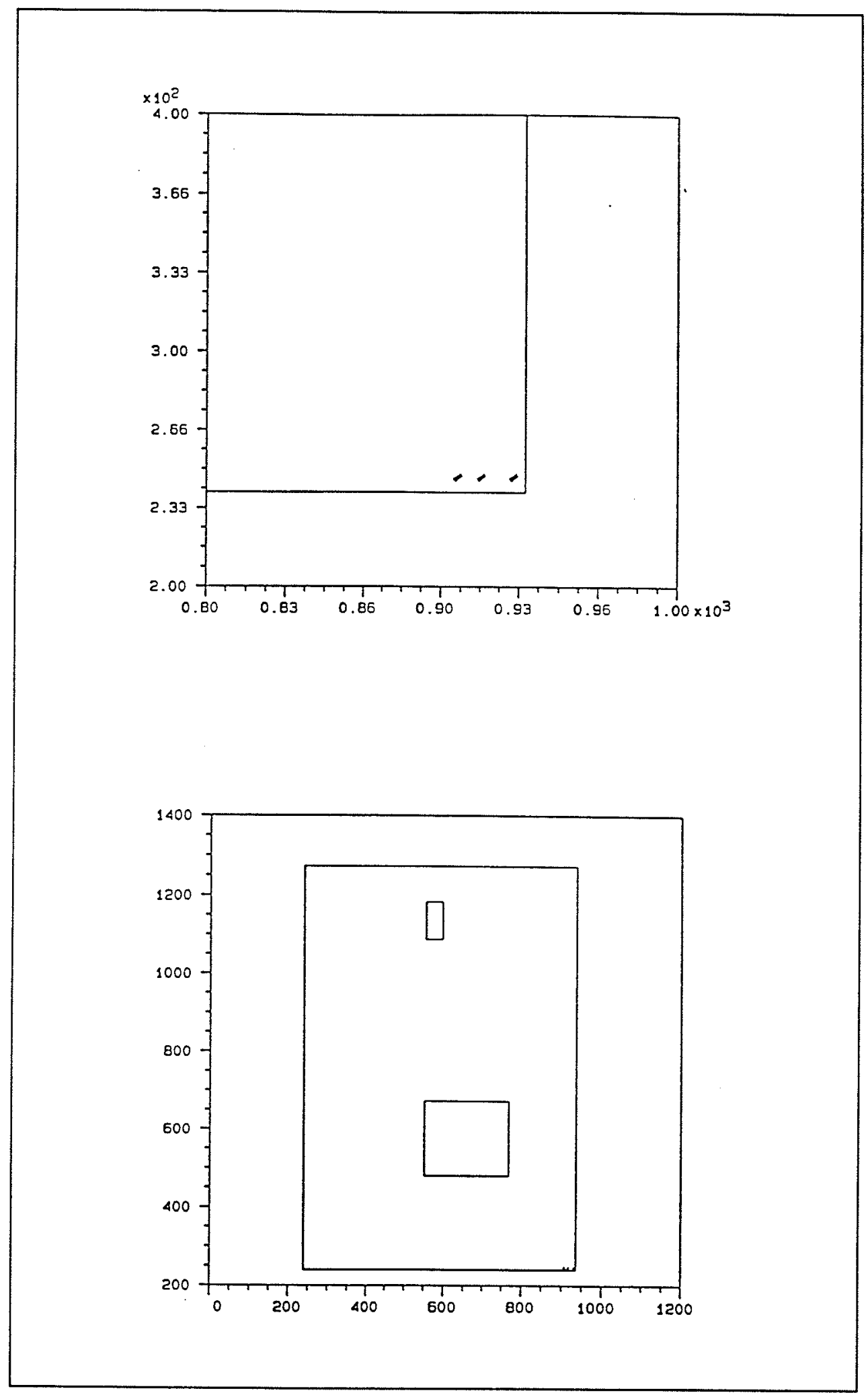

Figure 149. Cracking, day 59 

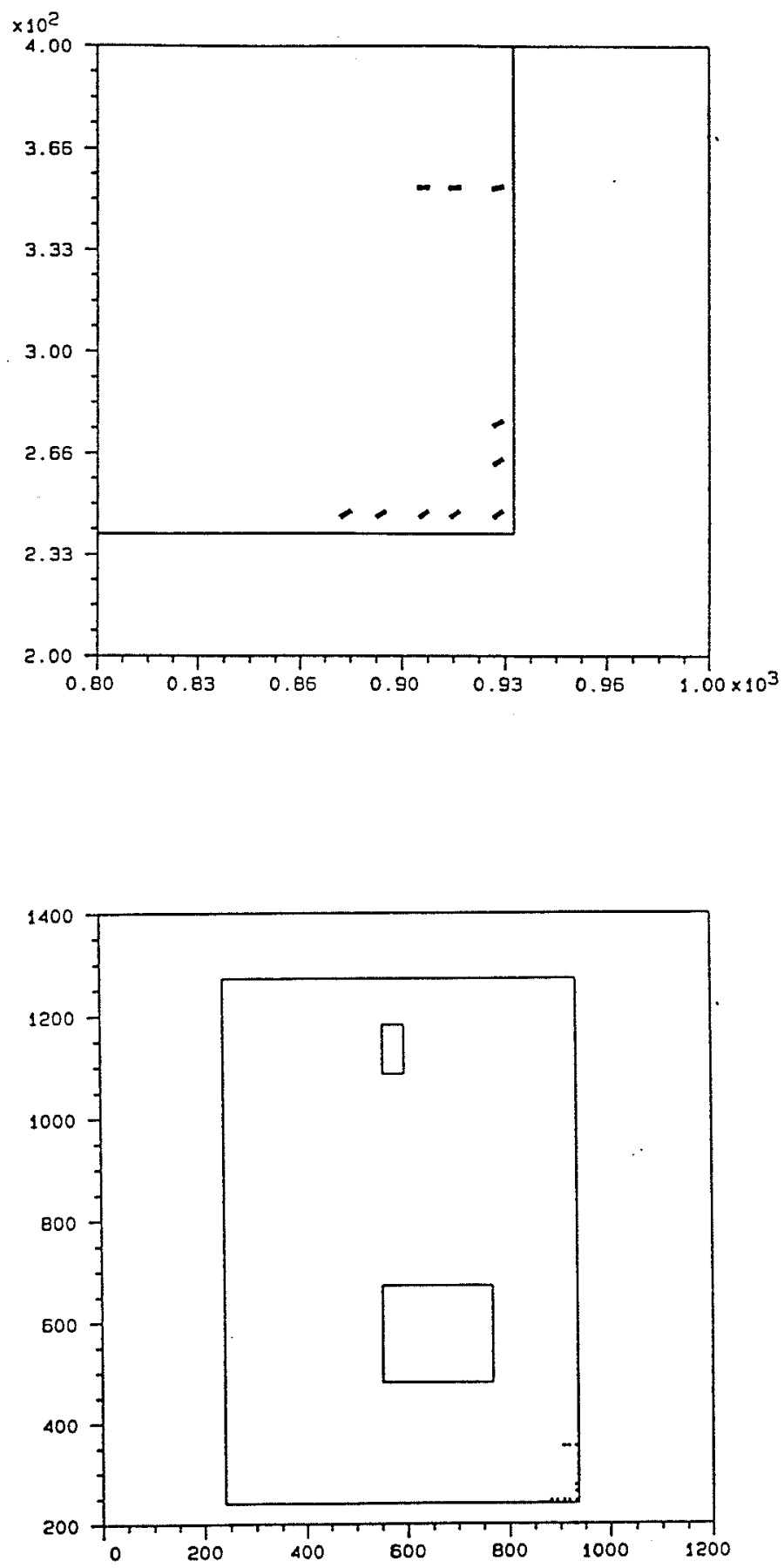

Figure 150. Cracking, day 77 


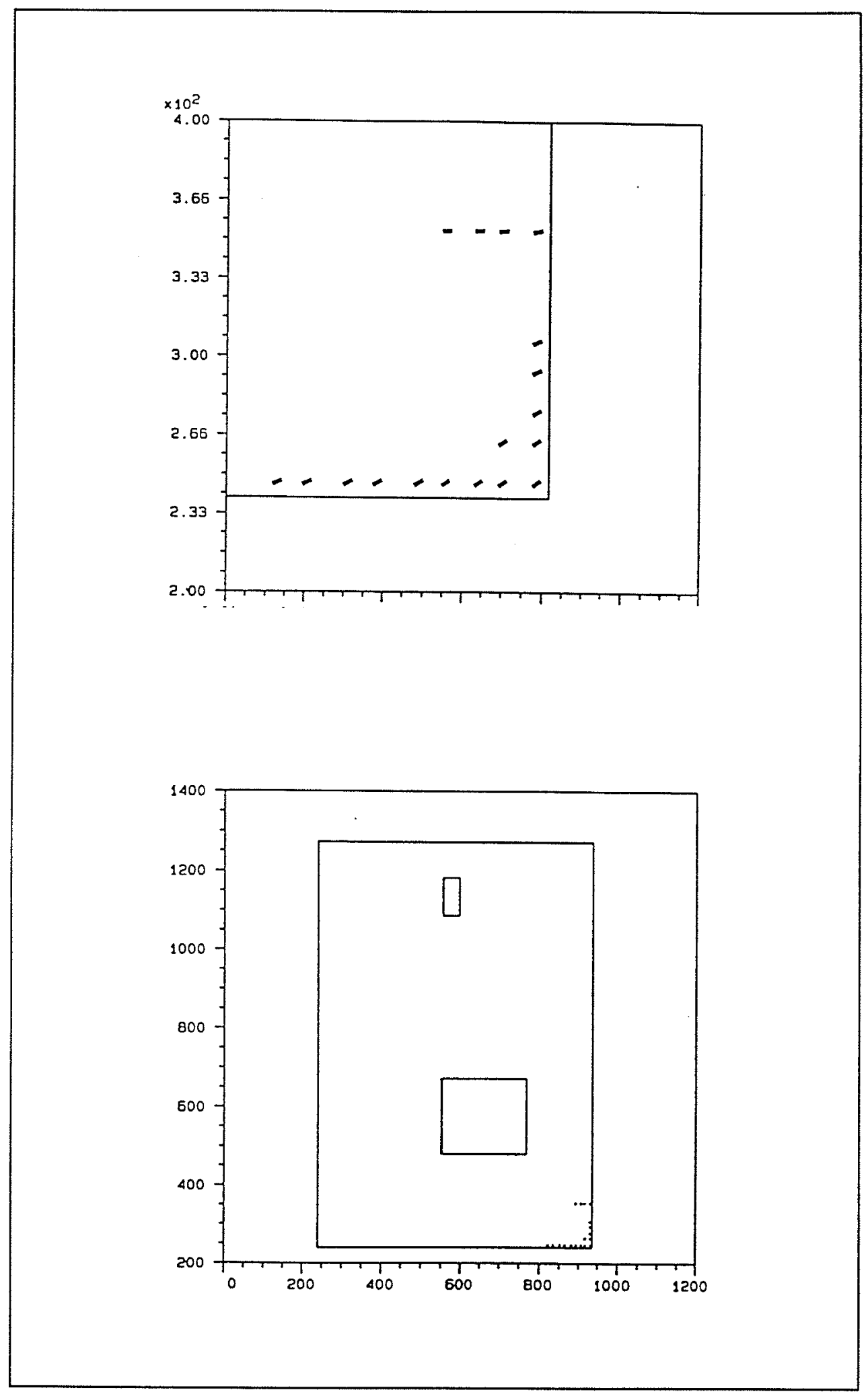

Figure 151. Cracking, day 303 


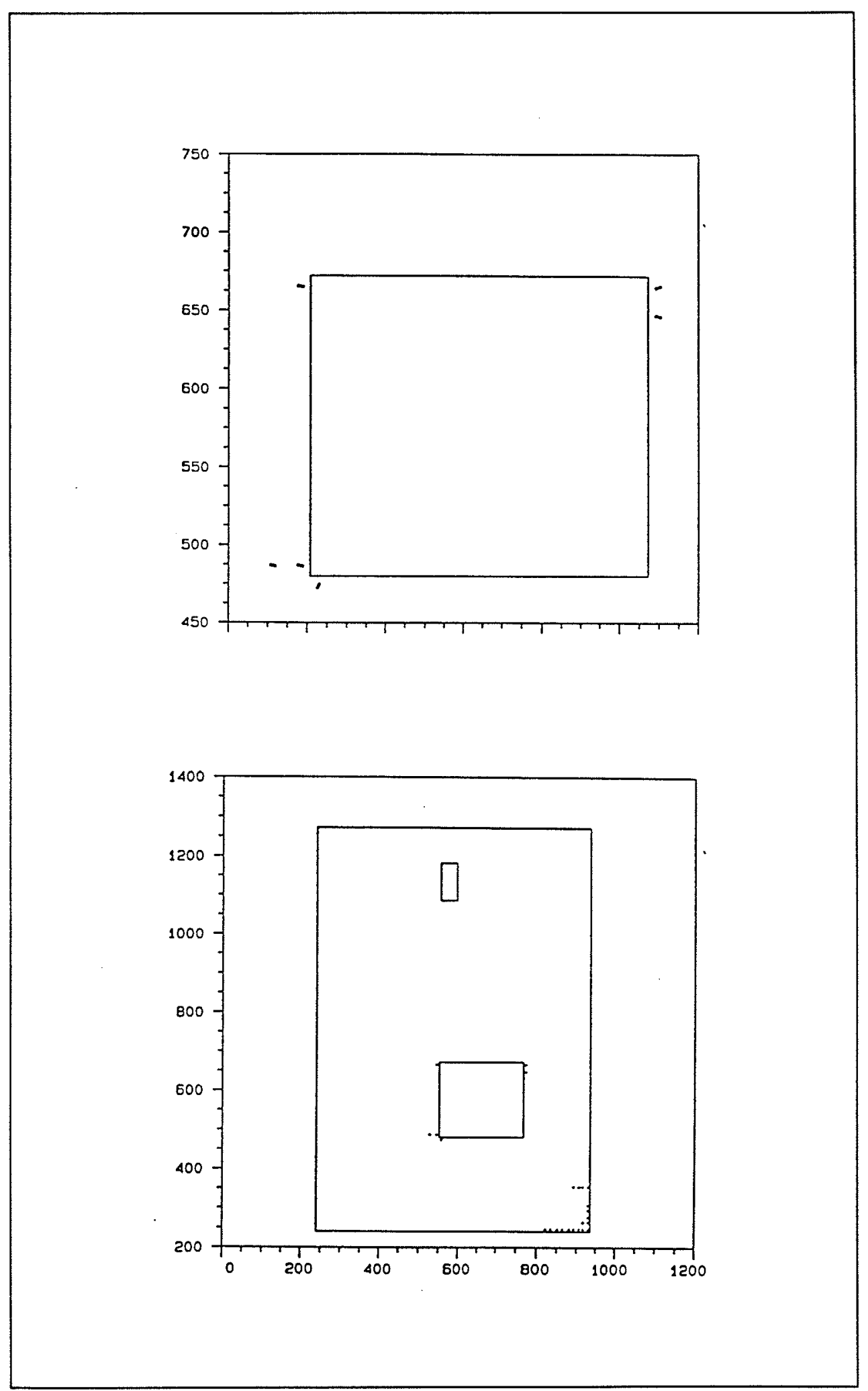

Figure 152. Cracking, day 454 


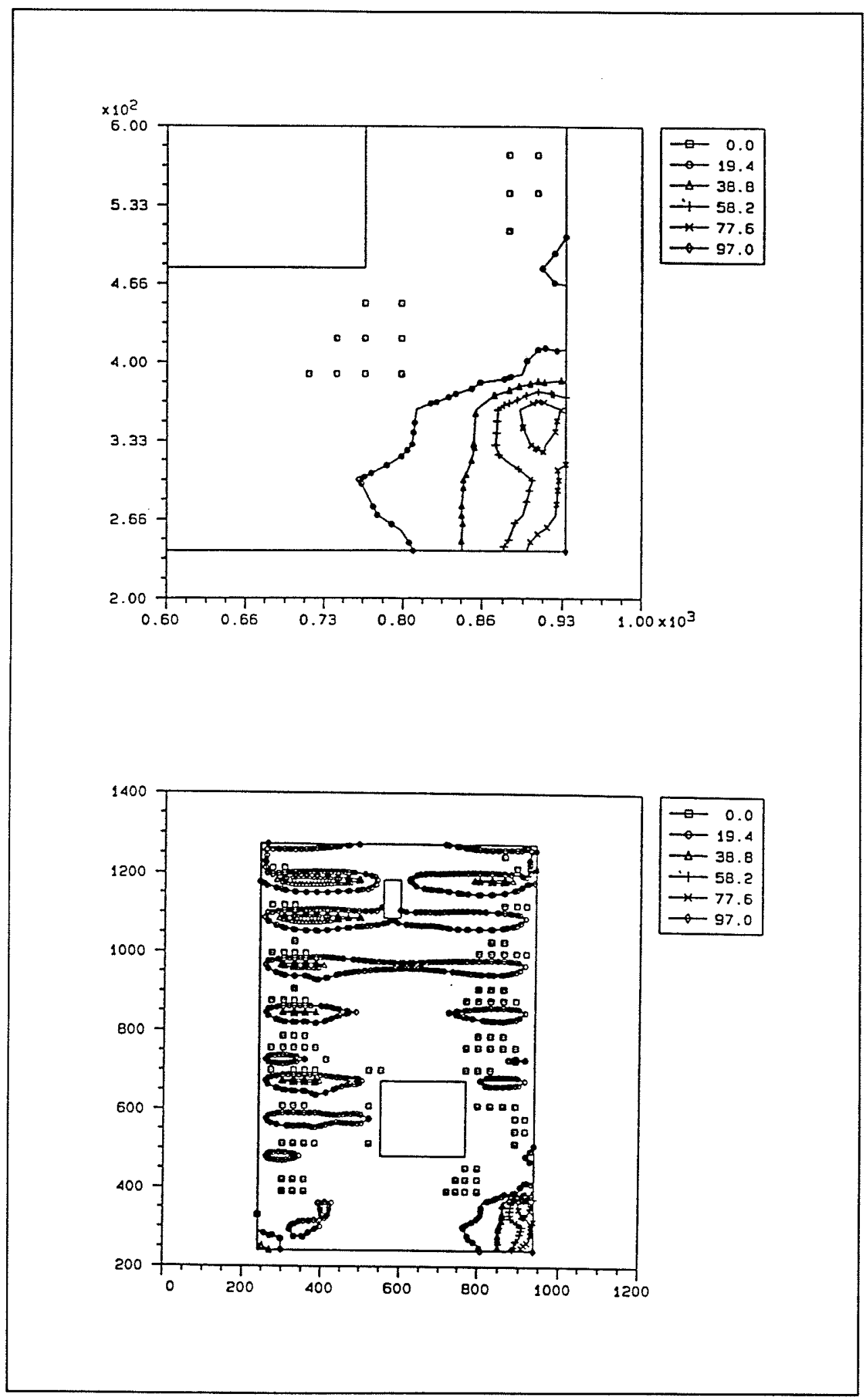

Figure 153. Cracking potential, day 49 

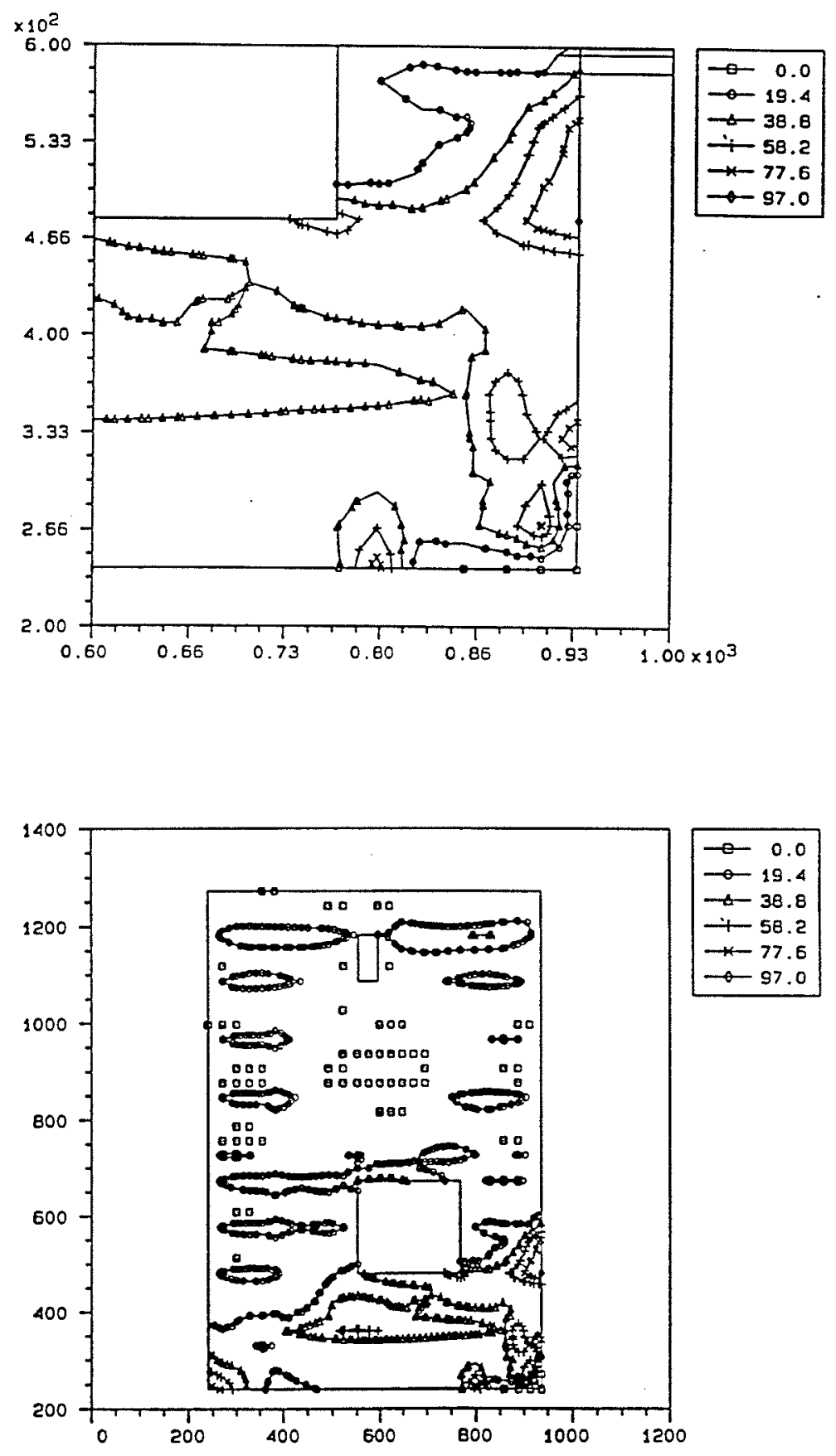

Figure 154. Cracking potential, day 283 


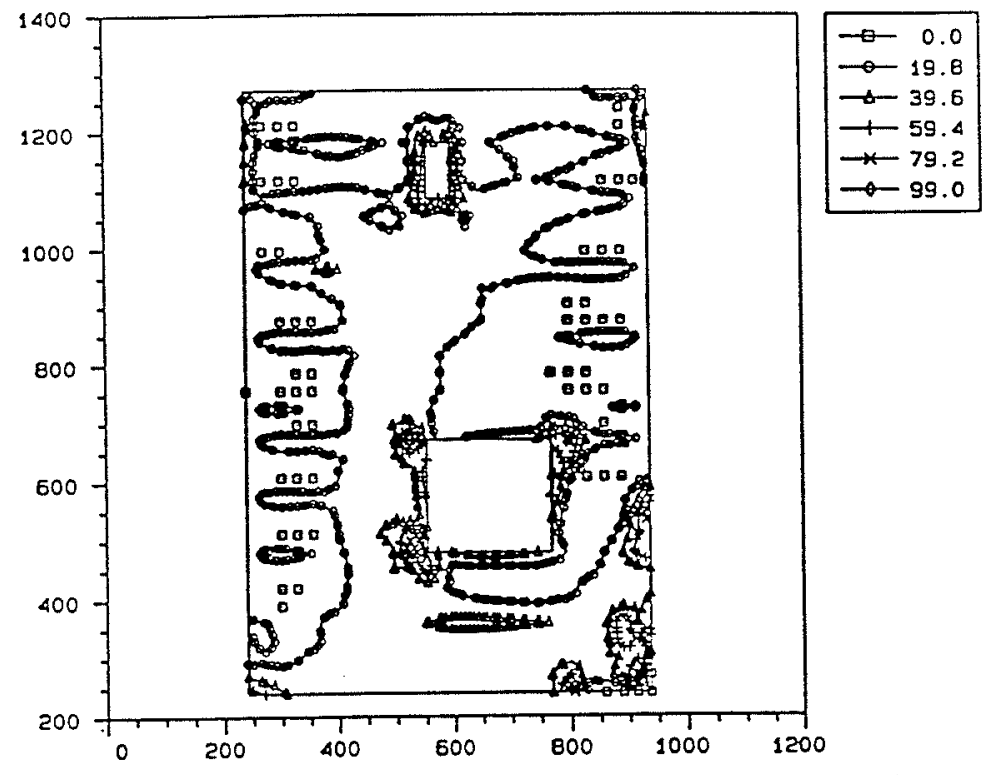

a) Monolith

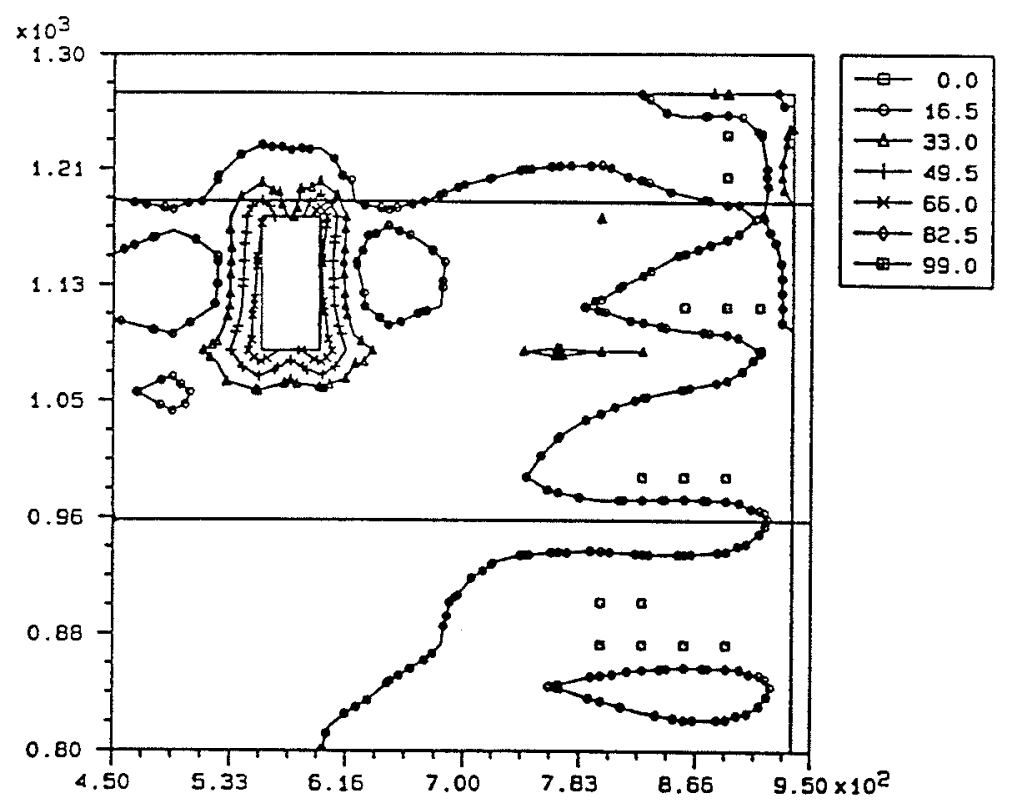

b) In gallery area

Figure 155. Cracking potential, day 454 


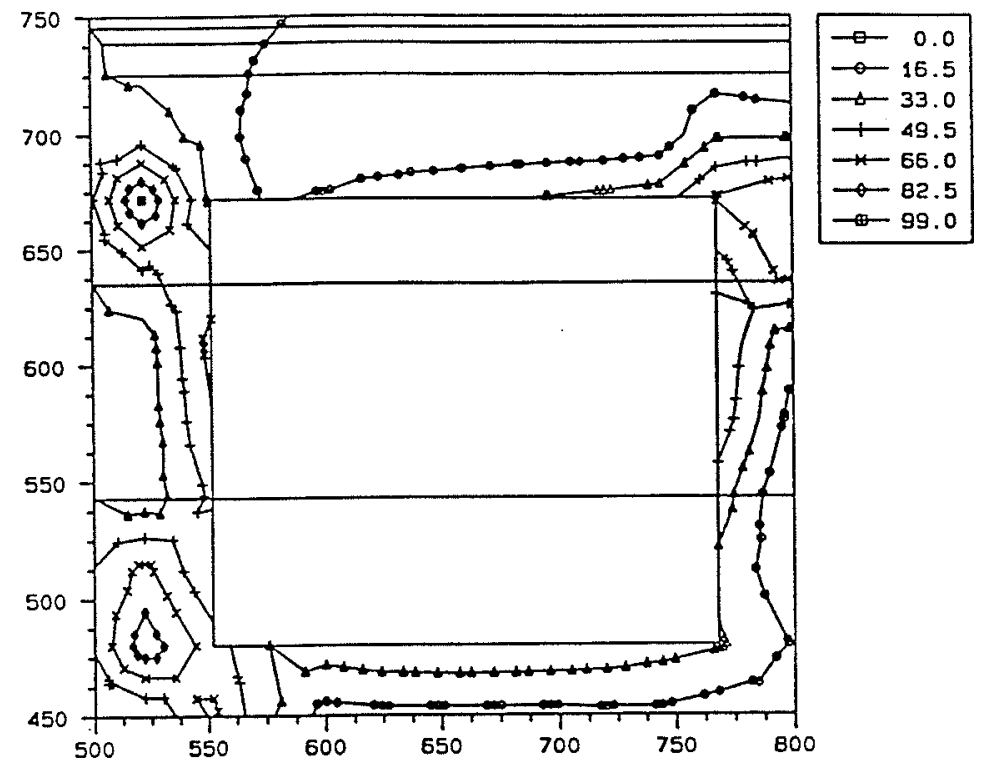

a) In culvert area

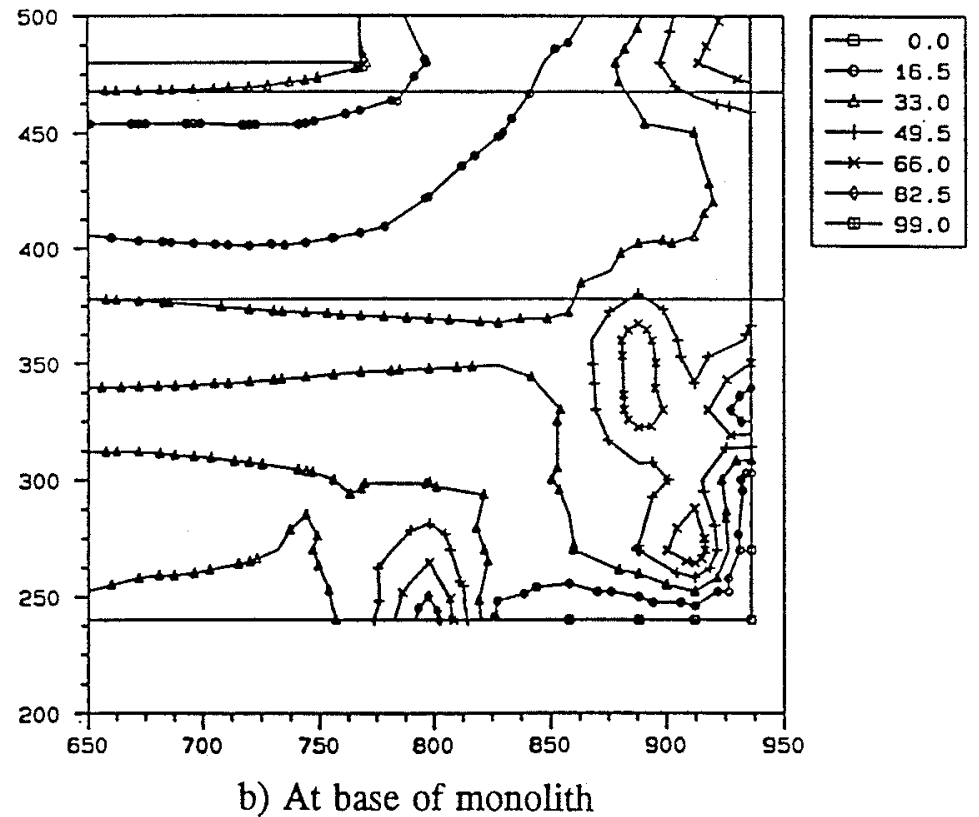

Figure 156. Cracking potential, day 454 

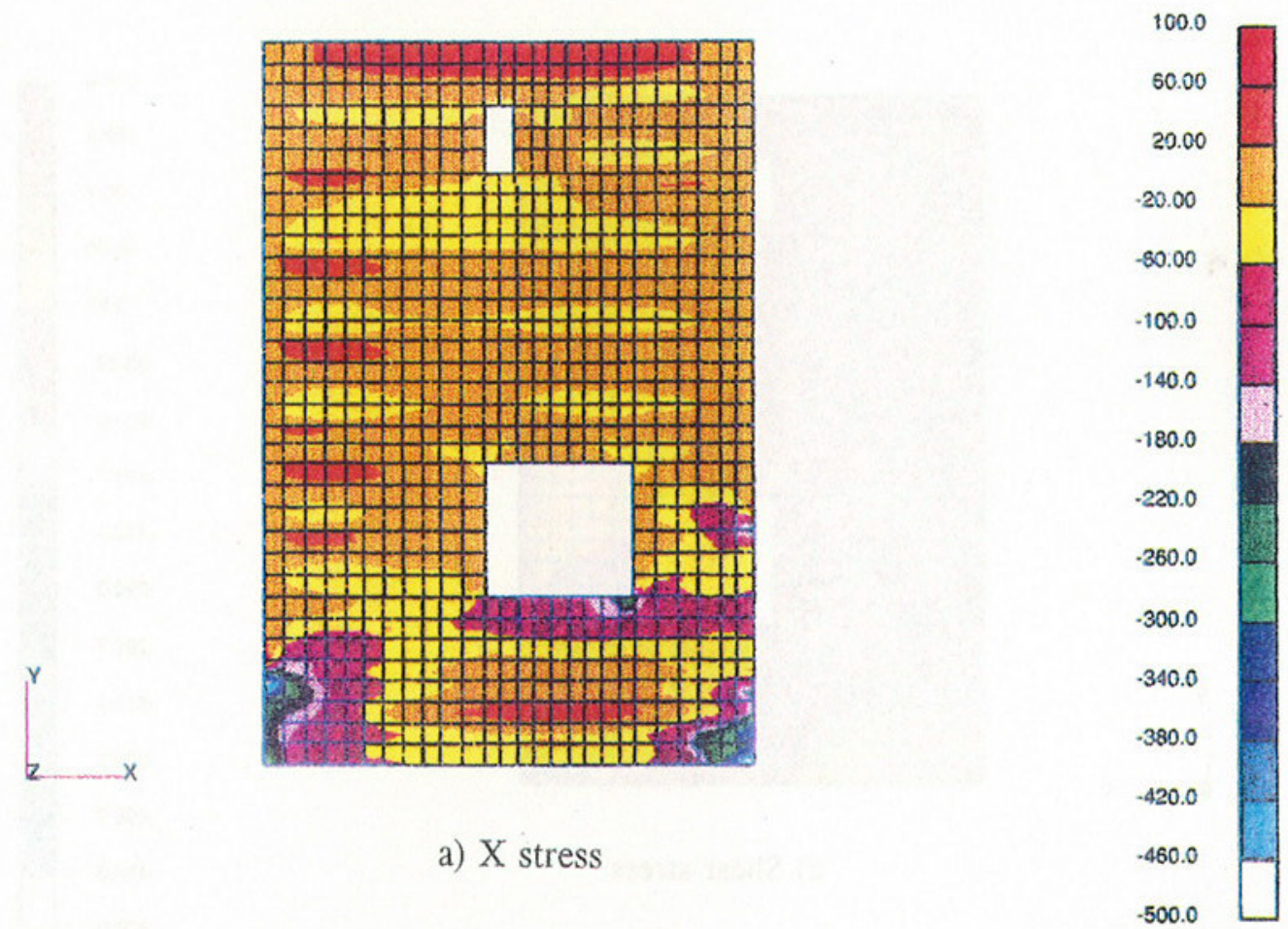

a) X stress
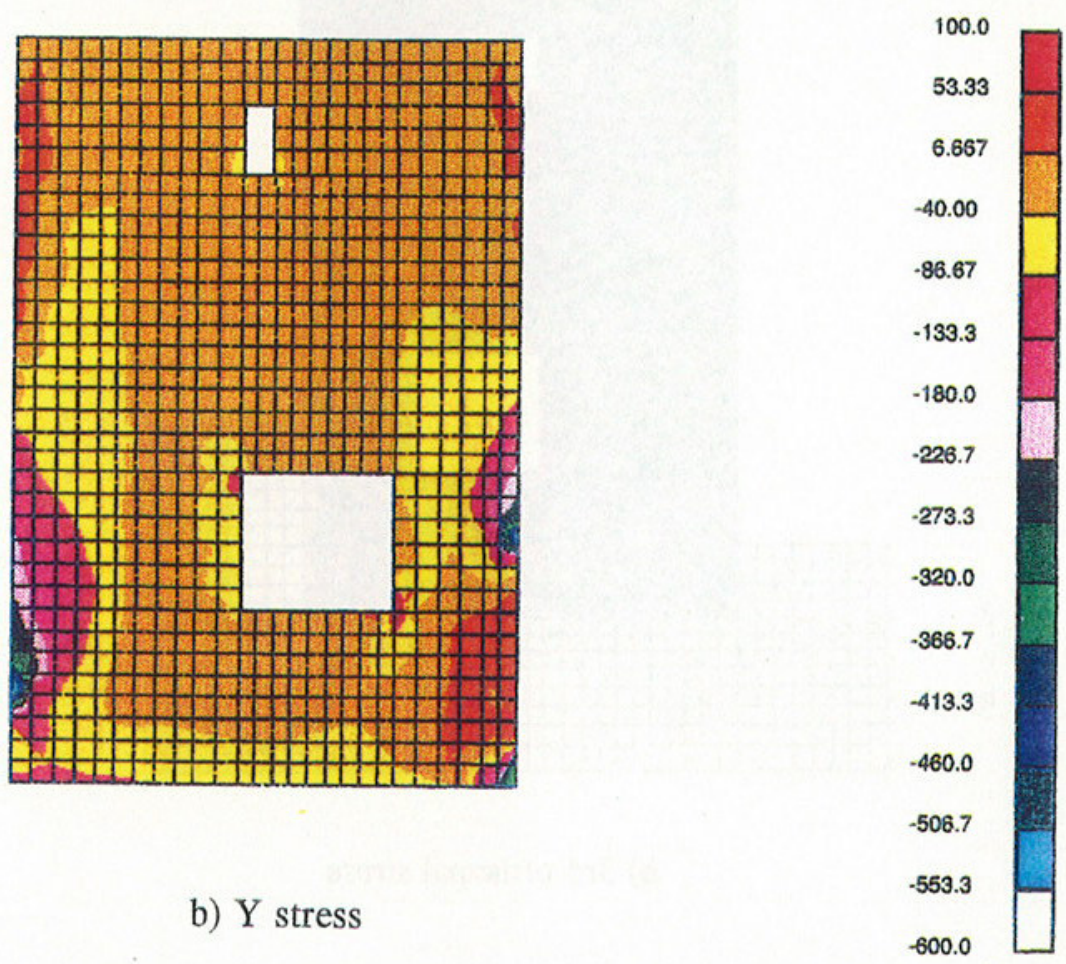

Figure 157. $X$ and $y$ stresses, day 60 


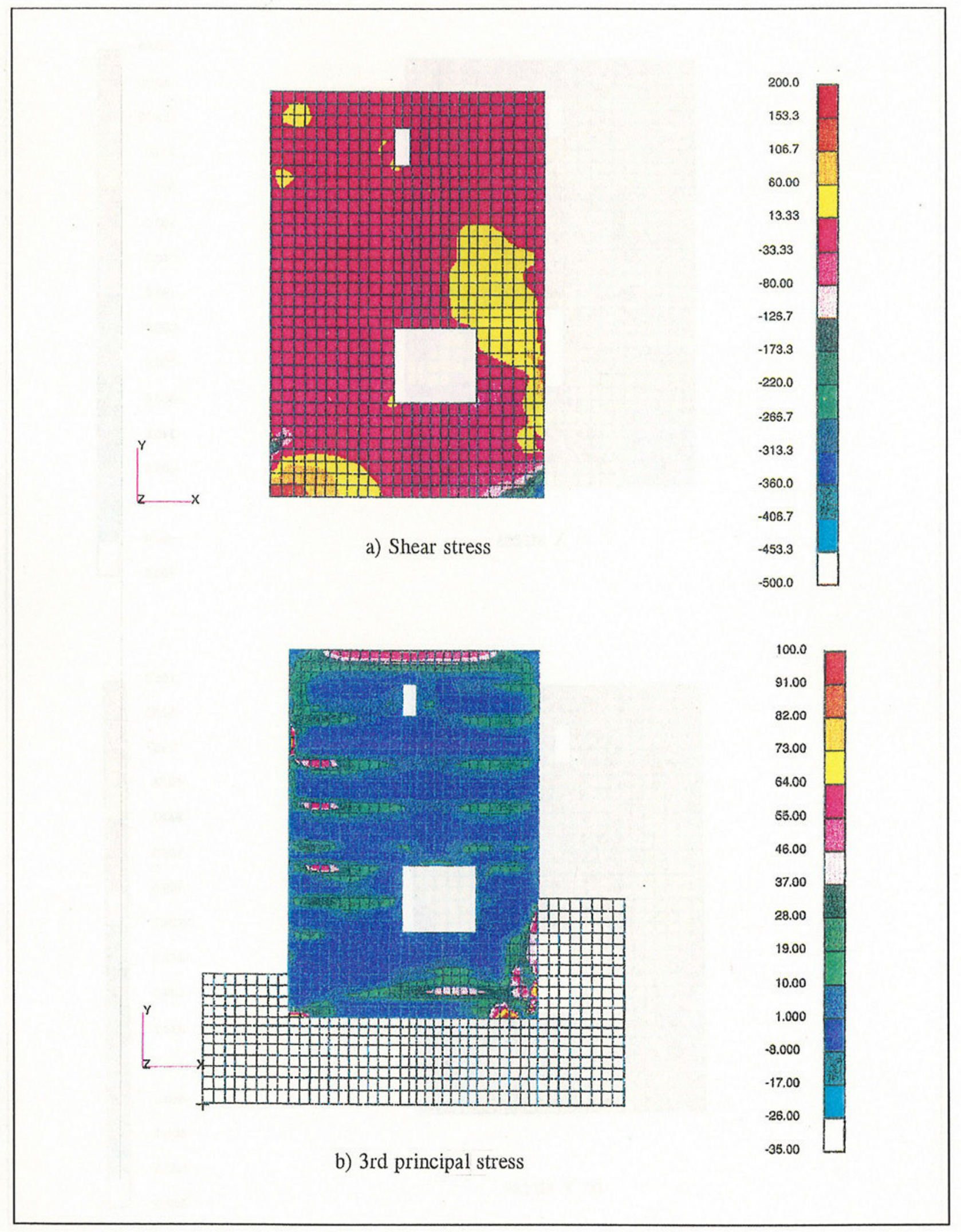

Figure 158. Shear and third principal stress, day 60 

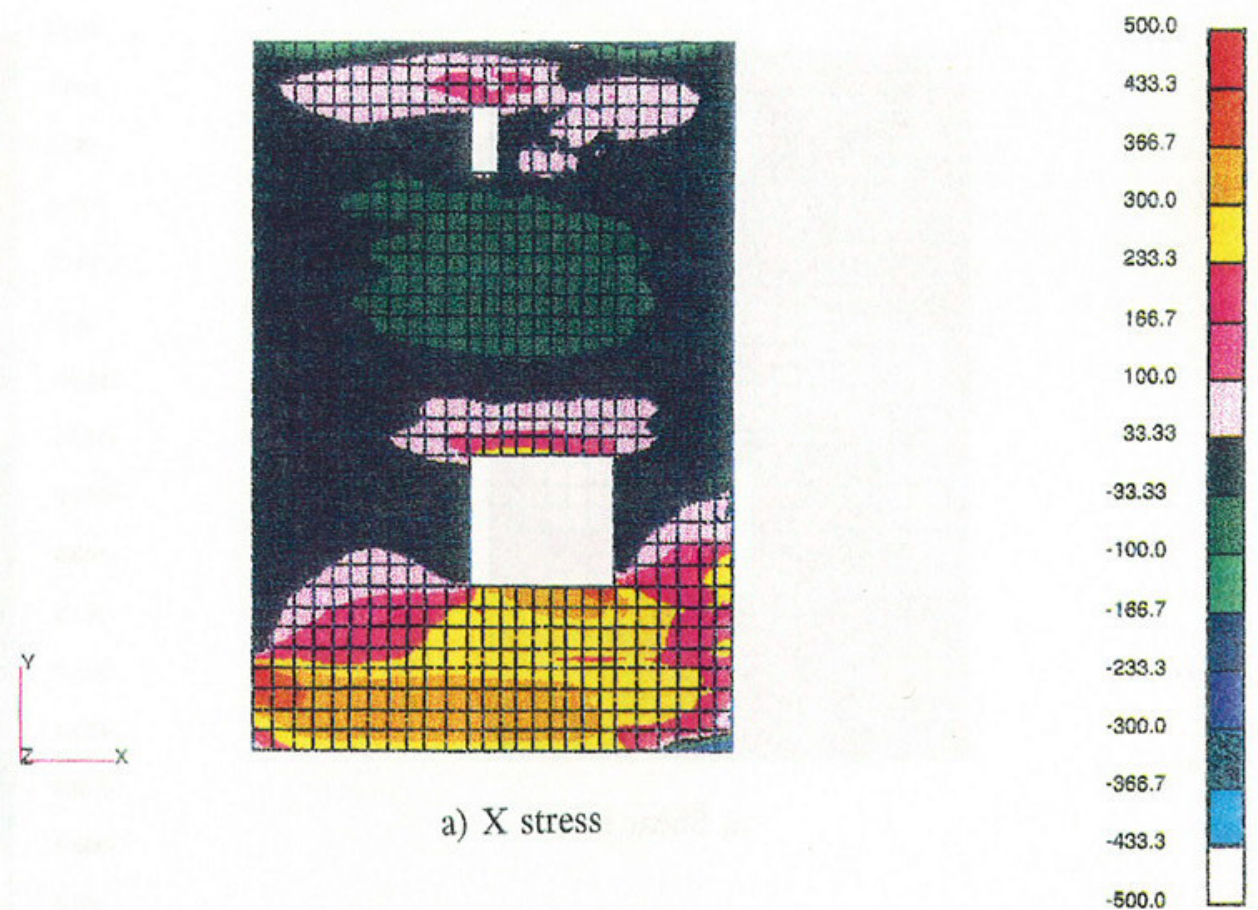

a) X stress
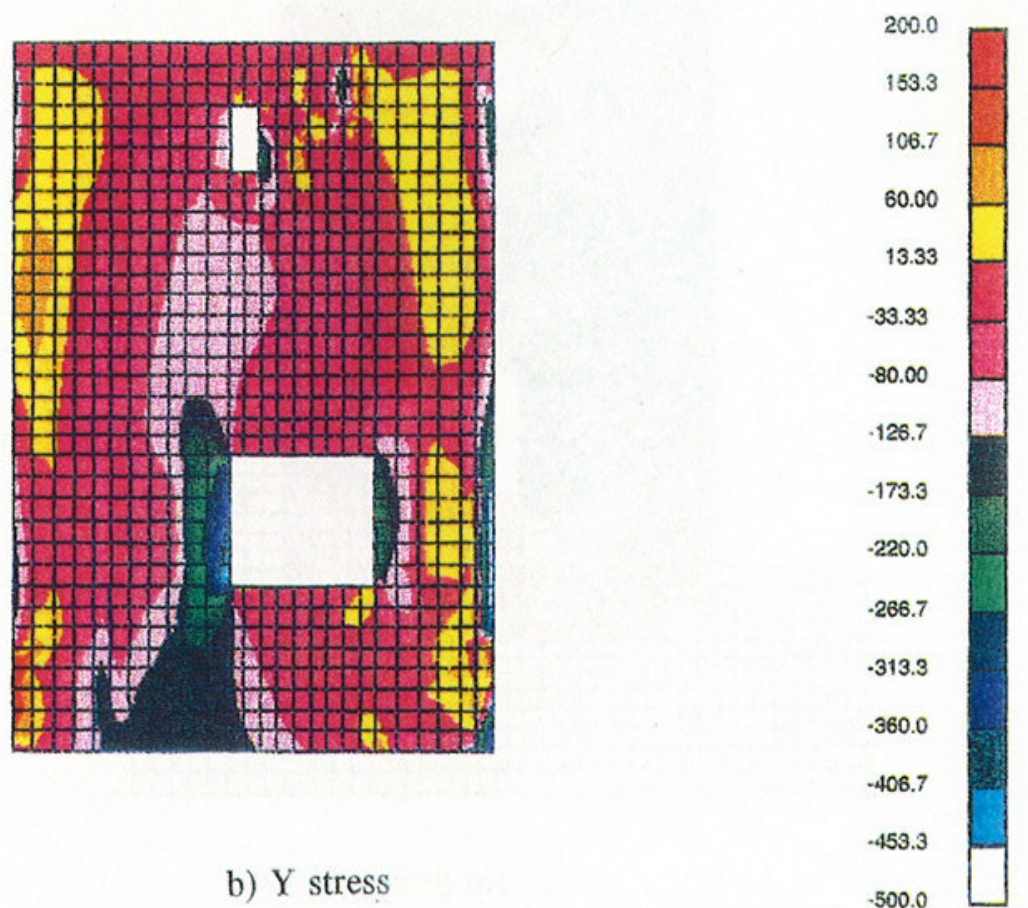

Figure 159. $X$ and $y$ stress, day 240 

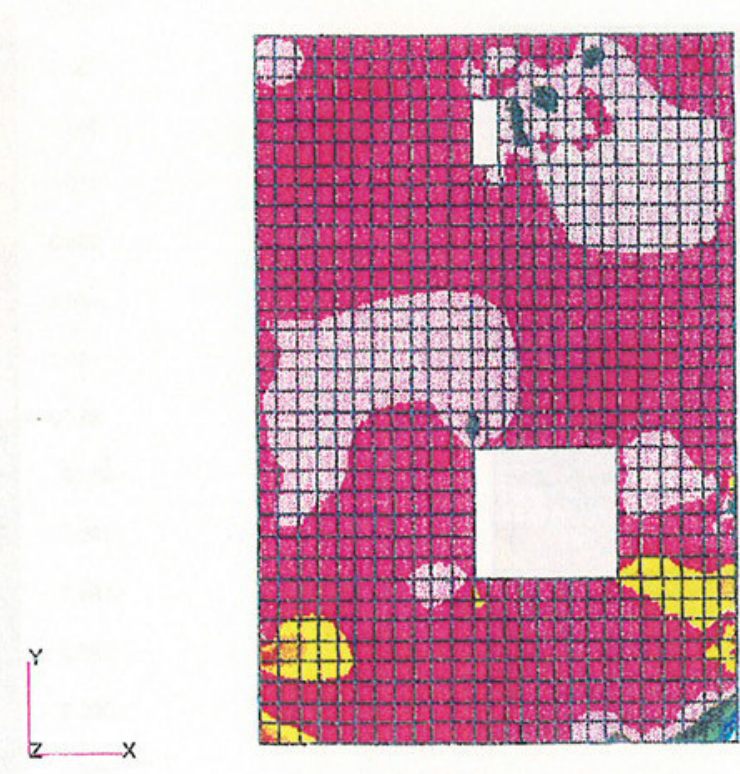

a) Shear stress
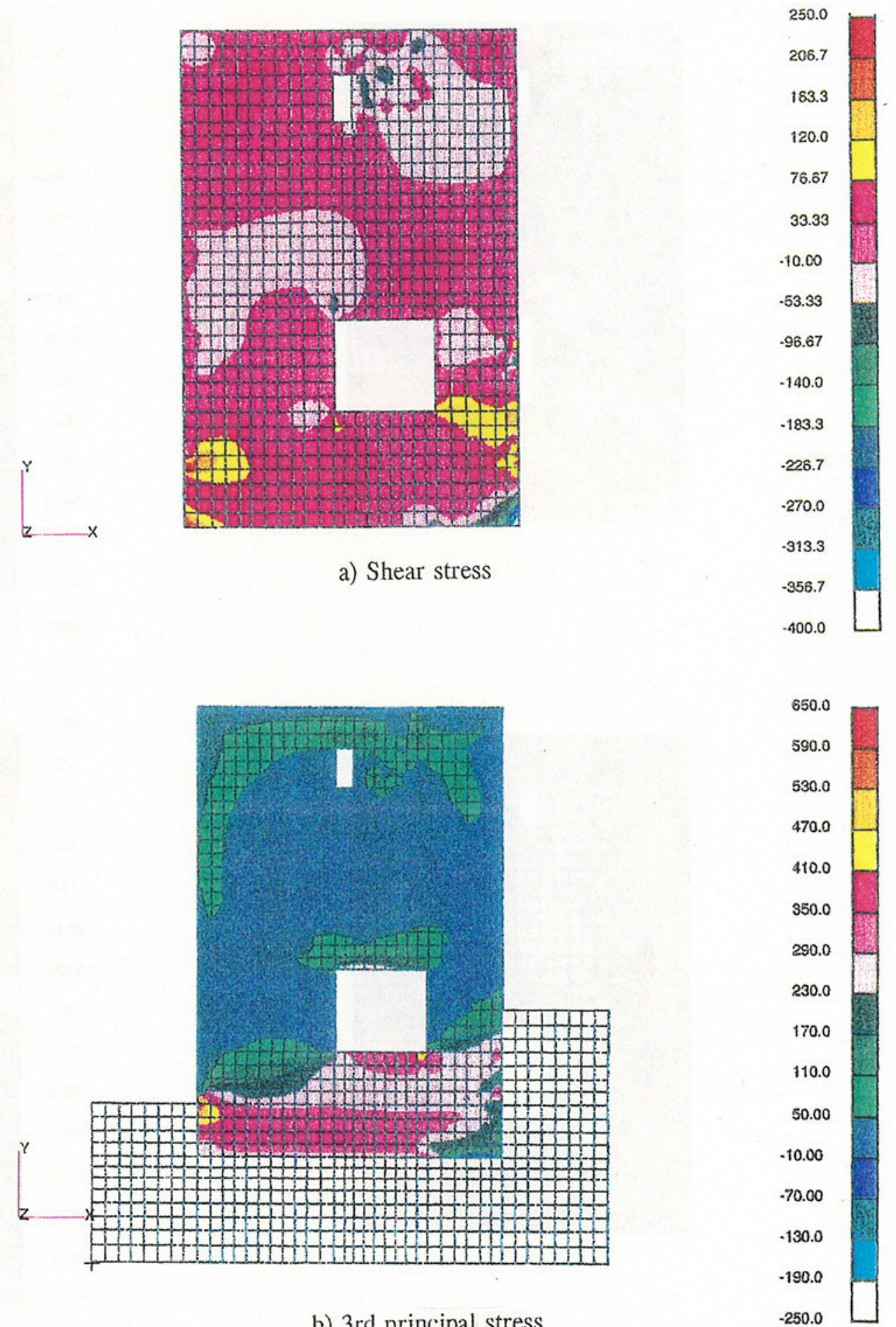

b) 3rd principal stress

$-250.0$

\section{Figure 160. Shear and third principal stress, day 240}



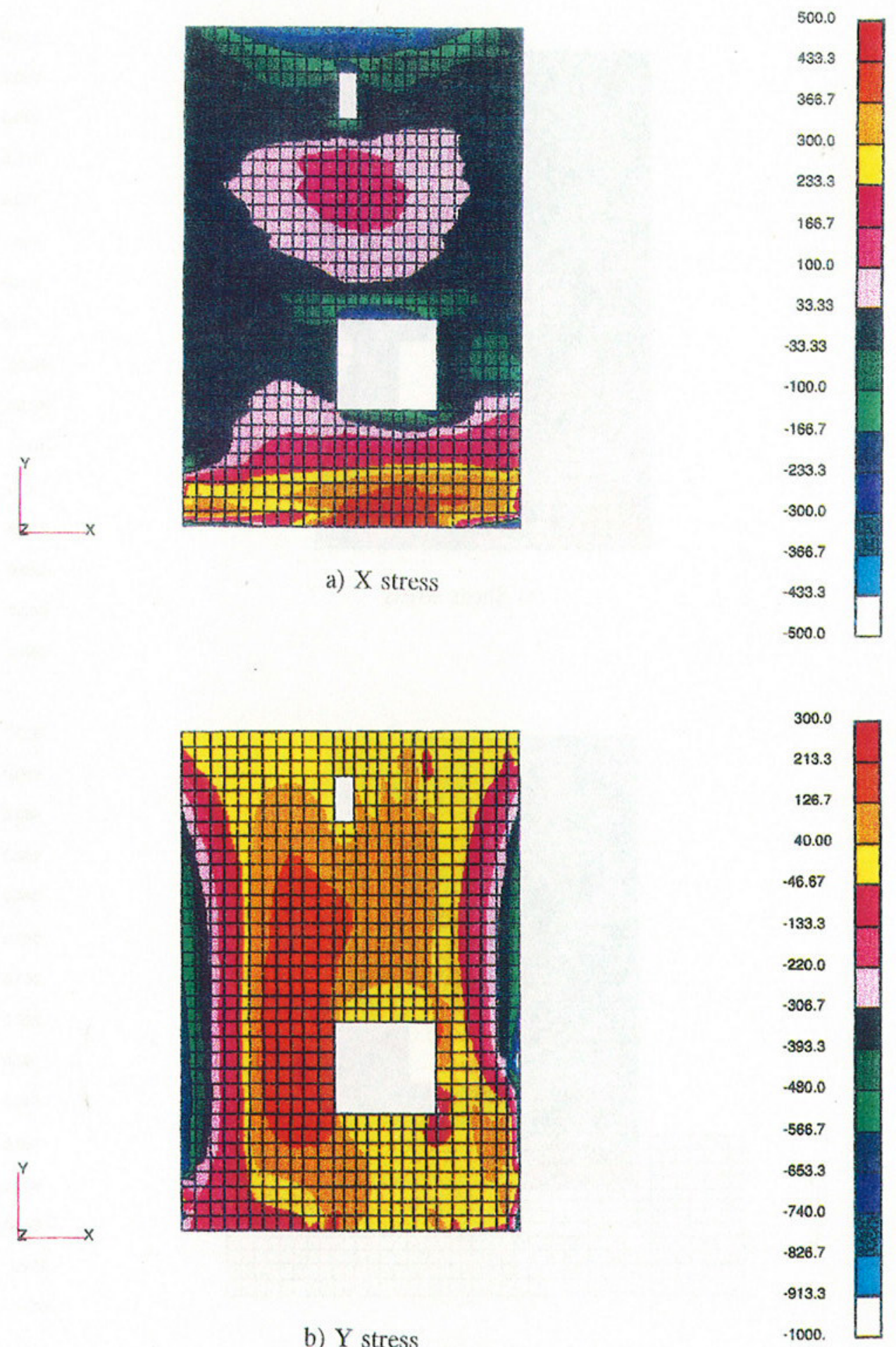

Figure 161. $X$ and $y$ stress, day 450 


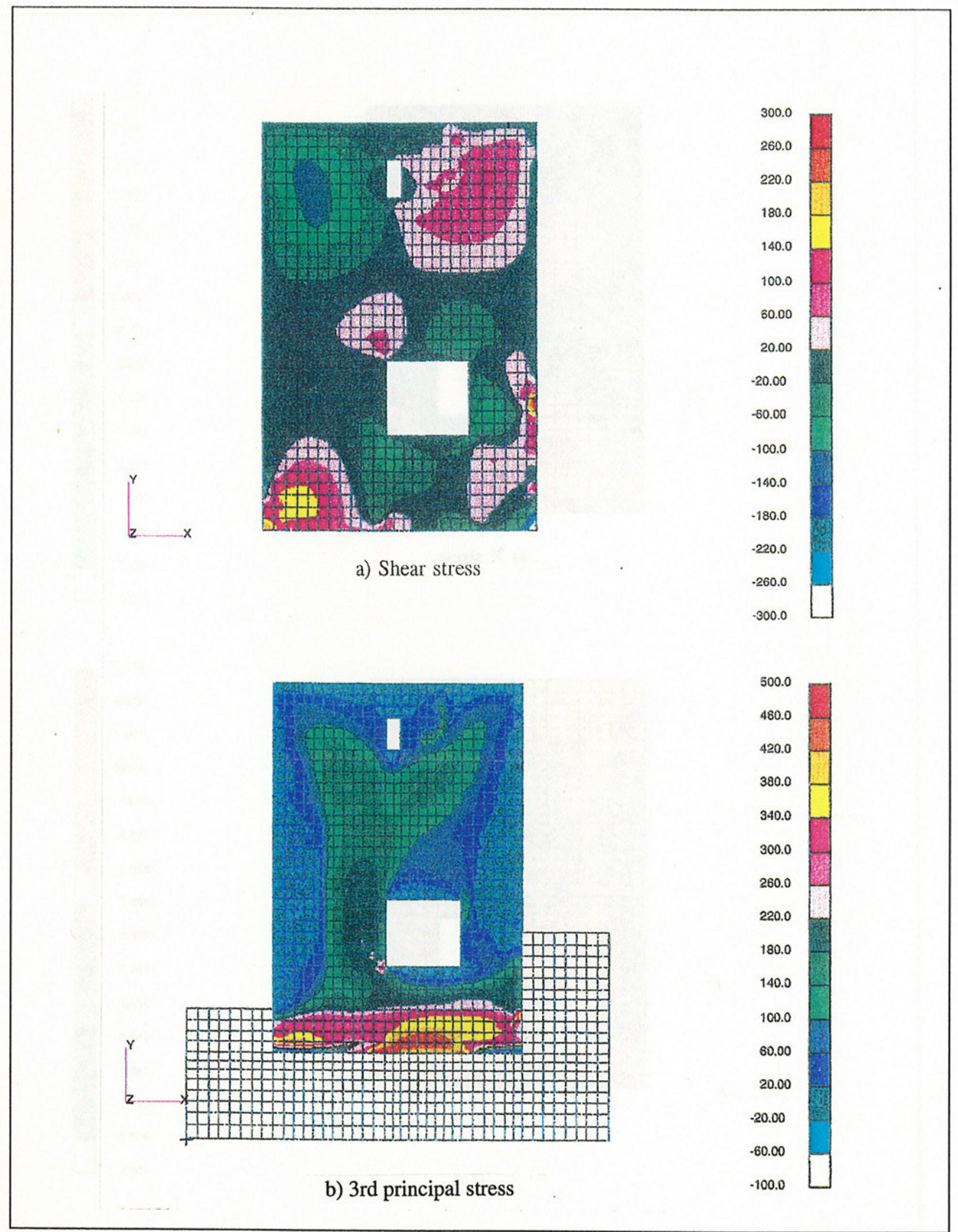

Figure 162. Shear and third principal stress, day 450 

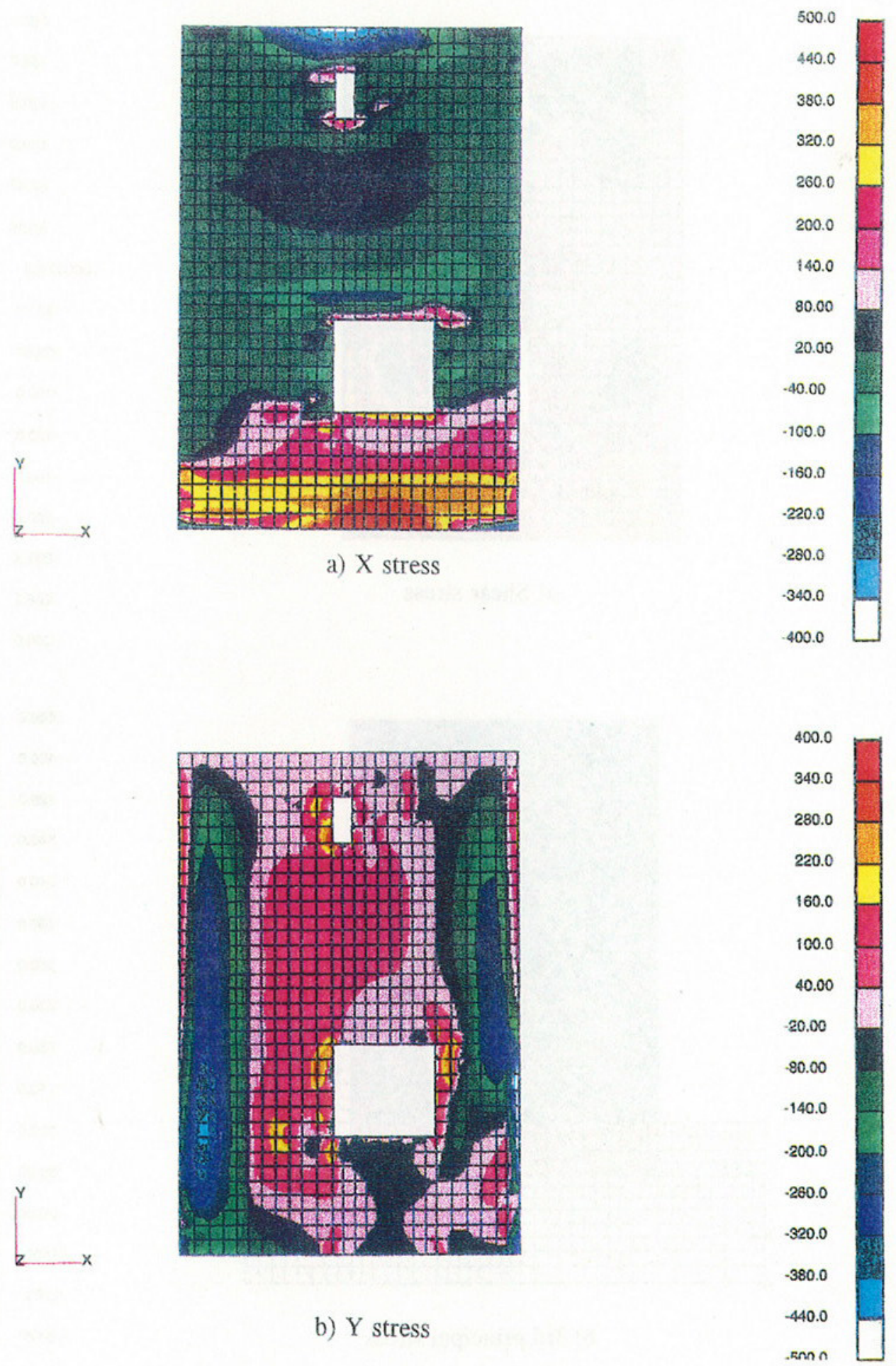

Figure 163. $\mathrm{X}$ and $\mathrm{y}$ stress, day 455 

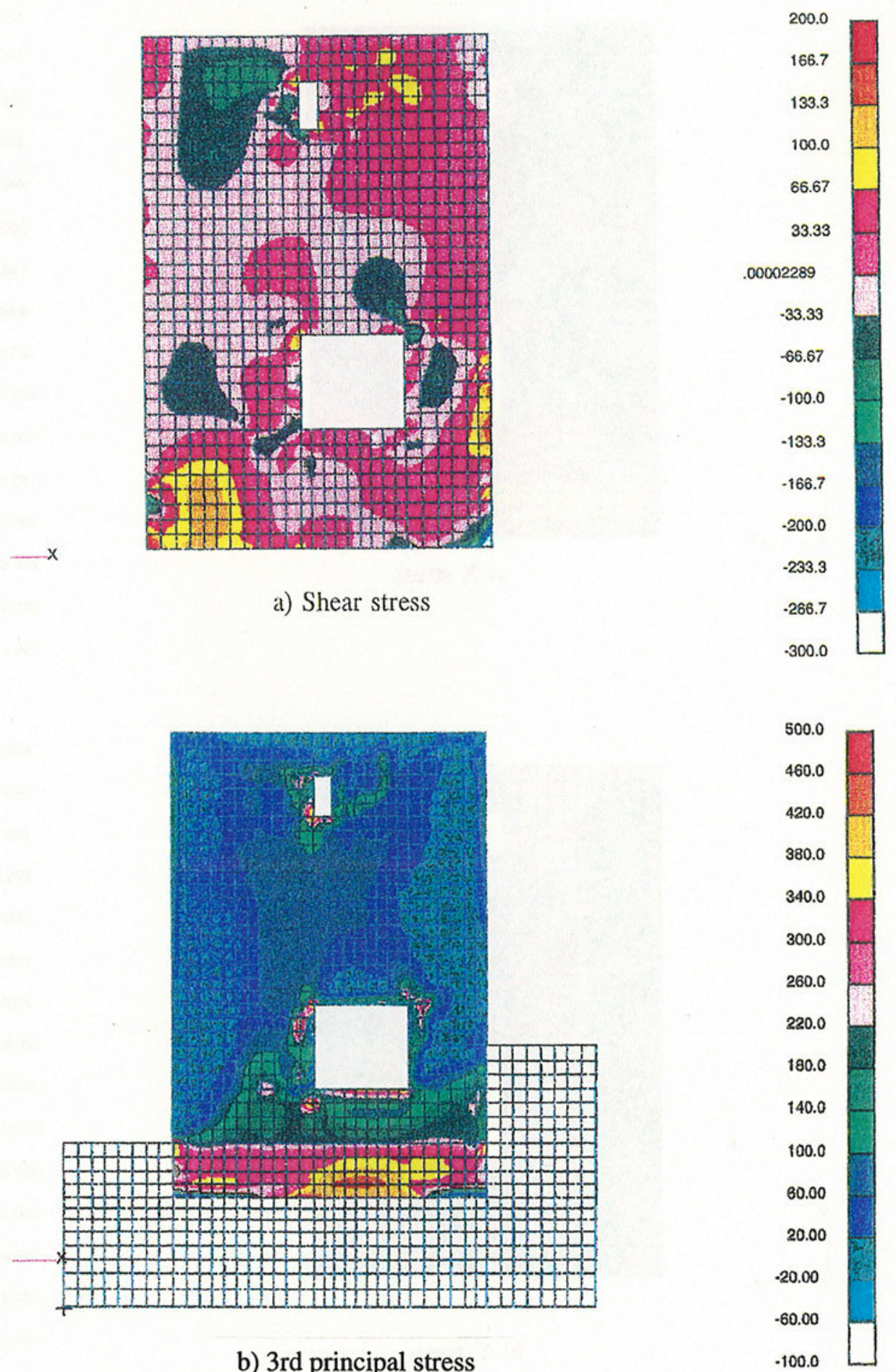

b) 3rd principal stress

Figure 164. Shear and third principal stress, day 455 


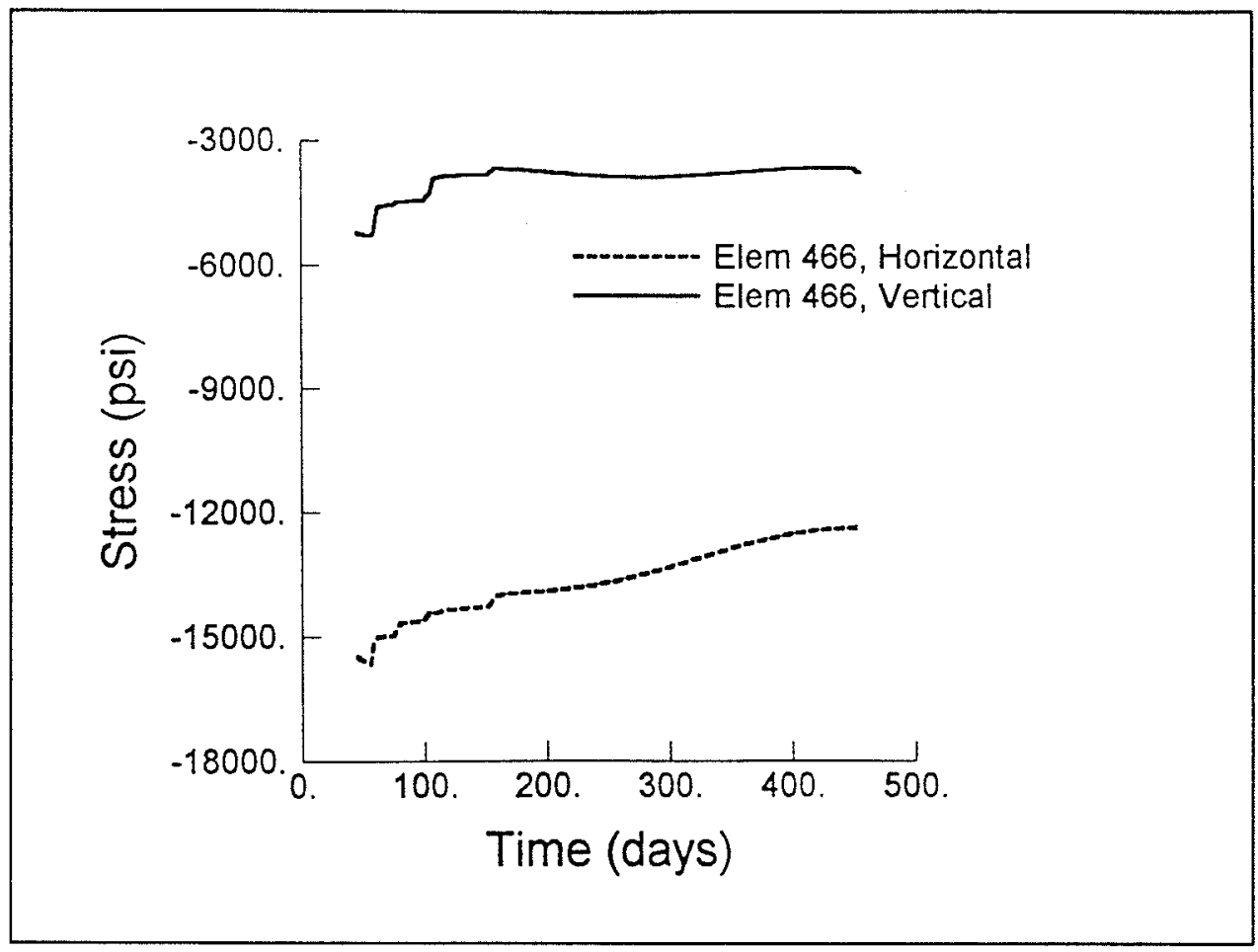

Figure 165. Stresses in horizontal reinforcing at lower right-hand element, lift 1

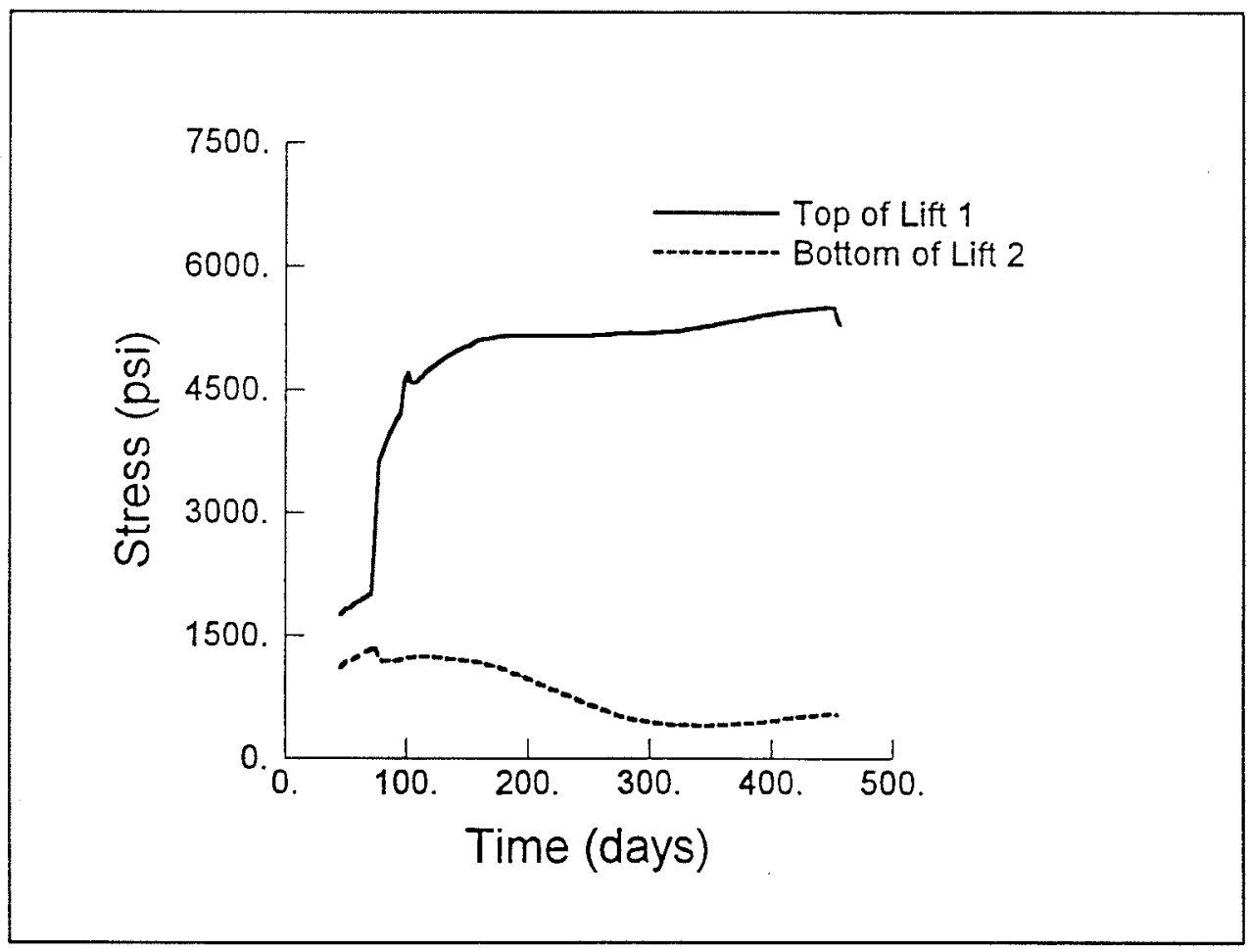

Figure 166. Stresses in right face vertical reinforcing near the interface between lifts 1 and 2 


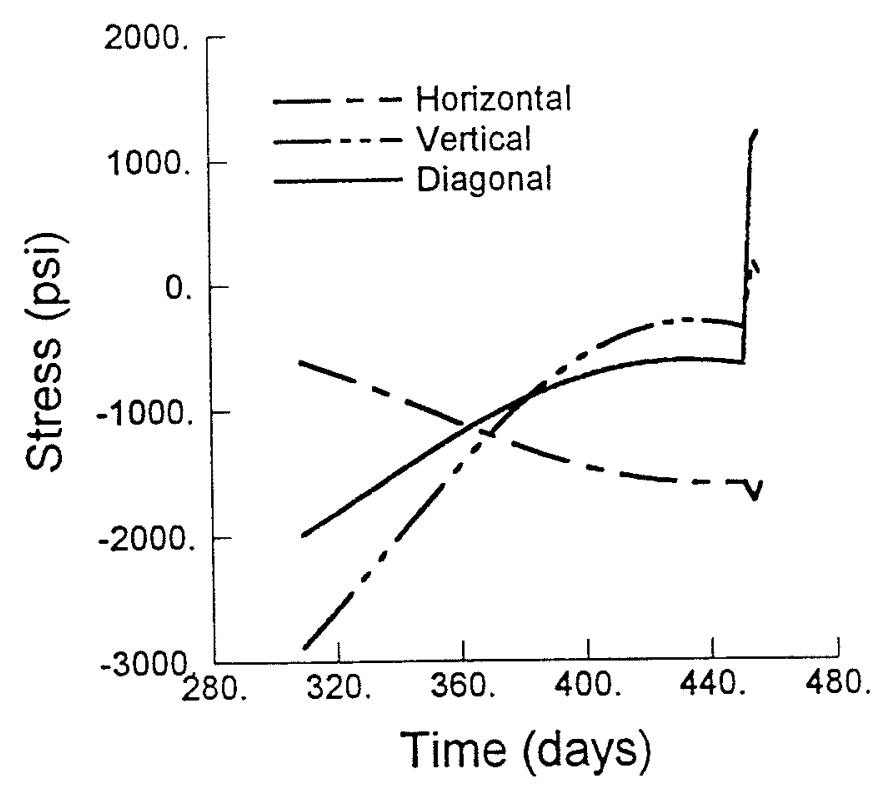

a) Element 548

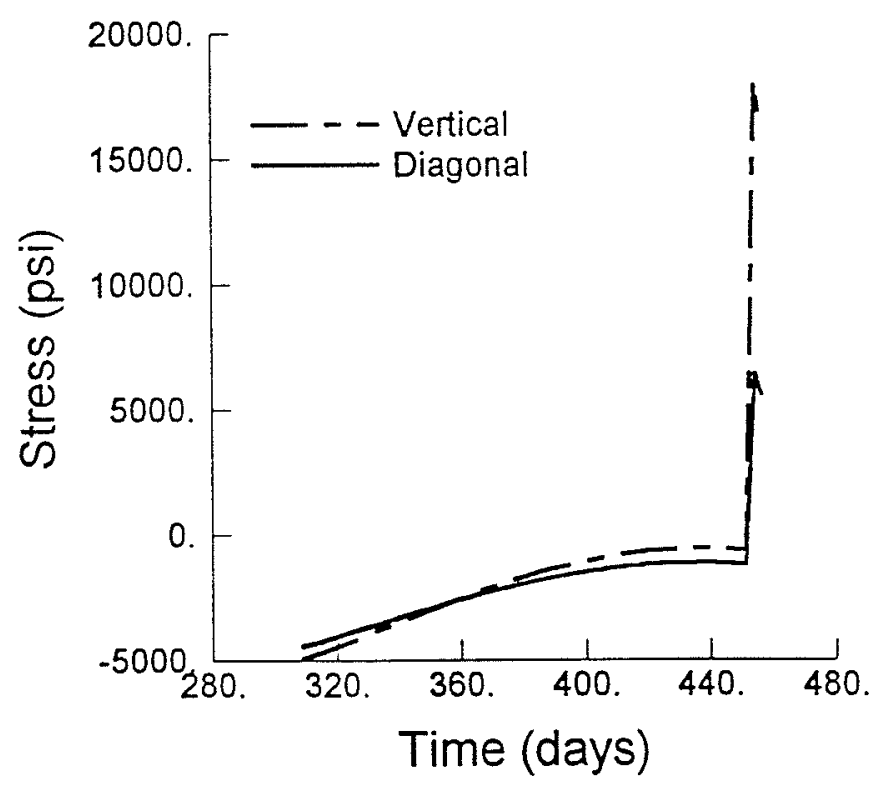

b) Element 669

Figure 167. Stresses in reinforcing at lower left-hand culvert comer 


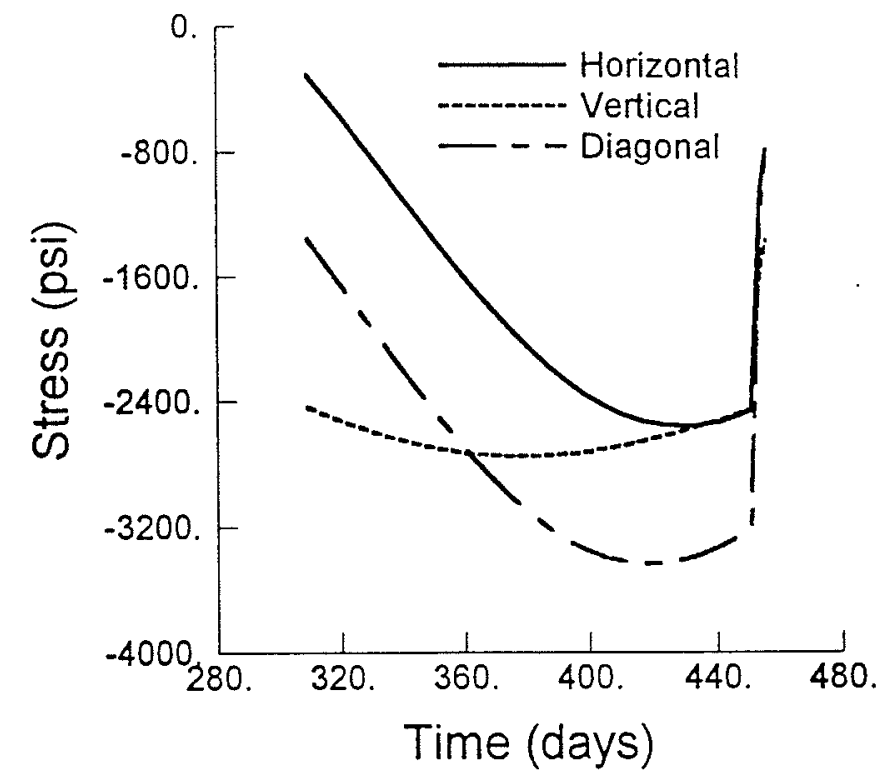

a) Element 597

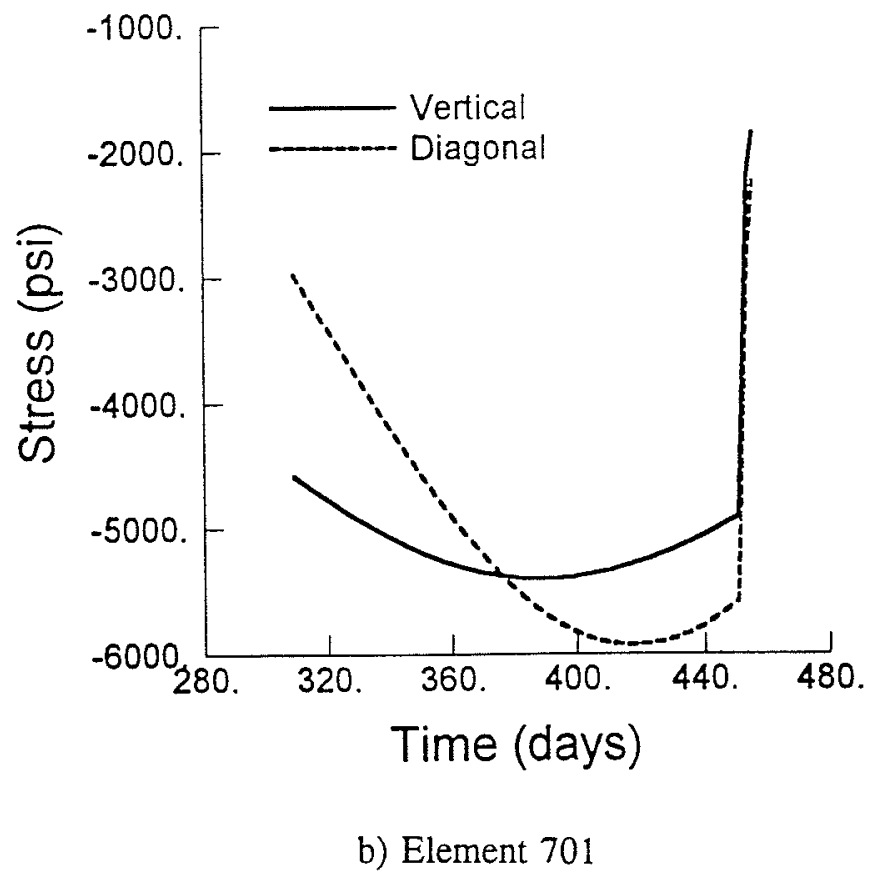

Figure 168. Stresses in reinforcing at lower right-hand culvert corner 
provided by the underlying rock. Although some cracking did occur at the base of the monolith, this cracking was generally only at the integration points closest to the rock and no additional cracking occurred in this area after day 303. Cracks in this area are not exposed to air or water and should not affect the structural integrity of the monolith. High stresses at the outer faces of the monolith were due to cooling at the exterior surface while interior temperatures remained relatively high. Cracking potential at exposed surfaces generally was under 40 percent throughout the analysis. High stresses and cracking at the culvert comers were the result of cooling at the inside face of the culvert and reached a peak after water was introduced into the culvert. Stresses in vertical reinforcement at culvert comers reached a peak of less than $20 \mathrm{ksi}$ at day 454 and then dropped with the application of service loads. On the final day of the analysis, cracking potential in this area was still greater than 80 percent. However, this cracking is a result of rapid cooling of the inside face of the culvert and should not progress further as temperatures become more uniform throughout the monolith. 


\section{Culvert Valve Monolith Analyses}

\section{Background}

Many of the placement parameters for the 3-D culvert valve monolith model were based on the 2-D analyses of other McAlpine monoliths and on previous work done for the Olmsted 3-D gate bay monolith (Fehl et al., in preparation). As in previous McAlpine analyses, maximum lift height was $10 \mathrm{ft}$, lifts were placed at 5-day intervals, and maximum concrete placement temperature was $70^{\circ} \mathrm{F}$. Since section thicknesses for this monolith were narrow when compared with previous monoliths, the use of two different concretes was not practical, and the exterior mixture was used throughout. Thermal material properties for the rock and exterior concrete are given in Tables 2 and 3, respectively; the concrete adiabatic temperature rise is shown in Figure 2; and mechanical properties are given in Tables 4, 5, and 6.

Concrete placement was initiated on June 21 (day 1), and the analyses were continued through day 500. At the end of construction on day 60 , all openings in the monolith were assumed to be closed until day 303, when spring film coefficients were applied and the vertical shaft was assumed to be open. Exposing the valve pit interior to still air at ambient temperature after day 303 prevented the development of reverse temperature gradients, in which valve pit interior temperatures are maintained near winter lows while exterior temperatures approach ambient. Reverse gradients are undesirable since they can cause high tensile stresses at the interior faces of openings and resulted in cracking at the interior of the gallery in the Olmsted culvert valve monolith analyses. At day 450, filling of the lock with water was simulated. Film coefficients for the heat transfer analysis are given in Table 7, with the exception of two modifications. Prior to closing the vertical culvert valve pit at day 60 , film coefficients at interior culvert and valve pit surfaces were based on still air and were $0.2 \mathrm{Btu} / \mathrm{day}-\mathrm{in}^{2}{ }^{\circ} \mathrm{F}$. Between days 60 and 303 , interior film coefficients were $0.01 \mathrm{Btu} / \mathrm{day}-\mathrm{in}^{2}{ }^{\circ} \mathrm{F}$ to simulate closure of the culvert, gallery, and vertical openings. At day 303 removal of the vertical shaft closure was simulated by returning the interior film coefficients for the culvert and vertical openings to $0.2 \mathrm{Btu} / \mathrm{day}-\mathrm{in}^{2}-^{\circ} \mathrm{F}$. Milestones for the heat transfer analysis are given in Table 9. 


\begin{tabular}{|l|l||}
\hline $\begin{array}{l}\text { Table } 9 \\
\text { Heat Transfer Analysis Milestones }\end{array}$ \\
\hline \hline Milestone & Day \\
\hline \hline Start of placement & 1 \\
\hline Final lift placement & 55 \\
\hline Closure of openings & 60 \\
\hline Change to fall film coefficient & 120 \\
\hline Change to winter film coefficient & 190 \\
\hline Minimum ambient temperature & 210 \\
\hline Change to spring film coefficient and open vertical shaft & 303 \\
\hline Change to summer film coefficient & 363 \\
\hline Flood with water & 450 \\
\hline
\end{tabular}

\section{Model Description}

The 3-D analysis modeled the upstream half of the monolith with symmetry conditions enforced at the center line and included the surrounding rock for a distance of $20 \mathrm{ft}$ from the outemost faces of the concrete. In the heat transfer analysis, boundaries at the outer vertical rock faces and at the model center line were adiabatic, and a constant temperature of $54^{\circ} \mathrm{F}$ was maintained at the rock base. The volume of included rock was based on previous heat transfer analyses in which constant soil temperatures were reached at a depth of 10 to $20 \mathrm{ft}$. This was a reasonable simplification, since conductivity and specific heat of the rock were similar to those used for soil in the Olmsted analyses (Gamer et al. 1992). Conductivity for the rock in these analyses was $2.62 \mathrm{Btu} / \mathrm{in}$.-day- ${ }^{\circ} \mathrm{F}$ and was $2.878 \mathrm{Btu} / \mathrm{in}$.-day- ${ }^{\circ} \mathrm{F}$ for the soil used in the Olmsted analyses. Likewise, the specific heat for rock in these analyses was $0.21 \mathrm{Btu} / \mathrm{lb} .-^{\circ} \mathrm{F}$ and for the Olmsted analyses was $0.289 \mathrm{Btu} / \mathrm{lb} .-^{\circ} \mathrm{F}$.

In general, maximum element size for previous 2-D analyses was approximately $30 \mathrm{in}$. by $30 \mathrm{in}$. based on the ABAQUS relationship between time-step and element length. For this analysis, the minimum time-step was increased 0.25 to 0.5 day, and the maximum element length along any face was increased to $48 \mathrm{in.}$ This increase in element and time-step size was required to limit the calculation time and memory required for the stress analysis. The final model consisted of 3,962 20-node brick elements (1,994 concrete and 1,968 rock) and 10,223 nodes. In the stress analysis, gap elements were included at the vertical concrete/rock interfaces. To provide corresponding nodes in both the heat transfer and stress analyses, interface elements were used at vertical concrete/rock interfaces in the heat transfer analysis. 
The grid used in the heat transfer and stress analyses is shown in Figure 169. Lift locations are shown in Figure 170.

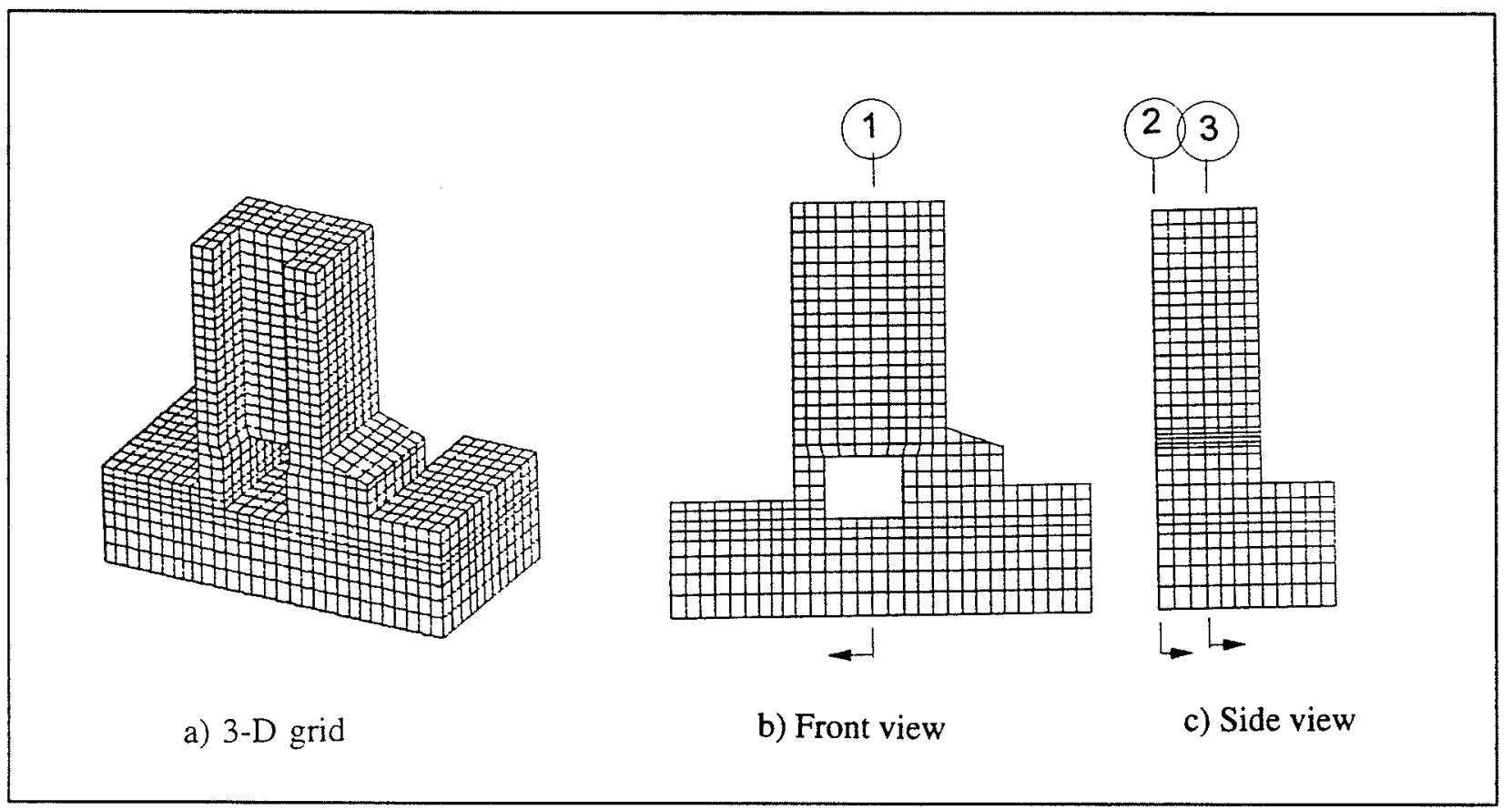

Figure 169. F.E. grid for 3-D analysis

As was done in the 2-D miter gate monolith analysis, the outer boundaries of the rock in the stress analysis were modeled as springs based on onedimensional calculations in a rock column. As in the miter gate monolith, a typical displacement was selected to obtain a uniform spring coefficient of $1,100,000 \mathrm{lb} / \mathrm{in}$., which was applied to all the boundary nodes of the rock. For a spring stiffness of EA/L, a rock elastic modulus of 7,500,000 psi, and an average tributary area of $450 \mathrm{in}^{2}$, this corresponds to a rock depth of approximately $255 \mathrm{ft}$. Reinforcement was included using the ABAQUS smeared reinforcing model. Reinforcement used in the stress analysis is shown in Figure 171. Although Figure 171a shows only transverse reinforcing, longitudinal reinforcement similar to the transverse reinforcement was included at vertical and horizontal reinforced faces.

\section{Heat Transfer Analysis Results}

The thermal response of the 3-D model is shown in a series of thermal contours at discrete points in time and history plots of nodal temperatures. Contour plots are three-dimensional plots of concrete surfaces and two-dimensional plots of a longitudinal section through the vertical shaft (Section 1, shown in Figure 169). In addition, temperature contours at horizontal sections through the center of the top three lifts are presented for days 363 and 404 . 


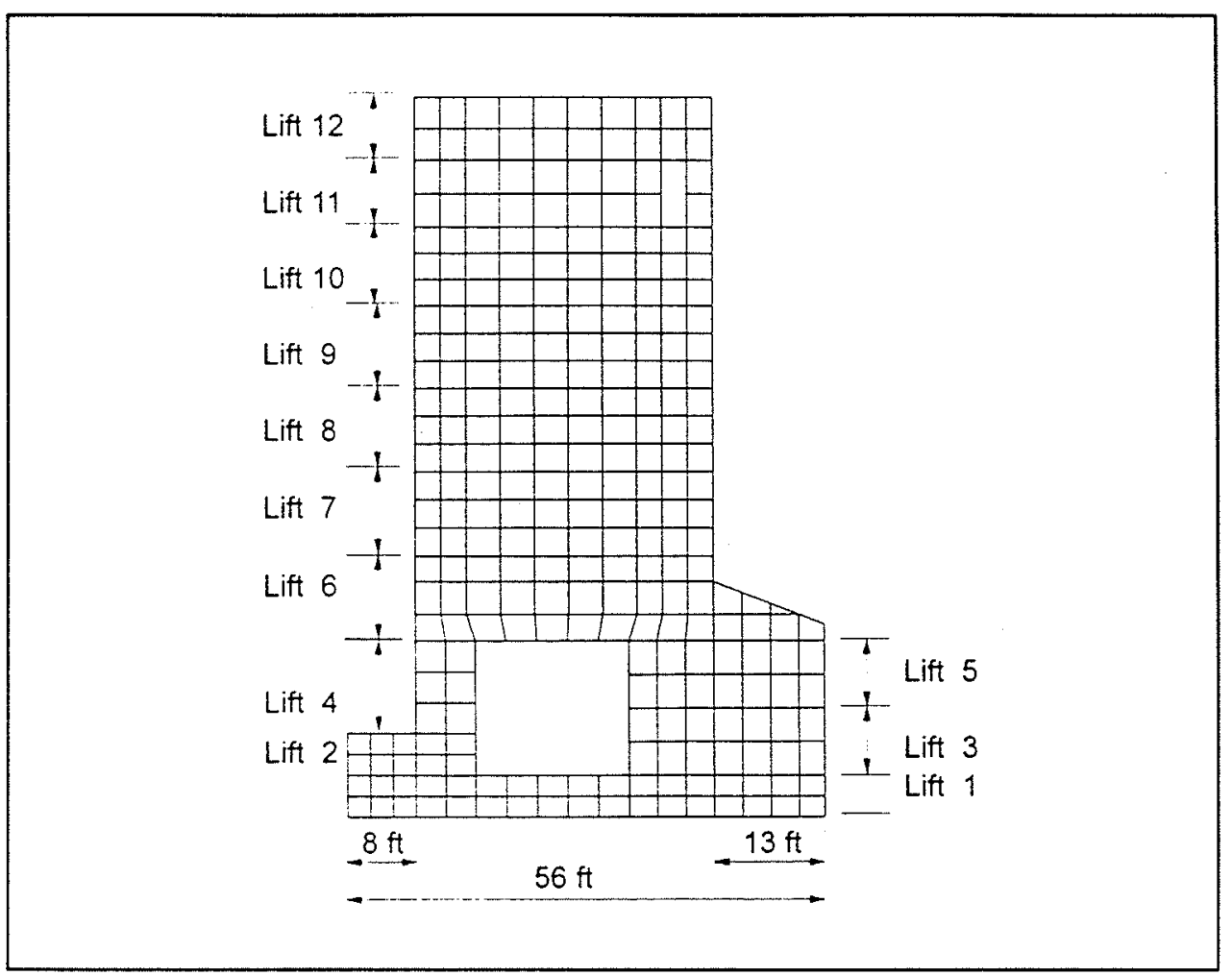

Figure 170. Concrete lifts
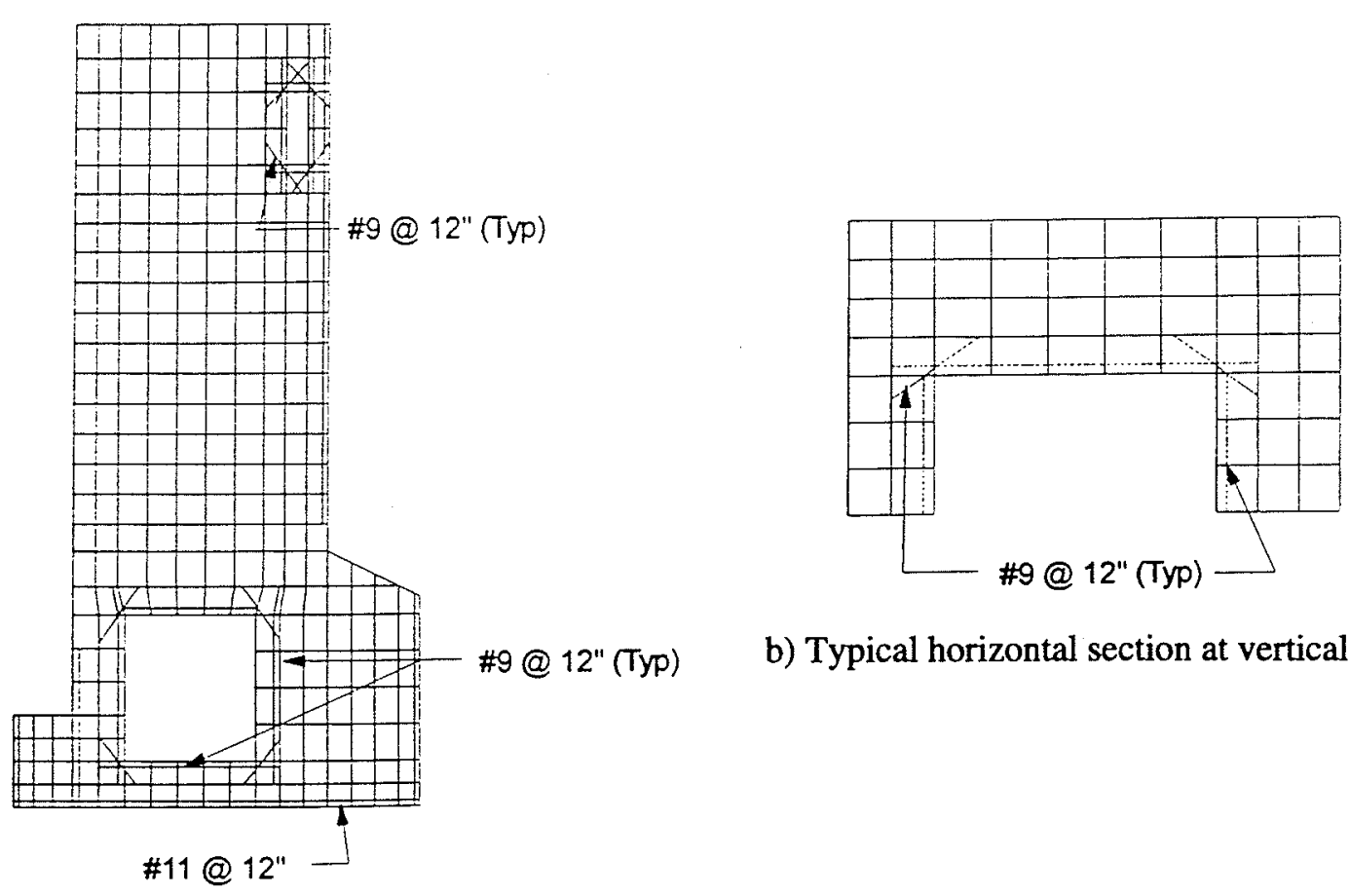

b) Typical horizontal section at vertical shaft

a) Typical vertical section

Figure 171. Monolith reinforcing 
As has been observed in previous analyses, concrete temperatures at exterior monolith faces were approximately equal to the ambient air temperature by approximately 50 to 60 days after placement. Temperatures at interior surfaces of the valve pit reached ambient shortly after day 303, when the cover was removed from the valve pit.

A frequent problem in culvert valve monoliths is cracking near the comers of the vertical opening at the top of the monolith. This cracking occurs when thin walls intersect with much thicker walls. Concrete in the interior of the thicker wall will be maintained at a relatively high temperature for some time after placement, while thinner walls tend to cool quickly. This cooling results in contraction of the thinner wall and can result in cracking. Cracking of this type can be prevented by minimizing temperature differences in the vertical shaft walls. In the McAlpine culvert valve monolith, vertical shaft walls are not extremely thick; the upstream wall is only $15 \mathrm{ft}$ thick, and the riverside and landside walls are 5 and $10 \mathrm{ft}$ thick, respectively. However, temperature gradients in this area were still a concern.

Figure 172 shows temperature contours at 60 days after the start of placement, the time at which all openings were modeled as closed and cooling of the valve pit walls could only occur through exterior surfaces. Maximum temperature in the most recently placed lifts (10 through 12 ) was $114^{\circ} \mathrm{F}$ and the maximum temperature difference across the monolith upstream wall was approximately $20^{\circ} \mathrm{F}$. By day 80 , shown in Figure 173, the maximum interior temperature in the thick upstream wall of the vertical opening had cooled to $109.5^{\circ} \mathrm{F}$, resulting in a difference in temperatures across the section of $26.5^{\circ} \mathrm{F}$. At the same time, temperatures in the thin valve pit sidewall were much closer to ambient, and the maximum difference in temperatures across the section was less than $10^{\circ} \mathrm{F}$.

By day 210, the maximum temperature in the thick upstream wall of the valve pit occurred near the interior surface and was $47^{\circ} \mathrm{F}$; maximum temperature at the interior surface of the valve pit was $46^{\circ} \mathrm{F}$; exterior concrete temperatures were close to the ambient temperature minimum of $23^{\circ} \mathrm{F}$; and the maximum temperature difference between the interior and exterior of the section was $24^{\circ} \mathrm{F}$. At the same time, temperatures in the thin sidewalls were almost uniform, with a maximum temperature difference across the section of only $5^{\circ} \mathrm{F}$. The highest concrete temperature was approximately $68^{\circ} \mathrm{F}$ in the floor under the landside culvert wall, resulting in a $45-^{\circ} \mathrm{F}$ gradient between the top and bottom surfaces of the concrete in this wall. Temperature contours for day 210 are shown in Figure 174.

Temperature contours for day 300 are shown in Figure 175. By this time, temperature gradients were driven by fluctuations in ambient temperature, and concrete in the interior of the culvert and valve pit was cooler than concrete at exterior faces. Minimum temperatures for the thick end wall and the thin inner wall were $38^{\circ} \mathrm{F}$ and $45^{\circ} \mathrm{F}$, respectively, while exterior faces were at approximately $55^{\circ} \mathrm{F}$, resulting in temperature differences across these walls of $12{ }^{\circ} \mathrm{F}$ and $10^{\circ} \mathrm{F}$. 


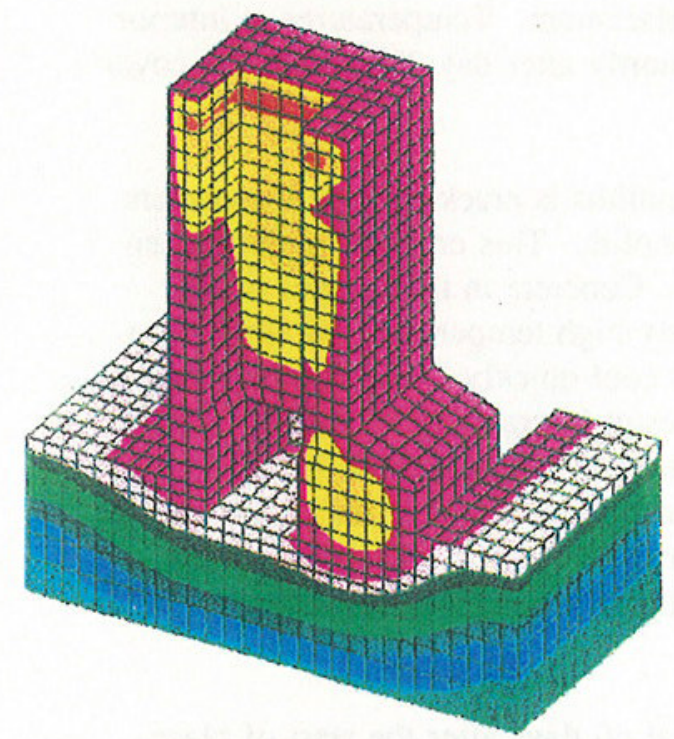

a) At monolith center

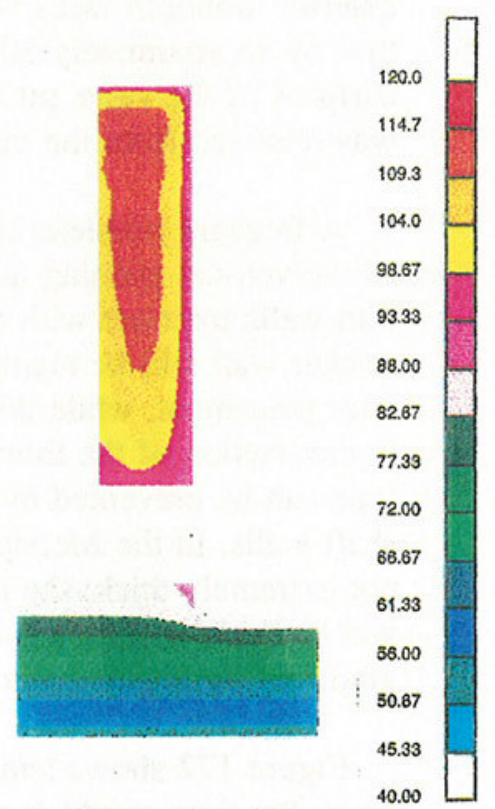

b) Section 1

Figure 172. Temperature contours, day 60

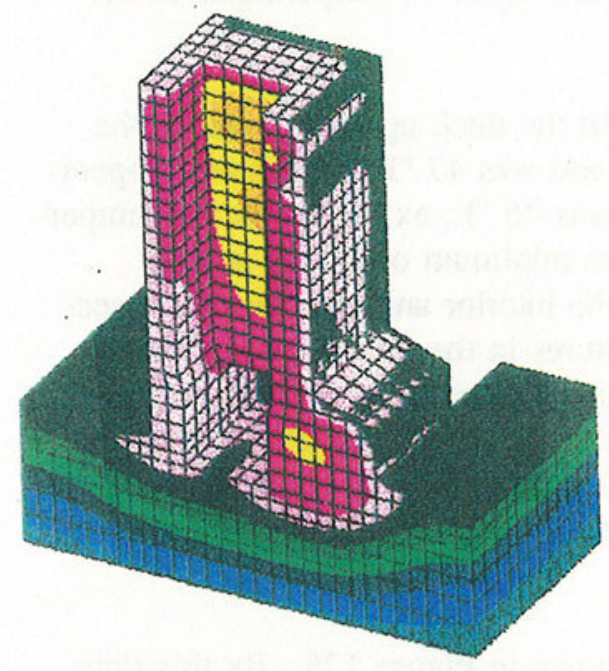

a) At monolith center

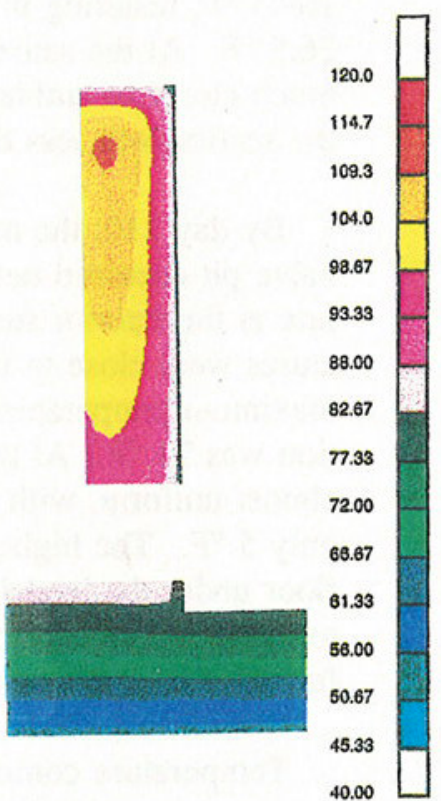

b) Section 1

Figure 173. Temperature contours, day 80 


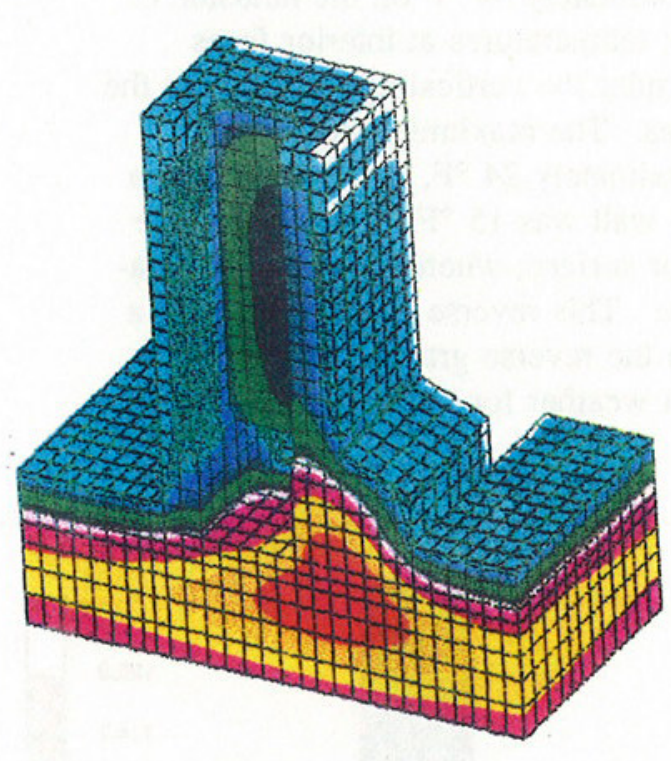

a) At monolith center

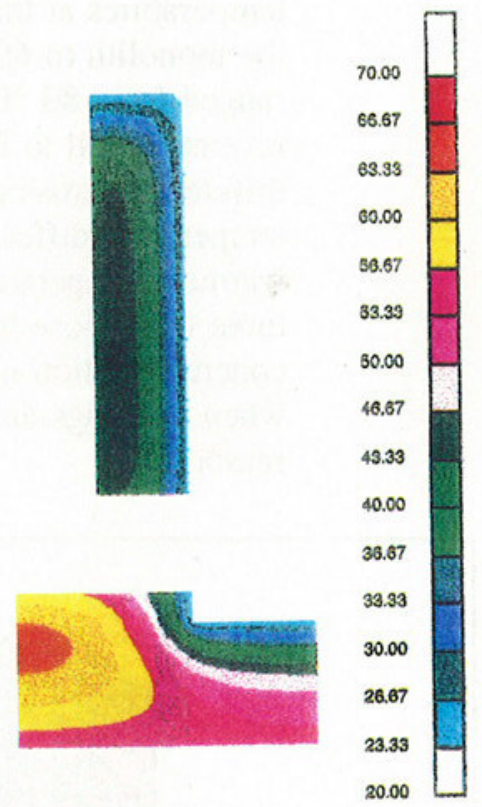

b) Section 1

Figure 174. Temperature contours, day 210

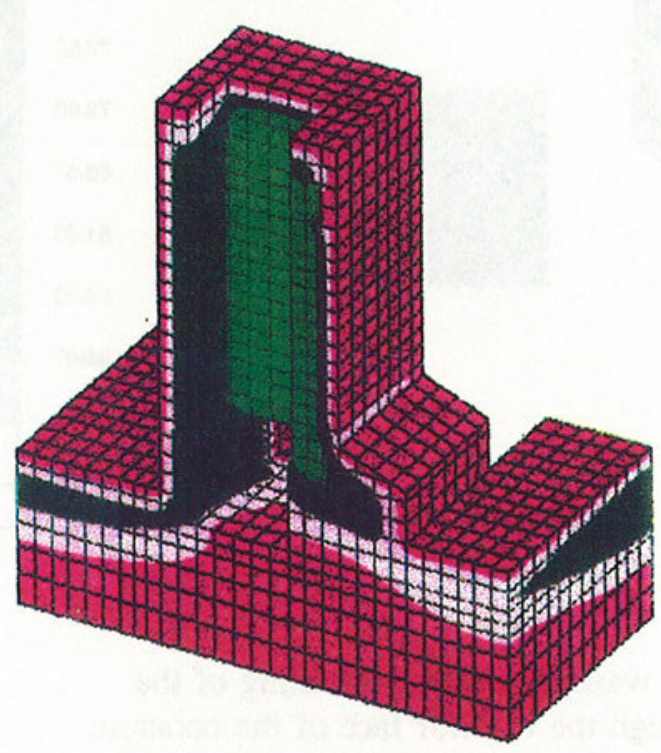

a) At monolith center

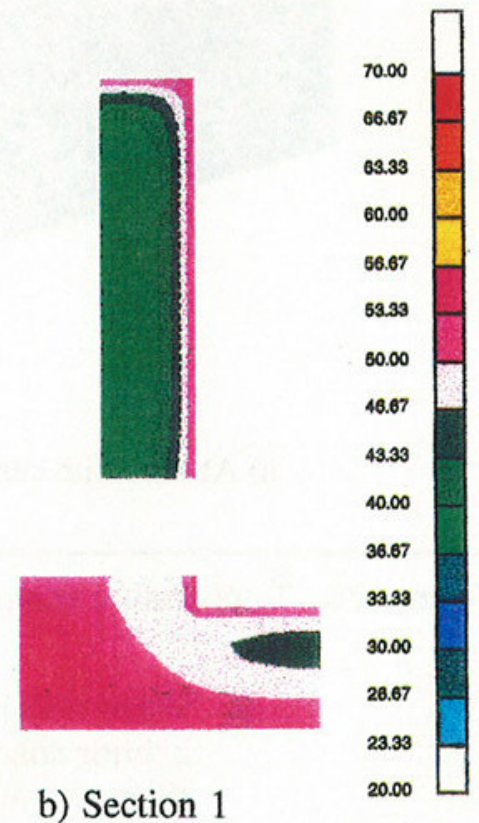

b) Section 1

Figure 175. Temperature contours, day 300 
Temperatures for day 363 are shown in Figures 176 and 177. By day 363, temperatures at the base ranged from approximately $54^{\circ} \mathrm{F}$ on the landside of the monolith to $60^{\circ} \mathrm{F}$ on the chamber side; temperatures at interior faces ranged from $80^{\circ} \mathrm{F}$ at the top of the floor under the vertical opening and at the upstream wall to $87^{\circ} \mathrm{F}$ at interior wall faces. The maximum temperature difference across a floor section was approximately $24^{\circ} \mathrm{F}$, and the maximum temperature difference across the upstream wall was $15^{\circ} \mathrm{F}$. In all cases, the warmest temperatures existed at the exterior surface, where concrete temperatures were close to the ambient temperature. This reverse gradient through a concrete section has a different effect from the reverse gradient that occurs when openings are left closed during warm weather for the following two reasons:

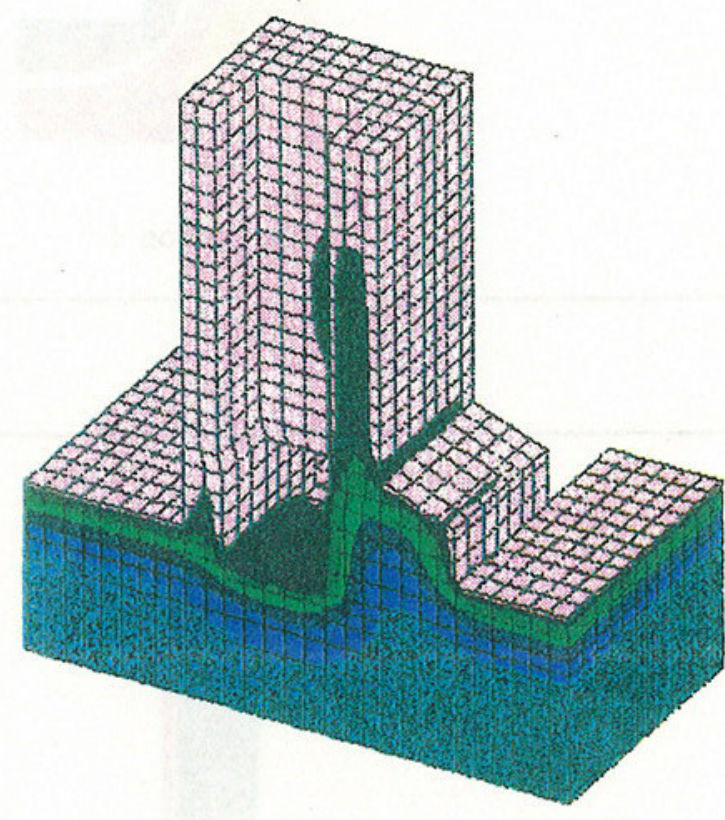

a) At monolith center

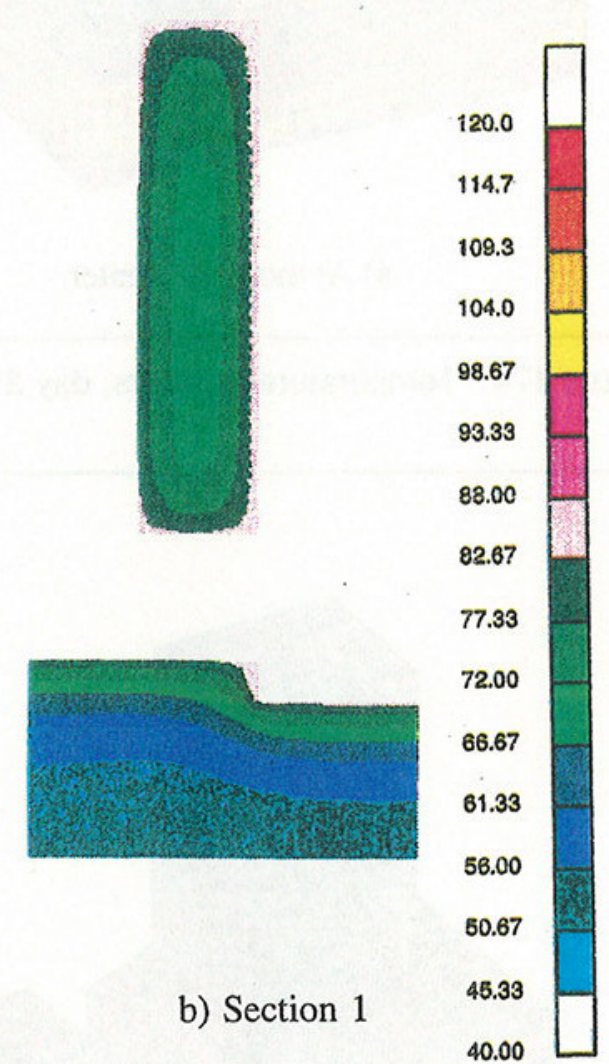

40.00

Figure 176. Temperature contours, day 363

a. When openings are closed during warmer weather, warming of the interior concrete occurs only through the exterior face of the concrete. When warming of the interior concrete occurs through both the interior and exterior surfaces, temperature differences across the section are reduced. 


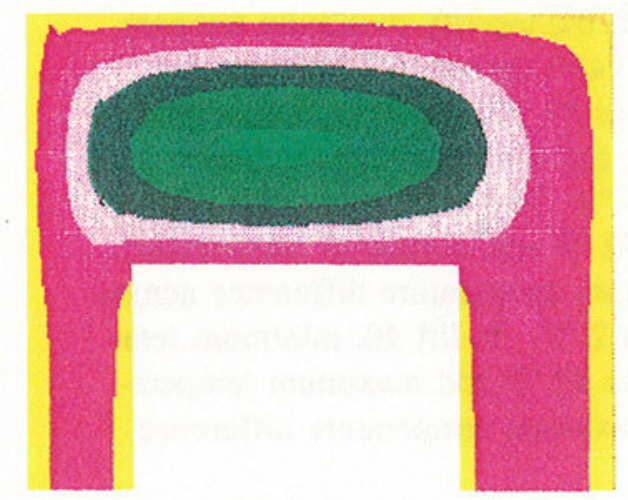

a) Center, Lift 12

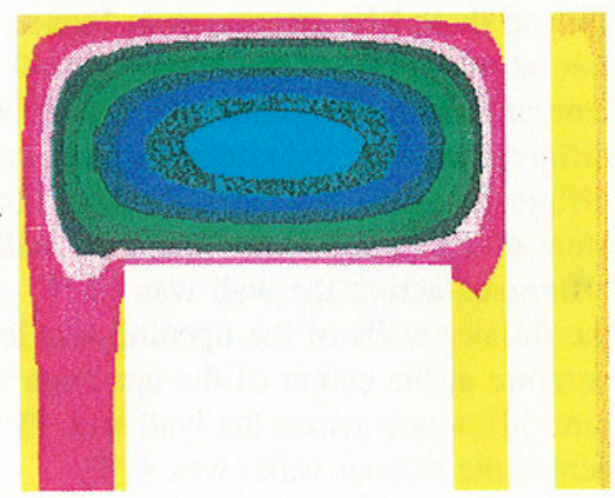

b) Center, Lift 11

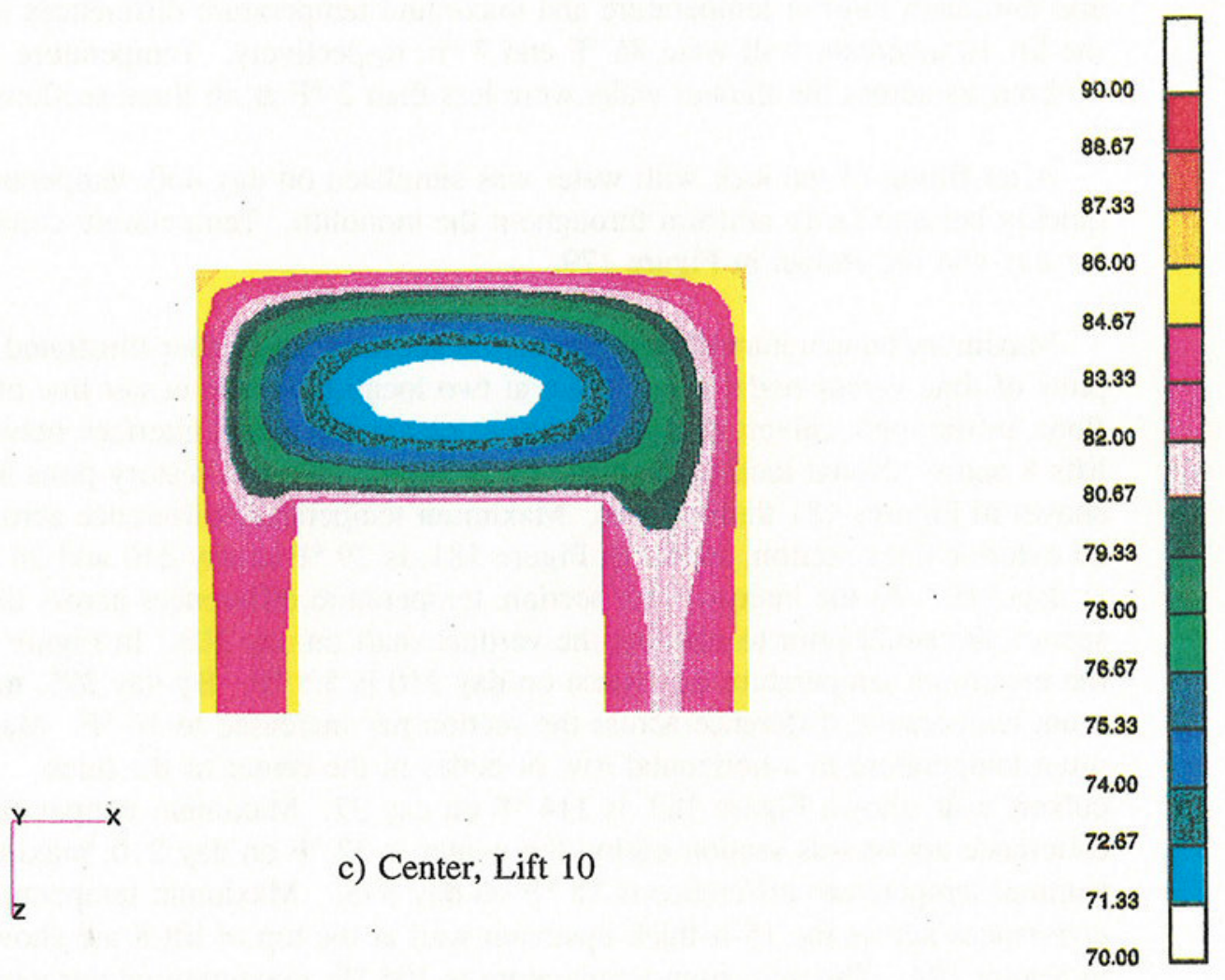

Figure 177. Temperature contours at horizontal sections, day 363

$b$. When openings remain closed during warmer weather, the coolest temperatures in the concrete will occur at or near the interior surfaces, inducing tensile stresses in these surfaces. When opening covers are removed, both interior and exterior surfaces warm with the ambient temperature, reducing tensile stresses in surface concrete. 
Temperature contours for day 363 at sections through the center of each of the top three lifts are shown in Figure 177. In the top lift, minimum temperature at the center of the upstream wall of the valve pit was $77^{\circ} \mathrm{F}$; minimum temperature at the center of the other walls was $84^{\circ} \mathrm{F}$; maximum temperature difference across the upstream wall was $8{ }^{\circ} \mathrm{F}$; and maximum temperature difference across the thinner side walls was $3^{\circ} \mathrm{F}$. In lift 11 , minimum temperature at the center of the upstream wall was $72^{\circ} \mathrm{F}$ and maximum temperature difference across the wall was $13^{\circ} \mathrm{F}$. Maximum temperature difference across the thinner walls of the opening was less than $2^{\circ} \mathrm{F}$. In lift 10 , minimum temperature at the center of the upstream wall was $70^{\circ} \mathrm{F}$ and maximum temperature difference across the wall was $15^{\circ} \mathrm{F}$. Maximum temperature difference across the thinner walls was $4^{\circ} \mathrm{F}$.

Temperature contours at the three wall sections for day 404 are shown in Figure 178. By this day, surface concrete had reached approximately $92^{\circ} \mathrm{F}$, and minimum interior temperature and maximum temperature differences in the lift 10 upstream wall were $85^{\circ} \mathrm{F}$ and $7^{\circ} \mathrm{F}$, respectively. Temperature differences across the thinner walls were less than $2^{\circ} \mathrm{F}$ at all three sections.

After filling of the lock with water was simulated on day 450 , temperatures quickly became fairly uniform throughout the monolith. Temperature contours for day 454 are shown in Figure 179.

Maximum temperature differences across sections are further illustrated in plots of time versus nodal temperature at two locations at the center line of the floor, in the thick culvert wall at the center plane, and at the interface between lifts 8 and 9. Nodal locations are shown in Figure 180, and history plots are shown in Figures 181 through 184. Maximum temperature difference across an exterior floor section, shown in Figure 181 , is $29^{\circ} \mathrm{F}$ at day 210 and $26^{\circ} \mathrm{F}$ at day 395. At the interior floor section, temperature differences across the section are small prior to opening the vertical shaft on day 303. In Figure 182, the maximum temperature difference on day 210 is $5.5^{\circ} \mathrm{F}$. By day 395 , maximum temperature difference across the section has increased to $16^{\circ} \mathrm{F}$. Maximum temperature in a horizontal row of nodes in the center of the thick culvert wall, shown Figure 183, is $114^{\circ} \mathrm{F}$ on day 37 . Maximum temperature difference across this section during the winter is $32^{\circ} \mathrm{F}$ on day 210 ; maximum summer temperature difference is $18^{\circ} \mathrm{F}$ on day 395. Maximum temperature differences across the 15-ft-thick upstream wall at the top of lift 8 are shown in Figure 184. The maximum temperature is $106^{\circ} \mathrm{F}$; maximum winter temperature difference across the section is $23^{\circ} \mathrm{F}$; and maximum summer temperature difference is $9^{\circ} \mathrm{F}$.

\section{Stress Analysis}

Cracking started at the base of lift 1 on day 40 . Initial cracking occurred near the outer edges of the floor in diagonal lines radiating outward from the center of the monolith. This cracking continued throughout the analysis until 


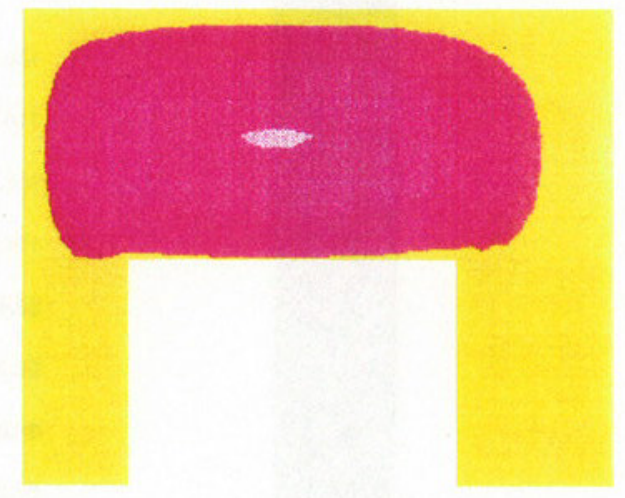

a) Center, Lift 12

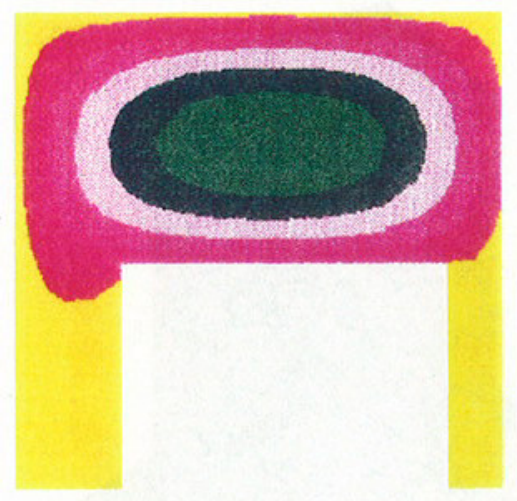

b) Center, Lift 11

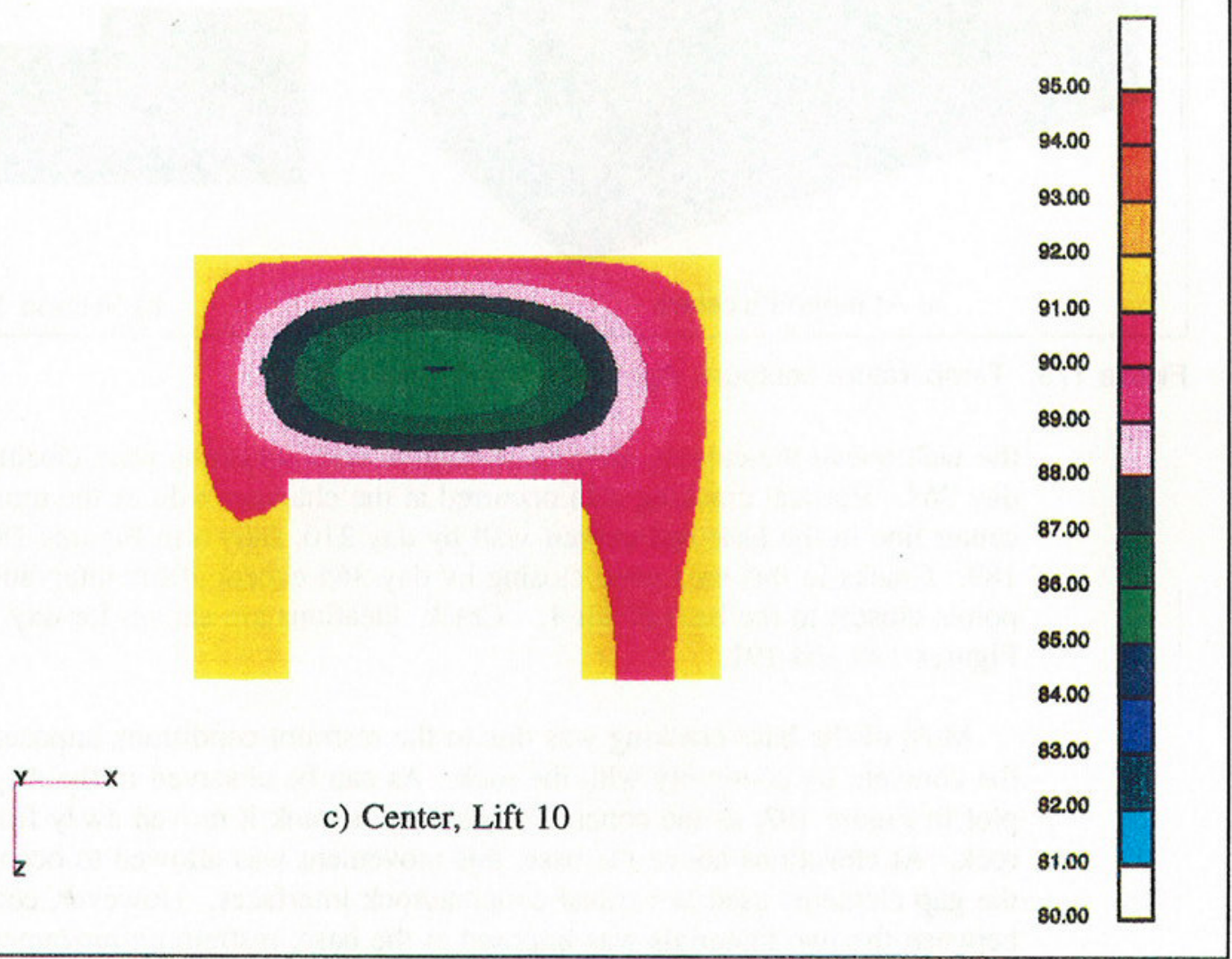

Figure 178. Temperature contours at horizontal sections, day 404

most of the integration points at the base of lift 1 were cracked, and cracking extended to integration points above the base at the outer edges of the concrete. Cracking at the outer face of the concrete under the culvert was initiated at day 100, shown in Figure 185, while cracking at the outer face of the concrete above the culvert started at day 150, as can be seen in Figures 186 and 187. Cracks at culvert corners were vertical, and by the end of the analysis had extended throughout the floor below the culvert and through the length of 


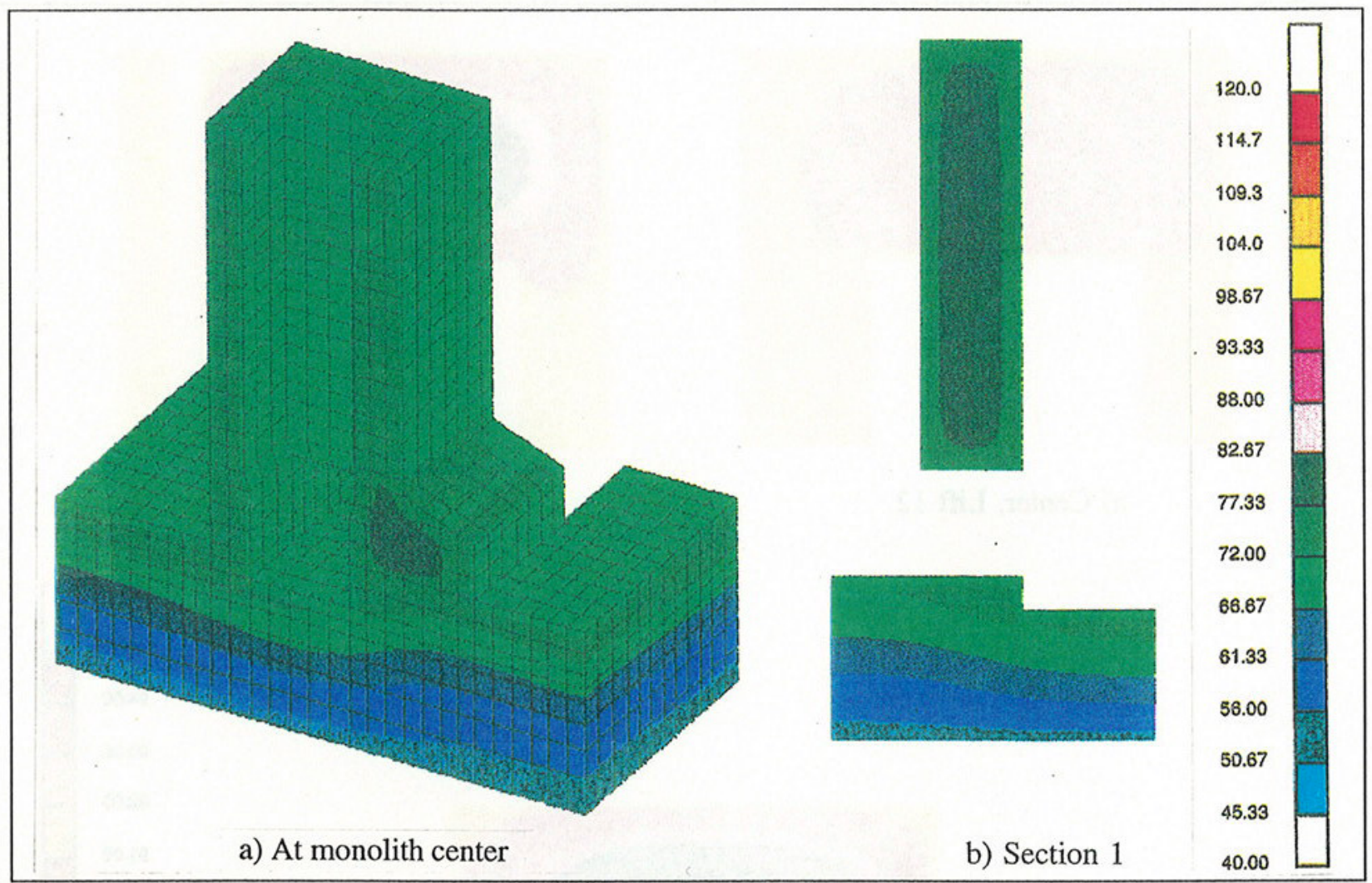

Figure 179. Temperature contours, day 454

the wall above the culvert, although cracks in both locations were closing by day 364. Vertical cracking also occurred at the chamber side of the monolith center line in the base and culvert wall by day 210, shown in Figures 188 and 189. Cracks in this area were closing by day 364 except at the integration points closest to the base of lift 1 . Crack locations are shown for day 364 in Figures 190 and 191.

Most of the base cracking was due to the restraint conditions imposed on the concrete by continuity with the rock. As can be observed in the displaced plot in Figure 192, as the concrete cooled and shrank it moved away from the rock. At elevations above the base, this movement was allowed to occur by the gap elements used at vertical concrete/rock interfaces. However, continuity between the two materials was imposed at the base, restraining movement and resulting in cracking. Since base cracking occurred throughout the analysis, high stresses were transmitted to lift 1 throughout the analysis by this restraint. Cracking potentials are shown at two sections: the center line of the monolith (Section 2) and a section along the upstream face of the vertical shaft (Section 3). In Figure 193, on day 170, cracking potentials at Section 2 approached 99 percent at the riverside of the floor and at the exterior face of the thick culvert wall. By day 210, shown in Figure 194, cracking in Section 2 had occurred at the top of the floor on the river side, and crack potentials had reached 99 percent in the riverside culvert wall and in the floor under 


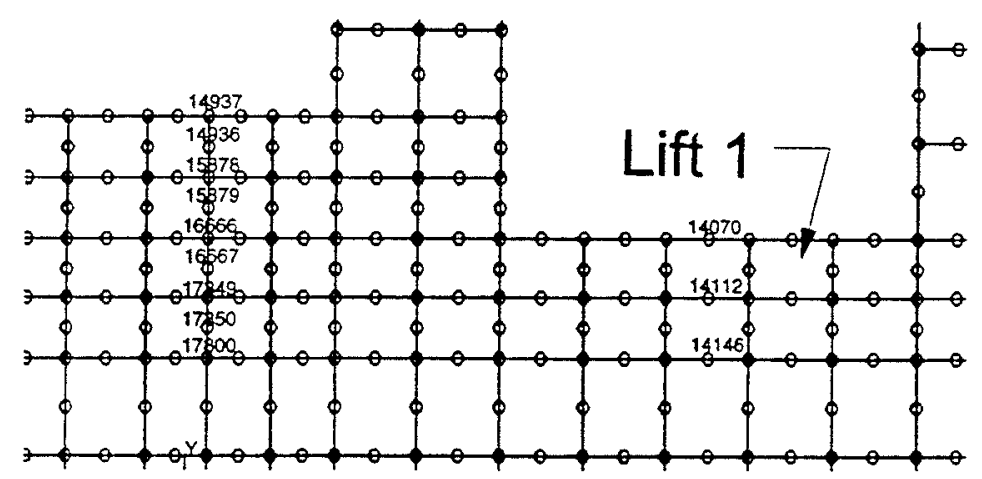

a) Nodes at center line of floor

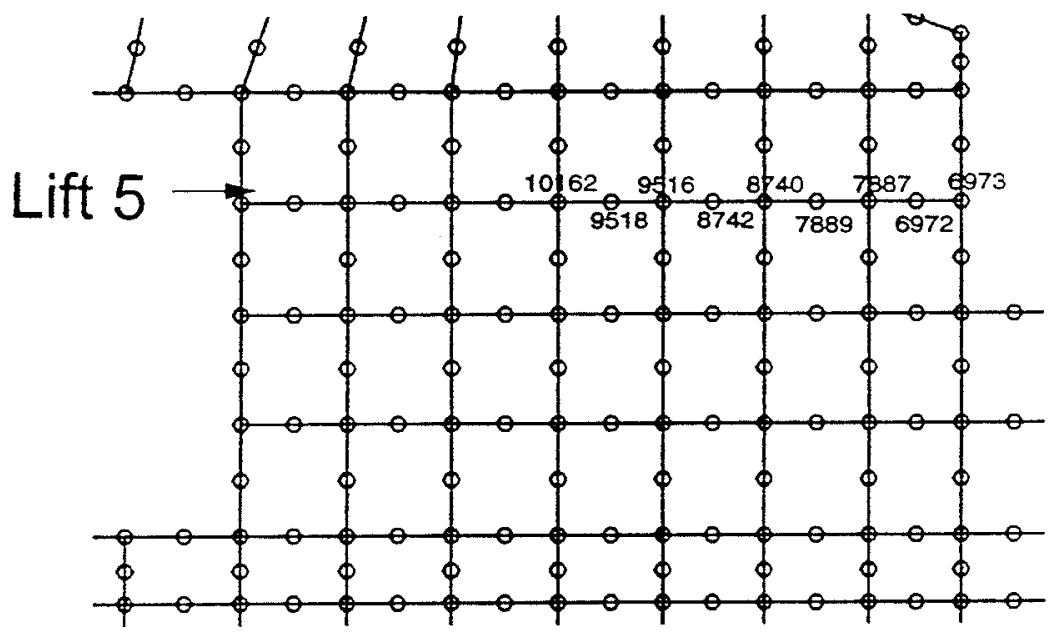

b) Nodes at center line of thick culvert wall

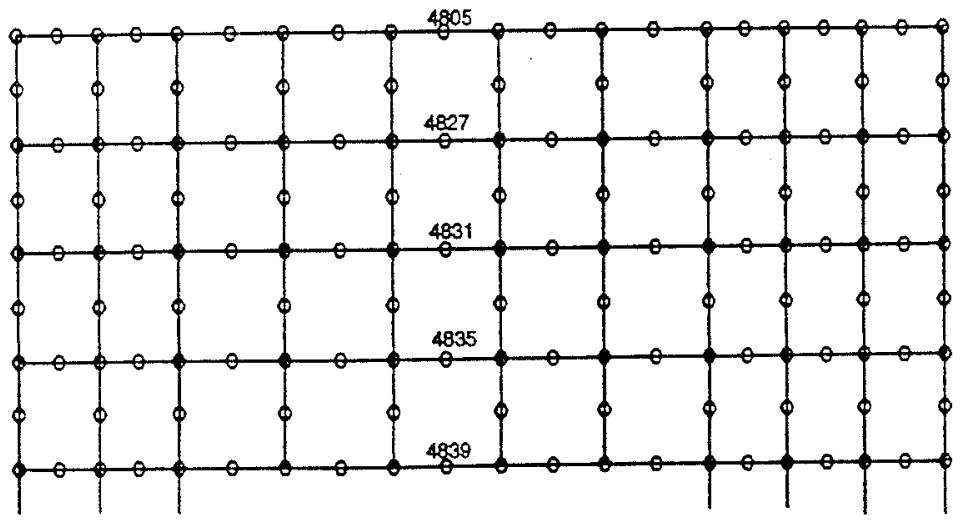

c) Nodes at lift 8/lift 9 interface, plan view

Figure 180. Nodal locations for time-temperature plots 


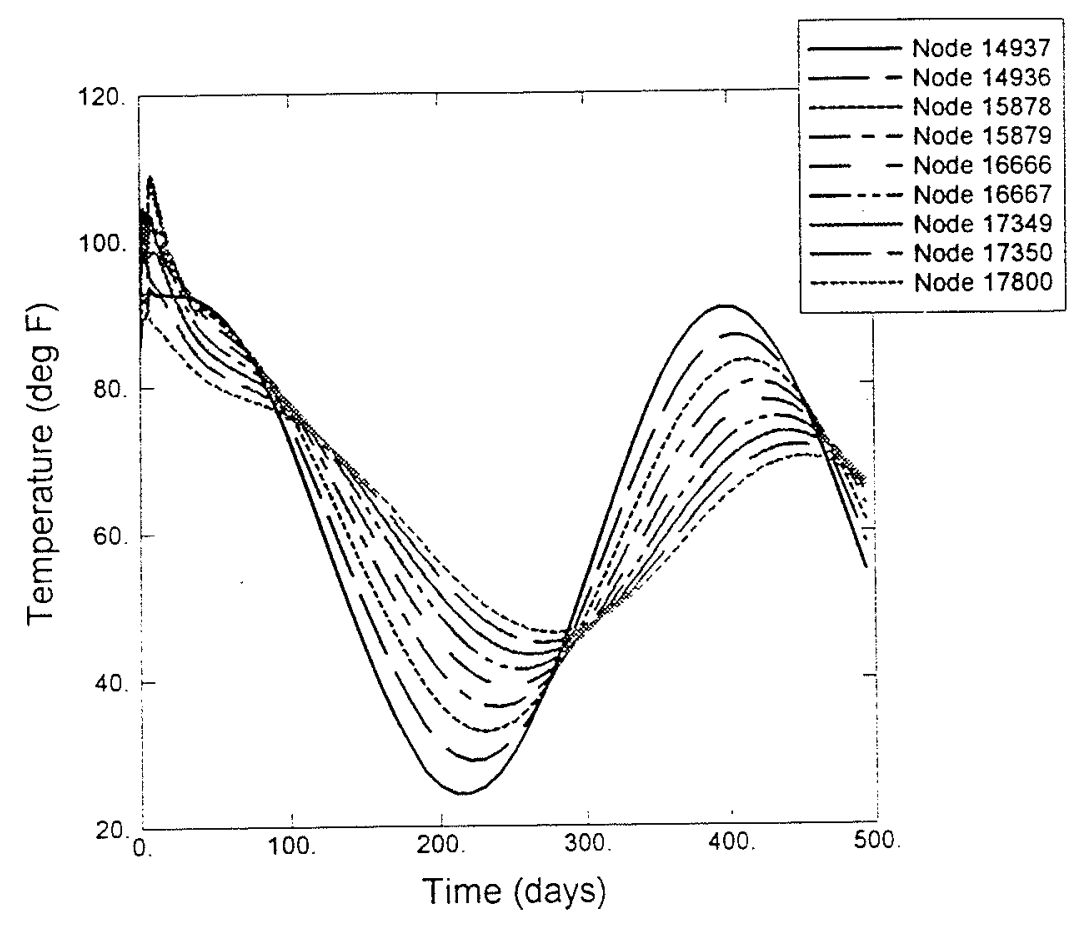

Figure 181. Nodal temperature history, exterior floor section

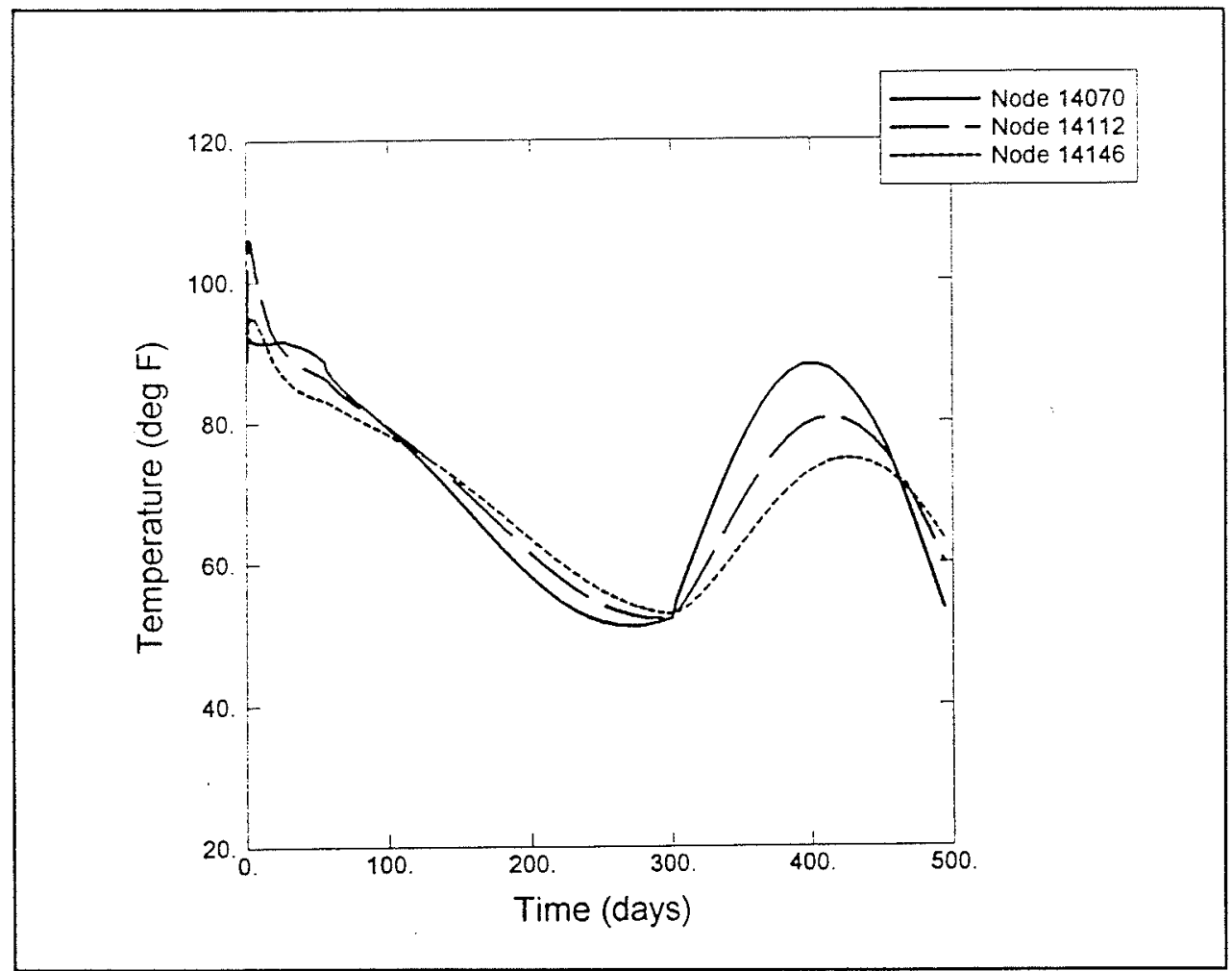

Figure 182. Nodal temperature history, interior floor section 


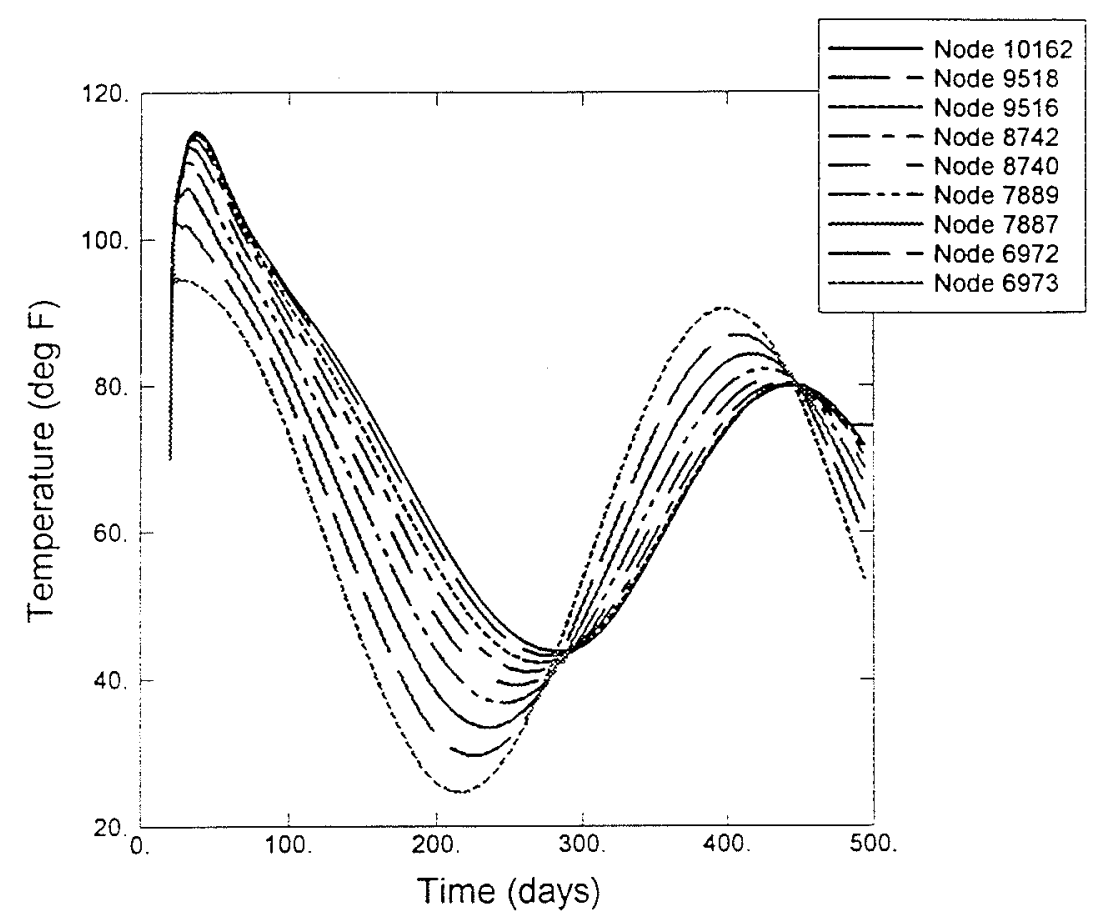

Figure 183. Nodal temperature history, thick culvert wall

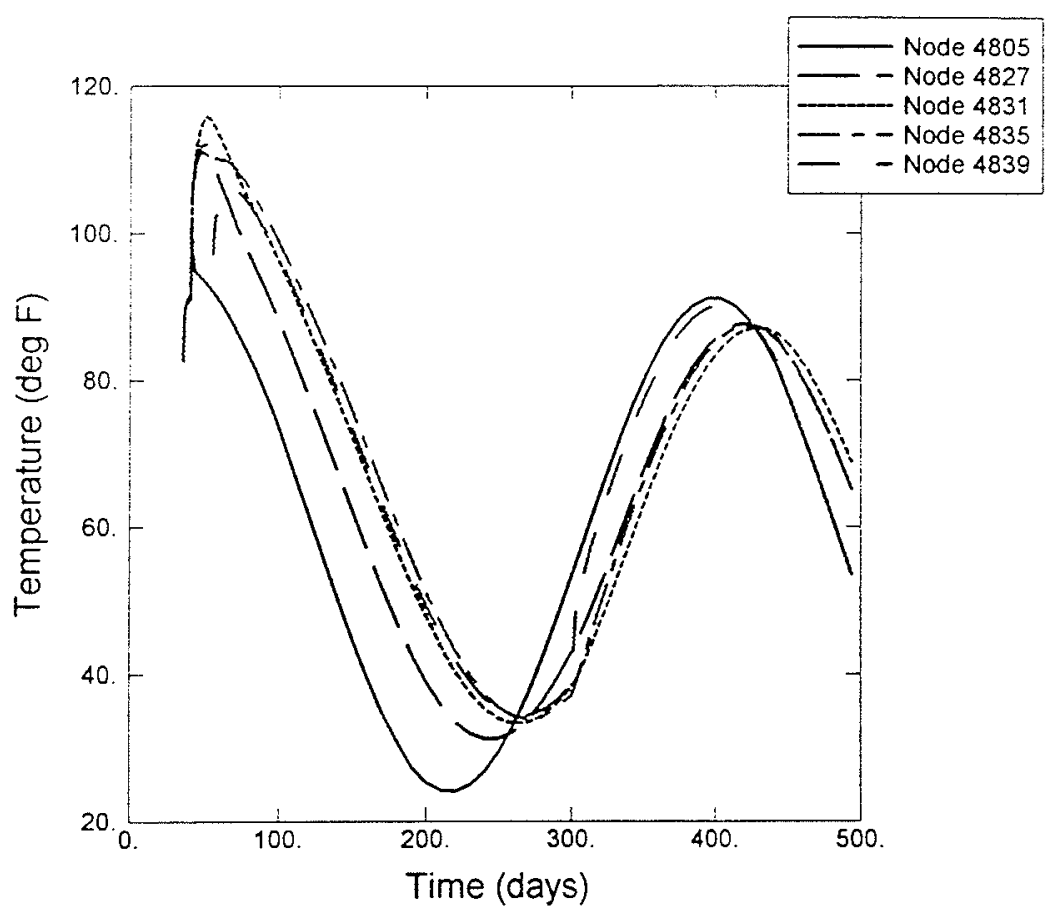

Figure 184. Nodal temperature history, lift $8 /$ lift 9 interface 


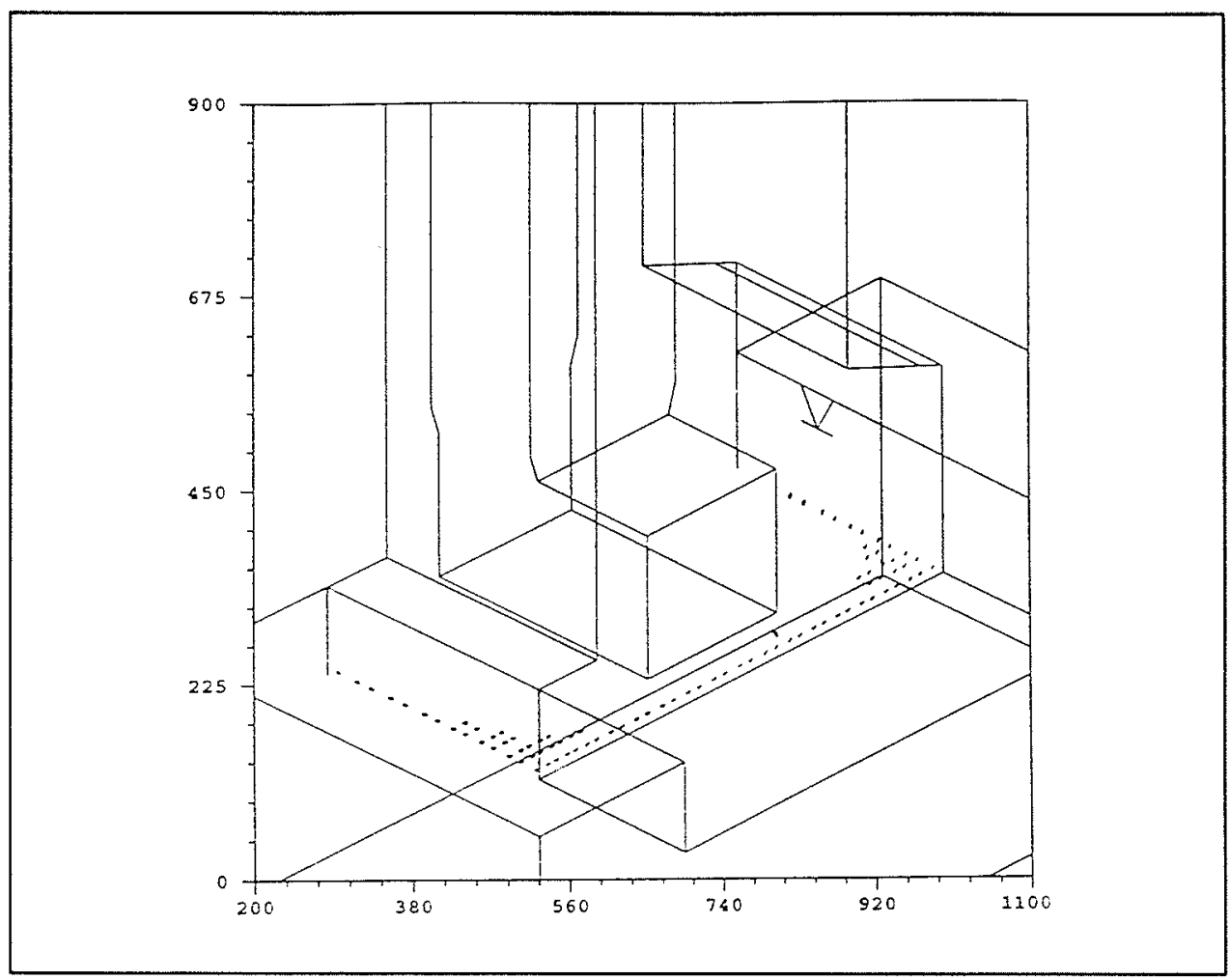

Figure 185. Concrete cracking, day 100

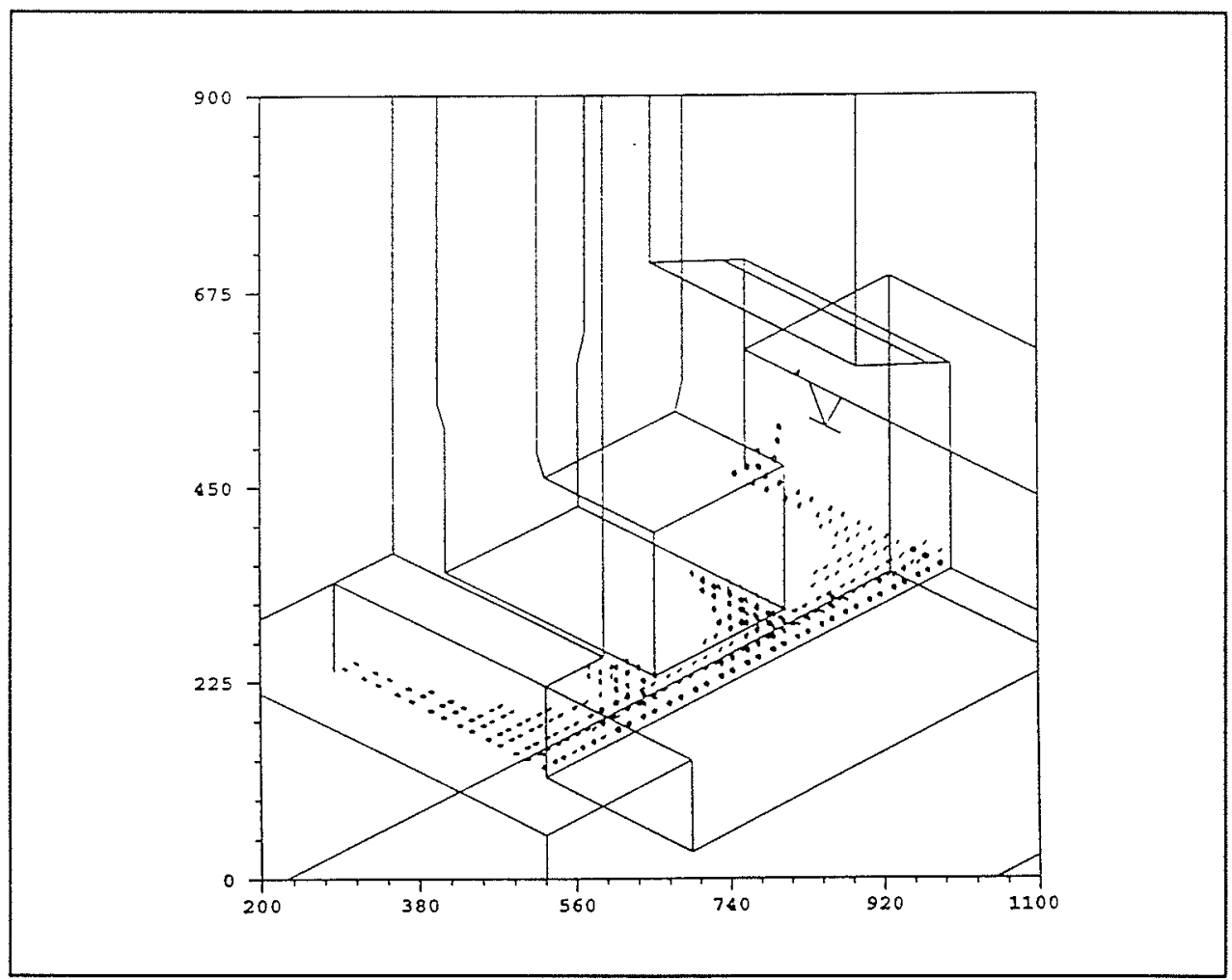

Figure 186. Concrete cracking, day 150 


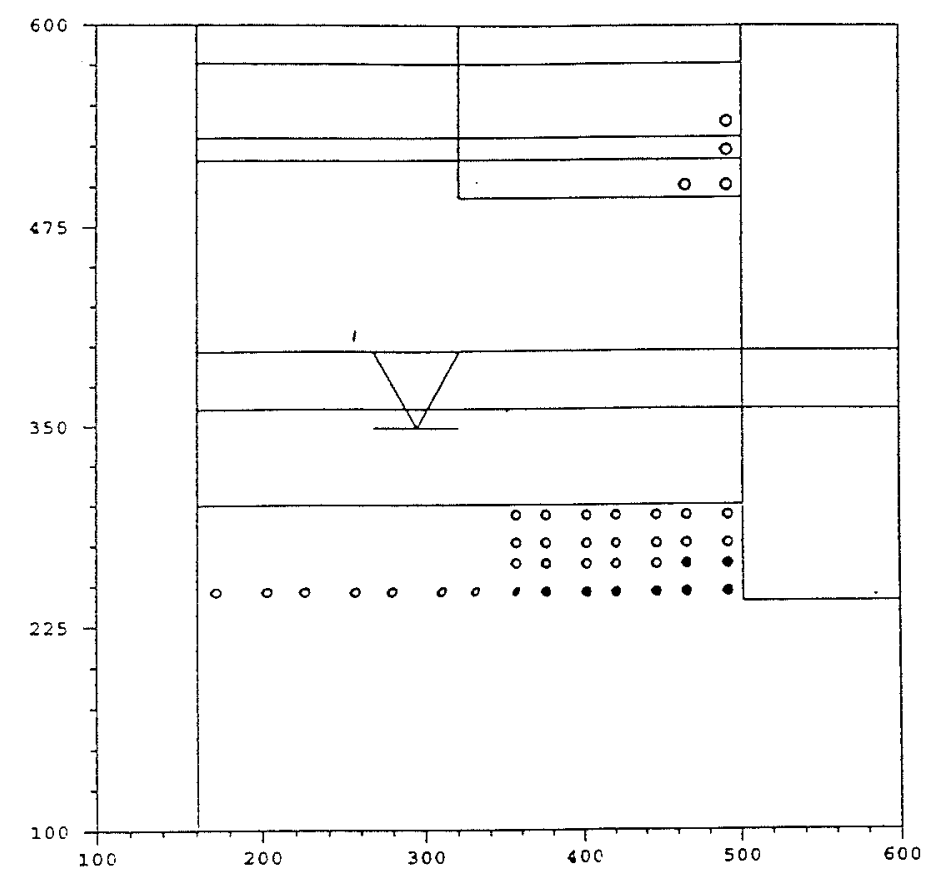

a) side view

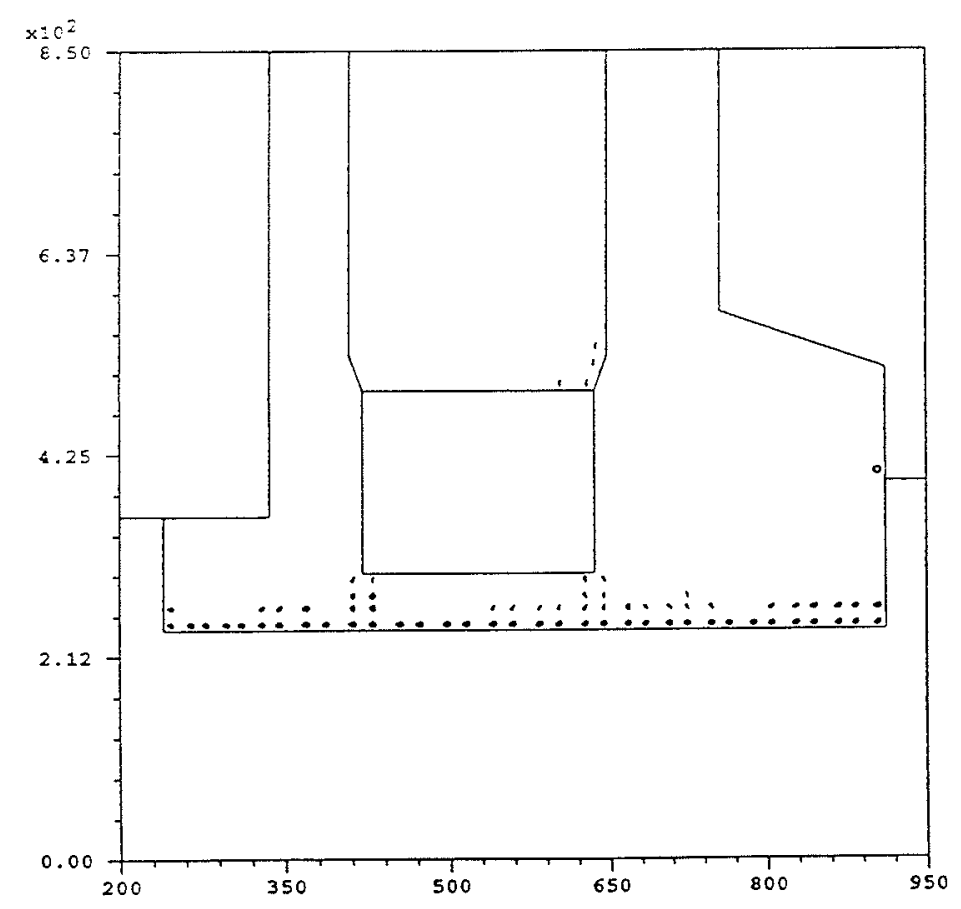

b) view from front

Figure 187. Concrete cracking, day 150 , normal views 


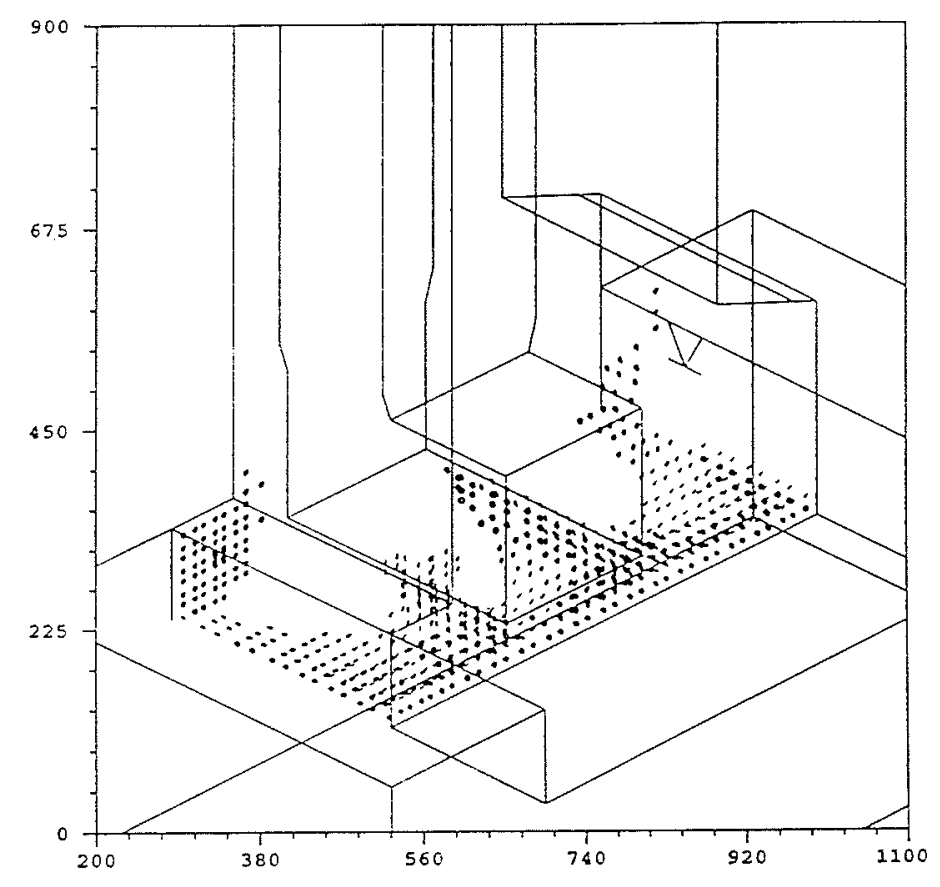

Figure 188. Concrete cracking, day 210

the culvert. Crack potentials in Section 3 were 99 percent throughout much of the base, and had reached 99 percent at the riverside upper comer of the culvert. By day 300 , cracking potentials above the top comers of the culvert had reached 99 percent in Section 3, shown in Figure 195, and cracking potentials of up to 99 percent still could be found in lift 1 . Since cracking over the culvert was initiated at the exterior face, this is just prior to the time at which this cracking extended through the entire upstream wall. By day 364 , shown in Figure 196, cracking potentials at Section 2 were less than 30 percent in the walls of the vertical opening and less than 75 percent in the landside culvert wall. Crack potentials in the base, which was still undergoing cracking, were as high as 99 percent. Cracking potentials in Section 3 had dropped to less than 30 percent throughout much of the section, but were still as high as 91 percent at the base, in the landside culvert wall, and above the top comer of the culvert on the landside of the monolith.

As can be seen in Figure 171, lift 1 was reinforced at the base with No. 11 bars at 12 in. in the transverse and longitudinal directions, with No. 9 bars at 12 in. in both directions directly under the culvert, and with diagonal bars on 12 in. centers at the culvert comers.

Reinforcing stress in the transverse bars under the exterior face of the culvert (elements 2316 and 2321, shown in the plan views of Figure 197, are plotted in Figure 198). The maximum reinforcing stress in the monolith occurred in the outer element directly under the culvert, element 2316. Maximum stress in the No. 9 transverse reinforcing was $40 \mathrm{ksi}$ at 180 days. This is 


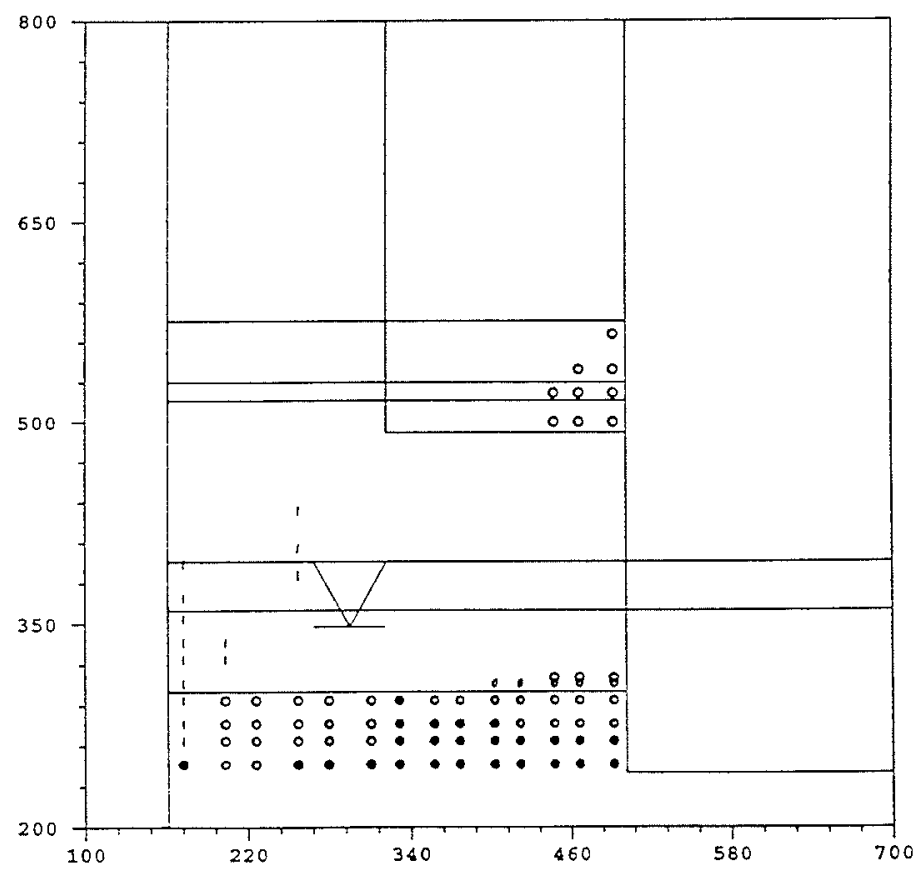

a) side view

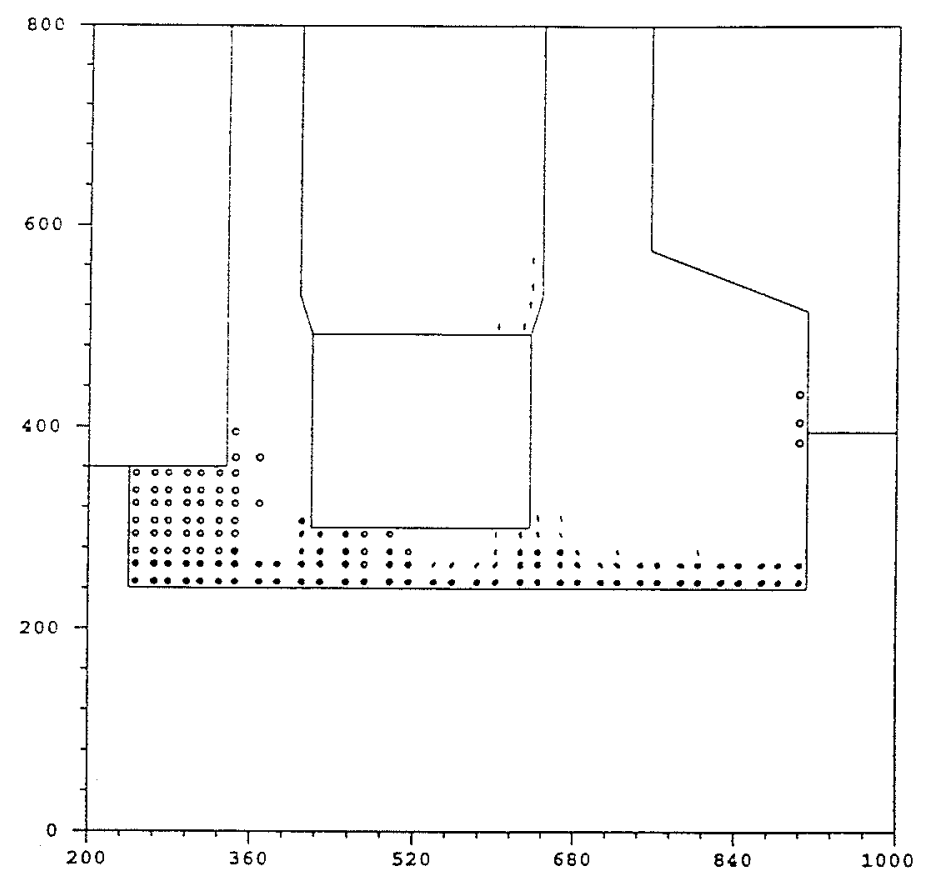

b) front view

Figure 189. Concrete cracking, day 210 , normal views 


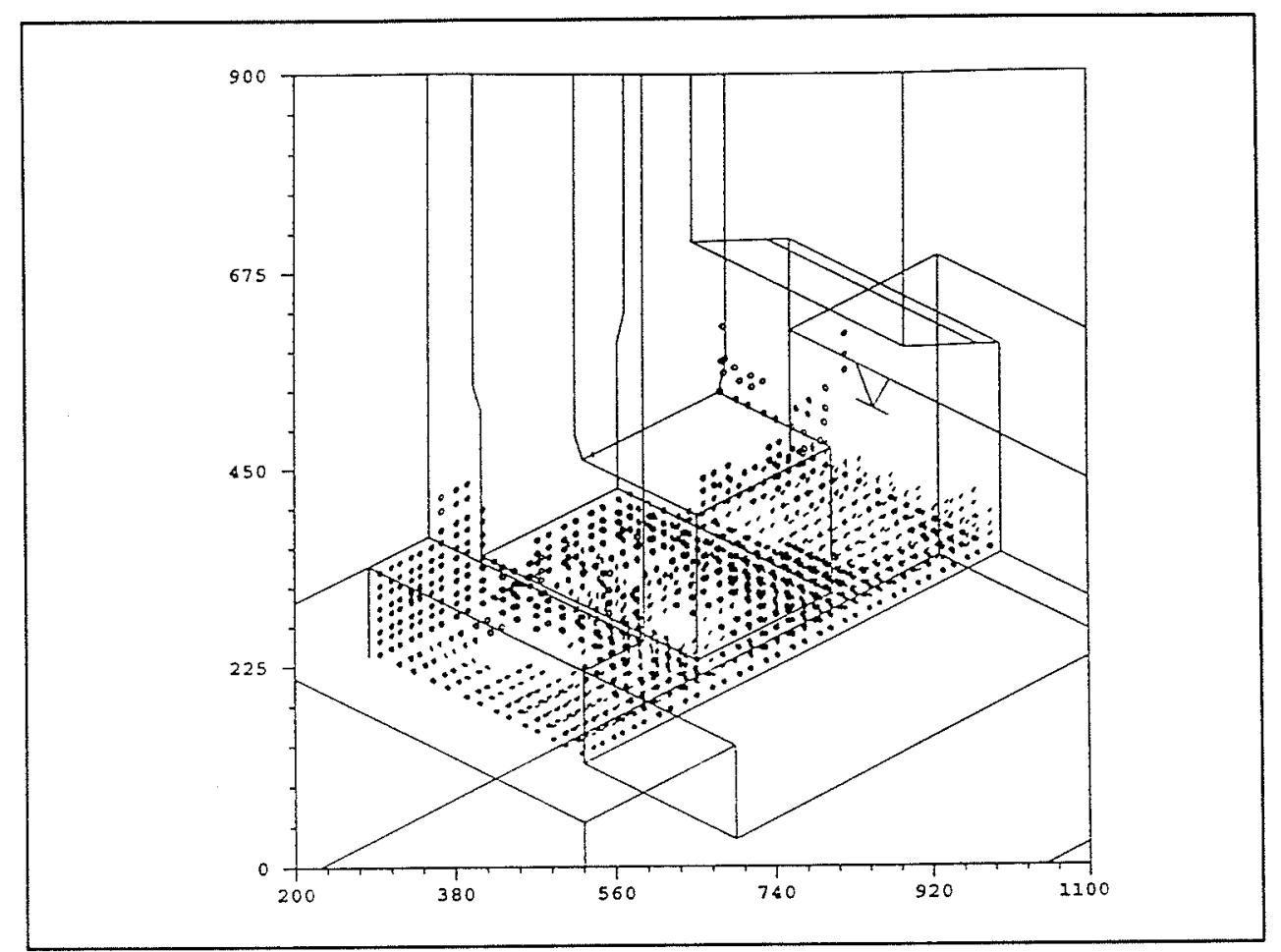

Figure 190. Concrete cracking, day 364

only two thirds of the 60-ksi tensile strength of the steel, and reinforcing stress dropped after day 180, approaching $0 \mathrm{ksi}$ by day 364 as cracks closed. Maximum stress in the No. 11 transverse reinforcing in element 2321, located directly below element 2316, was 22 ksi between 160 and 220 days. Stresses in this reinforcing became compressive by day 300 . Stresses are also shown in Figure 199 for the reinforcing in element 2281, located below the culvert at the center line of the monolith. Stress in the transverse reinforcing increased sharply after day 210 to a maximum of $27 \mathrm{ksi}$ on day 300, and dropped sharply after the cover was removed from the vertical opening on day 303 to roughly $17 \mathrm{ksi}$ at day 364 . Stress in the longitudinal reinforcing was only about $9 \mathrm{ksi}$, but stresses increased and decreased at roughly the same times. The timing of the changes in stress indicates that cracks in this element were initiated prior to day 210 and opened further between days 210 and 303, probably due to reverse temperature gradients.

Reinforcing stresses at longitudinal bars in the area of cracking at the center line are shown in Figure 201, and elements are located in Figure 200. The maximum tensile reinforcing stress in this area was $15 \mathrm{ksi}$ in element 952 . Maximum tensile stresses were reached between days 240 and 300, and decreased quickly after that time, reaching 0 psi in the elements at the top of lift 2 by day 364 .

Cracking above the culvert began in element 2285. This element is at the exterior face of the monolith directly above the top landside corner of the culvert, and is shown in Figure 202. Reinforcing stresses in the lateral 


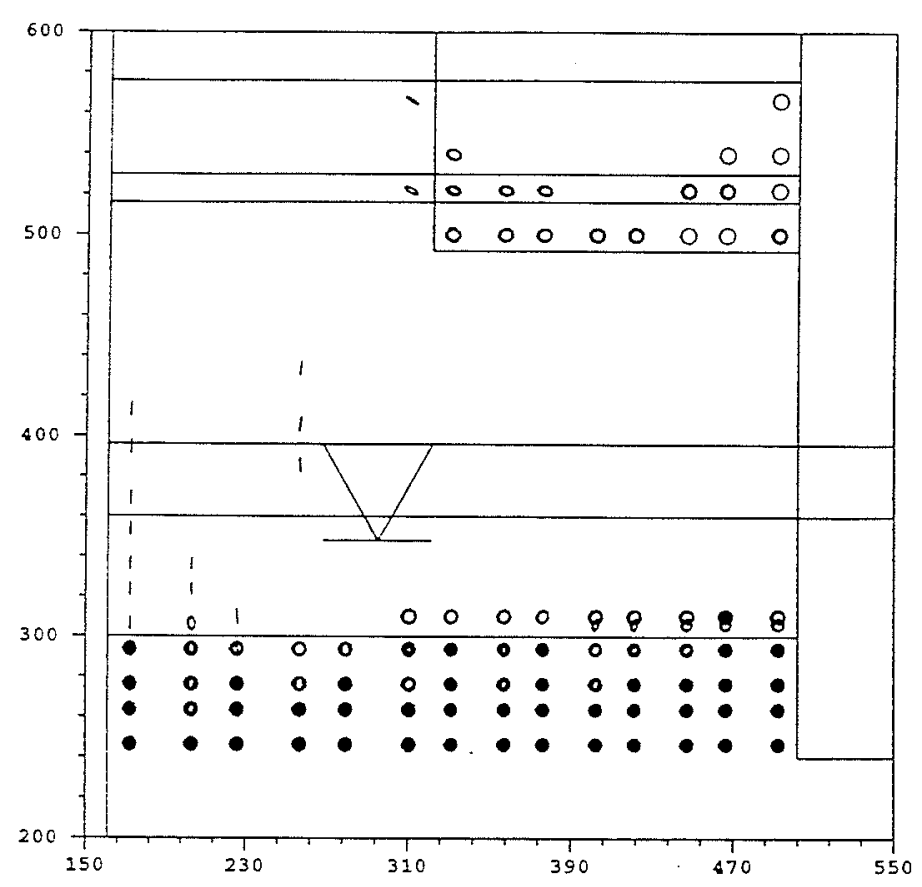

a) side view

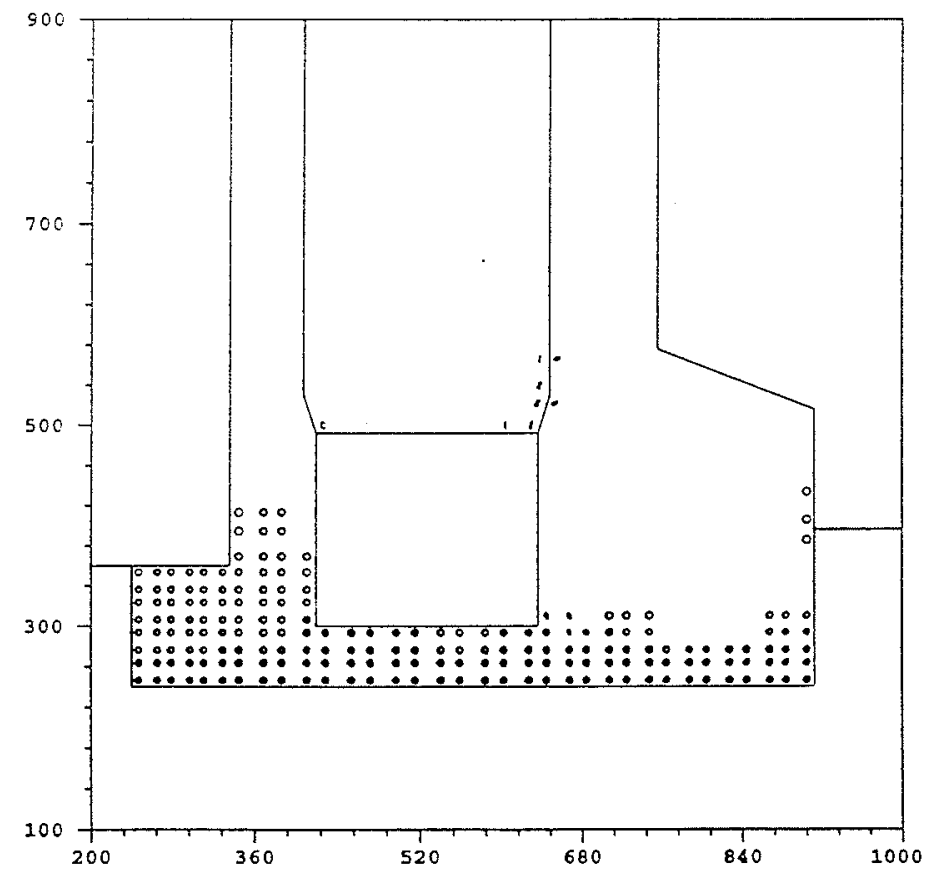

b) front view

Figure 191. Concrete cracking, day 364 , normal views 


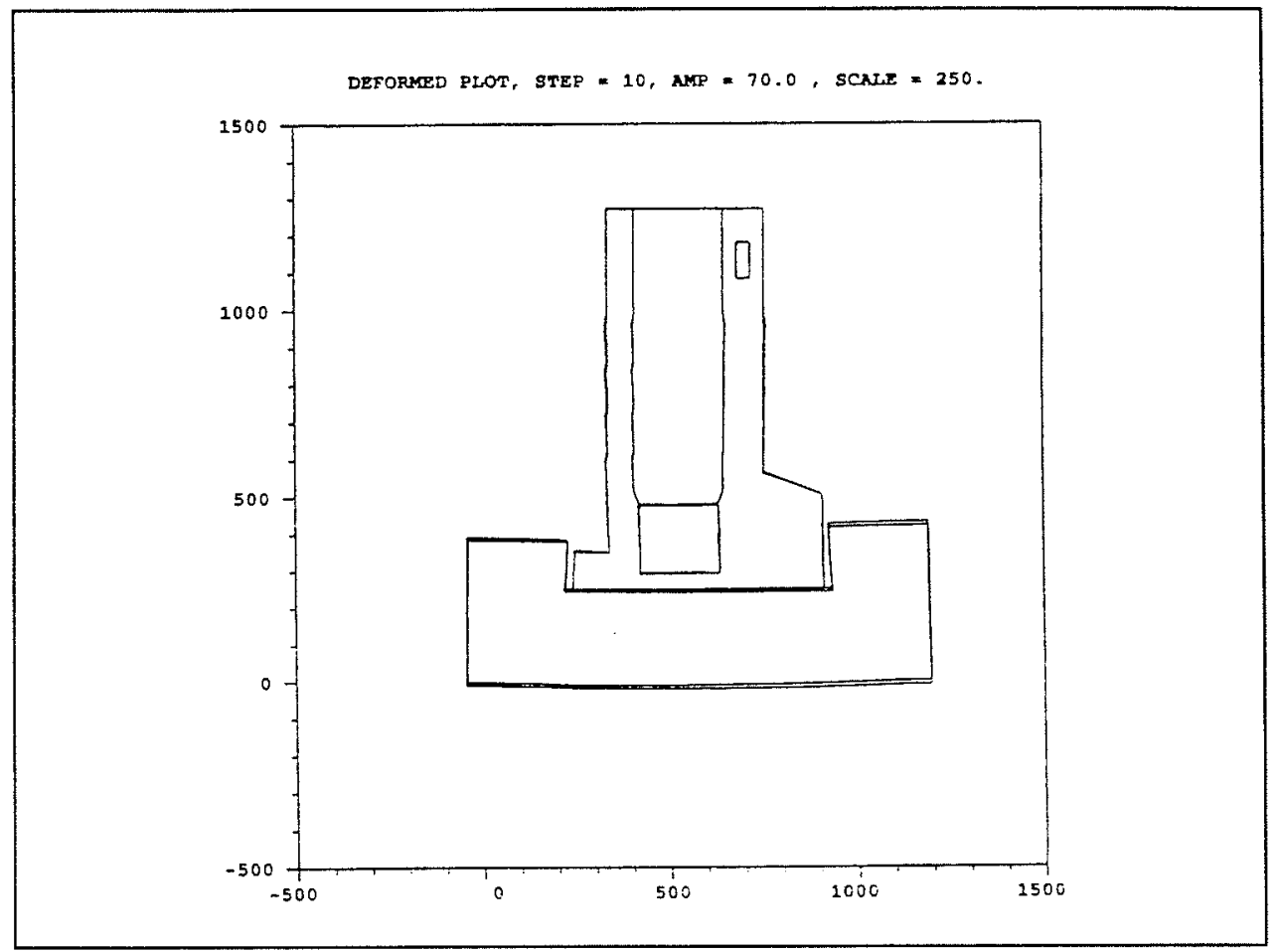

Figure 192. Displaced plot, day 70

reinforcing over the culvert are shown in Figure 203. Maximum tensile stress was $18 \mathrm{ksi}$ on day 190 . After day 200 , tensile stresses in the reinforcing dropped quickly, becoming compressive between days 270 and 280 as the cracks closed. Lateral reinforcing stresses at the inside face of the concrete above the culvert were not saved. However, stresses in the diagonal reinforcing of element 2282 are shown in Figure 204. This element is located on the interior vertical shaft face directly above the landside top culvert comer and is shown in Figure 205. Reinforcing stresses became tensile by day 270 , and increased sharply to a maximum of $14 \mathrm{ksi}$ on day 300 . Stresses dropped quickly after day 300 , indicating that cracking in this area was probably largely due to reverse temperature gradients and was limited by opening the valve pit on day 303 .

In no case did reinforcing stress exceed $40 \mathrm{ksi}$, and stresses in all reinforcing decreased after peak stresses were reached, indicating that cracks were either closed or decreasing in width. This indicates that although extensive cracking may occur, especially in lift 1 , this cracking should not affect the structural integrity of the culvert valve monolith. Cracks extending to the exterior surface of the concrete were located on the chamber side of the monolith at the center line and at all culvert comers. These cracks closed prior to filling the lock with water, and should not be expected to open after that time, since minimum water temperatures are approximately $20^{\circ} \mathrm{F}$ higher than minimum air temperatures, and temperature differences across sections should be small. All other cracking occurred due to base restraint and is not preventable 


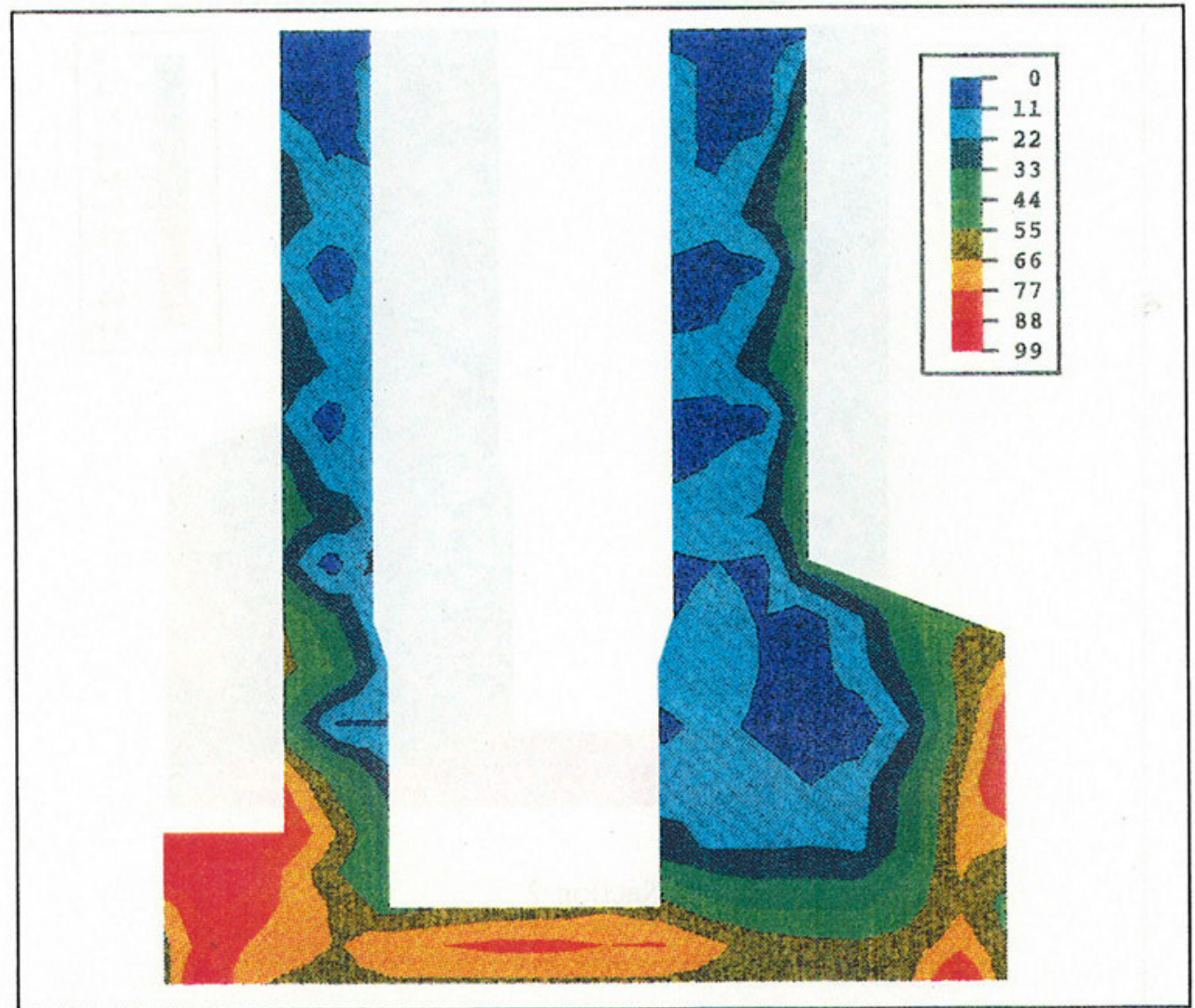

Figure 193. Cracking potential, Section 2, day 170

unless bond strength between the concrete and rock can be reduced. However, this bond is desirable in preventing sliding.

To verify that cracking was due to the bond at the concrete/rock interface, additional analyses were performed on the quarter symmetric 2-lift model shown in Figure 206. The initial analysis on the reduced model was a baseline analysis with continuity at the concrete/rock interface simulating a perfect bond. Materials, placement parameters, ambient conditions, and boundary conditions were unchanged from the previous analysis. In the second analysis, gap elements and a friction coefficient of 0.5 were provided at the horizontal rock/concrete interface. This simulated the restraint that would be provided at the base if a bond breaker was applied to a smooth rock face before concrete was placed.

Cracking at the base in the first analysis was initiated at day 30. By day 250 , most of the integration points directly above the concrete/rock interface had cracked, and cracking had extended upward at the outer edges of the base. Base cracking was diagonal, radiating outward from the center of the floor. In addition, some vertical cracking had occurred near one of the center planes of the model. A plot of cracking at day 250 for this analysis is shown in Figure 207. In the second analysis, two integration points at the base cracked on day 3.5. This cracking was due to incorrect temperature curves input for the 


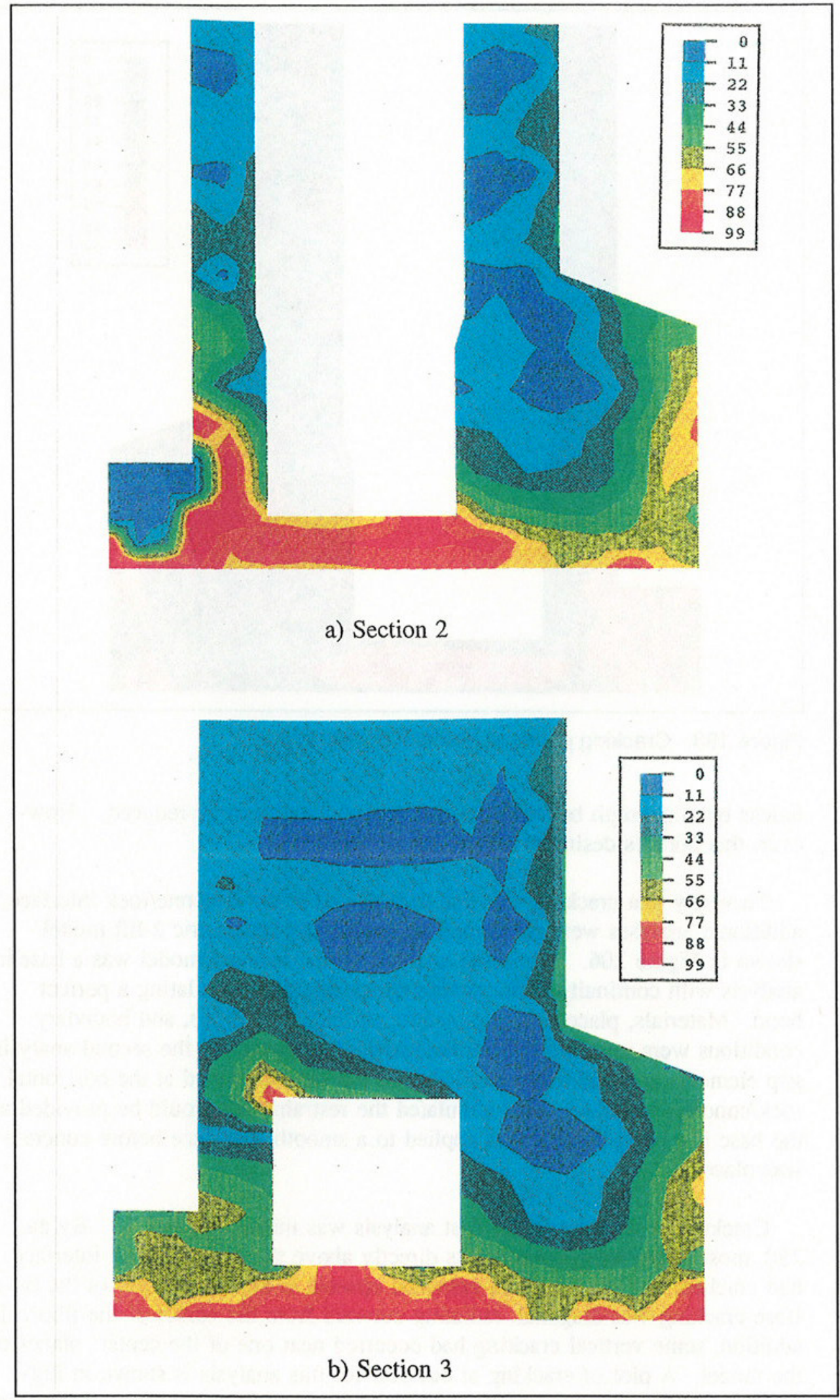

Figure 194. Cracking potential, day 210 


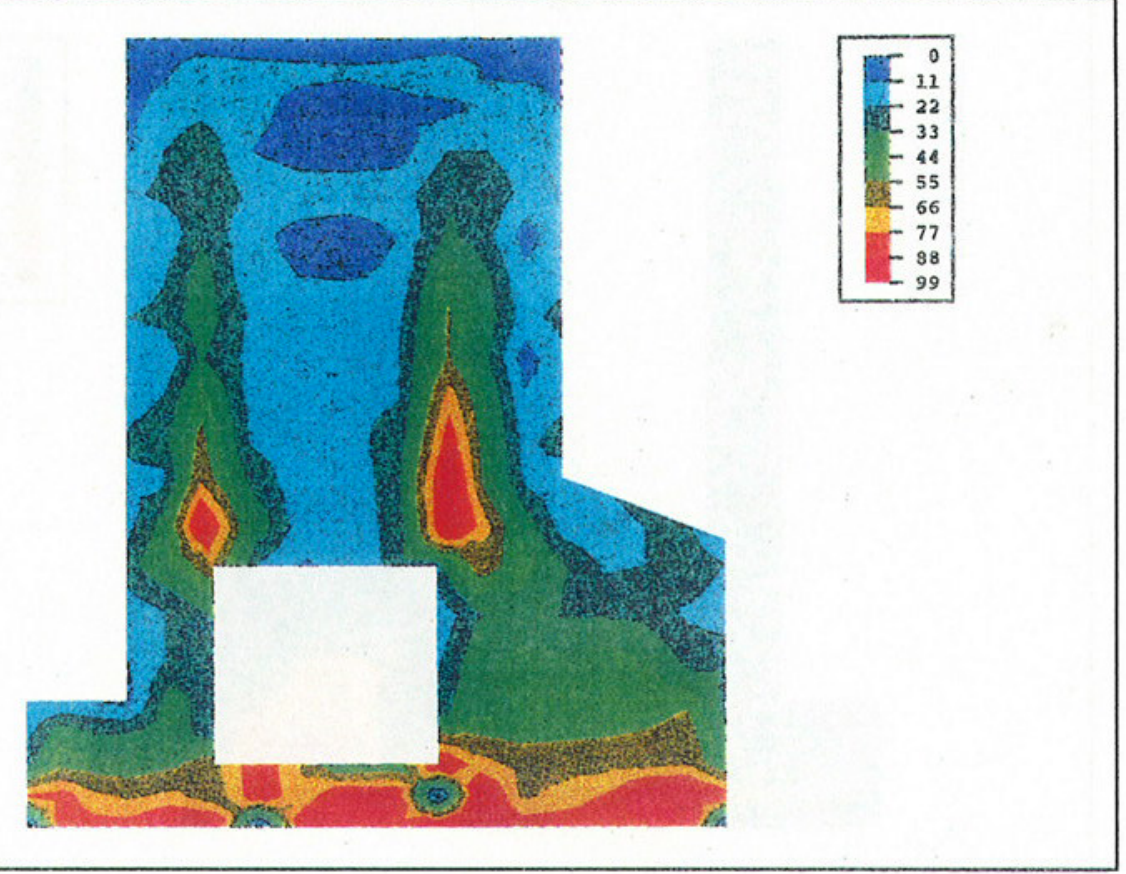

Figure 195. Cracking potential, Section 3 , day 300

new interface nodes in this location. Three additional cracks occurred at the center of the base between days 85 and 115; after day 114, no further cracking occurred. Plots of cracking at day 250 are shown in Figures 207 and 208.

Plots of cracking potentials for the second analysis (Figures 209 and 210) show high crack potentials near the center at days 84 and 108, just prior to cracking near these faces. After day 114, maximum crack potentials at the center faces decreased. Maximum crack potential at the center line on day 300 was 61 percent. The location of a layer of elements at the base of the concrete is given in Figure 211.

Figure 212 shows maximum reinforcing stresses in analysis 1 for the lift 1 elements shown in Figure 211. The maximum stress occurred in the element at the upstream face, element 359 , and was $15.5 \mathrm{ksi}$ on day 210 . As in the previous analysis, reinforcing stress in this outside element decreased after day 210. Maximum reinforcing stress at interior elements was $12.5 \mathrm{ksi}$ on day 260. By day 300, reinforcing stress in all elements was decreasing, although no cracks closed during the analysis.

Displaced plots at days 84 and 300 for analysis 1 are shown in Figure 213. By day 300, the difference in displacement at the outer face of the concrete had become apparent. Concrete at the horizontal rock/concrete interface has displaced relatively little, while the concrete above has moved away from the vertical rock face. 


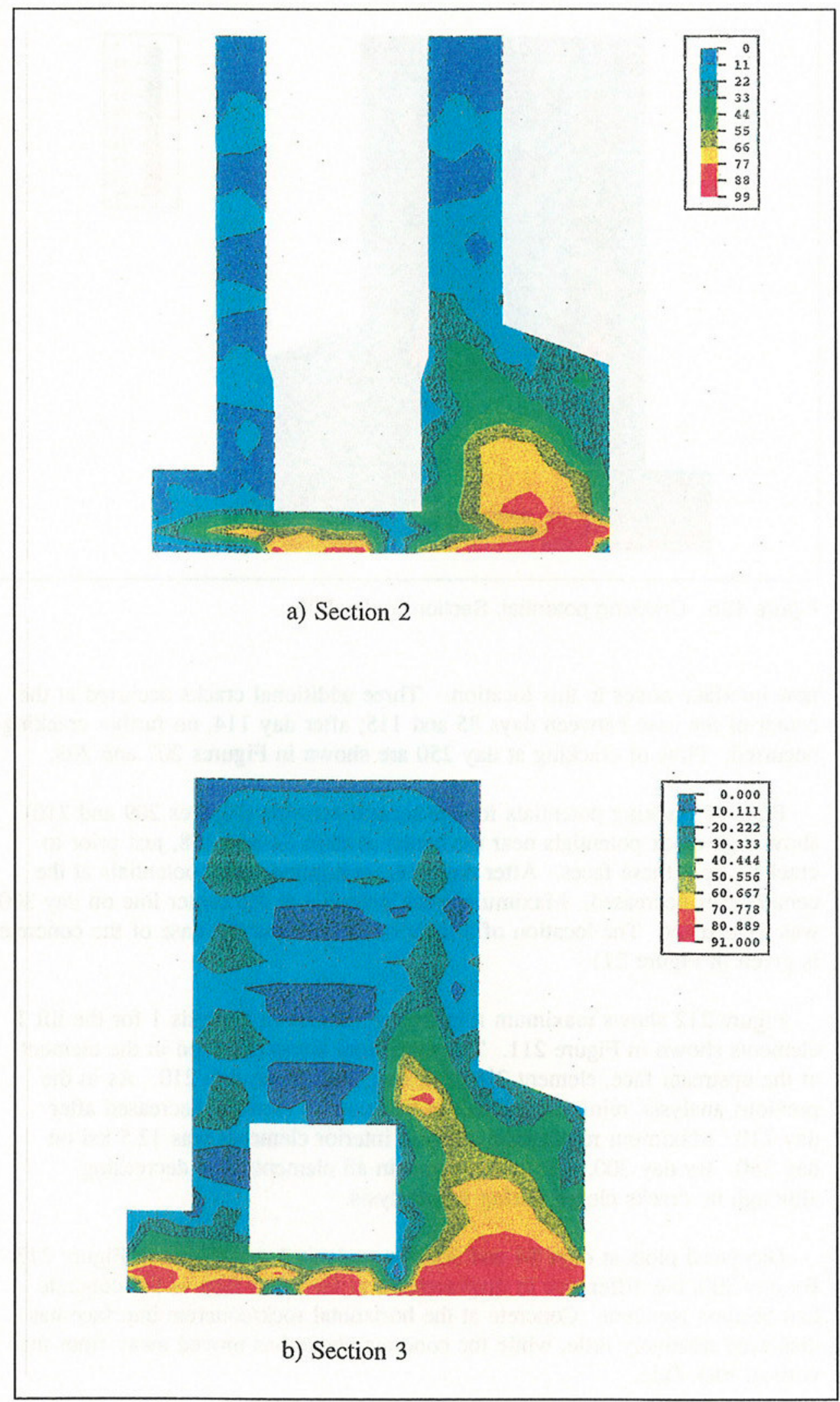

Figure 196. Cracking potential, day 364 


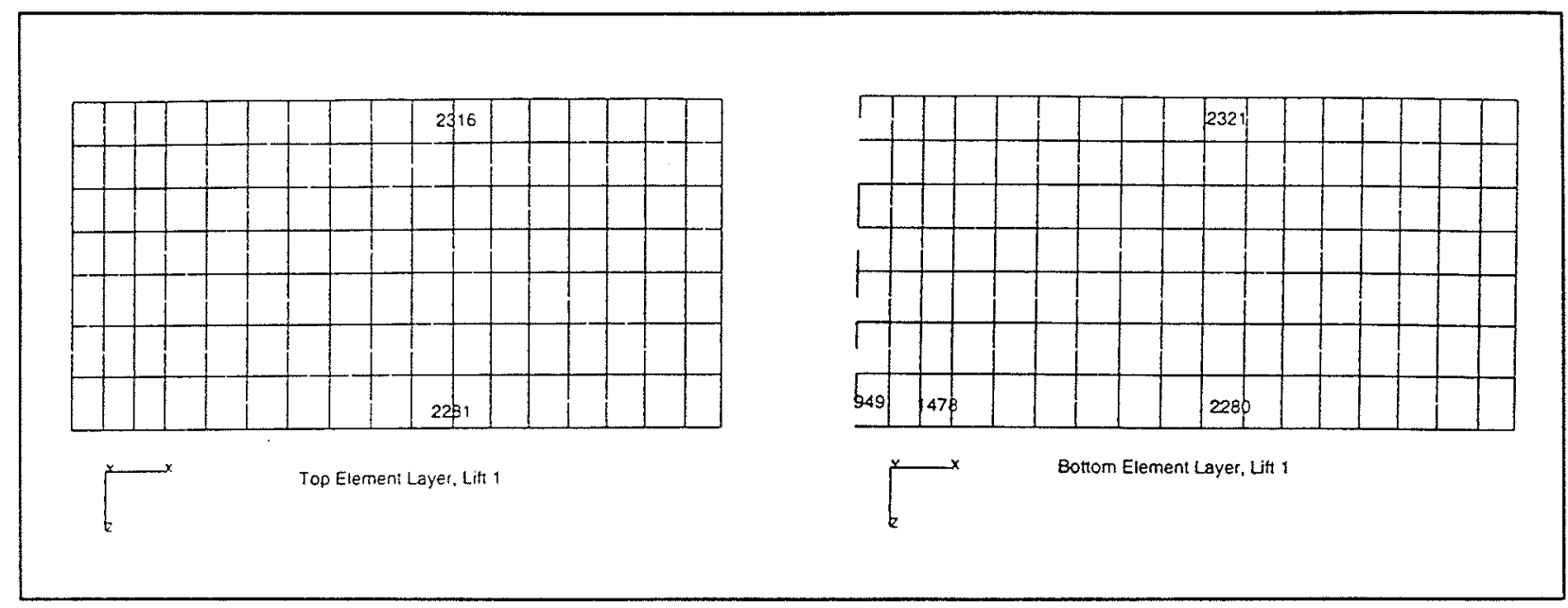

Figure 197. Lift 1 element locations, plan view

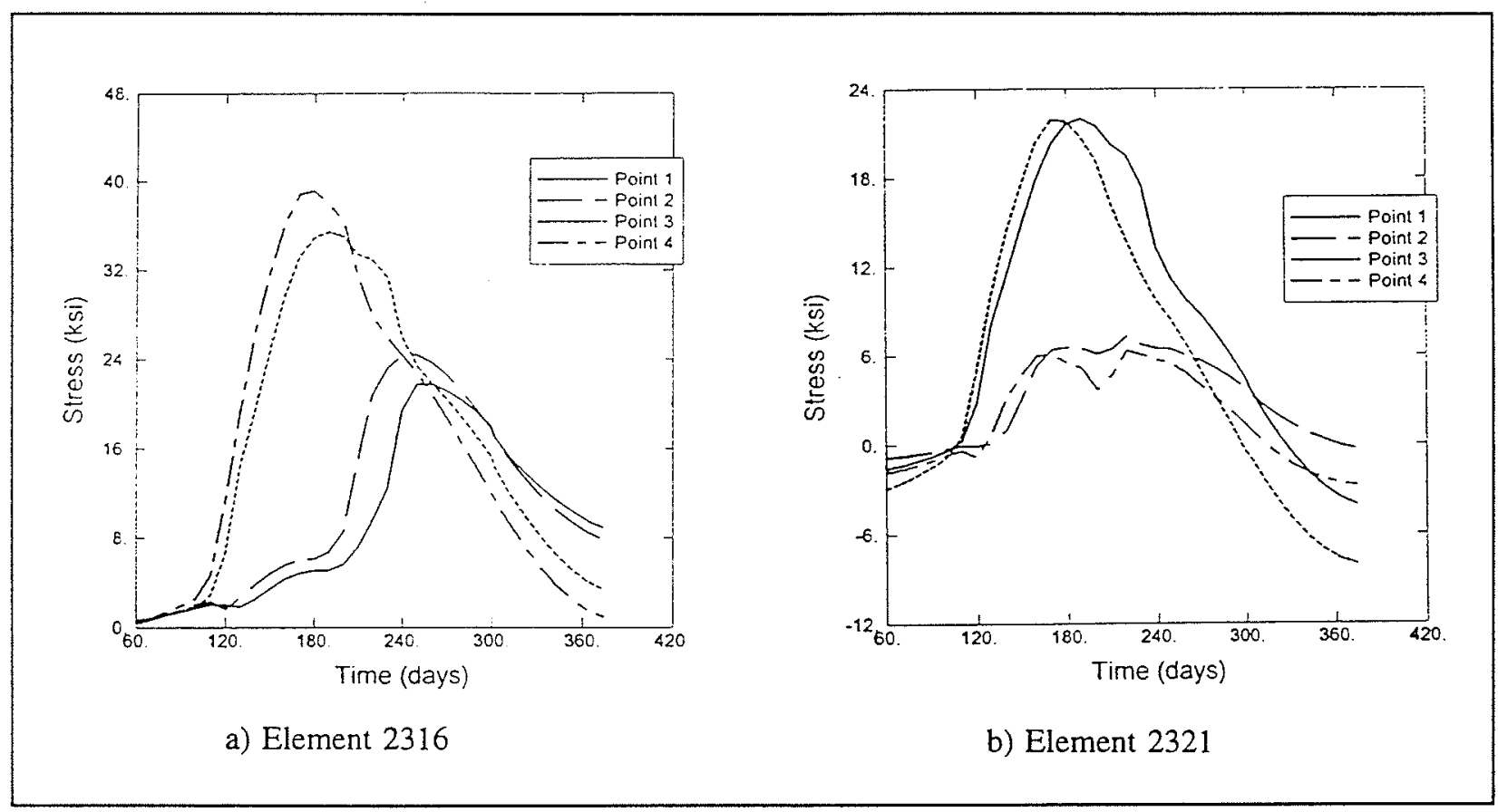

Figure 198. Transverse reinforcing stress, elements 2316 and 2321

These results verified that most lift 1 cracking was due to the restraint provided by the underlying rock. Debonding the rock/concrete interface in the second analysis greatly reduced cracking. 


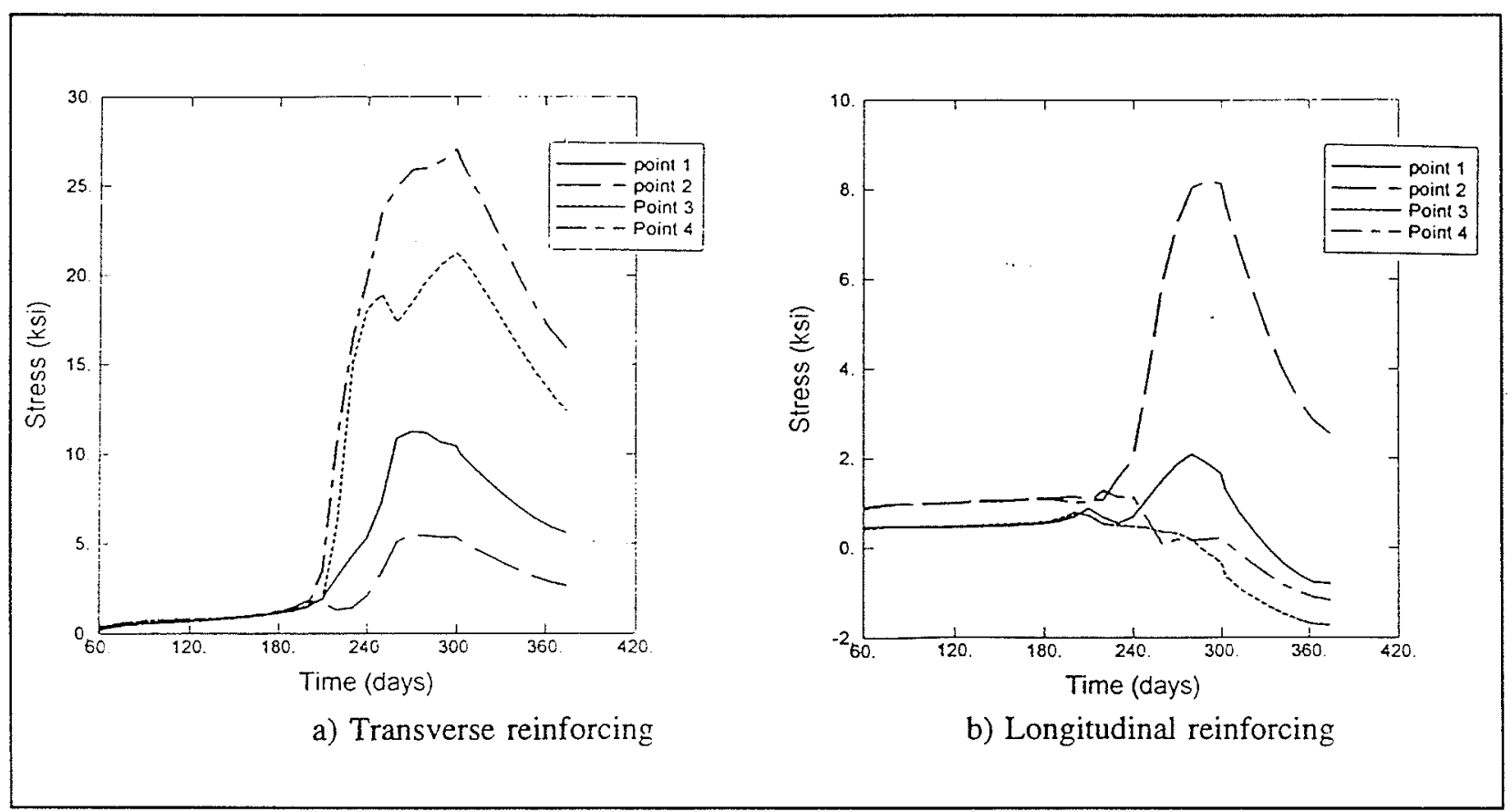

Figure 199. Reinforcing stress, element 2281

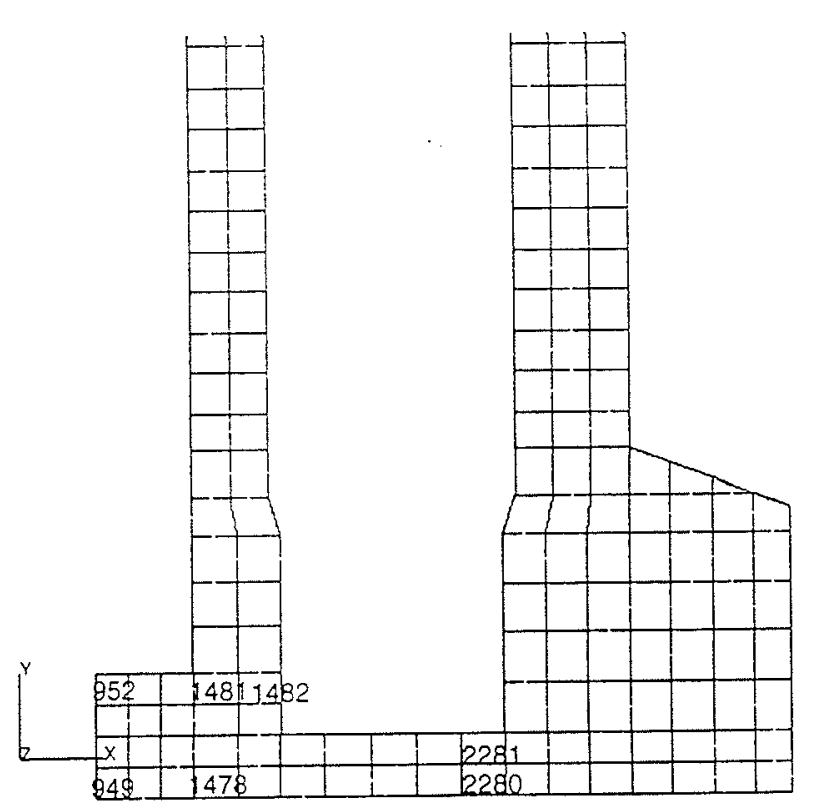

Figure 200. Location of elements at center line of monolith 


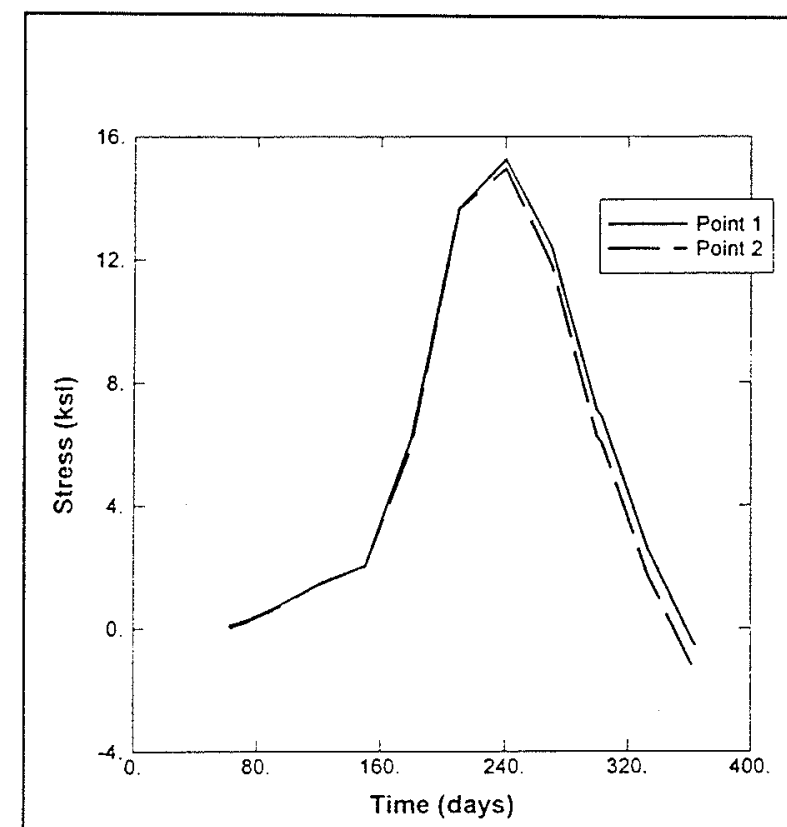

a) Element 952

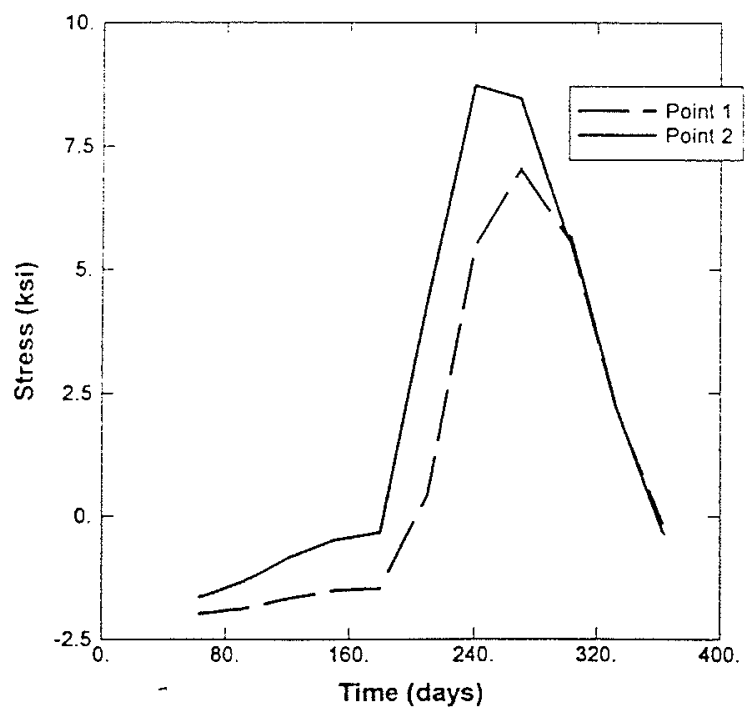

c) Element 1481

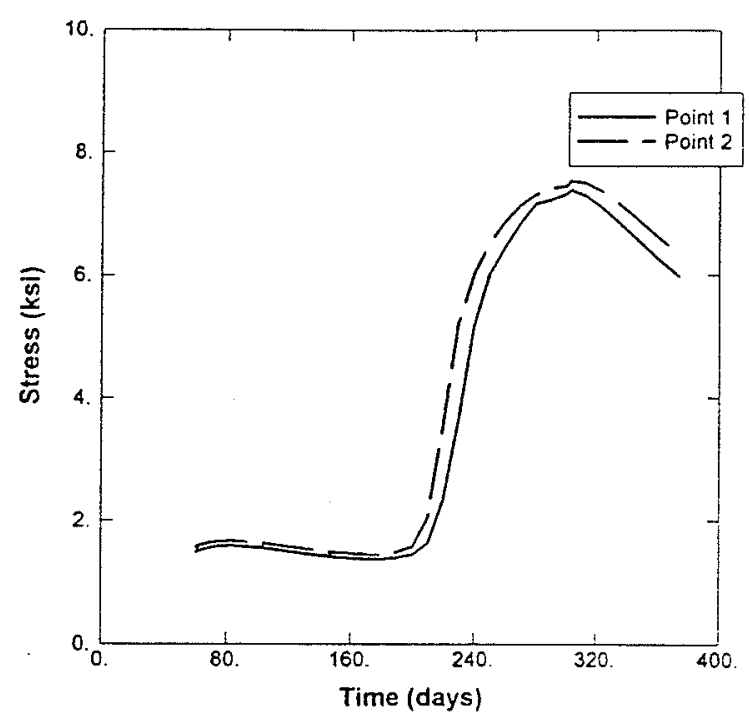

b) Element 1478

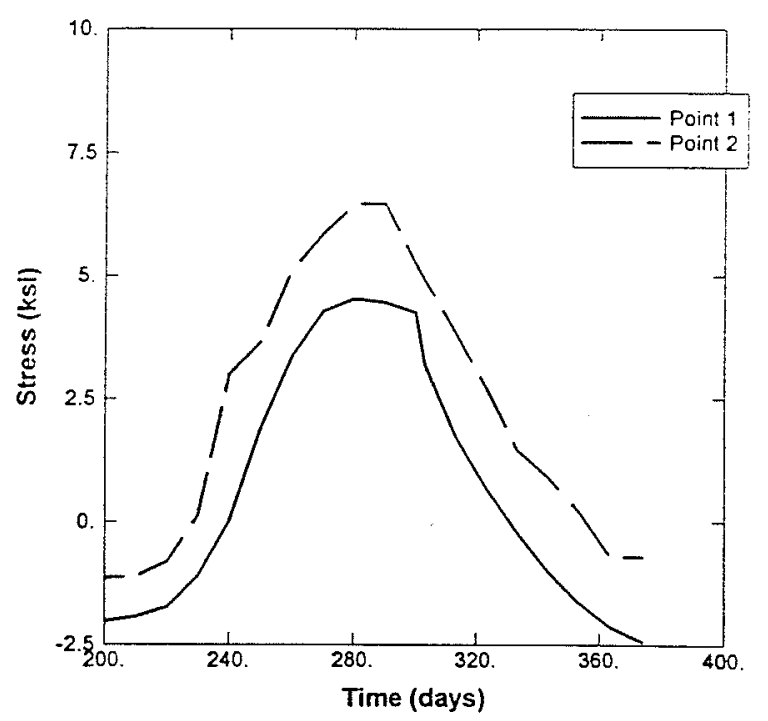

d) Element 1482

Figure 201. Longitudinal reinforcing stress in cracked elements at center line 


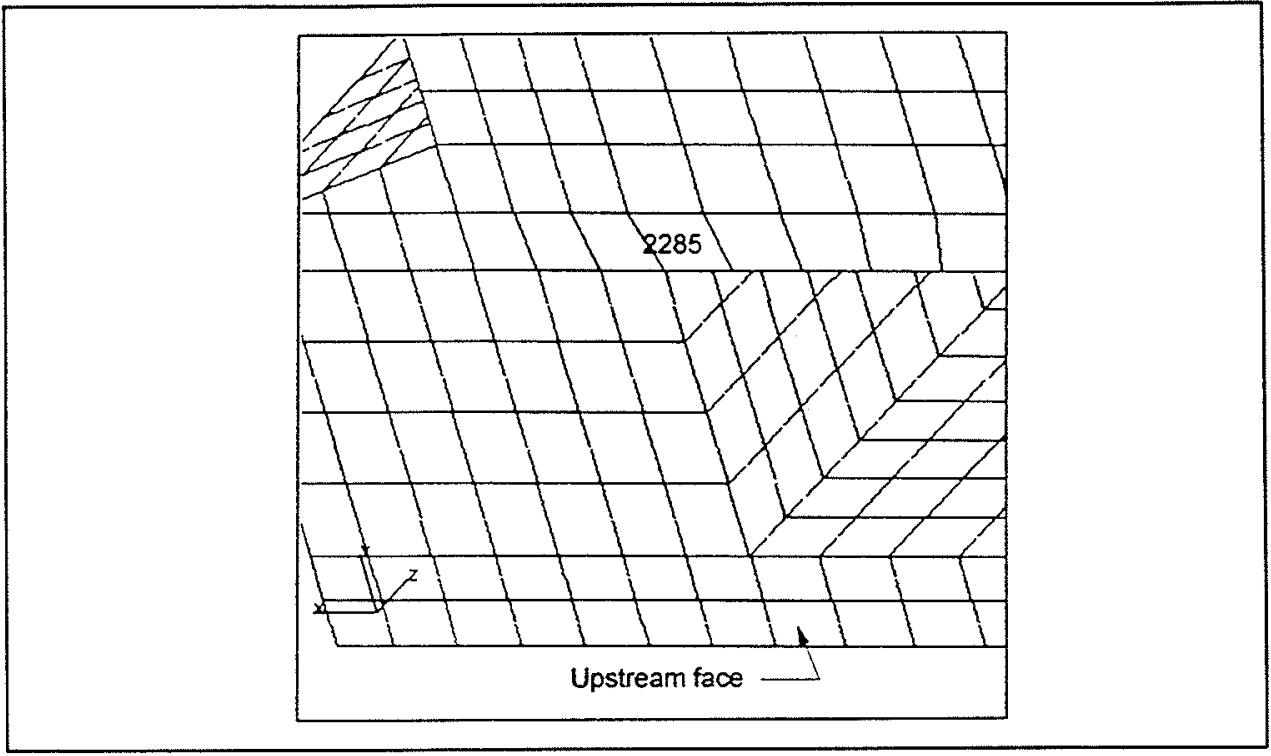

Figure 202. Location of element 2285

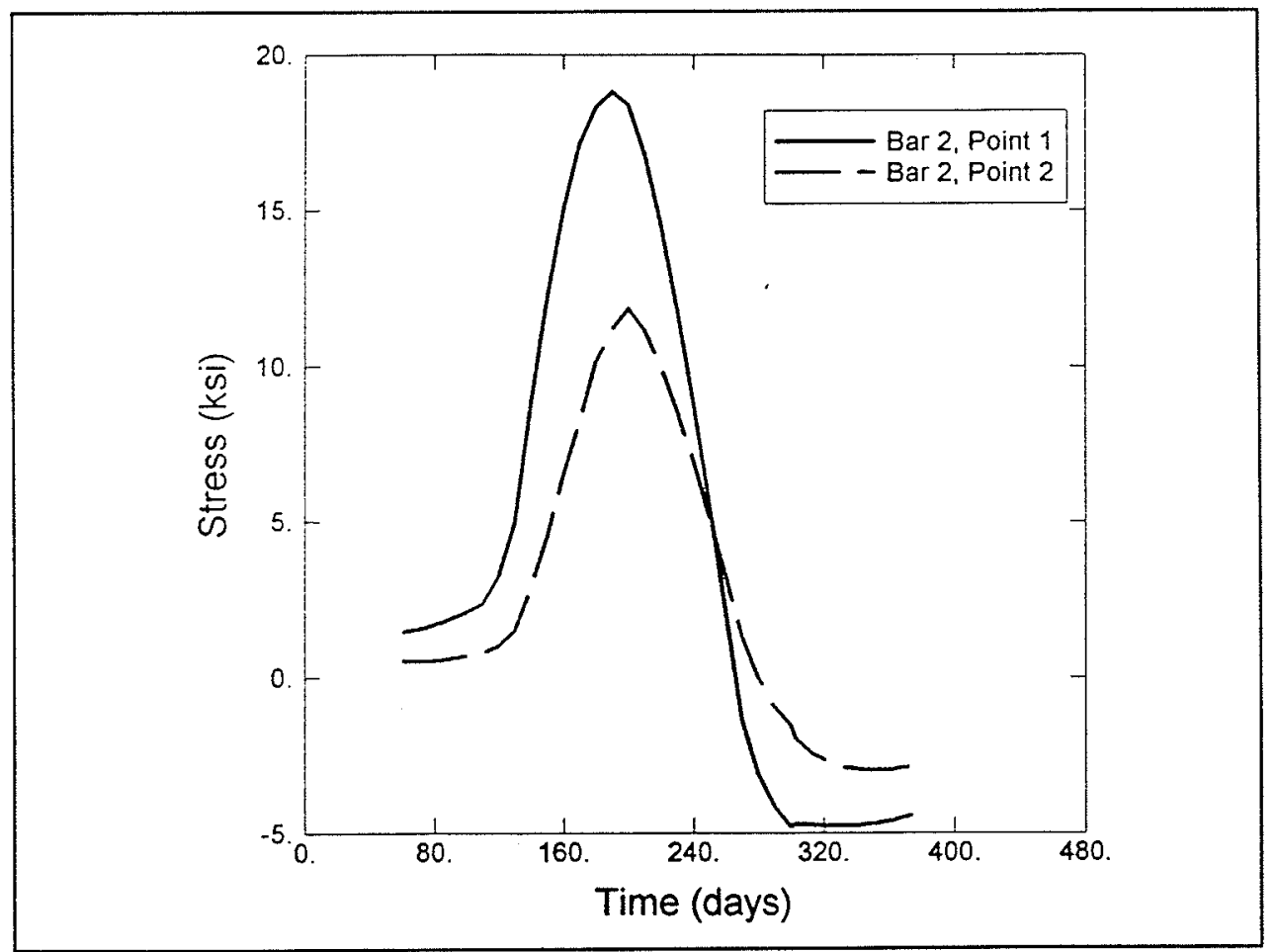

Figure 203. Transverse reinforcing stresses over outer culvert opening, element 2285 


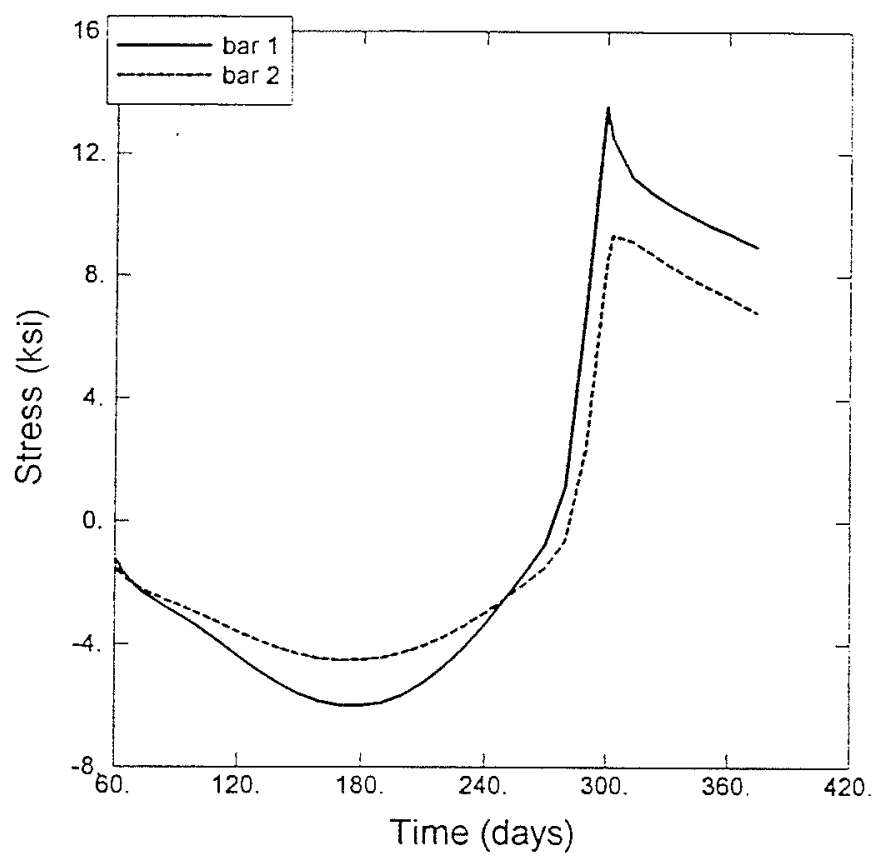

Figure 204. Diagonal reinforcing stresses at intersection of vertical shaft and culvert, element 2282

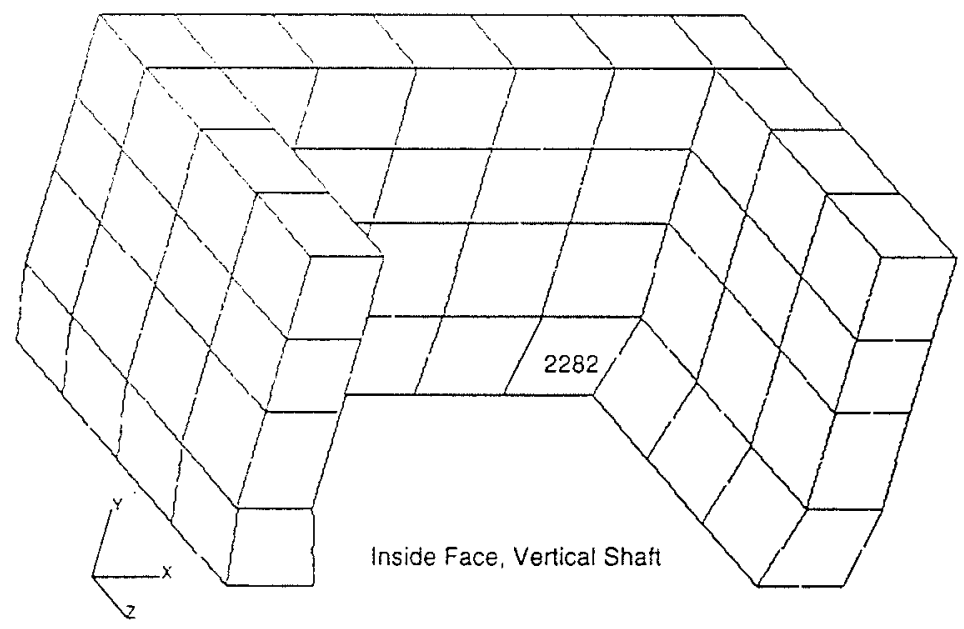

Figure 205. Location of element 2282 


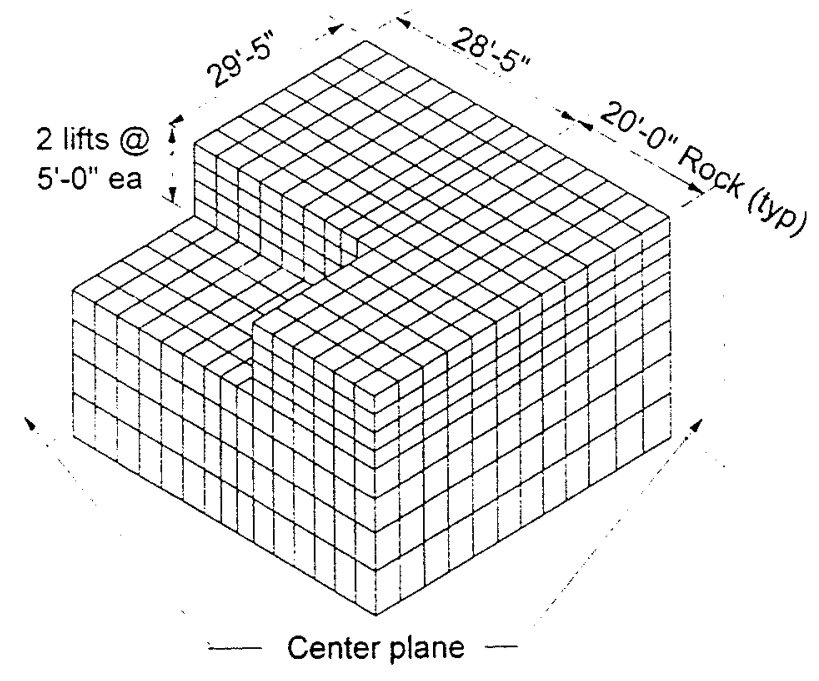

Figure 206. Quarter symmetric two-lift model

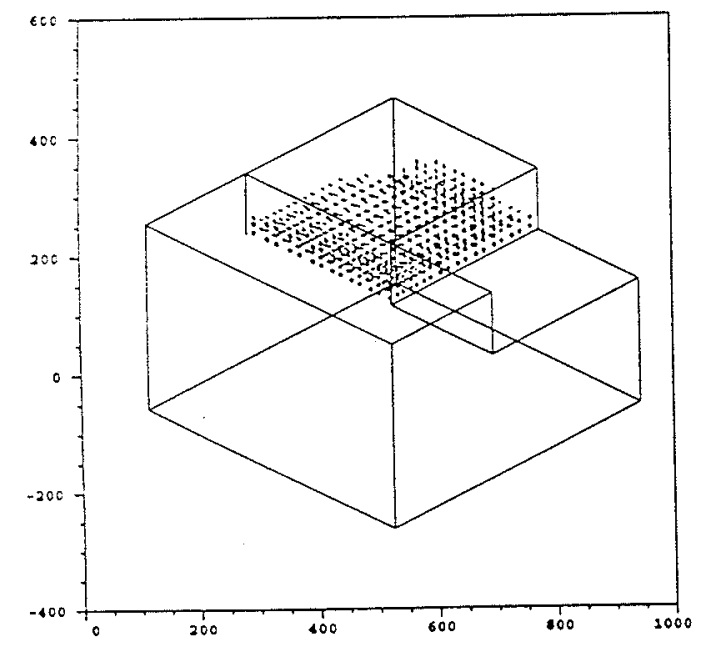

a) isometric view

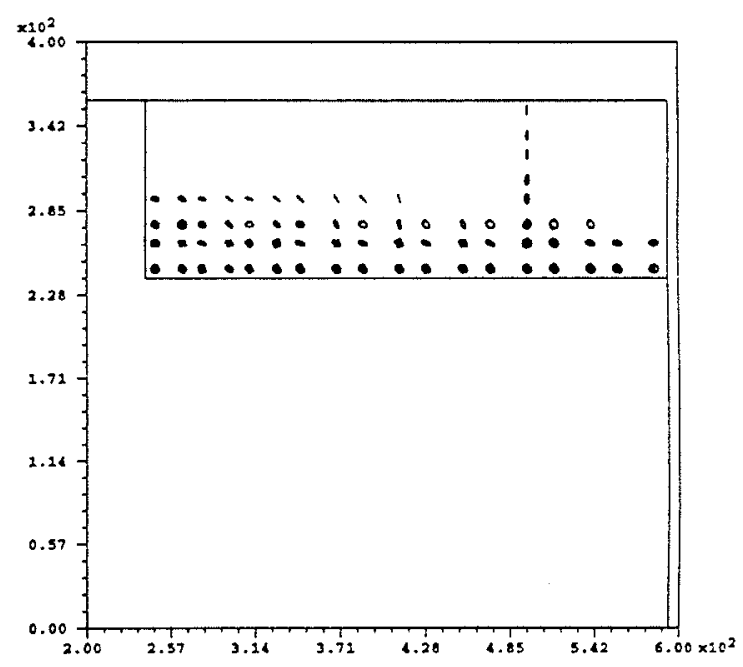

b) side view

Figure 207. Cracking, day 250, two-lift analysis 1 


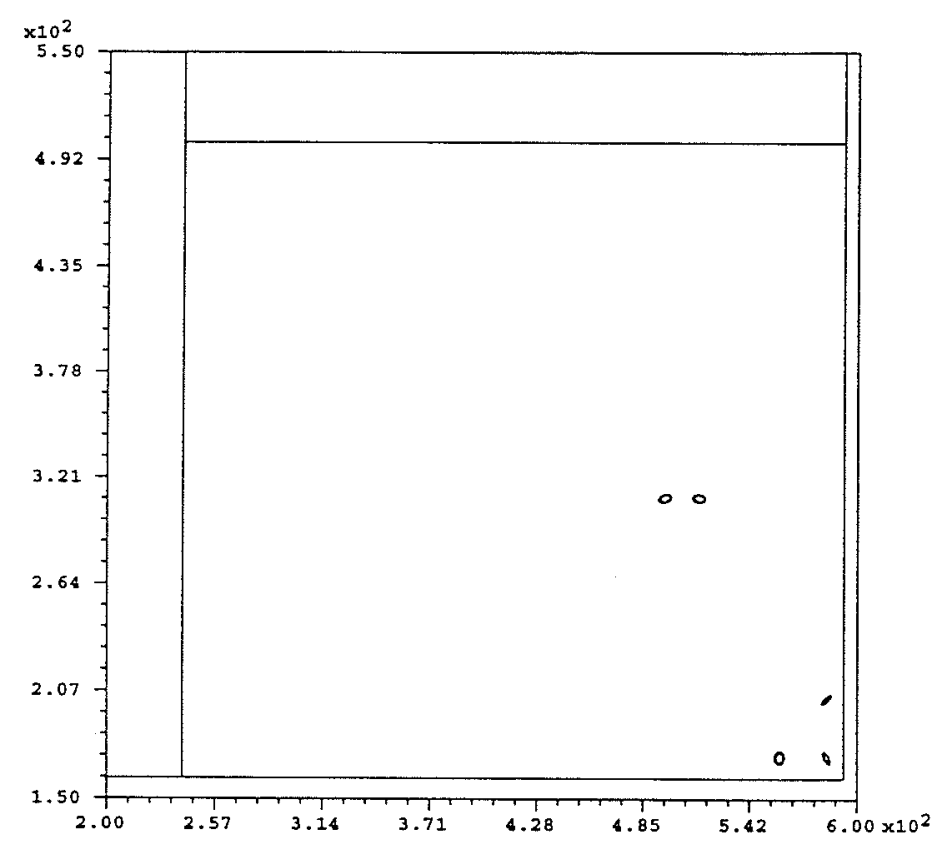

a) plan view

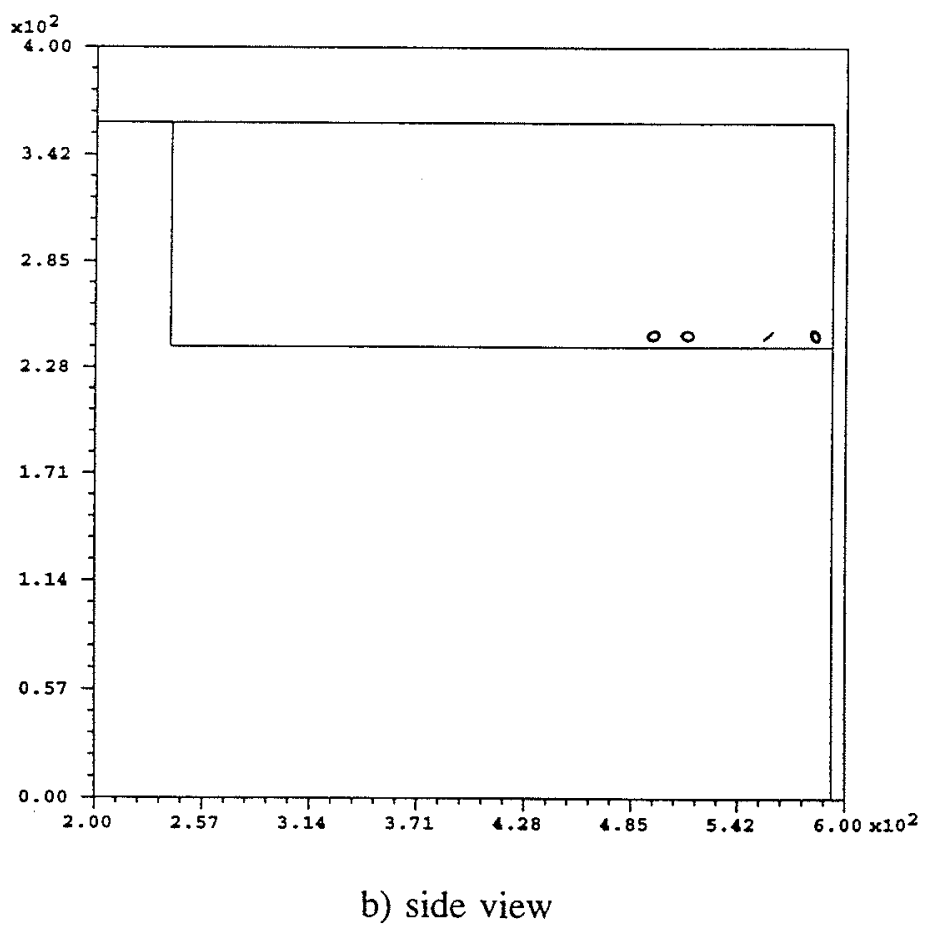

Figure 208. Cracking, day 250, two-lift analysis 2 


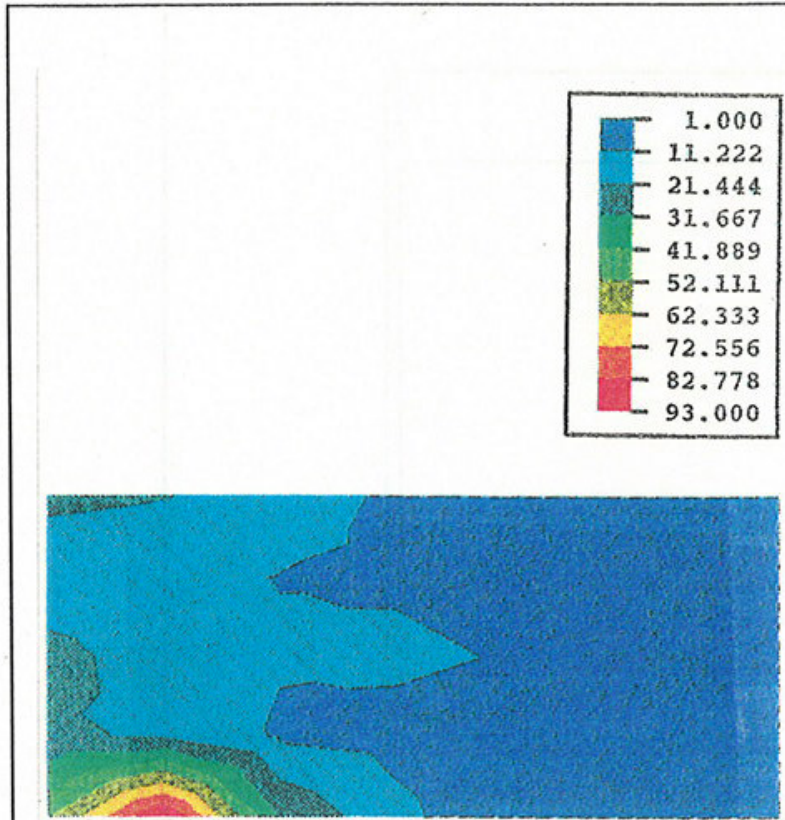

a) day 84

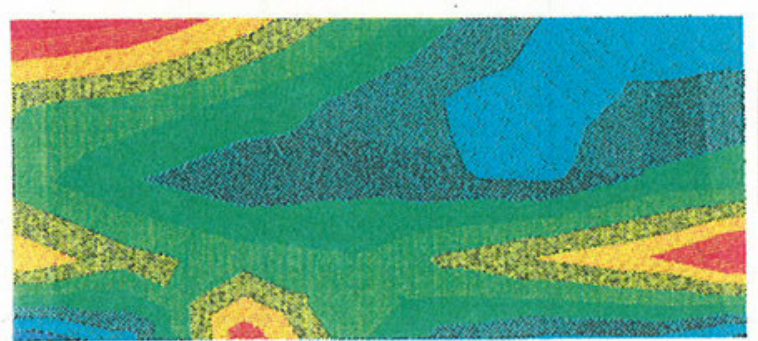

b) day 210
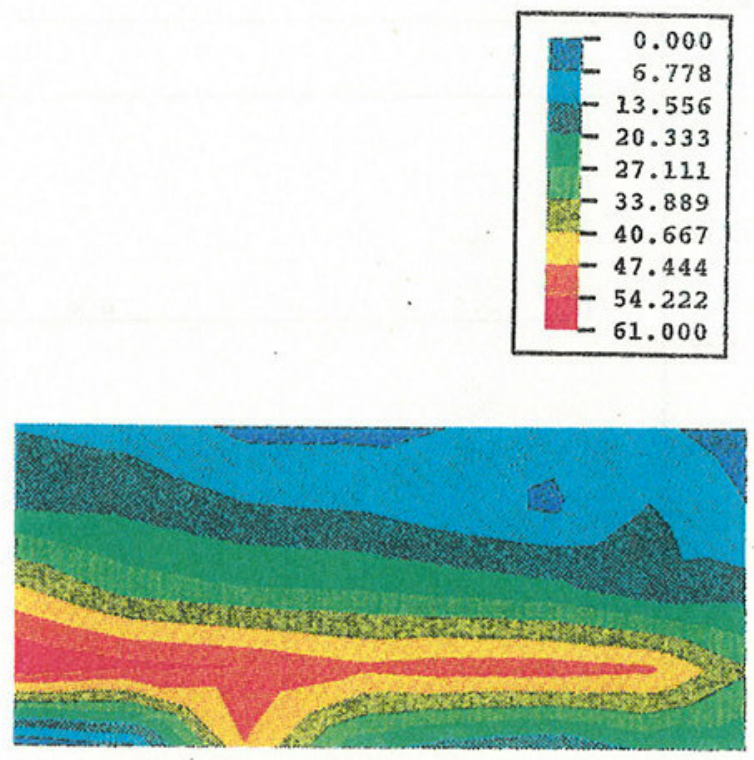

c) day 300

Figure 209. Cracking potentials at first center line of two-lift model, analysis 2 

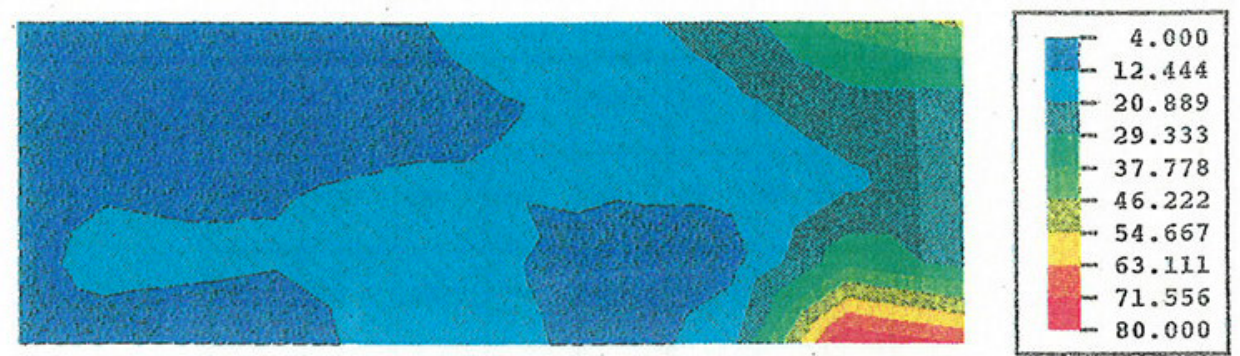

a) day 108
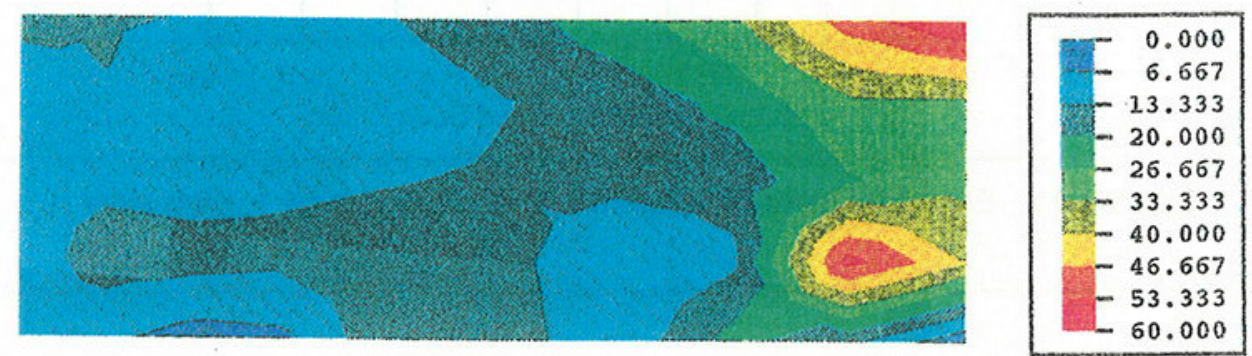

b) day 114
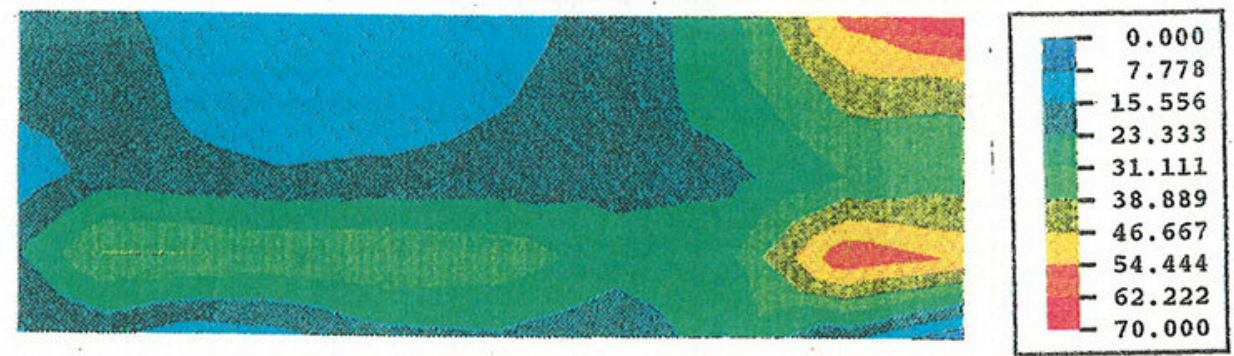

c) day 210

Figure 210. Cracking potentials at second center line of two-lift analysis 2 


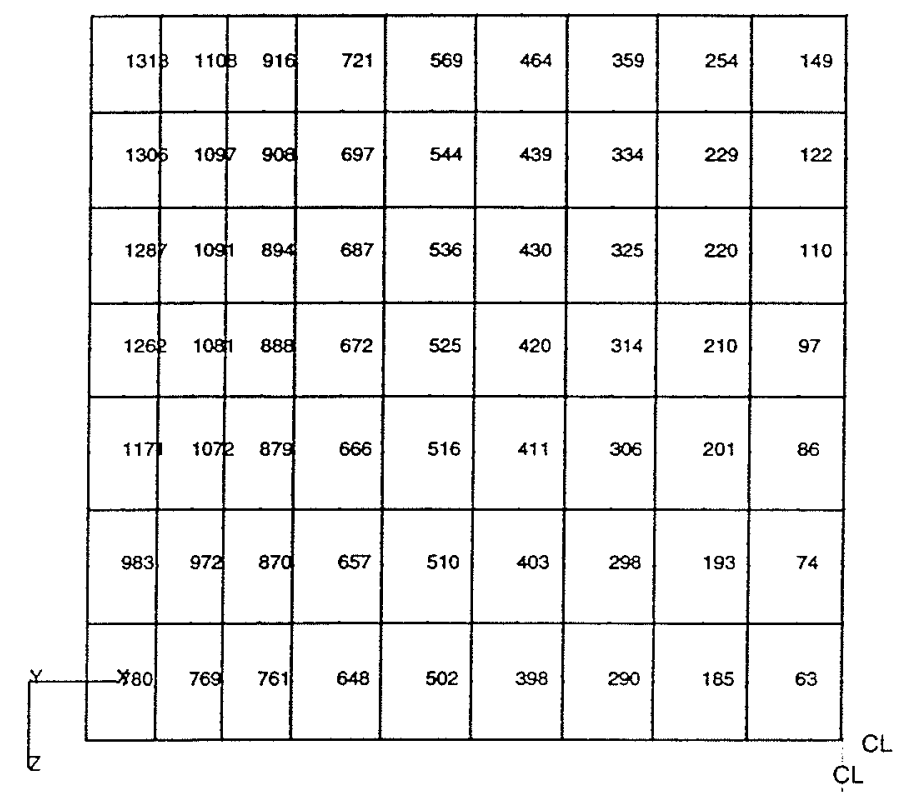

Figure 211. Element locations at base of two-lift model lift 1, plan view

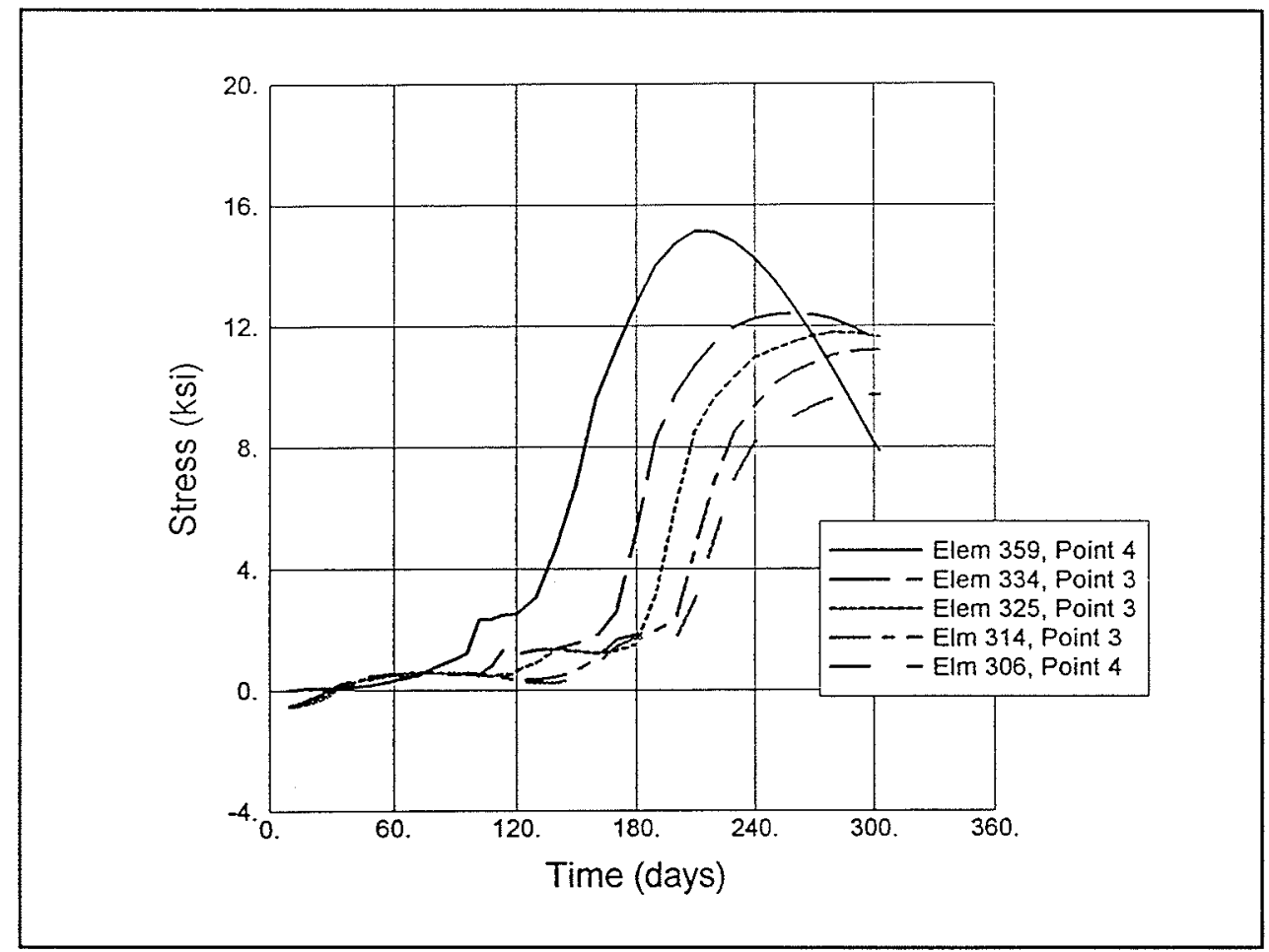

Figure 212. Transverse reinforcing stress at elements from Figure 211 


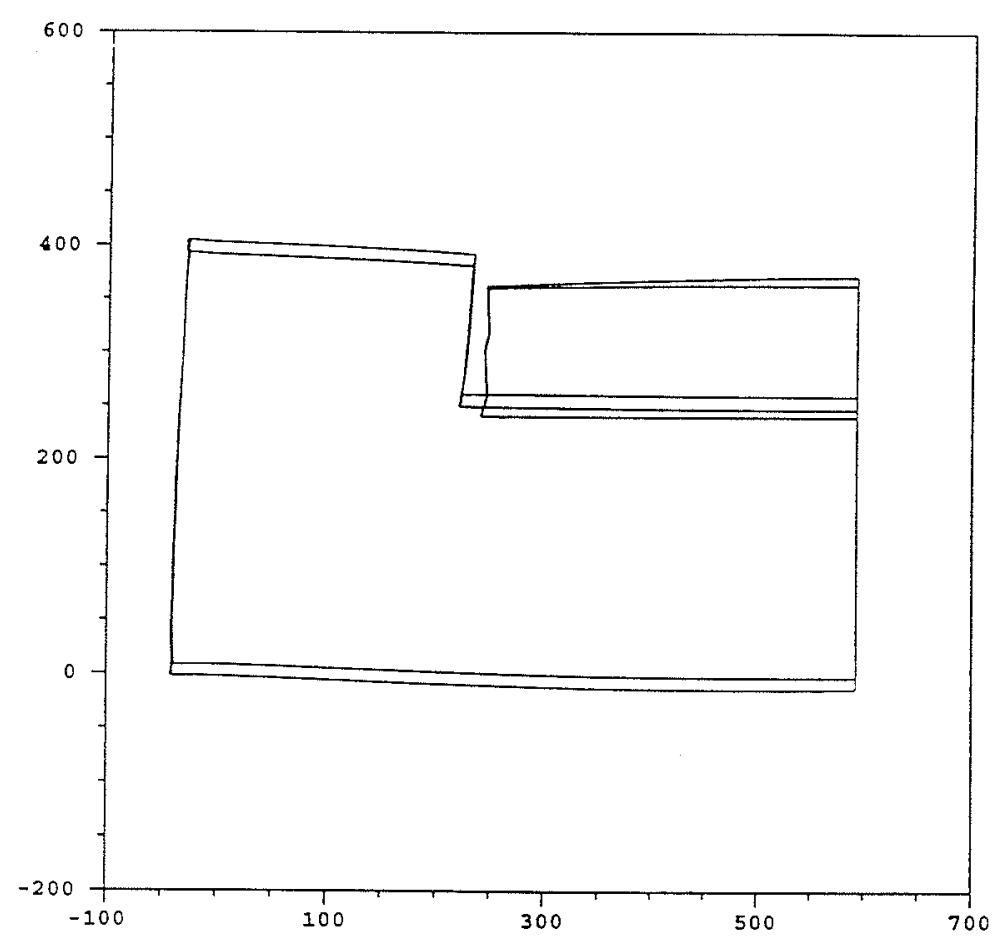

a) day 84

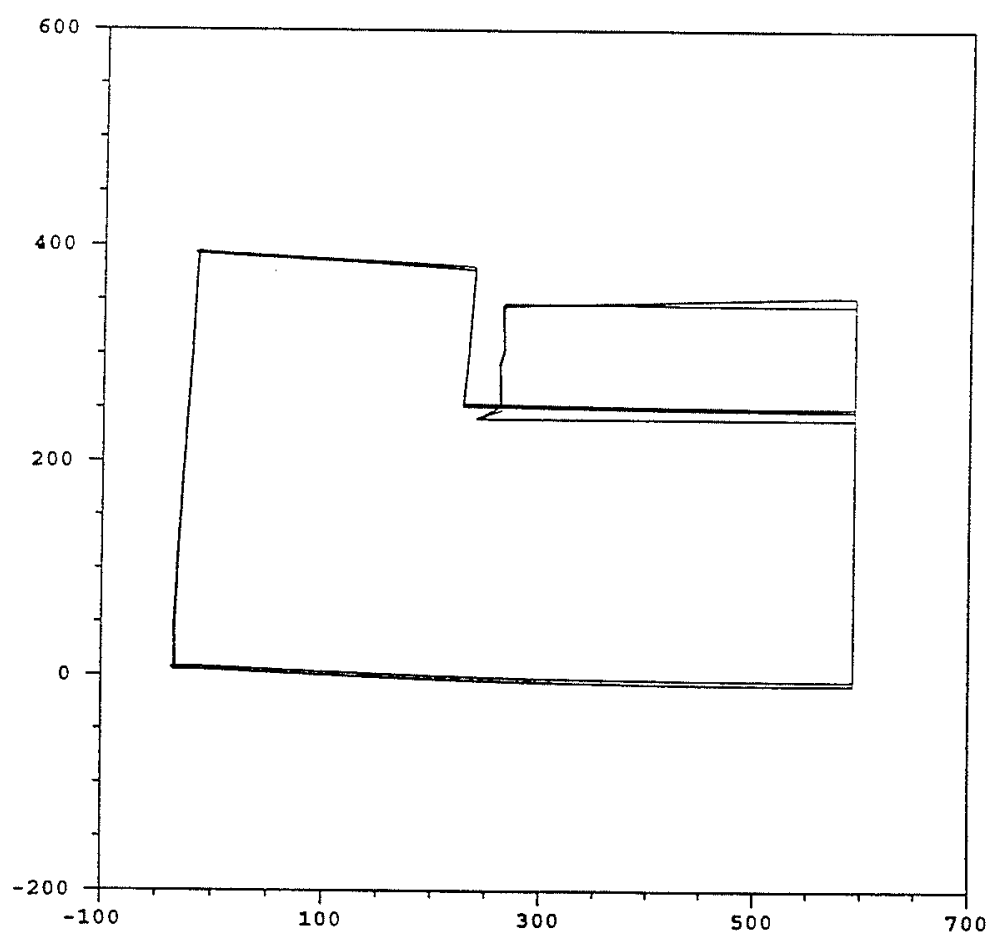

b) day 300

Figure 213. Displaced shape, two-lift analysis 1 


\section{Summary}

Cracking in the one half monolith model can be related to three factors:

a. Extensive diagonal cracking occurred in lift 1 due to the restraint imposed on the concrete by the assumption of total bond between the concrete and rock. This cracking is comparable to cracking that occurs when overlays are applied to existing concrete during lock repairs. Diagonal cracking in the new concrete usually begins at the interface between the new and existing concrete and may extend through the entire thickness of the overlay. This cracking is due to the restraint provided by the existing concrete and may be alleviated or prevented by reducing the bond strength between the new and existing concrete. However, unlike the overlay cracking, the diagonal cracks in the culvert valve monolith floor will not be exposed to exterior conditions and should not affect the structural integrity of the monolith.

b. Vertical cracking at the exterior face near culvert comers occurred in midwinter and was due to high tensile stresses at the surface caused by temperature gradients across the upstream wall. Reinforcing stresses in this area began to drop as ambient temperature increased, and cracks at the surface closed by day 364 . Similar vertical cracking also occurred at the floor center line on day 210 and closed by day 364 .

c. Cracking near interior surfaces occurred prior to day 300 , and was largely due to cold interior temperatures prior to removal of the vertical shaft cover. This cracking either closed or was in the process of closing as is evidenced by reductions in reinforcing stress in these areas by day 364 .

None of the cracking that was observed in the gate valve monolith analysis should affect the structural integrity of the monolith. All cracks except those due to the base restraint either closed or were closing by day 300 , and maximum reinforcing stresses never exceeded $40 \mathrm{ksi}$. Based on the results of these analyses, cracking in the culvert valve monolith is well understood, and no new analyses should be required.

Surface cracking, both interior and exterior, was due to temperature gradients across sections. These gradients can be limited cheaply by not covering the vertical shaft opening. However, this would leave the vulnerable valve pit interior comers exposed to freezing temperatures and moisture, which could result in high surface tensile stresses and cracking. If protection for interior valve pit surfaces is desired during the winter months, the vertical shaft should be covered prior to the onset of freezing temperatures, and the cover should be removed as soon as freezing temperatures are no longer expected. Covering the vertical opening during warmer months will result in larger than necessary temperature differences between interior and exterior concrete, since cooling and warning will only be able to occur through the exterior concrete surface. 


\section{Conclusions and Recommendations}

\section{Conclusions}

The NISA of the McAlpine Lock Replacement was a successful study, as it achieved the objectives that were set out at the beginning of the study as well as provided additional information about the construction of the lock wall monoliths. The study was successful in showing that concrete could be placed in lifts up to $10 \mathrm{ft}$ high and that a maximum placing temperature of $70^{\circ} \mathrm{F}$ may be used. Further analyses also showed that these same parameters could be used in the construction of the miter gate and culvert valve monoliths.

It was also discovered during the course of the study that it would be very beneficial to prevent bonding between the concrete and rock at vertical interfaces. This was a result of the valuable insight that a NISA study can provide with respect to the behavior of a massive concrete structure. The analyses also showed that the manner in which the reinforcing is used is very effective, since the only areas which exhibit cracking or relatively high cracking potentials are near the base of the monolith and around the gallery. Both of these locations are reinforced.

The effect of a complete bond between the rock and concrete at the horizontal interfaces was shown to be significant during the course of the culvert valve monolith analyses. It was demonstrated through the use of a small parametric study that assuming complete bond between the rock and the concrete is the mechanism which creates the extensive cracking at the base of the monolith. Despite the extent of cracking which occurs, it can be concluded that this cracking mechanism is restricted to the base of the structure and will not affect its function. The cracking predicted in the analysis of the culvert valve monolith would likely be predicted if a three-dimensional analysis of the miter gate monolith were performed, but based on the understanding of the cracking as described above it has been concluded that a three-dimensional analysis of the miter gate monolith is not required.

An item that came to light during the course of the study was that the method for predicting the direction of a crack should be investigated further. 
The cracking criterion is a stress/strain criterion as discussed in Chapter 2, but the direction is based solely on the maximum principal strain direction. It was discovered that even for initial cracking, the directions of maximum principal stress and maximum principal strain do not necessarily correspond with one another due to creep, which occurs primarily at early times. A closer investigation of this aspect of the cracking criteria is needed.

\section{Recommendations}

Based on the conditions assumed for the analyses performed, the following recommendations are made:

a. The maximum placing temperature of the concrete should be specified as $70^{\circ} \mathrm{F}$.

b. Maximum lift heights of $10 \mathrm{ft}$ may be specified on all chamber monoliths and miter gate monoliths.

c. Any vertical rock/concrete interface should be treated with some type of a bond breaker such that no tension can be transmitted across that interface.

d. Insulation with a minimum insulating value of $\mathrm{R}=2 \mathrm{hr}-\mathrm{ft}^{2}-{ }^{\circ} \mathrm{F} / \mathrm{Btu}$ should be applied for a period of 45 days for any concrete placed between November 1 and April 1. In addition, any concrete which is not at least 30 days old on November 1 should be insulated beginning on November 1 until it has reached an age of 45 days.

$e$. Reinforcing below the elevation of the bottom of the culvert should use No. 11 bars at 12 -in. spacing in all chamber and culvert valve monoliths.

$f$. While there may be an explanation for the difference between the crack direction computed by ANACAP-U and methods using Mohr's circle, further investigation should be pursued as to which term (i.e. principal stress or principal strain) should be used for computing the direction of cracking.

Should changes be made to the basic assumptions outlined in this report with respect to performing the analyses, additional analyses should be performed to confirm that the changes do not detrimentally affect the behavior of the structure. 


\section{References}

Anatech Research Corporation. (1992). "ANACAP-U software" (computer program), La Jolla, CA.

Bombich, A. A., Neeley, B. D., and Gamer, S. B. "Concrete mixture selection and characterization study McAlpine Locks Replacement, Ohio River," in preparation, U.S. Amy Engineer Waterways Experiment Station, Vicksburg, MS.

Fehl, B. D., Gamer, S. B., James, R. J., Dunham, R. S., and Zhang, L. "Nonlinear, incremental structural analysis of the lower miter gate monolith at Olmsted Locks," in preparation, U.S. Army Engineer Waterways Experiment Station, Vicksburg, MS.

Foster, J., and Jones, H. W. (1994). "Procedure for static analysis of gravity dams including foundation effects using the finite element method-Phase 1b," Technical Report ITL-94-5, U.S. Army Engineer Waterways Experiment Station, Vicksburg, MS.

Gamer, S. B., Bombich, A. A., Norman, C. D., Merrill, C. A., Fehl, B. D., and Jones, H. W. (1992). "Nonlinear, Incremental Structural Analysis of Olmsted Locks and Dams-Volume I, Main Text," Technical Report SL92-28, U.S. Army Engineer Waterways Experiment Station, Vicksburg, MS.

Hibbitt, Karlsson, and Sorensen. (1989). ABAQUS User's Manual, Version 4.9. Providence, RI.

Truman, K. Z., Petruska, D., and Ferhi, A. (1992). "Evaluation of thermal and incremental construction effects for monoliths AL-3 and AL-5 of the Melvin Price Locks and Dams," Contract Report ITL-92-3, U.S. Army Engineer Waterways Experiment Station, Vicksburg, MS. 

Public reporting burden for this collection of information is estimated to average 1 hour per response, including the time for reviewing instructions, searching existing data sources, gathering and maintaining the data needed, and completing and reviewing the collection of information. Send comments regarding this burden estimate or any other aspect of this Davis Highway, Suite 1204. Arlington, VA 22202-4302, and to the Office of Management and gudget Paperwork Reduction Project (0704-0188), Washington, DC 20503.

\begin{tabular}{|l|l|l}
\hline 1. AGENCY USE ONLY (Leave blank) & $\begin{array}{c}\text { 2. REPORT DATE } \\
\text { May } 1997\end{array}$ & $\begin{array}{l}\text { 3. REPORT TYPE AND DATES COVERED } \\
\text { Final report }\end{array}$
\end{tabular}

4. TITLE AND SUBTITLE

5. FUNDING NUMBERS

Nonlinear, Incremental Structural Analysis of McAlpine Lock Replacement

for Chamber, Miter Gate, and Culvert Valve Monoliths

6. AUTHOR(S)

Barry D. Fehl, Guillermo A. Riveros, Sharon Garner

7. PERFORMING ORGANIZATION NAME(S) AND ADDRESS(ES)

U.S. Army Engineer Waterways Experiment Station

3909 Halls Ferry Road

Vicksburg, MS 39180-6199

8. PERFORMING ORGANIZATION REPORT NUMBER

Technical Report

ITL-97-4

9. SPONSORING/MONITORING AGENCY NAME(S) AND ADDRESS(ES)

10. SPONSORING / MONITORING AGENCY REPORT NUMBER

U.S. Army Corps of Engineers

Washington, DC 20314-1000

\section{SUPPLEMENTARY NOTES}

Available from National Technical Information Service, 5285 Port Royal Road, Springfield, VA 22161.

\begin{tabular}{|l|l|}
\hline 12a. DISTRIBUTION / AVALABILITY STATEMENT & 12b. DISTRIBUTION CODE \\
Approved for public release; distribution is unlimited. &
\end{tabular}

13. ABSTRACT (Maximum 200 words)

In January 1993, the U.S. Army Engineer (USAE) District, Louisville, requested that the USAE Waterways Experiment Station perform a nonlinear, incremental structural analysis (NISA) of the McAlpine Lock Replacement project. The NISA process has been used for approximately the last 10 years to evaluate massive concrete structures for their constructability and to provide a means for considering the effects of various changes to construction procedures. The McAlpine project will be constructed at the existing McAlpine locks, which are located in the shipping canal of the Ohio River at mile 607.

The NISA was successful, as it achieved the objectives set out at the beginning of the study and also provided additional information about the construction of the lock wall monoliths. The study showed that concrete could be placed in lifts up to $10 \mathrm{ft}$ high and that a maximum placing temperature of $70^{\circ} \mathrm{F}$ may be used. Analyses showed that these same parameters could also be used in the construction of the miter gate monolith and culvert valve monolith. The study also showed that the manner in which reinforcing is used is very effective, since the only areas that exhibited cracking or relatively high cracking potentials were near the base of the monolith or around the gallery (both of these locations are reinforced).

\begin{tabular}{|c|c|c|c|}
\hline \multirow{3}{*}{$\begin{array}{l}\text { 14. SUBJECT TERMS } \\
\text { Culvert valve monolith } \\
\text { Lock wall monolith } \\
\text { McAlpine locks }\end{array}$} & \multirow{3}{*}{\multicolumn{2}{|c|}{$\begin{array}{l}\text { Miter gate monolith } \\
\text { NISA } \\
\text { Nonlinear, incremental structural analysis }\end{array}$}} & $\begin{array}{l}\text { 15. NUMBER OF PAGES } \\
207\end{array}$ \\
\hline & & & 16. PRICE CODE \\
\hline & & & \\
\hline $\begin{array}{l}\text { 17. SECURITY CLASSIFICATION } \\
\text { OF REPORT }\end{array}$ & $\begin{array}{l}\text { 18. SECURITY CLASSIFICATION } \\
\text { OF THIS PAGE }\end{array}$ & $\begin{array}{l}\text { 19. SECURITY CLASSIFICATION } \\
\text { OF ABSTRACT }\end{array}$ & 20. LIMITATION OF ABSTRACT \\
\hline UNCLASSIFIED & UNCLASSIFIED & & \\
\hline
\end{tabular}


